University of Louisville

ThinkIR: The University of Louisville's Institutional Repository

Electronic Theses and Dissertations

$5-2006$

\title{
Addressing freight imbalance in the truckload trucking industry through hierarchical planning.
}

Anthony S. Humphrey

University of Louisville

Follow this and additional works at: https://ir.library.louisville.edu/etd

\section{Recommended Citation}

Humphrey, Anthony S., "Addressing freight imbalance in the truckload trucking industry through hierarchical planning." (2006). Electronic Theses and Dissertations. Paper 652.

https://doi.org/10.18297/etd/652

This Doctoral Dissertation is brought to you for free and open access by ThinkIR: The University of Louisville's Institutional Repository. It has been accepted for inclusion in Electronic Theses and Dissertations by an authorized administrator of ThinkIR: The University of Louisville's Institutional Repository. This title appears here courtesy of the author, who has retained all other copyrights. For more information, please contact thinkir@louisville.edu. 


\title{
ADDRESSING FREIGHT IMBALANCE IN THE TRUCKLOAD TRUCKING INDUSTRY THROUGH HIERARCHICAL PLANNING
}

\author{
By
}

Anthony S. Humphrey

M.S.I.E.,University of Arkansas, 1993

B.S.I.E., Louisiana Tech University, 1991

\author{
A Dissertation \\ Submitted to the Faculty of the \\ Graduate School of the University of Louisville \\ in Partial Fulfillment of the Requirements \\ for the Degree of \\ Doctor of Philosophy \\ Department of Industrial Engineering \\ J.B. Speed School of Engineering \\ University of Louisville \\ Louisville, Kentucky
}

May 2006 
ADDRESSING FREIGHT IMBALANCE IN THE TRUCKLOAD TRUCKING INDUSTRY

THROUGH HIERARCHICAL PLANNING

By

Anthony S. Humphrey

M.S.I.E.,University of Arkansas, 1993

B.S.I.E., Louisiana Tech University, 1991

A Dissertation Approved on

May 8, 2006

By the following Dissertation Committee:

G. Don Tayylor, Ph.D., P.E.

Committee Chairman

Dr. Suraj M. Alexander, Ph.D., P.E.

Dr. Gail W. DePuy, Ph.D., P.E.

Dr. Richard Germain, Ph.D.

Dr. John S. Usher, Ph.D., P.E. 


\section{DEDICATION}

\section{To Sondra-}

The unsung hero of this journey.

To Lauren, Jonathan, and Matthew-

Our blessings 


\section{ACKNOWLEDGEMENTS}

The progress of this dissertation could not have taken place without the guidance from my advisor and friend, Don Taylor. Your insight and encouragement have proven to be beneficial. Your challenges have helped me to excel. Thank you also to my committee members - Dr. Suraj Alexander, Dr. Gail DePuy, Dr. Richard Germain, and Dr. John Usher. Your critiques have challenged me and your expertise has made this research better. Thank you for your time and patience. The completion of my degree signifies that I can now be considered an associate - a collegue. But, I will forever remember these days and think of you as mentors. Thank you also to the Logistics and Distribution Institute (LoDI) who assisted me during my time at the University of Louisville and provided the funds and means to do this research. In addition, thank you J.B. Hunt Inc. for your industrial support to these research problems.

There have been friends who have encouraged me during these past years, but my ultimate support group is my family. I will always be endebted. Thank you Mother and Daddy for your inspiration and the conviction you instilled in me to always do my best. You taught me early in life the value of education. And you always placed in front of me opportunities for excellence. Thank you Jerry and Peggy Crain for your encouragement and the gift of your daughter. You have always been there for us and you have been critical to our success.

And, finally, to the ones who have been affected by this degree the most. Sondra. Words can not express how grateful I am for God's gift to me. Your love, patience, 
dedication, encouragement, and, at times, critiques, helped us achieve something that at times we didn't see was possible. Thank you for everything you have done and for the many times you lifted me up. This degree is yours too. You shared equally in the sweat and tears. You have been a trooper. I love you. Lauren, Jonathan, and Matthew. May you one day understand the love we have for you and the sacrifices that were made and life lessons that were learned during our stay in Louisville. Too many times you heard us say "Wait... Be Patient.. Not Now." I pray that one day you will strive for excellence in whatever you do. You can do anything you set your mind too - Daddy's degree proves that - and there is nothing you can ever do to make us stop loving you.

We Did It!

"Humphrey's..... HOORAY" 


\section{ABSTRACT \\ Addressing Freight Imbalance \\ in the Truckload Trucking Industry \\ Through Hierarchical Planning}

Anthony S. Humphrey

May 13, 2006

Freight imbalance is a problem that negatively affects drivers and carriers within the truckload trucking industry. One result of this problem is that the industry experiences high annual driver turnover, exceeding 130\% annually. The turnover can be attributed in part to driver dissatisfaction due to the inability of the carriers to provide regular driving tours as a result of freight imbalance. However, due to the complexity of the imbalance, carriers have difficulty combating the problem. This dissertation examines three problems addressing freight imbalance from a hierarchical planning perspective.

The Weekend Draying Problem focuses is an operational planning approach for addressing weekend truckload dispatching. The application of this methodology to a nationwide trucking network reveals that a carrier can experience significant customer service improvements while at the same time meeting the needs and expectations of their drivers. As a result, more regular driving tours can be established.

The Driver Domicile Problem uses tactical planning to examine nationwide driver recruitment strategies. With driver turnover and driver retention emposing significant burdens on the truckload trucking industry, the proposed strategy reveals key locations 
where a potential driver base could be recruited that would improve the carrier's ability to provide the drivers with more regular tours and frequent "get home" opportunities. Results highlight which factors contribute to the best design of a nationwide domicile plan.

The Distribution Center Location Problem is a stragic plan for the design of various sized distribution networks that minimize trucking costs without affecting delivery requirements. Whereas historical design focused on time and distance minimization, these networks address freight imbalance by focusing on cost minimization.

Examination and analysis of these problems is conducted through discrete event system simulation, computer modeling, and mathematical programming. Outcomes from the research of these problems are industrially relevant. The application of these methodoligies will assist the truckload trucking carriers in dealing with inherent freight imbalance issues and helping them overcome many challenges they face. Collectively this dissertation demonstrates ways to address freight imbalance both in the short term planning horizon and the long term planning horizon. 


\section{TABLE OF CONTENTS}

TABLE OF CONTENTS.......................................................................................................

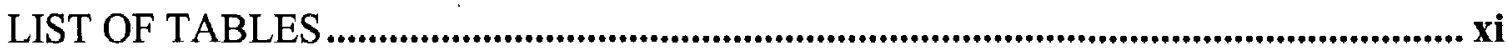

LIST OF FIGURES ...........................................................................................................

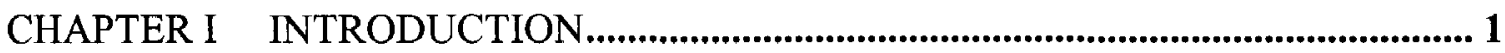

1.1 The Science of Transportation ............................................................................ 1

1.2 Freight Imbalance in the Truckload Freight Industry .......................................... 2

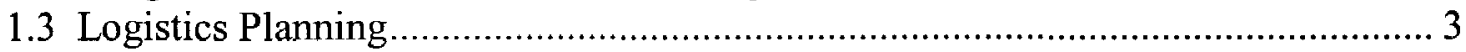

1.4 Addressing Freight Imbalance Through Hierarchical Planning ............................... 4

1.4.1 Operational Planning - The Weekend Problem............................................. 6

1.4.2 Tactical Planning - The Driver Domicile Problem ............................................ 7

1.4.3 Strategic Planning - The Distribution Center Location Problem...................... 8

CHAPTER II REVIEW OF LITERATURE ..................................................................... 10

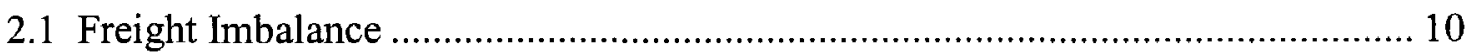

2.2 Fleet Scheduling and Management .................................................................. 13

2.3 Hierarchical Planning and Logistics Applications............................................... 14

2.4 The Weekend Problem............................................................................... 17

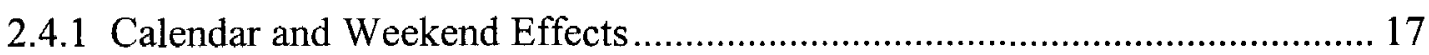

2.4.2 Vehicle Routing and Driver Assignment ...................................................... 19

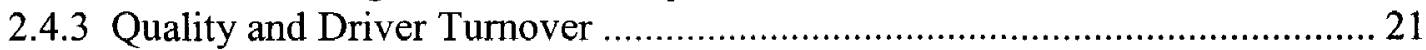

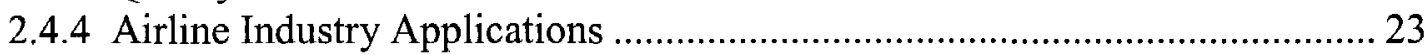

2.5 The Driver Domicile Problem .......................................................................... 24

2.5.1 Causes and Effects of Driver Turnover ..................................................... 24

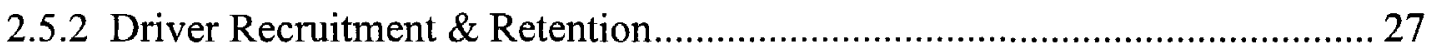

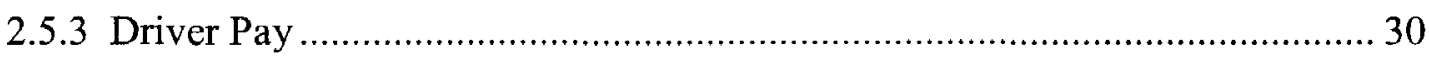

2.5.4 Existing Driver Domicile Research ............................................................... 31

2.5.5 The Traveling Salesman Location Problem (TSLP) ...................................... 34

2.6 The Distribution Center Location Problem........................................................ 36

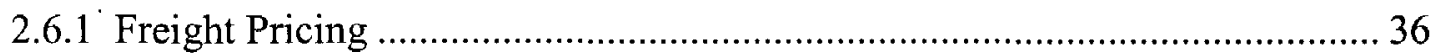

2.6.2 Empty Repositioning and Backhauls ........................................................ 39

2.6.3 Distribution Center Location Research....................................................... 40

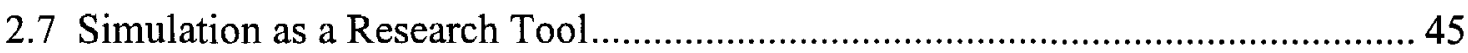

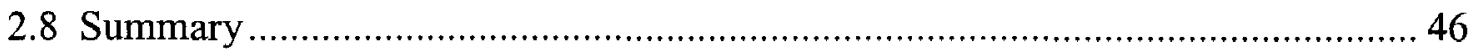




\section{CHAPTER III}

OPERATIONAL PLANNING The Weekend Draying Problem ............................. 49

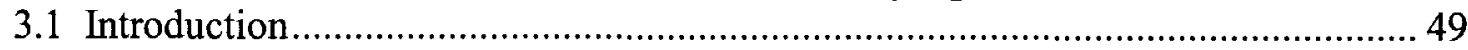

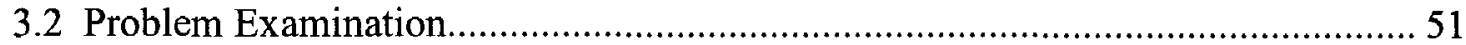

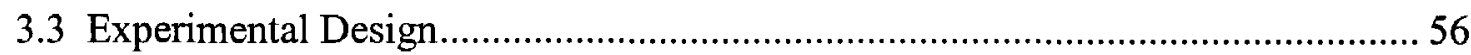

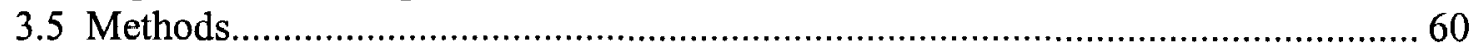

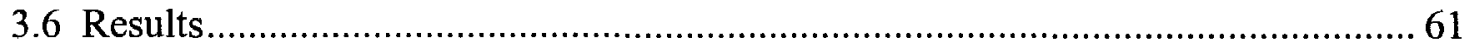

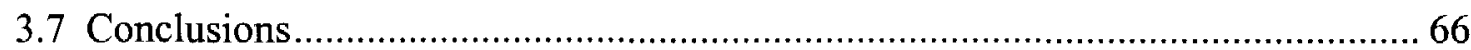

\section{CHAPTER IV}

TACTICAL PLANNING The Driver Domicile Problem ............................................ 69

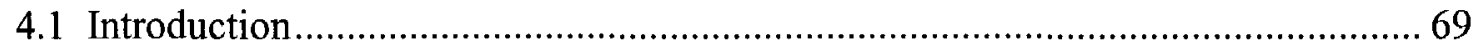

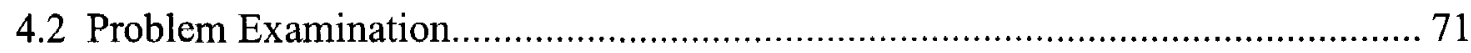

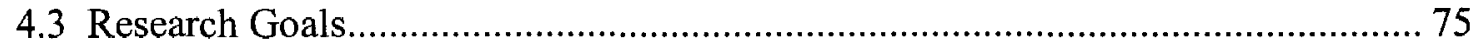

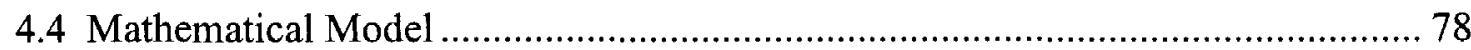

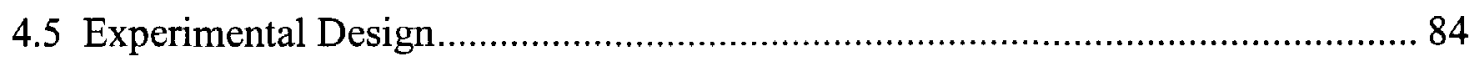

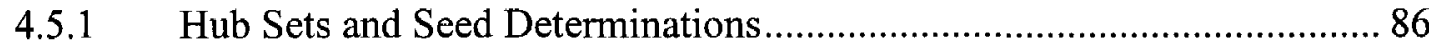

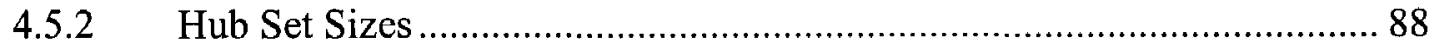

4.5.3 Ownership Assignments ....................................................................... 89

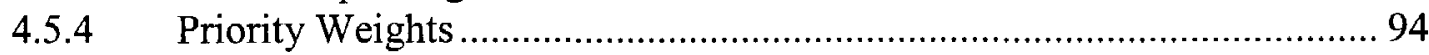

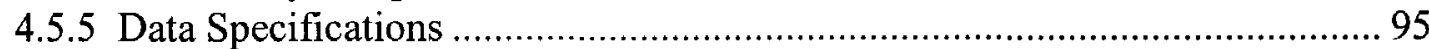

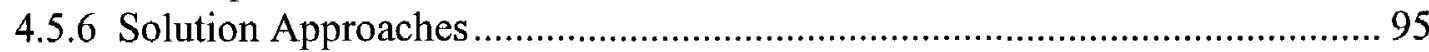

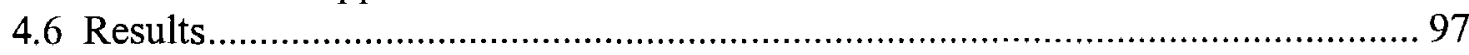

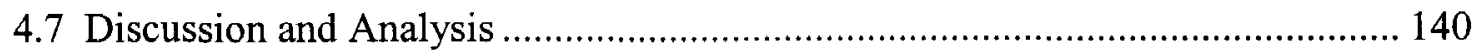

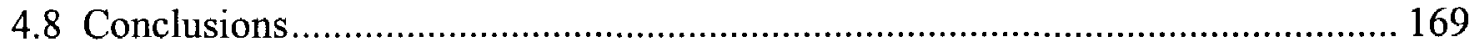

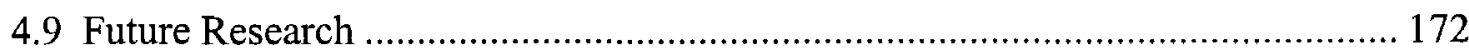

\section{CHAPTER V}

STRATEGIC PLANNING The Distribution Center Location Problem............. 175

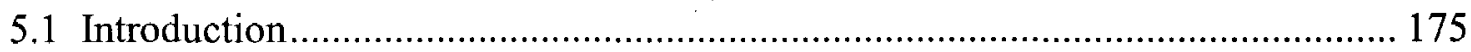

5.2 Examination of Freight Rate Structures......................................................... 176

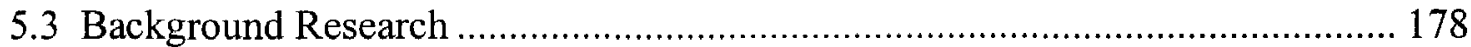

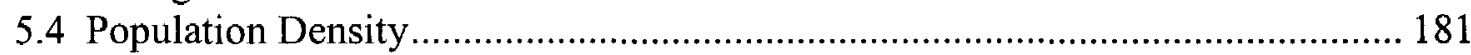

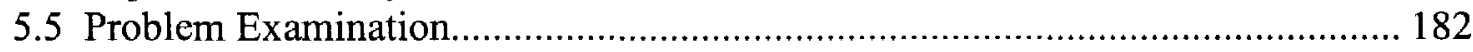

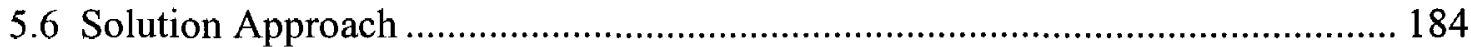

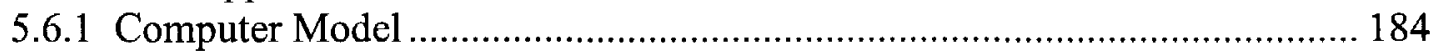

5.6.2 Mathematical Problem Description .............................................................. 186

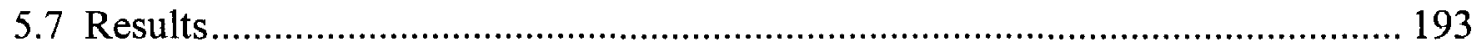

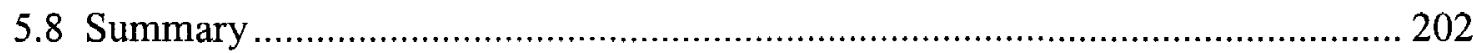

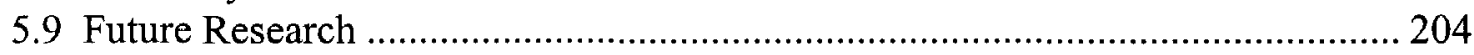

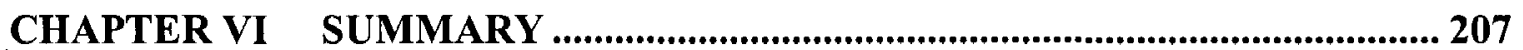

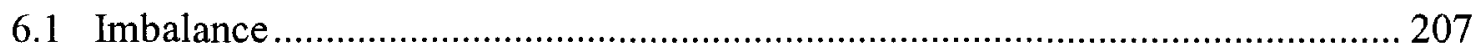

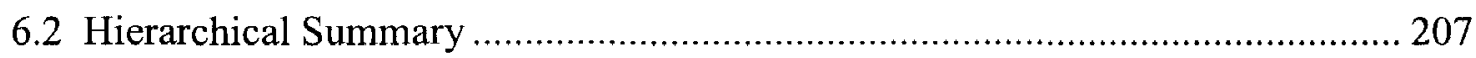

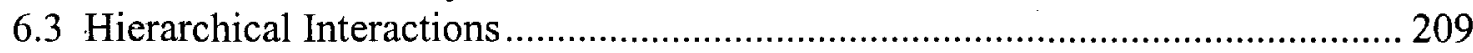

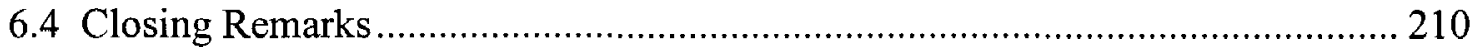


APPENDIX 1: SIMNET Code: The Weekend Problem 224

APPENDIX 2: SIMNET Code: In Support of The Domicile Problem 238

APPENDIX 4: LINGO Code: The Domicile Problem 240 APPENDIX 5: SIMNET Code: The Domicile Problem. 266 


\section{LIST OF TABLES}

Table 1-1 Summary of Hierarchical Planning in Logistics Applications ........................... 5

Table 3-1 - Simulation Output with Number of Drivers Constrained ............................... 62

Table 3-2 - ANOVA Summary - Drivers Constrained ………………….......................6 63

Table 3-3 - Simulation Output with Number of Drivers Unconstrained ........................... 65

Table 3-4 - ANOVA Summary - Drivers Unconstrained ……………………..................6

Table 4-1 - Comparison of Set Sizes Versus Total Mileage Ownership ........................... 89

Table 4-2 - List of 96 Highway Hub Seeds.................................................................. 90

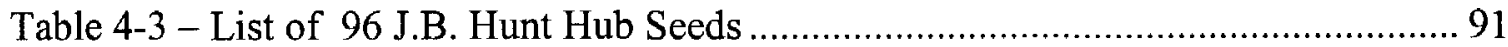

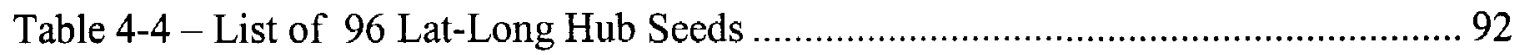

Table 4-5 - LINGO Optimization vs. SIMNET Heuristic .............................................. 99

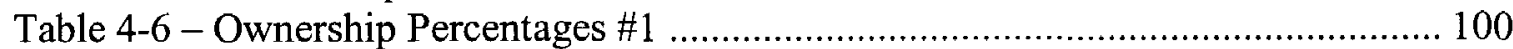

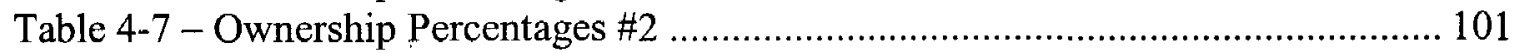

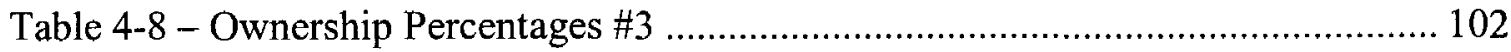

Table 4-9- Ownership Percentages \#4 ..................................................................... 103

Table 4-10- Ownership Percentages \#5 …….......................................................... 104

Table 4-11 - Ownership Percentages \#6 …………............................................... 105

Table 4-12 - Ownership Percentages \#7 ................................................................. 106

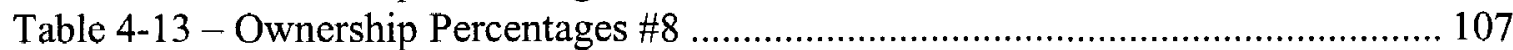

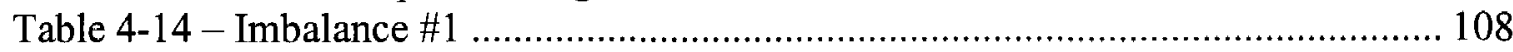

Table 4-15 - Imbalance \#2 …………..................................................................... 109

Table 4-16 - Imbalance \#3 ………......................................................................... 110

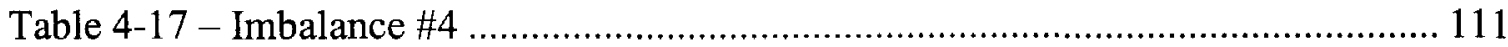

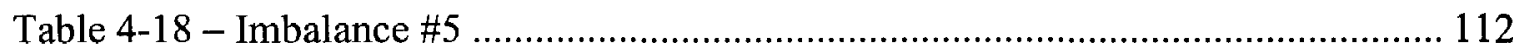

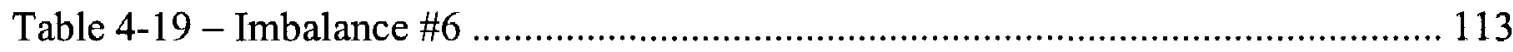

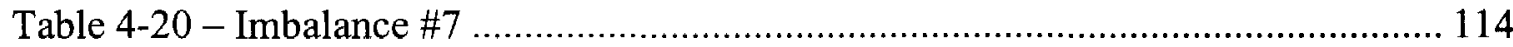

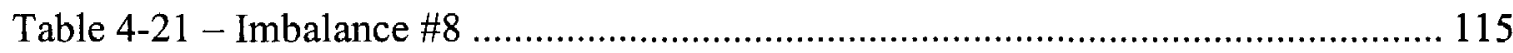

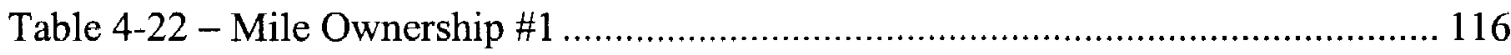

Table 4-23 - Mile Ownership \#2 …………............................................................ 117

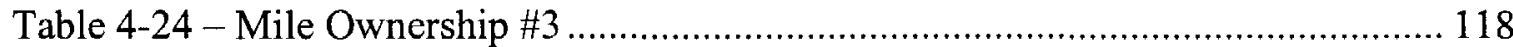

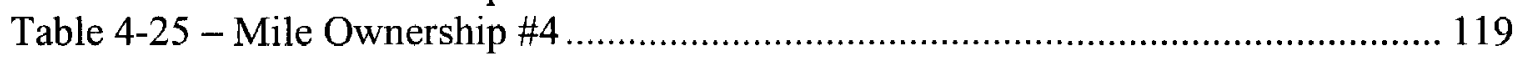

Table 4-26 - Mile Ownership \#5 …………….......................................................... 120

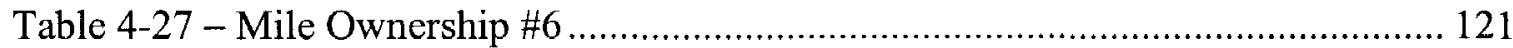

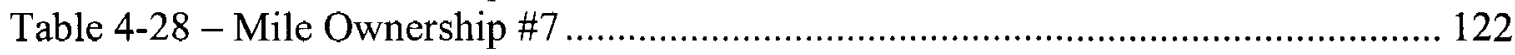

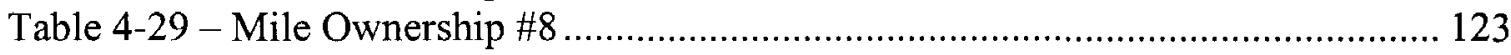

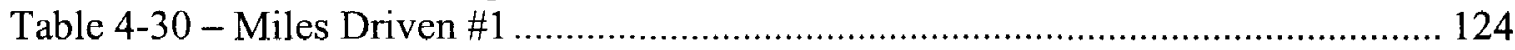

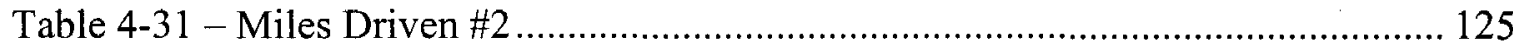

Table 4-32 - Miles Driven \#3 ........................................................................... 126

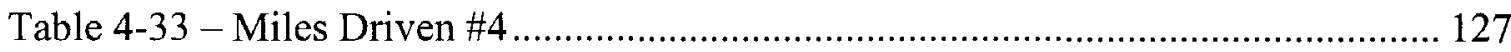




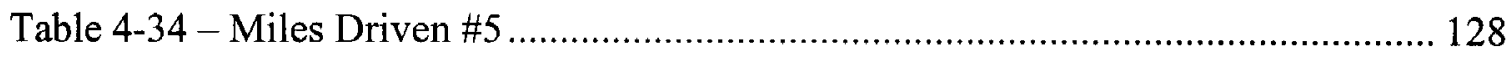

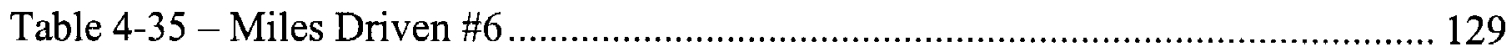

Table 4-36 - Miles Driven \#7 ……………………............................................ 130

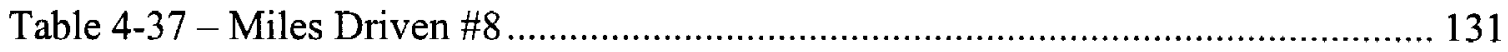

Table 4-38 - Drivers Required \#1 ........................................................................ 132

Table 4-39 - Drivers Required \#2 …………….................................................... 133

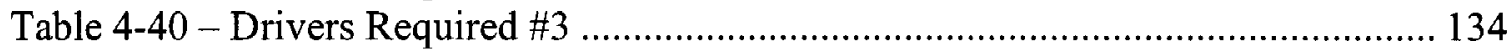

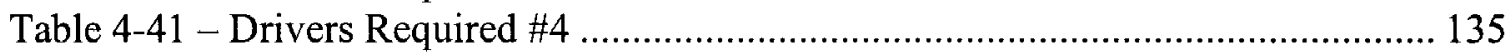

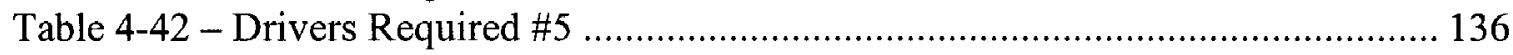

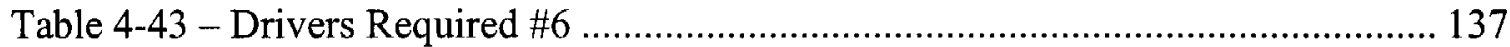

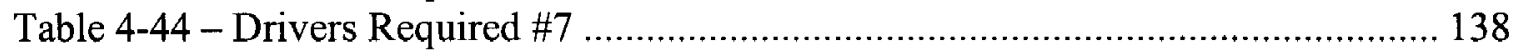

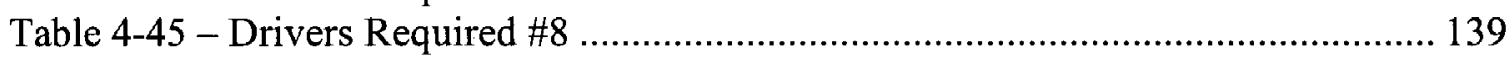

Table 4-46 - ANOVA: Percentage of Routes Owned ……………………………...... 141

Table 4-47 - ANOVA: Percentage of Loads Owned ................................................... 142

Table 4-48 - ANOVA: Percentage of Miles Owned ................................................... 143

Table 4-49 - ANOVA: Route Imbalance …………................................................ 146

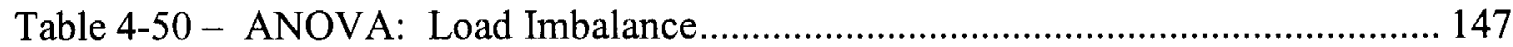

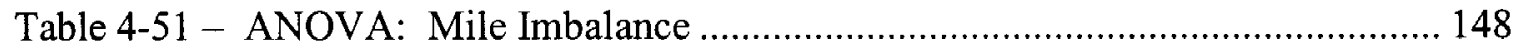

Table 4-52 - ANOVA: Outbound Miles Owned ....................................................... 152

Table 4-53 - ANOVA: Inbound Miles Owned........................................................... 153

Table 4-54 - ANOVA: Pass-Thru Miles Owned......................................................... 154

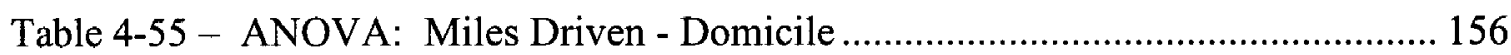

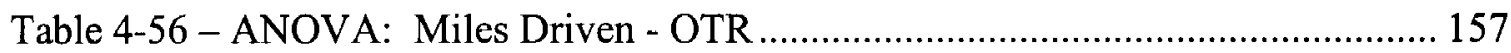

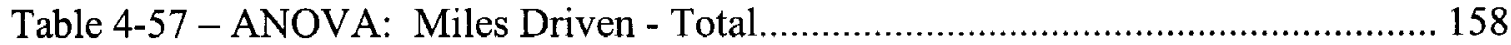

Table 4-58 - ANOVA: Driver Requirements - Domicile............................................... 161

Table 4-59 - ANOVA: Driver Requirements - OTR..................................................... 162

Table 4-60 - ANOVA: Driver Requirements - Total .................................................... 163

Table 4-61 - Tukey Analysis for Hub Seeds and Mileage Ownership............................ 166

Table 4-62 - Tukey Analysis for Hub Seeds and Domiciled Drivers ............................. 167

Table 4-63 - Tukey Analysis for Assignment Rule and Mileage Ownership ................ 168

Table 5-1 - Chicago Consulting's "10 Best Warehouse Network 2005"....................... 180

Table 5-2 - Chicago Consulting vs. J.B. Hunt Hot Spots............................................. 184

Table 5-3 - Cost and Distance Results for CCON Networks...................................... 193

Table 5-4 - Cost and Distance Results for JBHT Networks ........................................ 196

Table 5-5 - City-by-City Cost Comparisons for CCON vs JBHT Alternatives............. 198

Table 5-6 - Cost and Distance Results for Hybrid CCON/JBHT Networks .................. 199 


\section{LIST OF FIGURES}

Figure 2-1 - Annual Average Daily Truck Traffic Flow Map -- 1998 Data ................... 11

Figure 2-2 - Daily Freight Volume Distribution ............................................................ 18

Figure 3-1 - Example - Current Scenario / Friday ……………….................................... 52

Figure 3-2 - Example - Current Scenario / Saturday ....................................................... 53

Figure 3-3 - Example - Draying Scenario / Friday ………...............................................5 54

Figure 3-4 - Example - Draying Scenario / Saturday …………………............................. 55

Figure 4-1 - Outbound Freight Ownership.................................................................... 72

Figure 4-2 - Inbound Freight Ownership ………......................................................... 73

Figure 4-3 - Pass-Thru Freight Ownership ................................................................... 73

Figure 4-4 - OTR Freight Ownership ........................................................................ 74

Figure 4-5 - Summary Depiction of Experimental Design Elements ........................... 85

Figure 4-6 - Interaction Plot - 3-Way - \% Miles.......................................................... 145

Figure 4-7 -- Interaction Plot - 6 -Way - Mile Imbalance ........................................... 149

Figure 4-8 -- Interaction Plot - 3-Way - Miles Driven Domicile ................................. 159

Figure 4-9 - Interaction Plot - 3-Way - Miles Driven OTR ……….............................. 160

Figure 4-10 - Interaction Plot - 3-Way - Drivers Required Domicile........................... 164

Figure 4-11 - Interaction Plot - 3-Way - Drivers Required OTR ................................. 164

Figure 4-12 - Preferred Domicile Network ………...................................................... 170

Figure 5-1 - Truckload Freight Structures............................................................... 177

Figure 5-2 - U.S. Population Density Map.............................................................. 182

Figure 5-3 - Computer Model Flow Chart ................................................................ 188

Figure 5-4 - Rate Calculation for County Centroids ...................................................... 191

Figure 5-5-CCON: Network Size vs Cost and Distance Reductions ........................... 200

Figure 5-6 - JBHT: Network Size vs Cost and Distance Reductions.............................. 201

Figure 5-7 - Hybrid: Network Size vs Cost and Distance Reductions........................... 201 


\section{CHAPTER I \\ INTRODUCTION}

\subsection{The Science of Transportation}

The need for transportation, either by road, rail, water, air, or pipeline, is necessary because people and/or goods and services are not located or produced where they are needed or consumed. The demand for transportation services arises from the mismatch between where people or products are and where they will be later sold or used in subsequent manufacturing processes (Daskin and Owen 2003). Transportation science, the study of transportation, is a scientific discipline that examines all facets of transportation where underlying principles that govern transportation are identified and are used to explain the behavior of the transportation system. As Hall (2003) states:

"Transportation scientists are motivated by the desire to explain spatial interactions that result in movement of people or objects from place to place... It (transportation science) is fundamentally a quantitative discipline, relying on mathematical models and optimization algorithms to explain the phenomena of transportation."

Hall goes on to explain that the inherent nature of transportation systems is to progress towards a state of imbalance and disequilibrium. The study of transportation problems, like any of the problems in the natural sciences, arose out of human curiosity to explain how the world behaves and then to be able to influence future behavior. Therefore, considering the scope of transportation science, this dissertation is intended to examine the imbalance that exists specifically in the truckload freight industry. 


\subsection{Freight Imbalance in the Truckload Freight Industry}

The truckload freight industry is affected by freight imbalance in a variety of ways (Taylor 2003). Since nearly $75 \%$ of all freight is transported by truck at some point in the distribution chain (Engel 1998), our nation's economy is significantly affected by the inefficiencies associated with freight imbalance. In addition to the stochastic nature of freight demand (Hall 1999), other sources of imbalance include cyclical freight patterns due to daily or seasonal freight volumes (Powell 1996, Godfrey and Powell 2000); location characteristics due to outbound and inbound flows between producing and consuming regions (Friesz et al. 1983, Harker 1987, Harker and Friesz 1986a and 1986b); and driver domicile issues (Taylor and Whicker 2002). These sources of imbalance confuse the flows of both freight and resources within the truckload freight network. Furthermore, addressing imbalance is complicated by federally mandated driver hours-of-service (HOS) rules (Huang and Walter 2000). As a result, the cost of for-hire transportation has risen to increased levels that haven't been seen before (Bohman 2004).

Regardless of the source, the problem of freight imbalance critically affects drivers and carriers throughout the truckload industry. One result of this logistics problem is that the industry yearly experiences high driver turnover (Nguyen 2005) which some researchers have quantified as being greater than $150 \%$ annually for individual carriers (Corsi and Fanara 1988, Gupta et al. 1996, Griffen et al. 2000). As a comparison, research conducted within the less-than-truckload (LTL) industry (Mele 1989a, Mele 1989b) shows that driver turnover for city drivers and linehaul drivers is approximately $4.5 \%$ and $10 \%$ respectively. The work of Gupta et al. (1996) also supports 
these findings. Recent survey results from the American Trucking Association (ATA) (Vise 2004) shows that LTL turnover remains below 20\%. The ATA has been collecting quarterly data for the industry since 1995 . Only three times has the overall quarterly industry turnover reached $120 \%$ or more (Nguyen 2005). Two of those times have been in the $4^{\text {th }}$ quarter of $2004(136 \%)$ and the $1^{\text {st }}$ quarter of $2005(120 \%)$. The turnover can be partly attributed to driver dissatisfaction (Taylor and Meinert 2000) and due in part to the inability of the truckload carriers to provide regular driving tours (Kutanoglu et al. 2001, Hall 2004). With an estimated 403,000 hires per year (Christenson et al. 1997), the exorbitant turnover rates cost the truckload trucking approximately between $\$ 2.4$ billion (Griffin et al. 2000) and \$2.8 billion annually (Rodriquez et al. 2000).

\subsection{Logistics Planning}

Historically, because of the complexity of a nationwide trucking network, existing research in transportation science or supply chain modeling usually focus on isolated strategies that seek to find local optima (Min and Zhou 2002). Global solutions, on the other hand, are much more difficult to formulate and, in practice, even more difficult to implement. The time spectrum for developing strategies is compounded by the scope of the issues being examined, both in terms of problem size and problem complexity. In addition, a company's internal bureaucracy often creates an inertia that prohibits changes in policy or network structure, especially in the short-term. Planning within an organization must exist at many levels as well as in many functional areas. It is an ongoing process with separate goals for the short, medium, and long-term time horizons (Lambert et al. 1998). 
Lambert et al. (1998) and Shapiro (2001) describe three hierarchical levels of planning that occur in logistics management and in business environments in general. They are the strategic plan (long-term horizon), the tactical plan (intermediate term horizon), and operational plan (short-term horizon). Crainic and Laporte (1997) and Crainic (2003) discuss logistics from a historical perspective and provide comprehensive references to established research in the field of freight transportation planning models. Schmidt and Wilhelm (2000) look specifically at these three planning hierarchies from an international supply chain management perspective. Key points from each of these references are summarized in Table 1-1.

\subsection{Addressing Freight Imbalance Through Hierarchical Planning}

The focus of this research is to examine and seek solutions to three of the types of freight imbalance planning problems that a truckload trucking organization could face. According to Table 1-1, location planning, personnel planning, and routing and dispatching problems have been suitably shown to be adequate for study at the strategic, tactical, and operational planning levels respectively. This dissertation will examine specific problems at each of the three hierarchical logistics planning levels shown in Table 1-1. These three scenarios showcase how a proactive truckload freight carrier can comprehensively combat freight imbalance throughout the short-term to long range planning horizons. Brief descriptions of the problems will be examined in the next three sections of this chapter. Comprehensive problem discussions can be found in Chapters III, IV, and V respectively. The research is industrially relevant as demonstrated through support and data provided by J.B. Hunt Transport, Inc. (JBHT), one of the largest 


\begin{tabular}{|c|c|c|c|}
\hline $\begin{array}{l}\text { Planning } \\
\text { Type }\end{array}$ & $\begin{array}{l}\text { Typical Time } \\
\text { Horizon }\end{array}$ & Characteristics & $\begin{array}{c}\text { Example } \\
\text { Applications }\end{array}$ \\
\hline Strategic & $\begin{array}{c}5+\text { Years } \\
\text { Goal: } \\
\text { Design of the } \\
\text { Logistics Network }\end{array}$ & $\begin{array}{l}\text { - Broad goals } \\
\text { - Low detail } \\
\text { - Open to change } \\
\text { - Focus is on } \\
\text { resources and } \\
\text { competition } \\
\text { - Few financial } \\
\text { details } \\
\text { - Involves resource } \\
\text { acquisition }\end{array}$ & $\begin{array}{ll}- & \text { Location } \\
& \text { Planning } \\
\circ & \text { Network design } \\
\circ & \text { Regional planning } \\
\circ & \text { Multimodal } \\
& \text { planning } \\
\circ & \text { Warehouse } \\
& \text { conceptualization }\end{array}$ \\
\hline Tactical & $\begin{array}{c}1 \text { to } 5 \text { Years } \\
\text { Goal: } \\
\text { Prescribes } \\
\text { Management Policies }\end{array}$ & $\begin{array}{l}\text { - More detail } \\
\text { - Targeted financial } \\
\text { goals } \\
\text { - Considers causes \& } \\
\text { effects } \\
\text { - Involves resource } \\
\text { allocation }\end{array}$ & 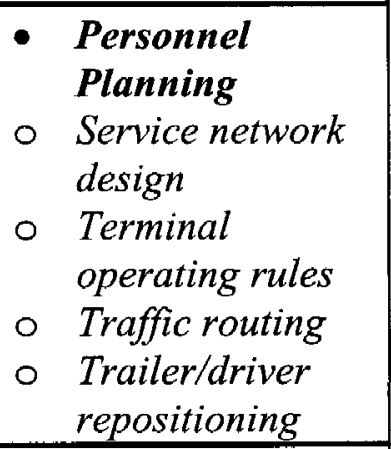 \\
\hline Operational & \begin{tabular}{|c|} 
Day-to-Day \\
$<1$ Year \\
Goal: \\
Schedules operations \\
to meet customer \\
objectives
\end{tabular} & $\begin{array}{l}\text { - Specific details } \\
\text { - } \quad \text { Ready to implement } \\
\text { - } \quad \text { Firm goals } \\
\text { - Heavy financial } \\
\text { orientation } \\
\text { - Involves resource } \\
\text { execution }\end{array}$ & 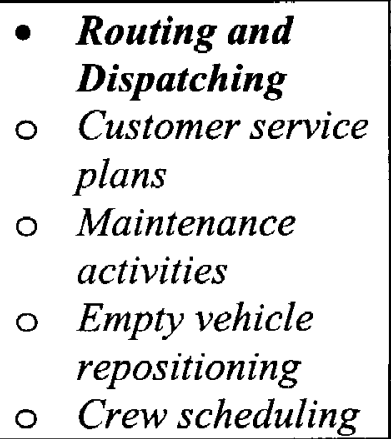 \\
\hline
\end{tabular}

Table 1-1 Summary of Hierarchical Planning in Logistics Applications

publicly held truckload trucking companies in the United States and one of the largest transportation logistics companies in North America (J.B. Hunt 2005). All three problems are analyzed via discrete event system simulation, computer modeling, and/or mathematical programming. 


\subsubsection{Operational Planning - The Weekend Problem}

At the operational level, the day-to-day logistics plans are performed by local management in a highly dynamic environment where the time factor plays an important role (Crainic 2003). One of the day-day-problems experienced by the truckload freight industry is that in addition to long-term seasonality in freight volume, there also exists a cycle that changes on a daily basis (Powell 1996, Godfrey and Powell 2000). The highest freight volumes occur during the weekdays whereas the weekend freight volume drips significantly. This imbalance presents a problem for drivers and carriers, neither of whom wants to be idle through the weekend.

One possible solution is to creatively acquire additional Friday freight (freight that previously would have been refused by the carrier do to capacity constraints) without disrupting customer requested ship schedules. This can be achieved via a technique known as 'yard stacking'. In this technique, before being dispatched on Friday for a long-haul, an arriving driver initially picks up a load to make a short 'dray' move from the customer site to the carrier's closest existing terminal yard. During the weekend, another arriving driver picks up the drayed load, thus guaranteeing his or her own longhaul opportunity based on the efforts of the previous driver who had performed the Friday dray move.

This problem does not require a considerable financial investment. By making use of existing terminals to conduct the yard stacking, a feasible network already exists. The most significant details needing to be addressed during implementation are to establish dispatching rules that meet the yard stacking objectives. Since there are only minor issues to be resolved before implementation of the new procedures could begin, 
this scenario is a good representation of a problem that addresses daily/weekly freight imbalance through operational planning.

\subsubsection{Tactical Planning - The Driver Domicile Problem}

Medium term planning is addressed at the tactical level. The planning aims are to determine, over a medium-term horizon (typically 1 to 5 years), an efficient allocation and utilization of resources that can produce the best possible performance of the system as a whole (Crainic 2003). Another problem experienced by the truckload freight industry is due to the spatial mismatch between producing and consuming locations. Frequently, after a drop-off, a driver with an empty trailer is not conveniently located at or near the pick-up point of his next dispatch. On one hand, the tractor/trailer is a resource with impersonal attributes and no intellectual regard to where, when, or how frequently it will be used. The driver, on the other hand, is a highly sought resource with personal attributes and the fortitude to dictate to a carrier the acceptable conditions of his or her work. The driver's schedule, unlike equipment, is also governed by federally defined hours of service rules and an agreement with the carrier as to the frequency he or she should expect to be returned home after an extended driving tour.

The carrier must simultaneously meet organizational objectives, governmental regulations, and customer service goals while adhering to the needs of their drivers to return to their domiciles (homes) on a regular basis. Since it would be infeasible to think that the carriers would consider moving drivers from one domicile to another, the carrier would therefore consider future strategies for recruiting drivers from specific domiciles. The problem becomes an issue of identifying where the cost effective domiciles exist. 
Analysis of this problem examines what characteristics lead to determining good domiciles. Hall (2004), who examined the problem in an LTL network, reports that the most similar topic related to this problem is the "deadhead" problem and that domicile location theory has not been addressed to any significant degree in the transportation literature. Because recruiting new drivers from specific domiciles could not be immediately put in practice due to a carrier's existing driver workforce, this scenario represents a problem that addresses freight imbalance through tactical planning.

\subsubsection{Strategic Planning - The Distribution Center Location Problem}

Crainic (2003) states that an organization who engages in strategic planning will typically involve the highest level of management. Eventually, large capital investments over long-term horizons will be made. Migliore and Catalano (2003) show how the planning of terminal locations and sizes can involve both strategic and tactical planning over a 15 year horizon. Distribution center strategic planning allows a company to determine the effectiveness of various sites before significant capital expenditures must be made (Tompkins and Harmelink 1992). Some of the largest capital investments experienced by organizations involve the design of the physical network and the location of major facilities. When examining the physical network, much of the existing literature considers customer service a critical objective. Granted, if a carrier desires to compete for business in the truckload market, customer service is essential (Engel 1998). The question is, "How does one define customer service?" A survey of the literature shows that many researchers define customer service as the maximum time or distance between a demand and the facility serving it (Daskin and Owen 2003). But, distance alone does 
not always directly relate to transportation costs. Instead, freight rates are influenced by market conditions that are the result of inefficient and imbalanced freight conditions. Harris (2005c) states that a successful warehouse network design should consider both inbound and outbound transportation costs.

In 2004, Taylor et al. prepared exploratory research where they examined the feasibility of creating distribution networks of various sizes (one to ten distribution center locations) based on customer service and cost goals for truck freight rates and market types rather than the traditional goals implored by average distance minimization models. They compiled transportation costs for both homogeneous and hybrid networks using simplistic assumptions. That introductory work suggests that significant savings for the U.S. freight bill have the potential of being realized.

Based on the preliminary results prescribed in Taylor et al. (2004), an extension is developed under more realistic assumptions. Since this problem addresses the issue of distribution center location, a significant financial investment with long range preparation, this scenario adequately represents the characteristics of a strategic planning problem. 


\section{CHAPTER II}

\section{REVIEW OF LITERATURE}

Many approaches have been implemented to combat freight imbalance directly. These methods include optimization, heuristics, and simulation studies. Other approaches have attempted to combat freight imbalance indirectly. That research has examined such things as driver turnover, driver recruitment and retention strategies, freight pricing, and fleet management. This chapter discusses relevant research related to these issues as well as specific research regarding hierarchical planning and each of the three problems examined herein. This chapter discusses both problem types and solution techniques.

\subsection{Freight Imbalance}

As mentioned in Chapter I, freight imbalance is inevitable across all logistics disciplines as well as in the truckload freight industry. Freight imbalance is correlated to population and manufacturing. Across the United States and other countries, separate population and manufacturing centers arise because of their unique economies of scale. As a result, distribution of people and goods is not uniformly distributed and the freight network is inherently imbalanced (Hall 2003). Figure 2-1 (Fekpe et al., 2002) shows a graphical depiction of the daily U.S. truck traffic for 1998. 


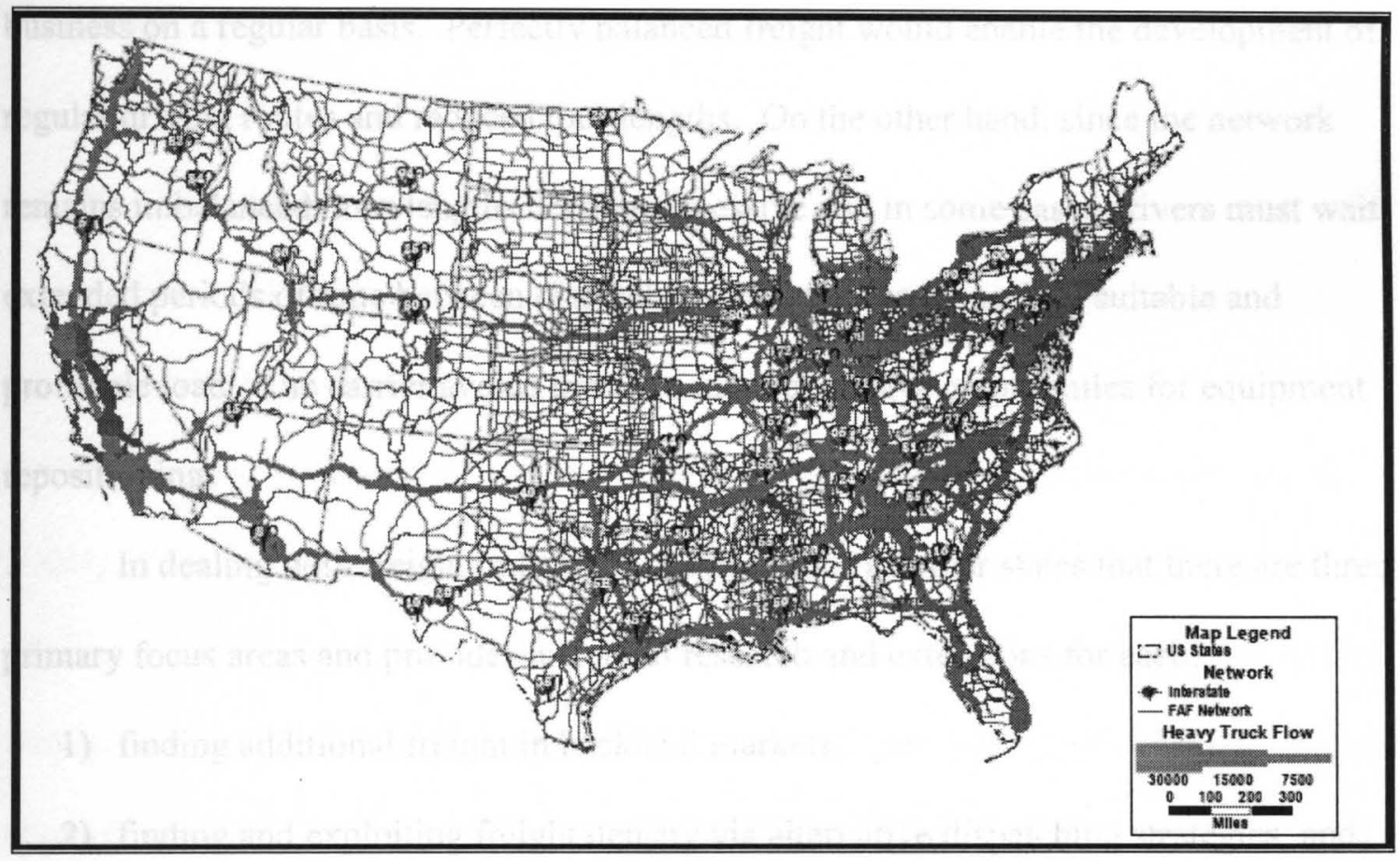

Figure 2-1- Annual Average Daily Truck Traffic Flow Map -- 1998 Data (Fekpe et al., 2002)

Taylor (2003) provides a comprehensive discussion of truckload freight imbalance and reviews various ways that carriers attempt to manage it. Since manufacturing and consumption both occur at discrete points, Taylor describes how individual locations are either freight sources (also called headhaul markets) because manufacturing is relatively greater than the population base, or locations are either net receivers (also called backhaul markets) because manufacturing is relatively less than the population base. Inefficiencies and price differences occur when attempts are made to reconcile the two market types. Hall (1999) quantifies imbalance in the LTL industry. Cheung and Chen (1998) and Crainic et al. (1993) address imbalance issues specific to maritime transport and Sherali and Suharko (1998) examine the effects of imbalance in the rail industry. 
Taylor (2003) claims that imbalance affects the way a carrier performs their business on a regular basis. Perfectly balanced freight would enable the development of regular driving routes and reduced tour lengths. On the other hand, since the network remains imbalanced, tour lengths become excessive and in some cases drivers must wait extended periods of time between dispatches while the carrier seeks a suitable and profitable load. The carrier avoids trying to incur excessive empty miles for equipment repositioning.

In dealing with freight imbalance, Taylor (2003) further states that there are three primary focus areas and provides historical research and extensions for each:

1) finding additional freight in backhaul markets,

2) finding and exploiting freight density via alternative dispatching strategies, and,

3) developing yield management strategies to assist with freight management in the presence of imbalance.

Spatial equilibrium models (SEM's) are models which solve the simultaneous equilibria of plural regional markets under the existence of transportation costs between two regions. Nagurney (2005) examines SEM's related to transportation network infrastructure from a geographical and spatial systems perspective. However, she does not specifically address pricing related to the imbalance. A subset of SEM's are spatial price equilibrium models (Friesz et al. 1983, Harker and Friesz 1986a and 1986b, Harker 1987). This class of models has been well studied for the prediction of interregional commodity flows (Current et al. 1990). They simultaneously determine flows between producing and consuming regions as well as the selling and buying prices that satisfy the spatial equilibrium conditions. However, their elaborate formulations become large and 
complex when applied to realistic situations and they become impractical for aggregate modeling.

\subsection{Fleet Scheduling and Management}

One way to address freight imbalance is through fleet management. Because of the complexity of solving a problem globally through linear programming, Powell et al. (1995) produced a dynamic modeling approach called the Logistics Queuing Network (LQN). They examined driver to freight assignments in unbalanced capacity situations. Their application proposes a system of smaller subproblems that are solved individually through simulation. Their approach was found to find near optimal solutions quickly and allowed analysts to perform "What-if" scenarios in a timely manner.

Arunapuram et al. (2003) present a variation of the vehicle routing problem (VRP) where it is assumed that a full truckload of demand will be sent outbound. They use a branch-and-bound algorithm. They seek to determine minimum cost routes for shipping a given number of truckloads between specified pairs of cities. Their research focused more on local solutions between specific pairs of cities rather than a global solution.

Yang et al. (2002) introduced a real-time multi-vehicle truckload pick-up and delivery problem. They examined costs of freight imbalance such as empty travel, jobs delayed, and jobs rejected. They introduce a new optimization-based policy and compare it to other rules that had been developed in existing research efforts. Although they examine the costs of freight imbalance, they admittedly simplify the problem with 
assumptions that do not consider working hour regulations, getting drivers home, or the suitability of driver and equipment to a potential dispatch.

A final research effort that has the potential for future study applications was developed by Powell et al. (2003). They establish a set of definitions, assumptions, rules, and equations to describe a broad set of problems with a unique terminology. Their paradigm addresses problem types that they have coined Dynamic Resource Transformation Problems (DRTP). They apply their paradigm to an example of a truckload driver assignment problem involving deadhead and domicile characteristics. Their presentation does not solve the problem. However it is an example of the versatility of their paradigm and how such a truckload problem could be formulated.

\subsection{Hierarchical Planning and Logistics Applications}

Hierarchical planning is primarily business terminology with broad applications (Lambert et al. 1998, Crainic and Laporte 1997, Crainic 2003). Usually, the hierarchy of the definitions (see also Table 1-1) includes strategic planning (long-term planning encompassing broad details), tactical planning (medium-term planning), and operational planning (short-term planning with specific details). However, Min and Zhou (2002) in their historical perspective of the past, present, and future of supply chain modeling introduce alternative terminology during their discourse on supply chain decision variables. They specifically discuss ranges of planning based on the breadth or depth of decision variables that must be addressed. In a broad sense, they identify location problems (the determination of plant, warehouse, distribution center, and supply source locations) as the most general type of planning problem. They identify allocation 
problems (the determination of location to customer assignments) as the mid range type of planning problem. And finally, in a more detailed sense, they identify network structuring problems (determination of location sizes, service sequence, inventory levels, and size of workforce). Their research applies to the supply chain in a general sense, and does not specifically address the truckload industry.

One caveat that Min and Zhou make note of is that "Considering the broad spectrum of a supply chain, no model can capture all aspects of supply chain processes". They mention that the most successful research only addresses a few items of interest and then finds creative ways to link that research to the conclusions drawn from other research. With this in mind, they state that supply chain models can be classified into two manners:

1) Models based on a mathematical formulation of a problem (deterministic, stochastic, hybrid, or IT-driven models), and

2) Problem scopes and applications (inventory control, production, routing, location, and transportation).

Within the context of this dissertation, I will be conducting research involving Min and Zhou's second classification.

Bowers et al. (2002) summarize the challenges that arise during the assignment of drivers to loads in the truckload motor carrier industry. They also address the operational planning process of implementing a real-time dispatch system in such an environment. They do not develop a new optimization model, but they attempt to explain, at the operational planning level, the difficulties with implementation. Those difficulties include incomplete data, erroneous data, illogical decisions of drivers or dispatchers that 
cannot be quantified, network stochasticity, forecast accuracy, credibility of computer models, and free will. In conclusion, they state that just as there is no perfect world, analysts must accept that neither will there be a perfect model. Nevertheless, master planning still has its benefits and should not be eliminated.

Simchi-Levi and Simchi-Levi (2003) discuss creating a supply chain strategy. With much of the same rhetoric as Bowers et al. (2002), Simchi-Levi and Simchi-Levi state that supply chains are inherently complex and encompass the entire process from customers to suppliers. They stress that supply chain strategy involves network planning to balance inventory, transportation, and manufacturing. In discussing planning characteristics, they differentiate between network planning (which typically involves long-term plans over many years) and supply chain planning (which is done over months or weeks with a high frequency of re-planning). They note that the lower the planning level, the more detailed the plans have to be. However, a benefit of lower planning levels (i.e. operational planning) is that results are typically delivered quickly. In the scope of the research in this dissertation, their insight demonstrates the benefits of being able to precede potential long-term results (i.e. the distribution center location problem and the driver domicile problem) with a few immediate results that can be quickly implemented (i.e. the weekend problem).

Taylor et al. (2001) examine multi-zone dispatching in truckload trucking. They examine zone dispatching methods via computer simulation. Their predominant evaluation criterion was to minimize empty repositioning costs. Their research provides planning approaches that could address freight imbalance at both the tactical and operational planning levels. Roy and Delorme (1989) build an LTL network 
optimization model for addressing imbalance at the tactical planning level. Their approach seeks to simultaneously satisfy the double criteria of economic efficiency and service quality. They target tactical planning because they are emphasizing the design of the service network and the subsequent routing of freight. Schmidt and Wilhelm (2000) look at aspects of international logistics networks and describe modeling issues related to each of three planning levels: strategic, tactical, and operational. They highlight issues facing multinational companies and describe roles of the decision makers. Their primary focus is in a manufacturing environment rather than in trucking or transportation. A review of related hierarchical planning literature is provided.

\subsection{The Weekend Problem}

The following sections break down existing literature that is directly related to the characteristics of the weekend problem.

\subsubsection{Calendar and Weekend Effects}

A review of existing literature shows that there has been little emphasis on the cyclical imbalance of freight during the course of week. Powell (1996) developed a realtime dynamic scheduling tool. He provided an introduction to the load matching problem for truckload motor carriers and an overview of a different modeling approaches.

Though his emphasis was not on weekend issues, he discussed how daily load distributions influenced the ability to assign loads. As part of his research, he analyzed the daily distributions for loads being called in and reported that Monday and Friday were the heaviest days of the week and that Saturday and Sunday were significantly smaller. 
Figure 2-2 shows the cyclical nature of the daily load distribution as reported by Powell. The bars in Figure 2-2 represent the daily freight volumes whereas the solid line represents an average daily freight volume (14.29\%) if, ideally, freight volume remained level throughout the week. Data provided by J.B. Hunt for this research shows a similar, but not identical, cyclical pattern to that presented in Figure 2-2. Powell (1991) states that a carrier may be able to encourage additional weekend freight by actively soliciting it, presumably through economic incentives for the shippers. Powell et al. (2000) extends this research with a further look at dynamic routing and scheduling.

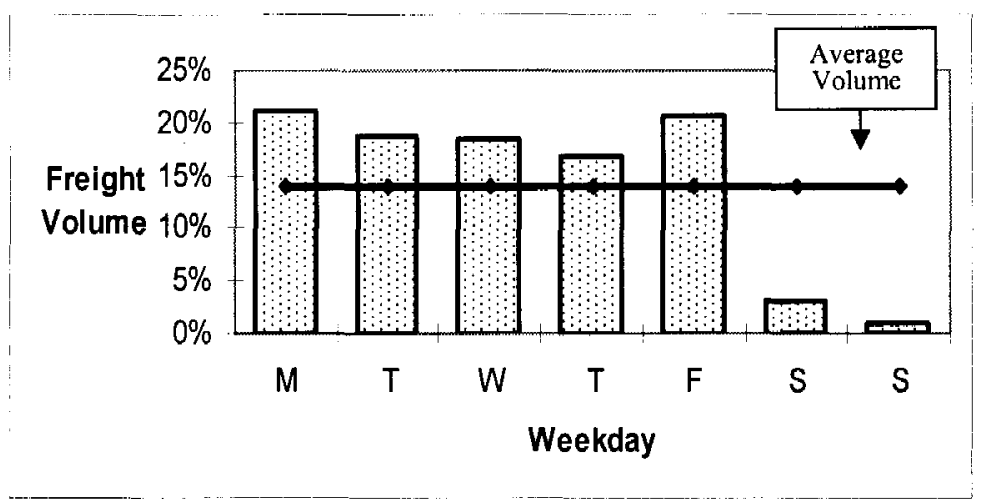

Figure 2-2 - Daily Freight Volume Distribution (Powell, 1996)

Godfrey and Powell (2000) addressed the problem of forecasting daily freight demands for a large freight transportation application. Over their time-horizon they must forecast spatial activities on a daily basis that are subject to multiple, complex calendar affects. Their research primarily looks at an adaptive freight forecasting approach in the presence of cyclical calendar events such as seasons, holidays, and promotions rather than weekday or weekend freight patterns. 
Other interesting research studies that are outside the realm of truckload trucking comes from Srinivasan et al. (1995) and Muto (1996). These research entries also look at the cyclical nature of forecasting in the midst of calendar effects. They examine special period peak load forecasting on electrical power systems. Muto (1996) presents a peak load forecasting for special days (i.e. Saturdays, Sundays, and holidays) which cannot be dealt with by models that describe electrical consumption that occurs between Monday through Friday. Muto proposes a separate forecasting algorithm specifically designed for these times. Srinivasan et al. (1995) describe the implementation and forecasting results using a fuzzy neural technique. They have found an applied technique that is capable of forecasting accurately on weekdays as well as on weekends.

\subsubsection{Vehicle Routing and Driver Assignment}

Although there has not been existing research specific to this problem, there have been several related efforts. Powell (1991) provides an overview of different types of truckload problems (vehicle routing, driver assignment, driver/crew scheduling, and dynamic fleet management). This research examines driver assignment and driver/crew scheduling. Powell mentions that the driver assignment problem is the most complicated to implement because of the range of issues that must be balanced. Some of those issues that are incorporated in this research are minimizing total empty miles, satisfying driver requests to return home, and satisfying shipper needs. Powell also defines four major components related to truckload operations: driver assignment (determination of drivers to loads), empty repositioning (fleet management when there are more drivers than loads), load selection/evaluation (determination of which loads to accept when number of 
loads exceed drivers), and load solicitation (the process of attracting additional freight when number of drivers exceed loads). This dissertation looks specifically at driver assignment and load selection/evaluation and also considers empty repositioning as dray assignments are made. However, unlike Powell who talks about the merits of load solicitation through price incentives, the strategy in this dissertation allows a carrier to creatively solicit additional Friday capacity so that it can be processed on the weekend when more drivers and equipment are available.

The process of draying has been well researched in the literature. The Old English origin of the term dray refers to a low, strong, heavy, sideless cart that was used for hauling by horse (Merriam-Webster 2005). Within today's transportation industry, the term typically refers to that portion, either occurring at the beginning or end of an intermodal journey, where rail freight is transported via truck to or from another location not accessible by rail. Cordeau et al. (1998) provide a comprehensive survey of optimization models for train routing and scheduling and discuss how the use of drays had been incorporated in the decision making. Taylor et al. (2002) argue that as the trucking industry becomes more competitive, carriers will need to be creative with finding cost-cutting solutions to trucking issues. They experimented with methods to reduce total empty miles and circuitous miles when making intermodal drayage movements. Within this dissertation, a new manner of using drays is introduced so that carriers may reduce the level of empty weekend repositioning while potentially increasing miles driven on the weekends.

Braver et al. (1999) surveyed dispatchers to find out the role that shipper demands played on the determination of accepting or declining specific loads. Their findings 
indicated that there was a lot of emphasis placed on meeting delivery requirements, but their study did not report about the impact of meeting specific pick-up requirements. J.B. Hunt, however, emphasizes that if their company cannot meet specific pick-up requirements, shippers will contact other carriers until one is found that can meet both requests. During the time between pick-up and delivery, however, it is the discretion of the carrier to operate efficiently. It is during this time that the yard stacking technique can potentially be exploited.

\subsubsection{Quality and Driver Turnover}

Quality has been another issue related to the trucking industry. Taylor and Meinert (2000) state that the primary difference between LTL and truckload carriers from a driver perspective is tour design. From a driver viewpoint, they claim that a driver is primarily concerned with three issues: (i) pay; (ii) tour length; and (iii) job quality while on the road. Mele (1989a and 1989b) point out that turnover rates among truckload trucking companies can range from $85 \%$ to $110 \%$ per year, while it is typically less than $10 \%$ for LTL drivers. The work of Gupta et al. (1996) also supports these findings and Vise (2004) states that current LTL industry turnover is less than $20 \%$. Richardson (1994) claimed that over-the-road (OTR) driver turnover was approximately $110-120 \%$ industry wide. Other researchers concur with these findings and present individual industry examples where OTR turnover rates extend up to $200 \%$ annually (Corsi and

Fanara 1988, Gupta et al. 1996, Griffen et al. 2000, Staplin et al. 2003). However, recent data from the ATA reports that turnover rate for the industry reached a record level of $136 \%$ during the $4^{\text {th }}$ Quarter of 2004 (Transport Topics 2005) and still remains high 
through the $1^{\text {st }}$ Quarter of 2005 (Nguyen 2005, American Trucking Association 2005) at $120 \%$. Whicker's (1998) evaluation of driver turnover has turned over the point that exit interviews performed by J.B. Hunt indicate that $70 \%$ of current turnover is based on tour length issues and is not based on pay. Kilcarr (2001) reports that the industry has traditionally thrown more money at the problem, yet turnover continues to creep back up. He goes on to state that "If trucking companies could figure out a way to give drivers more home time, rather than simply more pay, that might help solve a lot of the driver turnover problem."

In the wake of high turnover within a competitive industry, Schwartz (1992) asserts that driver recruitment and retention is a key truckload trucking business strategy. Taylor and Meinert (2000) claim that a carrier's ability to recruit and retain drivers is a highly desirable quality trait. According to Cox (2004), carriers who improve pay and keep miles high will have a large pool of drivers to choose from. Whereas, Goodson (2000) states that a carrier's success depends heavily on its ability to "keep drivers happy" by assigning them profitable loads. Retaining drivers requires that the carrier must help keep drivers satisfied in their jobs by giving them reasonable tours. Cullen (2003) comments on the state of the trucking industry and claims there are two undeniable aspects of driver turnover and driver shortage. First, it will never go away. Second, carriers can never stop investing to address it. The driver shortage stems in part from wage and negative life style attributes (i.e. minimal family time) for long-haul truck drivers (Richardson 1994). Therefore, there remains an ongoing emphasis to address turnover and create a win-win situation for both drivers and carriers. 
Other research examining driver turnover, driver recruitment, and driver pay can be examined in sections $2.5 .1,2.5 .2$, and 2.5.3.

\subsubsection{Airline Industry Applications}

In regard to weekend scheduling, research related to weekend airline equipment planning is also examined. A comprehensive review of the current state of airline crew scheduling issues can be found in Barnhart et al. (2003). Previously, Rushmeier and Kontogiorgis (1997) developed a computer optimization tool for weekday fleet assignments. They described the unique issues involved with managing a fleet of aircraft during the week when demand was high, and the problems that came about during the weekend when airlines had to be repositioned without enough passenger demand to meet airline capacity. Kontogiorgis and Acharya (1999) extend this research by developing a weekend fleet scheduler optimization.

Klincewicz and Rosenwein (1995) develop a weekday "skeleton" staffing schedule to handle the daily, repetitive workloads experienced between Mondays through Fridays. However, as they note, the passenger demand pattern changes on weekends by significantly decreasing. The decrease in demand produces "exceptions" to the skeleton schedule. The authors describe a network flow formulation to identify and suggest possible exceptions that would be profitable. They use graph theory to detect flight legs that are profitable and unprofitable during weekends.

Though airline passenger demand is not the same as truckload freight demand, some challenges are similar. Kontogiorgis and Acharya mention that weekend planning must balance two opposing objectives. A weekend schedule must be produced that is 
different enough from the weekday to capture changes in demand patterns and yet similar enough to avoid excessive reassignments and their resulting high costs. The integration of weekday and weekend goals is part of the challenge that is undertaken in this research. Unfortunately, airline fleet scheduling does not have much direct application to the truckload trucking problem. Airline customers, unlike freight, have very specific demand schedules and would be unwilling to submit themselves to a system that would result in intermediate, overnight layovers as is proposed by the draying of Friday freight.

\subsection{The Driver Domicile Problem}

The following sections discuss existing literature identified as being related to the driver domicile problem. Other issues relating to driver turnover have been reviewed previously in section 2.4.3. However, within section 2.5 , the driver turnover emphasis looks at turnover from a perspective that addresses both its causes and effects. A leading cause of driver turnover is the infrequency that driver's return home on a regular basis. Also related to driver turnover are recruitment and retention strategies as well as driver pay issues.

\subsubsection{Causes and Effects of Driver Turnover}

Rodriquez et al. (2000) surveyed top managers of 15 nation-wide, non-union truckload carriers who estimated that each incident of turnover cost their company between $\$ 50-\$ 5000$. From the range of responses, the researchers point out that managers do not have a good understanding of the true costs and business losses associated with driver turnover. Though some costs can be easily calculated, 
consequential costs are often overlooked or appear incalculable. From data collected by Rodriquez et al., an average turnover cost for all surveyed carriers was calculated to be $\$ 8,234$ per incident (with a range from $\$ 2,243$ and $\$ 20,729$ ).

Rodriquez et al. grouped the turnover costs into four broad categories:

1. Entry and exit administration costs,

2. Fixed asset costs due to idle equipment,

3. Profit loss due to idle equipment, and,

4. Other costs.

They estimate that driver turnover costs the entire truckload industry as much as $\$ 2.8$ billion annually.

Another comprehensive study in 1996 by Gupta et al. surveyed 379 top managers of truckload and LTL companies. Of the companies surveyed, the average quit rate among all driver types was $27 \%$, but ranged between $0 \%-250 \%$ with the highest turnover rates experienced by truckload companies. The major reasons cited for quitting were pay and benefits, time away from home, and dispatcher problems. Truckload drivers were found to be routed home about four times per month whereas LTL drivers were home almost every day. They found that $90 \%$ of drivers leave one company to go to work for another company (an industry phenomenon called churning). Only $10 \%$ of the drivers quit the trucking business altogether. When drivers were asked to identify the most important factors that influenced them to leave their present employer, too much time away from home and long hours were among the top five most cited factors. From this response it appears that carriers can partially overcome the driver shortage problem by letting drivers balance their time on the road and their time with family. 
Though a lot of existing research attributes voluntary turnover to driver dissatisfaction, Kalnbach and Griffen (2002) attempted to go beyond that theory and identify other predictive factors that would lead to voluntary turnover. Their research indicated that much of the voluntary turnover involved quick, impulsive decisions. They found that $30.7 \%$ of the voluntary turnovers occurred within 0-6 months after a driver was hired. Drivers with less conscientiousness and who possessed greater skills were also quicker to voluntarily quit. For them, there was no personally held stigma about maintaining their loyalty to the company. They also believed they had options with other companies because of their personal skills. As a result of Kalnbach and Griffen's research, they concluded that most drivers felt the carrier could have done something proactive to prevent their voluntary turnover decision. Instead, expectations of the carrier contributed to impulsive decisions by the drivers.

FleetOwner (2004) reported that in spite of record high turnover rates, many truckload carriers have been increasing drivers pay. Less-than-truckload companies, on the other hand, already offer higher pay as well as the promise of more time at home during nights and weekends. FleetOwner claims that in spite of the pay increases, the inability of truckload carriers to provide more nights at home is a hot-button issue affecting driver turnover.

Staplin et al. (2003) examined issues related to driver safety. Their primary conclusion shows that if drivers can be retained, companies would have better safety records (i.e. fewer accidents). They suggest that smaller trucking companies offer operational benefits to drivers that encourage driver retention and result in safer operations even if the actual pay level is somewhat lower than what drivers could earn if 
employed with a larger firm. These benefits include more personal relationships among owners, managers, dispatchers, drivers, and the drivers' families. Another conclusion made by Staplin et al. is that individual drivers with two or more employments for a period of two or more years are likely to have higher accident rates. Related work is presented by Rodriguez et al. (2003). They examine the combinational effects that driver compensation and work conditions play on driver safety. They examine data over a 26 month period and correlate them to assembled demographical driver profiles. They found that as a driver's tenure increases, the probability of the driver having a zero crash count (i.e. the probability of a driver having zero crash incidents since the date they were hired) increases over the driver's first 5.81 years with the firm before it subsequently begins to decrease. However, the zero crash count probabilities of tenured drivers does not decrease below that of new hires until drivers have approximately eleven years of tenure. Rodriguez et al. also report that drivers zero crash count probabilities decrease as a driver's pay increases. Their findings are consistent across multiple driver demographics.

\subsubsection{Driver Recruitment \& Retention}

Fifteen company executives interviewed by Christenson et al. (1997) claim that the industry shortage of qualified drivers is moderate or severe. They also report that the long haul, full truckload segment suffers the most from the shortage of drivers.

Furthermore, the Midwest, a considerable region for headhaul markets, was the leading region for driver shortages. The researchers went on to survey 801 drivers who had been with their respective companies for $5+$ years. Although hours of work and time with 
family was the number three reason indicated for driver turnover, in response to 21 job attributes, steadiness of work (i.e. consistent driving assignments) was cited as the most important job attribute that drivers wish their carriers could improve. Other attributes rounding out the top five mentioned by drivers were support from the company while on the road, genuine care of managers, hours of work, and pay.

Research by Min (2002) arrived at three conclusions regarding driver retention strategy. First of all, competitive pay was not found be an integral part of building a good relationship between carrier and drivers. Research from the ATA (Christenson et al. 1997) bears this out. They report that about $80 \%$ of the driver shortage problem is due to driver churning (moving from one company to another with the same pay.) Instead, Min reports that job security has been found to influence driver retention more than driver pay. Second, Min found that experience and tenure influences turnover whereas a driver's age does not. This implies that a company's recruitment and retention strategies should emphasize long-term job stability. And finally, Min found that the size of the firm adversely affects turnover. Smaller companies retain drivers better than larger companies because they are able to provide more personal care and attention to their drivers.

Min and Lambert (2000) rank the most prevalent incentives (both monetarily and non-monetarily) that carriers use to retain and motivate drivers. They also analyze how effective those incentives are. Their results show that although pay incentives are appreciated, they do not retain drivers on their own. They conclude that driver shortage is the symptom of driver management and that the shortage is a serious threat to the competitiveness of trucking firms and industry. 
Min and Emam (2003) have findings that indicate unionized or full-time drivers are less likely to cause turnover than non-unionized or part-time drivers. Therefore, to counteract that trend, they argue that relatively large firms should pay more attention to developing a positive work environment (i.e. better fringe benefits, career advancement opportunity, flexible schedules, and job security). Min and Emam state that nurturing a strong bond between drivers and dispatchers will have a positive impact on driver retention. This research alludes to the premise that there would be less driver turnover if dispatchers could impart a greater influence in "taking care" of their drivers by doing things such as, for example, getting them home more regularly.

Other research related to driver retention includes Keller and Ozment (1999) who look at dispatcher effectiveness. They develop a model based on behavioral theory. Their research found that drivers get home about once every three weeks. Furthermore, they conclude that dispatchers have a greater impact on a firm's ability to retain drivers than was previously known. They state the following:

"It is now widely acknowledged that the shortage of qualified drivers is not nearly as serious as once believed; however, turnover remains at extreme levels. Most driver turnover is due to drivers leaving one firm for another with similar pay and working conditions. While there is some evidence of increasing pay scales, few firms are able to afford this strategy. Thus, it becomes paramount to determine what triggers a driver's decision to quit. In an environment where employees feel they are underpaid and spend too much time away from friends and family, it is important for direct supervisors to be sensitive and responsive to their needs."

Research commissioned by the American Truck Association (Johnston and Packer 1987) identified steps that would allow the industry to correct driver shortages.

First of all, it was recommended that carriers could overhire and let natural attrition bring driver levels back to acceptable levels. However, with turnover rates as high as $150 \%$ or 
more, this strategy wouldn't last long. Secondly, carriers could encourage retention by providing better pay, more regular and predictable hours, and greater benefits.

Maslow's "Hierarchy of Human Needs" and Herzberg's "Two-Factor Theory of Job Satisfaction" were part of the industrial psychology theory that motivated the work of Griffen et al. (2000). Their findings show that voluntary turnover in the truckload industry often exceeds $150 \%$ whereas it is in the single digits or teens for many other comparible industries. Wages, fringe benefits, and time at home where the most critical psychological factors that were found to affect driver motivation.

\subsubsection{Driver Pay}

A historical perspective of employment and wage trends for trucking employees over the last 30 years was conducted by Engel (1998). She surmises that deregulation and the ensuing intense competition forced the trucking industry to change the quality and types of services it rendered. She also noted that although wage levels are relatively higher in trucking than in the total private economy, real earnings in trucking have declined more rapidly since the early 1970 's. As a result, carriers are faced with demand that force them to aggressively pursue strategies that yield more and more cost reductions or increased efficiency. The ability to realize fewer costs associated with return trips to driver domiciles is one area that could make an impact.

Lafontaine and Masten (2002) contribute to the understanding of contracting practices in the trucking industry. They differentiate between two prevalent types of compensation. Drivers are usually paid by the mile or an agreed upon percentage of the shipper's freight bill. They examine factors which influence driver-carrier contracts and 
derive a mathematical framework for bringing equilibrium to both parties (drivers and carriers). Rodriguez et al. (2003) provide additional demographic driver profiles and pay attributes conducted over a 26 month study of a large truckload trucking firm. Their results suggest that occupational and labor market factors, such as pay, tenure at the job, and percent of miles driven during winter months, have a significantly better explanatory power of crash frequency than demographic factors.

\subsubsection{Existing Driver Domicile Research}

As the previous two sections show, the literature offers abundant research relating to driver turnover and, subsequently, ways to retain and motivate good drivers. Although numerous studies have been conducted to demonstrate that driver turnover is excessive and that driver domicile issues are a leading cause, the literature lacks a depth of research related to handling driver domicile problems. Hall (2004), however, provided a significant contribution to domicile theory. His research emphasized the design of longhaul LTL networks and worked on determining how drivers should be distributed among locations. One of the things he was able to show was that by concentrating drivers to a limited number of terminals, the carrier could have a greater flexibility to respond to random demand variations. Hall identifies key decisions in the design of long-haul networks and claims that from a planning standpoint domicile problems can be addressed from the operational planning level all the way up to the strategic planning level. However, since he is examining an LTL network, he is proposing regular routes and fleet sizes that go between an existing set of known terminals. Furthermore, the routes logically begin and end at the same places where fleets are based. This largely eliminates 
the need for deadheading equipment. Conversely, the type of modeling framework presented by Hall cannot be directly carried over to the truckload trucking industry where routes are more random. A problem genre closer in relationship to the parameters of the truckload industry can be found in airline crew scheduling problems (Barnhart et al. 2003). These problems, unlike LTL problems, focus on assigning crews with fixed domiciles to a set of variable routes.

Within the truckload trucking environment are a number of research efforts introduced by Taylor and others (Taylor et al. 1999a, Meinert and Taylor 1999, Taylor and Meinert 2000, Taylor et al. 2001) that used computer simulation and were shown to have consequential domicile effects. None of these works address domicile issues directly. Rather, domicile knowledge was gained as the natural consequence of studying other trucking problems. For instance, Taylor et al. (2001) examined multi-zone dispatching by assigning drivers to geographical zones that they did not leave. Instead, the drivers dropped freight at zone boundaries so that it could be picked up (swapped) by a driver from an adjacent zone. As a result of their study they found that drivers domiciled at the swap yards were ensured of having frequent domicile returns. If empty travel is required for a domicile return, the move was probably small due to the geographical restrictions placed on the drivers. This work was preceded by Taylor and Meinert (2000) which focused on clinical trials and Taylor et al. (1999a) which was limited to a single-zone implementation. A historical perspective of dispatching methods used in attempts to regularize truckload freight was summarized by Meinert and Taylor (1999). This perspective also included a brief look at zone dispatching. 
Taylor (2002) discusses freight density. He briefly summarizes a suite of software tools used to find and exploit various types of freight density. Each type of density can be analyzed and exploited to produce more efficient and more "regular" driving tours. As a result, drivers can use the density to return more frequently to their domiciles. He describes an economy of scale that occurs when locations have dense return or pass-through freight. He suggests that those areas may be candidates for the establishment of driver domiciles.

The research of Taylor et al. (1999b) examined the use of dedicated fleets among trucking companies. The goal was to produce regular lanes that, in turn, may satisfy drivers with more regular tours. They examined levels of inter-facility freight density to determine appropriate levels that would permit the use of dedicated fleets. Domiciles were discussed in the context of closed-loop tours which were said to help return drivers home more frequently.

The findings of Taylor and Whicker (2002) show that the placement of drivers in different domicile sets highly influences the outcomes of tour lengths when "popcorn" dispatching was utilized. The name "popcorn" is used to describe a dispatching method where drivers bounce randomly among the confined network and return to their domicile relatively frequently, although at random times. Their conclusions show that the placement or selection of domiciles affects the amount of time a driver will be away from home.

The objective of the work presented by Kutanoglu et al. (2001) was to build a driver-based aggregate planning model that would determine driver needs by domicile. Their research described new optimization and simulation tools to address driver 
dispatching and tour formation in truckload trucking. However, they did not attempt to identify ideal domicile locations.

The work of Coslovich et al. (2003) primarily considers transportation costs and fleet management issues incurred within the truckload industry. From a strategic planning perspective, their goals minimized present and future operating costs incurred by carriers. They consider the drivers' desires to return to their domiciles after carrying specific series of hauls. Resources (drivers, trucks, and trailers) were positioned at the end of each day to be in proximity to the next day's origin. Although driver domicile decisions were not their research motivation (they stated that driver desires only compose minor costs), their model incorporated drivers' needs to return home regularly so that turnover could be controlled. Their approach used integer programming and Lagrangian relaxation to decompose the overall problem into three solvable sub-problems.

\subsubsection{The Traveling Salesman Location Problem (TSLP)}

The traveling salesman location problem is an evolution of the traditional traveling salesman problem (TSP) or vehicle routing problems (VRP). Comprehensive discussions of these problems can be found by Gutin and Punnen (2002) and Toth and Vigo (2001) respectively. Whereas the traditional TSP's seek to minimize the total distance traveled from a fixed starting location, the TSLP's add the complexity that the starting location (i.e. domicile) can not only be changed, but it can be optimized.

Handler and Mirchandani (1979) state that the TSLP is difficult to solve because it involves the simultaneous solutions of both traveling salesman problems and location problems. Burness and White (1976) introduce the problem. They seek to determine a 
location where total travel costs are minimized. Their solution is an iterative approach that simultaneously solves multiple TSP's for each improvement iteration of the starting location. Travel times are deterministic. Mirchandani and Odoni (1979) examine TSLP's where the travel times are random variables with known probability distributions. They show that when the travel times are substituted by their expected values that inferior locations will be identified in the solution. And finally, Hakimi (1964) examines weighted graphs to find their absolute center and absolute median. It is shown that the optimum location of a switching center in a communications network (such as a telephone interconnection system) always occurs at a vertex of the graph. On the other hand, the best location for a police station or a hospital is not necessarily at an intersection. Rather, since the goal is usually to minimize the maximum travel distance to the outlying points of the service area, then one must find the absolute center of the graph. Hakimi's results were used by subsequent practitioners of TSLP problems.

Berman and Simchi-Levi (1986, 1988a, 1988b, 1988c, 2001) conduct multiple research projects related to the TSLP's. In 1986 they solve a multi-stop (i.e. delivery vehicles) problem for a tree network. In 1988a they examine simple networks and describe special cases where efficient algorithms could be developed during future research. In 1988c they address the dual problem of finding the optimal home (domicile) location for a given tour sequence and the reverse problem of finding the optimal tour sequence for a given home (domicile). In 1988b, while presenting a heuristic for the network problem, they share interesting asymptotic results for the behavior of the expected distance traveled. They found that when the number of uniformly distributed demand points is very large, and all demand points have equal demand probabilities, then 
the expected distance traveled does not depend on the starting location of the tour. This type of result may have practical applications in a nationwide truckload trucking study of domiciles. In 2001, they provided a solution technique for TSLP's in a stochastic network.

Although the TSLP's have obtained considerable attention in the literature, it should be noted that their theories were built upon small networks and several simplifying assumptions. But considering the size of the U.S., developing a TSLP for a nationwide truckload trucking network with infinite demand points and random travel times would be computationally prohibitive. Nevertheless, one may be able to formulate such a network by using a modified TSLP approach (Bodin et al. 2003).

\subsection{The Distribution Center Location Problem}

The following sections review the scope of literature that have been found regarding the distribution center location problem.

\subsubsection{Freight Pricing}

The price for freight in and out of headhaul and backhaul markets is the result of freight imbalance in the network. Therefore the problem of locating a distribution center will be influenced by the types of freight rates (both inbound and outbound) that would exist in various locations. Although the price for freight can be established through standardized rate schedules or by a one-to-one agreement between a shipper and a carrier, there are other ways that a shipper can manage their supply chain to secure better freight rates for themselves. Harris (2005d) states that a trucking network should consider both 
the acquisition (inbound) costs and not just the costs from the warehouse to the customer (outbound). Harris (2005b, 2005d) also states that few companies do this well. In fact, according to Deloitte (2003), only $7 \%$ of companies effectively manage their supply chains. However, these companies are $73 \%$ more profitable than other manufacturers. Due to rapidly rising truckload freight costs, management of supply chain costs is very unstable. The causes of the instability include recent federal hours of service revisions, escalation of diesel and gasoline prices, shortage of drivers, and increases in driver pay within the truckload industry to combat driver turnover. As a result, freight rates have increased rapidly (Bohman 2004).

Ledyard et al. (2002) introduces the theory of combined value auctions for establishing partnerships between shippers and carriers. They look at the costs of freight lanes and determine if it would be profitable to accept single lanes or lane pools. The authors attempted to use the combined value auctions to handle short-term freight imbalance issues. Raychaudhuri and Veeramani (2005) consider bidding strategies in multi-round auctions for transportation services. Their research problem addresses the determination of sets of bundles to bid on, bidding strategies, and best bid scenarios that would maximize shipper profits.

Friesz et al. (1998) produced research with the purpose of creating a dynamic description of interregional commodity movements which have steady states consistent with traditional static spatial price equilibrium models. Using an operations research approach to solve their problem, their research examines price dynamics and how a state of disequilibrium can be brought into balance over time. 
Fares were considered by Fernández et al. (2003) when they examined intercity routing decisions. They presented a demand-supply equilibrium for the modeling of interurban, multi-modal, freight transportation systems. In conclusion they surmised that transportation fares paid by shippers must be related to the operating costs experienced by carriers. In the formulation proposed, fares were equal to marginal costs plus profit.

Another strategy that has been used to partially defeat imbalance is yield management (Taylor et al. 2001, Taylor 2003). Although the trucking industry lags behind other industry segments, the research discusses the ability to fix pricing by using yield management strategies, which can go a long way to shape customer behavior and to add discipline to carrier load acceptance policies. Some freight delivery lanes are much more expensive than others based on the fact that freight imbalance creates good and bad marketing areas. Carriers use yield management to focus on full network aggregate capacity and to identify profitable lanes.

Finally, sometimes carriers loosen their profit objectives for the sake of keeping idle drivers and equipment moving when business is slow. For instance, Goodson (2003) states that from a carrier perspective, companies must be smarter with the freight they acquire instead of just trying to accept freight on slow days that may not meet their profitability needs. To demonstrate this he uses an example of a carrier who relies on tap accounts (accounts that a carrier can contact when it needs extra freight). The logic of the carrier is that it is "OK" to give up some profits now, if you can avoid idle trucks when things get slow. Goodson goes on to show that excessive use of tap accounts may seem acceptable in the short term, but they are actually very costly in the long term. Arcelus et al. (1998), who examined linehaul moves of a large Canadian LTL company, 
confer with Goodson. They describe how, traditionally, moneymaking headhaul routes with premium prices have subsidized moneylosing backhaul routes where freight opportunities are scarce. As a result, the trucking firm compensates for this imbalance by taking whatever freight is available, even if at a loss. As an alternative, Arcelus et al. provide a tool for revising pricing decisions for the entire dynamic shipping plan rather than only considering single shipments.

\subsubsection{Empty Repositioning and Backhauls}

Because of network freight imbalance, it has already been established that there will be times were equipment is not located where a freight demand exists. In those instances an empty repositioning move will need to be made by the carrier so that they can obtain the load for pick-up. Calişkan and Hall (2003) develop an efficient operational model to optimize empty equipment and crew movements in the long-haul portions of an LTL network. Unlike many distance minimization models, their objective is to minimize transportation, driver, and backorder costs while satisfying all demand subject to route length. Using a dynamic mixed integer program model, they consider the costs of repositioning equipment along unbalanced demand-supply arcs.

Jordan and Burns (1984) examine truck backhauling on two terminal networks by formulating a mathematical model for routing trucks to minimize empty truck-miles. Their research considers two terminals and the effect of directional freight flow between them. Jordan and Burns provide strong rationale that backhauling should be an important factor in determining terminal location as well as in the selection of suppliers. Although a goal of their research was to determine backhaul attractiveness, the domain of their 
problem is limited due to the fact that it does not provide any analysis to problems of continental scale. An extension of this work was provided by Jordan (1987) when he examined the multi-terminal problem. The formulation presented is a mathematical program. However, the model is most useful as a weekly or monthly planning tool. The output of the problem identifies which terminals should backhaul with each other, the approximate number of loads that would be involved, and the empty-truck mile savings.

Arcelus et al. (1998), who consider the long-haul portion of an LTL empty haul problem, attempt to optimize backhaul. Sensitivity analysis is used to draw conclusions regarding whether or not it is profitable to take on additional freight for specific origin and destination pairs. They examine the situations where a truck finds itself in a backhaul market where it is essentially stuck. The dilemma for the firm is to make a decision whether or not to take unprofitable freight or to move empty to another location where more profitable freight is available.

\subsubsection{Distribution Center Location Research}

Increasing customer service is a goal of distribution network design, a task that most logistics professionals are familiar with and one that large companies reanalyze frequently (Harris 2005a). Reanalysis is necessary because plans are based largely on future predictions that will require updating as better information regarding the future is obtained (Tompkins and Harmelink 1992). Two common ways to influence customer service are through the determination of where a company should locate their warehouses and how many warehouses they should have. 
Location analysis research is broad and multidisciplinary. Conventional methods (Francis et al. 1992) have focused primarily on distance minimization solutions. However, Current et al. (1990) have reviewed different multi-objective examples within the problem domain and have grouped the objectives into four broader categories:

1. Cost minimization (which includes distance minimization)

2. Demand coverage or demand assignment objectives

3. Profit maximization

4. Environmental concerns

Cost minimization and demand-oriented objectives were found to comprise the majority of the research problems (greater than $90 \%$ ) whereas profit maximization and environmental concerns were only seen in about $10 \%$ of the objective functions.

Contrary to Current et al., however, is work done by Ronen (1997) that disproves the notion presented by Current et al. that cost minimization and distance minimization are one in the same. Cost, of course, will be related to distance. But Ronen's research establishes that solution approaches which concentrate purely on distance minimization can be less effective than approaches focusing on cost. In an examination of LTL shipments, it was found that the distance minimization problems were $35 \%$ more costly than the cost minimization problems. It should be noted that the costs observed by Ronen were attributed to alternate modes (types of trucks) of dispatch. The effect of market conditions due to freight imbalance was not considered. Zhou et al. (2002), in research conducted for the relocation of a national retailer's existing distribution center, concur with Ronen by stating that location problems should consider shipping cost as the primary objective function criterion. 
Daskin and Owen (2003) and Daskin (1995) present various problem classes and identify traditional solution algorithms for discrete and network location problems. Their problem classes are set covering models (appropriate for use when there is a critical service distance, time, or cost that cannot be exceeded for specific origin and destination pairs), average distance models (appropriate for use when there is a need to restrict the total distance traveled among all nodes), and undesirable facility location models (used in modeling the locations of facilities such as prisons, power plants, and solid waste repositories that need to be located far away from concentrated demand nodes or population centers). Daskin and Owen state that these problem classes have been found to be NP-hard and are therefore difficult to solve using integer programming. However, greedy or improvement heuristics, graph-theoretic algorithms, branch and bound, and Lagrangian relaxation are methodologies used to find good solutions (Daskin 1995).

One problem with location analysis such as set covering models (Current et al. 1990, Daskin 1995, and Daskin and Owen 2003) is that they often recommend locating more terminals than can be afforded. However, in addition to costs required to establish and operate additional distribution centers, the network inventory will be diluted such that more "slow moving" items are created at each distribution center. As a result, although transportation costs may decrease, a proportionately greater inventory investment must be maintained (Harris 2005b). Furthermore, Harris states that eventually transportation costs are in jeopardy of rising again when the network size increases. This happens when slow moving items force individual customer orders to be filled by multiple warehouses. This dilemma may offset anticipated transportation gains that result from having warehouses closer to an expected customer base. However, 
although Harris alludes to a fine line between network size and transportation costs, he does not expand on the possibility of a market-based positioning warehouse approach.

Campbell (1990) examines changes in freight density for a fixed region. He develops a continuous approximation model for a general freight carrier that serve a fixed region with an increasing demand density. As the freight density increases, transportation terminals are added to the network in an attempt to decrease overall transportation costs. Although transportation costs are considered, Campbell simplifies the problem by assuming that demand density is uniform throughout the region which counters the goals set forth in this dissertation. In Campbell (1993), the author did further research regarding optimal terminal locations where he once again assumed that demand was uniformly distributed and flowed equally between origins and destinations. Jordan and Burns (1984) and Jordan (1987) also assume uniform demand across the service areas during their research regarding desirable terminal locations for n-sized networks. Keaton (1993) examines the economics of traffic density over an LTL network. A finding of the research was that the average cost per shipment fell sharply as traffic volume increased over a region of fixed size. However, the research was conducted over a hypothetical network and did not use actual data to substantiate its results.

Migliore and Catalano (2003) and Taniguchi et al. (1997) determine the optimal location and size of logistics terminals. Migliore and Catalano break the problem down into a strategic planning model where facility and transportation costs influence terminal locations. They then proceed to provide preliminary detail at the tactical planning level where dispatchers have input regarding the assignment of freight flows. As part of the 
strategic problem, they also examine expected freight trends through the year 2015 . Taniguchi et al. also look at the location problem through long-term strategic planning. In their work they specifically consider the road network and traffic conditions which contribute to their transportation cost function. However, they do not examine how market-based freight imbalance would also contribute to the transportation costs.

In spite of concerns about the adequacy of locating warehouses based on distance minimization criteria and about network size, periodically Chicago Consulting (2005) provides a list entitled "The 10 Best Warehouse Networks". Although many parameters could be considered when assembling their list, they choose to base results solely on the lowest possible transit lead-times to customers within the continental US. Their list includes ten sets of recommended warehouse locations ranging from a single-facility network to a ten facility network.

The recommendations of Chicago Consulting were challenged by Taylor et al. (2004). Their work compared the networks prescribed by Chicago Consulting to that of networks based on market types and transportation costs. Their results indicated that explicitly considering outbound freight rates as a primary site selection criterion can lead to considerable savings. In conclusion, they offer motivation for future research. For instance, in the development of their simulation model, they used population data from the U.S. National Geodetic Survey as a surrogate freight base. Zhou et al. (2002) remark that customer demand in typical location problems is often aggregated according to arbitrary population centers or census districts. They go on to say that such points do not represent true sources of customer demands. As a result, the allocation of aggregated 
customers to distribution centers can lead to underutilization of distribution centers and the deterioration of customer services.

\subsection{Simulation as a Research Tool}

Throughout this review of literature different techniques have been observed for handling the research presented. For instance, in research relating to driver turnover and recruitment, surveys were collected and conclusions were drawn from statistical interpretation. Some research involved mathematical formulations that were solved using linear programming or operations research methods. A few problems, because of their complexity, used approximation techniques to find near-optimal solutions in situations where exhaustive techniques would have been computationally prohibitive. Other problems relied on heuristics, operational paradigms, graph theory, or simply set up mathematical relationships to be solved later. Finally, several of the research problems used computer simulation to examine the effects of stochastic conditions.

The question becomes "What is the best research tool to use when dealing with freight imbalance problems?" Of course, the real answer depends on the scope of the problem and what will be examined. Computer simulation mimics the operations of realworld processes over time and has been found to be a useful and powerful tool for the design and operation of transportation models (Banks et al. 2005). Carson et al. (1997) explored the merits, problems, benefits, and consequences related to the application of simulation for logistics and transportation problems. They claimed that the logistics and transportation problems most suitable for the use of simulation are: 
1. New designs,

2. Evaluation of alternative networks, and

3. Refinement and redesign of existing operations.

Furthermore, Carson et al. describe that the problems best suited to simulation are large stochastic problems with dynamic behavior that don't require a real-time solution. Other applications include problems that cannot be formulated mathematically and problems that rarely, if ever reach steady state conditions. In such problems interactions are complex and cannot be easily solved using theoretical or other analytical tools. As a result of the findings presented in this section, this dissertation will use simulation to analyze the three types of freight imbalance planning problems previously identified. The SIMNET II language (Taha 1991) is selected as the primary research tool. It will be used to perform discrete event system simulation as well as being used as a general purpose programming tool.

\subsection{Summary}

This chapter has shown an extensive review of the existing literature related to the dissertation goals. Although the breadth of work concerning truckload freight imbalance issues is considerable, opportunities still remain to contribute to the present field. In closing, the following observations can be reiterated.

Freight imbalance greatly affects the truckload freight industry. It is inevitable and inherent. Imbalance affects the way a carrier conducts their business. Scheduling and fleet management are some of the techniques have traditionally been used to address imbalance. Hierarchical planning (covering long-term, medium-term, and short-term 
horizons) has been a common approach for addressing problems in many business applications. Application examples were shown in Table 1-1. However, it should be noted that a comprehensive hierarchical planning approach has not specifically studied freight imbalance in the truckload trucking problem.

Chapter 1 proposed three specific problems that could be addressed through hierarchical planning: 'The Weekend Problem', 'The Driver Domicile Problem', and 'The Distribution Center Location Problem'. The literature shows that existing research has been conducted for facets of each problem. But no current research has been found that comprehensively addresses the problems through a freight imbalance perspective.

In the truckload industry, numerous researchers have shown that driver turnover is both critically high and increasing. Whereas the delivery of freight is a cornerstone to the nation's economy, turnover is an issue that must be addressed. Driver frustration regarding driving tours, pay, and infrequency of trips home are significant causes of turnover. However, researchers surmise that carriers can make proactive decisions to circumvent turnover and retain drivers. Addressing truckload freight imbalance through hierarchical planning may be a credible approach. Furthermore, a long-term outcome of confronting freight imbalance is that transportation costs may be reduced as a result of driver turnover decrease and better distribution center location planning.

In the final analysis, the review of literature shows that new work involving truckload freight imbalance, especially work that considers different hierarchical planning horizons, would compliment the scope of research that presently exists. In addition, it has been shown that the use of discrete event system simulation is a viable analysis tool for problems of the size, complexity, and stochasticity presented in this 
dissertation. Other research analysis tools, such as integer or linear programming, have shown to be computationally prohibitive in many cases. 


\section{CHAPTER III \\ OPERATIONAL PLANNING The Weekend Draying Problem}

\subsection{Introduction}

The truckload freight industry experiences long-term seasonality in freight volume as well as cyclical changes on a weekly basis. Freight volume generally peaks on Mondays and Friday, whereas freight volumes on the remaining weekdays are lower. During the weekdays, because of the freight abundance, some carriers are selective with the freight that they accept because they do not have the resources to haul everything they are offered. However, freight volume drops off significantly on the weekend.

This imbalance often causes problems for the random OTR drivers who are on a driving tour during the weekend. Because drivers are only paid for miles driven, lack of weekend freight means that driver wages are drastically reduced. Many drivers find themselves in circumstances where they must wait for freight to become available as company assets sit idle. Some drivers who are stranded from home without a return load may have to return home empty. The irony of the situation is that carriers who are starved for weekend freight may have actually turned down Friday freight because they lacked capacity at that time. A carrier could operate their resources more effectively if the freight volumes were more level throughout the week.

This problem could be addressed through operational planning. Through the addition of short-term dispatching rules, the existing infrastructure of the trucking 
network would not need to be altered. For instance, one possible solution to the problem is to find ways to accept higher volumes of Friday freight without disrupting customer ship schedules that may mandate a Friday pick-up. It is possible that this can be achieved via a technique known as 'yard stacking' in which drivers make one or more short 'dray' moves between customer sites and the carrier's closest terminal yard on Friday. This temporary storage of freight sets up good long-haul opportunities for additional drivers arriving on Saturday or Sunday. By doing this, carriers can increase their Friday capacity by pushing some of it into one of the weekend days. The approach is similar to the problem of making intermodal drays in support of rail moves where the rail move is comparable to the OTR weekend deliveries. This technique has had some limited field testing, but not to the level performed in this research. In an examination of old habits that Goodson (1999) argues must be broken in today's competitive truckload environment, he states that "...the constant swap of favors is how a lot of difficult hauls get moved." The participation of J.B. Hunt Transport, Inc. (JBHT), one of the largest publicly held truckload trucking company in the United States (J. B. Hunt 2005), helped motivate this research and ensures its industrial relevance.

The objective of this research is to examine, via discrete event system simulation, various yard stacking alternatives that would enable carriers to operate with higher utilizations on weekends. Solution alternatives are compared to a baseline scenario in which yard stacking is not permitted given a set of current hub locations and freight data provided by J.B. Hunt. 


\subsection{Problem Examination}

As indicated in the literature review, the reduction of driver turnover, via increased miles and improved quality of driver life, is a key motivator for this research. In spite of high industry-wide driver turnover, adequate studies for creative solutions to the problem have not been found. The approach used herein is to examine the feasibility of manipulating Friday capacity and moving it into the weekend, thus making the total Friday through Sunday freight volume more level with the rest of the week. Once there, the freight that was moved can be combined with the existing weekend freight to create more freight opportunities for drivers.

Freight companies must carefully manage the number of drivers that they employ in spite of the daily imbalance. Having a large number of drivers enables the carrier to accept more freight during the week, but a larger number of drivers remain idle on weekends because few weekend long-hauls are available. On the other hand, if the carrier operates with fewer drivers, they may be able to satisfy most of their drivers with good weekend hauls, but they often miss out on peak freight opportunities during the week. If not handled properly, there can be loss of goodwill between drivers and carriers operating under the proposed paradigm. This chapter explores the procedure where a carrier accepts freight demand that exceeds normal Friday capacity and moves it into the weekend. This procedure attempts to do this without increasing the number of drivers or amount of equipment. Therefore, it can be implemented quickly and is clearly within the time frame of typical operational planning decisions.

To illustrate the problem, consider the "Current Scenario" diagrammed in Figure 3-1 where $D_{j}$ denotes the drop-off destination of inbound load $j, P_{i}$ denotes the pick-up 
origin of outbound loads $i$, and $T$ represents the location of a nearby terminal available for yard stacking. In the Current Scenario, a driver arrives to the region and drops off freight at destination $D_{l}$. After the drop-off, the driver is dispatched to pick up an outbound load. Suppose two loads with mandated Friday pick-ups are available for this driver, at $P_{1}$ and $P_{2}$. The dispatcher makes an assignment between the two outbound loads and, in this example, the driver is sent to pick up the load at origin $P_{l}$. If the carrier is unable to bring in another driver to the region, the load at $P_{2}$ is lost to a competitor who will be able to meet the mandated pick-up requirements.

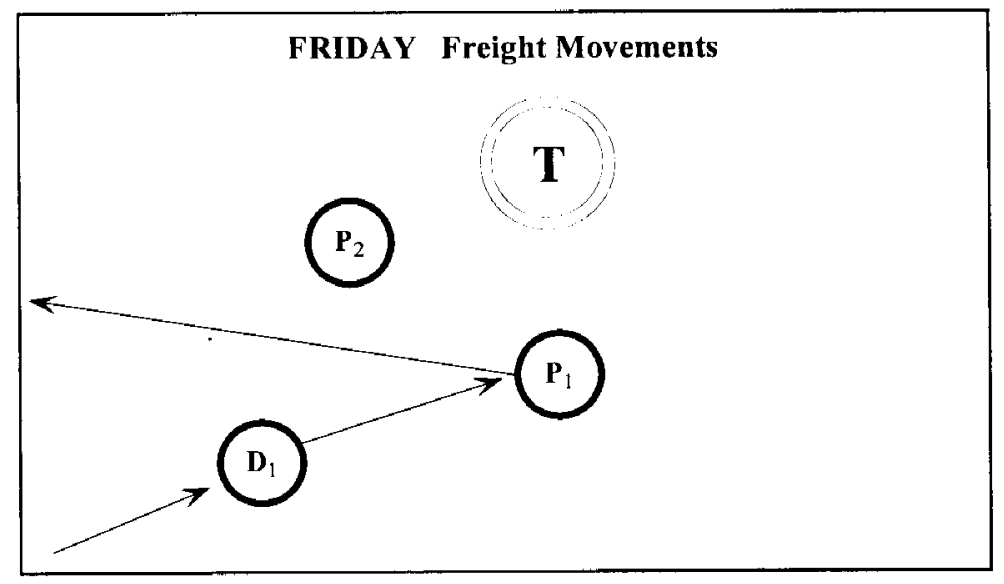

Figure 3-1 - Example - Current Scenario / Friday

Now examine Figure 3-2 to see what happens on Saturday. At this point a second driver is in the region and drops off a load at destination $D_{2}$. After drop-off, this driver is available to be assigned to an outbound load. However, since the driver arrived on Saturday instead of Friday, the outbound load $P_{2}$, as mentioned previously, is no longer available (signified by the ' $X^{\prime}$ ). The driver may wait until Sunday or Monday before an assignment can be made, or the carrier may face the additional costs of an empty repositioning move. If the carrier looks outside of the region to attempt to find an alternative pick-up, $P_{3}$, for the driver isolated at $D_{2}$, then a subsequent driver may 
eventually be isolated. Continuing to reposition drivers in this manner, though locally appealing, may correct the imbalance within one region, but may also create a new imbalance in another region.

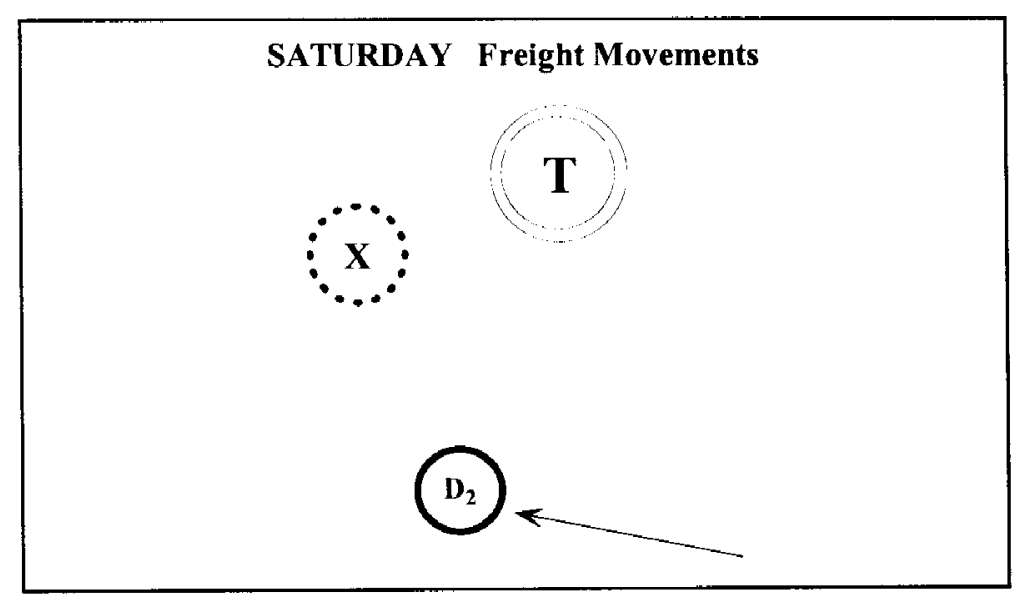

Figure 3-2 - Example - Current Scenario / Saturday

This research looks at the possibility of finding a method for acquiring additional freight on Friday so that two drivers, one arriving on Friday and one arriving on Saturday, each have long-hauls through the weekend. Figure 3-3 demonstrates the freight movements that would occur on Friday under the "Draying Scenario". The starting conditions diagrammed in Figure 3-3 are the same as the conditions previously diagrammed in Figure 3-1. Inbound freight is dropped off at destination $D_{l}$ and two potential outbound freight origins are represented by $P_{I}$ and $P_{2}$. However, in this scenario, the driver who drops off the load at destination $D_{I}$ will be dispatched to outbound freight origin $P_{2}$ instead of $P_{1}$. The driver will pick up the freight at $P_{2}$ and dray it to the terminal $T$. The freight will be positioned at the terminal until another driver is available sometime in the weekend. After the dray is completed, the driver proceeds to $P_{I}$ to pick up the outbound freight. Although the driver may not enjoy 
performing the intermediate dray, he or she may be paid a small premium in addition to the mileage for performing the dray. Furthermore, in the future the driver may be the recipient of long-haul weekend load because another driver has performed a weekend dray. The draying driver may also be rewarded with an especially attractive outbound load in return for performing the dray.

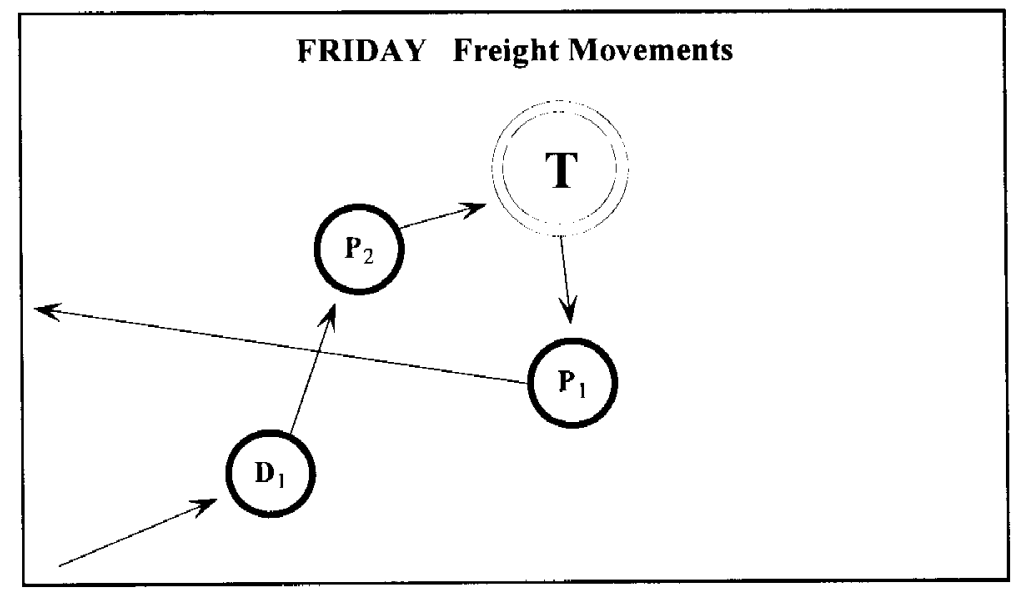

Figure 3-3 - Example - Draying Scenario / Friday

It is important here to mention an important issue. When the carrier considers freight as a potential dray candidate, they must evaluate whether or not the draying of the freight would violate either of the shipper's time demands. By picking up the dray candidate freight at its origin on Friday, the carrier will obviously satisfy the shipper's mandated pick-up time. However, the carrier should only arrange the dray if they will be able to also meet the shipper's requested delivery time. Sometimes there is not enough time to temporarily hold the freight at a terminal yard. Other times, there may be sufficient slack between pick-up and drop-off times to perform such a move. If the carrier can satisfy each of these shipper's time requirements, then the load will meet the 
criteria of a dray candidate. Furthermore, the shipper, being satisfied, will not be concerned with the intermediate moves that the carrier performs along the way.

Figure 3-4 demonstrates what happens on Saturday during the Draying Scenario. At this point, the outbound load $P_{2}$ is still stacked at the terminal $T$. During the day, an inbound driver comes to the region and delivers a load at destination $D_{2}$. Previously, under the Current Scenario, the driver at $D_{2}$ could not be assigned a next load because none would be available. However, under the Draying Scenario, the driver can be dispatched to the terminal to pick up $P_{2}$ and haul it to its final destination.

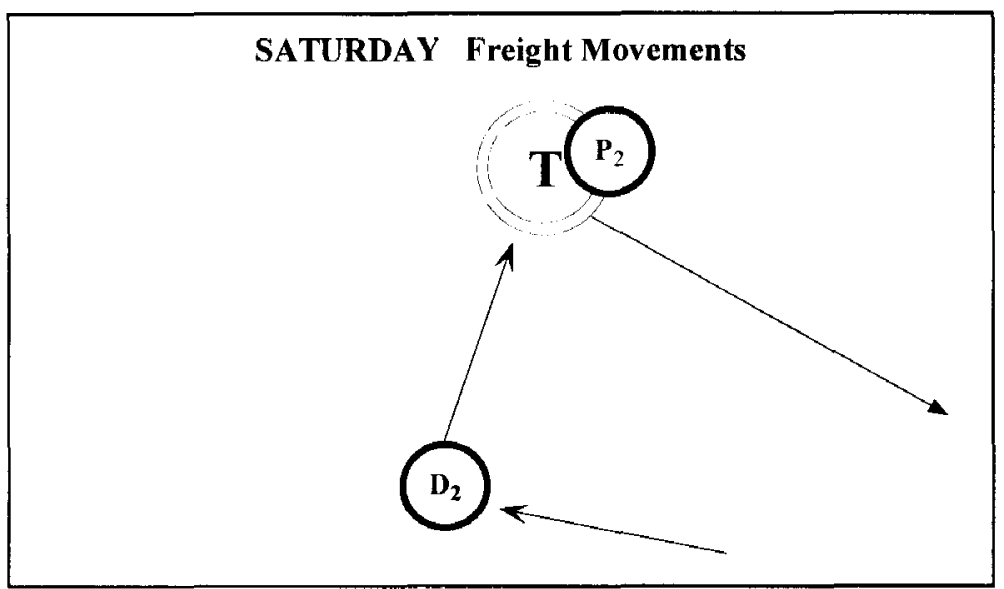

Figure 3-4 - Example - Draying Scenario / Saturday

The Draying Scenario does not affect any other operational changes Monday through Thursday. The changes proposed here will only affect dispatching on Fridays through Sundays. Also, in addition to the drayed freight that will be picked up on weekends, the carrier will continue to pick up other freight that becomes available during the weekends. 


\subsection{Experimental Design}

In this experiment, four experimental design factors are examined. The first design factor, 'Weekend', is binary. When 'Weekend' is considered off (Weekend=Off), the modeled scenario depicts the default state of the dispatching rules currently in use. When 'Weekend' is considered on (Weekend=On), the modeled scenarios represents the proposed dispatching rules that permit the weekend draying of freight. This design issue is the most important issue of the study because it involves the analysis of the original research goal - "What effect does weekend draying have on truckload trucking?" A load is not allowed to be a viable dray candidate, as discussed previously, unless it is determined that performing the dray would not violate either of the shipper's mandated pick-up and drop-off times.

The second design factor is the data source. At the beginning of the project J.B. Hunt provided historical load data. However, the daily freight volumes are different than those that have been discussed in the literature by Powell (1996). Although comparisons of the two distributions show that they have a similar physical shape with higher freight volumes during the weekdays and lower freight volumes during the weekends, the actual day to day volume percentages are different. In fact, the daily load distributions reported by Powell show a more significant drop in weekend freight volume than initially

considered based on the J.B. Hunt historical data. Therefore, to test for robustness of the procedures, two data sets (Data $=$ Historical and Data $=$ General) are used to evaluate the sensitivity of the solutions. Both data sets have the same number of total weekly loads, although their day-to-day freight volumes differ. 
The third design factor involved the location of the yard stacking terminals. One possibility is the 19 existing terminals proposed by J.B. Hunt. However, J.B. Hunt also uses two proprietary software systems called 'Hub Finder' and 'Domicile Finder' to analyze the characteristics of loads in a data file to recommend alternative terminal locations. Hub Finder examines dense freight origin and destination areas and returns the coordinates of the centroids of the areas. Domicile Finder tries to find dense pass-thru regions that will minimize driver out-of-route miles. By analyzing data with each of these data analyzers, two alternative sets of terminal locations are developed. The names given to identify each of the three sets of 19 terminal locations are 'Existing', 'HubFinder', and 'DomFinder'.

The final design factor of this experiment involves two types of driver operating conditions: constrained and unconstrained. In simulations where the drivers are constrained, an arbitrary cap of 1550 drivers is established in the fleet (an unspecified percentage, for propriety reasons, of J.B. Hunt's actual driver fleet). A similar and proportional reduction in load availability is also used. By limiting the number of drivers in the system, the model is purposely placed in situations where some loads will have to be refused. They will be refused because available drivers cannot be dispatched in time to pick the loads up while still meeting the customer's delivery requirements. In another set of simulations, the drivers are allowed to be unconstrained. With a limitless supply of drivers, loads are never refused by the simulated carrier. This extreme condition is used to evaluate the effects of draying under unconstrained conditions.

The factorial design of the four design factors results in 24 total simulation scenarios. However, since the two sets of driver conditions (constrained and 
unconstrained) results in incompatible scenarios in terms of available capacity, they are analyzed in two separate groups of twelve. The baseline scenario for both driver operating conditions was the simulation scenario where Weekend $=$ Off, Data Source $=$ Historical, and Terminal Locations $=$ Existing. These two baseline scenarios represent the current operating procedures.

The three main participants in the truckload trucking industry, the carrier, the shipper, and the drivers, each have different objectives. For weekend draying to be successful and to be considered a quality endeavor, all participants will need outcomes that benefit each of them, regardless of how those outcomes affect the other participants. As such, four responses are identified that are important to the participants:

1. The percentage of loads refused (for constrained scenarios),

2. The average number of drivers required (for unconstrained scenarios),

3. The percentage of loads delivered late, and,

4. The average miles driven per driver per day.

The percentage of loads refused and the average number of required drivers are dependent upon the simulated driver conditions. For instance, when drivers are constrained, the percentage of refused loads can be examined. A goal of the carrier would be to find ways to be able to pick up more loads without having to increase their personnel or equipment. Historical analysis shows that carriers currently refuse many Friday loads because they don't have the capacity to meet the end of the week peak in freight volume. However, if a carrier can use the proposed technique to refuse fewer Friday loads, this will be an attractive outcome of this study. Furthermore, if carriers can generate more weekend freight opportunities without soliciting freight through economic 
incentives for the shipper, this would also be attractable to the carrier.

On the other hand, when drivers are unconstrained, there is, in effect, a limitless number of drivers at the carrier's disposal. The carrier would never refuse to pick up any load. Therefore, in these simulated conditions the average number of drivers in the system is examined instead of examining the percentage of loads that are refused. The unconstrained scenarios would help a carrier to determine if the weekend conditions affect the size of the fleet that needs to be maintained.

The percentage of late deliveries is a performance measurement that interests both shippers and carriers. If weekend draying is put in place, then many Friday loads may be delayed 24 hours or more before they are actually picked up at a terminal and a driver begins hauling them their final destination. What impact would this have on the delivery? For the carrier, they would not want to experience an increase in late deliveries as a tradeoff for acquiring new freight. An increase in late deliveries may negatively impact a carrier's ability to maintain customers. From a quality standpoint, the carrier and shipper are both interested in having on-time deliveries that meet the shipper's requested delivery requirements.

Finally, to encourage drivers to be willing to accept this new weekend dray philosophy, the average daily miles per driver performance measurement is examined. Drivers may be unwilling to participate in weekend draying if they don't recognize a benefit for themselves. Therefore, the impact weekend draying has on the drivers must be strongly considered. The goal of the driver is to maintain a high number of driven miles per day. If they can experience a daily mileage increase and/or a pay incentive, 
then they will be more fulfilled in their jobs and they will be interested in participating in weekend draying.

\subsection{Methods}

The experiments described have been examined using a discrete-event system simulation and the SIMNET II language on a personal computer. One generic SIMNET II simulation model with multiple control features was developed to support the research for this paper (see Appendix 1). By changing one or more control values, the basic model is easily adapted to behave in each of the ways described in the experimental design. Verification of the simulation code has been performed using inherent software features, such as SIMNET II's "\$TRACE" function, which provides step-by-step details of the logic and decision flows of each line of code during execution. Simulations have been run under both extreme and restrictive parameter conditions to isolate specific scenarios and to test the model accuracy. Furthermore, small data sets designed to force entities down specific paths have been used to validate the simulated results.

Freight data to support this research was supplied by J.B. Hunt. Sufficient data is available to perform 18 replications of each scenario. Each replication consists of three weeks of freight data. Since each replication of the system starts empty and idle, the first two weeks of freight data are used to seed (warm-up) the freight network before statistics are collected. Output statistics are collected during the third week of each replication. At the end of each replication, the statistics and entities are cleared to insure independence of runs. Each new replication begins empty and idle. Each simulation scenario of 18 replications takes approximately 3 hours of computer run time. Twenty four different scenarios are simulated. 
The simulation model maintains the status of each driver's position, miles driven, future freight assignments, and sleep or driving status. The model accounts for United States Department of Transportation (DoT) driving rules to ensure that maximum driving hours are not exceeded. The model also maintains the status and position of all the freight. Freight assignments are made through routines that find available drivers who met acceptable proximity conditions. If a freight assignment cannot be made, then the freight is refused (in the capacitated driver scenarios only), statistics are updated, and the freight is eliminated from further consideration. If an assignment is made, then the identified driver is dispatched. At the load drop-off, counters are updated and lateness statistics are updated if necessary.

In scenarios where weekend draying is allowed, segments of code are enacted on Fridays that make decisions regarding whether a load will be picked up for immediate delivery or drayed to a nearby terminal for Saturday pick-up. The dispatching decision is made during an eight hour window for viewing and making decisions on upcoming loads (Taylor and McDowell 2002). Before a load can be designated as a dray candidate, it has to meet criteria regarding its shipper requested delivery time, estimated delivery time, length of final haul, and proximity of available drivers who would be involved in the dray and pick-up. Finally the closest available terminal that can allow yard stacking is selected and the dray move is performed.

\subsection{Results}

Table 3-1 presents the output of the twelve simulated scenarios under the constrained driver conditions. The baseline scenario represents the system in its current 
state where weekend draying is not permitted. The results shown in Table 3-1 have all been disguised to protect propriety information of J.B. Hunt. The baseline scenario has been given the normalized values of 1.00 and all other scenarios have been compared as a proportion of the baseline scenario.

\begin{tabular}{|c|c|c|c|c|c|c|c|}
\hline & \multicolumn{3}{|c|}{ Simulation Scenario } & \multicolumn{3}{|c|}{ Normalized Results } \\
\hline & & $\begin{array}{l}\text { Weekend } \\
\text { Condition }\end{array}$ & $\begin{array}{l}\text { Data } \\
\text { Source }\end{array}$ & $\begin{array}{l}\text { Terminal } \\
\text { Locations }\end{array}$ & $\begin{array}{l}\text { \% Loads } \\
\text { Refused }\end{array}$ & $\begin{array}{c}\% \text { Loads } \\
\text { Late }\end{array}$ & $\begin{array}{l}\text { Average } \\
\text { Miles Per } \\
\text { Driver }\end{array}$ \\
\hline \multirow[t]{12}{*}{$\begin{array}{l}\text { Baseline } \\
\text { Scenario }\end{array}$} & $>>$ & Off & Historical & Existing & 1.00 & 1.00 & 1.00 \\
\hline & & Off & Historical & HubFinder & 1.00 & 1.00 & 1.00 \\
\hline & & Off & Historical & DomFinder & 1.00 & 1.00 & 1.00 \\
\hline & & Off & General & Existing & 1.07 & 1.02 & 0.99 \\
\hline & & Off & General & HubFinder & 1.07 & 1.02 & 0.99 \\
\hline & & Off & General & DomFinder & 1.07 & 1.02 & 0.99 \\
\hline & & On & Historical & Existing & 0.90 & 0.90 & 0.99 \\
\hline & & On & Historical & HubFinder & 0.91 & 0.90 & 0.98 \\
\hline & & On & Historical & DomFinder & 0.92 & 0.92 & 0.99 \\
\hline & & On & General & Existing & 0.95 & 0.91 & 0.97 \\
\hline & & On & General & HubFinder & 0.97 & 0.91 & 0.96 \\
\hline & & On & General & DomFinder & 0.98 & 0.93 & 0.98 \\
\hline
\end{tabular}

Table 3-1 - Simulation Output with Number of Drivers Constrained

Analysis of Variance (ANOVA) is used to determine the statistical significance of the various factors for each of three performance measures. Alpha levels of 0.05 are utilized to determine whether or not statistical differences existed between various scenarios. Table 3-2 shows a summary of the individual ANOVA's for the constrained driver scenarios. The ANOVA's did not show any two or three-way interactions among the three factors (weekend condition, data source, or terminal locations). Therefore, 
Table 3-2 identifies each factor's contribution as a main effect based on the ANOVA decision variable ' $p$ '.

\begin{tabular}{|c|c|c|c|}
\hline \multirow[b]{2}{*}{ : } & \multicolumn{3}{|c|}{$\begin{array}{c}\text { ANOVA Summary of Main Effects } \\
\text { Drivers Constrained }\end{array}$} \\
\hline & $\%$ Loads Refused & $\%$ Loads Late & $\begin{array}{l}\text { Average Miles Per } \\
\text { Driver }\end{array}$ \\
\hline $\begin{array}{l}\text { Weekend } \\
\text { Condition } \\
\text { "Off" or "On" }\end{array}$ & $\begin{array}{c}\text { Significant } \\
p=0.000 \\
\text { "On" = Significantly Fewer }\end{array}$ & $\begin{array}{c}\text { Significant } \\
p=0.000 \\
\text { "On" = Significantly Fewer }\end{array}$ & $\begin{array}{c}\text { Significant } \\
\qquad p=0.004 \\
\text { "On" = Significantly Fewer }\end{array}$ \\
\hline $\begin{array}{l}\text { Data } \\
\text { Source } \\
\text { "Histoncar" or } \\
\text { "Genera" }\end{array}$ & $\begin{array}{l}\text { Significant } \\
\qquad=0.000 \\
\text { "Historical" = Significantly Fewer }\end{array}$ & $\begin{array}{c}\text { Non-Significant } \\
p=0.473\end{array}$ & $\begin{array}{c}\text { Non-Significant } \\
p=0.325\end{array}$ \\
\hline $\begin{array}{l}\text { Terminal } \\
\text { Locations } \\
\text { "Exist": "Hub". } \\
\text { "Dom" }\end{array}$ & $\begin{array}{c}\text { Non-Significant } \\
\quad p=0.552\end{array}$ & $\begin{array}{c}\text { Non-Significant } \\
\quad p=0.899\end{array}$ & $\begin{array}{c}\text { Non-Significant } \\
p=0.873\end{array}$ \\
\hline
\end{tabular}

Table 3-2 - ANOVA Summary - Drivers Constrained

The interpretations of Table 3-1 and Table 3-2 support the expectation that weekend draying has significant contributions for a carrier. Table 3-2 shows that when a carrier uses the weekend yard stacking scheme as proposed, it will be significant for all three performance measures regardless of the data distribution or terminal locations used. The percentage of loads refused and the percentage of loads that are delivered late both decrease when the weekend scheme is in effect. These two conditions will appeal to both the carrier and the shipper. The reason that fewer loads are being delivered late is due to the protocol for selecting weekend loads for yard stacking. Loads are only considered for yard stacking if there is a sufficient time window to make the dray and still be able to 
deliver the load to its final destination on time. Since only 'on time' load candidates are chosen for yard stacking, overall lateness statistics subsequently decrease.

The simulation experiment shows that the average miles per driver will decrease under the weekend scheme. Although the mileage decrease may seem inconsequential (1-2\%), drivers would not be happy to commit to short weekend drays knowing that their overall miles would be in jeopardy of also decreasing. One interpretation of this result is that although fewer loads are being refused with the weekend scheme, perhaps the wrong types of loads are being accepted. In turn, drivers may be substituting several small hauls for the long-hauls that they had been accustomed to getting previously. Controls would need to be put in place to prevent this phenomenon in practice.

Table 3-2 also shows that the general data incurs a significantly higher percentage of refused loads than does the historical data. Nevertheless, as pointed out previously, by using the weekend scheme, a carrier can expect to see a decrease of their percentage of loads refused regardless of their actual freight distribution. The relevance of this information would be important throughout the truckload industry to know that the weekend scheme is robust enough to benefit a carrier under different weekly freight distributions.

Table 3-3 provides the output of the twelve simulated scenarios under the unconstrained driver conditions. Once again, the baseline scenario represents the current state of the system and all data have been compared to the baseline scenario.

Furthermore, in these scenarios, the output response 'Number of Drivers' has replaced the previously used response 'Percent Loads Refused'. 


\begin{tabular}{|c|c|c|c|c|c|c|c|}
\hline & & \multicolumn{3}{|c|}{ Simulation Scenario } & \multicolumn{3}{|c|}{ Normalized Results } \\
\hline & & $\begin{array}{l}\text { Weekend } \\
\text { Condition }\end{array}$ & $\begin{array}{c}\text { Data } \\
\text { Source }\end{array}$ & $\begin{array}{l}\text { Terminal } \\
\text { Locations }\end{array}$ & $\begin{array}{l}\text { Number } \\
\text { of } \\
\text { Drivers }\end{array}$ & $\begin{array}{c}\% \text { Loads } \\
\text { Late }\end{array}$ & $\begin{array}{c}\text { Average } \\
\text { Miles Per } \\
\text { Driver }\end{array}$ \\
\hline \multirow[t]{12}{*}{$\begin{array}{l}\text { Baseline } \\
\text { Scenario }\end{array}$} & $\gg$ & Off & Historical & Existing & 1.00 & 1.00 & 1.00 \\
\hline & & Off & Historical & HubFinder & 1.00 & 1.00 & 1.00 \\
\hline & & Off & Historical & DomFinder & 1.00 & 1.00 & 1.00 \\
\hline & & Off & General & Existing & 1.03 & 1.01 & 0.99 \\
\hline & & Off & General & HubFinder & 1.03 & 1.01 & 0.99 \\
\hline & & Off & General & DomFinder & 1.03 & 1.01 & 0.99 \\
\hline & & On & Historical & Existing & 0.99 & 0.90 & 0.99 \\
\hline & & On & Historical & HubFinder & 1.00 & 0.90 & 0.99 \\
\hline & & On & Historical & DomFinder & 0.99 & 0.94 & 0.99 \\
\hline & & On & General & Existing & 1.02 & 0.90 & 0.97 \\
\hline & & On & General & HubFinder & 1.03 & 0.90 & 0.96 \\
\hline & & On & General & DomFinder & 1.03 & 0.93 & 0.97 \\
\hline
\end{tabular}

Table 3-3 - Simulation Output with Number of Drivers Unconstrained

The ANOVA results for alpha levels of 0.05 are shown in Table 3-4. Once again, the individual ANOVA's did not show any two or three-way interactions among the three factors (weekend condition, data source, or terminal locations). Therefore, Table 3-4 describes each factor's contribution as a main effect based on the ANOVA decision variable ' $p$ '. Unlike the constrained driver scenarios, Table 3-4 points out that the weekend scheme is only significant in regards to the percentage of loads delivered late. From Table 3-3 it can be observed that regardless of the freight distribution or an improvement in the location of the terminals, the weekend scheme can significantly reduce the percentage of late loads. This, once again, would be appreciated by both the carrier and shippers alike. However, neither the number of drivers used nor the average miles per driver are significantly affected by the weekend scheme. This may be a better 
outcome for the driver. Previously, in the constrained problem, the drivers received significantly fewer miles. In this unconstrained problem, now the drivers do not have a significant decrease in their average miles driven. The only other significant outcome for the unconstrained problem is that the number of drivers required is greater for the general data set than for the historical data set.

\begin{tabular}{|c|c|c|c|}
\hline & \multicolumn{3}{|c|}{$\begin{array}{c}\text { ANOVA Summary of Main Effects } \\
\text { Drivers Unconstrained }\end{array}$} \\
\hline & Number of Drivers & $\%$ Loads Late & $\begin{array}{l}\text { Average Miles Per } \\
\text { Driver }\end{array}$ \\
\hline $\begin{array}{l}\text { Weekend } \\
\text { Condition } \\
\text { "Or" or "On" }\end{array}$ & $\begin{array}{c}\text { Non-Significant } \\
\qquad p=0.476\end{array}$ & $\begin{array}{c}\text { Significant } \\
p=0.000 \\
\text { "On" = Significantly Fewer }\end{array}$ & $\begin{array}{c}\text { Non-Significant } \\
\qquad p=0.128\end{array}$ \\
\hline $\begin{array}{l}\text { Data } \\
\text { Source } \\
\text { "Historical" or } \\
\text { "Generer" }\end{array}$ & $\begin{array}{l}\text { Significant } \\
\qquad p=0.000 \\
\text { "Historical" = Significantly Fewer }\end{array}$ & $\begin{array}{c}\text { Non-Significant } \\
\quad p=0.756\end{array}$ & $\begin{array}{l}\text { Non-Significant } \\
\qquad p=0.063\end{array}$ \\
\hline $\begin{array}{l}\text { Terminal } \\
\text { Locations } \\
\text { "Exist", "Hub", } \\
\text { "Dom" }\end{array}$ & $\begin{array}{l}\text { Non-Significant } \\
\qquad p=0.906\end{array}$ & $\begin{array}{c}\text { Non-Significant } \\
\quad p=0.741\end{array}$ & $\begin{array}{l}\text { Non-Significant } \\
\qquad p=0.910\end{array}$ \\
\hline
\end{tabular}

Table 3-4 - ANOVA Summary - Drivers Unconstrained

\subsection{Conclusions}

The purpose of these experiments have been to examine what effect, if any, that a weekend yard stacking scheme would have on a truckload carrier. This research has shown that with capacitated driver limitations, a weekend yard stacking approach would be a viable dispatching strategy. Results show that this dispatching strategy will result in fewer loads rejected, fewer late deliveries, and fewer average miles driven per driver.

These outcomes would, respectively, result in higher revenues, improved customer 
service, and lower costs for the carrier. These results are not significantly dependent on terminal locations. However, daily freight volumes significantly affect load rejections but have no bearing on late deliveries nor average miles driven per driver. If there are no capacity limitations on the number of drivers, then the weekend strategy will only significantly reduce late deliveries.

The main factor examined is having the weekend scheme "on" or "off" because a truckload carrier has direct control over this factor. Carriers do not control their freight distributions and terminal locations are relatively fixed. However, by modeling these additional factors, it can be shown that the weekend scheme still maintains an advantage in a variety of scenarios that could be applicable to multiple carriers. It is also shown that the adaptation of weekend freight leveling can be beneficial to both the carrier and the shippers, while being relatively neutral to drivers. It is further shown that the weekend scheme could be beneficial to both carriers who currently are refusing Friday freight (because they have reached an operational constraint on their number of drivers) and for those carriers who currently are not refusing Friday freight (because they currently have enough drivers to meet their Friday freight volume).

The weekend condition and data source are found to be significant factors on some levels. However, terminal locations are never determined to be significant. This is not an alarming research outcome. The existing terminal locations in use by J.B. Hunt have already been strategically placed across the country. When alternative locations are established with Hub Finder and Domicile Finder, other good terminal locations are identified, but they are still similar to the original set of locations. As a result, none of 
the terminal sets perform significantly better or worse than any other set of terminal locations.

Weekend freight leveling through use of yard stacking as examined in this chapter has not been presented previously in the literature. Beyond the scope of this study, additional research implications of weekend draying could include analysis on acceptable dray lengths, multiple-day draying as opposed to Friday only draying, optimization techniques, search heuristics to determine best dray candidate loads, experimentation with the number of terminals, or development of a cost model as another response. Similarly, additional research could focus on alternative driver pay or customer incentive systems to make the method more attractive to drivers. 


\section{CHAPTER IV \\ TACTICAL PLANNING \\ The Driver Domicile Problem}

\subsection{Introduction}

The most recent year-end statistics compiled by the American Trucking Association (ATA) reveal that driver turnover for the truckload trucking industry reached record levels in 2005 (Nguyen, 2006). Annual driver turnover in large truckload linehaul carriers (carriers with annual revenues greater than $\$ 30$ million) was $130 \%$. In 2004 , the second worst year on record, large carriers recorded a $121 \%$ annual turnover. These statistics suggest that a large truckload trucking company could theoretically have seen all of its drivers leave and then some of their replacements also depart within a 12 month period. Smaller linehaul carriers, with their ability to maintain more personable drivercompany relationships, typically have lower turnover than their larger counterparts. Nevertheless, in 2005 they also experienced a record level of $96 \%$. By comparison, the less-than-truckload (LTL) industry averaged 15\% turnover during 2005.

These statistics coupled with the findings presented in the literature review provide support for the motivation behind this research. Hiring and retaining quality drivers is one of the most persistent and important issues facing the trucking industry. Driver recruitment and retention have been shown to be key factors to a truckload carrier's bottom line. Rodriquez et al. (2000) determined that the costs of turnover, 
which included personnel, recruitment, insurance, and safety, were approximately $\$ 2.8$ billion annually for the truckload industry. However, demand for trucking services rises as companies continue to seek ways to reduce their inventories. As a result, with shorter times between replenishment, companies need goods more frequently. The ATA reports that the trucking industry was short 20,000 drivers in 2005 and forecasts the gap could grow to 110,000 drivers by 2014 (Global Insights 2005). Currently there are about 1.4 million truck drivers and more than 600,000 registered motor carriers (U.S. Dept of Transportation, 2005) in the United States. The driver shortage situation has created a crisis in the industry; however, steps to correct it and its underlying causes are possible.

The severity of the situation is underscored by the economic impact the shortage has on the nation's economy and the health of the truckload companies. However, the industry has not defined a long-term solution or strategy to solve the problem, forcing individual companies to find their own solutions based on available resources. Those companies that find solutions will be the winners. Those that don't will fail or go out of business as only the fittest are surviving.

Researchers have identified multiple factors that lead to driver turnover. One of the most prominent causes is driver dissatisfaction resulting from long hours and extended time away from home. Kalnbach and Griffen (2002) concluded that drivers believe voluntary turnover would decline if carriers were more proactive in preventing it. An examination of these causes has also been addressed by Taylor and Meinert (2000). Although it has been established that imbalance is inherent in the truckload freight network, the burden of recruiting and retaining drivers before they become frustrated rests upon the carriers. Therefore, if through tactical planning, carriers could develop 
recruitment strategies targeting new drivers who had better opportunities to return home regularly (because of the location of their domiciles), carriers may reduce the increasing turnover trend.

\subsection{Problem Examination}

The Driver Domicile problem requires a tactical planning approach. It addresses imbalance by examining the carrier's ability to recruit from specific areas or regions that would have a greater opportunity to return drivers home regularly. The concept behind the problem is that if imbalance causes difficulties for carriers to return drivers home regularly, then a carrier should examine where driver recruitment should be targeted. So the question becomes, "What recruitment strategies should a carrier undertake?". It is the goal of this chapter to determine if a link can be established between the examination of nationwide freight profiles and the specific placement of driver domiciles

In the truckload industry, individual freight characteristics consist primarily of an outbound (origin) location and an inbound (destination) location. Unlike the LTL industry which utilizes one or more intermediate breakbulk locations to sort and consolidate freight based on their final destinations, truckload freight can be simply described by the straight line lane approximation encompassed by the two origin and destination endpoints alone. In addition, the characteristics of a nationwide truckload network would include the location of specific hubs. The network hubs are locations where equipment (tractors and trailers) can be stored or maintained, or where drivers wait to be dispatched. Ideally, drivers domiciled closest to high volume hub locations would be easiest to satisfy because frequent "get home" opportunities would exist for them. On 
the other hand, drivers domiciled at low volume hub locations would have a more difficult time acquiring loaded trips that returned them to their home domicile on a regular basis. Instead, the carrier may have to allow the drivers to return to their domiciles empty and absorb the "deadhead" costs.

In this dissertation four ownership designations are defined and used to categorize each freight lane and to identify high volume hub locations. These designations are:

- outbound freight ownership,

- inbound freight ownership,

- pass-thru freight ownership, and,

- over-the-road (OTR) freight ownership.

Each specific hub (domicile) location will have a unique designation with each freight lane. For example, consider the relationship between a hub location and a freight lane with an origin (O) and destination (D) as depicted in Figure 4-1. The freight lane would be designated as an outbound ownership for the hub if the distance between the hub and the origin location is within a maximum prescribed boundary from the origin. All hubs within an origin's maximum specified boundary, or radius, could be considered for outbound freight ownership. Likewise, in Figure 4-2, the freight lane would be designated as an inbound ownership for the hub because the distance between the hub and the destination location is within a maximum prescribed (radius) boundary.

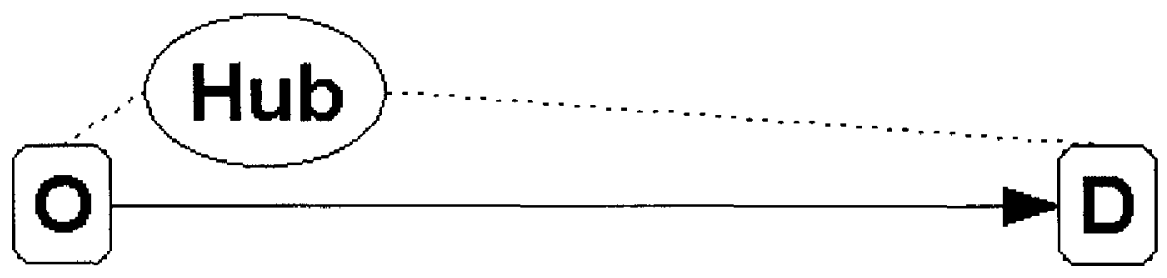

Figure 4-1 - Outbound Freight Ownership 


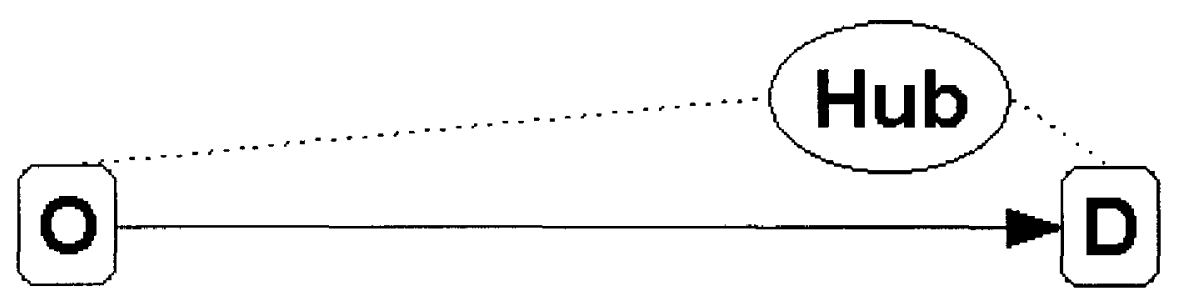

Figure 4-2 - Inbound Freight Ownership

In other situations, a hub may not be located near the lane's origin nor the lane's destination. However, the location of the hub may be found to be in close proximity to the straight line defined by the freight lane. Figure 4-3 shows that a hub situated close to any points on the freight lane could be designated as pass thru freight ownership for the hub. Similarly to the outbound and inbound ownership scenarios, a relationship between the distance from the hub to the freight lane could help determine when this type of ownership exists. It should be noted that for pass-thru conditions, a driver would incur out-of-route miles when returning to his domicile. This would happen because he would be deviating from the straight line freight lane.

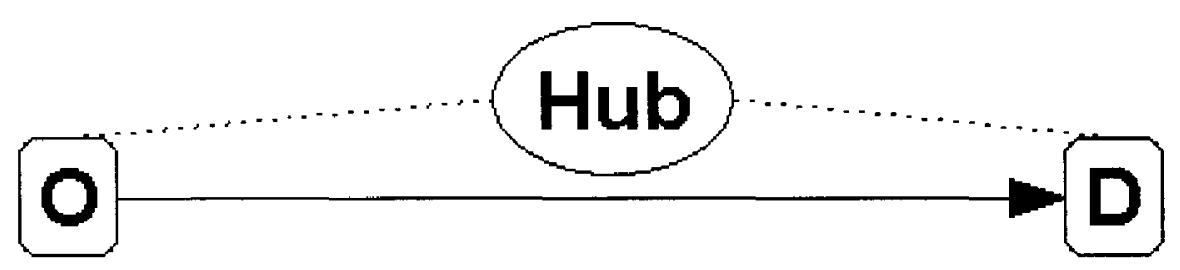

Figure 4-3 - Pass-Thru Freight Ownership

Thus far three types of hub ownership designations have been defined. By ownership, it is meant that a hub's location would enable it to claim all of the volume of freight moving across the freight lane. As mentioned before, the hub locations with the highest volumes would provide the greatest number of opportunities for drivers to return 
home regularly. Although the carrier may prefer either outbound or inbound freight lanes, the existence of pass-thru freight lanes would yield many more domicile opportunities. On another note, Figures 4-1, 4-2, and 4-3 depict situations where the hub location offers only one type of ownership designation. However, considering the length of the freight lane and the lengths of the radii defining the outbound, inbound, and passthru boundaries, it would be possible that a single hub could have multiple ownership designations. In these cases, only one ownership designation should be selected and the freight lane's volume should not be counted more than once.

The fourth and final ownership designation, which may be more accurately described as a non-ownership situation, is depicted in Figure 4-4. This figure shows the situation where a hub is located significantly away from the origin, destination, and all points along the freight lane. In this situation, the relationship between this hub and the freight lane is not a good fit and the freight volume will not be owned by the current hub. Instead, it would be owned by another hub that provides a better fit, if it is owned at all. If a better hub does not exist, then a driver will have to be specifically dispatched overthe-road to the freight lane. These situations are designated as OTR freight ownerships.

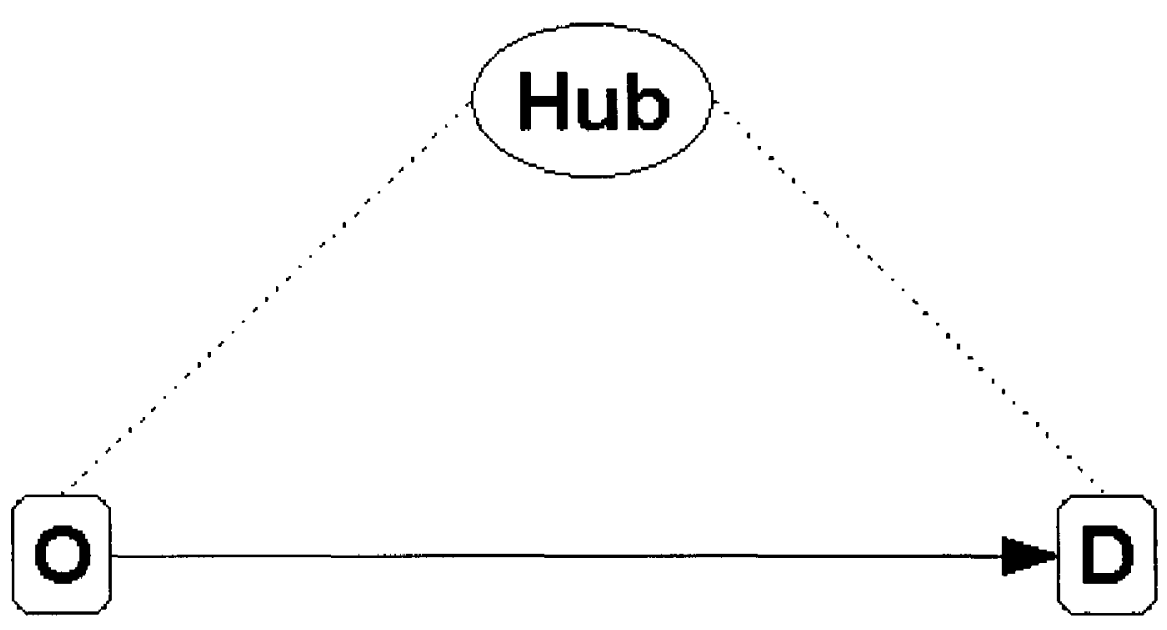

Figure 4-4 - OTR Freight Ownership 
Collectively the set of hubs, freight lanes, and freight volumes define the trucking network. Each hub will have a unique ownership relationship to each freight lane. In whole, it would be desired to have $100 \%$ of the freight lanes owned (either as outbound, inbound, or pass-thru) by one or more hubs. However, for freight lanes that are not owned, as depicted in Figure 4-4, specific over-the-road measures must be taken to haul the freight on individual case bases. The objective is to identify a set of hubs that can capture the highest percentage of freight with minimal circuitous (out of route) miles incurred.

\subsection{Research Goals}

The purpose of this research is to attempt to simultaneously satisfy the opposing personal objectives of carriers and drivers through strategic determination of appropriate driver domiciles. For carriers to stay in business in a competitive environment, they must be able to provide their services for reasonable prices. After all, they want to make a profit. They accomplish this in part by minimizing operational costs and maximizing equipment and personnel utilizations. However, inherent network freight imbalance works against what carriers want to accomplish. As a result, personnel and equipment are often found out of place with regard to freight locations and must therefore be inefficiently repositioned to meet dispatching requirements. The operational costs incurred must be absorbed by the carrier.

The strategy of drivers is also simple to understand. They want to make as much money as possible, but they also want to maintain a satisfying quality of life (Taylor and 
Meinert 2000). Since a driver's wages depend on the amount of miles driven, then the driver's strategy could be restated in terms of drivers acquiring as many miles as possible. Generally, a truckload driver prefers a good long haul rather than several short or intermediate hauls. But, miles alone do not meet all of a driver's basic needs. An additional part of a driver's quality of life depends on having favorable working conditions with reasonable opportunities to get home.

If drivers perceive that their pay or quality of life is not where they expect it to be, then numerous researchers (for example, Rodriquez et al. 2000, Gupta et al. 1996, Kalnbach and Griffen 2002) have shown that drivers do not hold any deeply held allegiances to the company they are with and easily inclined to voluntarily leave. Although not all driver's leave the industry entirely, many are merely churned within the industry by moving from carrier to carrier. Regardless of the type of driver movement, turnover in the truckload industry has been shown to be historically high.

The Driver Domicile Problem directly addresses the desire drivers have to increase their quality of life. Because freight imbalance and stochasticity affect driving tours, carriers cannot guarantee regular routes to their drivers. However, by identifying driver recruitment areas, perhaps a potential pool of drivers can be drawn from locations where it would be easier for the carrier to return each driver home on a regular basis. This would definitely be attractive to drivers and may reduce the driver turnover of participating carriers. As an added bonus of turnover reduction, carriers may indirectly reduce their direct and incidental turnover expenses, which, as stated previously, have been estimated to be as much as $\$ 2.8$ billion annually. Furthermore, if the carriers are 
able to decrease their expenses, they may subsequently be able to pass on savings to shippers.

The goal of the Driver Domicile research is to identify and locate regions that are best supported by dense outbound, inbound, and pass-thru freight. As described in Section 4.2, domiciles with the most assigned freight ownership are specified as the 'best' locations to domicile drivers. The identification of these regions will be followed by calculations that recommend a suggested number of drivers domiciled at each hub location to satisfy the overall trucking operations. In addition, post network analysis will describe the overall coverage of owned freight lanes, the existence of network imbalances, mileage statistics, and driver requirements of the effective network.

This domicile research is unique because many researchers have focused on helping motor carriers identify causes of turnover, but there has not been adequate research addressing ways to reduce driver turnover from an operational perspective. Suzuki (2005) noted similar omissions in his research. He sought to identify which companies would be candidates for turnover reduction and what levels of reduction should be their targeted. Suzuki built a computer based decision tool applied to a medium-sized truckload carrier. General conclusions were that a carrier whose objective was to achieve a very high overall profit would need to have a driver turnover rate a lower level than the industry average. If, however, the carrier's objective was to attain a relatively moderated or low profit, the carrier's turnover rate could be allowed to be higher than the industry average. In other words, a company's turnover rate was found to be uniquely correlated to each carrier's profitability goals. 
From my research new insight will be given on driver domicile issues. Whereas existing research has identified issues, this research will provide a plan. Ongoing driver turnover trends tell us that current methods of addressing turnover have not been adequate. If new highs in turnover levels continue to be reached on a yearly basis, then practical research within the driver domicile domain would be welcomed by the truckload trucking community.

\subsection{Mathematical Model}

Before beginning the analytical study of the Driver Domicile Problem, this section presents the basic mathematical description of the problem along with the unique parameters and boundaries that define it. Section 4.2 examined the problem and introduced the terminology of the four freight ownership designations. As a review, those designations are outbound freight ownership, inbound freight ownership, pass-thru freight ownership, and an OTR freight ownership. By default, any freight volume that is not specifically assigned either an outbound, inbound, or pass-thru ownership designation by any hub will receive an OTR designation.

The parameters of the Driver Domicile Problem contain the following elements:

I - The set of all unique outbound (origin) freight locations,

$$
\text { where } i=1 \text { to } \mathrm{I} \text {. }
$$

J - The set of all unique inbound (destination) freight locations,

$$
\text { where } j=1 \text { to } \mathrm{J} \text {. }
$$

$\mathbf{K}-$ The set of all unique hub (domicile) locations, where $k=1$ to $\mathrm{K}$.

$\mathbf{X}_{i j}-$ The volume (the number of trips) along the freight lane from $i$ to $j$. 
$\mathrm{Dij}_{i j}$ - The distance on freight lane $i-j$ from outbound (origin) location $i$ to inbound (destination) location $j$.

Dik $_{i k}$-The distance from outbound (origin) location $i$ to domicile $k$.

$\mathbf{D j}_{\mathbf{j k}}$-The distance from inbound (destination) location $j$ to domicile $k$.

RO - An origin's maximum radius for outbound ownership claims on freight volumes.

RI - A destination's maximum radius for inbound ownership claims on freight volumes.

C - Maximum circuitous (out of route) distance for pass-thru ownership claims on freight volumes.

$\boldsymbol{\alpha}-$ Outbound priority weight.

及 - Inbound priority weight.

$\gamma$ - Pass-thru priority weight.

In addition, the problem also includes the following decision variables which define the manner in which each hub may or may not own (or claim) the volume along each freight lane. These decision variables are binary.

$$
\begin{aligned}
& \mathbf{O B}_{i k}=\left\{\begin{array}{ll}
1 & \text { if domicile ' } \mathrm{k} \text { ' should claim } \mathrm{X}_{\mathrm{ij}} \text { as outbound freight vo lume } \\
0 & \text { otherwise }
\end{array}\right\} \\
& \mathbf{I B}_{j k}=\left\{\begin{array}{ll}
1 & \text { if domicile ' } \mathrm{k} \text { ' should claim } \mathrm{X}_{\mathrm{ij}} \text { as inbound freight vo lume } \\
0 & \text { otherwise }
\end{array}\right\}
\end{aligned}
$$




$$
\mathbf{P T}_{i j k}=\left\{\begin{array}{ll}
1 & \text { if domicile ' } \mathrm{k}^{\prime} \text { should claim } \mathrm{X}_{\mathrm{ij}} \text { as pass - thru freight vo lume } \\
0 & \text { otherwise }
\end{array}\right\}
$$

This problem falls into the class of assignment problems. For example, given a set of hubs $\mathrm{K}$, outbound locations I, and inbound locations $\mathrm{J}$, the problem's objective, discussed in Section 4.2, is to maximize the assignment of freight volumes to specific hubs. After the assignment is made, mileage assessment and statistics can be observed. The objective function is shown by Equation 4-1. Note that the objective function also includes the weight parameters $\boldsymbol{\alpha}, \boldsymbol{\beta}$, and $\gamma$ which define the priority that should be given to each outbound, inbound, or pass-thru assignment. For instance, if a single freight volume can be claimed by multiple domiciles in multiple manners, then the domicile with the highest $\boldsymbol{\alpha}, \boldsymbol{\beta}$, or $\boldsymbol{\gamma}$ weight would be the preferred assignment.

\section{Maximize:}

$$
\sum_{i} \sum_{j} \sum_{k} D i j_{i j} X_{i j}\left(\alpha O B_{i k}+\beta I B_{j k}+\gamma P T_{i j k}\right)
$$

The constraints of this problem are as follows:

\section{Subject To:}

$$
D i k_{i k} * O B_{i k} \leq R O \quad \forall i k
$$

Equation 4-2 places restrictions on the outbound assignments. The variable $\boldsymbol{O B}_{\boldsymbol{i k}}$ is allowed to take on a value of 1 if the distance $\boldsymbol{D i k} \boldsymbol{k}_{\boldsymbol{i k}}$ (the distance from outbound location ' $\boldsymbol{i}$ ' to hub location ' $\boldsymbol{k}$ ') is less than or equal to the maximum allowable outbound radius $\boldsymbol{R} \boldsymbol{O}$. One constraint for all combinations of outbound locations $\boldsymbol{I}$ and hubs $\boldsymbol{K}$ will 
be required. Equation 4-3 places the same type of restriction towards inbound assignments.

$$
D j k_{j k} * I B_{j k} \leq R I \quad \forall j k
$$

In a similar fashion, the equation restricting the pass-thru, or circuitous, assignments follows the form of Equations 4-2 and 4-3. However, there is a difference. For any freight lane defined between points ' $\boldsymbol{i}$ ' and ' $\boldsymbol{j}$ ', there would be an infinite number of interior points on that lane. Whereas Equations 4-2 and 4-3 could reference unique endpoints ' $\boldsymbol{i}$ ' and ' $\boldsymbol{j}$ ' specifically, proposing a maximum allowable radius between hub location ' $\boldsymbol{k}$ ' to the infinite points along the ' $\boldsymbol{i}-\boldsymbol{j}$ ' lane would be mathematically exhaustive. Instead, a separate relationship between ' $\boldsymbol{k}$ ' and lane ' $\boldsymbol{i}-\boldsymbol{j}$ ' must be identified.

Here, the definition of circuity is introduced. Circuity is defined as the additional distance that would be incurred by traveling from location ' $i$ ' to location ' $\boldsymbol{j}$ ' while going through location ' $\boldsymbol{k}$ '. This distance would be considered an "out of route" distance. Equation 4-4 depicts the mathematical definition of circuity and Equation 4-5 substitutes the circuity calculation into a problem constraint. Note that for a given combination of ' $\boldsymbol{i}$ ', ' $\boldsymbol{j}$ ', and ' $\boldsymbol{k}$ ', Equation 4-5 will only permit parameter $\boldsymbol{P} \boldsymbol{T}_{i j \boldsymbol{k}}$ to receive a value of 1 if the circuity is less than or equal to the maximum allowable circuity value $C$.

$$
\begin{gathered}
\text { Circuity }=D i k_{i k}+D j k_{j k}-D i j_{i j} \\
\left(D i k_{i k}+D j k_{j k}-D i j_{i j}\right) P T_{i j k} \leq C \quad \forall i j k
\end{gathered}
$$

The constraints presented to this point have defined if and when hubs may make specific claims on freight volumes. However, since any freight volume can only be assigned to one and only one hub, Equation 4-6 satisfies this constraint. Equation 4-6 
states that for all outbound locations ' $\boldsymbol{i}$ ' and inbound locations ' $\boldsymbol{j}$ ', the summation of all possible ownership designations across all hubs ' $k$ ' must be less than or equal to 1 . This constraint insures that the freight volume along each freight lane ' $\boldsymbol{i}-\boldsymbol{j}$ ' will not be claimed by multiple hubs.

$$
\sum_{k}\left(O B_{i k}+I B_{j k}+P T_{i j k}\right) \leq 1 \quad \forall i j
$$

The final equations of the mathematical model depict assignments based on weights. These equations come in pairs that mimic the conditional 'If' statement found in such math optimization software such as LINGO 9.0 (Lindo Systems Inc. 2006) which will be used later during problem analysis. The right hand side of each respective pair of equations takes on a value of either 0 or 1 for all situations when the condition holds true. For instance, the left hand side of Equation 4-7 forces the assignment of $\boldsymbol{I B}_{\boldsymbol{j} \boldsymbol{k}}$ to be a value of 0 for all conditions when the outbound weighted product $D_{i k} \boldsymbol{i}_{i k} \boldsymbol{\alpha}$ is less than the inbound weighted product $D j k_{j k} * \boldsymbol{\beta}$ (meaning that the outbound assignment would be preferred over the inbound assignment for domicile ' $k$ '). On the other hand, if the outbound product is not less than the inbound product, as shown in Equation 4-8, $\boldsymbol{I B}_{\boldsymbol{j} \boldsymbol{k}}$ would be allowed to take either binary value 0 or 1 depending on the outcomes of the complete optimization. In other words, Equation 4-7 doesn't actually assign $\boldsymbol{I B}_{\boldsymbol{j} \boldsymbol{k}}$, but it prevents $\boldsymbol{I B}_{\boldsymbol{j k}}$ from being selected if the assignment of another ownership type would be better. Likewise, Equations 4-9 through 4-18 each make assignments based on similar conditional assessments for the remainder of the inbound, outbound, and pass-thru variables.

$$
\begin{array}{ll}
I B_{j k}=0 \quad \forall i j k, \text { and, } \\
& D i k_{i k} \alpha<D j k_{j k} \beta
\end{array}
$$




$$
I B_{j k} \leq 1
$$

$$
P T_{i j k}=0
$$$$
P T_{i j k} \leq 1
$$

$$
O B_{i k}=0
$$$$
O B_{i k} \leq 1
$$$$
P T_{i j k}=0
$$$$
P T_{i j k} \leq 1
$$$$
O B_{i k}=0
$$

$$
O B_{i k} \leq 1
$$

$$
I B_{j k}=0
$$

$\forall i j k$, and,

$$
D i k_{i k} \alpha \geq D j k_{j k} \beta
$$

$\forall i j k, \quad$ and,

$$
D i k_{i k} \alpha<\left(D i k_{i k}+D j k_{j k}-D i j_{i j}\right) \gamma
$$

$\forall i j k, \quad$ and,

$D i k_{i k} \alpha \geq\left(D i k_{i k}+D j k_{j k}-D i j_{i j}\right) \gamma$

$\forall i j k, \quad$ and,

$D j k_{j k} \beta<D i k_{i k} \alpha$

$\forall i j k$, and,

$D j k_{j k} \beta \geq D i k_{i k} \alpha$

$\forall i j k$, and,

$D j k_{j k} \beta<\left(D i k_{i k}+D j k_{j k}-D i j_{i j}\right) \gamma$

$\forall i j k$, and,

$D j k_{j k} \beta \geq\left(D i k_{i k}+D j k_{j k}-D i j_{i j}\right) \gamma$

$\forall i j k$, and,

$$
\left(D i k_{i k}+D j k_{j k}-D i j_{i j}\right) \gamma<D i k_{i k} \alpha
$$

$\forall i j k$, and,

$$
\left(D i k_{i k}+D j k_{j k}-D i j_{i j}\right) \gamma \geq D i k_{i k} \alpha
$$

$\forall i j k$, and,

$$
\left(D i k_{i k}+D j k_{j k}-D i j_{i j}\right) \gamma<D j k_{j k} \beta
$$




$$
\begin{array}{ll}
I B_{j k} \leq 1 \quad & \forall i j k, \quad \text { and }, \\
& \left(D i k_{i k}+D j k_{j k}-D i j_{i j}\right) \gamma \geq D j k_{j k} \beta
\end{array}
$$

The final constraints of the mathematical model specify that the variables $O B_{i k}$, $I B_{j k}$, and $P T_{i j k}$ are required to assume only binary values.

$$
O B_{i k}, \quad I B_{j k}, \quad P T_{i j k} \quad \text { Binary }
$$

\subsection{Experimental Design}

The primary baseline for comparison between alternative hub sets is the percentage of the total loaded miles owned by each hub set. All miles owned within each hub set would be freight volumes available for delivery by a group of drivers domiciled at the set's individual hub locations. These miles would be favored by drivers because of their high concentration to a targeted hub location. All un-owned miles, referred to as OTR miles, would require dispatches on a case by case basis. Hence, OTR miles would be unattractive to drivers because their tours would be irregular and return trips towards a driver's home domicile would be unpredictable.

Based on the general problem statements presented thus far, this section will define and describe the elements composing this research's experimental plan. Figure 4.5 diagrams a summary overview of the entire plan. The diagram shows that the experimental plan is composed of six factors. They are:

1. Hub Sets and Seed Determinations

2. Hub Set Sizes

3. Ownership Assignments 


\section{Experimental Plan}

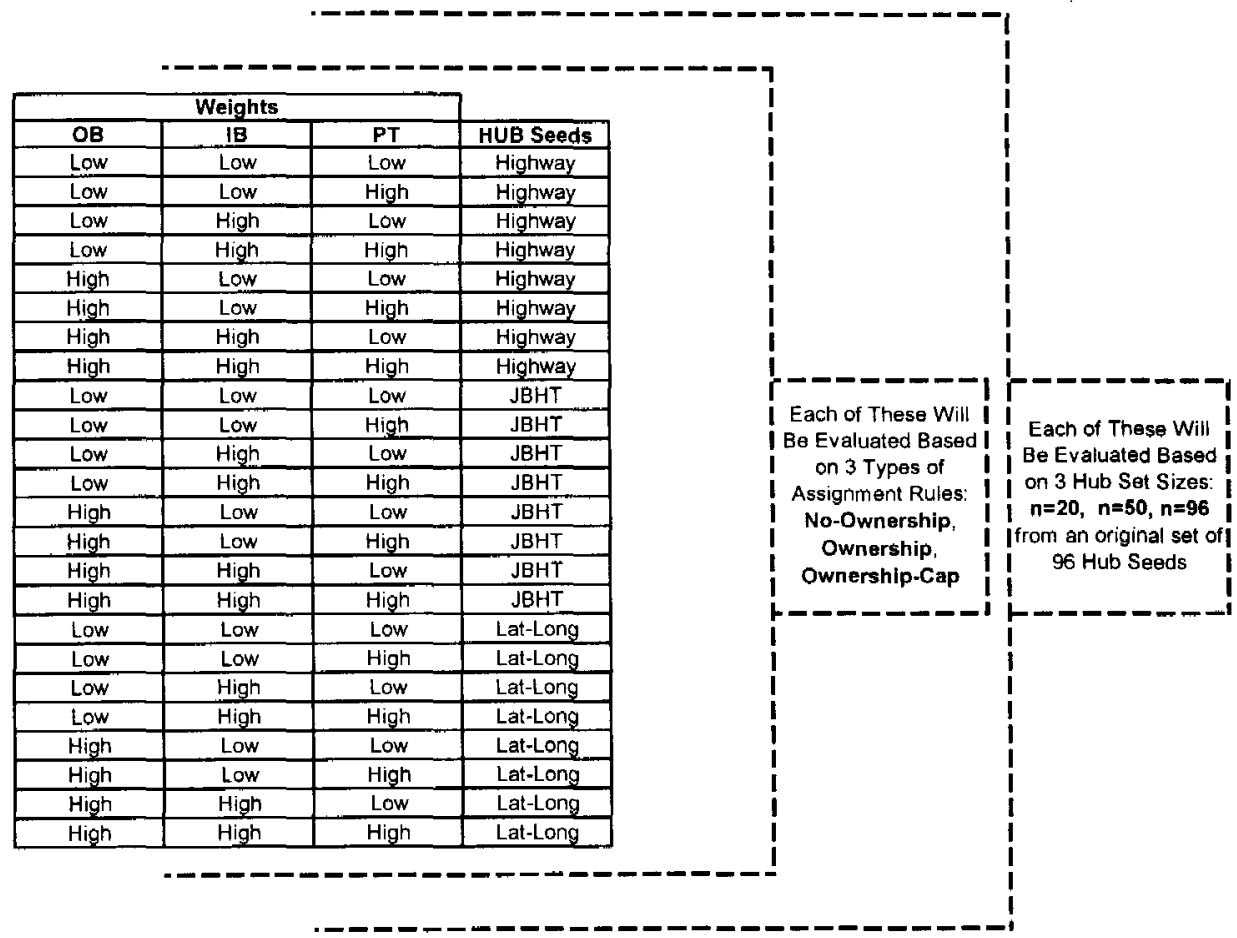

\begin{tabular}{|c|c|c|c|c|}
\hline \multicolumn{5}{|c|}{ bits } \\
\hline Factors: & \multicolumn{3}{|c|}{ 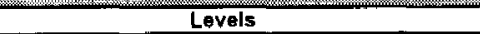 } & Experiments \\
\hline OB Weight & Low & High & & 2 \\
\hline IB Weight & Low & High & & 2 \\
\hline PT Weight & LOW & High & & 2 \\
\hline HUB Seeds & Lat-Long & Highway & $\sqrt{B H T}$ & 3 \\
\hline $\begin{array}{l}\text { Assignment } \\
\text { Rules }\end{array}$ & No-Ownership & Ownership & Ownership-Cap & 3 \\
\hline Hub Set Sizes & $n=96$ & $n=50$ & $n=20$ & 3 \\
\hline & & Total & periments: & 216 \\
\hline
\end{tabular}

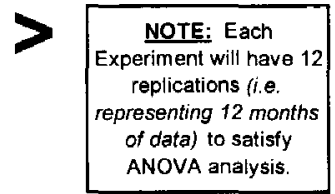

Response Weasurements

\begin{tabular}{|c|c|c|c|c|c|}
\hline $\begin{array}{l}\% \text { Routes } \\
\text { Used By } \\
\text { Domiciled } \\
\text { Drivers }\end{array}$ & $\begin{array}{c}\text { Total Route } \\
\text { Imbalance } \\
\text { (Absolute } \\
\text { Deviation) }\end{array}$ & \begin{tabular}{|c|}
$\begin{array}{c}\text { Outbound } \\
\text { Miles } \\
\text { Incurred By } \\
\text { Domiciled } \\
\text { Drivers }\end{array}$ \\
\end{tabular} & $\begin{array}{c}\text { Total Miles } \\
\text { Driven }\end{array}$ & $\begin{array}{l}\text { Total Drivers } \\
\text { Required }\end{array}$ & \multirow{3}{*}{$\begin{array}{l}\text { NOTE: For the No- } \\
\text { Ownership scenarios, } \\
\text { since multiple hubs are } \\
\text { allowed to claim } \\
\text { ownership for the same } \\
\text { freight lane volume, } \\
\text { then mileage and driver } \\
\text { values will need to be } \\
\text { approximated based on } \\
\text { normalized non- } \\
\text { ownership statistics. }\end{array}$} \\
\hline $\begin{array}{l}\% \text { Loads } \\
\text { Used By } \\
\text { Domiciled } \\
\text { Drivers }\end{array}$ & $\begin{array}{l}\text { Total Load } \\
\text { Imbalance } \\
\text { (Absolute } \\
\text { Deviation) }\end{array}$ & \begin{tabular}{|c|} 
Inbound \\
Miles \\
Incurred By \\
Domiciled \\
Drivers \\
\end{tabular} & $\begin{array}{c}\text { Miles Driven } \\
\text { by Domiciled } \\
\text { Drivers }\end{array}$ & $\begin{array}{l}\text { Domiciled } \\
\text { Drivers } \\
\text { Required }\end{array}$ & \\
\hline $\begin{array}{c}\% \text { Miles Used } \\
\text { By Domiciled } \\
\text { Driver's }\end{array}$ & $\begin{array}{c}\text { Total Mile } \\
\text { Imbalance } \\
\text { (Absolute } \\
\text { Deviation) }\end{array}$ & \begin{tabular}{|c|} 
Pass-Thru \\
Miles \\
Incurred By \\
Domiciled \\
Drivers
\end{tabular} & $\begin{array}{c}\text { Miles Driven } \\
\text { by OTR } \\
\text { Drivers }\end{array}$ & $\begin{array}{l}\text { OTR Drivers } \\
\text { Required }\end{array}$ & \\
\hline
\end{tabular}

Data Tabulation is performed with a computer model developed in SIMNET II and an optimization model developed in LINGO 9.0. Statistical Analysis is performed with MiniTab 14.0

Figure 4-5 - Summary Depiction of Experimental Design Elements 
- Priority Weights

4. Outbound

5. Inbound

6. Pass-Thru

Each of these factors will be discussed in Sections 4.5.1, 4.5.2, 4.5.3, and 4.5.4. Section 4.5.5 will discuss the experimental trials and replications. And, finally, Section 4.5.6 will complete the discussion of the plan by the solution approaches and response measurements that have been chosen for evaluation and analysis.

\subsubsection{Hub Sets and Seed Determinations}

The first factor of the plan is the determination of alternative sets of 'seed' hub candidates. This research's factorial design used three methods (three levels) for seeding the model with hub candidates. Each set of hub candidates targeted different locations based on different criteria.

First, major inter-state highway locations were identified. The rationale for this is that trucks would pass through many of these locations anyway and therefore lower excess circuity would be incurred by locating domiciles near these major inter-state highway locations. Because of the location of the design of the U.S. inter-state highway system, major cities and hence major markets for driver recruitment would be found near these prominent intersections. Using a map of the inter-state highway system, 96 candidate hub locations within the continental United States were identified based on this seed rationale. 
A second set of seed hubs were locations that make sense from a business infrastructure viewpoint. The industrial motivator for this research is J.B. Hunt Transport, Inc. (JBHT). As one of the largest truckload trucking companies in the world, their existing infrastructure provided plausible seed candidates from their experience in developing a nationwide freight network. This infrastructure includes maintenance terminals and intermodal ramp groups. Also, there are more 'conceptual' infrastructure elements such as pricing hubs, locations with high-profit outbound rates, and the locations of dedicated fleets supporting large individual customers. For a direct comparison, 96 of the JBHT 'infrastructure' points were selected as potential domicile hub locations. This set of points was assimilated by considering 38 terminal locations, 23 intermodal ramp locations, 25 high-profit outbound locations, 10 major service hub locations, and dedicated contract service locations with more than 50 drivers. After deleting duplicates, pricing hubs were then added according to geographical coverage needs until 96 cities were determined.

The third rationale for building a hub seed set was based on freight density. Whereas the previous two rationales focused on inter-state and business infrastructures respectively, this seeding approach considered historical freight data. A computer model (see Appendix 2) was written to generate a nationwide grid and tabulated freight density by grid location from one year of historical freight data. The data consisted of individual freight lane records composed of origin latitudes and longitudes, and destination latitudes and longitudes. In addition, each freight record contained freight volume information signifying the number of loads along each freight lane. The computer model established a $1^{\circ}$ by $1^{\circ}$ nationwide latitude-longitude grid and then proceeded to rectilinearly map each 
freight lane. If an individual freight lane was determined to begin, end, or pass through any grid location, then that grid location's volume would be increased by the volume of the freight record. To be consistent with the set sizes of the two previous seed sets, the 96 most dense grid locations were identified as seed hub candidates.

\subsubsection{Hub Set Sizes}

The second factor of the experimental plan is the size of the hub sets. As discussed in the previous section during the determination of alternative seeded hub sets, each set was composed of 96 candidates. However, a carrier may not want to distribute their domiciles so broadly. Therefore, the purpose for this factor is to examine the robustness of each seeded hub set under scenarios when the numbers of candidates in the seeded hub set vary. The three levels of this factor were $n=25,50$, and 96. Table 4-1 gives a comparison of each seeded hub set's ability to own miles. Historical data was once again used for this analysis. Table 4-1 shows that as the set size ' $n$ ' increases, the ability of a set to own increased mileage follows a rule of diminishing returns. For instance, when considering the Highway hub set, the 25 top hub candidates $(n=25)$ are able to own $63.77 \%$ of the total mile volume. However, when $\mathrm{n}$ is doubled in size to $n=$ 50 , only approximately $21 \%$ more miles are claimed. And, when $n$ is almost doubled again to $n=96$, approximately $15 \%$ more miles are claimed. This relationship of diminishing returns between set size and ownership holds true across all seeded hub sets. 


\begin{tabular}{|c|c|c|c|}
\hline \multirow{4}{*}{ Percentage of Owned Mlles } \\
\hline & \multicolumn{3}{|c|}{ Seeded Hub Sets } \\
& Highway & $\underline{\text { JBHT }}$ & Lat-Long \\
\hline $\mathrm{n}=25$ & $63.77 \%$ & $63.84 \%$ & $60.08 \%$ \\
\hline $\mathrm{n}=50$ & $84.60 \%$ & $83.44 \%$ & $78.12 \%$ \\
\hline $\mathrm{n}=96$ & $99.81 \%$ & $99.81 \%$ & $90.72 \%$ \\
\hline
\end{tabular}

Table 4-1 - Comparison of Set Sizes Versus Total Mileage Ownership

Since the first two factors of the experimental design are concerned with seeded hub sets and set sizes, they go hand in hand. Therefore, Tables 4-2, 4-3, and 4-4 provide a summary of these two factors by listing each hub set's 96 candidates as well as identifying the hub seeds that would be included in set sizes $n=25,50$, and 96 . Note that in Tables 4-2 and 4-3 the individual hub locations are referenced by their city name. Whereas in Table 4-4 the individual hub locations, derived from a nationwide $1^{\circ}$ by $1^{\circ}$ latitude-longitude grid, are referenced simply by their latitude and longitude locations.

\subsubsection{Ownership Assignments}

The third factor of the experimental design deals with limitations based on the way ownership claims are assigned to individual hubs. There are three levels to this factor: 'no-ownership', 'ownership', and 'capped'. The first level, 'no-ownership', allows any hub to claim any freight lane's volume if the hub is located within the limitations of the maximum outbound or inbound radii $(\boldsymbol{R} \boldsymbol{O}$ and $\boldsymbol{R} \boldsymbol{I})$ or pass-thru circuity (C) values as denoted previously by Equations 4-2 through 4-5. Duplicate ownerships among different hubs are permissible. Therefore, multiple hubs may claim ownership for 


\begin{tabular}{|c|c|c|c|c|c|c|c|}
\hline 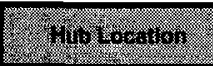 & 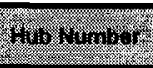 & $2+2+26$ & 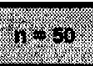 & 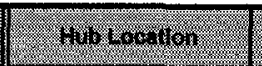 & s.6. & 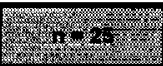 & 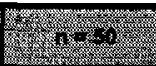 \\
\hline ALBUQUERQUE & 78 & $\checkmark$ & $\checkmark$ & ALBANY & 9 & & \\
\hline AMARILLO & 74 & $\checkmark$ & $\checkmark$ & AUGUSTA, ME & 1 & & \\
\hline BLOOMINGTON. IL & 50 & $\checkmark$ & $\checkmark$ & BATON ROUGE & 57 & & \\
\hline CHEYENNE & 76 & $\checkmark$ & $\checkmark$ & BILLINGS & 81 & & \\
\hline CHICAGO & 46 & $\checkmark$ & $\checkmark$ & BOSTON & 3 & & \\
\hline CINCINNATI & 38 & $\checkmark$ & $\checkmark$ & BUFFALO,NY & 19 & & \\
\hline COLUMBUS & 32 & $\checkmark$ & $\checkmark$ & BUFFALO, $W Y$ & 79 & & \\
\hline DENVER & 77 & $\checkmark$ & $\checkmark$ & BUTTE & 87 & & \\
\hline DES MOINES & 61 & $\checkmark$ & $\checkmark$ & CHARLOTTE & 22 & & \\
\hline FLAGSTAFF & 83 & $\checkmark$ & $\checkmark$ & COLUMBIA, SC & 23 & & \\
\hline INDIANAPOLIS & 43 & $\checkmark$ & $\checkmark$ & FARǴ & 70 & & \\
\hline JOPLIN & 63 & $\checkmark$ & $\checkmark$ & FORT LAUDERDALE & 21 & & \\
\hline KANSAS CITY & 64 & $\checkmark$ & $\checkmark$ & HARTFORD & 6 & & \\
\hline LAS VEGAS & 89 & $\checkmark$ & $\checkmark$ & HERMISTON, OR & 92 & & \\
\hline LITTLE ROCK & 58 & $\checkmark$ & $\checkmark$ & HOUSTON & 65 & & \\
\hline LOS ANGELES & 91 & $\checkmark$ & $\checkmark$ & JACKSON & 53 & & \\
\hline LOUISVILLE & 41 & $\checkmark$ & $\checkmark$ & JACKSONVILLE & 26 & & \\
\hline MEMPHIS & 52 & $\checkmark$ & $\checkmark$ & KENT, TX & 75 & & \\
\hline OKLAHOMA CITY & 72 & $\checkmark$ & $\checkmark$ & MOBILE & 48 & & \\
\hline OMAHA & 67 & $\checkmark$ & $\checkmark$ & MONTGOMERY & 42 & & \\
\hline PHOENIX & 85 & $\checkmark$ & $\checkmark$ & NEW HAVEN & 7 & & \\
\hline QUAD CITIES & 56 & $\checkmark$ & $\checkmark$ & NEW ORLEANS & 54 & & \\
\hline ST LOUIS & 55 & $\checkmark$ & $\checkmark$ & NEW YORK CITY & 8 & & \\
\hline TULSA & 66 & $\checkmark$ & $\checkmark$ & NORFOLK & 12 & & \\
\hline WICSHITA & 71 & $\checkmark$ & $\checkmark$ & PHILADELPHIA & 10 & & \\
\hline ALBERT LEA, MN & 60 & & $\checkmark$ & POCATELLO & 86 & & \\
\hline ASHVILLE, NC & 31 & & $\checkmark$ & PORTLAND, OR & 96 & & \\
\hline ATLANTA & 36 & & $\checkmark$ & PROVIDENCE & 2 & & \\
\hline BIRMINGHAM & 45 & & $\checkmark$ & RALEIGH & 18 & & \\
\hline CHARLESTON, WV & 27 & & $\checkmark$ & RICHMOND & 16 & & \\
\hline CHATTANOOGA & 40 & & $\checkmark$ & ROCHESTER & 17 & & \\
\hline CLEVELAND & 28 & & $\checkmark$ & SAN ANTONIO & 73 & & \\
\hline COVE FORT, UT & 88 & & $\checkmark$ & SAN DIEGO & 90 & & \\
\hline DALLAS & 69 & & $\checkmark$ & SAN FRANCISCO & 94 & & \\
\hline DETROIT & 34 & & $\checkmark$ & SAVANNAH & 25 & & \\
\hline HARRISBURG & 14 & & $\checkmark$ & SCRANTON & 11 & & \\
\hline KNOXVILLE & 35 & & $\checkmark$ & SEATTLE & 95 & & \\
\hline LAKE CITY, KY & 49 & & $\checkmark$ & SPARTANBURG, SC & 29 & & \\
\hline LANSING & 39 & & $\checkmark$ & SPRINGFIELD, MA & 5 & & \\
\hline LAS CRUCES & 80 & & $\checkmark$ & ST. PAUL & 59 & & \\
\hline LEXINGTON & 37 & & $\checkmark$ & SYRACUSE & 13 & & \\
\hline MADISON & 54 & & $\checkmark$ & TAMPA & 30 & & \\
\hline MILWAUKEE & 47 & & $\checkmark$ & TUCSON & 82 & & \\
\hline NASHVILLE & 44 & & $\checkmark$ & WASHINGTON, DC & 15 & & \\
\hline PITTSBURG & 20 & & $\checkmark$ & WHITE RIVER JUNCTI & 4 & & \\
\hline SACRAMENTO & 93 & & $\checkmark$ & WYTHEVILLE, VA & 24 & & \\
\hline SALT LAKE CITY & 84 & & $\checkmark$ & & & & \\
\hline SHREVEPORT & 62 & & $\checkmark$ & & & & \\
\hline SOUIXFALLS & 68 & & $\checkmark$ & & & & \\
\hline TOLEDO & 33 & & $\checkmark$ & & & & \\
\hline
\end{tabular}

Table 4-2 - List of 96 Highway Hub Seeds Based On Prominent Intersection Criteria 


\begin{tabular}{|c|c|c|c|c|c|c|c|}
\hline 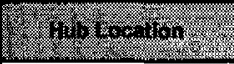 & Hitu vinuor. & $\sqrt{1}=28$ & $n=89$ & 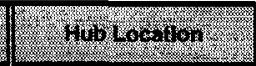 & 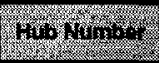 & 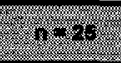 & 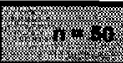 \\
\hline CEDAR RAPIDS IA & 19 & $\checkmark$ & $\checkmark$ & ALBANY NY & 54 & & \\
\hline CHAMPAIGN IL & 21 & $\checkmark$ & $\checkmark$ & ALLENTOWN PA & 67 & & \\
\hline CHICAGO IL & 22 & $\checkmark$ & $\checkmark$ & ASHEVILLE NC & 48 & & \\
\hline COLUMBUS OH & 59 & $\checkmark$ & $\checkmark$ & BALTIMORE MD & 35 & & \\
\hline DENVER CO & 12 & $\checkmark$ & $\checkmark$ & BATON ROUGE LA & 32 & & \\
\hline DES MOINES IA & 20 & $\checkmark$ & $\checkmark$ & BRISTOL TN & 74 & & \\
\hline EFFINGHAM IL & 23 & $\checkmark$ & $\checkmark$ & BUFFALO NY & 55 & & \\
\hline EVANSVILLE IN & 25 & $\checkmark$ & $\checkmark$ & CHARLOTTE NC & 49 & & \\
\hline FORT SMITH AR & 3 & $\checkmark$ & $\checkmark$. & COLUMBIA SC & 72 & & \\
\hline HUNTINGTON IN & 26 & $\checkmark$ & $\checkmark$ & EAST BRUNSWICK NJ & 53 & & \\
\hline INDIANAPOLIS IN & 27 & $\checkmark$ & $\checkmark$ & EAU CLAIRE WI & 92 & & \\
\hline KANSAS CITY MO & 43 & $\checkmark$ & $\checkmark$ & EL PASO TX & 80 & & \\
\hline LITTLE ROCK AR & 4 & $\checkmark$ & $\checkmark$ & FRESNO CA & 7 & & \\
\hline LOS ANGELES CA & 8 & $\checkmark$ & $\checkmark$ & GREENVILLE SC & 73 & & \\
\hline LOUISVILLE KYIIN & 31 & $\checkmark$ & $\checkmark$ & HOUSTON TX & 81 & & \\
\hline LOWELL AR & 5 & $\checkmark$ & $\checkmark$ & JACKSONVILLE FL & 13 & & \\
\hline OKLAHOMA CITY OK & 64 & $\checkmark$ & $\checkmark$ & MACON GA & 16 & & \\
\hline OMAHA NE & 51 & $\checkmark$ & $\checkmark$ & MARTINSVILLE VA & 85 & & \\
\hline PHOENIXAZ & 6 & $\checkmark$ & $\checkmark$ & MERIDIAN MS & 46 & & \\
\hline ROCKFORD IL & 24 & $\checkmark$ & $\checkmark$ & MINNEAPOLIS MN & 42 & & \\
\hline SAN BERNADINO CA & 10 & $\checkmark$ & $\checkmark$ & MONTGOMERY AL & 2 & & \\
\hline SPRINGFIELD MO & 44 & $\checkmark$ & $\checkmark$ & OCALA FL & 14 & & \\
\hline ST. LOUIS MO & 45 & $\checkmark$ & $\checkmark$ & ODESSA TX & 82 & & \\
\hline TULSA OK & 65 & $\checkmark$ & $\checkmark$ & PHILADELPHIA PA & 69 & & \\
\hline WICHITA KS & 28 & $\checkmark$ & $\checkmark$ & PORTLAND ME & 37 & & \\
\hline ATLANTA GA & 15 & & $\checkmark$ & PORTLAND OR & 66 & & \\
\hline ATTICA OH & 57 & & $\checkmark$ & RICHLAND MS & 47 & & \\
\hline BIRMINGHAM, AL & 1 & & $\checkmark$ & RICHMOND CA & 9 & & \\
\hline BOWLING GREEN KY & 29 & & $\checkmark$ & RICHMOND VA & 86 & & \\
\hline CHATTANOOGA TN & 75 & & $\checkmark$ & ROANOKE VA & 87 & & \\
\hline CINCINNATI OH & 58 & & $\checkmark$ & ROCKY MOUNT NC & 50 & & \\
\hline DALLAS TX & 79 & & $\checkmark$ & SAGINAW MI & 41 & & \\
\hline DETROIT MI & 38 & & $\checkmark$ & SAN ANTONIO TX & 83 & & \\
\hline GRAND RAPIOS MI & 39 & & $\checkmark$ & SAVANNAH GA & 17 & & \\
\hline HAGERSTOWN MD & 36 & & $\checkmark$ & SCRANTON PA & 71 & & \\
\hline HARRISBURG PA & 68 & & $\checkmark$ & SEABROOK NH & 52 & & \\
\hline KALAMAZOO MI & 40 & & $\checkmark$ & SHREVEPORT LA & 33 & & \\
\hline KNOXVILLE TN & 76 & & $\checkmark$ & STOCKTON CA & 11 & & \\
\hline LEXINGTON KY & 30 & & $\checkmark$ & SUMNER WA & 90 & & \\
\hline LIMA OH & 60 & & $\checkmark$ & SYRACUSE NY & 56 & & \\
\hline MADISON WI & 93 & & $\checkmark$ & TIFTON GA & 18 & & \\
\hline MEMPHIS TN & 77 & & $\checkmark$ & VANCOUVER WA & 91 & & \\
\hline MILWAUKEE WI & 94 & & $\checkmark$ & VIRGINIA BEACH VA & 88 & & \\
\hline NASHVILLE TN & 78 & & $\checkmark$ & WAUSAU WI & 95 & & \\
\hline NILES OH & 61 & & $\checkmark$ & WINCHESTER VA & 89 & & \\
\hline NITRO WV & 96 & & $\checkmark$ & WORCESTER MA & 34 & & \\
\hline PENINSULA OH & 62 & & $\checkmark$ & & & & \\
\hline PITTSBURG PA & 70 & & $\checkmark$ & & & & \\
\hline TOLEDO OH & 63 & & $\checkmark$ & & & & \\
\hline TYLER TX & 84 & & $\checkmark$ & & & & \\
\hline
\end{tabular}

Table 4-3 - List of 96 J.B. Hunt Hub Seeds Based On Prominent Infrastructure Criteria 


\begin{tabular}{|c|c|c|c|c|c|c|c|}
\hline 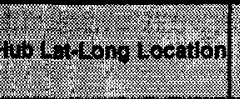 & Hit rumber & $n=26$ & $\sqrt[n]{n+\infty}$ & 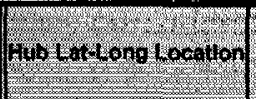 & Hub rambing & 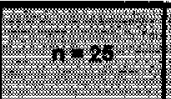 & 2. \\
\hline $33,-97$ & 25 & $\checkmark$ & $\checkmark$ & $33,-97$, & 25 & & \\
\hline $34,-108$ & 66 & $\checkmark$ & $\checkmark$ & $34,-108$ & 66 & & \\
\hline $34,-110$, & 28 & $\checkmark$ & $\checkmark$ & $34,-110$, & 28 & & \\
\hline $34,-118$ & 1 & $\checkmark$ & $\checkmark$ & $34,-118$ & 1 & & \\
\hline $34,-84$. & 55 & $\checkmark$ & $\checkmark$ & $34,-84$ & 55 & & \\
\hline $35,-107$, & 58 & $\checkmark$ & $\checkmark$ & $35,-107$, & 58 & & \\
\hline $35,-90$ & 79 & $\checkmark$ & $\checkmark$ & $35,-90$ & 79 & & \\
\hline $35,-92$, & 29 & $\checkmark$ & $\checkmark$ & $35 ;-92$, & 29 & & \\
\hline 36. -105 , & 86 & $\checkmark$ & $\checkmark$ & $36,-105$ & 86 & & \\
\hline $38,-102$, & 77 & $\checkmark$ & $\checkmark$ & $38,-102$ & 77 & & \\
\hline $38,-110$, & 95 & $\checkmark$ & $\checkmark$ & $38,-110$, & 95 & & \\
\hline $38,-85$ & 36 & $\checkmark$ & $\checkmark$ & $38,-85$ & 36 & & \\
\hline $38,-99$, & 93 & $\checkmark$ & $\checkmark$ & $38,-99$ & 93 & & \\
\hline $39,-100$ & 80 & $\checkmark$ & $\checkmark$ & $39,-100$, & 80 & & \\
\hline $39,-102$ & 57 & $\checkmark$ & $\checkmark$ & $39,-102$ & 57 & & \\
\hline $39,-103$ & 61 & $\checkmark$ & $\checkmark$ & $39,-103$ & 61 & & \\
\hline $39,-105$, & 83 & $\checkmark$ & $\checkmark$ & $39,-105$, & 83 & & \\
\hline $39,-96$, & 87 & $\checkmark$ & $\checkmark$ & $39,-96$ & 87 & & \\
\hline $39,-99$, & 94 & $\checkmark$ & $\checkmark$ & $39,-99$ & 94 & & \\
\hline $40,-82$ & 46 & $\checkmark$ & $\checkmark$ & $40,-82$, & 46 & & \\
\hline $40,-83$, & 3 & $\checkmark$ & $\checkmark$ & $40,-83$ & 3 & & \\
\hline $40,-94$, & 96 & $\checkmark$ & $\checkmark$ & $40,-94$ & 96 & & \\
\hline $41,-82$ & 37 & $\checkmark$ & $\checkmark$ & $41,-82$ & 37 & & \\
\hline $41,-90$, & 65 & $\checkmark$ & $\checkmark$ & $41,-90$ & 65 & & \\
\hline 42. -88 & 2 & $\checkmark$ & $\checkmark$ & $42,-88$, & 2 & & \\
\hline $34,-109$, & 30 & & $\checkmark$ & $34,-109$, & 30 & & \\
\hline $35,-109$ & 47 & & $\checkmark$ & $35,-109$ & 47 & & \\
\hline 36, -109 & 50 & & $\checkmark$ & $36,-109$ & 50 & & \\
\hline $36,-111$, & 59 & & $\checkmark$ & $36,-111$. & 59 & & \\
\hline $37,-90$, & 88 & & $\checkmark$ & $37,-90$ & 88 & & \\
\hline $38,-100$ & 84 & & $\checkmark$ & $38,-100$ & 84 & & \\
\hline $38,-106$ & 42 & & $\checkmark$ & $38,-106$, & 42 & & \\
\hline 38, -107 , & 51 & & $\checkmark$ & $38,-107$, & 51 & & \\
\hline $38,-108$, & 56 & & $\checkmark$ & $38,-108$ & 56 & & \\
\hline $38,-86$, & 14 & & $\checkmark$ & $38,-86$ & 14 & & \\
\hline $38,-87$, & 32 & & $\checkmark$ & $38,-87$, & 32 & & \\
\hline $38,-88_{r}$ & 48 & & $\checkmark$ & $38,-88$, & 48 & & \\
\hline $38,-91$ & 81 & & $\checkmark$ & $38,-91$, & 81 & & \\
\hline $38,-92$, & 27 & & $\checkmark$ & $38,-92$, & 27 & & \\
\hline $38,-93$, & 90 & & $\checkmark$ & $38,-93$ & 90 & & \\
\hline 39, -101, & 60 & & $r$ & $39,-101$, & 60 & & \\
\hline 39, -104 & 67 & & $\checkmark$ & $39,-104$, & 67 & & \\
\hline $39,-85$, & 7 & & $\checkmark$ & $39 .-85$ & 7 & & \\
\hline $39,-86$, & 41 & & $\checkmark$ & 39. -86 , & 41 & & \\
\hline $39,-95$, & 33 & & $\checkmark$ & $39,-95$, & 33 & & \\
\hline $40,-85$, & 17 & & $\checkmark$ & $40,-85$ & 17 & & \\
\hline $40,-87$, & 24 & & $\checkmark$ & & & & \\
\hline $40,-93$, & 74 & & $\checkmark$ & & & & \\
\hline $41,-83$ & 89 & & $\checkmark$ & & & & \\
\hline $41,-89$ & 68 & & $\checkmark$ & & & & \\
\hline
\end{tabular}

Table 4-4 - List of 96 Lat-Long Hub Seeds Based On Prominent Freight Densities 
the same freight lane volume. After all ownership considerations are tabulated, each of the hub volumes are normalized based on their respective share of the total available freight volume that could have been claimed. The normalization is performed so that post assignment driver and mileage statistics can be calculated that would be comparable in scale to other ownership assignment types.

The second level of the ownership assignment factor is 'ownership'. Whereas the 'no-ownership' level allowed duplicate ownership of the same freight lane's volume, the ownership scenario explicitly assigns a freight lane's volume to one and only one hub. For all hubs with potential ownership claims, the final ownership assignment is given to the single hub that is located nearest the origin, nearest the destination, or an intermediate hub that can be passed through with minimal circuity. Whereas the 'no-ownership' scenarios have unrestricted assignments, the 'ownership' scenario restricts the assignment to the hub possessing the 'best fit'. This method ensures that each load cannot be used as 'get home' freight for multiple locations. Equation 4-6, presented previously, mathematically depicts the ownership assignment type.

The final level of the ownership assignment is the 'capped' ownership. Under this assignment rule, assignments are made exactly as they are under the 'ownership' scenario. However, each hub is restricted with a driver capacity constraint. Therefore each hub may only be allowed to claim volumes from additional freight lanes until the hub meets its driver capacity restriction. The rationale for this scenario is to examine the possibility that a carrier would want to limit the size of a hub or to control the number of drivers that would have to be managed at a hub. This limitation forces the distribution of drivers across multiple hubs so that any single hub does not accumulate a significantly 
disproportionate number of drivers. For this research the capacity value was set at 200 drivers per domicile. Following the notation set forth in Section 4-4, the number of drivers at any hub location can be calculated (Equation 4-20) as follows, where $M$ is a new parameter that defines the number of miles that can be driven by each driver per day and $\boldsymbol{T}$ is a parameter defining the number of days in the planning horizon.

$$
\begin{aligned}
& \# \text { Drivers }=\left(\sum_{i} \sum_{j} X_{i j}\left(D i j_{i j} O B_{i k}+D i j_{i j} I B_{j k}+\left(D i k_{i k}+D j k_{j k}-D i j_{i j}\right) P T_{i j k}\right) / M / T\right. \\
& \forall k
\end{aligned}
$$

\subsubsection{Priority Weights}

The final three experimental factors can all be grouped together under the general definition of priority weights. Since there are three types of ownership, there are also three priority weights. These weights are relative. Each weight may assume any value, but the values do not have to sum to any specific total quantity. There are two levels for each of these three weights - low $(0.25)$ and hi $(0.75)$. For any number of hubs, the assignment precedence is given first to the hub associated with the highest weight. If more than one hub possesses the same weight, then precedence once again defaults to the hub that minimizes either the distance from the hub to the outbound or inbound location, or to the hub that minimizes the circuitous distance. The use of weights allows a given hub located a greater distance away from a freight lane a priority of assignment versus a hub located a smaller distance to the freight lane. These conditional assignments were developed by Equations 4-7 through 4-12 in Section 4.4.

This concludes the discussion of the problem factors. In summary, Figure 4-5 shows that the full factorial design of all levels for all six factors requires 216 total 
experiments. Each experiment is repeated for 12 replications (from 12 months of historical data) to satisfy a final ANOVA analysis.

\subsubsection{Data Specifications}

The data needed to support the problem analysis includes concludes freight data, seeded hub locations, and procedural parameters. The freight data comes from J.B. Hunt, Inc and consists of individual records representing origin to destination volumes (in truckloads). Twelve months of data have been supplied. In addition to freight volumes, the individual records also include origin latitudes and longitudes, and destination latitudes and longitudes. The seeded hub locations were discussed in Sections 4.5.1 and 4.5.2. Each hub is identified by a hub number, a latitude, and a longitude. Procedural parameters are user-defined values that would remain constant for all experiments. In this problem, those parameters include the maximum allowable outbound radius $(\boldsymbol{R} \boldsymbol{O}=$ 50 miles $)$, the maximum allowable inbound radius $(\boldsymbol{R} I=50 \mathrm{miles})$, and the maximum allowable circuity distance ( $\boldsymbol{C}=50$ miles $)$ were recommended by J.B. Hunt.

\subsubsection{Solution Approaches}

Two methods for solving this problem have been developed - a computer optimization model, and a computer heuristic. The optimization model has been developed using LINGO 9.0. The coded model appears in Appendix 3. Although the Driver Domicile Problem can be solved with an optimization suite such as LINGO, the number of variables and constraints for a large problem make the problem computationally difficult. However, the optimization model can be used for smaller data 
sets and its answers can be compared to the output of the computer heuristic.

Furthermore, cross comparison of the results of the two models can help verify the validity of both the optimization and the heuristic.

Due to size constraints, the primary tool for modeling these experiments is a computer heuristic model written using the SIMNET II simulation language on a PC. Although the problem is deterministic, the SIMNET II platform provides an adequate way of modeling the problem described herein. The heuristic has been used on all 216 experiments and each of their replications. The SIMNET II model reads each freight lane record and makes appropriate ownership assignments based on the rules provided in Sections 4-4 and 4-5. The coded SIMNET II model appears in Appendix 4.

Computer output from the heuristic consists of five categories of response measurements (see Figure 4-5, Experimental Plan, shown previously). The response measurements are as follows:

Ownership coverage - This statistic is an indicator of how well each hub set can effectively cover the available freight. These measurements calculate percentages of the amount of routes (freight lanes), loads, and miles that are claimed by a given hub set. A value of $100 \%$ would indicate that all possible claims had been made and no freight would need to be hauled by an OTR driver other than a domiciled driver.

Imbalance - This statistic is a measure of the overall imbalance of a given hub set. No inference is made about whether the balance is primarily attributed to either outbound or inbound freight. However, this statistic sums up each hub's individual absolute imbalance. For a given hub ' $k$ ', its imbalance is calculated by Equation 4-21. 
Imbalance at hub ' $\mathrm{k}^{\prime}=\left|\sum_{i} X_{i j} D i j_{i j} O B_{i k}-\sum_{j} X i j_{i j} D i j_{i j} I B_{j k}\right| \quad \forall k$

Owned Miles - These statistics are the summary of the miles owned by each hub set. They are broken down into outbound, inbound, and pass-thru miles.

Miles Driven - These statistics reveal an approximation to the actual mileage that will be driven under each experimental scenario. The number of miles driven by domiciled drivers and the number of miles driven by other OTR drivers are individually tabulated and summed to reveal the total miles driven. These actual mileage statistics help determine the number and types of drivers that would be required under a given scenario.

Drivers Required - These statistics approximate the number of drivers that would be needed to support each experimental scenario. The number of domiciled drivers and the number of other OTR drivers are individually tabulated and then summed to reveal the total number of drivers required.

Full post-model statistical analysis of these response measurements is performed using MiniTab 14.0 for each experimental scenario.

\subsection{Results}

An optimization model was developed using LINGO 9.0 based on the mathematical model presented in Section 4.4. The LINGO 9.0 package is a comprehensive optimization design tool and mathematical formulator. The LINGO results were compared to the results from the heuristic developed with SIMNET II on 5 test problems ranging from 10 to 500 freight lanes and using 96 hubs each. The integer 
linear program was solved globally by the branch and bound technique. Table 4-5 shows a comparison of the two solution methods. Both models reached identical answers for the total number and percentage of miles owned. However, the distribution of owned miles was assigned to hubs differently by each model. The optimization models were able to assign a greater proportion of owned outbound and inbound hub miles than did each of the corresponding heuristic models. As a result, the solution to the optimization models required fewer miles driven. However, the LINGO optimization model took considerably more time to run than did the SIMNET model $(46+$ minutes versus $1+$ minutes for 500 freight loads). An analysis of variance for the percentage of miles driven found that there is no statistical difference $(p=0.182)$ between the two model means at the $\alpha=0.05$ level. Furthermore, since a realistic one month data set would consist of approximately 4,000 freight lanes, the additional run time required to reach an optimal solution does not yield a significantly improved advantage over the heuristic solution. Therefore it would be unnecessary to run the optimization model for future network analysis. 


\section{LINGO Optimization VS. SIMNET Heuristic}

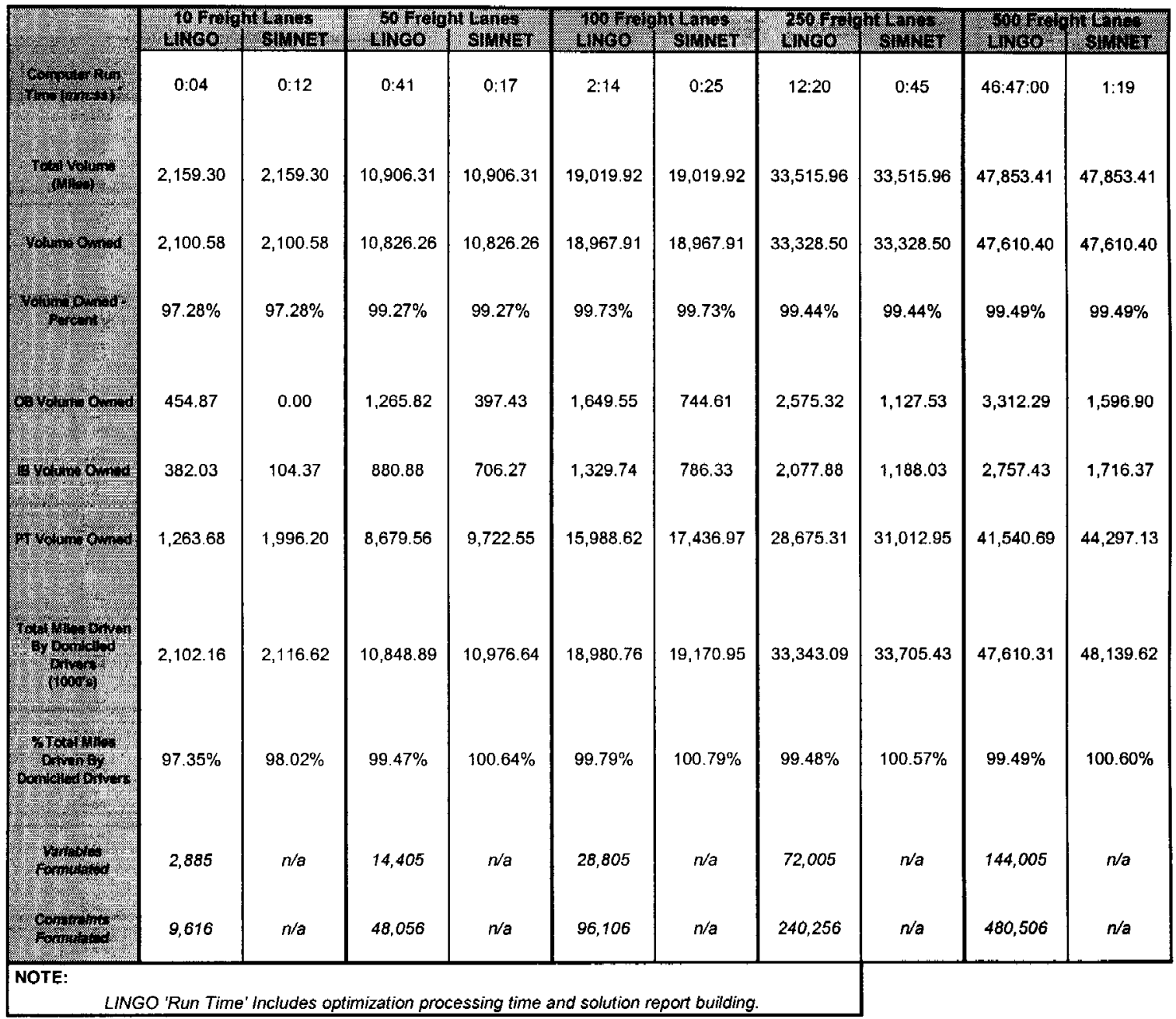

Table 4-5 - LINGO Optimization vs. SIMNET Heuristic

The following tables (Table 4-6 through Table 4-45) and charts provide a summary of the results (fifteen metrics each scenario) obtained for all 216 experimental scenarios as determined by the SIMNET model. Discussion of these results and statistical analysis appear in Section 4.7. 


\begin{tabular}{|c|c|c|c|c|c|c|c|c|c|c|c|}
\hline Data & Type & Size & OB & IB & PT & \multicolumn{2}{|c|}{$\%$ Routes } & \multicolumn{2}{|c|}{$\%$ Loads } & \multicolumn{2}{|c|}{$\%$ Miles } \\
\hline & & & & & & Mean & Var & Mean & Var & Mean & Var \\
\hline \multicolumn{12}{|l|}{ Weights: } \\
\hline HW & No-Owner & 96 & 0.25 & 0.25 & 0.25 & 99.08 & 0.018 & 99.17 & 0.036 & 99.81 & 0.004 \\
\hline $\mathrm{JB}$ & No-Owner & 96 & 0.25 & 0.25 & 0.25 & 99.44 & 0.007 & 99.47 & 0.018 & 99.80 & 0.003 \\
\hline $\mathrm{LL}$ & No-Owner & 96 & 0.25 & 0.25 & 0.25 & 79.49 & 1.171 & 79.68 & 2.827 & 90.67 & 1.998 \\
\hline HW & Owner & 96 & 0.25 & 0.25 & 0.25 & 99.08 & 0.018 & 99.17 & 0.037 & 99.81 & 0.004 \\
\hline $\mathrm{JB}$ & Owner & 96 & 0.25 & 0.25 & 0.25 & 99.45 & 0.007 & 99.47 & 0.018 & 99.81 & 0.003 \\
\hline LL & Owner & 96 & 0.25 & 0.25 & 0.25 & 79.50 & 1.174 & 79.68 & 2.825 & 90.67 & 1.996 \\
\hline HW & Capped & 96 & 0.25 & 0.25 & 0.25 & 98.33 & 1.142 & 98.88 & 0.204 & 99.67 & 0.064 \\
\hline$J B$ & Capped & 96 & 0.25 & 0.25 & 0.25 & 97.92 & 0.709 & 98.86 & 0.101 & 99.34 & 0.072 \\
\hline LL & Capped & 96 & 0.25 & 0.25 & 0.25 & 78.28 & 4.714 & 79.15 & 3.212 & 90.13 & 2.918 \\
\hline HW & No-Owner & 50 & 0.25 & 0.25 & 0.25 & 76.09 & 1.047 & 76.87 & 1.785 & 84.58 & 1.634 \\
\hline $\mathrm{JB}$ & No-Owner & 50 & 0.25 & 0.25 & 0.25 & 71.72 & 0.944 & 74.21 & 3.098 & 83.40 & 4.672 \\
\hline LL & No-Owner & 50 & 0.25 & 0.25 & 0.25 & 63.46 & 0.801 & 65.16 & 3.627 & 78.09 & 6.577 \\
\hline $\mathrm{HW}$ & Owner & 50 & 0.25 & 0.25 & 0.25 & 76.09 & 1.043 & 76.87 & 1.782 & 84.58 & 1.629 \\
\hline $\mathrm{JB}$ & Owner & 50 & 0.25 & 0.25 & 0.25 & 71.72 & 0.946 & 74.21 & 3.100 & 83.40 & 4.671 \\
\hline LL & Owner & 50 & 0.25 & 0.25 & 0.25 & 63.46 & 0.802 & 65.16 & 3.630 & 78.09 & 6.584 \\
\hline $\mathrm{HW}$ & Capped & 50 & 0.25 & 0.25 & 0.25 & 74.78 & 3.332 & 76.32 & 1.490 & 83.88 & 1.928 \\
\hline$J B$ & Capped & 50 & 0.25 & 0.25 & 0.25 & 68.48 & 3.198 & 72.90 & 2.064 & 81.71 & 3.957 \\
\hline $\mathrm{LL}$ & Capped & 50 & 0.25 & 0.25 & 0.25 & 60.31 & 3.695 & 62.97 & 2.761 & 73.92 & 4.088 \\
\hline HW & No-Owner & 25 & 0.25 & 0.25 & 0.25 & 43.69 & 1.862 & 48.06 & 5.560 & 63.73 & 15.170 \\
\hline $\mathrm{JB}$ & No-Owner & 25 & 0.25 & 0.25 & 0.25 & 40.43 & 1.878 & 45.11 & 5.681 & 63.80 & 19.589 \\
\hline $\mathrm{LL}$ & No-Owner & 25 & 0.25 & 0.25 & 0.25 & 44.97 & 0.931 & 49.86 & 2.099 & 60.06 & 5.606 \\
\hline HW & Owner & 25 & 0.25 & 0.25 & 0.25 & 43.69 & 1.863 & 48.06 & 5.556 & 63.73 & 15.159 \\
\hline JB & Owner & 25 & 0.25 & 0.25 & 0.25 & 40.43 & 1.882 & 45.11 & 5.678 & 63.80 & 19.599 \\
\hline $\mathrm{LL}$ & Owner & 25 & 0.25 & 0.25 & 0.25 & 44.97 & 0.928 & 49.86 & 2.102 & 60.06 & 5.607 \\
\hline $\mathrm{HW}$ & Capped & 25 & 0.25 & 0.25 & 0.25 & 39.72 & 11.137 & 46.39 & 4.605 & 60.71 & 13.803 \\
\hline JB & Capped & 25 & 0.25 & 0.25 & 0.25 & 35.57 & 11.663 & 43.07 & 4.571 & 60.98 & 19.378 \\
\hline LL & Capped & 25 & 0.25 & 0.25 & 0.25 & 40.26 & 12.443 & 47.10 & 3.019 & 54.85 & 6.122 \\
\hline
\end{tabular}

Table 4-6 - Ownership Percentages \#1

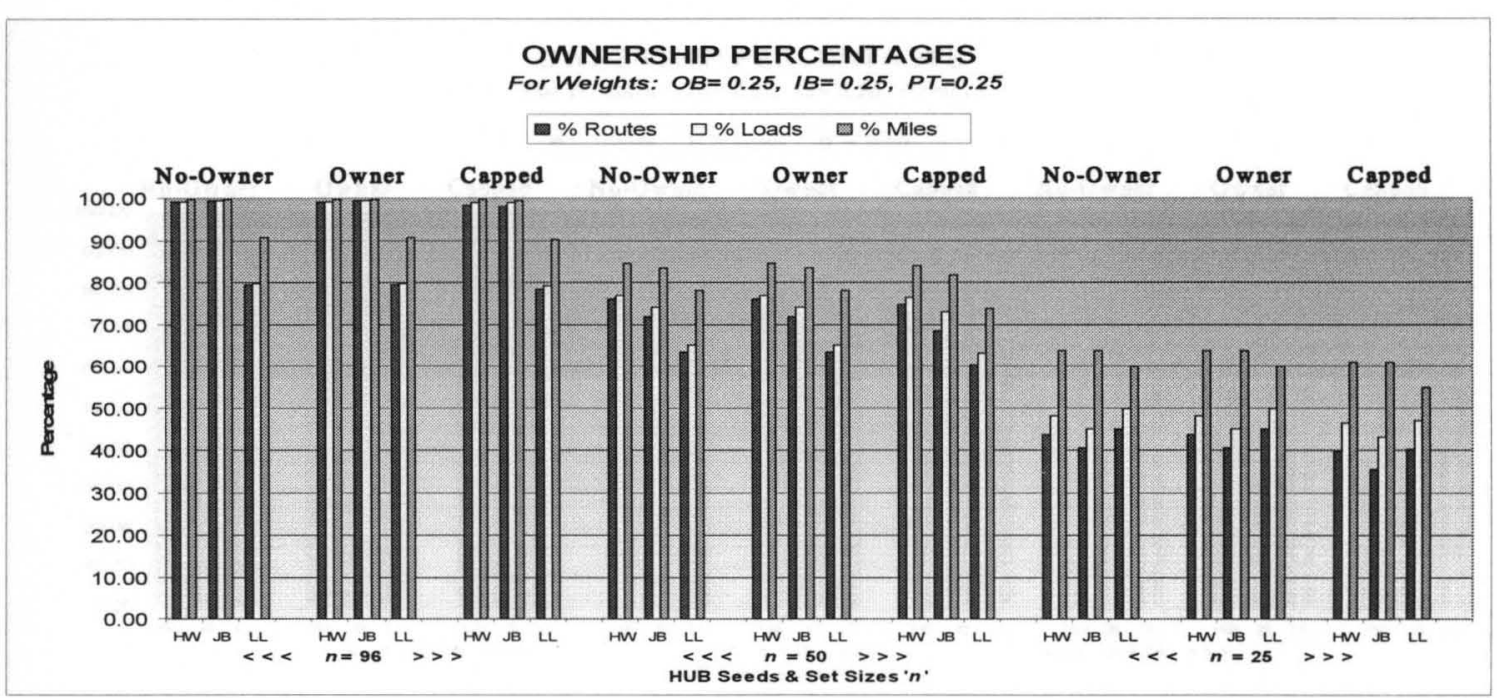




\begin{tabular}{|c|c|c|c|c|c|c|c|c|c|c|c|}
\hline \multirow{3}{*}{$\begin{array}{c}\text { Data } \\
\text { Weights: } \\
\text { OB: } 0.25\end{array}$} & \multirow[t]{2}{*}{ Type } & \multirow[t]{2}{*}{ Size } & \multirow[t]{3}{*}{ OB } & \multirow[t]{3}{*}{ IB } & \multirow[t]{3}{*}{ PT } & \multicolumn{2}{|c|}{$\%$ Routes } & \multicolumn{2}{|c|}{$\%$ Loads } & \multicolumn{2}{|c|}{$\%$ Miles } \\
\hline & & & & & & \multirow[t]{2}{*}{ Mean } & \multirow[t]{2}{*}{$\underline{\text { Var }}$} & \multirow[t]{2}{*}{ Mean } & \multirow[t]{2}{*}{$\underline{\text { Var }}$} & \multirow[t]{2}{*}{ Mean } & \multirow[t]{2}{*}{$\underline{\text { Var }}$} \\
\hline & 0.25 PT: & 0.75 & & & & & & & & & \\
\hline $\mathrm{HW}$ & No-Owner & 96 & 0.25 & 0.25 & 0.75 & 99.08 & 0.018 & 99.17 & 0.036 & 99.81 & 0.004 \\
\hline $\mathrm{JB}$ & No-Owner & 96 & 0.25 & 0.25 & 0.75 & 99.44 & 0.007 & 99.47 & 0.018 & 99.80 & 0.003 \\
\hline LL & No-Owner & 96 & 0.25 & 0.25 & 0.75 & 79.49 & 1.171 & 79.68 & 2.827 & 90.67 & 1.998 \\
\hline $\mathrm{HW}$ & Owner & 96 & 0.25 & 0.25 & 0.75 & 99.08 & 0.018 & 99.17 & 0.037 & 99.81 & 0.004 \\
\hline $\mathrm{JB}$ & Owner & 96 & 0.25 & 0.25 & 0.75 & 99.45 & 0.007 & 99.47 & 0.018 & 99.81 & 0.003 \\
\hline LL & Owner & 96 & 0.25 & 0.25 & 0.75 & 79.50 & 1.174 & 79.68 & 2.825 & 90.67 & 1.996 \\
\hline HW & Capped & 96 & 0.25 & 0.25 & 0.75 & 98.33 & 1.152 & 98.90 & 0.188 & 99.68 & 0.060 \\
\hline $\mathrm{JB}$ & Capped & 96 & 0.25 & 0.25 & 0.75 & 97.92 & 0.709 & 98.86 & 0.101 & 99.34 & 0.072 \\
\hline LL & Capped & 96 & 0.25 & 0.25 & 0.75 & 78.28 & 4.714 & 79.15 & 3.212 & 90.13 & 2.918 \\
\hline $\mathrm{HW}$ & No-Owner & 50 & 0.25 & 0.25 & 0.75 & 76.31 & 1.063 & 76.97 & 1.682 & 84.62 & 1.558 \\
\hline $\mathrm{JB}$ & No-Owner & 50 & 0.25 & 0.25 & 0.75 & 71.72 & 0.944 & 74.21 & 3.098 & 83.40 & 4.672 \\
\hline $\mathrm{LL}$ & No-Owner & 50 & 0.25 & 0.25 & 0.75 & 63.46 & 0.801 & 65.16 & 3.627 & 78.09 & 6.577 \\
\hline HW & Owner & 50 & 0.25 & 0.25 & 0.75 & 76.31 & 1.065 & 76.97 & 1.682 & 84.62 & 1.556 \\
\hline $\mathrm{JB}$ & Owner & 50 & 0.25 & 0.25 & 0.75 & 71.72 & 0.946 & 74.21 & 3.100 & 83.40 & 4.671 \\
\hline LL & Owner & 50 & 0.25 & 0.25 & 0.75 & 63.46 & 0.802 & 65.16 & 3.630 & 78.09 & 6.584 \\
\hline HW & Capped & 50 & 0.25 & 0.25 & 0.75 & 75.03 & 3.337 & 76.45 & 1.354 & 83.94 & 1.814 \\
\hline $\mathrm{JB}$ & Capped & 50 & 0.25 & 0.25 & 0.75 & 68.48 & 3.198 & 72.90 & 2.064 & 81.71 & 3.957 \\
\hline LL & Capped & 50 & 0.25 & 0.25 & 0.75 & 60.31 & 3.695 & 62.97 & 2.761 & 73.92 & 4.088 \\
\hline HW & No-Owner & 25 & 0.25 & 0.25 & 0.75 & 43.68 & 1.897 & 48.12 & 5.497 & 63.75 & 15.126 \\
\hline $\mathrm{JB}$ & No-Owner & 25 & 0.25 & 0.25 & 0.75 & 40.43 & 1.878 & 45.11 & 5.681 & 63.80 & 19.589 \\
\hline LL & No-Owner & 25 & 0.25 & 0.25 & 0.75 & 44.97 & 0.931 & 49.86 & 2.099 & 60.06 & 5.606 \\
\hline $\mathrm{HW}$ & Owner & 25 & 0.25 & 0.25 & 0.75 & 43.68 & 1.898 & 48.12 & 5.500 & 63.75 & 15.119 \\
\hline $\mathrm{JB}$ & Owner & 25 & 0.25 & 0.25 & 0.75 & 40.43 & 1.882 & 45.11 & 5.678 & 63.80 & 19.599 \\
\hline LL & Owner & 25 & 0.25 & 0.25 & 0.75 & 44.97 & 0.928 & 49.86 & 2.102 & 60.06 & 5.607 \\
\hline $\mathrm{HW}$ & Capped & 25 & 0.25 & 0.25 & 0.75 & 39.71 & 11.653 & 46.47 & 4.574 & 60.74 & 13.833 \\
\hline JB & Capped & 25 & 0.25 & 0.25 & 0.75 & 35.57 & 11.663 & 43.07 & 4.571 & 60.98 & 19.378 \\
\hline LL & Capped & 25 & 0.25 & 0.25 & 0.75 & 40.26 & 12.443 & 47.10 & 3.019 & 54.85 & 6.122 \\
\hline
\end{tabular}

Table 4-7 - Ownership Percentages \#2

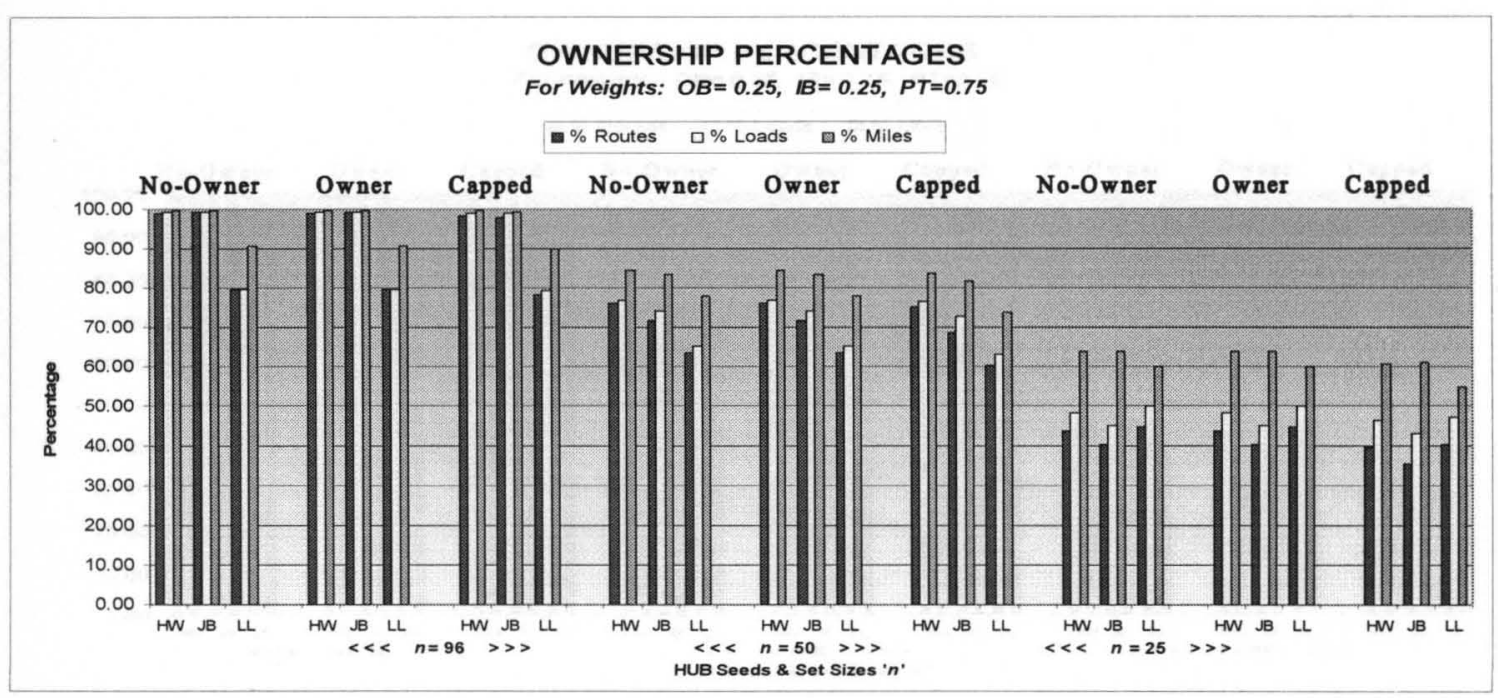




\begin{tabular}{|c|c|c|c|c|c|c|c|c|c|c|c|}
\hline Data & Type & Size & OB & IB & PT & \multicolumn{2}{|c|}{$\%$ Routes } & \multicolumn{2}{|c|}{$\%$ Loads } & \multicolumn{2}{|c|}{$\%$ Miles } \\
\hline & & & & & & Mean & Var & Mean & Var & Mean & Var \\
\hline \multicolumn{12}{|l|}{ Weights: } \\
\hline $\mathrm{HW}$ & No-Owner & 96 & 0.25 & 0.75 & 0.25 & 99.08 & 0.018 & 99.17 & 0.036 & 99.81 & 0.004 \\
\hline $\mathrm{JB}$ & No-Owner & 96 & 0.25 & 0.75 & 0.25 & 99.44 & 0.007 & 99.47 & 0.018 & 99.80 & 0.003 \\
\hline LL & No-Owner & 96 & 0.25 & 0.75 & 0.25 & 79.49 & 1.171 & 79.68 & 2.827 & 90.67 & 1.998 \\
\hline $\mathrm{HW}$ & Owner & 96 & 0.25 & 0.75 & 0.25 & 99.08 & 0.018 & 99.17 & 0.037 & 99.81 & 0.004 \\
\hline JB & Owner & 96 & 0.25 & 0.75 & 0.25 & 99.45 & 0.007 & 99.47 & 0.018 & 99.81 & 0.003 \\
\hline LL & Owner & 96 & 0.25 & 0.75 & 0.25 & 79.50 & 1.174 & 79.68 & 2.825 & 90.67 & 1.996 \\
\hline $\mathrm{HW}$ & Capped & 96 & 0.25 & 0.75 & 0.25 & 98.31 & 1.158 & 98.88 & 0.196 & 99.67 & 0.062 \\
\hline $\mathrm{JB}$ & Capped & 96 & 0.25 & 0.75 & 0.25 & 97.92 & 0.709 & 98.86 & 0.101 & 99.34 & 0.072 \\
\hline LL & Capped & 96 & 0.25 & 0.75 & 0.25 & 78.28 & 4.714 & 79.15 & 3.212 & 90.13 & 2.918 \\
\hline $\mathrm{HW}$ & No-Owner & 50 & 0.25 & 0.75 & 0.25 & 75.79 & 1.161 & 76.70 & 1.863 & 84.44 & 1.752 \\
\hline$J B$ & No-Owner & 50 & 0.25 & 0.75 & 0.25 & 71.72 & 0.944 & 74.21 & 3.098 & 83.40 & 4.672 \\
\hline LL & No-Owner & 50 & 0.25 & 0.75 & 0.25 & 63.46 & 0.801 & 65.16 & 3.627 & 78.09 & 6.577 \\
\hline HW & Owner & 50 & 0.25 & 0.75 & 0.25 & 75.79 & 1.159 & 76.70 & 1.861 & 84.44 & 1.751 \\
\hline JB & Owner & 50 & 0.25 & 0.75 & 0.25 & 71.72 & 0.946 & 74.21 & 3.100 & 83.40 & 4.671 \\
\hline LL & Owner & 50 & 0.25 & 0.75 & 0.25 & 63.46 & 0.802 & 65.16 & 3.630 & 78.09 & 6.584 \\
\hline HW & Capped & 50 & 0.25 & 0.75 & 0.25 & 74.40 & 3.681 & 76.12 & 1.528 & 83.72 & 2.013 \\
\hline JB & Capped & 50 & 0.25 & 0.75 & 0.25 & 68.48 & 3.198 & 72.90 & 2.064 & 81.71 & 3.957 \\
\hline LL & Capped & 50 & 0.25 & 0.75 & 0.25 & 60.31 & 3.695 & 62.97 & 2.761 & 73.92 & 4.088 \\
\hline HW & No-Owner & 25 & 0.25 & 0.75 & 0.25 & 43.86 & 1.908 & 48.45 & 5.199 & 63.79 & 14.502 \\
\hline JB & No-Owner & 25 & 0.25 & 0.75 & 0.25 & 40.43 & 1.878 & 45.11 & 5.681 & 63.80 & 19.589 \\
\hline LL & No-Owner & 25 & 0.25 & 0.75 & 0.25 & 44.97 & 0.931 & 49.86 & 2.099 & 60.06 & 5.606 \\
\hline HW & Owner & 25 & 0.25 & 0.75 & 0.25 & 43.86 & 1.907 & 48.45 & 5.200 & 63.79 & 14.501 \\
\hline JB & Owner & 25 & 0.25 & 0.75 & 0.25 & 40.43 & 1.882 & 45.11 & 5.678 & 63.80 & 19.599 \\
\hline LL & Owner & 25 & 0.25 & 0.75 & 0.25 & 44.97 & 0.928 & 49.86 & 2.102 & 60.06 & 5.607 \\
\hline $\mathrm{HW}$ & Capped & 25 & 0.25 & 0.75 & 0.25 & 39.70 & 12.052 & 46.67 & 4.137 & 60.71 & 13.203 \\
\hline JB & Capped & 25 & 0.25 & 0.75 & 0.25 & 35.57 & 11.663 & 43.07 & 4.571 & 60.98 & 19.378 \\
\hline LL & Capped & 25 & 0.25 & 0.75 & 0.25 & 40.26 & 12.443 & 47.10 & 3.019 & 54.85 & 6.122 \\
\hline
\end{tabular}

Table 4-8 - Ownership Percentages \#3

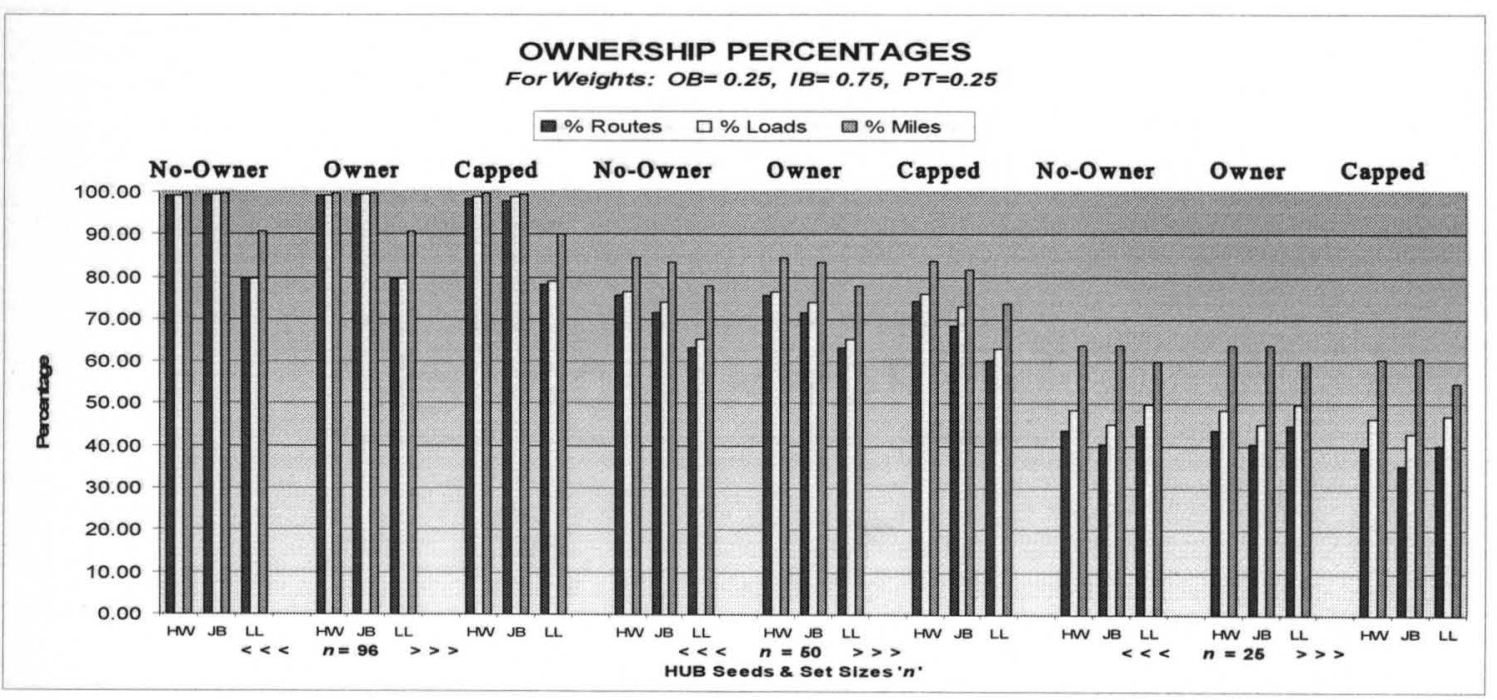




\begin{tabular}{|c|c|c|c|c|c|c|c|c|c|c|c|}
\hline Data & Type & Size & OB & IB & PT & $\% \mathrm{Rc}$ & utes & $\%$ Lo & ads & $\% M$ & les \\
\hline & & & & & & Mean & Var & Mean & Var & Mean & Var \\
\hline$\frac{\text { Weights: }}{\text { OB: } 0.25}$ & 0.75 PT: & 0.75 & & & & & & & & & \\
\hline $\mathrm{HW}$ & No-Owner & 96 & 0.25 & 0.75 & 0.75 & 99.05 & 0.018 & 99.06 & 0.043 & 99.80 & 0.005 \\
\hline $\mathrm{JB}$ & No-Owner & 96 & 0.25 & 0.75 & 0.75 & 99.44 & 0.007 & 99.47 & 0.018 & 99.80 & 0.003 \\
\hline $\mathrm{LL}$ & No-Owner & 96 & 0.25 & 0.75 & 0.75 & 79.49 & 1.171 & 79.68 & 2.827 & 90.67 & 1.998 \\
\hline $\mathrm{HW}$ & Owner & 96 & 0.25 & 0.75 & 0.75 & 99.05 & 0.018 & 99.06 & 0.043 & 99.80 & 0.004 \\
\hline $\mathrm{JB}$ & Owner & 96 & 0.25 & 0.75 & 0.75 & 99.45 & 0.007 & 99.47 & 0.018 & 99.81 & 0.003 \\
\hline LL & Owner & 96 & 0.25 & 0.75 & 0.75 & 79.50 & 1.174 & 79.68 & 2.825 & 90.67 & 1.996 \\
\hline $\mathrm{HW}$ & Capped & 96 & 0.25 & 0.75 & 0.75 & 98.30 & 1.284 & 98.78 & 0.239 & 99.67 & 0.068 \\
\hline $\mathrm{JB}$ & Capped & 96 & 0.25 & 0.75 & 0.75 & 97.92 & 0.709 & 98.86 & 0.101 & 99.34 & 0.072 \\
\hline $\mathrm{LL}$ & Capped & 96 & 0.25 & 0.75 & 0.75 & 78.28 & 4.714 & 79.15 & 3.212 & 90.13 & 2.918 \\
\hline $\mathrm{HW}$ & No-Owner & 50 & 0.25 & 0.75 & 0.75 & 76.16 & 1.037 & 76.85 & 1.766 & 84.54 & 1.610 \\
\hline $\mathrm{JB}$ & No-Owner & 50 & 0.25 & 0.75 & 0.75 & 71.72 & 0.944 & 74.21 & 3.098 & 83.40 & 4.672 \\
\hline $\mathrm{LL}$ & No-Owner & 50 & 0.25 & 0.75 & 0.75 & 63.46 & 0.801 & 65.16 & 3.627 & 78.09 & 6.577 \\
\hline $\mathrm{HW}$ & Owner & 50 & 0.25 & 0.75 & 0.75 & 76.16 & 1.035 & 76.85 & 1.765 & 84.54 & 1.609 \\
\hline $\mathrm{JB}$ & Owner & 50 & 0.25 & 0.75 & 0.75 & 71.72 & 0.946 & 74.21 & 3.100 & 83.40 & 4.671 \\
\hline $\mathrm{LL}$ & Owner & 50 & 0.25 & 0.75 & 0.75 & 63.46 & 0.802 & 65.16 & 3.630 & 78.09 & 6.584 \\
\hline HW & Capped & 50 & 0.25 & 0.75 & 0.75 & 74.85 & 3.439 & 76.30 & 1.429 & 83.85 & 1.870 \\
\hline $\mathrm{JB}$ & Capped & 50 & 0.25 & 0.75 & 0.75 & 68.48 & 3.198 & 72.90 & 2.064 & 81.71 & 3.957 \\
\hline $\mathrm{LL}$ & Capped & 50 & 0.25 & 0.75 & 0.75 & 60.31 & 3.695 & 62.97 & 2.761 & 73.92 & 4.088 \\
\hline $\mathrm{HW}$ & No-Owner & 25 & 0.25 & 0.75 & 0.75 & 43.68 & 1.874 & 48.07 & 5.612 & 63.73 & 15.190 \\
\hline JB & No-Owner & 25 & 0.25 & 0.75 & 0.75 & 40.43 & 1.878 & 45.11 & 5.681 & 63.80 & 19.589 \\
\hline $\mathrm{LL}$ & No-Owner & 25 & 0.25 & 0.75 & 0.75 & 44.97 & 0.931 & 49.86 & 2.099 & 60.06 & 5.606 \\
\hline $\mathrm{HW}$ & Owner & 25 & 0.25 & 0.75 & 0.75 & 43.68 & 1.877 & 48.07 & 5.619 & 63.73 & 15.201 \\
\hline$J B$ & Owner & 25 & 0.25 & 0.75 & 0.75 & 40.43 & 1.882 & 45.11 & 5.678 & 63.80 & 19.599 \\
\hline $\mathrm{LL}$ & Owner & 25 & 0.25 & 0.75 & 0.75 & 44.97 & 0.928 & 49.86 & 2.102 & 60.06 & 5.607 \\
\hline $\mathrm{HW}$ & Capped & 25 & 0.25 & 0.75 & 0.75 & 39.70 & 11.872 & 46.40 & 4.648 & 60.72 & 13.891 \\
\hline$J B$ & Capped & 25 & 0.25 & 0.75 & 0.75 & 35.57 & 11.663 & 43.07 & 4.571 & 60.98 & 19.378 \\
\hline LL & Capped & 25 & 0.25 & 0.75 & 0.75 & 40.26 & 12.443 & 47.10 & 3.019 & 54.85 & 6.122 \\
\hline
\end{tabular}

Table 4-9- Ownership Percentages \#4

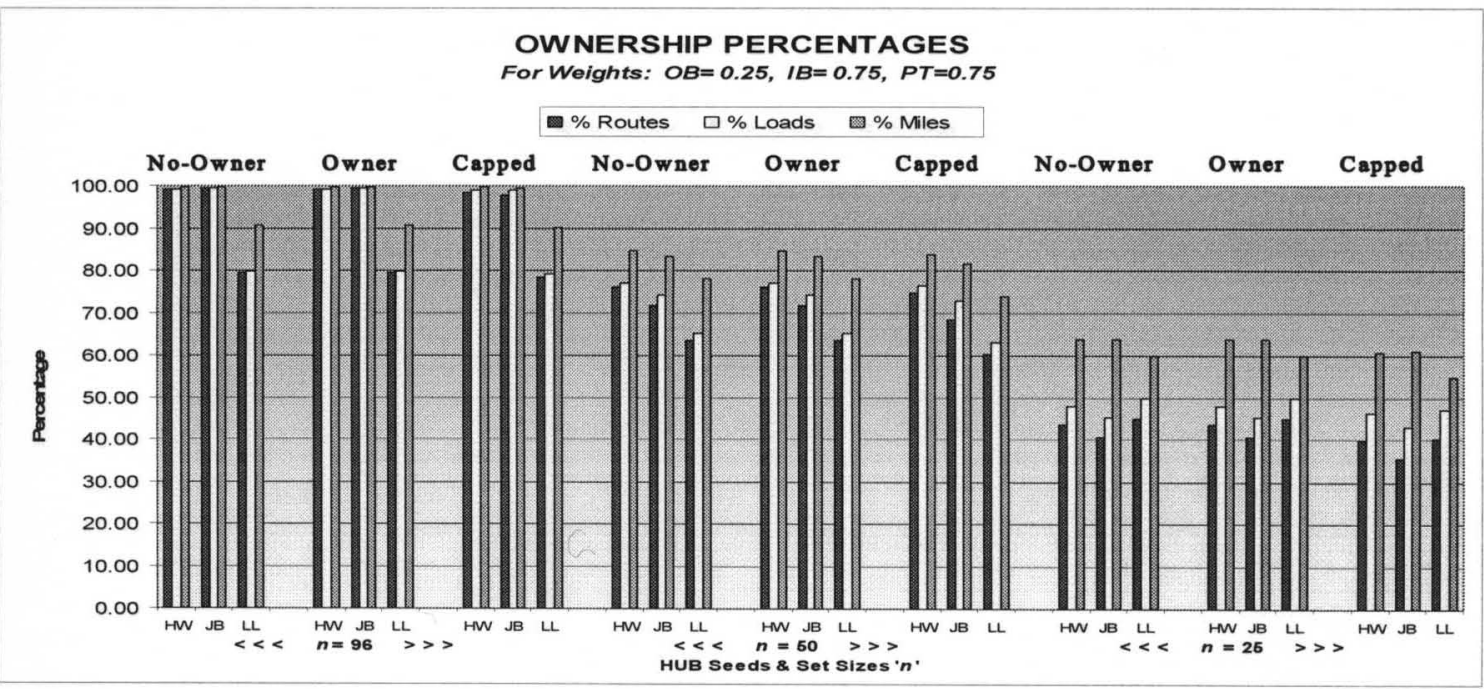




\begin{tabular}{|c|c|c|c|c|c|c|c|c|c|c|c|}
\hline \multirow[t]{2}{*}{ Data } & \multirow[t]{2}{*}{ Type } & \multirow[t]{2}{*}{ Size } & \multirow[t]{3}{*}{ OB } & \multirow[t]{3}{*}{ IB } & \multirow[t]{3}{*}{ PT } & \multicolumn{2}{|c|}{ \% Routes } & \multicolumn{2}{|c|}{$\%$ Loads } & \multicolumn{2}{|c|}{$\%$ Miles } \\
\hline & & & & & & Mean & $\underline{\text { Var }}$ & Mean & Var & Mean & Var \\
\hline \multicolumn{9}{|c|}{$\begin{array}{l}\text { Weights: } \\
\text { OB: } 0.75 \text { IB: } 0.25 \text { PT: } 0.25\end{array}$} & & & \\
\hline HW & No-Owner & 96 & 0.75 & 0.25 & 0.25 & 99.08 & 0.018 & 99.17 & 0.036 & 99.81 & 0.004 \\
\hline JB & No-Owner & 96 & 0.75 & 0.25 & 0.25 & 99.44 & 0.007 & 99.47 & 0.018 & 99.80 & 0.003 \\
\hline LL & No-Owner & 96 & 0.75 & 0.25 & 0.25 & 79.49 & 1.171 & 79.68 & 2.827 & 90.67 & 1.998 \\
\hline HW & Owner & 96 & 0.75 & 0.25 & 0.25 & 99.08 & 0.018 & 99.17 & 0.037 & 99.81 & 0.004 \\
\hline $\mathrm{JB}$ & Owner & 96 & 0.75 & 0.25 & 0.25 & 99.45 & 0.007 & 99.47 & 0.018 & 99.81 & 0.003 \\
\hline $\mathrm{LL}$ & Owner & 96 & 0.75 & 0.25 & 0.25 & 79.50 & 1.174 & 79.68 & 2.825 & 90.67 & 1.996 \\
\hline $\mathrm{HW}$ & Capped & 96 & 0.75 & 0.25 & 0.25 & 98.34 & 1.145 & 98.90 & 0.173 & 99.68 & 0.053 \\
\hline $\mathrm{JB}$ & Capped & 96 & 0.75 & 0.25 & 0.25 & 97.92 & 0.709 & 98.86 & 0.101 & 99.34 & 0.072 \\
\hline LL & Capped & 96 & 0.75 & 0.25 & 0.25 & 78.28 & 4.714 & 79.15 & 3.212 & 90.13 & 2.918 \\
\hline $\mathrm{HW}$ & No-Owner & 50 & 0.75 & 0.25 & 0.25 & 75.84 & 1.159 & 76.75 & 1.706 & 84.42 & 1.497 \\
\hline $\mathrm{JB}$ & No-Owner & 50 & 0.75 & 0.25 & 0.25 & 71.72 & 0.944 & 74.21 & 3.098 & 83.40 & 4.672 \\
\hline LL & No-Owner & 50 & 0.75 & 0.25 & 0.25 & 63.46 & 0.801 & 65.16 & 3.627 & 78.09 & 6.577 \\
\hline HW & Owner & 50 & 0.75 & 0.25 & 0.25 & 75.84 & 1.160 & 76.75 & 1.707 & 84.42 & 1.496 \\
\hline$J B$ & Owner & 50 & 0.75 & 0.25 & 0.25 & 71.72 & 0.946 & 74.21 & 3.100 & 83.40 & 4.671 \\
\hline LL & Owner & 50 & 0.75 & 0.25 & 0.25 & 63.46 & 0.802 & 65.16 & 3.630 & 78.09 & 6.584 \\
\hline HW & Capped & 50 & 0.75 & 0.25 & 0.25 & 74.47 & 3.464 & 76.20 & 1.248 & 83.73 & 1.642 \\
\hline $\mathrm{JB}$ & Capped & 50 & 0.75 & 0.25 & 0.25 & 68.48 & 3.198 & 72.90 & 2.064 & 81.71 & 3.957 \\
\hline LL & Capped & 50 & 0.75 & 0.25 & 0.25 & 60.31 & 3.695 & 62.97 & 2.761 & 73.92 & 4.088 \\
\hline HW & No-Owner & 25 & 0.75 & 0.25 & 0.25 & 43.67 & 1.883 & 48.86 & 5.872 & 63.80 & 14.828 \\
\hline$J B$ & No-Owner & 25 & 0.75 & 0.25 & 0.25 & 40.43 & 1.878 & 45.11 & 5.681 & 63.80 & 19.589 \\
\hline $\mathrm{LL}$ & No-Owner & 25 & 0.75 & 0.25 & 0.25 & 44.97 & 0.931 & 49.86 & 2.099 & 60.06 & 5.606 \\
\hline HW & Owner & 25 & 0.75 & 0.25 & 0.25 & 43.68 & 1.882 & 48.86 & 5.879 & 63.80 & 14.832 \\
\hline $\mathrm{JB}$ & Owner & 25 & 0.75 & 0.25 & 0.25 & 40.43 & 1.882 & 45.11 & 5.678 & 63.80 & 19.599 \\
\hline LL & Owner & 25 & 0.75 & 0.25 & 0.25 & 44.97 & 0.928 & 49.86 & 2.102 & 60.06 & 5.607 \\
\hline HW & Capped & 25 & 0.75 & 0.25 & 0.25 & 39.52 & 11.528 & 47.11 & 4.687 & 60.75 & 13.150 \\
\hline $\mathrm{JB}$ & Capped & 25 & 0.75 & 0.25 & 0.25 & 35.57 & 11.663 & 43.07 & 4.571 & 60.98 & 19.378 \\
\hline LL & Capped & 25 & 0.75 & 0.25 & 0.25 & 40.26 & 12.443 & 47.10 & 3.019 & 54.85 & 6.122 \\
\hline
\end{tabular}

Table 4-11- Ownership Percentages \#5

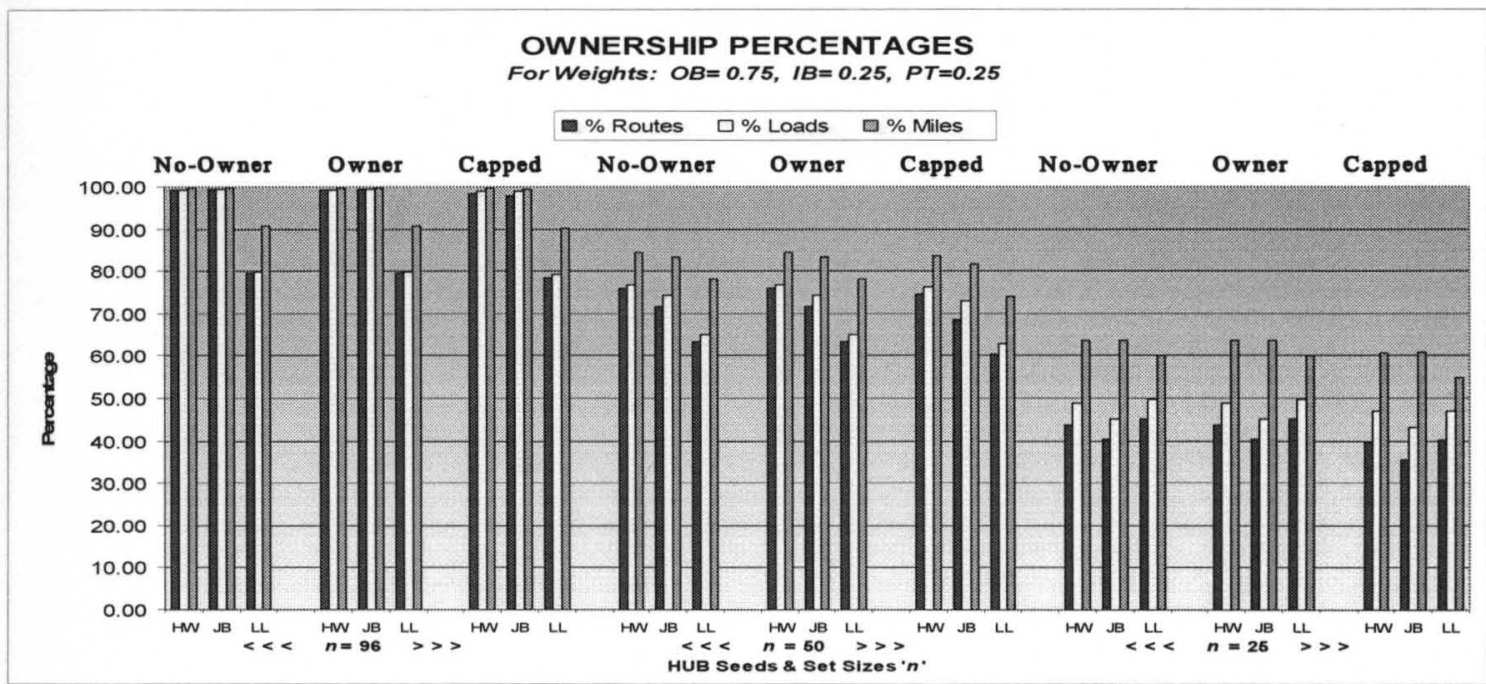




\begin{tabular}{|c|c|c|c|c|c|c|c|c|c|c|c|}
\hline \multirow{3}{*}{$\begin{array}{c}\text { Data } \\
\text { Weights: } \\
O B: 0.75\end{array}$} & \multirow[t]{2}{*}{ Type } & \multirow[t]{2}{*}{ Size } & \multirow[t]{3}{*}{ ов } & \multirow[t]{3}{*}{ IB } & \multirow[t]{3}{*}{ PT } & \multicolumn{2}{|c|}{ \% Routes } & \multicolumn{2}{|c|}{$\%$ Loads } & \multicolumn{2}{|c|}{$\%$ Miles } \\
\hline & & & & & & \multirow{2}{*}{\multicolumn{2}{|c|}{ Mean }} & \multirow[t]{2}{*}{ Mean } & \multirow[t]{2}{*}{$\underline{\text { Var }}$} & \multirow[t]{2}{*}{ Mean } & \multirow[t]{2}{*}{$\underline{\text { Var }}$} \\
\hline & 0.25 PT: & 0.75 & & & & & & & & & \\
\hline HW & No-Owner & 96 & 0.75 & 0.25 & 0.75 & 99.03 & 0.019 & 99.15 & 0.036 & 99.81 & 0.004 \\
\hline $\mathrm{JB}$ & No-Owner & 96 & 0.75 & 0.25 & 0.75 & 99.44 & 0.007 & 99.47 & 0.018 & 99.80 & 0.003 \\
\hline $\mathrm{LL}$ & No-Owner & 96 & 0.75 & 0.25 & 0.75 & 79.49 & 1.171 & 79.68 & 2.827 & 90.67 & 1.998 \\
\hline HW & Owner & 96 & 0.75 & 0.25 & 0.75 & 99.03 & 0.019 & 99.15 & 0.036 & 99.81 & 0.004 \\
\hline $\mathrm{JB}$ & Owner & 96 & 0.75 & 0.25 & 0.75 & 99.45 & 0.007 & 99.47 & 0.018 & 99.81 & 0.003 \\
\hline $\mathrm{LL}$ & Owner & 96 & 0.75 & 0.25 & 0.75 & 79.50 & 1.174 & 79.68 & 2.825 & 90.67 & 1.996 \\
\hline HW & Capped & 96 & 0.75 & 0.25 & 0.75 & 98.28 & 1.108 & 98.86 & 0.167 & 99.67 & 0.055 \\
\hline $\mathrm{JB}$ & Capped & 96 & 0.75 & 0.25 & 0.75 & 97.92 & 0.709 & 98.86 & 0.101 & 99.34 & 0.072 \\
\hline $\mathrm{LL}$ & Capped & 96 & 0.75 & 0.25 & 0.75 & 78.28 & 4.714 & 79.15 & 3.212 & 90.13 & 2.918 \\
\hline HW & No-Owner & 50 & 0.75 & 0.25 & 0.75 & 76.17 & 1.048 & 76.79 & 1.715 & 84.54 & 1.605 \\
\hline $\mathrm{JB}$ & No-Owner & 50 & 0.75 & 0.25 & 0.75 & 71.72 & 0.944 & 74.21 & 3.098 & 83.40 & 4.672 \\
\hline LL & No-Owner & 50 & 0.75 & 0.25 & 0.75 & 63.46 & 0.801 & 65.16 & 3.627 & 78.09 & 6.577 \\
\hline HW & Owner & 50 & 0.75 & 0.25 & 0.75 & 76.17 & 1.047 & 76.78 & 1.713 & 84.54 & 1.607 \\
\hline$J B$ & Owner & 50 & 0.75 & 0.25 & 0.75 & 71.72 & 0.946 & 74.21 & 3.100 & 83.40 & 4.671 \\
\hline LL & Owner & 50 & 0.75 & 0.25 & 0.75 & 63.46 & 0.802 & 65.16 & 3.630 & 78.09 & 6.584 \\
\hline $\mathrm{HW}$ & Capped & 50 & 0.75 & 0.25 & 0.75 & 74.87 & 3.252 & 76.25 & 1.378 & 83.86 & 1.837 \\
\hline $\mathrm{JB}$ & Capped & 50 & 0.75 & 0.25 & 0.75 & 68.48 & 3.198 & 72.90 & 2.064 & 81.71 & 3.957 \\
\hline LL & Capped & 50 & 0.75 & 0.25 & 0.75 & 60.31 & 3.695 & 62.97 & 2.761 & 73.92 & 4.088 \\
\hline HW & No-Owner & 25 & 0.75 & 0.25 & 0.75 & 43.69 & 1.914 & 48.15 & 5.503 & 63.76 & 15.141 \\
\hline JB & No-Owner & 25 & 0.75 & 0.25 & 0.75 & 40.43 & 1.878 & 45.11 & 5.681 & 63.80 & 19.589 \\
\hline LL & No-Owner & 25 & 0.75 & 0.25 & 0.75 & 44.97 & 0.931 & 49.86 & 2.099 & 60.06 & 5.606 \\
\hline HW & Owner & 25 & 0.75 & 0.25 & 0.75 & 43.70 & 1.918 & 48.15 & 5.498 & 63.76 & 15.143 \\
\hline $\mathrm{JB}$ & Owner & 25 & 0.75 & 0.25 & 0.75 & 40.43 & 1.882 & 45.11 & 5.678 & 63.80 & 19.599 \\
\hline $\mathrm{LL}$ & Owner & 25 & 0.75 & 0.25 & 0.75 & 44.97 & 0.928 & 49.86 & 2.102 & 60.06 & 5.607 \\
\hline HW & Capped & 25 & 0.75 & 0.25 & 0.75 & 39.69 & 11.099 & 46.48 & 4.511 & 60.75 & 13.760 \\
\hline $\mathrm{JB}$ & Capped & 25 & 0.75 & 0.25 & 0.75 & 35.57 & 11.663 & 43.07 & 4.571 & 60.98 & 19.378 \\
\hline LL & Capped & 25 & 0.75 & 0.25 & 0.75 & 40.26 & 12.443 & 47.10 & 3.019 & 54.85 & 6.122 \\
\hline
\end{tabular}

Table 4-11 - Ownership Percentages \#6

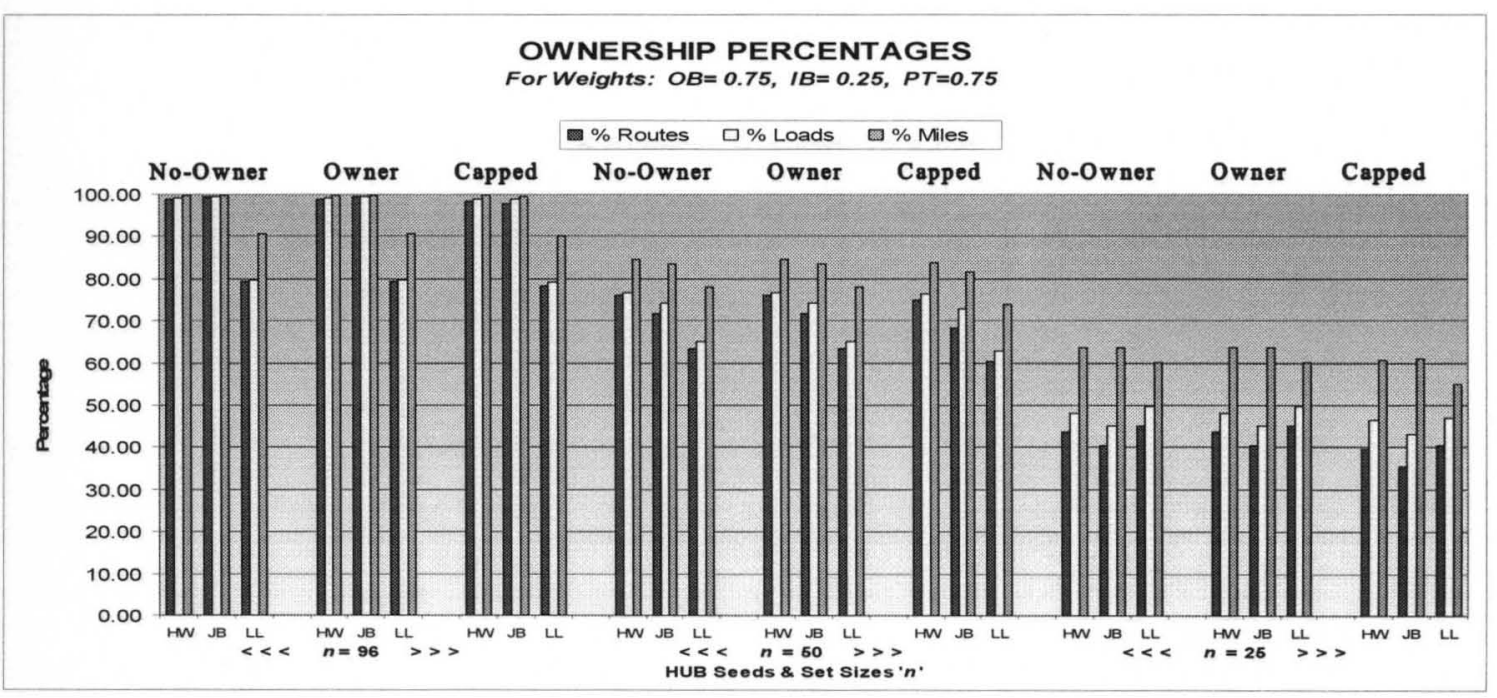




\begin{tabular}{|c|c|c|c|c|c|c|c|c|c|c|c|}
\hline \multirow{3}{*}{$\begin{array}{c}\text { Data } \\
\text { Weights: } \\
O B: 0.75\end{array}$} & \multirow[t]{2}{*}{ Type } & \multirow[t]{2}{*}{ Size } & \multirow[t]{3}{*}{ OB } & \multirow[t]{3}{*}{ IB } & \multirow[t]{3}{*}{ PT } & \multicolumn{2}{|c|}{ \% Routes } & \multicolumn{2}{|c|}{$\%$ Loads } & \multicolumn{2}{|c|}{$\%$ Miles } \\
\hline & & & & & & \multirow[t]{2}{*}{ Mean } & \multirow[t]{2}{*}{$\underline{\text { Var }}$} & \multirow[t]{2}{*}{ Mean } & \multirow[t]{2}{*}{$\underline{\text { Var }}$} & \multirow[t]{2}{*}{ Mean } & \multirow[t]{2}{*}{$\underline{\text { Var }}$} \\
\hline & 0.75 PT: & 0.25 & & & & & & & & & \\
\hline $\mathrm{HW}$ & No-Owner & 96 & 0.75 & 0.75 & 0.25 & 98.97 & 0.017 & 99.13 & 0.034 & 99.80 & 0.004 \\
\hline $\mathrm{JB}$ & No-Owner & 96 & 0.75 & 0.75 & 0.25 & 99.44 & 0.007 & 99.47 & 0.018 & 99.80 & 0.003 \\
\hline $\mathrm{LL}$ & No-Owner & 96 & 0.75 & 0.75 & 0.25 & 79.49 & 1.171 & 79.68 & 2.827 & 90.67 & 1.998 \\
\hline HW & Owner & 96 & 0.75 & 0.75 & 0.25 & 98.97 & 0.017 & 99.14 & 0.034 & 99.80 & 0.004 \\
\hline JB & Owner & 96 & 0.75 & 0.75 & 0.25 & 99.45 & 0.007 & 99.47 & 0.018 & 99.81 & 0.003 \\
\hline $\mathrm{LL}$ & Owner & 96 & 0.75 & 0.75 & 0.25 & 79.50 & 1.174 & 79.68 & 2.825 & 90.67 & 1.996 \\
\hline HW & Capped & 96 & 0.75 & 0.75 & 0.25 & 98.23 & 1.081 & 98.85 & 0.180 & 99.67 & 0.056 \\
\hline $\mathrm{JB}$ & Capped & 96 & 0.75 & 0.75 & 0.25 & 97.92 & 0.709 & 98.86 & 0.101 & 99.34 & 0.072 \\
\hline LL & Capped & 96 & 0.75 & 0.75 & 0.25 & 78.28 & 4.714 & 79.15 & 3.212 & 90.13 & 2.918 \\
\hline HW & No-Owner & 50 & 0.75 & 0.75 & 0.25 & 75.74 & 1.137 & 76.92 & 1.735 & 84.53 & 1.513 \\
\hline$J B$ & No-Owner & 50 & 0.75 & 0.75 & 0.25 & 71.72 & 0.944 & 74.21 & 3.098 & 83.40 & 4.672 \\
\hline $\mathrm{LL}$ & No-Owner & 50 & 0.75 & 0.75 & 0.25 & 63.46 & 0.801 & 65.16 & 3.627 & 78.09 & 6.577 \\
\hline HW & Owner & 50 & 0.75 & 0.75 & 0.25 & 75.74 & 1.139 & 76.92 & 1.734 & 84.53 & 1.512 \\
\hline JB & Owner & 50 & 0.75 & 0.75 & 0.25 & 71.72 & 0.946 & 74.21 & 3.100 & 83.40 & 4.671 \\
\hline $\mathrm{LL}$ & Owner & 50 & 0.75 & 0.75 & 0.25 & 63.46 & 0.802 & 65.16 & 3.630 & 78.09 & 6.584 \\
\hline HW & Capped & 50 & 0.75 & 0.75 & 0.25 & 74.32 & 3.733 & 76.34 & 1.327 & 83.82 & 1.729 \\
\hline JB & Capped & 50 & 0.75 & 0.75 & 0.25 & 68.48 & 3.198 & 72.90 & 2.064 & 81.71 & 3.957 \\
\hline LL & Capped & 50 & 0.75 & 0.75 & 0.25 & 60.31 & 3.695 & 62.97 & 2.761 & 73.92 & 4.088 \\
\hline $\mathrm{HW}$ & No-Owner & 25 & 0.75 & 0.75 & 0.25 & 43.83 & 1.870 & 48.29 & 5.147 & 63.82 & 14.318 \\
\hline JB & No-Owner & 25 & 0.75 & 0.75 & 0.25 & 40.43 & 1.878 & 45.11 & 5.681 & 63.80 & 19.589 \\
\hline LL & No-Owner & 25 & 0.75 & 0.75 & 0.25 & 44.97 & 0.931 & 49.86 & 2.099 & 60.06 & 5.606 \\
\hline $\mathrm{HW}$ & Owner & 25 & 0.75 & 0.75 & 0.25 & 43.83 & 1.872 & 48.29 & 5.149 & 63.82 & 14.328 \\
\hline JB & Owner & 25 & 0.75 & 0.75 & 0.25 & 40.43 & 1.882 & 45.11 & 5.678 & 63.80 & 19.599 \\
\hline LL & Owner & 25 & 0.75 & 0.75 & 0.25 & 44.97 & 0.928 & 49.86 & 2.102 & 60.06 & 5.607 \\
\hline HW & Capped & 25 & 0.75 & 0.75 & 0.25 & 39.57 & 12.610 & 46.49 & 3.946 & 60.72 & 12.908 \\
\hline $\mathrm{JB}$ & Capped & 25 & 0.75 & 0.75 & 0.25 & 35.57 & 11.663 & 43.07 & 4.571 & 60.98 & 19.378 \\
\hline LL & Capped & 25 & 0.75 & 0.75 & 0.25 & 40.26 & 12.443 & 47.10 & 3.019 & 54.85 & 6.122 \\
\hline
\end{tabular}

Table 4-12 - Ownership Percentages \#7

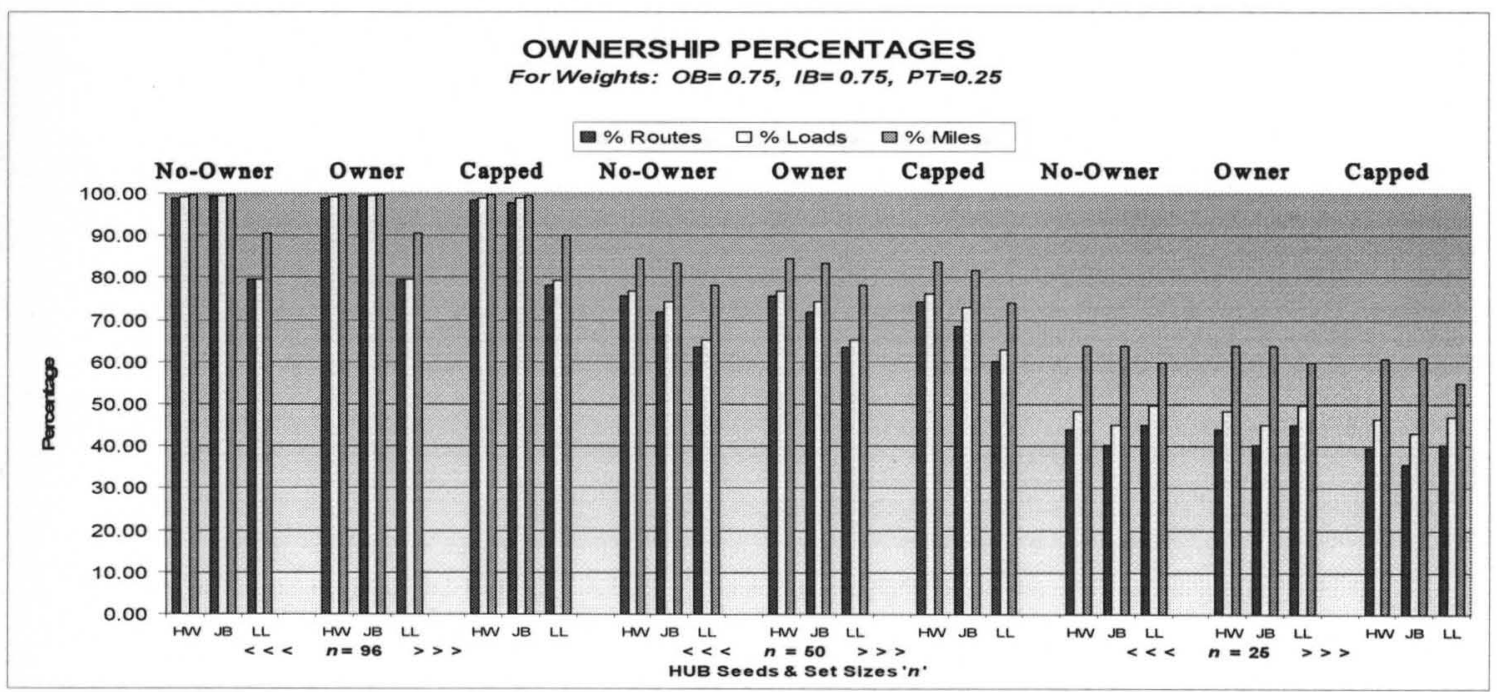




\begin{tabular}{|c|c|c|c|c|c|c|c|c|c|c|c|}
\hline \multirow{2}{*}{$\begin{array}{c}\text { Data } \\
\text { Weights: } \\
\text { OB: } 0.75 \\
\end{array}$} & Type & Size & \multirow[t]{2}{*}{ OB } & \multirow[t]{2}{*}{ IB } & \multirow[t]{2}{*}{ PT } & \multicolumn{2}{|c|}{$\%$ Routes } & \multicolumn{2}{|c|}{$\%$ Loads } & \multicolumn{2}{|c|}{$\%$ Miles } \\
\hline & 75 PT: & 0.75 & & & & Mean & $\underline{\text { Var }}$ & Mean & Var & Mean & $\underline{\text { Var }}$ \\
\hline $\mathrm{HW}$ & No-Owner & 96 & 0.75 & 0.75 & 0.75 & 99.08 & 0.018 & 99.17 & 0.036 & 99.81 & 0.004 \\
\hline JB & No-Owner & 96 & 0.75 & 0.75 & 0.75 & 99.44 & 0.007 & 99.47 & 0.018 & 99.80 & 0.003 \\
\hline$\underline{\mathrm{LL}}$ & No-Owner & 96 & 0.75 & 0.75 & 0.75 & 79.49 & 1.171 & 79.68 & 2.827 & 90.67 & 1.998 \\
\hline HW & Owner & 96 & 0.75 & 0.75 & 0.75 & 99.08 & 0.018 & 99.17 & 0.037 & 99.81 & 0.004 \\
\hline JB & Owner & 96 & 0.75 & 0.75 & 0.75 & 99.45 & 0.007 & 99.47 & 0.018 & 99.81 & 0.003 \\
\hline LL & Owner & 96 & 0.75 & 0.75 & 0.75 & 79.50 & 1.174 & 79.68 & 2.825 & 90.67 & 1.996 \\
\hline HW & Capped & 96 & 0.75 & 0.75 & 0.75 & 98.33 & 1.153 & 98.88 & 0.206 & 99.67 & 0.064 \\
\hline $\mathrm{JB}$ & Capped & 96 & 0.75 & 0.75 & 0.75 & 97.92 & 0.709 & 98.86 & 0.101 & 99.34 & 0.072 \\
\hline LL & Capped & 96 & 0.75 & 0.75 & 0.75 & 78.28 & 4.714 & 79.15 & 3.212 & 90.13 & 2.918 \\
\hline HW & No-Owner & 50 & 0.75 & 0.75 & 0.75 & 76.12 & 1.024 & 76.87 & 1.789 & 84.57 & 1.633 \\
\hline $\mathrm{JB}$ & No-Owner & 50 & 0.75 & 0.75 & 0.75 & 71.72 & 0.944 & 74.21 & 3.098 & 83.40 & 4.672 \\
\hline $\mathrm{LL}$ & No-Owner & 50 & 0.75 & 0.75 & 0.75 & 63.46 & 0.801 & 65.16 & 3.627 & 78.09 & 6.577 \\
\hline HW & Owner & 50 & 0.75 & 0.75 & 0.75 & 76.12 & 1.022 & 76.87 & 1.789 & 84.57 & 1.631 \\
\hline $\mathrm{JB}$ & Owner & 50 & 0.75 & 0.75 & 0.75 & 71.72 & 0.946 & 74.21 & 3.100 & 83.40 & 4.671 \\
\hline LL & Owner & 50 & 0.75 & 0.75 & 0.75 & 63.46 & 0.802 & 65.16 & 3.630 & 78.09 & 6.584 \\
\hline HW & Capped & 50 & 0.75 & 0.75 & 0.75 & 74.81 & 3.293 & 76.31 & 1.485 & 83.87 & 1.913 \\
\hline $\mathrm{JB}$ & Capped & 50 & 0.75 & 0.75 & 0.75 & 68.48 & 3.198 & 72.90 & 2.064 & 81.71 & 3.957 \\
\hline LL & Capped & 50 & 0.75 & 0.75 & 0.75 & 60.31 & 3.695 & 62.97 & 2.761 & 73.92 & 4.088 \\
\hline HW & No-Owner & 25 & 0.75 & 0.75 & 0.75 & 43.66 & 1.858 & 48.04 & 5.575 & 63.70 & 15.226 \\
\hline $\mathrm{JB}$ & No-Owner & 25 & 0.75 & 0.75 & 0.75 & 40.43 & 1.878 & 45.11 & 5.681 & 63.80 & 19.589 \\
\hline LL & No-Owner & 25 & 0.75 & 0.75 & 0.75 & 44.97 & 0.931 & 49.86 & 2.099 & 60.06 & 5.606 \\
\hline HW & Owner & 25 & 0.75 & 0.75 & 0.75 & 43.66 & 1.862 & 48.04 & 5.578 & 63.70 & 15.232 \\
\hline JB & Owner & 25 & 0.75 & 0.75 & 0.75 & 40.43 & 1.882 & 45.11 & 5.678 & 63.80 & 19.599 \\
\hline LL & Owner & 25 & 0.75 & 0.75 & 0.75 & 44.97 & 0.928 & 49.86 & 2.102 & 60.06 & 5.607 \\
\hline $\mathrm{HW}$ & Capped & 25 & 0.75 & 0.75 & 0.75 & 39.70 & 10.974 & 46.37 & 4.594 & 60.68 & 13.827 \\
\hline JB & Capped & 25 & 0.75 & 0.75 & 0.75 & 35.57 & 11.663 & 43.07 & 4.571 & 60.98 & 19.378 \\
\hline LL & Capped & 25 & 0.75 & 0.75 & 0.75 & 40.26 & 12.443 & 47.10 & 3.019 & 54.85 & 6.122 \\
\hline
\end{tabular}

Table 4-13 - Ownership Percentages \#8

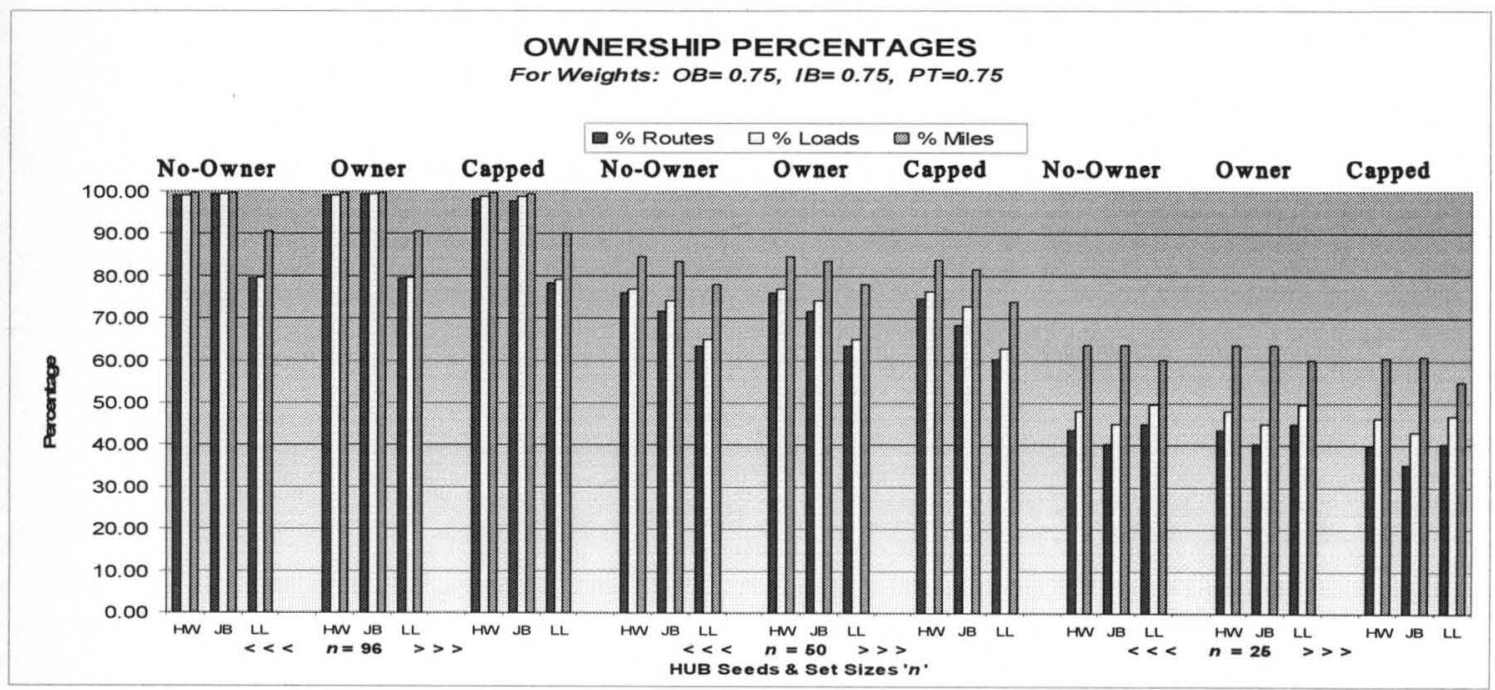




\begin{tabular}{|c|c|c|c|c|c|c|c|c|c|c|c|}
\hline Data & Type & Size & OB & IB & PT & \multicolumn{2}{|c|}{ Route Imbalance } & \multicolumn{2}{|c|}{ Load Imbalance } & \multicolumn{2}{|c|}{ Mile Imbalance } \\
\hline \multicolumn{12}{|c|}{ 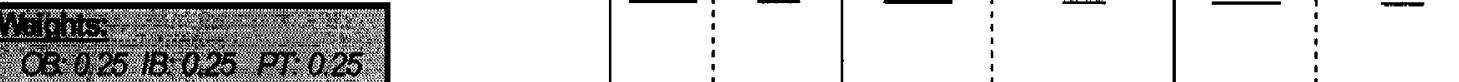 } \\
\hline$H W$ & No-Owner & 96 & 0.25 & 0.25 & 0.25 & 56.97 & 29.602 & $2,543.29$ & $20,541.648$ & $1,579.94$ & $92,584.017$ \\
\hline $\mathrm{JB}$ & No-Ouner & 96 & 0.25 & 0.25 & 0.25 & 49.65 & 6.542 & $2,474.67$ & 22975.395 & $1,624.76$ & $76,677.217$ \\
\hline$\amalg$ & No-Owner & 96 & 0.25 & 0.25 & 0.25 & 10.42 & 1.100 & 505.50 & 1,722724 & 319.17 & $5,118.108$ \\
\hline HW & Owner & 96 & 0.25 & 0.25 & 0.25 & 68.08 & 26.629 & $4,460.67$ & $742,939.879$ & $1,038.37$ & 45.383 .351 \\
\hline $\mathrm{JB}$ & Owner & 96 & 0.25 & 0.25 & 0.25 & 72.42 & 44.629 & $4,463.08$ & $438,908.629$ & $1,268.87$ & $4,222,928$ \\
\hline$\amalg$ & Owner & 96 & 0.25 & 0.25 & 0.25 & 32.50 & 22.273 & $2,166.92$ & 104,952992 & 700.75 & $10,674.929$ \\
\hline $\mathrm{HW}$ & Capped & 96 & 0.25 & 0.25 & 0.25 & 71.08 & 41.902 & $4,539.92$ & $735,867.720$ & $1,091.43$ & $45,253.507$ \\
\hline $\mathrm{JB}$ & Capped & 96 & 0.25 & 0.25 & 0.25 & 86.33 & 214.242 & $4,637.67$ & $441,237.515$ & $1,659.49$ & $65,240.149$ \\
\hline$\amalg$ & Capped & 96 & 0.25 & 0.25 & 0.25 & 34.42 & 20.265 & $2,193.75$ & 115,202023 & 700.19 & $14,978.726$ \\
\hline HW & No-Owner & 50 & 0.25 & 0.25 & 0.25 & 28.83 & 7.594 & $1,364.01$ & $10,428.094$ & 944.60 & $62,958.431$ \\
\hline $\mathrm{JB}$ & No-Owner & 50 & 0.25 & 0.25 & 0.25 & 26.69 & 6.005 & $1,354.85$ & $9,460.763$ & 993.77 & $46,350.976$ \\
\hline せ & No-Owner & 50 & 0.25 & 0.25 & 0.25 & 11.91 & 0.367 & 710.92 & $5,767.558$ & 495.36 & 17,072499 \\
\hline HW & Owner & 50 & 0.25 & 0.25 & 0.25 & 45.92 & 24.265 & $2,843.83$ & $295,978.515$ & 719.33 & $18,033.920$ \\
\hline $\mathrm{JB}$ & Owner & 50 & 0.25 & 0.25 & 0.25 & 44.42 & 12.811 & $2,344.25$ & $245,522.023$ & 704.13 & $8,543.618$ \\
\hline せ & Owner & 50 & 0.25 & 0.25 & 0.25 & 31.67 & 22.242 & $2,155.33$ & $102,180.061$ & 698.73 & $10,549.936$ \\
\hline$H W$ & Capped & 50 & 0.25 & 0.25 & 0.25 & 48.58 & 32.992 & $2,929.17$ & 302910.333 & 776.38 & $20,864.032$ \\
\hline $\mathrm{JB}$ & Capped & 50 & 0.25 & 0.25 & 0.25 & 53.83 & 91.788 & $2,485.58$ & $235,600.992$ & 993.74 & $22,887.462$ \\
\hline 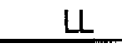 & Capped & 50 & 0.25 & 0.25 & 0.25 & 33.58 & 18.992 & $2,182.17$ & 112.062 .697 & 698.18 & $14, \pi 71.374$ \\
\hline $\overrightarrow{H W}$ & No-Owner & 25 & 0.25 & 0.25 & 0.25 & 17.35 & 1.549 & 969.46 & $31,308.817$ & 883.21 & $81,831.614$ \\
\hline$J B$ & No-Owner & 25 & 0.25 & 0.25 & 0.25 & 16.66 & 0.771 & 926.33 & $16,863.133$ & 891.39 & 59,562249 \\
\hline $\mathrm{L}$ & No-Owner & 25 & 0.25 & 0.25 & 0.25 & 8.73 & 5024 & 900.17 & $19,555.108$ & 692.33 & $44,620.993$ \\
\hline $\mathrm{HW}$ & Omner & 25 & 0.25 & 0.25 & 0.25 & 27.08 & 15.720 & $1,368.58$ & $30,438.447$ & 436.08 & 3,762454 \\
\hline $\mathrm{JB}$ & Omner & 25 & 0.25 & 0.25 & 0.25 & 25.08 & 10.265 & $1,092.25$ & $33,602.023$ & 384.49 & 2916.291 \\
\hline 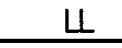 & Ouner & 25 & 0.25 & 0.25 & 0.25 & 26.08 & 20.063 & $2,080,08$ & $88,730.992$ & 664.77 & $7,934.709$ \\
\hline $\mathrm{HW}$ & Capped & 25 & 0.25 & 0.25 & 0.25 & 28.67 & 14.606 & $1,440.25$ & $41,654.386$ & 485.43 & $7,888.310$ \\
\hline JB & Capped & 25 & 0.25 & 0.25 & 0.25 & 32.33 & 31.697 & $1,215.33$ & $47,844,970$ & 674.79 & $17,959.780$ \\
\hline LL & Capped & 25 & 0.25 & 0.25 & 0.25 & 27.42 & 16.992 & $2,104.17$ & $94,463.606$ & 662.10 & $11,117.647$ \\
\hline
\end{tabular}

Table 4-14 - Imbalance \#1 


\begin{tabular}{|c|c|c|c|c|c|c|c|c|c|c|c|}
\hline \multirow{2}{*}{\multicolumn{3}{|c|}{ 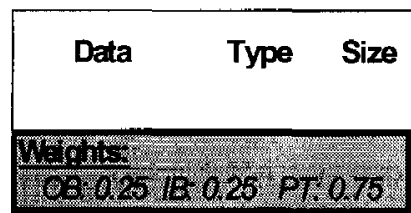 }} & \multirow[t]{2}{*}{ OB } & \multirow[t]{2}{*}{ IB } & \multirow[t]{2}{*}{ PT } & \multicolumn{2}{|c|}{ Route Imbalance } & \multicolumn{2}{|c|}{ Load Imbalance } & \multicolumn{2}{|c|}{ Mile Imbalance } \\
\hline & & & & & & Mean : & $\underline{\text { Var }}$ & Mean & Var & Mean & $\underline{\text { Var }}$ \\
\hline $\mathrm{HW}$ & No-Omer & 96 & 0.25 & 0.25 & 0.75 & 13.02 & 1.821 & 739.32 & $11,003.342$ & 463.35 & $13,211.866$ \\
\hline $\mathrm{JB}$ & No-Ominer & 96 & 0.25 & 0.25 & 0.75 & 49.65 & 6.542 & $2,474.67$ & $22,975.395$ & $1,624.76$ & $76,677.217$ \\
\hline せ & No-Ouner & 96 & 0.25 & 0.25 & 0.75 & 10.42 & 1.100 & 505.50 & 1,722724 & 319.17 & $5,118.108$ \\
\hline $\mathrm{HW}$ & Owner & 96 & 0.25 & 0.25 & 0.75 & 8.25 & 2.386 & 277.83 & $4,196.152$ & 33.33 & 43.232 \\
\hline $\mathrm{JB}$ & Owner & 96 & 0.25 & 0.25 & 0.75 & 72.42 & 44.629 & $4,463.08$ & $438,908.629$ & $1,268.87$ & $4,222,928$ \\
\hline ᄂ & Owner & 96 & 0.25 & 0.25 & 0.75 & 32.50 & 22.273 & $2,166.92$ & 104,952992 & 700.75 & $10,674.929$ \\
\hline$H W$ & Capped & 96 & 0.25 & 0.25 & 0.75 & 8.00 & 1.636 & 270.75 & $4,923.477$ & 31.68 & 75292 \\
\hline $\mathrm{JB}$ & Capped & 96 & 0.25 & 0.25 & 0.75 & 86.33 & 214.242 & $4,637.67$ & $441,237.515$ & $1,659.49$ & $65,240.149$ \\
\hline L & Capped & 96 & 0.25 & 0.25 & 0.75 & 34.42 & 20.265 & $2,193.75$ & $115,202,023$ & 700.19 & $14,978.726$ \\
\hline $\mathrm{HW}$ & No-Owner & 50 & 0.25 & 0.25 & 0.75 & 6.34 & 1.645 & 453.68 & $7,137.171$ & 375.77 & 16,502072 \\
\hline $\mathrm{JB}$ & No-Owner & 50 & 0.25 & 0.25 & 0.75 & 26.69 & 6.005 & $1,354.85$ & $9,460.763$ & 993.77 & $46,350.976$ \\
\hline$\amalg$ & No-Owner & 50 & 0.25 & 0.25 & 0.75 & 11.91 & 0.367 & 710.92 & $5,767.558$ & 495.36 & $17,072.499$ \\
\hline $\mathrm{HW}$ & Owner & 50 & 0.25 & 0.25 & 0.75 & 2.67 & 0.788 & 37.33 & 353.879 & 8.34 & 17.814 \\
\hline $\mathrm{JB}$ & Owner & 50 & 0.25 & 0.25 & 0.75 & 44.42 & 12.811 & $2,344.25$ & $245,522,023$ & 704.13 & $8,543.618$ \\
\hline$\amalg$ & Ouner & 50 & 0.25 & 0.25 & 0.75 & 31.67 & 22.242 & $2,155.33$ & $102,180.061$ & 698.73 & $10,549.936$ \\
\hline $\mathrm{HW}$ & Capped & 50 & 0.25 & 0.25 & 0.75 & 2.42 & 1.356 & 30.25 & 374.386 & 6.69 & 32882 \\
\hline $\mathrm{JB}$ & Capped & 50 & 0.25 & 0.25 & 0.75 & 53.83 & 91.788 & $2,485.58$ & $235,600.992$ & 993.74 & $22,887.462$ \\
\hline Ш & Capped & 50 & 0.25 & 0.25 & 0.75 & 33.58 ! & 18.992 & $2,182.17$ & 112,062697 & 698.18 & $14,771.374$ \\
\hline HW & No-Owner & 25 & 0.25 & 0.25 & 0.75 & 2.07 & 0.168 & 284.08 & $8,173.351$ & 335.89 & $17,050.728$ \\
\hline $\mathrm{JB}$ & No-Omner & 25 & 0.25 & 0.25 & 0.75 & 16.66 & 0.771 & 926.33 & $16,863,133$ & 891.39 & $59,562.249$ \\
\hline せ & No-Ouner & 25 & 0.25 & 0.25 & 0.75 & 8.73 & 5.024 & 900.17 & $19,555,108$ & 692.33 & $44,620.993$ \\
\hline HW & Owner & 25 & 0.25 & 0.25 & 0.75 & 1.33 & 1.152 & 23.83 & 482.152 & 5.56 & 27.238 \\
\hline $\mathrm{JB}$ & Owner & 25 & 0.25 & 0.25 & 0.75 & 25.08 & 10.265 & $1,092.25$ & $33,602.023$ & 384.49 & 2,9162291 \\
\hline$\amalg$ & Owner & 25 & 0.25 & 0.25 & 0.75 & 26.08 & 20.083 & $2,080.08$ & $88,730.992$ & 664.77 & $7,934.709$ \\
\hline $\mathrm{HW}$ & Capped & 25 & 0.25 & 0.25 & 0.75 & 1.00 & 0.909 & 15.67 & 421.697 & 3.30 & 25.497 \\
\hline $\mathrm{JB}$ & Capped & 25 & 0.25 & 0.25 & 0.75 & 32.33 & 31.697 & $1,215.33$ & $47,844.970$ & 674.79 & $17,959.780$ \\
\hline 凹 & Capped & 25 & 0.25 & 0.25 & 0.75 & $27.42 !$ & 16.992 & $2,104.17$ & $94,463.606$ & 662.10 & $11,117,647$ \\
\hline
\end{tabular}

Table 4-15 - Imbalance \#2 


\begin{tabular}{|c|c|c|c|c|c|c|c|c|c|c|c|}
\hline Data & Type & Size & OB & IB & PT & \multicolumn{2}{|c|}{ Route Imbalance } & \multicolumn{2}{|c|}{ Load Imbalance } & \multicolumn{2}{|c|}{ Mile Imbalance } \\
\hline \multicolumn{12}{|c|}{ 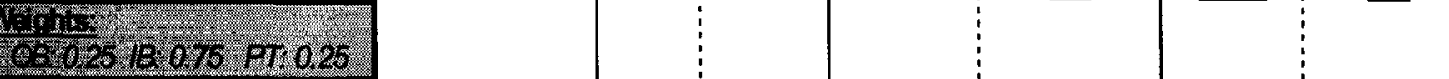 } \\
\hline $\mathrm{HW}$ & No-Owner & 96 & 0.25 & 0.75 & 0.25 & 95.67 & 58.363 & $3,771.85$ & $29,768.026$ & $2,154.68$ & $33,526 \mathrm{~m}$ \\
\hline$J B$ & No-Owner & 96 & 0.25 & 0.75 & 0.25 & 49.65 & 6.542 & $2,474.67$ & $22,975.395$ & $1,624.76$ & $76,677.217$ \\
\hline$\Perp$ & No-Owner & 96 & 0.25 & 0.75 & 0.25 & 10.42 & 1.100 & 505.50 & 1,722724 & 319.17 & $5,118.108$ \\
\hline HW & Omer & 96 & 0.25 & 0.75 & 0.25 & 324.83 & 867.424 & $13,918.75$ & $7,108,332568$ & $3,884.19$ & $495,058.704$ \\
\hline$J B$ & Owner & 96 & 0.25 & 0.75 & 0.25 & 72.42 & 44.629 & $4,463.08$ & $438,908.629$ & $1,268.87$ & 4,222928 \\
\hline U & Owner & 96 & 0.25 & 0.75 & 0.25 & 32.50 & 22.273 & $2,166.92$ & $104,952.992$ & 700.75 & $10,674.929$ \\
\hline HW & Capped & 96 & 0.25 & 0.75 & 0.25 & 313.17 & 713.788 & $13,635.33$ & $6,856,440.788$ & $3,763.89$ & $452,644.424$ \\
\hline $\mathrm{JB}$ & Capped & 96 & 0.25 & 0.75 & 0.25 & 86.33 & 214.242 & $4,637.67$ & $441,237.515$ & $1,659.49$ & $65,240,149$ \\
\hline$\amalg$ & Capped & 96 & 0.25 & 0.75 & 0.25 & 34.42 & 20.265 & $2,193.75$ & 115,202023 & 700.19 & $14,978.726$ \\
\hline HW & $\mathrm{No}$-Owner & 50 & 0.25 & 0.75 & 0.25 & 64.22 & 13.919 & $2,329.86$ & $14,869.875$ & $1,459.65$ & $68,724.364$ \\
\hline JB & $\mathrm{No}$-Omner & 50 & 0.25 & 0.75 & 0.25 & 26.69 & 6005 & $1,354.85$ & $9,460.763$ & 993.77 & $46,350.976$ \\
\hline$\Perp$ & No-Ouner & 50 & 0.25 & 0.75 & 0.25 & 11.91 & 0.367 & 710.92 & $5,767.558$ & 495.36 & 17,072499 \\
\hline HW & Owner & 50 & 0.25 & 0.75 & 0.25 & 234.50 & 426.273 & $9,147.83$ & $2,550,043.788$ & $2,754.95$ & $228,172.238$ \\
\hline$J B$ & Owner & 50 & 0.25 & 0.75 & 0.25 & 44.42 & 12811 & $2,344.25$ & 245,522023 & 704.13 & $8,543.618$ \\
\hline せ & Owner & 50 & 0.25 & 0.75 & 0.25 & 31.67 & 22.242 & $2,155.33$ & $102,100.061$ & 698.73 & $10,549.936$ \\
\hline HW & Capped & 50 & 0.25 & 0.75 & 0.25 & 222.25 & 271.659 & $8,878.42$ & $2,391,969.902$ & $2,635.09$ & $192,862,503$ \\
\hline $\mathrm{JB}$ & Capped & 50 & 0.25 & 0.75 & 0.25 & 53.83 & 91.788 & $2,485.58$ & $235,600.992$ & 993.74 & $22,887.462$ \\
\hline せ & Capped & 50 & 0.25 & 0.75 & 0.25 & 33.58 & 18.992 & $2,182.17$ & 112,062697 & 698.18 & $14,771.374$ \\
\hline HW & No-Owner & 25 & 0.25 & 0.75 & 0.25 & 41.27 & 6929 & $1,579.67$ & $20,104.984$ & $1,179.80$ & $70,483.027$ \\
\hline$J B$ & $\mathrm{No}$-Owner & 25 & 0.25 & 0.75 & 0.25 & 16.66 & 0.771 & 926.33 & $16,863.133$ & 891.39 & 59,562249 \\
\hline & No-Owner & 25 & 0.25 & 0.75 & 0.25 & 8.73 & 5.024 & 900.17 & $19,555.108$ & 692.33 & $44,620.993$ \\
\hline HW & Owner & 25 & 0.25 & 0.75 & 0.25 & 154.25 & 192.568 & $6,132.67$ & $655,585.879$ & $1,928.16$ & $96,308.159$ \\
\hline JB & Owner & 25 & 0.25 & 0.75 & 0.25 & 25.08 & 10.265 & $1,092.25$ & $33,602,023$ & 384.49 & $2,916.291$ \\
\hline Ш & Owner & 25 & 0.25 & 0.75 & 0.25 & 26.08 & 20.083 & $2,080.08$ & $88,730.992$ & 664.77 & $7,934.709$ \\
\hline HW & Capped & 25 & 0.25 & 0.75 & 0.25 & 139.75 & 121.841 & $5,843.83$ & 625.777 .242 & $1,791.91$ & 82905.271 \\
\hline JB & Capped & 25 & 0.25 & 0.75 & 0.25 & 32.33 & 31.697 & $1,215.33$ & $47,844.970$ & 674.79 & $17,959.780$ \\
\hline Ш & Capped & 25 & 0.25 & 0.75 & 0.25 & 27.42 & 16.992 & $2,104.17$ & $94,463.606$ & 662.10 & $11,117.647$ \\
\hline
\end{tabular}

Table 4-16 - Imbalance \#3 


\begin{tabular}{|c|c|c|c|c|c|c|c|c|c|c|c|}
\hline Data & Type & Size & OB & IB & PT & \multicolumn{2}{|c|}{ Route Imbalance } & \multicolumn{2}{|c|}{ Load Imbalance } & \multicolumn{2}{|c|}{ Mile Imbalance } \\
\hline \multicolumn{12}{|c|}{ 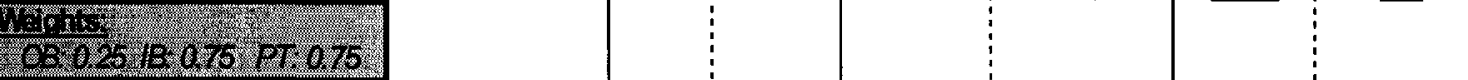 } \\
\hline $\mathrm{HW}$ & No-Omer & 96 & 0.25 & 0.75 & 0.75 & $147.56 !$ & 132.418 & $5,927.51$ & $629,190.961$ & $3,125.11$ & $228,735.796$ \\
\hline $\mathrm{JB}$ & No-Owner & 96 & 0.25 & 0.75 & 0.75 & 49.65 & 6.542 & $2,474.67$ & $22,975.395$ & $1,624.76$ & $76,677.217$ \\
\hline せ & No-Owner & 96 & 0.25 & 0.75 & 0.75 & 10.42 & 1.100 & 505.50 & $1,722.724$ & 319.17 & $5,118.108$ \\
\hline $\mathrm{HW}$ & Owner & 96 & 0.25 & 0.75 & 0.75 & $183.75 !$ & 210.932 & 8,37267 & $4,550,367.697$ & $1,956.87$ & $361,500.831$ \\
\hline $\mathrm{JB}$ & Ouner & 96 & 0.25 & 0.75 & 0.75 & 72.42 & 44.629 & $4,463.08$ & $438,908.629$ & $1,268.87$ & 4,222928 \\
\hline$\amalg$ & Owner & 96 & 0.25 & 0.75 & 0.75 & 32.50 & 22.273 & $2,166.92$ & $104,952,992$ & 700.75 & $10,674.929$ \\
\hline $\mathrm{HW}$ & Capped & 96 & 0.25 & 0.75 & 0.75 & 186.25 & 244.750 & $8,339.58$ & $4,430,795902$ & $1,971.17$ & $379,626.908$ \\
\hline $\mathrm{JB}$ & Capped & 96 & 0.25 & 0.75 & 0.75 & 86.33 & 214.242 & $4,637.67$ & $441,237.515$ & $1,659.49$ & $65,240.149$ \\
\hline 4 & Capped & 96 & 0.25 & 0.75 & 0.75 & 34.42 & 20.265 & $2,193.75$ & 115,202023 & 700.19 & $14,978.726$ \\
\hline $\mathrm{HW}$ & No-Owner & 50 & 0.25 & 0.75 & 0.75 & 94,32 & 31.755 & $3,794.56$ & $269,342,419$ & $2,126.69$ & $105,769.865$ \\
\hline JB & No-Owner & 50 & 0.25 & 0.75 & 0.75 & 26.69 & 6.005 & $1,354.85$ & $9,460.763$ & 993.77 & $46,350.976$ \\
\hline 凹 & No-Owner & 50 & 0.25 & 0.75 & 0.75 & 11.91 & 0.367 & 710.92 & $5,767.558$ & 495.36 & 17,072499 \\
\hline $\mathrm{HW}$ & Owner & 50 & 0.25 & 0.75 & 0.75 & 129.83 & 142.152 & $5,393.58$ & $2,373,843720$ & $1,327.65$ & $237,750.851$ \\
\hline $\mathrm{JB}$ & Owner & 50 & 0.25 & 0.75 & 0.75 & 44.42 & 12.811 & $2,344.25$ & $245,522,023$ & 704.13 & $8,543.618$ \\
\hline せ & Owner & 50 & 0.25 & 0.75 & 0.75 & 31.67 & 22.242 & $2,155.33$ & $102,180.061$ & 698.73 & $10,549.936$ \\
\hline$\overline{\mathrm{HW}}$ & Capped & 50 & 0.25 & 0.75 & 0.75 & 131.50 & 139.364 & $5,353.67$ & $2,243,847.515$ & $1,337.17$ & $245,883.653$ \\
\hline $\mathrm{JB}$ & Capped & 50 & 0.25 & 0.75 & 0.75 & 53.83 & 91.788 & $2,485.58$ & $235,600.992$ & 993.74 & $22,887.462$ \\
\hline$\longleftarrow$ & Capped & 50 & 0.25 & 0.75 & 0.75 & 33.58 & 18.992 & $2,182.17$ & 112,06269 & 698.18 & $14,771.374$ \\
\hline$\overline{\mathrm{HW}}$ & No-Owner & 25 & 0.25 & 0.75 & 0.75 & 61.09 & 12.974 & $2,622.09$ & $113,071.208$ & $1,857.83$ & $95,918.452$ \\
\hline $\mathrm{JB}$ & No-Owner & 25 & 0.25 & 0.75 & 0.75 & 16.66 & 0.771 & 926.33 & $16,863.133$ & 891.39 & 59,562249 \\
\hline$\longleftrightarrow$ & No-Omner & 25 & 0.25 & 0.75 & 0.75 & 8.73 & 5.024 & 900.17 & $19,555.108$ & 692.33 & $44,620.993$ \\
\hline $\mathrm{HW}$ & Owner & 25 & 0.25 & 0.75 & 0.75 & 83.00 & 71.455 & $3,512.33$ & $892,190.606$ & 905.83 & $94,184.879$ \\
\hline $\mathrm{JB}$ & Owner & 25 & 0.25 & 0.75 & 0.75 & 25.08 & 10.265 & $1,092.25$ & 33,602023 & 384.49 & $2,916.291$ \\
\hline L & Owner & 25 & 0.25 & 0.75 & 0.75 & 26.08 & 20.083 & $2,080.08$ & $88,730.992$ & 664.77 & $7,934.709$ \\
\hline $\mathrm{HW}$ & Capped & 25 & 0.25 & 0.75 & 0.75 & $83.08:$ & 66.265 & $3,450.42$ & $861,287.538$ & 899.19 & $106,037.241$ \\
\hline $\mathrm{JB}$ & Capped & 25 & 0.25 & 0.75 & 0.75 & 32.33 & 31.697 & $1,215.33$ & $47,844.970$ & 674.79 & $17,959.780$ \\
\hline$\bigsqcup$ & Capped & 25 & 0.25 & 0.75 & 0.75 & 27.42 & 16.992 & $2,104.17$ & $94,463.606$ & 662.10 & $11,117.647$ \\
\hline
\end{tabular}

Table 4-17 - Imbalance \#4 


\begin{tabular}{|c|c|c|c|c|c|c|c|c|c|c|c|}
\hline \multirow{2}{*}{ 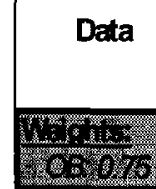 } & Type & Size & \multirow[t]{2}{*}{ OB } & \multirow[t]{2}{*}{ IB } & \multirow[t]{2}{*}{ PT } & \multicolumn{2}{|c|}{ Route Imbalance } & \multicolumn{2}{|c|}{ Load Imbalance } & \multicolumn{2}{|c|}{ Mile Imbalance } \\
\hline & 248 : & & & & & \multicolumn{2}{|c|}{ Mean : Var } & Mean & $\underline{\text { Var }}$ & Mean & $\underline{\text { Var }}$ \\
\hline $\mathrm{HW}$ & No-Owner & 96 & 0.75 & 0.25 & 0.25 & 101.48: & 69.908 & $3,688.97$ & $96,623.302$ & $2,236.44$ & $124,746.531$ \\
\hline $\mathrm{JB}$ & $\mathrm{No}-\mathrm{O}$ mer & 96 & 0.75 & 0.25 & 0.25 & 49.65 & 6.542 & $2,474.67$ & $22,975.395$ & $1,624.76$ & $76,677.217$ \\
\hline$\amalg$ & $\mathrm{No}$-Ouner & 96 & 0.75 & 0.25 & 0.25 & 10.42 & 1.100 & 505.50 & 1,722724 & 319.17 & $5,118.108$ \\
\hline$H W$ & Owner & 96 & 0.75 & 0.25 & 0.25 & 315.42 & 677.174 & $13,609.58$ & $7,732,817.538$ & $3,876.36$ & 573,312844 \\
\hline $\mathrm{JB}$ & Owner & 96 & 0.75 & 0.25 & 0.25 & 72.42 & 44.629 & $4,463.08$ & $438,908.629$ & $1,268.87$ & 4,222928 \\
\hline 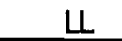 & Owner & 96 & 0.75 & 0.25 & 0.25 & 32.50 & 22.273 & $2,166.92$ & 104,952992 & 700.75 & $10,674.929$ \\
\hline$H W$ & Capped & 96 & 0.75 & 0.25 & 0.25 & 319.67: & 764.242 & $13,847.17$ & $7,281,700.152$ & $4,062.70$ & $719,300.504$ \\
\hline $\mathrm{JB}$ & Capped & 96 & 0.75 & 0.25 & 0.25 & 86.33 & 214.242 & $4,637.67$ & $441,237.515$ & $1,659.49$ & 65.240 .149 \\
\hline$\amalg$ & Capped & 96 & 0.75 & 0.25 & 0.25 & 34.42 & 20.265 & $2,193.75$ & $115,202,023$ & 700.19 & $14,978.726$ \\
\hline HW & No-Omner & 50 & 0.75 & 0.25 & 0.25 & 53.54 & 18.944 & $2,151.39$ & $46,579.464$ & $1,322.82$ & $57,249.026$ \\
\hline $\mathrm{JB}$ & Na-Omner & 50 & 0.75 & 0.25 & 0.25 & 26.69 & 6.005 & $1,354.85$ & $9,460.763$ & 993.77 & $46,350.976$ \\
\hline U & $\mathrm{No}-\mathrm{O}$ mer & 50 & 0.75 & 0.25 & 0.25 & 11.91 & 0.367 & 710.92 & $5,767.558$ & 495.36 & 17,072499 \\
\hline HW & Owner & 50 & 0.75 & 0.25 & 0.25 & 228.50 & 209.000 & $9,115.33$ & $3,784,722606$ & $2,743.74$ & $377,571.582$ \\
\hline $\mathrm{JB}$ & Onner & 50 & 0.75 & 0.25 & 0.25 & 44.42 & 12811 & $2,344.25$ & 245,522023 & 704.13 & $8,543.618$ \\
\hline せ & Ouner & 50 & 0.75 & 0.25 & 0.25 & 31.67 & 22.242 & $2,155.33$ & $102,180.061$ & 698.73 & $10,549.936$ \\
\hline HW & Capped & 50 & 0.75 & 0.25 & 0.25 & $230.33 !$ & 171.152 & $9,320.58$ & $3,485,582992$ & $2,895.13$ & $470,471.768$ \\
\hline JB & Capped & 50 & 0.75 & 0.25 & 0.25 & 53.83 & 91.788 & $2,485.58$ & $235,600.992$ & 993.74 & $22,887.462$ \\
\hline Ш & Capped & 50 & 0.75 & 0.25 & 0.25 & 33.58 & 18.992 & $2,182.17$ & 112,062697 & 698.18 & $14,771.374$ \\
\hline HW & No-Owner & 25 & 0.75 & 0.25 & 0.25 & 29.78 & 5.016 & $1,482.24$ & $22,813.235$ & $1,119.83$ & $79,690.803$ \\
\hline $\mathrm{JB}$ & No-Ouner & 25 & 0.75 & 0.25 & 0.25 & 16.66 & 0.771 & 926.33 & $16,863.133$ & 891.39 & $59,562.249$ \\
\hline$\amalg$ & No-Owner & 25 & 0.75 & 0.25 & 0.25 & 8.73 & 5.024 & 900.17 & $19,555.108$ & 692.33 & $44,620.993$ \\
\hline HW & Owner & 25 & 0.75 & 0.25 & 0.25 & $131.67 !$ & 115.879 & $5,475.25$ & $1,509,325,114$ & $1,878.22$ & $189,027.839$ \\
\hline $\mathrm{JB}$ & Owner & 25 & 0.75 & 0.25 & 0.25 & 25.08 & 10.265 & $1,092.25$ & 33,602023 & 384.49 & $2,916.291$ \\
\hline せ & Ouner & 25 & 0.75 & 0.25 & 0.25 & 26.08 & 20.083 & $2,080.08$ & $88,730.992$ & 664.77 & $7,934.709$ \\
\hline$H W$ & Capped & 25 & 0.75 & 0.25 & 0.25 & $125.83 !$ & 82.515 & $5,597.17$ & $1,341,068.879$ & $1,971.27$ & 249,882036 \\
\hline $\mathrm{JB}$ & Capped & 25 & 0.75 & 0.25 & 0.25 & 32.33 & 31.697 & $1,215.33$ & $47,844.970$ & 674.79 & $17,959.780$ \\
\hline$\amalg$ & Capped & 25 & 0.75 & 0.25 & 0.25 & 27.42 & 16.992 & $2,104.17$ & $94,463.606$ & 662.10 & $11,117.647$ \\
\hline
\end{tabular}

Table 4-18 - Imbalance \#5 


\begin{tabular}{|c|c|c|c|c|c|c|c|c|c|c|c|}
\hline \multirow{3}{*}{$\begin{array}{l}\text { Data } \\
\text { tary }\end{array}$} & \multirow[t]{2}{*}{ Type } & \multirow[t]{2}{*}{ Size } & \multirow[t]{3}{*}{$\mathrm{OB}$} & \multirow[t]{3}{*}{ IB } & \multirow[t]{3}{*}{ PT } & \multicolumn{2}{|c|}{ Route Imbalance } & \multicolumn{2}{|c|}{ Load Imbalance } & \multicolumn{2}{|c|}{ Mile Imbalance } \\
\hline & & & & & & \multirow[t]{2}{*}{ Mean : } & \multirow[t]{2}{*}{$\underline{\text { Var }}$} & \multirow[t]{2}{*}{ Mean } & \multirow[t]{2}{*}{$\underline{\text { Var }}$} & \multirow[t]{2}{*}{ Mean } & \multirow[t]{2}{*}{ Var } \\
\hline & 25 & & & & & & & & & & \\
\hline HW & No-Owner & 96 & 0.75 & 0.25 & 0.75 & 159.10 & 175.034 & $5,471.96$ & $856,632,194$ & $2,547.35$ & $226,021.599$ \\
\hline $\mathrm{JB}$ & No-Owner & 96 & 0.75 & 0.25 & 0.75 & 49.65 & 6.542 & $2,474.67$ & $22,975.395$ & $1,624.76$ & 76.677 .217 \\
\hline 凹 & No-Omner & 96 & 0.75 & 0.25 & 0.75 & 10.42 & 1.100 & 505.50 & $1,722.724$ & 319.17 & $5,118.108$ \\
\hline HW & Owner & 96 & 0.75 & 0.25 & 0.75 & $185.42 !$ & 262265 & $8,465.58$ & $5,885,175,356$ & $1,970.63$ & $331,196.786$ \\
\hline $\mathrm{JB}$ & Ouner & 96 & 0.75 & 0.25 & 0.75 & 72.42 & 44.629 & $4,463.08$ & $438,908.629$ & $1,268.87$ & $4,222.928$ \\
\hline 凹 & Ouner & 96 & 0.75 & 0.25 & 0.75 & 32.50 & 22.273 & $2,166.92$ & 104,952992 & 700.75 & $10,674.929$ \\
\hline HW & Capped & 96 & 0.75 & 0.25 & 0.75 & 190.75 & 418.386 & $8,533.42$ & $6,157,478.265$ & $2,027.88$ & $385,337.845$ \\
\hline $\mathrm{JB}$ & Capped & 96 & 0.75 & 0.25 & 0.75 & $86.33 !$ & 214.242 & $4,637.67$ & $441,237.515$ & $1,659.49$ & 65.240 .149 \\
\hline 凹 & Capped & 96 & 0.75 & 0.25 & 0.75 & 34.42 & 20.265 & $2,193.75$ & 115,202023 & 700.19 & $14,978.726$ \\
\hline$H W$ & No-Owner & 50 & 0.75 & 0.25 & 0.75 & 92.87 & 49.599 & $3,159.78$ & $514,647.229$ & $1,453.35$ & $138,283.678$ \\
\hline JB & No-Owner & 50 & 0.75 & 0.25 & 0.75 & 26.69 & 6.005 & $1,354.85$ & $9,460.763$ & 993.77 & $46,350.976$ \\
\hline せ & No-Owner & 50 & 0.75 & 0.25 & 0.75 & 11.91 & 0.367 & 710.92 & $5,767.558$ & 495.36 & 17,072499 \\
\hline HW & Owner & 50 & 0.75 & 0.25 & 0.75 & 131.08 & 82.265 & $5,576.58$ & $3,145,138.811$ & $1,435.45$ & $206,593.173$ \\
\hline$J B$ & Owner & 50 & 0.75 & 0.25 & 0.75 & $44.42 \vdots$ & 12.811 & $2,344.25$ & 245,522023 & 704.13 & $8,543.618$ \\
\hline Ш & Owner & 50 & 0.75 & 0.25 & 0.75 & 31.67 & 22242 & $2,155.33$ & $102,180.061$ & 698.73 & $10,549.936$ \\
\hline$H W$ & Capped & 50 & 0.75 & 0.25 & 0.75 & 135.33 & 130.606 & $5,632.17$ & $3,300,061.061$ & $1,484.51$ & $238,554.341$ \\
\hline$J B$ & Capped & 50 & 0.75 & 0.25 & 0.75 & 53.83 & 91.788 & $2,485.58$ & $235,600.992$ & 993.74 & $22,887.462$ \\
\hline Ш & Capped & 50 & 0.75 & 0.25 & 0.75 & 33.58 & 18.992 & $2,182.17$ & 112062.697 & 698.18 & $14,771.374$ \\
\hline$H W$ & No-Omner & 25 & 0.75 & 0.25 & 0.75 & 58.47 & 27.964 & $1,923.88$ & $293,143.978$ & $1,049.32$ & $100,913.697$ \\
\hline $\mathrm{JB}$ & $\mathrm{No}-\mathrm{O}$ mer & 25 & 0.75 & 0.25 & 0.75 & 16.66 & 0.771 & 926.33 & $16,863.133$ & 891.39 & $59,562.249$ \\
\hline 凹 & No-Owner & 25 & 0.75 & 0.25 & 0.75 & 8.73 & 5.024 & 900.17 & $19,555.108$ & 692.33 & $44,620.993$ \\
\hline HW & Omner & 25 & 0.75 & 0.25 & 0.75 & 78.50 & 46.091 & $3,247.42$ & $1,517,453.538$ & 997.37 & $127,790.972$ \\
\hline $\mathrm{JB}$ & Omner & 25 & 0.75 & 0.25 & 0.75 & 25.08 & 10.265 & $1,092.25$ & 33,602023 & 384.49 & 2916.291 \\
\hline Ш & Owner & 25 & 0.75 & 0.25 & 0.75 & 26.08 & 20.083 & $2,080.08$ & $88,730.992$ & $664 . \pi$ & $7,934.709$ \\
\hline$H W$ & Capped & 25 & 0.75 & 0.25 & 0.75 & 80.17 & 7.424 & $3,273.08$ & $1,655,080.811$ & $1,026.78$ & $156,465.384$ \\
\hline $\mathrm{JB}$ & Capped & 25 & 0.75 & 0.25 & 0.75 & 32.33 & 31.697 & $1,215.33$ & $47,844.970$ & 674.79 & $17,959.780$ \\
\hline せ & Capped & 25 & 0.75 & 0.25 & 0.75 & 27.42 & 16.992 & $2,104.17$ & $94,463.606$ & 662.10 & $11,117.647$ \\
\hline
\end{tabular}

Table 4-19 - Imbalance \#6 


\begin{tabular}{|c|c|c|c|c|c|c|c|c|c|c|c|}
\hline \multirow{2}{*}{ Data } & \multirow[t]{2}{*}{ Type } & \multirow[t]{2}{*}{ Size } & \multirow[t]{2}{*}{$\mathbf{O B}$} & \multirow[t]{2}{*}{ IB } & \multirow[t]{2}{*}{ PT } & \multicolumn{2}{|c|}{ Route Imbalance } & \multicolumn{2}{|c|}{ Load Imbalance } & \multicolumn{2}{|c|}{ Mile Imbalance } \\
\hline & & & & & & Mean & Var & Mean & Var & Mean & Var \\
\hline \multicolumn{12}{|c|}{ 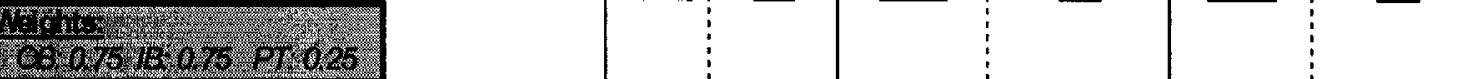 } \\
\hline HW & No-Owner & 96 & 0.75 & 0.75 & 0.25 & 71.43 & 36.598 & $3,223.30$ & 32216.964 & $1,994.48$ & $106,399.392$ \\
\hline $\mathrm{JB}$ & No-Omer & 96 & 0.75 & 0.75 & 0.25 & 49.65 & 6.542 & $2,474.67$ & $22,975.395$ & $1,624.76$ & $76,677.217$ \\
\hline$\amalg$ & No-Omer & 96 & 0.75 & 0.75 & 0.25 & 10.42 & 1.100 & 505.50 & 1,722724 & 319.17 & $5,118.108$ \\
\hline HW & Ouner & 96 & 0.75 & 0.75 & 0.25 & 116.08 & 114.265 & $7,099.50$ & $1,007,609.000$ & $2,065.77$ & $77,016.051$ \\
\hline $\mathrm{JB}$ & Owner & 96 & 0.75 & 0.75 & 0.25 & 72.42 & 44.629 & $4,463.08$ & $438,908.629$ & $1,268.87$ & 4,222928 \\
\hline Ш & Owner & 96 & 0.75 & 0.75 & 0.25 & 32.50 & 22.273 & $2,166.92$ & 104,952902 & 700.75 & $10,674.929$ \\
\hline HW & Capped & 96 & 0.75 & 0.75 & 0.25 & 119.83 & 118.152 & $7,148.17$ & $1,148,783.061$ & $2,193.65$ & $117,021.759$ \\
\hline $\mathrm{JB}$ & Capped & 96 & 0.75 & 0.75 & 0.25 & 86.33 & 214.242 & $4,637.67$ & $441,237.515$ & $1,659.49$ & $65,240.149$ \\
\hline U & Capped & 96 & 0.75 & 0.75 & 0.25 & 34.42 & 20.265 & $2,193.75$ & 115,202023 & 700.19 & $14,978.726$ \\
\hline HW & $\mathrm{No-Ouner}$ & 50 & 0.75 & 0.75 & 0.25 & 36.10 & 8.871 & $1,707.48$ & $20,375.469$ & $1,157.44$ & $58,966.722$ \\
\hline $\mathrm{JB}$ & No-Owner & 50 & 0.75 & 0.75 & 0.25 & 26.69 & 6.005 & $1,354.85$ & $9,460.763$ & 993.77 & $46,350.976$ \\
\hline せ & No-Owner & 50 & 0.75 & 0.75 & 0.25 & 11.91 & 0.367 & 710.92 & $5,767.558$ & 495.36 & 17,072499 \\
\hline$H W$ & Owner & 50 & 0.75 & 0.75 & 0.25 & 74.08 & 66.811 & $4,320.42$ & $335,466.629$ & $1,356.09$ & $33,194.274$ \\
\hline $\mathrm{JB}$ & Owner & 50 & 0.75 & 0.75 & 0.25 & 44.42 & 12.811 & $2,344.25$ & $245,522,023$ & 704.13 & $8,543.618$ \\
\hline$\amalg$ & Owner & 50 & 0.75 & 0.75 & 0.25 & 31.67 & 22242 & $2,155.33$ & 102180.061 & 698.73 & $10,549.936$ \\
\hline $\mathrm{HW}$ & Capped & 50 & 0.75 & 0.75 & 0.25 & 74.58 & 58.083 & $4,345.00$ & $480,054.364$ & $1,455.80$ & $73,084.337$ \\
\hline $\mathrm{JB}$ & Capped & 50 & 0.75 & 0.75 & 0.25 & 53.83 & 91.788 & $2,485.58$ & $235,600.992$ & 993.74 & $22,887.462$ \\
\hline$\amalg$ & Capped & 50 & 0.75 & 0.75 & 0.25 & 33.58 & 18.992 & $2,182.17$ & 112,062697 & 698.18 & $14,771.374$ \\
\hline $\mathrm{HW}$ & No-Omner & 25 & 0.75 & 0.75 & 0.25 & 21.48 & 3.508 & $1,121.95$ & $39,978.128$ & $1,018.32$ & 91,442686 \\
\hline $\mathrm{JB}$ & No-Omner & 25 & 0.75 & 0.75 & 0.25 & 16.66 & 0.771 & 926.33 & $16,863.133$ & 891.39 & $59,562.249$ \\
\hline 凹 & No-Omer & 25 & 0.75 & 0.75 & 0.25 & 8.73 & 5024 & 900.17 & $19,555.108$ & 692.33 & $44,620.993$ \\
\hline$H W$ & Owner & 25 & 0.75 & 0.75 & 0.25 & 39.58 & 46.003 & $2,029.17$ & $54,477.606$ & 847.25 & $6,467.675$ \\
\hline $\mathrm{JB}$ & Owner & 25 & 0.75 & 0.75 & 0.25 & 25.08 & 10.265 & $1,092.25$ & $33,602,023$ & 384.49 & 2916.291 \\
\hline$\amalg$ & Ouner & 25 & 0.75 & 0.75 & 0.25 & 26.08 & 20.083 & $2,080.08$ & $88,730.992$ & 664.77 & $7,934.709$ \\
\hline $\mathrm{HW}$ & Capped & 25 & 0.75 & 0.75 & 0.25 & 37.33 & 31.152 & $2,044.50$ & $138,927.909$ & 939.34 & $32,423.093$ \\
\hline $\mathrm{JB}$ & Capped & 25 & 0.75 & 0.75 & 0.25 & 32.33 & 31.697 & $1,215.33$ & $47,844.970$ & 674.79 & $17,969.780$ \\
\hline Ш & Capped & 25 & 0.75 & 0.75 & 0.25 & 27.42 & 16.992 & $2,104.17$ & $94,463.606$ & 662.10 & $11,117.647$ \\
\hline
\end{tabular}

Table 4-20 - Imbalance \#7 


\begin{tabular}{|c|c|c|c|c|c|c|c|c|c|c|c|}
\hline \multirow{2}{*}{ Data } & \multirow[t]{2}{*}{ Type } & \multirow[t]{2}{*}{ Size } & \multirow[t]{2}{*}{$\mathrm{OB}$} & \multirow[t]{2}{*}{ IB } & \multirow[t]{2}{*}{ PT } & \multicolumn{2}{|c|}{ Route Imbalance } & \multicolumn{2}{|c|}{ Load Imbalance } & \multicolumn{2}{|c|}{ Mile Imbalance } \\
\hline & & & & & & Mean & Var & Mean & Var & Mean & Var \\
\hline \multicolumn{12}{|c|}{ 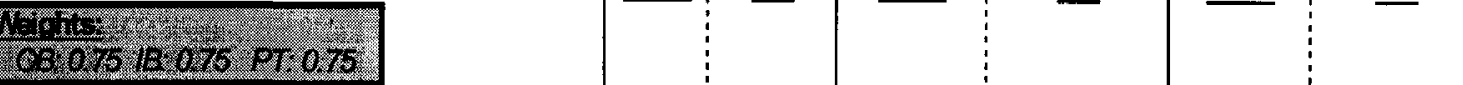 } \\
\hline$H W$ & No-Omer & 96 & 0.75 & 0.75 & 0.75 & 56.52 & 28.009 & $2,532.47$ & $21,247.673$ & $1,582.61$ & 94,195611 \\
\hline $\mathrm{JB}$ & No-Owner & 96 & 0.75 & 0.75 & 0.75 & 49.65 & 6.542 & $2,474.67$ & $22,975,395$ & $1,624.76$ & $76,677.217$ \\
\hline & No-Ouner & 96 & 0.75 & 0.75 & 0.75 & 10.42 & 1.100 & 505.50 & 1,722724 & 319.17 & $5,118.108$ \\
\hline HW & Owner & 96 & 0.75 & 0.75 & 0.75 & 64.00 & 28.545 & $4,331.00$ & 752,222909 & 983.82 & $44,319.981$ \\
\hline JB & Owner & 96 & 0.75 & 0.75 & 0.75 & 72.42 & 44.629 & $4,463.08$ & $438,908.629$ & $1,268.87$ & $4,222.928$ \\
\hline ㄴ & Owner & 96 & 0.75 & 0.75 & 0.75 & 32.50 & 22.273 & $2,166.92$ & $104,952,992$ & 700.75 & $10,674.929$ \\
\hline HW & Capped & 96 & 0.75 & 0.75 & 0.75 & 68.50 & 31.182 & $4,410.92$ & $734,543.356$ & $1,035.55$ & $43,491.391$ \\
\hline $\mathrm{JB}$ & Capped & 96 & 0.75 & 0.75 & 0.75 & 86.33 & 214.242 & $4,637.67$ & $441,237.515$ & $1,659.49$ & $65,240.149$ \\
\hline ㄴ & Capped & 96 & 0.75 & 0.75 & 0.75 & 34.42 & 20.265 & $2,193.75$ & 115202.023 & 700.19 & $14,978.726$ \\
\hline HW & No-Owner & 50 & 0.75 & 0.75 & 0.75 & 28.70 & 7.597 & $1,357.95$ & $11,301.488$ & 950.79 & 64,477.635 \\
\hline $\mathrm{JB}$ & No-Owner & 50 & 0.75 & 0.75 & 0.75 & 26.69 & 6.005 & $1,354.85$ & $9,460,763$ & 993.77 & 46,350976 \\
\hline ㄴ & No-Owner & 50 & 0.75 & 0.75 & 0.75 & 11.91 & 0.367 & 710.92 & $5,767.558$ & 495.36 & $17,072,499$ \\
\hline HW & Owner & 50 & 0.75 & 0.75 & 0.75 & 42.33 & 24.606 & $2, \pi 7.00$ & $319,883.273$ & 691.57 & $19,259.662$ \\
\hline $\mathrm{JB}$ & Owner & 50 & 0.75 & 0.75 & 0.75 & 44.42 & 12811 & $2,344.25$ & $245,522,023$ & 704.13 & $8,543.618$ \\
\hline Ш & Owner & 50 & 0.75 & 0.75 & 0.75 & 31.67 & 22.242 & $2,155.33$ & $102,180.061$ & 698.73 & $10,549.936$ \\
\hline HW & Capped & 50 & 0.75 & 0.75 & 0.75 & 46.58 & 31.174 & $2,863.58$ & $320,040.447$ & 747.69 & 22,162886 \\
\hline $\mathrm{JB}$ & Capped & 50 & 0.75 & 0.75 & 0.75 & 53.83 & 91.788 & $2,485.58$ & 235600.992 & 993.74 & $22,887.462$ \\
\hline Ш & Capped & 50 & 0.75 & 0.75 & 0.75 & 33.58 & 18.992 & $2,182.17$ & $112,062.697$ & 698.18 & $14,771.374$ \\
\hline$H W$ & No-Owner & 25 & 0.75 & 0.75 & 0.75 & 17.30 & 1.364 & 958.88 & $34,330.544$ & 881.99 & 83,265868 \\
\hline $\mathrm{JB}$ & No-Omner & 25 & 0.75 & 0.75 & 0.75 & 16.66 & 0.771 & 926.33 & $16,863.133$ & 891.39 & $58,562.249$ \\
\hline Ш & No-Ouner & 25 & 0.75 & 0.75 & 0.75 & 8.73 & 5.024 & 900.17 & $19,555.108$ & 692.33 & $44,620.993$ \\
\hline HW & Owner & 25 & 0.75 & 0.75 & 0.75 & 24.67 & 18.242 & $1,339.50$ & $29,467.727$ & 414.16 & $3,277.807$ \\
\hline JB & Owner & 25 & 0.75 & 0.75 & 0.75 & 25.08 & 10.265 & $1,092.25$ & $33,602,023$ & 384.49 & 2916.291 \\
\hline ப & Owner & 25 & 0.75 & 0.75 & 0.75 & 26.08 & 20.083 & $2,080.08$ & $88,730.992$ & 664.77 & $7,934.709$ \\
\hline $\mathrm{HW}$ & Capped & 25 & 0.75 & 0.75 & 0.75 & 27.83 & 12.515 & $1,411.83$ & $36,062.152$ & 462.48 & $6,849.580$ \\
\hline $\mathrm{JB}$ & Capped & 25 & 0.75 & 0.75 & 0.75 & 32.33 & 31.697 & $1,215.33$ & $47,844.970$ & 674.79 & $17,959.780$ \\
\hline ㄴ & Capped & 25 & 0.75 & 0.75 & 0.75 & 27.42 & 16.992 & $2,104.17$ & $94,463.606$ & 662.10 & $11,117.647$ \\
\hline
\end{tabular}

Table 4-21 - Imbalance \#8 


\begin{tabular}{|c|c|c|c|c|c|c|c|c|c|c|c|}
\hline \multirow{3}{*}{ Data } & \multirow[t]{2}{*}{ Type } & \multirow[t]{2}{*}{ Size } & \multirow[t]{3}{*}{ OB } & \multirow[t]{3}{*}{ IB } & \multirow[t]{3}{*}{ PT } & \multicolumn{2}{|c|}{ Outbound Miles } & \multicolumn{2}{|c|}{ Inbound Miles } & \multicolumn{2}{|c|}{ Pass Thru Miles } \\
\hline & & & & & & \multirow[t]{2}{*}{ Mean } & \multirow[t]{2}{*}{$\underline{\text { Var }}$} & \multirow[t]{2}{*}{ Mean } & \multirow[t]{2}{*}{$\underline{\text { Var }}$} & \multirow[t]{2}{*}{ Mean } & \multirow[t]{2}{*}{ Var } \\
\hline & .25 PT: & 0.25 & & & & & & & & & \\
\hline $\mathrm{HW}$ & No-Ouner & 96 & 0.25 & 0.25 & 0.25 & $3,276.36$ & $278,686.182$ & $3,615.79$ & $317,286,480$ & $84,945.08$ & $230,647,414.629$ \\
\hline $\mathrm{JB}$ & No-Ouner & 96 & 0.25 & 0.25 & 0.25 & $3,501.41$ & $339,854.896$ & 3,744.18: & $37,654.211$ & $84,591.58$ & $208,181,046,447$ \\
\hline Ш & $\mathrm{No}$-Ouner & 96 & 0.25 & 0.25 & 0.25 & 727.13 & $16,535.816$ & 897.12 & $18,027.182$ & $81,847.58$ & $242,065,340.447$ \\
\hline $\mathrm{HW}$ & Owner & 96 & 0.25 & 0.25 & 0.25 & $1,894.94$ & 302694.410 & 1,89243 & 362,372478 & $88,049.75$ & $196,215,671.295$ \\
\hline$J B$ & Ouner & 96 & 0.25 & 0.25 & 0.25 & $1,945.12$ & $148,358.089$ & 1,78254 & 139,915202 & $88,109.50$ & $197,923,248.273$ \\
\hline$\amalg$ & Ouner & 96 & 0.25 & 0.25 & 0.25 & $1,793.42$ & $152,189.629$ & $1,981.07$ & $144,744.070$ & $79,697.33$ & $176,475,290.061$ \\
\hline $\mathrm{HW}$ & Capped & 96 & 0.25 & 0.25 & 0.25 & $1,949.68$ & $356,417.385$ & $1,923.02$ & $405,618.942$ & $87,805.75$ & $182,778,319.114$ \\
\hline JB & Capped & 96 & 0.25 & 0.25 & 0.25 & $2,517.41$ & $361,093.246$ & $2,333.60$ & $229,999.634$ & $86,518.08$ & $172,436,632083$ \\
\hline Ш & Capped & 96 & 0.25 & 0.25 & 0.25 & $1,707.03$ & $138,667.605$ & 1,86290 & $120,628.428$ & $79,382.00$ & $171,258,398.727$ \\
\hline $\mathrm{HW}$ & $\mathrm{No}$-Owner & 50 & 0.25 & 0.25 & 0.25 & $2,176.14$ & $159,987.005$ & $2,600.27$ & $163,500.676$ & $73,067.08$ & $176,368,791.538$ \\
\hline $\mathrm{JB}$ & $\mathrm{No}-\mathrm{O}$ ner & 50 & 0.25 & 0.25 & 0.25 & $2,289.29$ & $152,555.479$ & 2,626.35: & $167,191.027$ & $71,861.00$ & $154,802,710.909$ \\
\hline$\amalg$ & No-Owner & 50 & 0.25 & 0.25 & 0.25 & $1,114.57$ & $41,028.540$ & $1,420.95$ & $46,248.452$ & $69,342.17$ & $172,390,864.515$ \\
\hline $\mathrm{HW}$ & Owner & 50 & 0.25 & 0.25 & 0.25 & $1,354.42$ & 187,897.967 & $1,299.91$ & $220,849.345$ & $75,189.25 !$ & $146,002,139.659$ \\
\hline$J B$ & Owner & 50 & 0.25 & 0.25 & 0.25 & $1,329.27$ & $110,001.595$ & 1,110.19 & 101,416.63 & $74,337.25$ & $146,316,017.114$ \\
\hline$\amalg$ & Ouner & 50 & 0.25 & 0.25 & 0.25 & $1,787.17$ & 149,912250 & $1,975.99$ & $143,796.992$ & $68,114.58$ & $131,237,184.265$ \\
\hline $\mathrm{HW}$ & Capped & 50 & 0.25 & 0.25 & 0.25 & $1,400.98$ & $219,978.075$ & $1,326.30$ & $252,701.659$ & $74,369.17$ & $117,900,476.333$ \\
\hline $\mathrm{JB}$ & Capped & 50 & 0.25 & 0.25 & 0.25 & $1,629.95$ & $148,103.771$ & $1,377.56$ & $78,974.602$ & $72,085.25$ & $109,900,379.295$ \\
\hline Ш & Capped & 50 & 0.25 & 0.25 & 0.25 & $1,700.78$ & $136,528.720$ & $1,857.82$ & $119,861.041$ & $64,364.83$ & $96,368,959.788$ \\
\hline $\mathrm{HW}$ & No-Owner & 25 & 0.25 & 0.25 & 0.25 & $1,806.61$ & 114,332171 & $2,313.64$ & $146,136,520$ & $54,552.75$ & $103,779,916.932$ \\
\hline $\mathrm{JB}$ & No-Owner & 25 & 0.25 & 0.25 & 0.25 & $1,852.49$ & $133,887.710$ & $2,390.31$ & $149,564.594$ & $54,500.83$ & $97,145,189.738$ \\
\hline$\amalg$ & No-Ouner & 25 & 0.25 & 0.25 & 0.25 & $1,521.57$ & $74,124.595$ & $1,972.70$ & $105,185,283$ & $51,782.33$ & $99,344,684.242$ \\
\hline $\mathrm{HW}$ & Owner & 25 & 0.25 & 0.25 & 0.25 & 935.68 & $116,553.317$ & 879.93 & $84,081.534$ & $56,857.33$ & $94,807,858.788$ \\
\hline$J B$ & Ouner & 25 & 0.25 & 0.25 & 0.25 & 645.65 & œ3,379.917 & 639.87 & $55,412,486$ & $57,458.17$ & $98,238,951.061$ \\
\hline Ш & Ouner & 25 & 0.25 & 0.25 & 0.25 & $1,720.92$ & $138,941.400$ & $1,940.06$ & $140,146.044$ & 51,615.58: & $77,421,553.902$ \\
\hline $\mathrm{HW}$ & Capped & 25 & 0.25 & 0.25 & 0.25 & 966.49 & $144,640.373$ & 887.87 & $111,487.451$ & $53,768.50$ & $45,882,129.545$ \\
\hline $\mathrm{JB}$ & Capped & 25 & 0.25 & 0.25 & 0.25 & 915.21 & $87,644.639$ & 850.34 & $52,026.271$ & $54,117.50$ & $50,283,371.909$ \\
\hline Ш & Capped & 25 & 0.25 & 0.25 & 0.25 & $1,627.68$ & $119,076.809$ & $1,814.64$ & $109,391.434$ & $46,779.17$ & $33,155,430.333$ \\
\hline
\end{tabular}

Table 4-22 - Mile Ownership \#1

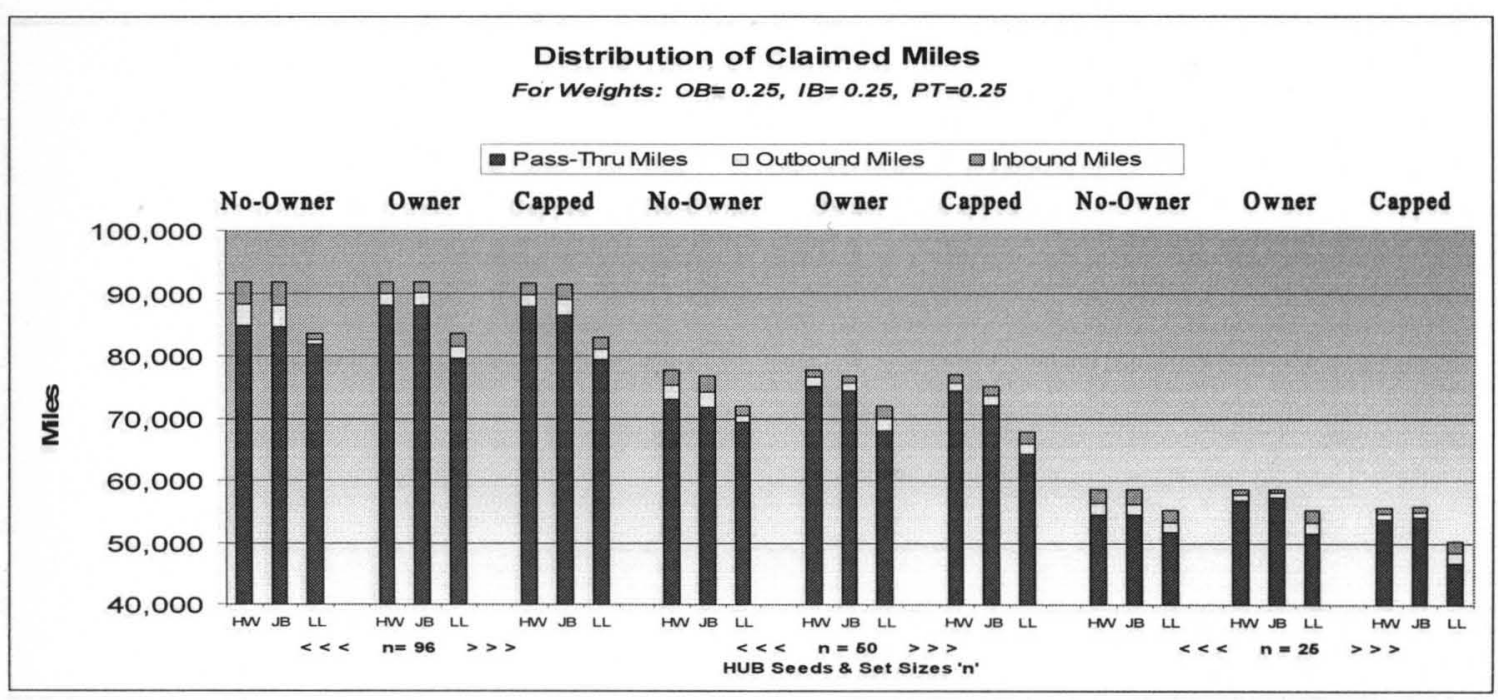




\begin{tabular}{|c|c|c|c|c|c|c|c|c|c|c|c|}
\hline \multirow{3}{*}{$\begin{array}{r}\text { Data } \\
\text { Weichts: }\end{array}$} & \multirow[t]{2}{*}{ Type } & \multirow[t]{2}{*}{ Size } & \multirow[t]{3}{*}{ OB } & \multirow[t]{3}{*}{ IB } & \multirow[t]{3}{*}{ PT } & \multicolumn{2}{|c|}{ Outbound Miles } & \multicolumn{2}{|c|}{ Inbound Miles } & \multicolumn{2}{|c|}{ Pass Thru Miles } \\
\hline & & & & & & \multirow[t]{2}{*}{ Mean } & \multirow[t]{2}{*}{$\underline{\text { Var }}$} & \multirow{2}{*}{ Mean } & \multirow[t]{2}{*}{$\underline{\text { Var }}$} & \multirow{2}{*}{ Mean } & \multirow[t]{2}{*}{$\underline{\text { Var }}$} \\
\hline & 0.25 PT: & & & & & & & & & & \\
\hline $\mathrm{HW}$ & No-Ouner & 96 & 0.25 & 0.25 & 0.75 & 638.21 & 16,042992 & 926.00 & $29,940.262$ & $90,272.92$ & $255,481,334.447$ \\
\hline $\mathrm{JB}$ & No-Ouner & 96 & 0.25 & 0.25 & 0.75 & $3,501.41$ & $339,854.806$ & 3,744.18 & $377,654.211$ & $84,591.58$ & $208,181,046.447$ \\
\hline$\amalg$ & No-Ouner & 96 & 0.25 & 0.25 & 0.75 & 727.13 & $16,535.816$ & 897.12 & $18,027.182$ & $81,847.58$ & $242,065,340.447$ \\
\hline $\mathrm{HW}$ & Onner & 96 & 0.25 & 0.25 & 0.75 & 21.06 & 36.444 & 20.81 & 53.971 & $91,795.33$ & $211,118,284.061$ \\
\hline $\mathrm{JB}$ & Owner & 96 & 0.25 & 0.25 & 0.75 & $1,945.12$ & $148,358.089$ & $1,782.54$ & 139,915:202 & $88,109.50$ & $197,923,248.273$ \\
\hline Ш & Onner & 96 & 0.25 & 0.25 & 0.75 & $1,793.42$ & $152,189.629$ & $1,981.07$ & $144,744.070$ & $79,697.33$ & $176,475,290.061$ \\
\hline $\mathrm{HW}$ & Capped & 96 & 0.25 & 0.25 & 0.75 & 20.23 & 57.136 & 17.72 & 43.721 & $91,647.50$ & $201,772,395000$ \\
\hline $\mathrm{JB}$ & Capped & 96 & 0.25 & 0.25 & 0.75 & $2,517.41$ & $361,003.246$ & $2,333.60$ & $229,999.634$ & $86,518.08$ & $172,436,632083$ \\
\hline Ш & Capped & 96 & 0.25 & 0.25 & 0.75 & $1,707.03$ & $138,667.685$ & $1,862.90$ & $120,628.428$ & $79,382.00$ & $171,258,398.727$ \\
\hline $\mathrm{HW}$ & No-Ouner & 50 & 0.25 & 0.25 & 0.75 & 541.98 & $14,465.259$ & 853.56 & $31,983.338$ & $76,486.42$ & $190,011,456.083$ \\
\hline $\mathrm{JB}$ & No-Ouner & 50 & 0.25 & 0.25 & 0.75 & $2,289.29$ & $152,555.479$ & $2,626.35$ & $167,191.027$ & $71,861.00$ & $154,802,710.900$ \\
\hline$\amalg$ & No-Ouner & 50 & 0.25 & 0.25 & 0.75 & $1,114.57$ & $41,028.540$ & $1,420.95$ & $46,248.452$ & $69,342.17$ & $172,390,864.515$ \\
\hline $\mathrm{HW}$ & Onner & 50 & 0.25 & 0.25 & 0.75 & 3.69 & 10.259 & 8.43 & 23.255 & $77,869.67$ & $156,424,309.697$ \\
\hline $\mathrm{JB}$ & Onner & 50 & 0.25 & 0.25 & 0.75 & $1,329.27$ & $110,001.595$ & 1,110.19: & $101,416.633$ & $74,337.25$ & $146,316,017.114$ \\
\hline$\amalg$ & Ouner & 50 & 0.25 & 0.25 & 0.75 & $1,787.17$ & 149,912250 & $1,975.99$ & $143,796.992$ & $68,114.58$ & $131,237,184.265$ \\
\hline $\mathrm{HW}$ & Capped & 50 & 0.25 & 0.25 & 0.75 & 286 & 18.360 & 5.33 & 25.161 & $77,143.75$ & $130,296,713.659$ \\
\hline JB & Capped & 50 & 0.25 & 0.25 & 0.75 & $1,629.95$ & $148,103.771$ & $1,377.56 !$ & $78,974.602$ & $72,085.25$ & $109,900,379.206$ \\
\hline$\amalg$ & Capped & 50 & 0.25 & 0.25 & 0.75 & $1,700.78$ & $136,528.720$ & $1,857.82$ & $119,861.041$ & $64,364.83$ & $96,368,959.738$ \\
\hline HW & No-Ouner & 25 & 0.25 & 0.25 & 0.75 & 458.27 & $10,630.982$ & 785.39 & $33,121.647$ & $57,449.00$ & $112,860,563.818$ \\
\hline $\mathrm{JB}$ & No-Ouner & 25 & 0.25 & 0.25 & 0.75 & $1,852.49$ & $133,887.710$ & 2,390.31: & $149,564.594$ & $54,500.83$ & $97,145,189.738$ \\
\hline Ш & No-Ouner & 25 & 0.25 & 0.25 & 0.75 & $1,521.57$ & $74,124.595$ & 1,972:70! & $105,185,283$ & $51,782.33$ & $99,344,684.242$ \\
\hline $\mathrm{HW}$ & Onner & 25 & 0.25 & 0.25 & 0.75 & 2.26 & 4.999 & 6.84 & 28.115 & $58,683.58$ & $97,823,453.356$ \\
\hline $\mathrm{JB}$ & Ouner & 25 & 0.25 & 0.25 & 0.75 & 645.65 & 63,379.917 & 639.87 & 55,412486 & $57,458.17$ & $98,238,951.061$ \\
\hline Ш & Ouner & 25 & 0.25 & 0.25 & 0.75 & $1,720.92$ & $138,941.400$ & $1,940.06:$ & $140,146,044$ & $51,615.58$ & $77,421,563.902$ \\
\hline $\mathrm{HW}$ & Capped & 25 & 0.25 & 0.25 & 0.75 & 1.09 & 7.523 & 2.78 & 22701 & $55,648.42$ & $48,504,070.629$ \\
\hline $\mathrm{JB}$ & Capped & 25 & 0.25 & 0.25 & 0.75 & 915.21 & $87,644.639$ & 850.34 & $52,026.271$ & $54,117.50$ & $50,283,371.909$ \\
\hline Ш & Capped & 25 & 0.25 & 0.25 & 0.75 & $1,627.68$ & $119,076.809$ & 1,814.64: & $109,391.434$ & $46,779.17$ & $33,155,430.333$ \\
\hline
\end{tabular}

Table 4-23 - Mile Ownership \#2

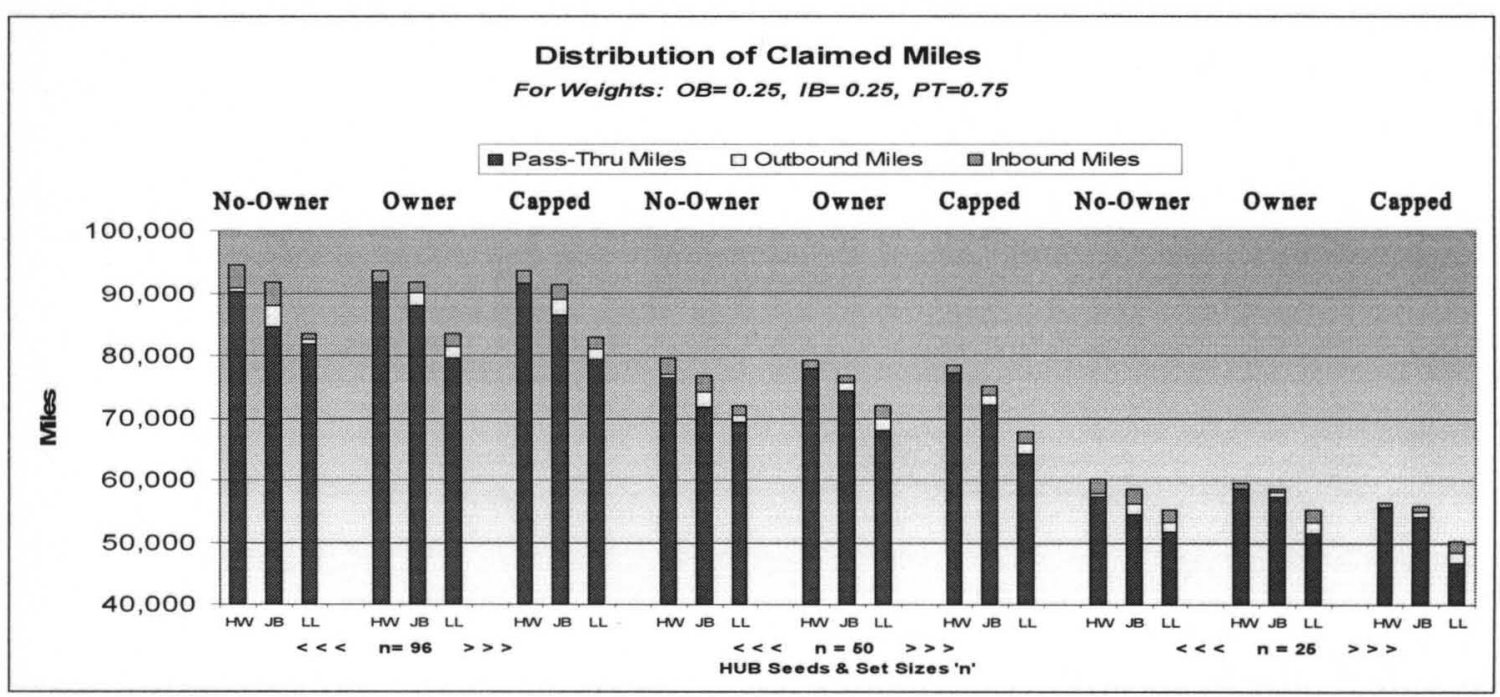




\begin{tabular}{|c|c|c|c|c|c|c|c|c|c|c|c|}
\hline \multirow{3}{*}{$\begin{array}{r}\text { Data } \\
\text { Weichts: } \\
\mathrm{OB:} 0.25\end{array}$} & \multirow[t]{2}{*}{ Type } & \multirow[t]{2}{*}{ Size } & \multirow[t]{2}{*}{$\mathrm{OB}$} & \multirow[t]{3}{*}{ IB } & \multirow[t]{3}{*}{ PT } & \multicolumn{2}{|c|}{ Outbound Miles } & \multicolumn{2}{|c|}{ Inbound Miles } & \multicolumn{2}{|c|}{ Pass Thru Miles } \\
\hline & & & & & & \multirow[t]{2}{*}{ Mean } & \multirow{2}{*}{$\underline{\text { Var }}$} & \multirow{2}{*}{ Mean } & \multirow{2}{*}{$\underline{\text { Var }}$} & \multirow{2}{*}{ Mean } & \multirow{2}{*}{ Var } \\
\hline & 75 PT: ( & & & & & & & & & & \\
\hline$\overline{\mathrm{HW}}$ & No-Ouner & 96 & 0.25 & 0.75 & 0.25 & $3,276.36$ & $278,688.859$ & 4,494.44 & 445,702441 & $84,066.25$ & $227,570,244.205$ \\
\hline $\mathrm{JB}$ & $\mathrm{No}-$ Onner & 96 & 0.25 & 0.75 & 0.25 & $3,501.41$ & $339,854.896$ & $3,744.18$ & $377,654.211$ & $84,591.58$ & $208,181,046447$ \\
\hline せ & $\mathrm{No}-\mathrm{O}$ ner & 96 & 0.25 & 0.75 & 0.25 & 727.13 & $16,535.816$ & 897.12 & $18,027.182$ & $81,847.58$ & $242,065,340,447$ \\
\hline $\mathrm{HW}$ & Onner & 96 & 0.25 & 0.75 & 0.25 & $1,407.28$ & $218,997.146$ & $5,188.19$ & $1,408,424.312$ & \begin{tabular}{|l}
$85,241.75$ \\
\end{tabular} & $190,674,265841$ \\
\hline$J B$ & Owner & 96 & 0.25 & 0.75 & 0.25 & $1,945.12$ & $148,358.089$ & 1,78254 & 139,915.202 & $88,109.50$ & $197,923,248.273$ \\
\hline$\amalg$ & Owner & 96 & 0.25 & 0.75 & 0.25 & $1,793.42$ & $152,189.629$ & $1,981.07$ & $144,744.070$ & $79,697.33$ & $176,475,290.061$ \\
\hline $\mathrm{HW}$ & Capped & 96 & 0.25 & 0.75 & 0.25 & $1,482.58$ & $269,773.628$ & $5,139.58$ & $1,392801.195$ & $\begin{array}{l}85,057.00 \\
\end{array}$ & $178,180,062000$ \\
\hline $\mathrm{JB}$ & Capped & 96 & 0.25 & 0.75 & 0.25 & $2,517.41$ & $361,093.246$ & $2,333.60$ & $229,999.634$ & 86,518.08: & $172,436,632083$ \\
\hline$\amalg$ & Capped & 96 & 0.25 & 0.75 & 0.25 & $1,707.03$ & 138,667.685 & $1,862.90$ & $120,628.428$ & $79,382.00$ & $171,258,398.727$ \\
\hline$\overline{\mathrm{HW}}$ & No-Owner & 50 & 0.25 & 0.75 & 0.25 & $2,172,63$ & $159,470.682$ & $3,283.14$ & $238,167.487$ & $72,262.00$ & $173,561,606.727$ \\
\hline $\mathrm{JB}$ & No-Owner & 50 & 0.25 & 0.75 & 0.25 & $2,289.29$ & 152555.479 & $2,626.35$ & $167,191.027$ & $71,861.00$ & $154,802,710.909$ \\
\hline$\amalg$ & No-Ouner & 50 & 0.25 & 0.75 & 0.25 & $1,114.57$ & $41,028.540$ & $1,420.95$ & $46,248.452$ & $69,342.17$ & $172,390,864.515$ \\
\hline $\mathrm{HW}$ & Ouner & 50 & 0.25 & 0.75 & 0.25 & $1,027.33$ & $143,683.046$ & $3,724.72$ & $773,234.331$ & $72,965.83$ & $142,298,095,606$ \\
\hline $\mathrm{JB}$ & Owner & 50 & 0.25 & 0.75 & 0.25 & $1,329.27$ & $110,001.595$ & 1,110.19! & $101,416.63$ & $74,337.25$ & $146,316,017.114$ \\
\hline$\amalg$ & Ouner & 50 & 0.25 & 0.75 & 0.25 & $1,787.17$ & 149,912250 & $1,975.99$ & $143,796.992$ & $68,114.58$ & $131,237,184.265$ \\
\hline $\mathrm{HW}$ & Capped & 50 & 0.25 & 0.75 & 0.25 & $1,084.68$ & $173,661.625$ & $3,658.59$ & $725,684.963$ & $72,206.17$ & $115,555,610.879$ \\
\hline $\mathrm{JB}$ & Capped & 50 & 0.25 & 0.75 & 0.25 & $1,629.95$ & $148,103.771$ & $1,377.56$ & $78,974.602$ & $72,085.25$ & $109,900,379.295$ \\
\hline$\amalg$ & Capped & 50 & 0.25 & 0.75 & 0.25 & $1,700.78$ & $136,528.720$ & $1,857.82$ & $119,861.041$ & $64,364.83$ & $96,368,959.738$ \\
\hline $\mathrm{HW}$ & No-Ouner & 25 & 0.25 & 0.75 & 0.25 & $1,808.27$ & 114,542785 & $2,697.78$ & $169,123.148$ & $54,221.00$ & $100,312,784.000$ \\
\hline $\mathrm{JB}$ & No-Ouner & 25 & 0.25 & 0.75 & 0.25 & $1,852.49$ & $133,887.710$ & $2,390.31$ & $149,564.594$ & $54,500.83$ & $97,145,189.788$ \\
\hline$\amalg$ & No-Ouner & 25 & 0.25 & 0.75 & 0.25 & $1,521.57$ & $74,124.595$ & 1,97270 & $105,185,283$ & 51,782.33: & $99,344,684.242$ \\
\hline $\mathrm{HW}$ & Owner & 25 & 0.25 & 0.75 & 0.25 & 747.38 & $92,966.078$ & $2,649.82$ & $374,555,997$ & $55,329.92$ & $93,791,234.447$ \\
\hline $\mathrm{JB}$ & Ouner & 25 & 0.25 & 0.75 & 0.25 & 645.65 & 63,379.917 & 639.87 & $55,412,486$ & $57,458.17$ & $98,238,951.061$ \\
\hline せ & Ouner & 25 & 0.25 & 0.75 & 0.25 & $1,720.92$ & $138,941.400$ & $1,940.06$ & $140,146,044$ & 51,615.58: & $77,421,553.902$ \\
\hline $\mathrm{HW}$ & Capped & 25 & 0.25 & 0.75 & 0.25 & 779.77 & $116,677.137$ & $2,545.26 !$ & $364,460.065$ & $52,294.75$ & $45,643,861.477$ \\
\hline $\mathrm{JB}$ & Capped & 25 & 0.25 & 0.75 & 0.25 & 915.21 & $87,644.699$ & 850.34 & $52,026.271$ & $54,117.50$ & $50,283,371.909$ \\
\hline Ш & Capped & 25 & 0.25 & 0.75 & 0.25 & $1,627.68$ & $119,076.809$ & $1,814.64$ & $109,391.434$ & $46,779.17$ & $33,155,430.333$ \\
\hline
\end{tabular}

Table 4-24 - Mile Ownership \#3

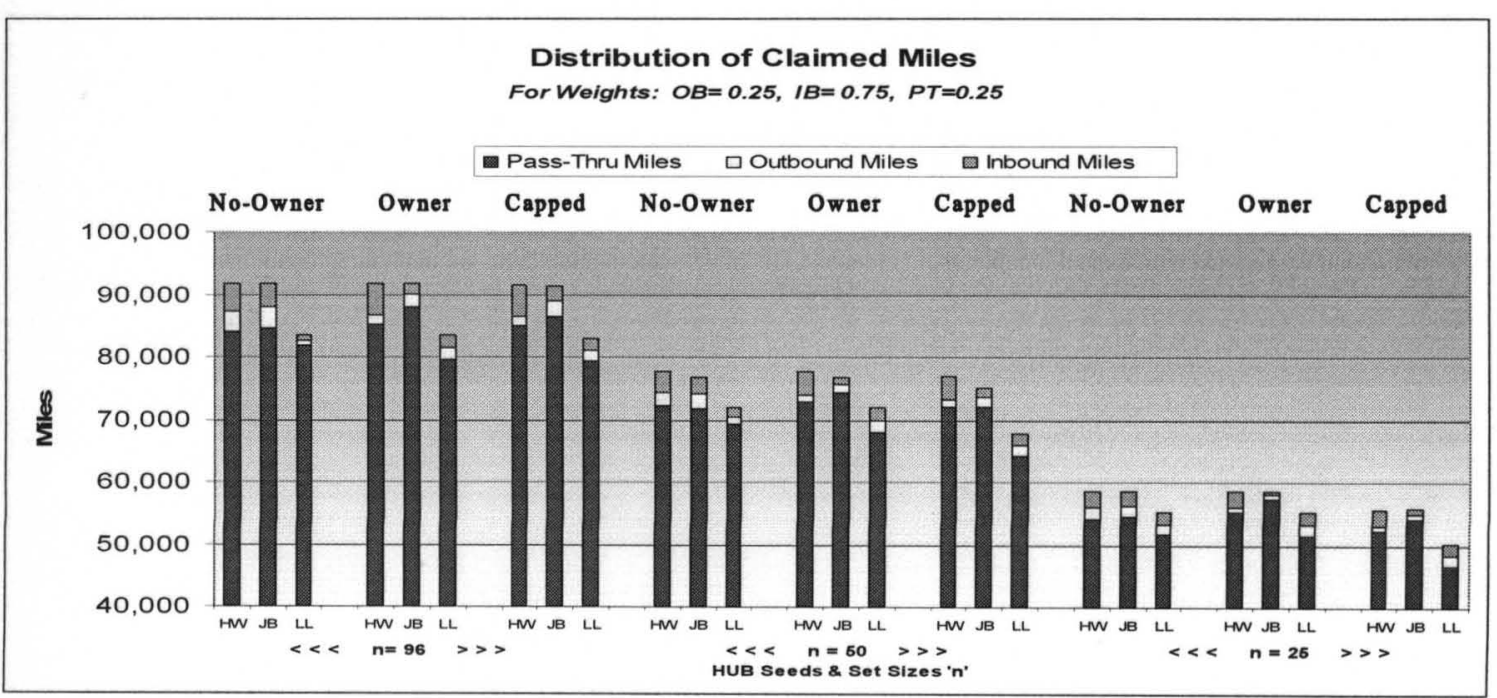




\begin{tabular}{|c|c|c|c|c|c|c|c|c|c|c|c|}
\hline \multirow{3}{*}{\begin{tabular}{|c} 
Data \\
$\frac{\text { Weights: }}{\mathrm{OB:} 0.25}$
\end{tabular}} & \multirow[t]{2}{*}{ Type } & \multirow[t]{2}{*}{ Size } & \multirow[t]{3}{*}{$\mathrm{OB}$} & \multirow[t]{3}{*}{ IB } & \multirow[t]{3}{*}{ PT } & \multicolumn{2}{|c|}{ Outbound Miles } & \multicolumn{2}{|c|}{ Inbound Miles } & \multicolumn{2}{|c|}{ Pass Thru Miles } \\
\hline & & & & & & \multirow[t]{2}{*}{ Mean } & \multirow[t]{2}{*}{ Var } & \multirow[t]{2}{*}{ Mean } & \multirow[t]{2}{*}{$\underline{\text { Var }}$} & \multirow[t]{2}{*}{ Mean } & \multirow{2}{*}{ Var } \\
\hline & 0.75 PT: & & & & & & & & & & \\
\hline $\mathrm{HW}$ & No-Owner & 96 & 0.25 & 0.75 & 0.75 & 636.36 & $15,983.498$ & $3,599.43$ & $316,099.783$ & 87,591.17 & $243,001,787.242$ \\
\hline JB & $\mathrm{No}-\mathrm{O}$ nner & 96 & 0.25 & 0.75 & 0.75 & $3,501.41$ & $339,854.896$ & $3,744.18$ & $37,654.211$ & $84,591.58$ & $208,181,046.447$ \\
\hline Ш & $\mathrm{Nb}-\mathrm{O}$ ner & 96 & 0.25 & 0.75 & 0.75 & 727.13 & $16,535.816$ & 897.12 & $18,027.182$ & $81,847.58$ & $242,065,340.447$ \\
\hline $\mathrm{HW}$ & Owner & 96 & 0.25 & 0.75 & 0.75 & 10.22 & 29.269 & $1,961.81$ & $361,433.301$ & $89,854.92$ & $203,27,293,720$ \\
\hline JB & Owner & 96 & 0.25 & 0.75 & 0.75 & $1,945.12$ & $148,358.009$ & 1,78254 & $139,915,202$ & $88,109.50$ & $197,923,248.273$ \\
\hline Ш & Ouner & 96 & 0.25 & 0.75 & 0.75 & $1,793.42$ & $152,189.629$ & $1,981.07$ & $144,744.070$ & $79,697.33$ & $176,475,290.061$ \\
\hline$\overline{H W}$ & Capped & 96 & 0.25 & 0.75 & 0.75 & 9.66 & 27.657 & $1,975.54$ & $382,829.117$ & $89,685.17$ & $192,371,024.697$ \\
\hline $\mathrm{JB}$ & Capped & 96 & 0.25 & 0.75 & 0.75 & $2,517.41$ & $361,003.246$ & $2,333.60$ & $229,999.634$ & $86,518.08$ & $172,436,632083$ \\
\hline Ш & Capped & 96 & 0.25 & 0.75 & 0.75 & $1,707.03$ & $138,667.685$ & $1,862.90$ & $120,628.428$ & $79,382.00$ & $171,258,398.727$ \\
\hline $\mathrm{HW}$ & No-Owner & 50 & 0.25 & 0.75 & 0.75 & 540.52 & $14,424.375$ & $2,585.14$ & $163,049.266$ & $74,687.00$ & $183,050,061.273$ \\
\hline $\mathrm{JB}$ & $\mathrm{No}-\mathrm{O}$ ner & 50 & 0.25 & 0.75 & 0.75 & $2,289.29$ & $152,555.479$ & $2,626.35$ & $167,191.027$ & $71,861.00$ & $154,802,710.909$ \\
\hline$\amalg$ & $\mathrm{Nb}-\mathrm{O} n \mathrm{ner}$ & 50 & 0.25 & 0.75 & 0.75 & $1,114.57$ & $41,028.540$ & $1,420.95$ & $46,248.452$ & $69,342.17$ & $172,390,864.515$ \\
\hline $\mathrm{HW}$ & Owner & 50 & 0.25 & 0.75 & 0.75 & 3.65 & 10.342 & $1,328.76$ & $237,567.807$ & $76,480.17$ & $150,722,417.061$ \\
\hline JB & Owner & 50 & 0.25 & 0.75 & 0.75 & $1,329.27$ & $110,001.595$ & 1,110.19 & $101,416.633$ & $74,337.25$ & $146,316,017.114$ \\
\hline$\amalg$ & Ouner & 50 & 0.25 & 0.75 & 0.75 & $1,787.17$ & 149,912250 & 1,975.99: & $143,796.992$ & $68,114.58$ & $131,237,184.265$ \\
\hline $\mathrm{HW}$ & Capped & 50 & 0.25 & 0.75 & 0.75 & 3.09 & 16.229 & $1,337.71$ & $248,577.851$ & $75,724.33 !$ & $123,949,796,606$ \\
\hline $\mathrm{JB}$ & Capped & 50 & 0.25 & 0.75 & 0.75 & $1,629.95$ & $148,103.771$ & $1,377.56$ & $78,974.602$ & $72,085.25$ & $109,900,379.295$ \\
\hline & Capped & 50 & 0.25 & 0.75 & 0.75 & $1,700.78$ & $136,528.720$ & $1,857.82$ & $119,861.041$ & $64,364.83$ & $96,368,959.738$ \\
\hline $\mathrm{HW}$ & $\mathrm{Nb}-\mathrm{O}$ ner & 25 & 0.25 & 0.75 & 0.75 & 458.13 & $10,624.124$ & $2,304.24 !$ & $145,813.485$ & $55,911.58$ & $108,194,502811$ \\
\hline $\mathrm{JB}$ & No-Owner & 25 & 0.25 & 0.75 & 0.75 & $1,852.49$ & $133,887.710$ & 2,390.31! & $149,564.594$ & $54,500.83$ & $97,145,189.738$ \\
\hline Ш & No-Owner & 25 & 0.25 & 0.75 & 0.75 & $1,521.57$ & $74,124.595$ & 1,972.70 & $105,185.283$ & $51,782.33$ & $99,344,684.242$ \\
\hline$\overline{H W}$ & Owner & 25 & 0.25 & 0.75 & 0.75 & 226 & 4.999 & 908.10 & $94,155.059$ & $57,763.67$ & $96,525,619.879$ \\
\hline $\mathrm{JB}$ & Ouner & 25 & 0.25 & 0.75 & 0.75 & 645.65 & $63,379.917$ & 639.87 & 55,412486 & $57,458.17$ & $98,238,951.061$ \\
\hline Ш & Ouner & 25 & 0.25 & 0.75 & 0.75 & $1,720.92$ & $138,941.400$ & 1,940.06! & $140,146.044$ & 51,615.58: & $77,421,553.902$ \\
\hline $\mathrm{HW}$ & Capped & 25 & 0.25 & 0.75 & 0.75 & 1.36 & 6.581 & 900.54 & $107,434.187$ & $54,728.83 !$ & $47,406,092152$ \\
\hline $\mathrm{JB}$ & Capped & 25 & 0.25 & 0.75 & 0.75 & 915.21 & $87,644.639$ & 850.34 & $52,026.271$ & $54,117.50$ & $50,283,371.909$ \\
\hline Ш & Capped & 25 & 0.25 & 0.75 & 0.75 & $1,627.68$ & $119,076.809$ & $1,814.64$ & $109,391.434$ & $46,779.17$ & $33,155,430.333$ \\
\hline
\end{tabular}

Table 4-25 - Mile Ownership \#4

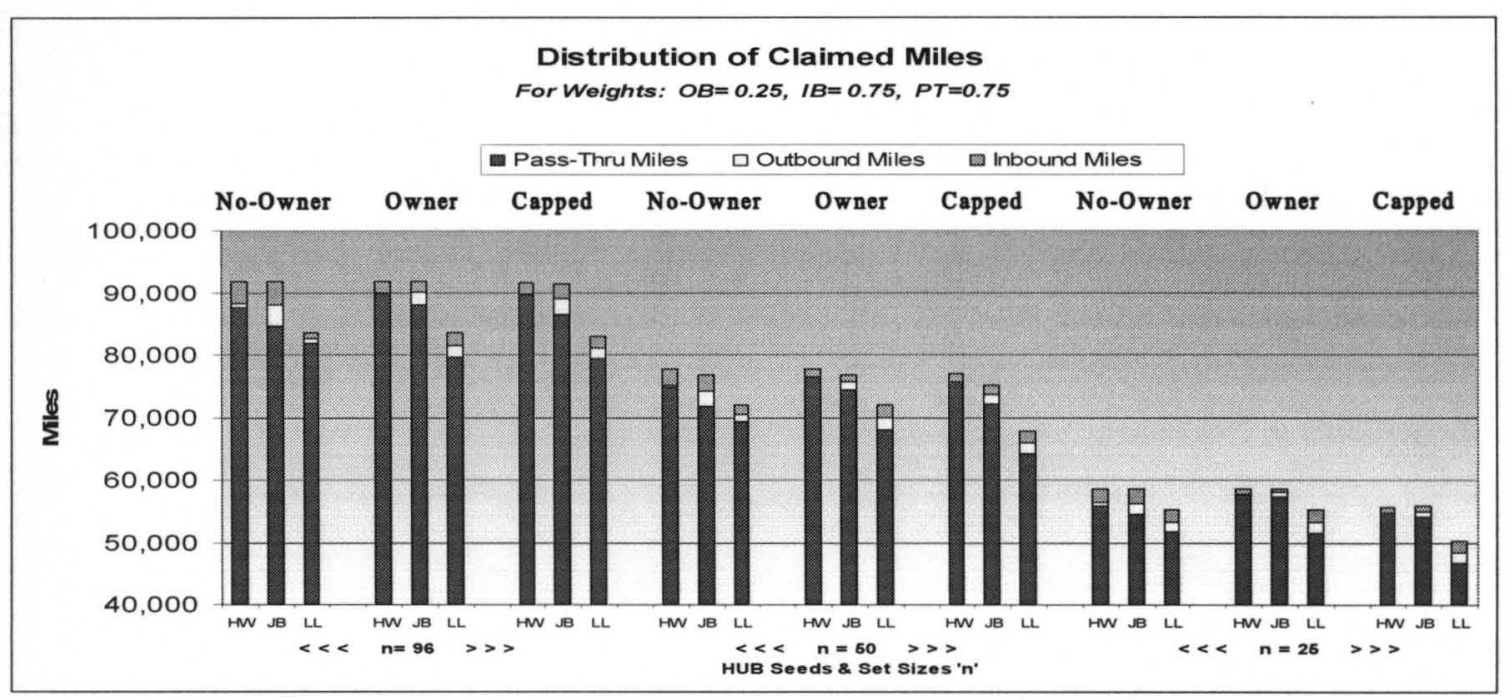




\begin{tabular}{|c|c|c|c|c|c|c|c|c|c|c|c|}
\hline \multirow{3}{*}{$\begin{array}{c}\text { Data } \\
\frac{\text { Weights: }}{\text { OB: } 0.75}\end{array}$} & \multirow[t]{2}{*}{ Type } & \multirow[t]{2}{*}{ Size } & \multirow[t]{3}{*}{$\mathrm{OB}$} & \multirow[t]{3}{*}{ IB } & \multirow[t]{3}{*}{ PT } & \multicolumn{2}{|c|}{ Outbound Miles } & \multicolumn{2}{|c|}{ Inbound Miles } & \multicolumn{2}{|c|}{ Pass Thru Miles } \\
\hline & & & & & & \multirow[t]{2}{*}{ Mean } & \multirow[t]{2}{*}{$\underline{\text { Var }}$} & \multirow[t]{2}{*}{ Mean } & \multirow[t]{2}{*}{$\underline{\text { Var }}$} & \multirow[t]{2}{*}{ Mean : } & \multirow[t]{2}{*}{$\underline{\text { Var }}$} \\
\hline & (1) & & & & & & & & & & \\
\hline HW & No-Owner & 96 & 0.75 & 0.25 & 0.25 & $4,320.28$ & $448,231.061$ & $3,615.79$ & $317,286.480$ & $83,901.08$ & $226,398,366,629$ \\
\hline JB & No-Owner & 96 & 0.75 & 0.25 & 0.25 & $3,501.41$ & $339,854.896$ & 3,744.18: & $37,654.211$ & $84,591.58$ & $208,181,046,447$ \\
\hline$\amalg$ & No-Ouner & 96 & 0.75 & 0.25 & 0.25 & 727.13 & $16,535.816$ & 897.12 & 18,027.182 & $81,847.58$ & $242,065,340.447$ \\
\hline HW & Ouner & 96 & 0.75 & 0.25 & 0.25 & $5,245.01$ & $1,407,969.995$ & $1,463.46 !$ & $228,511.542$ & 85,128.33! & 189,809,313.333 \\
\hline$J B$ & Ouner & 96 & 0.75 & 0.25 & 0.25 & $1,945.12$ & $148,358.089$ & $1,782.54$ & 139,915:202 & $88,109.50$ & $197,923,248.273$ \\
\hline Ш & Ouner & 96 & 0.75 & 0.25 & 0.25 & $1,793.42$ & $152,189.629$ & $1,981.07$ & $144,744.070$ & $79,697.33$ & $176,475,290.061$ \\
\hline $\mathrm{HW}$ & Capped & 96 & 0.75 & 0.25 & 0.25 & $5,430.87$ & $1,716,303.954$ & $1,495.69 !$ & $280,971.025$ & $84,762.83 !$ & $172,679,010.152$ \\
\hline $\mathrm{JB}$ & Capped & 96 & 0.75 & 0.25 & 0.25 & $2,517.41$ & $361,093.246$ & $2,333.60$ & $229,999.634$ & $86,518.08$ & $172,436,632083$ \\
\hline$\amalg$ & Capped & 96 & 0.75 & 0.25 & 0.25 & $1,707.03$ & $138,667.685$ & $1,862.90$ & $120,628.428$ & $79,382.00$ & $171,258,308.727$ \\
\hline HW & No-Owner & 50 & 0.75 & 0.25 & 0.25 & $2,869.37$ & $256,787.232$ & $2,595.54$ & 162,996.395 & $72,236.83 !$ & $173,097,055.242$ \\
\hline$J B$ & No-Owner & 50 & 0.75 & 0.25 & 0.25 & $2,289.29$ & $152,555.479$ & 2,626.35: & $167,191.027$ & $71,861.00 !$ & $154,802,710.909$ \\
\hline$\amalg$ & No-Ouner & 50 & 0.75 & 0.25 & 0.25 & $1,114.57$ & $41,028.540$ & $1,420.95 i$ & $46,248.452$ & $69,342.17$ & $172,390,864.515$ \\
\hline $\mathrm{HW}$ & Ouner & 50 & 0.75 & 0.25 & 0.25 & $3,698.61$ & $891,453.512$ & $1,005.01 !$ & 148,999.633 & $72,998.08 !$ & $143,104,169.538$ \\
\hline JB & Owner & 50 & 0.75 & 0.25 & 0.25 & $1,329.27$ & $110,001.595$ & $1,110.19$ & 101,416.633 & $74,337.25$ & $146,316,017.114$ \\
\hline Ш & Ouner & 50 & 0.75 & 0.25 & 0.25 & $1,787.17$ & 149,912250 & $1,975.99$ & $143,796.992$ & $68,114.58$ & $131,237,184.265$ \\
\hline $\mathrm{HW}$ & Capped & 50 & 0.75 & 0.25 & 0.25 & $3,840.24$ & $1,087,060.349$ & $1,024.36$ & $189,059.897$ & $72,098.75$ & $113,485,818.932$ \\
\hline $\mathrm{JB}$ & Capped & 50 & 0.75 & 0.25 & 0.25 & $1,629.95$ & $148,103.771$ & $1,377.56 !$ & $78,974.602$ & $72,085.25$ & $109,900,379.295$ \\
\hline Ш & Capped & 50 & 0.75 & 0.25 & 0.25 & $1,700.78$ & $136,528.720$ & $1,857.82$ & $119,861.041$ & $64,364.83:$ & $96,368,969.788$ \\
\hline HW & -Ouner & 25 & 0.75 & 0.25 & 0.25 & $2,255.82$ & $159,228.746$ & $2,316.28 !$ & $146,470.608$ & $54,168.00 !$ & $102,872,310.727$ \\
\hline $\mathrm{JB}$ & $\mathrm{No}$-Owner & 25 & 0.75 & 0.25 & 0.25 & $1,852.49$ & $133,887.710$ & $2,390.31$ & $149,564.594$ & $54,500.83$ & $97,145,189.788$ \\
\hline$\amalg$ & No-Ouner & 25 & 0.75 & 0.25 & 0.25 & $1,521.57$ & $74,124.595$ & $1,972.70$ & $105,185.283$ & $51,782.33$ & $99,344,684.242$ \\
\hline $\mathrm{HW}$ & Ouner & 25 & 0.75 & 0.25 & 0.25 & $2,599.18$ & 463,492141 & 735.88 & $58,825.543$ & $55,404.83$ & $94,018,977.970$ \\
\hline$J B$ & Ouner & 25 & 0.75 & 0.25 & 0.25 & 645.65 & $63,379.917$ & $639.87 !$ & 55,412486 & 57,458.17! & $98,238,951.061$ \\
\hline$\amalg$ & Ouner & 25 & 0.75 & 0.25 & 0.25 & $1,720.92$ & $138,941.400$ & 1,940.06! & $140,146.044$ & 51,615.58: & $7,421,553.902$ \\
\hline HW & Capped & 25 & 0.75 & 0.25 & 0.25 & $2,670.74$ & $601,225.189$ & 738.25 & $90,145.979$ & $52,262.08 !$ & $44,944,716.629$ \\
\hline $\mathrm{JB}$ & Capped & 25 & 0.75 & 0.25 & 0.25 & 915.21 & $87,644.639$ & $850.34 !$ & $52,026.271$ & 54,117.50! & $50,283,371.909$ \\
\hline$\amalg$ & Capped & 25 & 0.75 & 0.25 & 0.25 & $1,627.68$ & $119,076.809$ & $1,814.64$ & $100,391.434$ & $46,779.17$ & $33,155,430.333$ \\
\hline
\end{tabular}

Table 4-26 - Mile Ownership \#5

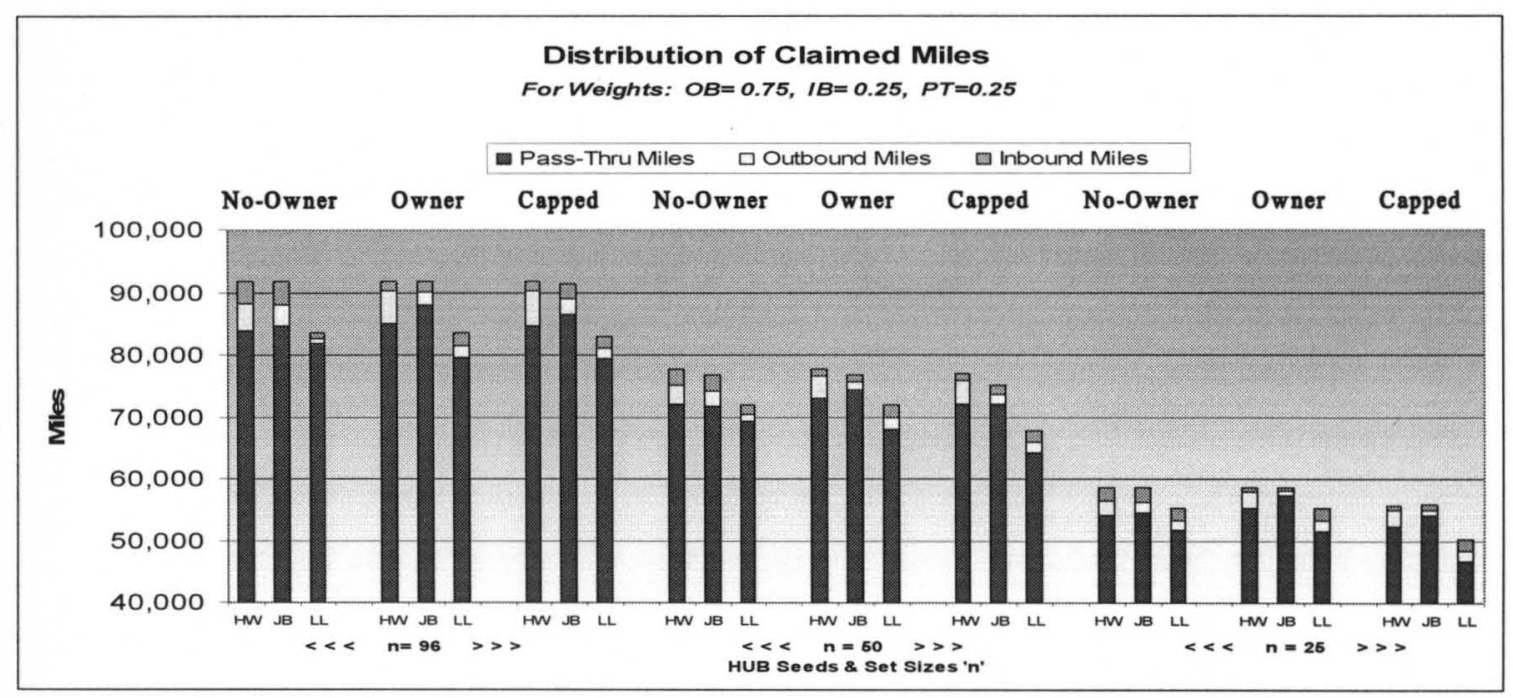




\begin{tabular}{|c|c|c|c|c|c|c|c|c|c|c|c|}
\hline \multirow{3}{*}{$\frac{\text { Data }}{\frac{\text { Weichts: }}{\text { WB: } 0.75}}$} & \multirow[t]{2}{*}{ Type } & \multirow[t]{2}{*}{ Size } & \multirow[t]{3}{*}{$\mathrm{OB}$} & \multirow[t]{3}{*}{ IB } & \multirow[t]{3}{*}{ PT } & \multicolumn{2}{|c|}{ Outbound Miles } & \multicolumn{2}{|c|}{ Inbound Miles } & \multicolumn{2}{|c|}{ Pass Thru Miles } \\
\hline & & & & & & \multirow[t]{2}{*}{ Mean } & \multirow[t]{2}{*}{ Var } & \multirow[t]{2}{*}{ Mean } & \multirow[t]{2}{*}{$\underline{\text { Var }}$} & \multirow[t]{2}{*}{ Mean } & \multirow[t]{2}{*}{ Var } \\
\hline & 5 PT: & & & & & & & & & & \\
\hline $\mathrm{HW}$ & No-Ouner & 96 & 0.75 & 0.25 & 0.75 & $3,253.86$ & $275,282,301$ & 922.22 & $30,178.237$ & $87,658.92$ & $242,879,145.174$ \\
\hline $\mathrm{JB}$ & $\mathrm{No}-\mathrm{O}$ ner & 96 & 0.75 & 0.25 & 0.75 & $3,501.41$ & $339,854.896$ & 3,744.18! & $37,654.211$ & $84,591.58$ & $208,181,046,447$ \\
\hline Ш & $\mathrm{Nb}$-Owner & 96 & 0.75 & 0.25 & 0.75 & 727.13 & $16,535.816$ & 897.12 & 18,027.182 & $81,847.58$ & $242,065,340,447$ \\
\hline $\mathrm{HW}$ & Ouner & 96 & 0.75 & 0.25 & 0.75 & $1,978.51$ & $327,164.571$ & 1286 & 42353 & $89,843.58$ & $203,017,359.720$ \\
\hline $\mathrm{JB}$ & Owner & 96 & 0.75 & 0.25 & 0.75 & $1,945.12$ & $148,358.009$ & $1,782.54$ & $139,915.202$ & $88,109.50$ & $197,923,248.273$ \\
\hline Ш & Owner & 96 & 0.75 & 0.25 & 0.75 & $1,793.42$ & $152,189.629$ & 1,981.07i & $144,744.070$ & $79,697.33$ & $176,475,290.061$ \\
\hline HW & Capped & 96 & 0.75 & 0.25 & 0.75 & $2,031.21$ & $385,008.603$ & 8.31 & 14.335 & $89,642.17 !$ & 191,989, 163.970 \\
\hline $\mathrm{JB}$ & Capped & 96 & 0.75 & 0.25 & 0.75 & $2,517.41$ & $361,093.246$ & $2,333.60$ & $229,999.634$ & $86,518.08$ & $172,436,632063$ \\
\hline Ш & Capped & 96 & 0.75 & 0.25 & 0.75 & $1,707.03$ & $138,667.685$ & 1,862.90: & $120,628.428$ & $79,382.00$ & $171,258,398.727$ \\
\hline HW & $\mathrm{Nb}-\mathrm{O}$ ner & 50 & 0.75 & 0.25 & 0.75 & $2,156.26$ & $157,546.596$ & 849.12 & $32,317.442$ & $74,801.00$ & $182,768,304.000$ \\
\hline $\mathrm{JB}$ & $\mathrm{Nb}-\mathrm{O}$ ner & 50 & 0.75 & 0.25 & 0.75 & $2,289.29$ & $152,5554,49$ & $2,626.35$ & $167,191.027$ & $71,861.00$ & $154,802,710.909$ \\
\hline Ш & $\mathrm{Nb}-\mathrm{O}$ ner & 50 & 0.75 & 0.25 & 0.75 & $1,114.57$ & $41,028.540$ & $1,420.95$ & $46,248.452$ & $69,342.17$ & $172,390,864.515$ \\
\hline $\mathrm{HW}$ & Owner & 50 & 0.75 & 0.25 & 0.75 & $1,441.02$ & $204,149.408$ & 8.34 & 24.157 & $76,357.00 !$ & $150,732,237.636$ \\
\hline $\mathrm{JB}$ & Owner & 50 & 0.75 & 0.25 & 0.75 & $1,329.27$ & $110,001.595$ & 1,110.19: & 101,416..63 & 74,337.25! & $146,316,017.114$ \\
\hline$\amalg$ & Ouner & 50 & 0.75 & 0.25 & 0.75 & $1,787.17$ & 149,912250 & $1,975.99$ & $143,796.992$ & $68,114.58$ & $131,237,184.265$ \\
\hline $\mathrm{HW}$ & apped & 50 & 0.75 & 0.25 & 0.75 & $1,485.54$ & $238,949.684$ & 3.79 & 6701 & $75,589.00 ;$ & $124,582,701.091$ \\
\hline $\mathrm{JB}$ & Capped & 50 & 0.75 & 0.25 & 0.75 & 1,629.95 & $148,103.771$ & $1,377.56$ & $78,974.602$ & $72,085.25 !$ & $109,900,379.295$ \\
\hline Ш & Capped & 50 & 0.75 & 0.25 & 0.75 & $1,700.78$ & $136,528.720$ & $1,857.82$ & $119,861.041$ & $64,364.83$ & $96,368,969.788$ \\
\hline HW & -Owner & 25 & 0.75 & 0.25 & 0.75 & 1,797.62 & $113,596.008$ & 785.50 & $33,130.658$ & $56,117.75$ & $108,383,349.477$ \\
\hline$J B$ & $\mathrm{Nb}-\mathrm{O}$ ner & 25 & 0.75 & 0.25 & 0.75 & $1,852.49$ & $133,887.710$ & 2,390.31 & $149,564.594$ & $54,500.83$ & $97,145,189.788$ \\
\hline Ш & $\mathrm{No}-\mathrm{O}$ ner & 25 & 0.75 & 0.25 & 0.75 & $1,521.57$ & $74,124.595$ & $1,972.70 !$ & $105,185.283$ & 51,782.33i & $99,344,684.242$ \\
\hline HW & Owner & 25 & 0.75 & 0.25 & 0.75 & $1,004.21$ & 126,232910 & 6.84 & 28.115 & 57,689.75! & $95,839,010.386$ \\
\hline $\mathrm{JB}$ & Ouner & 25 & 0.75 & 0.25 & 0.75 & 645.65 & $63,379.917$ & 639.87 & 55,412486 & 57,458.17! & $98,238,951.061$ \\
\hline せ & Ouner & 25 & 0.75 & 0.25 & 0.75 & $1,720.92$ & $138,941.400$ & $1,940.06 !$ & $140,146.044$ & 51,615.58: & $77,421,553.902$ \\
\hline $\mathrm{HW}$ & Capped & 25 & 0.75 & 0.25 & 0.75 & $1,028.57$ & $156,266.939$ & 1.78 & 4.128 & $54,629.42$ & $47,244,434,447$ \\
\hline $\mathrm{JB}$ & Capped & 25 & 0.75 & 0.25 & 0.75 & 915.21 & $87,644.639$ & 850.34 & $52,026.271$ & $54,117.50$ & $50,283,371.909$ \\
\hline Ш & Capped & 25 & 0.75 & 0.25 & 0.75 & $1,627.68$ & $119,076.809$ & $1,814.64$ & $109,391.434$ & $46,779.17$ & $33,155,430.333$ \\
\hline
\end{tabular}

Table 4-27 - Mile Ownership \#6

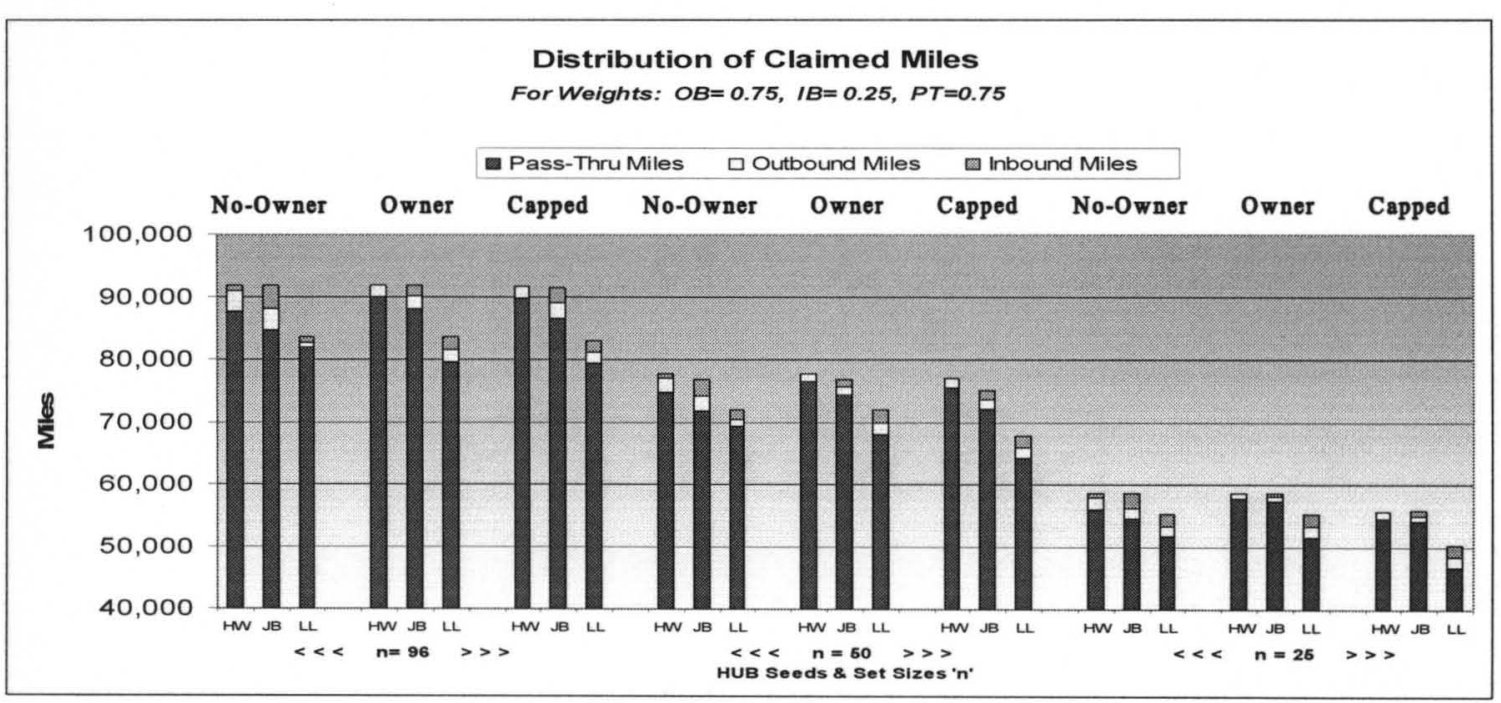




\begin{tabular}{|c|c|c|c|c|c|c|c|c|c|c|c|}
\hline \multirow{3}{*}{$\begin{array}{c}\text { Data } \\
\frac{\text { Weights: }}{\text { OB: } 0.75}\end{array}$} & \multirow[t]{2}{*}{ Type } & \multirow[t]{2}{*}{ Size } & \multirow[t]{3}{*}{$\mathrm{OB}$} & \multirow[t]{3}{*}{ IB } & \multirow[t]{3}{*}{ PT } & \multicolumn{2}{|c|}{ Outbound Miles } & \multicolumn{2}{|c|}{ Inbound Miles } & \multicolumn{2}{|c|}{ Pass Thru Miles } \\
\hline & & & & & & \multirow[t]{2}{*}{ Mean } & \multirow[t]{2}{*}{$\underline{\text { Var }}$} & \multirow[t]{2}{*}{ Mean } & \multirow[t]{2}{*}{$\underline{\text { Var }}$} & \multirow{2}{*}{ Mean } & \multirow[t]{2}{*}{$\underline{\text { Var }}$} \\
\hline & F & & & & & & & & & & \\
\hline$\overline{\mathrm{HW}}$ & No-Ouner & $\overline{96}$ & 0.75 & 0.75 & 0.25 & $4,320.46$ & $448,265.986$ & $4,494.63$ & $445,739.158$ & 83,017.33! & $223,364,527.515$ \\
\hline$J B$ & No-Ouner & 96 & 0.75 & 0.75 & 0.25 & $3,501.41$ & $339,854.896$ & $3,744.18$ & $37,654.211$ & $84,591.58$ & $208,181,046.447$ \\
\hline Ш & $\mathrm{No}-\mathrm{O}$ nner & 96 & 0.75 & 0.75 & 0.25 & 727.13 & $16,535.816$ & 897.12 & $18,027.182$ & $81,847.58$ & $242,065,340.447$ \\
\hline $\mathrm{HW}$ & Ouner & 96 & 0.75 & 0.75 & 0.25 & 4,131.12 & $992,137.390$ & $4,275.75$ & $1,079,267.599$ & 83,425.67! & $184,908,341.515$ \\
\hline $\mathrm{JB}$ & Ouner & 96 & 0.75 & 0.75 & 0.25 & $1,945.12$ & $148,358.089$ & $1,782.54$ & 139,915:202 & $88,109.50$ & $197,923,248.273$ \\
\hline$\amalg$ & Ouner & 96 & 0.75 & 0.75 & 0.25 & $1,793.42$ & $152,189.629$ & $1,981.07$ & $144,744.070$ & $79,697.33$ & $176,475,200.061$ \\
\hline $\mathrm{HW}$ & Capped & 96 & 0.75 & 0.75 & 0.25 & 4,336.22 & $1,333,578.431$ & 4,272.91 & $1,033,641.674$ & 83,069.75! & $168,518,773.659$ \\
\hline $\mathrm{JB}$ & Capped & 96 & 0.75 & 0.75 & 0.25 & $2,517.41$ & $361,093.246$ & $2,333.60$ & $229,999.634$ & $86,518.08$ & $172,436,632083$ \\
\hline$\amalg$ & Capped & 96 & 0.75 & 0.75 & 0.25 & $1,707.03$ & $138,667.685$ & $1,862.90$ & $120,628.428$ & $79,382.00$ & $171,258,398.727$ \\
\hline $\mathrm{HW}$ & $\mathrm{Na}-\mathrm{O}$ nner & 50 & 0.75 & 0.75 & 0.25 & $2,873.44$ & $256,514.222$ & $3,287.12$ & $238,745,390$ & $71,644.50$ & $171,358,226.091$ \\
\hline $\mathrm{JB}$ & $\mathrm{No}-\mathrm{O}$ ner & 50 & 0.75 & 0.75 & 0.25 & $2,289.29$ & $152,555.479$ & $2,626.35$ & $167,191.027$ & $71,861.00$ & $154,802,710.900$ \\
\hline Ш & $\mathrm{No}$-Owner & 50 & 0.75 & 0.75 & 0.25 & $1,114.57$ & $41,028.540$ & 1,420.95: & $46,248.452$ & $69,342.17$ & $172,390,864.515$ \\
\hline $\mathrm{HW}$ & Onner & 50 & 0.75 & 0.75 & 0.25 & $3,092.87$ & $707,043.245$ & $3,133.47$ & $625,474.095$ & 71,578.58! & $139,931,807.174$ \\
\hline $\mathrm{JB}$ & Ouner & 50 & 0.75 & 0.75 & 0.25 & $1,329.27$ & $110,001.595$ & 1,110.19 & 101,416.633 & $74,337.25 !$ & $146,316,017.114$ \\
\hline Ш & Onner & 50 & 0.75 & 0.75 & 0.25 & $1,787.17$ & 149,912250 & $1,975.99$ & $143,796.992$ & $68,114.58$ & $131,237,184.265$ \\
\hline $\mathrm{HW}$ & Capped & 50 & 0.75 & 0.75 & 0.25 & $3,241.71$ & $927,103.951$ & $3,112.32$ & $561,816.848$ & $70,687.42$ & $110,851,790.992$ \\
\hline $\mathrm{JB}$ & Capped & 50 & 0.75 & 0.75 & 0.25 & $1,629.95$ & $148,103.771$ & $1,377.56$ & $78,974.602$ & $72,085.25 !$ & $109,900,379.295$ \\
\hline Ш & Capped & 50 & 0.75 & 0.75 & 0.25 & $1,700.78$ & $136,528.720$ & $1,857.82$ & $119,861.041$ & $64,364.83$ & $96,368,959.788$ \\
\hline $\mathrm{HW}$ & $\mathrm{No}$-Owner & 25 & 0.75 & 0.75 & 0.25 & $2,256.93$ & $159,387.716$ & $2,699.71$ & $169,364.663$ & $53,806.75 !$ & $102,318,174.386$ \\
\hline $\mathrm{JB}$ & $\mathrm{Na}-\mathrm{O}$ ner & 25 & 0.75 & 0.75 & 0.25 & $1,852.49$ & $133,887.710$ & $2,390.31$ & $149,564.594$ & $54,500.83$ & $97,145,189.788$ \\
\hline せ & No-Owner & 25 & 0.75 & 0.75 & 0.25 & $1,521.57$ & $74,124.595$ & $1,972.70$ & $105,185,283$ & $51,782.33$ & $99,344,684.242$ \\
\hline $\mathrm{HW}$ & Onner & 25 & 0.75 & 0.75 & 0.25 & $2,154.25$ & $382,659.166$ & $2,202.30$ & 295,825841 & $54,406.75$ & $92,980,473.659$ \\
\hline $\mathrm{JB}$ & Owner & 25 & 0.75 & 0.75 & 0.25 & 645.65 & $63,379.917$ & 639.87 & 55,412486 & 57,458.17 & $98,238,951.061$ \\
\hline せ & Onner & 25 & 0.75 & 0.75 & 0.25 & $1,720.92$ & $138,941.400$ & 1,940.06: & $140,146.044$ & $51,615.58$ & $77,421,553.902$ \\
\hline $\mathrm{HW}$ & Capped & 25 & 0.75 & 0.75 & 0.25 & 2,247.86 & $535,767.242$ & 2,127.91 & 263,695274 & $51,263.50$ & $44,177,074.636$ \\
\hline $\mathrm{JB}$ & Capped & 25 & 0.75 & 0.75 & 0.25 & 915.21 & $87,644.639$ & 850.34 & $52,026.271$ & $54,117.50$ & $50,283,371.909$ \\
\hline Ш & Capped & 25 & 0.75 & 0.75 & 0.25 & $1,627.68$ & $119,076.809$ & 1,814.64i & $109,391.434$ & $46,779.17$ & $33,155,430.333$ \\
\hline
\end{tabular}

Table 4-28 - Mile Ownership \#7

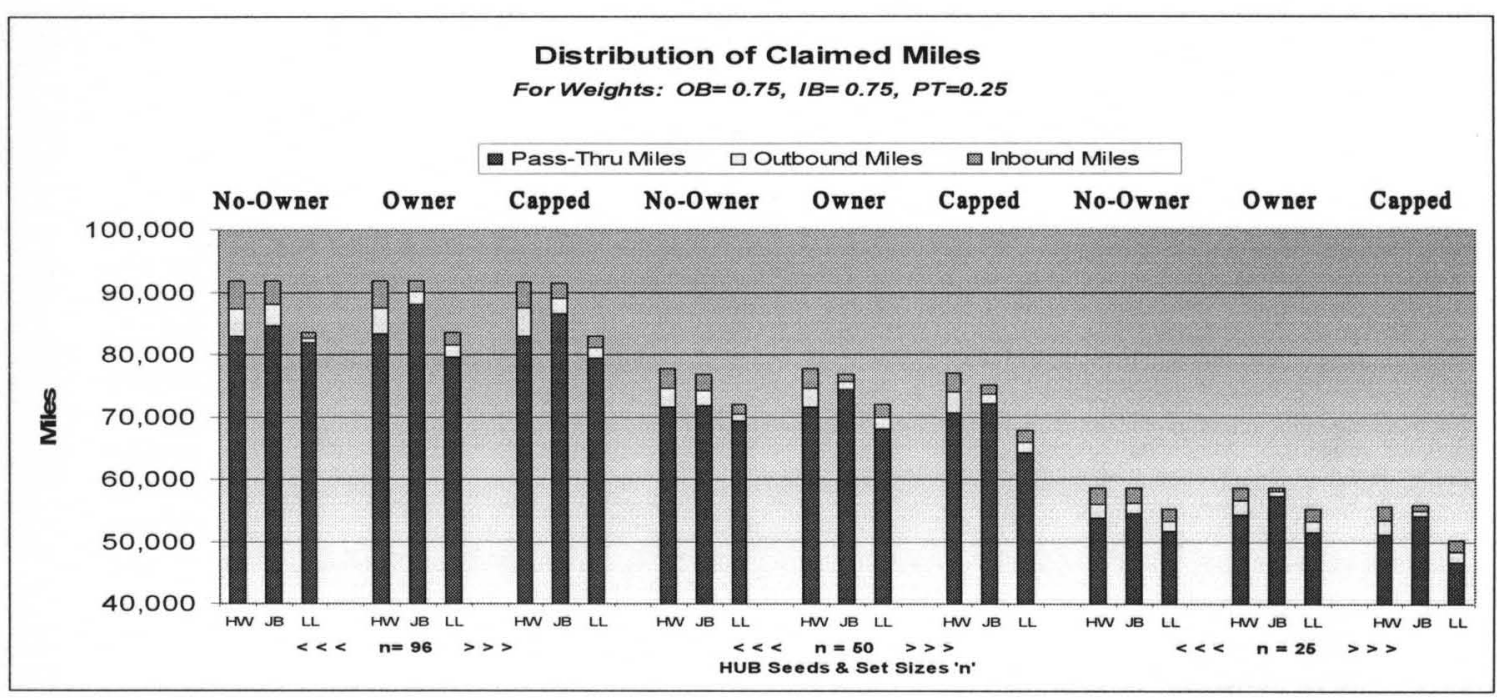




\begin{tabular}{|c|c|c|c|c|c|c|c|c|c|c|c|}
\hline \multirow{3}{*}{$\begin{array}{c}\text { Data } \\
\frac{\text { Weichts: }}{\mathrm{OB} \cdot 0.75}\end{array}$} & \multirow[t]{2}{*}{ Type } & \multirow[t]{2}{*}{ Size } & \multirow[t]{2}{*}{$\mathrm{OB}$} & \multirow[t]{2}{*}{ IB } & \multirow[t]{2}{*}{ PT } & \multicolumn{2}{|c|}{ Outbound Miles } & \multicolumn{2}{|c|}{ Inbound Miles } & \multicolumn{2}{|c|}{ Pass Thru Miles } \\
\hline & & & & & & \multirow[t]{2}{*}{ Mean } & \multirow[t]{2}{*}{ Var } & \multirow[t]{2}{*}{ Mean } & \multirow[t]{2}{*}{ Var } & \multirow[t]{2}{*}{ Mean } & \multirow[t]{2}{*}{$\underline{\text { Var }}$} \\
\hline & & & & & & & & & & & \\
\hline HW & No-Ouner & 96 & 0.75 & 0.75 & 0.75 & $3,253.79$ & 27,272690 & $3,599.75$ & $316,157.799$ & $84,983.58$ & $230,751,441.902$ \\
\hline $\mathrm{JB}$ & No-Ouner & 96 & 0.75 & 0.75 & 0.75 & $3,501.41$ & $339,854.896$ & $3,744.18$ & $37,654.211$ & $84,591.58$ & $208,181,046.447$ \\
\hline$\Perp$ & No-Ouner & 96 & 0.75 & 0.75 & 0.75 & 727.13 & 16,535816 & 897.12 & $18,027.182$ & $81,847.58$ & $242,065,340.447$ \\
\hline HW & Owner & 96 & 0.75 & 0.75 & 0.75 & $1,807.75$ & $273,904.124$ & $1,806.69$ & $341,783.278$ & 88,22267! & $196,794,864.242$ \\
\hline $\mathrm{JB}$ & Ouner & 96 & 0.75 & 0.75 & 0.75 & 1,945.12 & 148,358089 & $1,782.54$ & 139,915:202 & $88,109.50$ & $197,923,248.273$ \\
\hline Ш & Ouner & 96 & 0.75 & 0.75 & 0.75 & $1,793.42$ & $152,189.629$ & 1,981.07: & $144,744.070$ & $79,697.33$ & $176,475,200.061$ \\
\hline $\mathrm{HW}$ & Capped & 96 & 0.75 & 0.75 & 0.75 & $1,858.98$ & $317,307.976$ & $1,837.78 !$ & 385,052140 & $87,981.08$ & $183,605,070.447$ \\
\hline$J B$ & Capped & 96 & 0.75 & 0.75 & 0.75 & $2,517.41$ & 361,093246 & $2,333.60$ & $229,999.634$ & $86,518.08$ & $172,436,632083$ \\
\hline Ш & Capped & 96 & 0.75 & 0.75 & 0.75 & $1,707.03$ & 138,667.685 & $1,862.90$ & $120,628.428$ & 79,38200 & $171,258,396.727$ \\
\hline HW & $\mathrm{No}$-Ouner & 50 & 0.75 & 0.75 & 0.75 & $2,156.96$ & $15,648,403$ & 2,585.86! & $163,141.129$ & 73,09250 & $176,392,921.364$ \\
\hline JB & $\mathrm{No}-\mathrm{O}$ ner & 50 & 0.75 & 0.75 & 0.75 & 2,289.29 & 152,555479 & $2,626.35$ & $167,191.027$ & $71,861.00$ & $154,802,710.909$ \\
\hline Ш & No-Ouner & 50 & 0.75 & 0.75 & 0.75 & $1,114.57$ & $41,028.540$ & $1,420.95$ & $46,248.452$ & $69,34217 !$ & $172,390,864.515$ \\
\hline HW & Omner & 50 & 0.75 & 0.75 & 0.75 & $1,328.77$ & $177,219.232$ & 1,245.36! & $217,541.262$ & $75,261.17 !$ & $146,148,698.515$ \\
\hline$J B$ & Owner & 50 & 0.75 & 0.75 & 0.75 & $1,329.27$ & $110,001.595$ & 1,110.19 & $101,416.633$ & $74,337.25$ & $146,316,017.114$ \\
\hline$\amalg$ & Ouner & 50 & 0.75 & 0.75 & 0.75 & $1,787.17$ & 149,912250 & $1,975.99$ & $143,796.992$ & $68,114.58$ & $131,237,184.265$ \\
\hline $\mathrm{HW}$ & Capped & 50 & 0.75 & 0.75 & 0.75 & $1,371.82$ & $202,404.214$ & $1,27267 !$ & $251,339.239$ & $74,444.17 !$ & $118,208,265.788$ \\
\hline$J B$ & Capped & 50 & 0.75 & 0.75 & 0.75 & $1,629.95$ & $148,103.771$ & 1,377.56: & $78,974.602$ & $72,085.25 !$ & $109,900,379.295$ \\
\hline Ш & Capped & 50 & 0.75 & 0.75 & 0.75 & $1,700.78$ & $136,528.720$ & 1,857.82: & $119,861.041$ & $64,364.83:$ & $96,368,969.788$ \\
\hline HW & No-Ouner & 25 & 0.75 & 0.75 & 0.75 & $1,796.09$ & $113,403.500$ & 2,303.33! & $145,696.376$ & $54,551.33 !$ & $103,708,904.424$ \\
\hline$J B$ & $\mathrm{No}-\mathrm{O}$ ner & 25 & 0.75 & 0.75 & 0.75 & $1,852.49$ & $133,887.710$ & $2,390.31$ & $149,564.594$ & $54,500.83$ & $97,145,189.738$ \\
\hline$\amalg$ & No-Ouner & 25 & 0.75 & 0.75 & 0.75 & $1,521.57$ & $74,124.595$ & $1,972.70$ & 105,185283 & $51,78233:$ & $99,344,684.242$ \\
\hline HW & Ouner & 25 & 0.75 & 0.75 & 0.75 & 923.81 & $113,320.425$ & 838.62 & 82,335467 & $56,888.42$ & $94,754,004.447$ \\
\hline JB & Ouner & 25 & 0.75 & 0.75 & 0.75 & 645.65 & $63,379.917$ & 639.87 & 56,412486 & 57,458.17! & $98,238,961.061$ \\
\hline$\amalg$ & Ouner & 25 & 0.75 & 0.75 & 0.75 & $1,720.92$ & $138,941.400$ & 1,940.06: & $140,146.044$ & 51,615.58: & $77,421,553.902$ \\
\hline $\mathrm{HW}$ & Capped & 25 & 0.75 & 0.75 & 0.75 & 951.49 & 136,652855 & 847.95 & $111,485.700$ & $53,803.00$ & $45,968,890.000$ \\
\hline JB & Capped & 25 & 0.75 & 0.75 & 0.75 & 915.21 & $87,644.639$ & 850.34 & $52,026.271$ & $54,117.50 !$ & $50,283,371.909$ \\
\hline Ш & Capped & 25 & 0.75 & 0.75 & 0.75 & $1,627.68$ & $119,076.809$ & $1,814.64$ & $109,391.434$ & $46,779.17$ & $33,155,430.333$ \\
\hline
\end{tabular}

Table 4-29 - Mile Ownership \#8

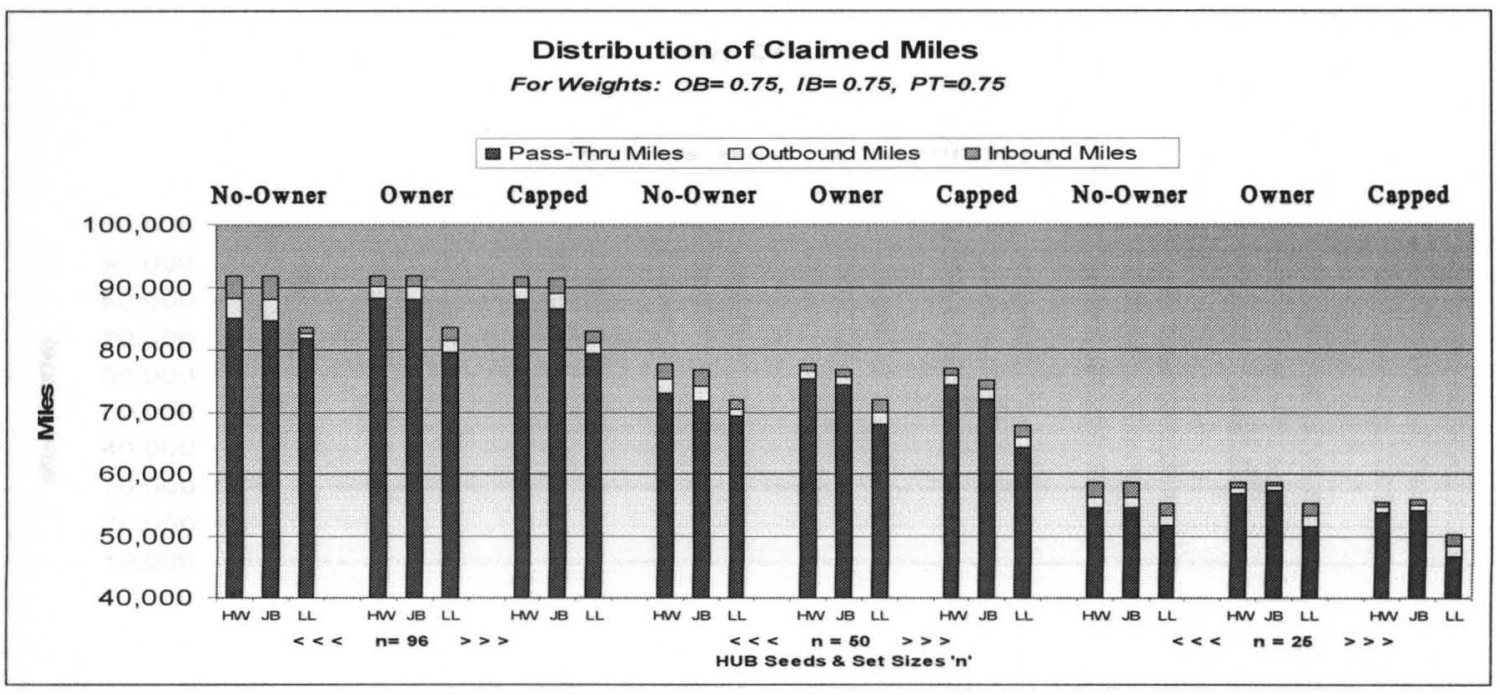




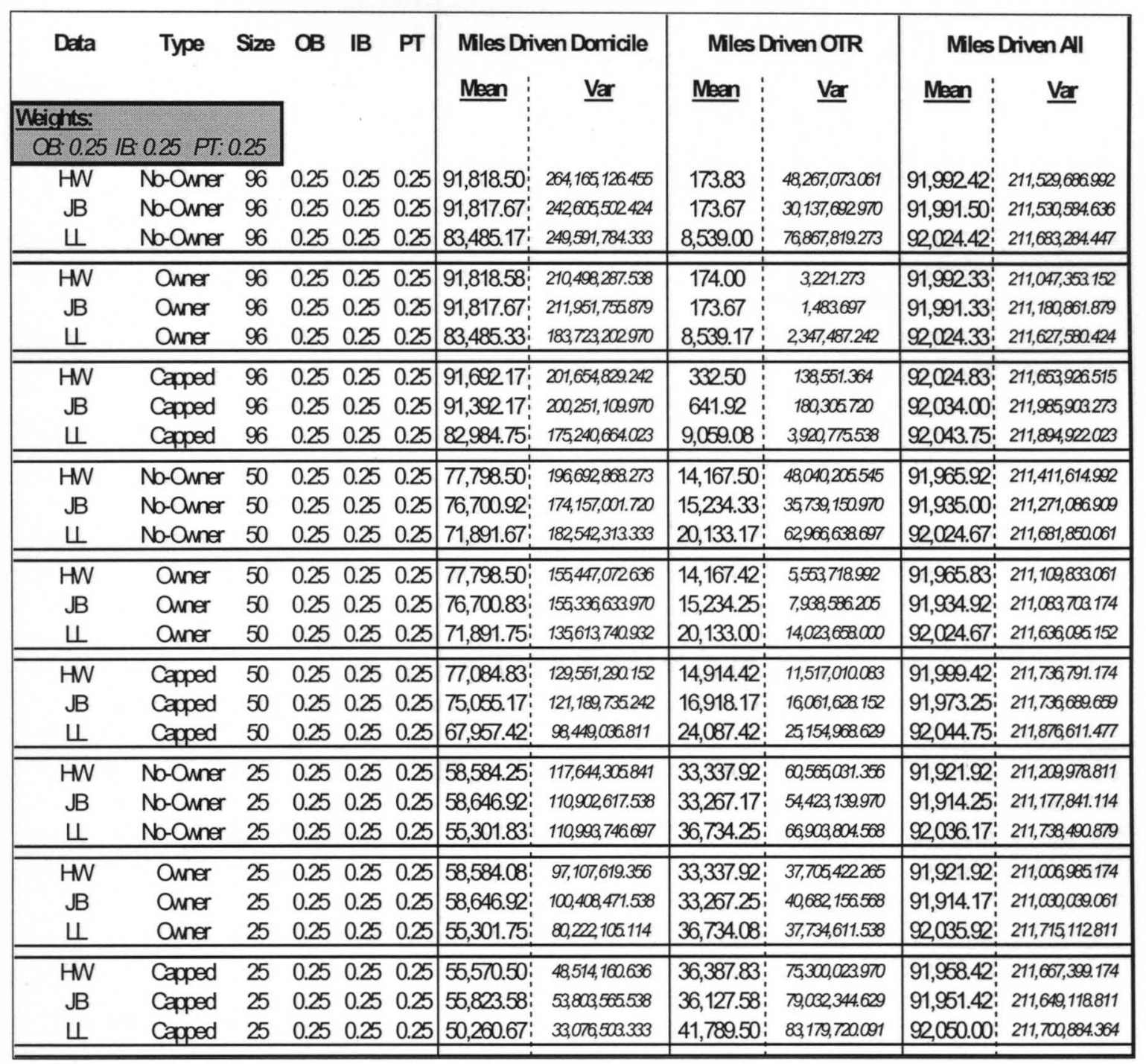

Table 4-30 - Miles Driven \#1

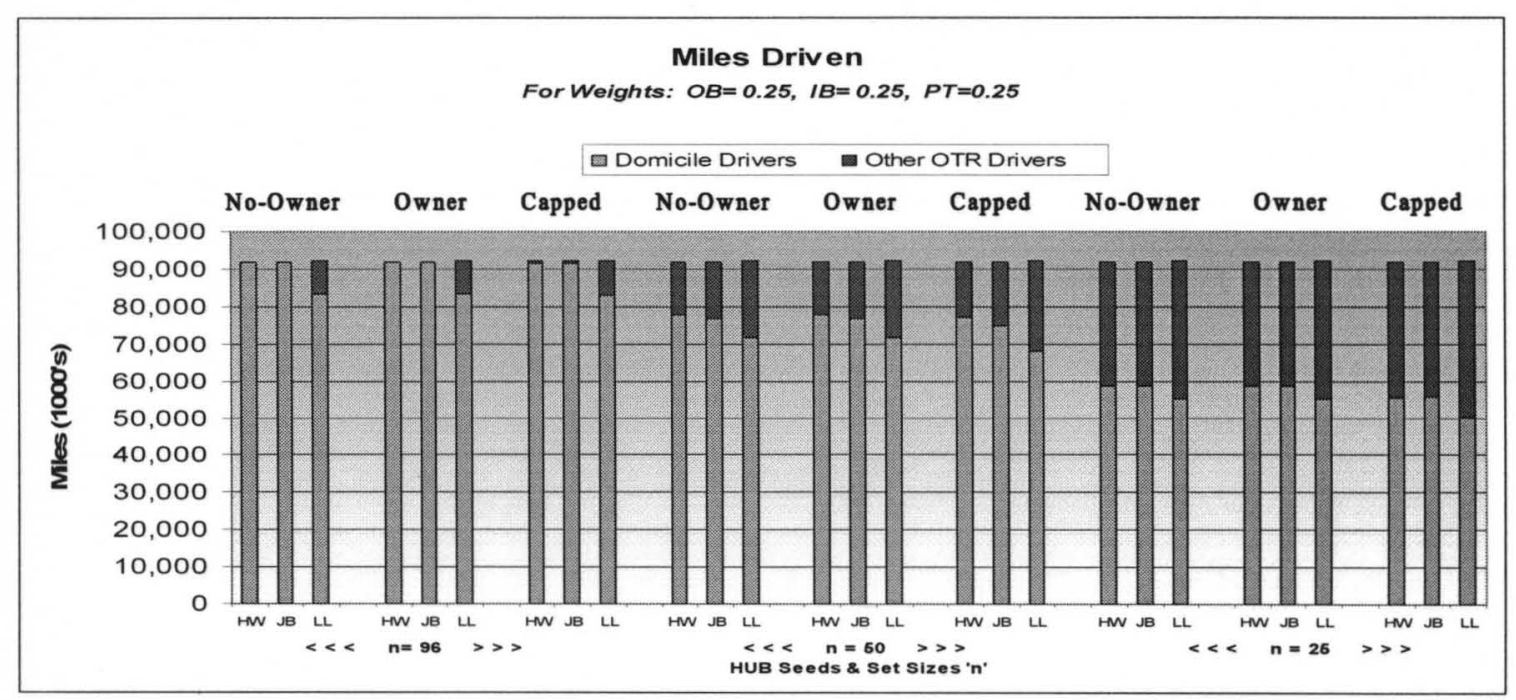




\begin{tabular}{|c|c|c|c|c|c|c|c|c|c|c|}
\hline \multirow{3}{*}{$\frac{\text { Deta }}{\frac{\text { Weights: }}{\text { OB: } 0.25}}$} & \multirow[t]{2}{*}{ Type } & \multirow[t]{2}{*}{ Size } & \multirow[t]{2}{*}{ OB } & \multirow[t]{2}{*}{ IB } & \multirow[t]{2}{*}{ PT } & \multicolumn{2}{|c|}{ Miles Driven Domicile } & \multicolumn{2}{|c|}{ Miles Driven OTR } & Miles Diven All \\
\hline & & & & & & Mean : & \multirow[t]{2}{*}{ Var } & \multirow{2}{*}{$\underline{\text { Menn }}$} & \multirow[t]{2}{*}{$\underline{\text { Var }}$} & \multirow{2}{*}{$\underline{\text { Var }}$} \\
\hline & & & & & & & & & & \\
\hline$\overline{\mathrm{HW}}$ & No-Ouner & 96 & 0.25 & 0.25 & 0.75 & 91,823.25: & $264,192,588.508$ & 173.83 & $48,267,073.061$ & $91,996.92 \quad 211,553,642992$ \\
\hline $\mathrm{JB}$ & $\mathrm{Na}-\mathrm{O}$ ner & 96 & 0.25 & 0.25 & 0.75 & $91,791.08$ & $242,469,252992$ & 173.67 & $30,137,692970$ & $91,965.00 \quad 211,406,497.273$ \\
\hline$\amalg$ & No-Ouner & 96 & 0.25 & 0.25 & 0.75 & $83,513.42$ & $249,757,5 / 2447$ & $8,539.00$ & $76,867,819.273$ & $92,05242: 211,808,787.174$ \\
\hline HW & Ouner & 96 & 0.25 & 0.25 & 0.75 & $92,130.92$ & $211,105,271.902$ & 174.00 & $3,221.273$ & $92,305.00: 211,659,989.818$ \\
\hline $\mathrm{JB}$ & Ouner & 96 & 0.25 & 0.25 & 0.75 & 91,817.67! & $211,951,755879$ & 173.67 & 1,483697 & $\begin{array}{lll}91,991.33 & 211,180,861.879\end{array}$ \\
\hline$\amalg$ & Ouner & 96 & 0.25 & 0.25 & 0.75 & $83,485.33$ & $183,723,202970$ & $8,539.17$ & $2,347,487.242$ & $92,024.33,211,027,580.424$ \\
\hline HW & Capped & 96 & 0.25 & 0.25 & 0.75 & 92,015.08! & $202,606,284.992$ & 325.25 & 129,5923386 & $92,340.50: 212,413,737.909$ \\
\hline $\mathrm{JB}$ & Capped & 96 & 0.25 & 0.25 & 0.75 & 91,39217 & $200,251,109.970$ & 641.92 & 180,305720 & $92,034.00: 211,965,900273$ \\
\hline$\amalg$ & Capped & 96 & 0.25 & 0.25 & 0.75 & $82,984.75$ & $175,240,664.023$ & $9,059.08$ & $3,920,775.538$ & $92,043.75: 211,894,922023$ \\
\hline HW & $\mathrm{No}$-Owner & 50 & 0.25 & 0.25 & 0.75 & $77,808.42$ & $196,740,230.083$ & $14,129.00$ & $48,054,295,636$ & $\begin{array}{rl:}91,937.42 & 211,281,863.902\end{array}$ \\
\hline $\mathrm{JB}$ & $\mathrm{Nb}-\mathrm{O}$ ner & 50 & 0.25 & 0.25 & 0.75 & $76,695.00$ & $174,126,943273$ & $15,234.33$ & $35,739,150,970$ & $\begin{array}{ll:l}91,929.08 & 211,248,627.356\end{array}$ \\
\hline$\amalg$ & $\mathrm{No}-\mathrm{O}$ ner & 50 & 0.25 & 0.25 & 0.75 & $71,933.75$ & $182,756,240.750$ & $20,133.17$ & $62,966,638697$ & $92,066.75: 211,876,5 / 5841$ \\
\hline $\mathrm{HW}$ & Ouner & 50 & 0.25 & 0.25 & 0.75 & $78,024.00$ & $156,233,970.545$ & 14,129.17! & $5,417,466.333$ & $92,153.08: 211,646,877.356$ \\
\hline $\mathrm{JB}$ & Onner & 50 & 0.25 & 0.25 & 0.75 & $76,700.83$ & $155,336,633970$ & $15,234.25$ & $7,938,596.205$ & $91,934,92 \quad 211,063,703174$ \\
\hline Ш & Ouner & 50 & 0.25 & 0.25 & 0.75 & $71,891.75$ & $135,613,740.932$ & $20,133.00$ & $14,023,658,000$ & $92,024,67: 211,056,056152$ \\
\hline $\mathrm{HW}$ & apped & 50 & 0.25 & 0.25 & 0.75 & $77,330.67 !$ & $130,845,875333$ & $14,858.83 !$ & $11,189,561.606$ & \begin{tabular}{|l|l|}
$92,189.50$ & $212,382,962455$ \\
\end{tabular} \\
\hline $\mathrm{JB}$ & Capped & 50 & 0.25 & 0.25 & 0.75 & $75,055.17$ & $121,189,735.242$ & 16,918.17 & 16,061,628, 152 & $91,973.25: 211,736,689.650$ \\
\hline 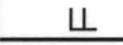 & Capped & 50 & 0.25 & 0.25 & 0.75 & $67,957.42$ & $98,449,036.811$ & $24,087.42$ & $25,154,908.629$ & $92,044.75: 211,876,611.477$ \\
\hline HW & $\mathrm{Nb}-\mathrm{O}$ ner & 25 & 0.25 & 0.25 & 0.75 & $58,903.75$ & $118,932,665295$ & 33,318.17! & $60,554,486,152$ & 92,221.83: 212,596,406515 \\
\hline$J B$ & $\mathrm{Nb}-\mathrm{O}$ ner & 25 & 0.25 & 0.25 & 0.75 & $58,758.33$ & $111,327,406333$ & $33,267.17$ & $54,423,139.970$ & $92,025.67: 211,600,887.515$ \\
\hline$\amalg$ & $\mathrm{Nb}-\mathrm{O}$ ner & 25 & 0.25 & 0.25 & 0.75 & 55,298.58: & $110,979,512629$ & $36,734.25$ & $66,903,804.568$ & $92,03275: 211,720,611.659$ \\
\hline $\mathrm{HW}$ & Ouner & 25 & 0.25 & 0.25 & 0.75 & 58,69225 & $97,286,758.750$ & $33,318.08$ & $37,596,590.447$ & $92,010.33: 211,306,480.061$ \\
\hline$J B$ & Ouner & 25 & 0.25 & 0.25 & 0.75 & $58,646.92$ & $100,408,471.538$ & $33,267.25$ & $40,682,156,568$ & $\begin{array}{ll:l}91,914.17 & 21,030,039.001\end{array}$ \\
\hline Ш & Ouner & 25 & 0.25 & 0.25 & 0.75 & 55,301.75: & $80,222,105,114$ & $36,734.08:$ & $37,734,611.538$ & $92,035.92: \quad 211,715,112811$ \\
\hline $\mathrm{HW}$ & Capped & 25 & 0.25 & 0.25 & 0.75 & $55,690.42$ & $48,463,492265$ & $36,358.42$ & $75,455,540.447$ & 92,048.83: $212,052,514,152$ \\
\hline$J B$ & Capped & 25 & 0.25 & 0.25 & 0.75 & $55,823.58$ & $53,803,5655338$ & $36,127.58$ & $79,032,344.629$ & $91,951.42: 211,649,118.811$ \\
\hline Ш & Capped & 25 & 0.25 & 0.25 & 0.75 & $50,260.67$ & $33,076,503.333$ & $41,789.50$ & $83,179,720.091$ & $92,050.00: 211,700,884.364$ \\
\hline
\end{tabular}

Table 4-31 - Miles Driven \#2

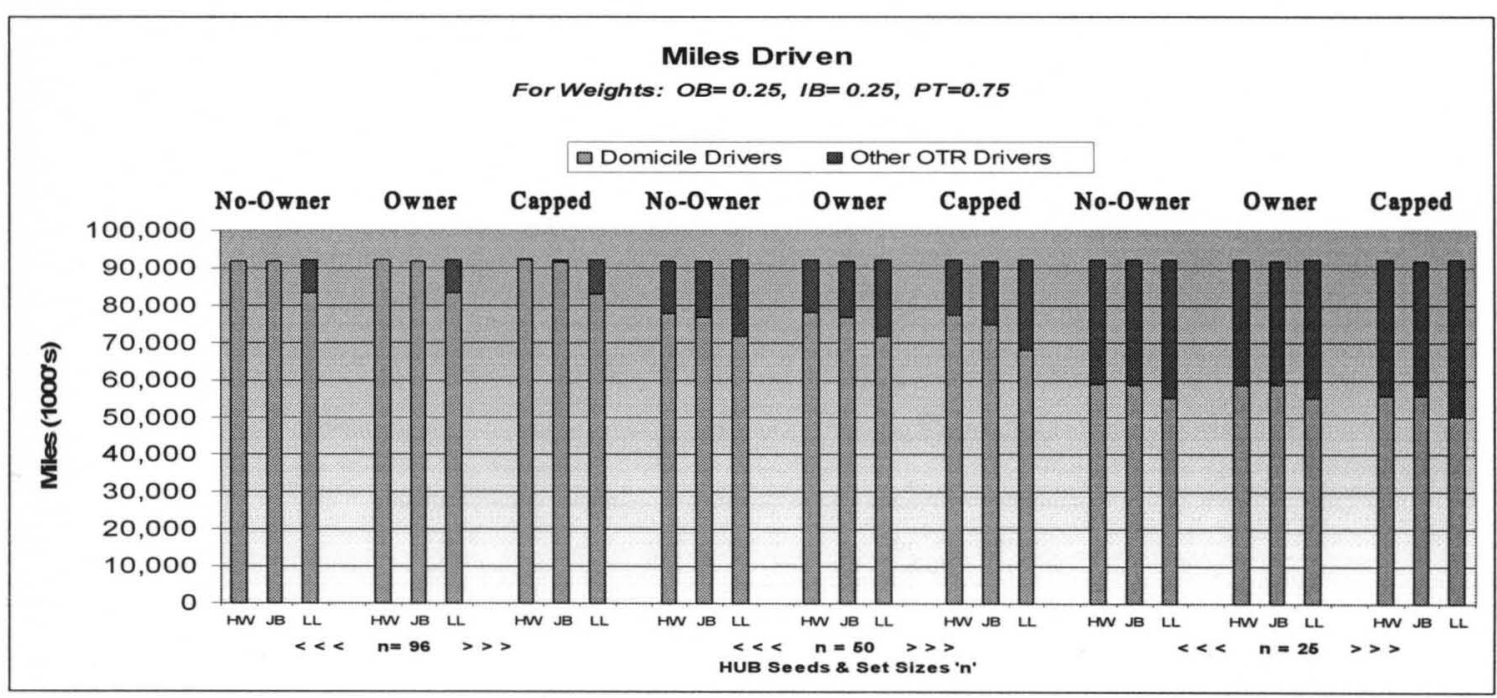




\begin{tabular}{|c|c|c|c|c|c|c|c|c|c|c|c|}
\hline \multirow{3}{*}{$\begin{array}{c}\text { Data } \\
\text { Weichts: } \\
\text { OB: } 0.25\end{array}$} & \multirow[t]{2}{*}{ Type } & \multirow[t]{2}{*}{ Size } & \multirow[t]{3}{*}{ OB } & \multirow[t]{3}{*}{ IB } & \multirow[t]{3}{*}{ PT } & \multicolumn{2}{|c|}{ Miles Driven Domicile } & \multicolumn{2}{|c|}{ Miles Driven OTR } & \multicolumn{2}{|c|}{ Miles Diven Al } \\
\hline & & & & & & \multirow[t]{2}{*}{ Mean } & \multirow[t]{2}{*}{$\underline{\text { Var }}$} & \multirow[t]{2}{*}{ Man } & \multirow[t]{2}{*}{$\underline{\text { Var }}$} & \multirow[t]{2}{*}{ Mean } & \multirow[t]{2}{*}{$\underline{\text { Var }}$} \\
\hline & 0.75 PT: ( & 0.25 & & & & & & & & & \\
\hline $\mathrm{HW}$ & $\overline{\mathrm{No}-\mathrm{O} \text { ner }}$ & 96 & 0.25 & 0.75 & 0.25 & 92, 131.08: & $265,961,418.083$ & 173.83 & $48,267,073.061$ & 92,304.83! & 212988,655970 \\
\hline $\mathrm{JB}$ & $\mathrm{No}$-Ouner & 96 & 0.25 & 0.75 & 0.25 & 91,817.67i & $242,605,502424$ & 173.67 & $30,137,692970$ & $91,991.50$ & $211,530,534,636$ \\
\hline Ш & $\mathrm{No}$-Ouner & 96 & 0.25 & 0.75 & 0.25 & $83,485.17$ & $249,591,784.333$ & $8,539.00$ & $76,867,819.273$ & $92,024.42$ & $211,683,284,447$ \\
\hline $\mathrm{HW}$ & Ouner & 96 & 0.25 & 0.75 & 0.25 & 91,743.33! & $210,367,372424$ & 174.00 & $3,221.273$ & 91,917.00! & $210,919,008,000$ \\
\hline$J B$ & Ouner & 96 & 0.25 & 0.75 & 0.25 & $91,817.67$ & $211,951,755879$ & 173.67 & 1,483697 & $91,991.33$ & $211,180,861.879$ \\
\hline$\amalg$ & Ouner & 96 & 0.25 & 0.75 & 0.25 & $83,485.33$ & $183,723,202970$ & $8,539.17$ & $2,347,487.242$ & 92,024.33! & $211,627,580,424$ \\
\hline $\mathrm{HW}$ & Capped & 96 & 0.25 & 0.75 & 0.25 & 91,618.58; & $201,600,563.174$ & 331.75 & $134,703.841$ & $91,950.50$ & $211,533,965545$ \\
\hline $\mathrm{JB}$ & Capped & 96 & 0.25 & 0.75 & 0.25 & $91,39217 !$ & $200,251,109.970$ & 641.92 & $180,305,720$ & $92,034.00$ & $211,985,903.273$ \\
\hline せ & Capped & 96 & 0.25 & 0.75 & 0.25 & $82,984.75$ & $175,240,664.023$ & $9,059.08$ & $3,920,7 / 15538$ & 92,043.75: & $211,894,922023$ \\
\hline $\mathrm{HW}$ & $\mathrm{No}$-Ouner & 50 & 0.25 & 0.75 & 0.25 & $77,859.75$ & $197,002,515477$ & $14,293.25$ & $47,966,844.932$ & 92,15283 & $212,25,837.788$ \\
\hline $\mathrm{JB}$ & $\mathrm{Na}-\mathrm{O}$ ner & 50 & 0.25 & 0.75 & 0.25 & $76,700.92$ & $174,157,001.720$ & $15,234.33$ & $35,739,150.970$ & $91,935.00$ & $211,271,086,909$ \\
\hline$\amalg$ & $\mathrm{No}-\mathrm{O}$ ner & 50 & 0.25 & 0.75 & 0.25 & 71,891.67! & $182,542,313.333$ & 20,133.17: & $62,966,638697$ & $92,024.67$ & $211,681,850.061$ \\
\hline $\mathrm{HW}$ & Owner & 50 & 0.25 & 0.75 & 0.25 & $77,619.50$ & $154,871,303.727$ & 14,293.17! & $5,739,120.697$ & $91,91250 !$ & $210,999,335.364$ \\
\hline$J B$ & Ouner & 50 & 0.25 & 0.75 & 0.25 & $76,700.83$ & $155,336,633.970$ & 15,234.25! & $7,938,596.205$ & $91,934.92$ & $211,083,700,174$ \\
\hline Ш & Ouner & 50 & 0.25 & 0.75 & 0.25 & $71,891.75$ & $135,613,740.932$ & 20,133.00: & $14,023,658.000$ & $92,024.67$ & $211,636,095,152$ \\
\hline $\mathrm{HW}$ & Capped & 50 & 0.25 & 0.75 & 0.25 & $76,885.25$ & $128,776,036,568$ & $15,061.33 !$ & $11,797,110.970$ & $91,946.67 !$ & $211,648,766.242$ \\
\hline $\mathrm{JB}$ & Capped & 50 & 0.25 & 0.75 & 0.25 & $75,055.17$ & $121,189,735.242$ & 16,918.17 & $16,061,628.152$ & $91,973.25$ & $211,736,689.659$ \\
\hline$\amalg$ & Capped & 50 & 0.25 & 0.75 & 0.25 & $67,957.42$ & $98,449,036.811$ & $24,087.42$ & $25,154,968629$ & $92,044.75$ & $211,876,611.47$ \\
\hline $\mathrm{HW}$ & $\mathrm{Nb}-\mathrm{O}$ ner & 25 & 0.25 & 0.75 & 0.25 & $58,726.58 !$ & $118,215,788.083$ & $33,283.67 !$ & $60,533,765879$ & $92,010.58$ & $211,619,021.902$ \\
\hline$J B$ & $\mathrm{Nb}-\mathrm{O}$ ner & 25 & 0.25 & 0.75 & 0.25 & $58,646.92$ & $110,902,617.538$ & $33,267.17$ & $54,423,139.970$ & 91,914.25: & $211,177,841.114$ \\
\hline せ & $\mathrm{Nb}-\mathrm{O}$ uner & 25 & 0.25 & 0.75 & 0.25 & $55,301.83$ & $110,993,746.697$ & $36,734.25$ & $66,903,804.568$ & 92,036.17! & $211,738,490.879$ \\
\hline $\mathrm{HW}$ & Onner & 25 & 0.25 & 0.75 & 0.25 & $58,606.75$ & $97,005,843.205$ & $33,283.92 !$ & $37,042,581.174$ & $91,890.67 !$ & $210,977,310.788$ \\
\hline$J B$ & Ouner & 25 & 0.25 & 0.75 & 0.25 & $58,646.92$ & $100,408,471.538$ & $33,267.25$ & $40,682,156,568$ & 91,914.17! & $211,000,039.061$ \\
\hline$\amalg$ & Ouner & 25 & 0.25 & 0.75 & 0.25 & $55,301.75$ & $80,222,105.114$ & $36,734.08$ & $37,734,611.538$ & 92,035.92: & $211,715,112811$ \\
\hline $\mathrm{HW}$ & Capped & 25 & 0.25 & 0.75 & 0.25 & $55,536.42$ & $48,119,075.720$ & $36,391.25$ & $74,765,723.295$ & 91,927.58! & $211,656,595174$ \\
\hline $\mathrm{JB}$ & Capped & 25 & 0.25 & 0.75 & 0.25 & $55,823.58$ & $53,803,565,538$ & $36,127.58$ & $79,032,344.629$ & $91,951.42$ & $211,649,118,811$ \\
\hline Ш & Capped & 25 & 0.25 & 0.75 & 0.25 & $50,260.67$ & $33,076,503.333$ & $41,789.50$ & $83,179,720.091$ & $92,050.00$ & $211,700,884.364$ \\
\hline
\end{tabular}

Table 4-32 - Miles Driven \#3

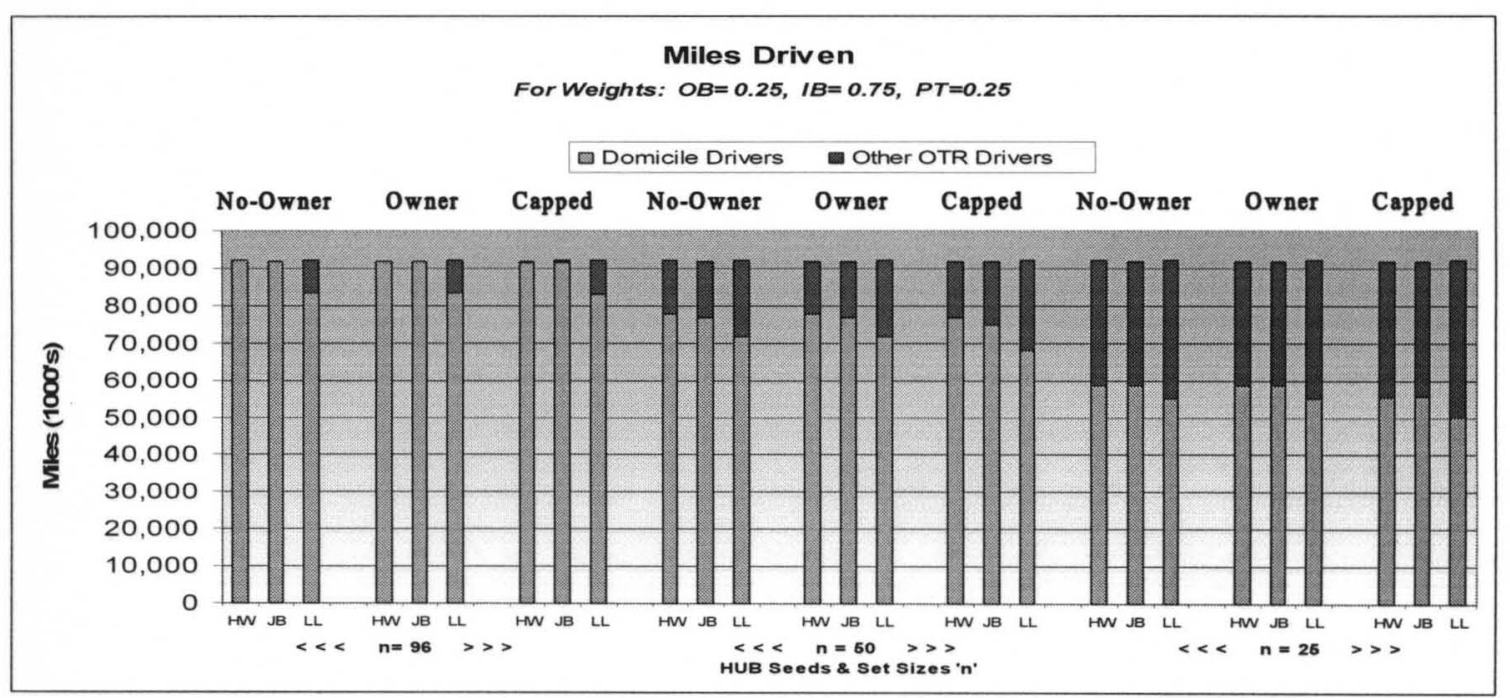




\begin{tabular}{|c|c|c|c|c|c|c|c|c|c|c|c|}
\hline \multirow{3}{*}{$\begin{array}{c}\text { Data } \\
\frac{\text { Weichts: }}{\text { OB: } 0.25}\end{array}$} & \multirow[t]{2}{*}{ Type } & \multirow[t]{2}{*}{ Size } & \multirow[t]{3}{*}{ OB } & \multirow[t]{3}{*}{ IB } & \multirow[t]{3}{*}{ PT } & \multicolumn{2}{|c|}{ Miles Driven Domicile } & \multicolumn{2}{|c|}{ Miles Driven OIR } & \multicolumn{2}{|c|}{ Miles Driven Al } \\
\hline & & & & & & \multirow[t]{2}{*}{ Mean : } & \multirow[t]{2}{*}{$\underline{\text { Var }}$} & \multirow[t]{2}{*}{ Mean } & \multirow[t]{2}{*}{$\underline{\text { Var }}$} & \multirow[t]{2}{*}{ Mean } & \multirow[t]{2}{*}{ Var } \\
\hline & 75 PT: & & & & & & & & & & \\
\hline $\mathrm{HW}$ & No-Owner & 96 & 0.25 & 0.75 & 0.75 & $92,039.58$ & $265,456,712083$ & 184.00 & $48,270,989.636$ & $92,223.50$ & $212613,348,455$ \\
\hline JB & $\mathrm{Nb}$-Ouner & 96 & 0.25 & 0.75 & 0.75 & $91,791.08$ & $242,469,252992$ & 173.67 & $30,137,092970$ & $91,965.00$ & $211,406,497.273$ \\
\hline Ш & $\mathrm{No}-\mathrm{O}$ wher & 96 & 0.25 & 0.75 & 0.75 & $83,513.42$ & $249,757,572447$ & $8,539.00$ & $76,867,819.273$ & 92,05242 & $211,808,787.174$ \\
\hline $\mathrm{HW}$ & Ouner & 96 & 0.25 & 0.75 & 0.75 & 91,949.75! & $210,741,809.114$ & 183.75 & $3,5882.205$ & 92,133.67! & $211,363,480,001$ \\
\hline $\mathrm{JB}$ & Ouner & 96 & 0.25 & 0.75 & 0.75 & 91,817.67: & $211,951,755879$ & 173.67 & 1,483697 & 91,991.33! & $211,180,861.879$ \\
\hline Ш & Ouner & 96 & 0.25 & 0.75 & 0.75 & $83,485.33$ & $183,723,202970$ & $8,539.17$ & $2,347,487.242$ & $92,024.33$ & $211,627,580.424$ \\
\hline$\overline{\mathrm{HW}}$ & Capped & 96 & 0.25 & 0.75 & 0.75 & $91,828.67$ & $201,784,679.515$ & 340.50 & $146,808.273$ & 92,169.17! & 212005975788 \\
\hline$J B$ & Capped & 96 & 0.25 & 0.75 & 0.75 & 91,39217 & $200,251,1009.970$ & 641.92 & 180,305720 & $92,034.00$ & $211,985,903.273$ \\
\hline Ш & Capped & 96 & 0.25 & 0.75 & 0.75 & $82,984.75$ & $175,240,664,023$ & $9,059.08$ & $3,920,7 \pi 5.538$ & $92,043.75$ & $211,804,922023$ \\
\hline$\overline{\mathrm{HW}}$ & No-Ouner & 50 & 0.25 & 0.75 & 0.75 & $77,866.08$ & $197,049,247.538$ & 14,198.17! & $48,034,543,242$ & $92,064.17$ & $211,868,657.788$ \\
\hline$J B$ & $\mathrm{No}$-Ouner & 50 & 0.25 & 0.75 & 0.75 & $76,695.00$ & $174,126,943.273$ & $15,234.33$ & $35,739,150.970$ & $91,929.08$ & $211,248,627.356$ \\
\hline Ш & No-Owner & 50 & 0.25 & 0.75 & 0.75 & $71,933.75$ & $182,756,240.750$ & 20,133.17 & $62,966,638697$ & $92,066.75$ & $211,876,5 / 5841$ \\
\hline $\mathrm{HW}$ & Onner & 50 & 0.25 & 0.75 & 0.75 & $77,851.08$ & $155,948,427.720$ & 14,198.17! & $5,472,482152$ & $92,049.25$ & $211,366,852205$ \\
\hline $\mathrm{JB}$ & Onner & 50 & 0.25 & 0.75 & 0.75 & $76,700.83$ & $155,336,633.970$ & $15,234.25$ & $7,938,586.205$ & $91,934.92$ & $211,083,703,174$ \\
\hline$\amalg$ & Ouner & 50 & 0.25 & 0.75 & 0.75 & $71,891.75$ & $135,613,740.932$ & $20,133.00$ & $14,023,658000$ & 92,024.67: & $211,036,095,152$ \\
\hline$\overline{\mathrm{HW}}$ & Capped & 50 & 0.25 & 0.75 & 0.75 & $77,139.25$ & $130,023,361.4 \pi$ & 14,945.58! & $11,409,642083$ & $92,085.00$ & $212,079,883091$ \\
\hline $\mathrm{JB}$ & Capped & 50 & 0.25 & 0.75 & 0.75 & $75,055.17$ & $121,189,735242$ & 16,918.17! & $16,061,028.152$ & 91,973.25: & $211,736,699.659$ \\
\hline$\amalg$ & Capped & 50 & 0.25 & 0.75 & 0.75 & $67,957.42$ & $98,449,036.811$ & $24,087.42$ & $25,154,968,629$ & $92,044.75$ & $211,876,611.477$ \\
\hline $\mathrm{HW}$ & No-Owner & 25 & 0.25 & 0.75 & 0.75 & $58,635.25$ & $117,850,459.205$ & $33,336.92$ & $60,565,031.356$ & 91,97225 & $211,435,810.932$ \\
\hline $\mathrm{JB}$ & No-Owner & 25 & 0.25 & 0.75 & 0.75 & $58,758.33$ & $111,327,405333$ & $33,267.17$ & $54,423,139.970$ & 92,025.67: & $211,690,887.515$ \\
\hline$\amalg$ & No-Owner & 25 & 0.25 & 0.75 & 0.75 & 55,298.58! & $110,979,512629$ & $36,734.25$ & $66,903,804.568$ & 92,03275 & $211,720,611.659$ \\
\hline $\mathrm{HW}$ & Onner & 25 & 0.25 & 0.75 & 0.75 & $58,618.50$ & $97,379,440.455$ & $33,336.83 !$ & $37,593,021.788$ & $91,955.08 !$ & $211,172,449.902$ \\
\hline$J B$ & Ouner & 25 & 0.25 & 0.75 & 0.75 & $58,646.92$ & $100,408,471.538$ & $33,267.25$ & $40,682,156,568$ & 91,914.17: & $211,000,039.061$ \\
\hline$\amalg$ & Ouner & 25 & 0.25 & 0.75 & 0.75 & $56,301.75$ & $80,222,105.114$ & $36,734.08$ & $37,734,611.538$ & 92,035.92: & $211,715,112811$ \\
\hline $\mathrm{HW}$ & Capped & 25 & 0.25 & 0.75 & 0.75 & 56,61283! & $48,423,238.879$ & $36,380.25 !$ & $75,560,601.477$ & 91,99275 & $211,893,333,650$ \\
\hline $\mathrm{JB}$ & Capped & 25 & 0.25 & 0.75 & 0.75 & 55,823.58: & $53,803,565538$ & $36,127.58$ & $79,032,344.629$ & $91,951.42$ & $211,649,118.811$ \\
\hline Ш & Capped & 25 & 0.25 & 0.75 & 0.75 & 50,260.67: & $33,076,503.333$ & $41,789.50$ & $83,179,720.091$ & $92,050.00$ & $211,700,884.364$ \\
\hline
\end{tabular}

Table 4-33 - Miles Driven \#4

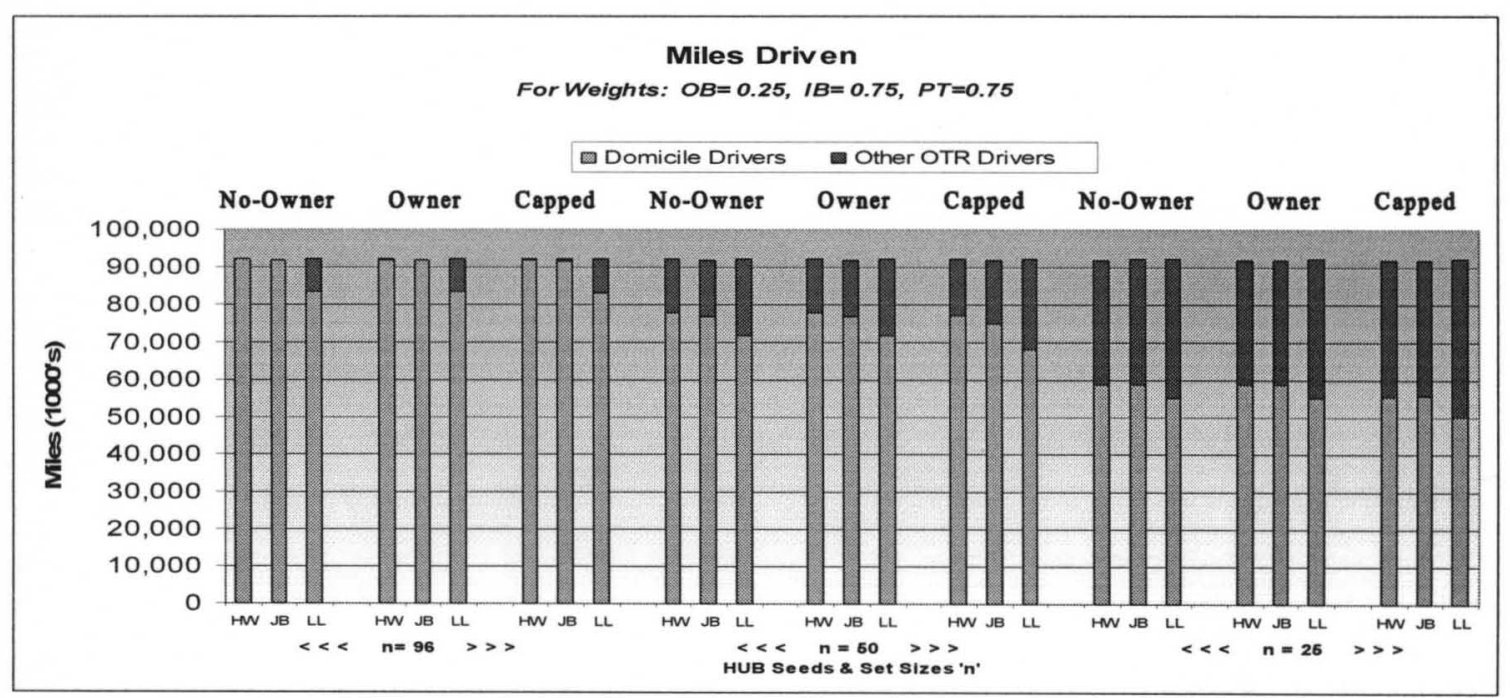




\begin{tabular}{|c|c|c|c|c|c|c|c|c|c|c|c|}
\hline \multirow{3}{*}{$\frac{\text { Deta }}{\frac{\text { Weichts: }}{\text { OB: } 0.75}}$} & \multirow[t]{2}{*}{ Type } & \multirow[t]{2}{*}{ Size } & \multirow[t]{3}{*}{$\mathbf{O B}$} & \multirow[t]{3}{*}{ IB } & \multirow[t]{3}{*}{ PT } & \multicolumn{2}{|c|}{ Miles Driven Domicile } & \multicolumn{2}{|c|}{ Miles Driven OTR } & \multicolumn{2}{|c|}{ Miles Driven Al } \\
\hline & & & & & & \multirow[t]{2}{*}{ Mean : } & \multirow[t]{2}{*}{$\underline{\text { Var }}$} & \multirow{2}{*}{$\underline{\text { Mean }}$} & \multirow[t]{2}{*}{$\underline{\text { Var }}$} & \multirow{2}{*}{ Mean } & \multirow[t]{2}{*}{$\underline{\text { Var }}$} \\
\hline & & & & & & & & & & & \\
\hline$\overline{\mathrm{HW}}$ & No-Ouner & 96 & 0.75 & 0.25 & 0.25 & $91,743.42$ & $263,729,892083$ & 173.83 & $48,267,073061$ & 91,917.08i & $211,177,962447$ \\
\hline $\mathrm{JB}$ & $\mathrm{Nb}$-Owner & 96 & 0.75 & 0.25 & 0.25 & $91,817.67$ & $242,605,502424$ & 173.67 & $30,137,092970$ & $91,991.50$ & $211,530,534.636$ \\
\hline Ш & $\mathrm{No}$-Ouner & 96 & 0.75 & 0.25 & 0.25 & $83,485.17$ & $249,591,784.333$ & $8,539.00$ & $76,867,819.273$ & 92,024.42: & $211,683,2844,477$ \\
\hline HW & Owner & 96 & 0.75 & 0.25 & 0.25 & $91,738.50 !$ & $210,390,043.909$ & 174.00 & $3,221.273$ & 91,91208' & $210,943,525902$ \\
\hline $\mathrm{JB}$ & Owner & 96 & 0.75 & 0.25 & 0.25 & $91,817.67$ & $211,951,755879$ & 173.67 & 1,483697 & 1,991.33! & $211,180,861.879$ \\
\hline Ш & Ouner & 96 & 0.75 & 0.25 & 0.25 & $83,485.33 !$ & $183,723,202970$ & $8,539.17$ & $2,347,487.242$ & 92,024.33! & $211,627,5800.424$ \\
\hline $\mathrm{H} W$ & Capped & 96 & 0.75 & 0.25 & 0.25 & $91,619.83 i$ & $202,304,508.333$ & 321.58 & 115,306447 & 91,941.33' & $211,427,138788$ \\
\hline $\mathrm{JB}$ & Capped & 96 & 0.75 & 0.25 & 0.25 & 91,39217 & $200,251,109.970$ & 641.92 & 180,305720 & $92,034.00$ & $211,965,903273$ \\
\hline$\amalg$ & Capped & 96 & 0.75 & 0.25 & 0.25 & $82,984.75$ & $175,240,664.023$ & $9,059.08$ & $3,920,775.538$ & $92,043.75$ & $211,894,922023$ \\
\hline $\mathrm{HW}$ & No-Ouner & 50 & 0.75 & 0.25 & 0.25 & 77,603.33! & $195,705,155,879$ & 14,309.17! & $47,979,453.970$ & $91,91250 !$ & $211,161,144.636$ \\
\hline $\mathrm{JB}$ & $\mathrm{No}-\mathrm{O}$ ner & 50 & 0.75 & 0.25 & 0.25 & $76,700.92$ & $174,157,001.720$ & 15,234.33! & $35,739,150.970$ & $91,935.00$ & $211,271,086900$ \\
\hline Ш & $\mathrm{No}-\mathrm{O}$ ner & 50 & 0.75 & 0.25 & 0.25 & $71,891.67 !$ & $182,542,313.333$ & 20,133.17: & $62,966,638,697$ & $92,024.67:$ & $211,681,850.001$ \\
\hline HW & uner & 50 & 0.75 & 0.25 & 0.25 & $77,601.33 !$ & $156,092,312242$ & 14,309.08; & $5,304,719.720$ & 91,910.67i & $211,024,630.242$ \\
\hline $\mathrm{JB}$ & Ouner & 50 & 0.75 & 0.25 & 0.25 & $76,700.83$ & $155,336,633970$ & 15,234.25: & $7,938,536.205$ & 91,934.92: & $211,063,703.174$ \\
\hline Ш & Ouner & 50 & 0.75 & 0.25 & 0.25 & $71,891.75$ & $133,613,740.932$ & 20,133.00: & $14,023,658.000$ & 92,024.67: & $211,636,095,152$ \\
\hline HW & Capped & 50 & 0.75 & 0.25 & 0.25 & $76,893.75 !$ & $131,363,865841$ & 15,047.67! & $10,799,225515$ & 91,941.00! & $211,584,751.091$ \\
\hline$J B$ & pped & 50 & 0.75 & 0.25 & 0.25 & $75,056.17$ & $121,189,735242$ & 16,918.17! & $16,061,028.152$ & 91,973.25! & $211,736,699.659$ \\
\hline$\amalg$ & Capped & 50 & 0.75 & 0.25 & 0.25 & $67,957.42$ & $98,449,006.811$ & 24,087.42 & $25,154,968,629$ & $92,044.75$ & $211,876,611.477$ \\
\hline HW & $\mathrm{No}-\mathrm{Oun}$ er & 25 & 0.75 & 0.25 & 0.25 & $58,619.67 !$ & $117,787,497.152$ & 33,270.83! & $60,527,255,424$ & 91,890.50! & $211,068,168.273$ \\
\hline JB & $\mathrm{Nb}$-Ouner & 25 & 0.75 & 0.25 & 0.25 & $58,646.92$ & $110,902,617.538$ & 33,267.17! & $54,423,139.970$ & 91,914.25! & $211,177,841.114$ \\
\hline Ш & $\mathrm{Nb}-\mathrm{O}$ hner & 25 & 0.75 & 0.25 & 0.25 & $55,301.83$ & $110,993,746,697$ & $36,734.25 !$ & $66,903,804.568$ & 92,036.17: & $211,738,490.879$ \\
\hline HN & & 25 & 0.75 & 0.25 & 0.25 & 58,621.58! & $97,609,994.811$ & 33,270.83! & $37,048,941.424$ & 91,89258! & $210,970,656992$ \\
\hline JB & nner & 25 & 0.75 & 0.25 & 0.25 & $58,646.92$ & $100,408,471.538$ & $33,267.25 !$ & $40,682,156,568$ & 91,914.17! & $211,030,039.061$ \\
\hline Ш & Ouner & 25 & 0.75 & 0.25 & 0.25 & $55,301.75 !$ & $80,222,105114$ & $36,734.08 !$ & $37,734,611.538$ & 92,035.92: & $211,715,112811$ \\
\hline $\mathrm{HW}$ & & 25 & 0.75 & 0.25 & 0.25 & 56,586.25! & $49,313,177.295$ & $36,340.00$ & $73,479,863273$ & 91,926.08! & $211,556,434.447$ \\
\hline $\mathrm{JB}$ & Capped & 25 & 0.75 & 0.25 & 0.25 & 55,823.58 & $53,803,565538$ & $36,127.58$ & $79,032,344.629$ & $91,951.42$ & $211,649,118.811$ \\
\hline Ш & Capped & 25 & 0.75 & 0.25 & 0.25 & $50,260.67$ & $33,076,500,333$ & $41,789.50$ & $83,179,720.091$ & $92,050.00$ & $211,700,884,364$ \\
\hline
\end{tabular}

Table 4-34 - Miles Driven \#5

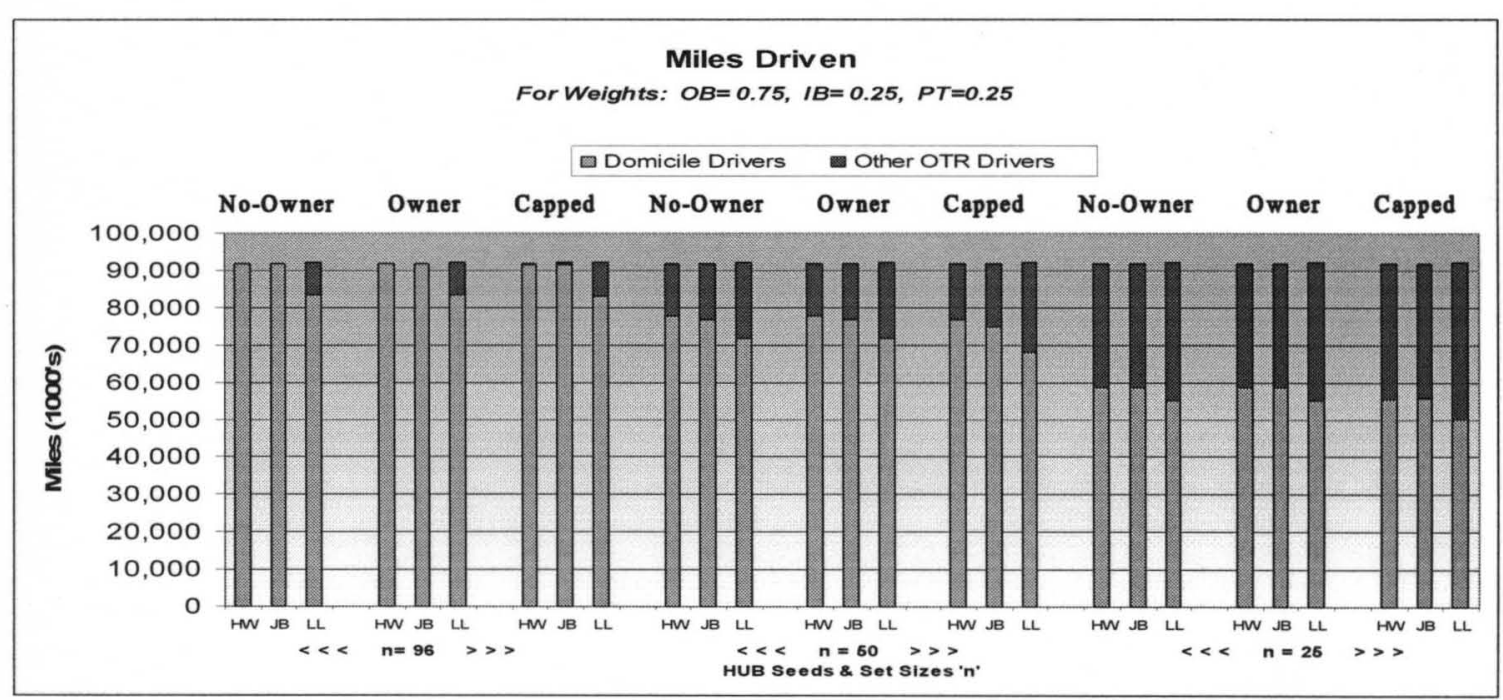




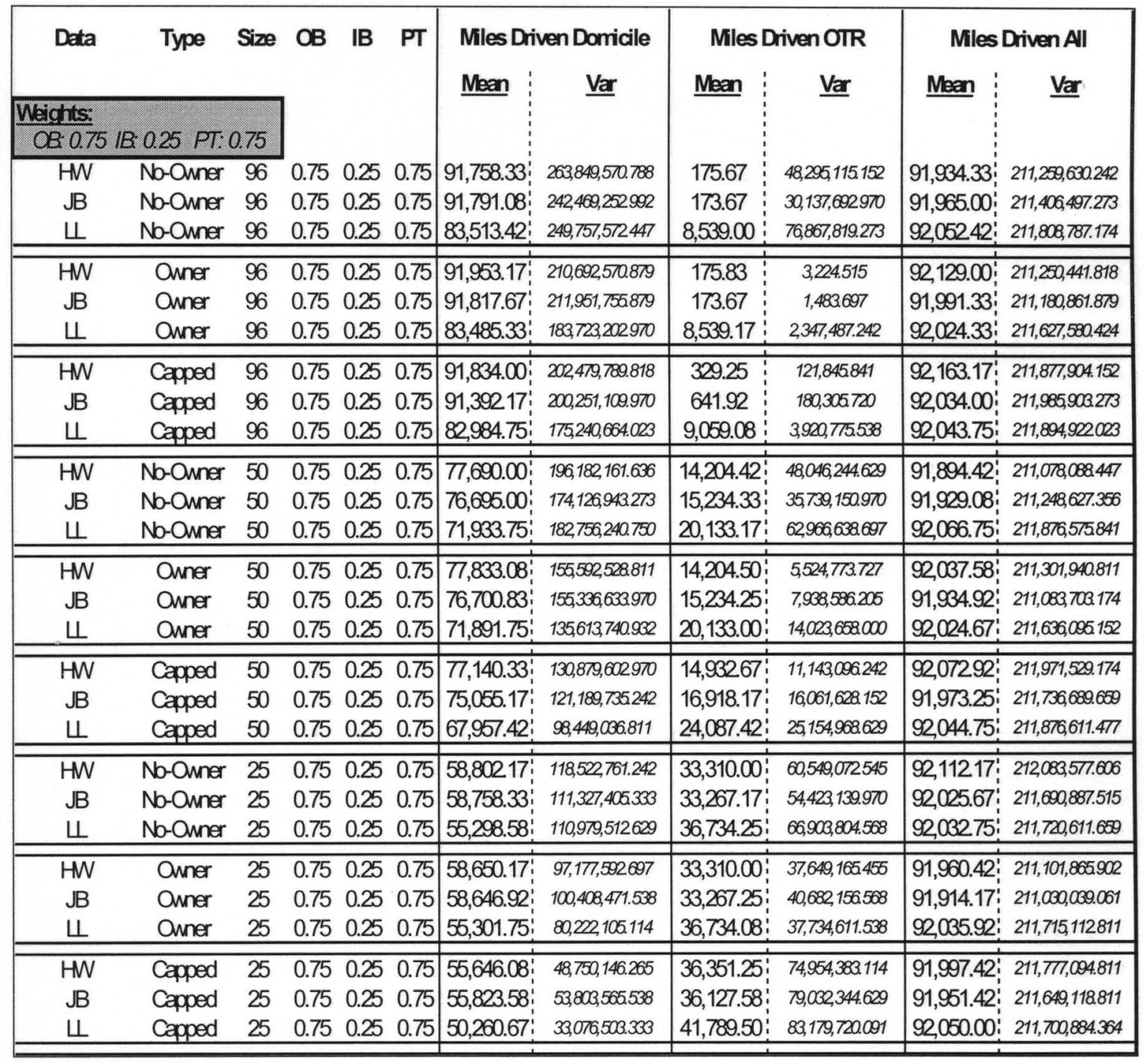

Table 4-35 - Miles Driven \#6

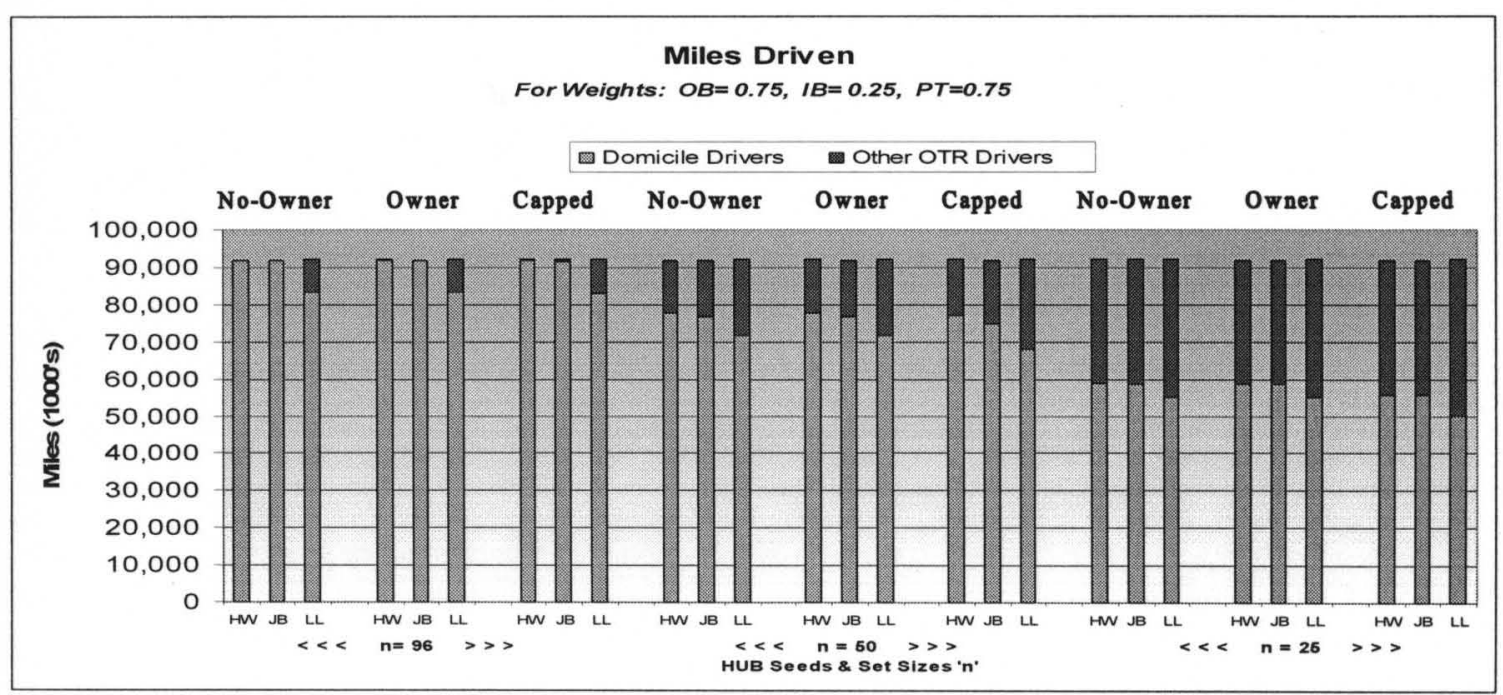




\begin{tabular}{|c|c|c|c|c|c|c|c|c|c|c|c|}
\hline \multirow{3}{*}{$\begin{array}{r}\text { Data } \\
\text { Weichts: } \\
\end{array}$} & \multirow[t]{2}{*}{ Type } & \multirow[t]{2}{*}{ Size } & \multirow[t]{3}{*}{ OB } & \multirow[t]{3}{*}{ IB } & \multirow[t]{3}{*}{ PT } & \multicolumn{2}{|c|}{ Miles Driven Domicile } & \multicolumn{2}{|c|}{ Miles Driven OTR } & \multicolumn{2}{|c|}{ Miles Driven All } \\
\hline & & & & & & \multirow[t]{2}{*}{ Mean : } & \multirow[t]{2}{*}{$\underline{\text { Var }}$} & \multirow[t]{2}{*}{ Mean } & \multirow[t]{2}{*}{$\underline{\text { Var }}$} & \multirow[t]{2}{*}{ Mean : } & \multirow[t]{2}{*}{ Var } \\
\hline & 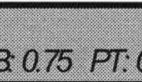 & & & & & & & & & & \\
\hline$\overline{\mathrm{HW}}$ & No-Ouner & 96 & 0.75 & 0.75 & 0.25 & $91,955.33$ & $264,996,011.152$ & 178.42 & $48,288,963.902$ & $92133.50^{i}$ & $212,188,481.909$ \\
\hline $\mathrm{JB}$ & $\mathrm{Nb}-\mathrm{O}$ ner & 96 & 0.75 & 0.75 & 0.25 & $91,817.67$ & $242,605,502424$ & 173.67 & $30,137,692970$ & $91,991.50$ & $211,530,584,606$ \\
\hline Ш & $\mathrm{No}-\mathrm{O}$ hner & 96 & 0.75 & 0.75 & 0.25 & $83,485.17$ & $249,591,784.333$ & $8,539.00$ & $76,867,819.273$ & $92,024.42$ & $211,683,284.447$ \\
\hline $\mathrm{HW}$ & Ouner & 96 & 0.75 & 0.75 & 0.25 & $91,694.83$ & $210,285,007.606$ & 178.42 & $3,194.447$ & 91,873.33! & $210,819,192970$ \\
\hline$J B$ & Ouner & 96 & 0.75 & 0.75 & 0.25 & $91,817.67$ & $211,951,755879$ & 173.67 & 1,483697 & $91,991.33$ & $211,180,861.879$ \\
\hline$\amalg$ & Ouner & 96 & 0.75 & 0.75 & 0.25 & $83,485.33$ & $183,723,202970$ & $8,539.17$ & $2,347,487.242$ & $92,024.33$ & $211,627,580,424$ \\
\hline$\overline{\mathrm{HW}}$ & Capped & 96 & 0.75 & 0.75 & 0.25 & $91,570.92$ & $201,921,821.174$ & 332.17 & $123,600.697$ & 91,903.17! & $211,354,338.515$ \\
\hline $\mathrm{JB}$ & Capped & 96 & 0.75 & 0.75 & 0.25 & 91,39217 & $200,251,109.970$ & 641.92 & 180,305720 & $92,034.00$ & $211,985,903.273$ \\
\hline$\amalg$ & Capped & 96 & 0.75 & 0.75 & 0.25 & $82,984.75$ & $175,240,664.023$ & $9,059.08$ & $3,920,7 \pi 5538$ & $92,043.75$ & $211,894,922023$ \\
\hline $\mathrm{HW}$ & $\mathrm{Nb}$-Ouner & 50 & 0.75 & 0.75 & 0.25 & $77,843.33$ & $196,949,181.697$ & $14,206.08$ & $48,039,339.720$ & 92,049.25! & $211,799,315659$ \\
\hline $\mathrm{JB}$ & $\mathrm{No}$-Ouner & 50 & 0.75 & 0.75 & 0.25 & $76,700.92$ & $174,157,001.720$ & $15,234.33$ & $35,739,150,970$ & $91,935.00$ & $211,271,086,900$ \\
\hline せ & No-Owner & 50 & 0.75 & 0.75 & 0.25 & 71,891.67! & $182,542,313,333$ & $20,133.17$ & $62,966,638697$ & 92,024.67: & $211,081,850.061$ \\
\hline $\mathrm{HW}$ & Omner & 50 & 0.75 & 0.75 & 0.25 & 77,67283 & $156,175,899.788$ & $14,205.92$ & $5,297,270.992$ & $91,878.83$ & $210,941,800.879$ \\
\hline $\mathrm{JB}$ & Onner & 50 & 0.75 & 0.75 & 0.25 & $76,700.83$ & $155,336,633.970$ & $15,234.25$ & $7,938,586.205$ & $91,934.92$ & $211,003,703,174$ \\
\hline$\Perp$ & Ouner & 50 & 0.75 & 0.75 & 0.25 & $71,891.75$ & $135,613,740.932$ & 20,133.00 & $14,023,658.000$ & 92,024.67! & $211,036,095152$ \\
\hline $\mathrm{HW}$ & Capped & 50 & 0.75 & 0.75 & 0.25 & $76,940.25$ & $130,355,118.386$ & 14,969.50! & $11,112,554.273$ & $91,909.67$ & $211,528,948061$ \\
\hline $\mathrm{JB}$ & Capped & 50 & 0.75 & 0.75 & 0.25 & $75,055.17$ & $121,189,735242$ & $16,918.17$ & $16,061,028,152$ & 91,973.25! & $211,736,689.659$ \\
\hline$\amalg$ & Capped & 50 & 0.75 & 0.75 & 0.25 & $67,957.42$ & $98,449,036.811$ & $24,087.42$ & $25,154,968629$ & $92,044.75$ & $211,876,611.47$ \\
\hline $\mathrm{HW}$ & No-Owner & 25 & 0.75 & 0.75 & 0.25 & $58,707.92$ & $118,165,504.992$ & $33,247.42$ & $60,519,997.356$ & $91,955.08$ & $211,363,494.811$ \\
\hline $\mathrm{JB}$ & No-Owner & 25 & 0.75 & 0.75 & 0.25 & $58,646.92$ & $110,902,617.538$ & $33,267.17$ & $54,423,139.970$ & 91,914.25! & $211,177,841.114$ \\
\hline$\amalg$ & No-Owner & 25 & 0.75 & 0.75 & 0.25 & 56,301.83 & $110,993,746.697$ & $36,734.25$ & $66,903,804.508$ & $92,036.17$ & $211,738,490.879$ \\
\hline$\overline{\mathrm{HW}}$ & Ouner & 25 & 0.75 & 0.75 & 0.25 & $58,624.83$ & $97,749,410.697$ & $33,247.33 !$ & $36,37,102970$ & $91,87233 !$ & $210,946,504.061$ \\
\hline JB & Onner & 25 & 0.75 & 0.75 & 0.25 & $58,646.92$ & $100,408,471.538$ & $33,267.25$ & $40,682,156,568$ & 91,914.17! & $211,030,009.061$ \\
\hline$\amalg$ & Ouner & 25 & 0.75 & 0.75 & 0.25 & $55,301.75$ & $80,222,105.114$ & $36,734.08$ & $37,734,611.538$ & 92,035.92! & $211,715,112811$ \\
\hline$\overline{H W}$ & Capped & 25 & 0.75 & 0.75 & 0.25 & $55,534.75$ & $48,534,381.659$ & $36,371.50$ & $73,941,005,000$ & $91,906.08$ & $211,561,026,620$ \\
\hline JB & Capped & 25 . & 0.75 & 0.75 & 0.25 & $55,823.58$ & $53,803,565.538$ & $36,127.58$ & $79,032,344.629$ & $91,951.42$ & $211,649,118811$ \\
\hline$\amalg$ & Capped & 25 & 0.75 & 0.75 & 0.25 & $50,260.67$ & $33,076,503.333$ & $41,789.50$ & $83,179,720.091$ & $92,050.00$ & $211,700,884.364$ \\
\hline
\end{tabular}

Table 4-36 - Miles Driven \#7

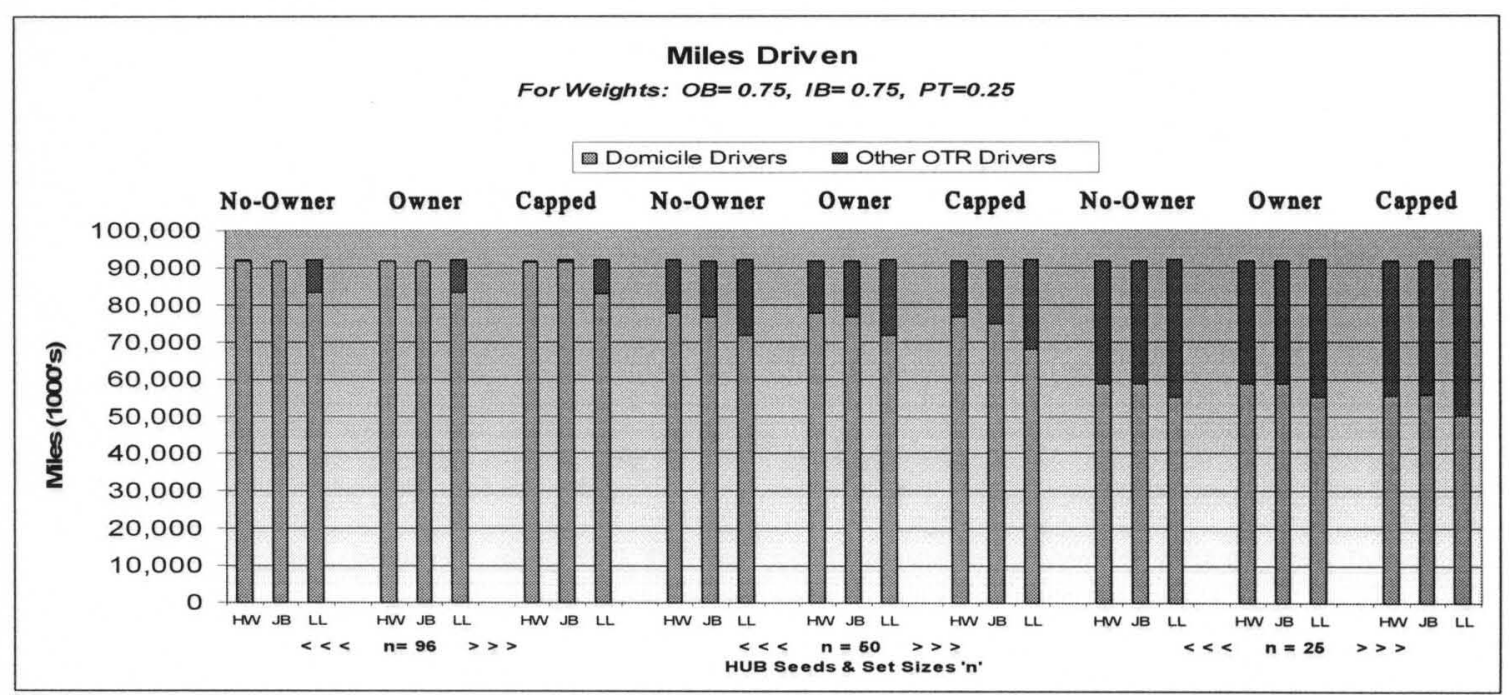




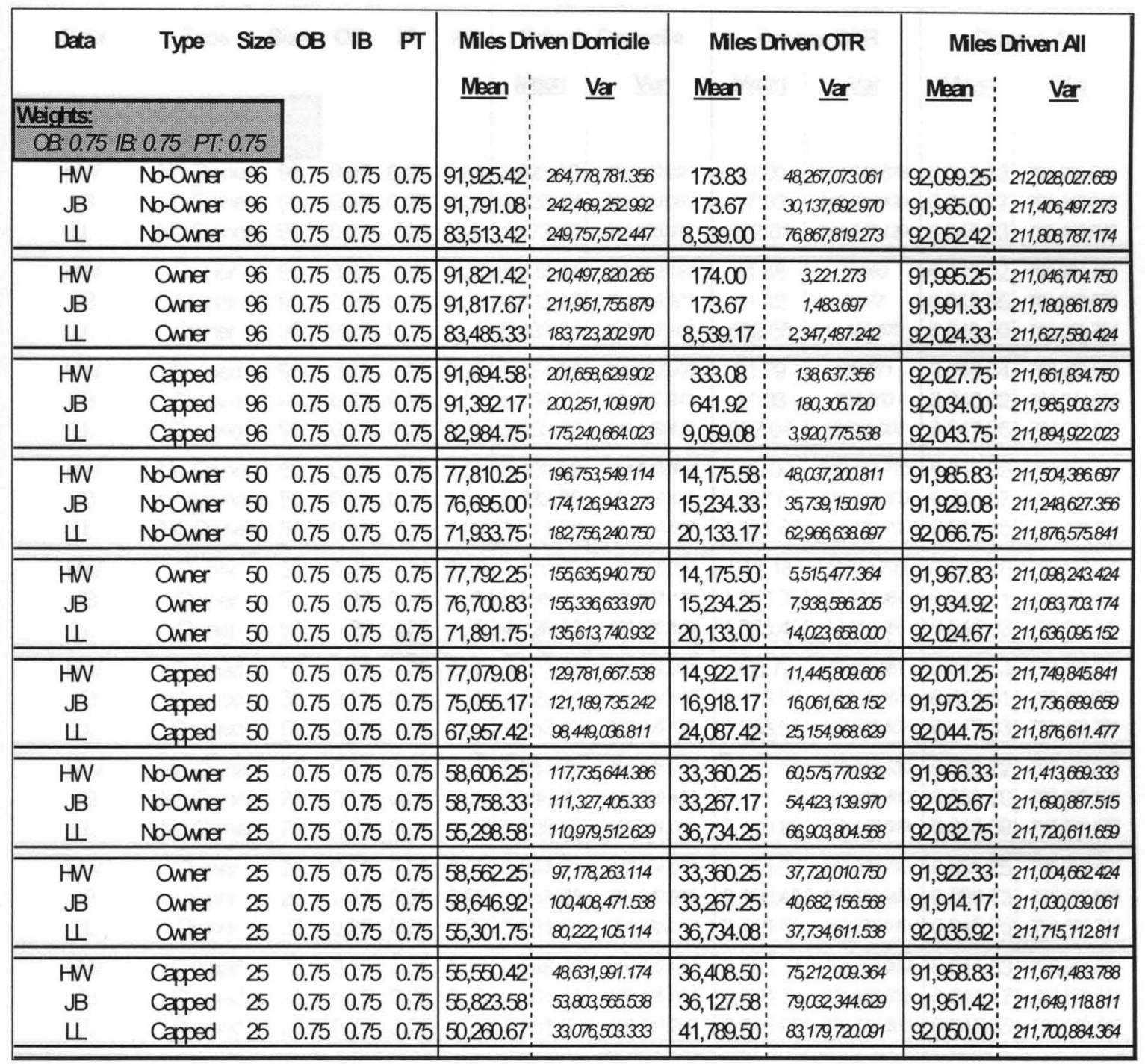

Table 4-37 - Miles Driven \#8

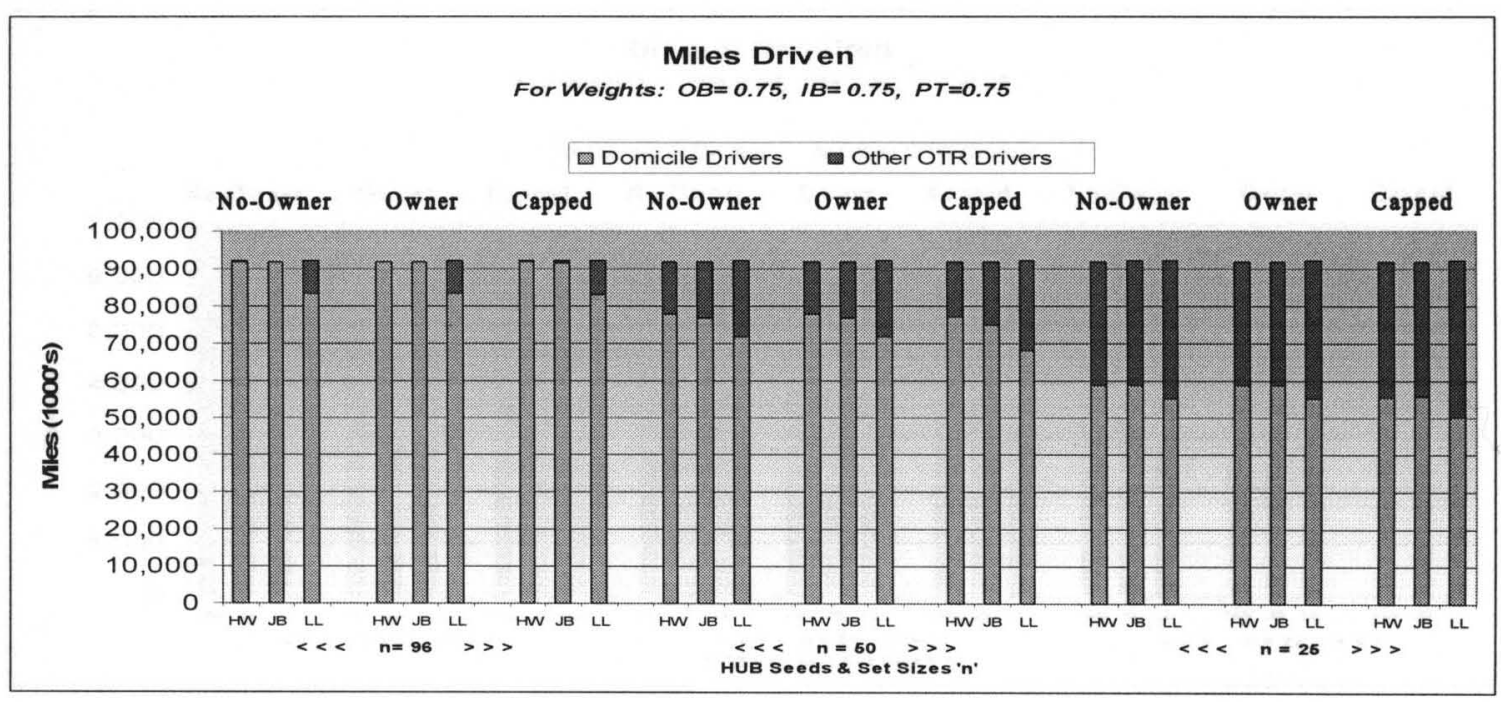




\begin{tabular}{|c|c|c|c|c|c|c|c|c|c|c|c|}
\hline \multirow[t]{2}{*}{ Data } & \multirow[t]{2}{*}{ Type } & \multirow[t]{2}{*}{ Size } & \multirow[t]{2}{*}{ OB } & \multirow[t]{2}{*}{ IB } & \multirow[t]{2}{*}{ PT } & \multicolumn{2}{|c|}{ Drivers Domicile } & \multicolumn{2}{|c|}{ Drivers OTR } & \multicolumn{2}{|c|}{ Drivers All } \\
\hline & & & & & & Mean & Var & Mean & Var & Mean & Var \\
\hline \multicolumn{12}{|l|}{ Weights: } \\
\hline HW & No-Owner & 96 & 0.25 & 0.25 & 0.25 & $6,023.93$ & $958,379.993$ & 19.90 & $233,645.678$ & $6,043.83$ & $791,933.852$ \\
\hline $\mathrm{JB}$ & No-Owner & 96 & 0.25 & 0.25 & 0.25 & $6,026.47$ & $881,099.063$ & 17.30 & $143,662.439$ & $6,043.77$ & $791,916.615$ \\
\hline щ & No-Omner & 96 & 0.25 & 0.25 & 0.25 & $5,473.92$ & $916,593.972$ & 572.01 & $381,547.129$ & $6,045.93$ & $792,455.548$ \\
\hline $\mathrm{HW}$ & Owner & 96 & 0.25 & 0.25 & 0.25 & $6,032.44$ & $788,232.127$ & 11.48 & 16.062 & $6,043.92$ & $790,821.131$ \\
\hline JB & Owner & 96 & 0.25 & 0.25 & 0.25 & $6,032.43$ & $794,746.201$ & 11.42 & 5.977 & $6,043.85$ & $791,242.658$ \\
\hline Ш & Owner & 96 & 0.25 & 0.25 & 0.25 & $5,483.34$ & $677,967.100$ & 562.66 & $11,586.572$ & $6,046.00$ & $793,060.761$ \\
\hline $\mathrm{HW}$ & Capped & 96 & 0.25 & 0.25 & 0.25 & $6,024.25$ & $752,870.906$ & 21.79 & 574.271 & $6,046.04$ & $793,123.522$ \\
\hline $\mathrm{JB}$ & Capped & 96 & 0.25 & 0.25 & 0.25 & $6,004.70$ & $749,392.313$ & 41.93 & 739.550 & $6,046.62$ & $794,344.662$ \\
\hline щ & Capped & 96 & 0.25 & 0.25 & 0.25 & $5,450.22$ & $642,149.434$ & 597.04 & $18,789.005$ & $6,047.26$ & $794,032.547$ \\
\hline $\mathrm{HW}$ & No-Owner & 50 & 0.25 & 0.25 & 0.25 & $5,103.09 !$ & $714,575.886$ & 939.00 & $240,197.725$ & $6,042.09$ & $791,506.144$ \\
\hline $\mathrm{JB}$ & No-Owner & 50 & 0.25 & 0.25 & 0.25 & $5,032.98$ & $630,158.432$ & $1,007.09$ & $175,581.309$ & $6,040.07$ & $791,009.200$ \\
\hline 凹 & No-Owner & 50 & 0.25 & 0.25 & 0.25 & 4,713.98: & $669,200.662$ & $1,331.97$ & $315,187.706$ & $6,045.95$ & $792,458.738$ \\
\hline HW & Owner & 50 & 0.25 & 0.25 & 0.25 & $5,110.00$ & $573,025.734$ & 932.16 & $23,910.700$ & 6,042.16i & $790,847.996$ \\
\hline $\mathrm{JB}$ & Owner & 50 & 0.25 & 0.25 & 0.25 & $5,036.78$ & $566,687.139$ & $1,003.33$ & $37,034.984$ & $6,040.11$ & $790,685.490$ \\
\hline แ & Owner & 50 & 0.25 & 0.25 & 0.25 & 4,720.63: & $492,870.503$ & $1,325.40$ & $63,310.456$ & $6,046.03$ & $793,033.792$ \\
\hline $\mathrm{HW}$ & Capped & 50 & 0.25 & 0.25 & 0.25 & $5,063.64$ & $471,112.351$ & 980.70 & $47,409.862$ & $6,044.33$ & $793,266.202$ \\
\hline$J B$ & Capped & 50 & 0.25 & 0.25 & 0.25 & 4,929.54: & $434,387.675$ & $1,113.07$ & $68,035.368$ & $6,042.61$ & $793,183.905$ \\
\hline 凹 & Capped & 50 & 0.25 & 0.25 & 0.25 & 4,463.42: & $353,050.153$ & $1,583.91:$ & $103,698.557$ & 6,047.33i & $793,878.721$ \\
\hline HW & No-Owner & 25 & 0.25 & 0.25 & 0.25 & $3,841.71$ & $429,176.958$ & $2,197.51$ & $289,249.339$ & $6,039.22$ & $790,827.240$ \\
\hline $\mathrm{JB}$ & No-Owner & 25 & 0.25 & 0.25 & 0.25 & 3,846.73! & $402,329.421$ & $2,191.97 !$ & $255,836.480$ & $6,038.70$ & $790,692.128$ \\
\hline ㄴ & No-Owner & 25 & 0.25 & 0.25 & 0.25 & $3,625.83$ & $408,001.001$ & $2,420.86 !$ & $318,140.543$ & 6,046.69i & $792,640.804$ \\
\hline $\mathrm{HW}$ & Owner & 25 & 0.25 & 0.25 & 0.25 & $3,844.71$ & $347,834.003$ & $2,194.54 !$ & $168,203.712$ & $6,039.25$ & $790,360.499$ \\
\hline$J B$ & Owner & 25 & 0.25 & 0.25 & 0.25 & $3,848.28$ & $359,947.975$ & $2,190.45$ & $184,651.299$ & 6,038.73! & $790,439.816$ \\
\hline ㄴ & Owner & 25 & 0.25 & 0.25 & 0.25 & 3,631.10: & $291,135.067$ & 2,415.66! & $154,376.919$ & $6,046.76:$ & $793,191.730$ \\
\hline HW & Capped & 25 & 0.25 & 0.25 & 0.25 & $3,648.49$ & $158,542.860$ & $2,393.14$ & $313,169.904$ & $6,041.63$ & $792,861.834$ \\
\hline $\mathrm{JB}$ & Capped & 25 & 0.25 & 0.25 & 0.25 & $3,664.39$ & $178,105.604$ & 2,376.77! & $333,687.538$ & $6,041.17$ & $792,770.476$ \\
\hline ㄴ & Capped & 25 & 0.25 & 0.25 & 0.25 & $3,301.60$ & $109,642.209$ & $2,746.06$ & $330,774.565$ & $6,047.66$ & $793,018.440$ \\
\hline
\end{tabular}

Table 4-38 - Drivers Required \#1

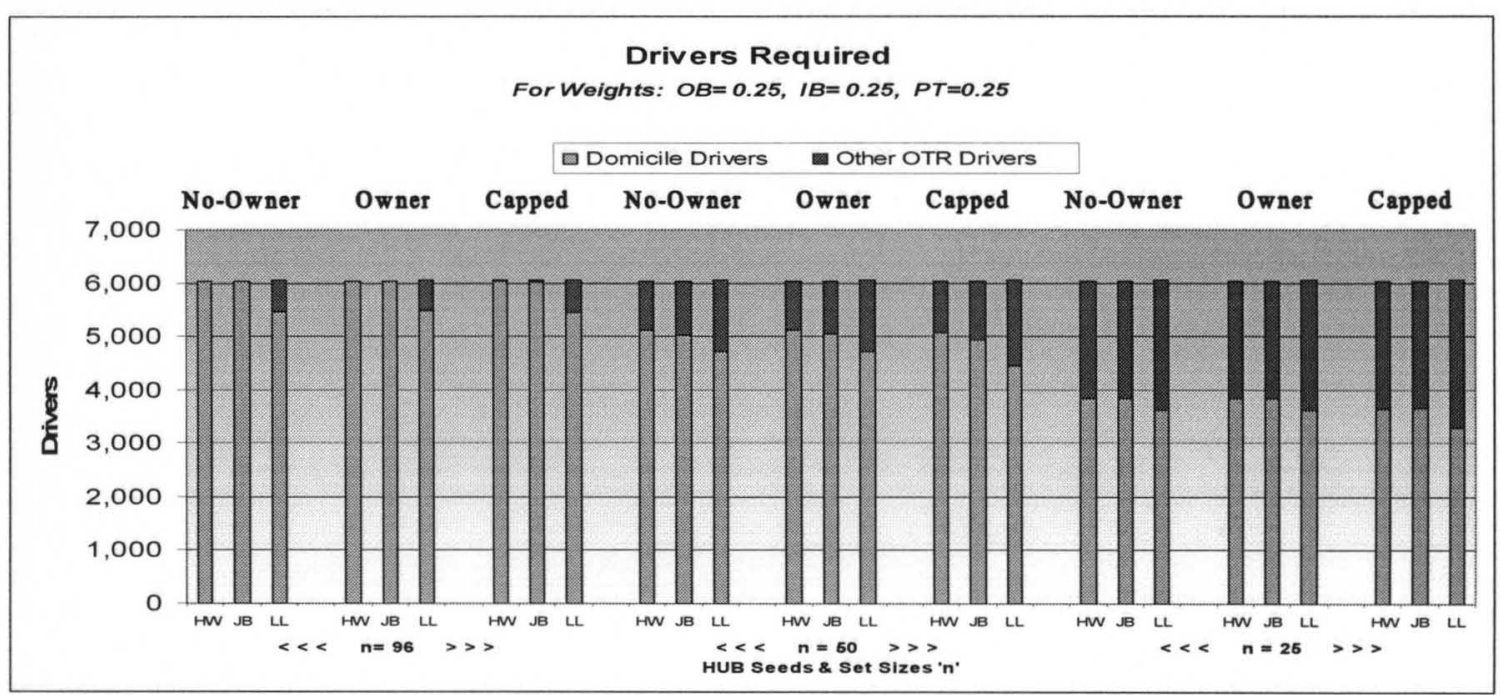




\begin{tabular}{|c|c|c|c|c|c|c|c|c|c|c|c|}
\hline Data & Type & Size & OB & IB & PT & \multicolumn{2}{|c|}{ Drivers Domicile } & \multicolumn{2}{|c|}{ Drivers OTR } & \multicolumn{2}{|c|}{ Drivers All } \\
\hline \multicolumn{12}{|l|}{$\frac{\text { Weights: }}{\text { OB: } 0.25}$} \\
\hline $\mathrm{HW}$ & No-Owner & 96 & 0.25 & 0.25 & 0.75 & $6,024.23$ & $958,478.117$ & 19.90 & $233,646.237$ & $6,044.13$ & $792,012.065$ \\
\hline JB & No-Owner & 96 & 0.25 & 0.25 & 0.75 & $6,024.73$ & $880,588.205$ & 17.30 & $143,662.439$ & $6,042.03$ & $791,471.219$ \\
\hline ㄴ & No-Owner & 96 & 0.25 & 0.25 & 0.75 & $5,475.76$ & $917,212.818$ & 572.01 & $381,547.129$ & $6,047.77$ & $792,903.000$ \\
\hline HW & Owner & 96 & 0.25 & 0.25 & 0.75 & $6,053.08$ & $791,364.084$ & 11.48 & 16.067 & 6,064.56! & $793,997.380$ \\
\hline $\mathrm{JE}$ & Owner & 96 & 0.25 & 0.25 & 0.75 & 6,032.43! & $794,746.201$ & 11.42 & 5.977 & $6,043.85$ & $791,242.658$ \\
\hline 凹 & Owner & 96 & 0.25 & 0.25 & 0.75 & $5,483.34$ & $677,967.100$ & 562.66 & $11,586.572$ & $6,046.00$ & $793,060.761$ \\
\hline HW & Capped & 96 & 0.25 & 0.25 & 0.75 & $6,045.57$ & $757,751.169$ & 21.31 & 536.792 & 6,066.88: & $796,865.623$ \\
\hline $\mathrm{JB}$ & Capped & 96 & 0.25 & 0.25 & 0.75 & 6,004.70 & $749,392.313$ & 41.93 & 739.550 & $6,046.62$ & $794,344.662$ \\
\hline щ & Capped & 96 & 0.25 & 0.25 & 0.75 & $5,450.22$ & $642,149.434$ & 597.04 & $18,789.005$ & $6,047.26$ & $794,032.547$ \\
\hline HW & No-Owner & 50 & 0.25 & 0.25 & 0.75 & $5,103.75$ & $714,758.160$ & 936.48 & $240,279.526$ & $6,040.23 !$ & $791,045.547$ \\
\hline $\mathrm{JB}$ & No-Owner & 50 & 0.25 & 0.25 & 0.75 & $5,032.58$ & $630,063.907$ & $1,007.09$ & $175,581.309$ & $6,039.67$ & $790,911.941$ \\
\hline$\amalg$ & No-Owner & 50 & 0.25 & 0.25 & 0.75 & 4,716.74: & $669,984.398$ & $1,331.97$ & $315,187.706$ & $6,048.71$ & $793,134.410$ \\
\hline HW & Owner & 50 & 0.25 & 0.25 & 0.75 & $5,124.89$ & $576,486.086$ & 929.62 & 23,291.976 & $6,054.51$ & $793,379.965$ \\
\hline $\mathrm{JB}$ & Owner & 50 & 0.25 & 0.25 & 0.75 & $5,036.78$ & $566,687.139$ & $1,003.33$ & $37,034.984$ & $6,040.11$ & $790,685.490$ \\
\hline 凹 & Owner & 50 & 0.25 & 0.25 & 0.75 & $4,720.63 i$ & $492,870.503$ & $1,325.40$ & $63,310.456$ & $6,046.03$ & $793,033.792$ \\
\hline HW & ipped & 50 & 0.25 & 0.25 & 0.75 & $5,079.86$ & $476,681.277$ & 977.03 & $46,006.687$ & $6,056.89$ & $796,214.552$ \\
\hline JB & Capped & 50 & 0.25 & 0.25 & 0.75 & $4,929.54 !$ & $434,387.675$ & $1,113.07$ & $68,035.368$ & $6,042.61$ & $793,183.905$ \\
\hline せ & Capped & 50 & 0.25 & 0.25 & 0.75 & 4,463.42i & $353,050.153$ & $1,583.91$ & $103,698.557$ & $6,047.33 i$ & $793,878.721$ \\
\hline HW & -Owner & 25 & 0.25 & 0.25 & 0.75 & 3,862.66: & $433,874.733$ & $2,196.21$ & $289,223.181$ & 6,058 & $795,602.092$ \\
\hline $\mathrm{JB}$ & No-Owner & 25 & 0.25 & 0.25 & 0.75 & $3,854.04$ & $403,860.300$ & $2,191.97$ & $255,836.480$ & $6,046.02$ & $792,477.887$ \\
\hline 凹 & No-Owner & 25 & 0.25 & 0.25 & 0.75 & 3,625.61: & $407,949.848$ & $2,420.86:$ & $318,140.543$ & $6,046.48$ & $792,591.684$ \\
\hline HW & Owner & 25 & 0.25 & 0.25 & 0.75 & $3,851.85$ & $348,470.017$ & $2,193.24$ & $167,718.482$ & $6,045.09$ & $791,679.400$ \\
\hline JB & Owner & 25 & 0.25 & 0.25 & 0.75 & 3,848.28: & $359,947.975$ & $2,190.45$ & $184,651.299$ & $6,038.73$ & $790,439.816$ \\
\hline 凹 & Owner & 25 & 0.25 & 0.25 & 0.75 & 3,631.10: & $291,135.067$ & $2,415.66:$ & $154,376.919$ & 6,046.76: & $793,191.730$ \\
\hline HW & Capped & 25 & 0.25 & 0.25 & 0.75 & $3,656.40$ & $158,249.294$ & $2,391.21$ & $313,788.645$ & $6,047.60$ & $794,520.713$ \\
\hline JB & Capped & 25 & 0.25 & 0.25 & 0.75 & $3,664.39$ & $178,105.604$ & $2,376.77 !$ & $333,687.538$ & $6,041.17$ & $792,770.476$ \\
\hline 凹 & Capped & 25 & 0.25 & 0.25 & 0.75 & 3,301.60: & $109,642.209$ & $2,746.06 !$ & $330,774.565$ & $6,047.66$ & $793,018.440$ \\
\hline
\end{tabular}

Table 4-39 - Drivers Required \#2

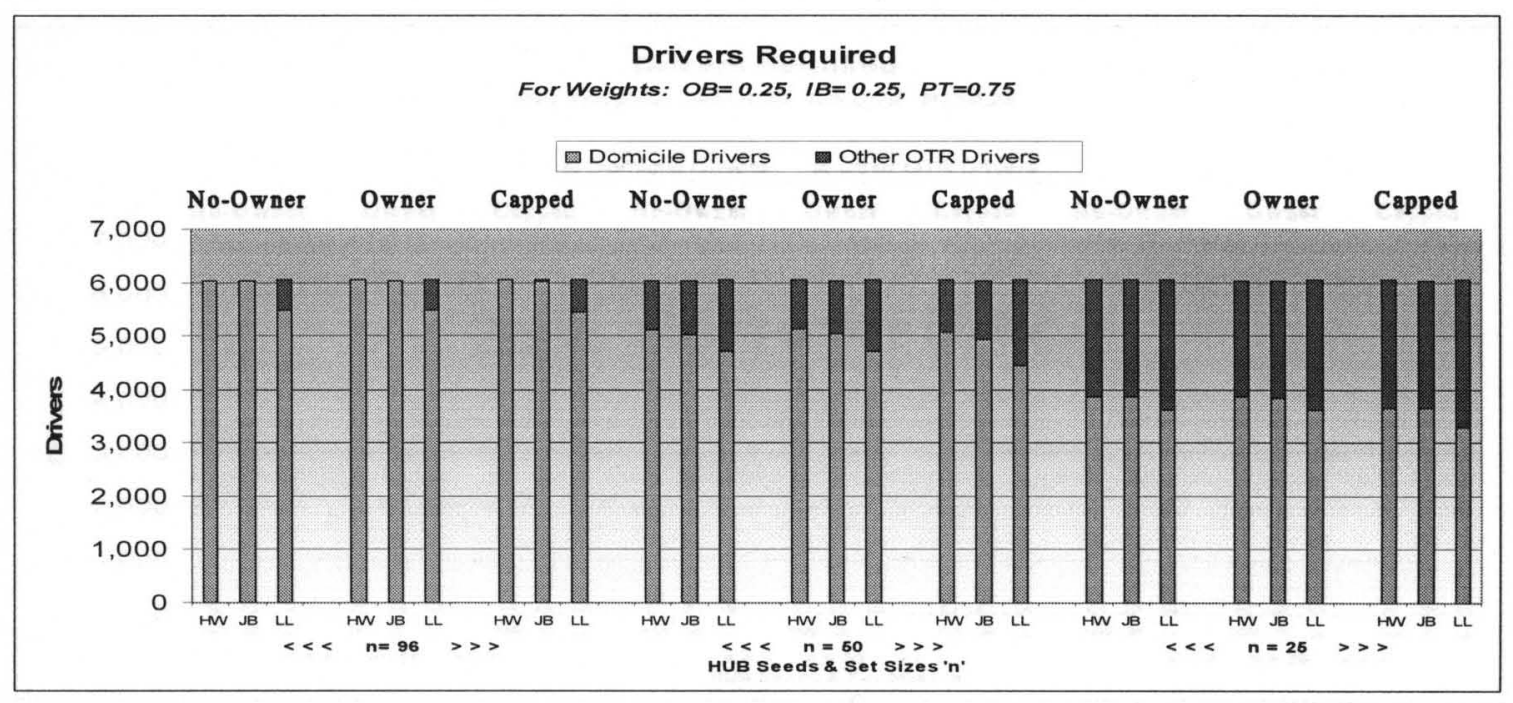




\begin{tabular}{|c|c|c|c|c|c|c|c|c|c|c|c|}
\hline \multirow{2}{*}{ Data } & \multirow[t]{2}{*}{ Type } & \multirow[t]{2}{*}{ Size } & \multirow[t]{2}{*}{ OB } & \multirow[t]{2}{*}{ IB } & \multirow[t]{2}{*}{ PT } & \multicolumn{2}{|c|}{ Drivers Domicile } & \multicolumn{2}{|c|}{ Drivers OTR } & \multicolumn{2}{|c|}{ Drivers All } \\
\hline & & & & & & Mean & Var & Mean & Var & Mean & Var \\
\hline \multicolumn{12}{|c|}{ 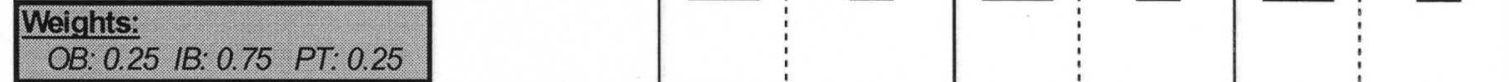 } \\
\hline $\mathrm{HW}$ & No-Owner & 96 & 0.25 & 0.75 & 0.25 & $6,044.43$ & $964,916.867$ & 19.90 & $233,646.237$ & $6,064.33$ & $797,103.713$ \\
\hline $\mathrm{JB}$ & No-Owner & 96 & 0.25 & 0.75 & 0.25 & $6,026.47$ & $881,099.063$ & 17.30 & $143,662.439$ & $6,043.77$ & $791,916.615$ \\
\hline щ & No-Owner & 96 & 0.25 & 0.75 & 0.25 & $5,473.92$ & $916,593.972$ & 572.01 & $381,547.129$ & $6,045.93$ & $792,455.548$ \\
\hline $\mathrm{HW}$ & Owner & 96 & 0.25 & 0.75 & 0.25 & $6,027.49$ & $787,645.711$ & 11.48 & 16.070 & 6,038.97! & $790,228.974$ \\
\hline $\mathrm{JB}$ & Owner & 96 & 0.25 & 0.75 & 0.25 & $6,032.43$ & $794,746.201$ & 11.42 & 5.977 & $6,043.85$ & $791,242.658$ \\
\hline u & Owner & 96 & 0.25 & 0.75 & 0.25 & $5,483.34$ & $677,967.100$ & 562.66 & $11,586.572$ & $6,046.00$ & $793,060.761$ \\
\hline $\mathrm{HW}$ & Capped & 96 & 0.25 & 0.75 & 0.25 & $6,019.39$ & $752,896.719$ & 21.73 & 557.492 & $6,041.13$ & $792,549.283$ \\
\hline $\mathrm{JB}$ & Capped & 96 & 0.25 & 0.75 & 0.25 & $6,004.70$ & $749,392.313$ & 41.93 & 739.550 & $6,046.62$ & $794,344.662$ \\
\hline แ & Capped & 96 & 0.25 & 0.75 & 0.25 & $5,450.22$ & $642,149.434$ & 597.04 & $18,789.005$ & $6,047.26$ & $794,032.547$ \\
\hline $\mathrm{HW}$ & No-Owner & 50 & 0.25 & 0.75 & 0.25 & $5,107.10$ & $715,697.709$ & 947.24 & $239,935.822$ & $6,054.35$ & $794,549.539$ \\
\hline $\mathrm{JB}$ & No-Owner & 50 & 0.25 & 0.75 & 0.25 & $5,032.98$ & $630,158.432$ & $1,007.09$ & $175,581.309$ & $6,040.07$ & $791,009.200$ \\
\hline แL & No-Owner & 50 & 0.25 & 0.75 & 0.25 & 4,713.98: & $669,200.662$ & $1,331.97$ & $315,187.706$ & 6,045.95: & $792,458.738$ \\
\hline $\mathrm{HW}$ & Owner & 50 & 0.25 & 0.75 & 0.25 & $5,098.18$ & $570,482.157$ & $940.47 \vdots$ & $24,787.022$ & $6,038.65$ & $790,406.264$ \\
\hline$J B$ & Owner & 50 & 0.25 & 0.75 & 0.25 & $5,036.78$ & $566,687.139$ & $1,003.33$ & $37,034.984$ & $6,040.11$ & $790,685.490$ \\
\hline แ & Owner & 50 & 0.25 & 0.75 & 0.25 & $4,720.63$ & $492,870.503$ & $1,325.40$ & $63,310.456$ & $6,046.03$ & $793,033.792$ \\
\hline $\mathrm{HW}$ & Capped & 50 & 0.25 & 0.75 & 0.25 & $5,050.49$ & $467,934.913$ & $990.37 !$ & $48,615.159$ & $6,040.86$ & $792,882.630$ \\
\hline $\mathrm{JB}$ & Capped & 50 & 0.25 & 0.75 & 0.25 & $4,929.54$ & $434,387.675$ & $1,113.07$ & $68,035.368$ & $6,042.61$ & $793,183.905$ \\
\hline 凹 & Capped & 50 & 0.25 & 0.75 & 0.25 & $4,463.42$ & $353,050.153$ & 1,583.91: & $103,698.557$ & 6,047.33i & $793,878.721$ \\
\hline $\mathrm{HW}$ & No-Owner & 25 & 0.25 & 0.75 & 0.25 & $3,851.06$ & $431,270.561$ & 2,193.96! & $289,182.382$ & $6,045.02$ & $792,233.275$ \\
\hline $\mathrm{JB}$ & No-Owner & 25 & 0.25 & 0.75 & 0.25 & $3,846.73$ & $402,329.421$ & $2,191.97$ & $255,836.480$ & $6,038.70$ & $790,692.128$ \\
\hline แL & No-Owner & 25 & 0.25 & 0.75 & 0.25 & $3,625.83$ & $408,001.001$ & $2,420.86$ & $318,140.543$ & $6,046.69$ & $792,640.804$ \\
\hline $\mathrm{HW}$ & Owner & 25 & 0.25 & 0.75 & 0.25 & $3,846.29$ & $347,570.577$ & $2,190.90$ & $164,800.299$ & $6,037.19$ & $790,234.942$ \\
\hline $\mathrm{JB}$ & Owner & 25 & 0.25 & 0.75 & 0.25 & $3,848.28$ & $359,947.975$ & $2,190.45$ & $184,651.299$ & $6,038.73$ & $790,439.816$ \\
\hline $\mathrm{LL}$ & Owner & 25 & 0.25 & 0.75 & 0.25 & $3,631.10$ & $291,135.067$ & $2,415.66$ & $154,376.919$ & $6,046.76$ & $793,191.730$ \\
\hline $\mathrm{HW}$ & & 25 & 0.25 & 0.75 & 0.25 & & $157,361.369$ & 2,393.25! & $310,211.775$ & & $792,805.100$ \\
\hline JB & Capped & 25 & 0.25 & 0.75 & 0.25 & $3,664.39$ & $178,105.604$ & $2,376.77$ & $333,687.538$ & $6,041.17$ & $792,770.476$ \\
\hline $\mathrm{LL}$ & Capped & 25 & 0.25 & 0.75 & 0.25 & $3,301.60$ & $109,642.209$ & $2,746.06$ & $330,774.565$ & $6,047.66$ & $793,018.440$ \\
\hline
\end{tabular}

Table 4-40 - Drivers Required \#3

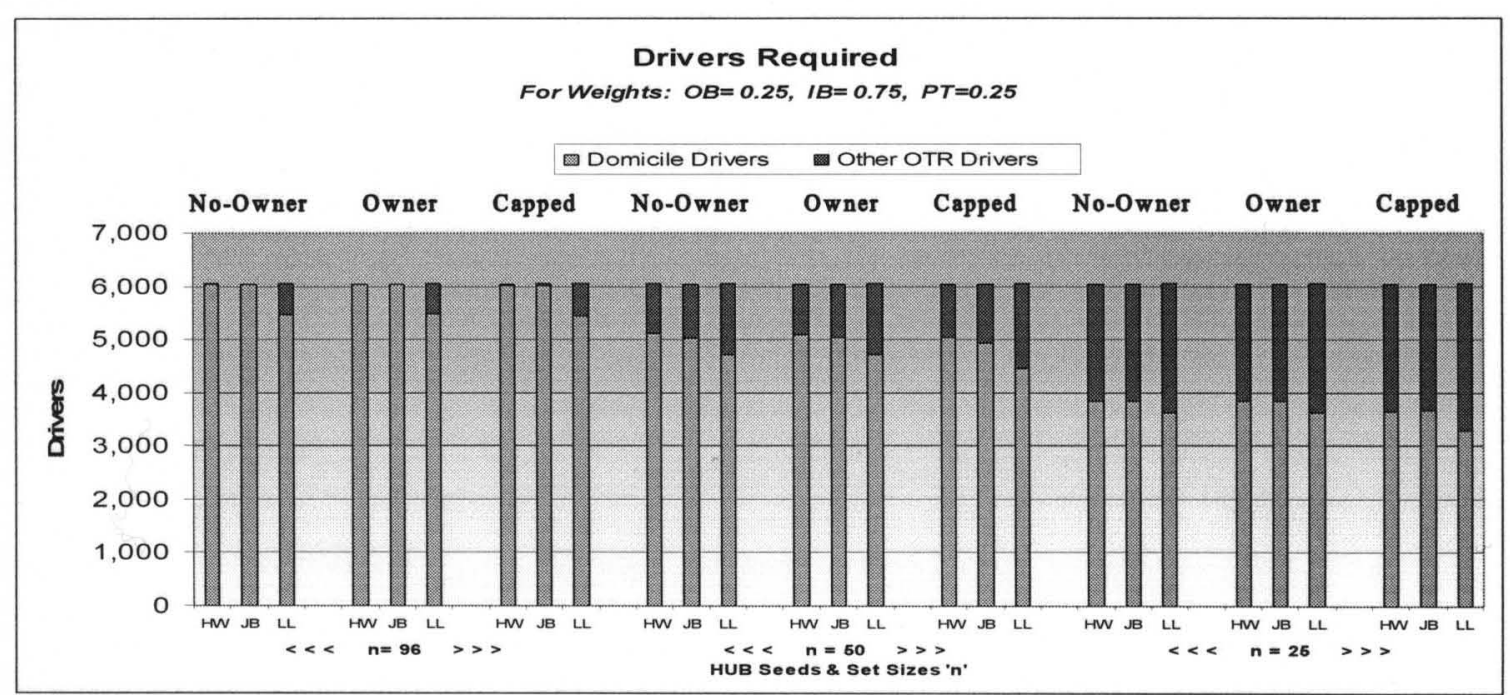




\begin{tabular}{|c|c|c|c|c|c|c|c|c|c|c|c|}
\hline \multirow{3}{*}{$\begin{array}{c}\text { Data } \\
\text { Weights: } \\
\text { OB: } 0.25\end{array}$} & \multirow[t]{2}{*}{ Type } & \multirow[t]{2}{*}{ Size } & \multirow[t]{3}{*}{ OB } & \multirow[t]{3}{*}{ IB } & \multirow[t]{3}{*}{ PT } & \multicolumn{2}{|c|}{ Drivers Domicile } & \multicolumn{2}{|c|}{ Drivers OTR } & \multicolumn{2}{|c|}{ Drivers All } \\
\hline & & & & & & \multirow[t]{2}{*}{ Mean } & \multirow[t]{2}{*}{$\underline{\text { Var }}$} & \multirow[t]{2}{*}{ Mean } & \multirow[t]{2}{*}{$\underline{\text { Var }}$} & \multirow[t]{2}{*}{ Mean } & \multirow[t]{2}{*}{$\underline{\text { Var }}$} \\
\hline & 0.75 PT: & & & & & & & & & & \\
\hline $\mathrm{HW}$ & No-Owner & $\overline{96}$ & 0.25 & 0.75 & 0.75 & $6,038.43$ & $963,065.767$ & 20.57 & $233,666.375$ & $6,058.99$ & $795,757.741$ \\
\hline $\mathrm{JB}$ & No-Owner & 96 & 0.25 & 0.75 & 0.75 & $6,024.73$ & $880,588.205$ & 17.30 & $143,662.439$ & $6,042.03$ & $791,471.219$ \\
\hline せ & No-Owner & 96 & 0.25 & 0.75 & 0.75 & $5,475.76$ & $917,212.818$ & 572.01 & $381,547.129$ & 6,047.77: & $792,903.000$ \\
\hline $\mathrm{HW}$ & Owner & 96 & 0.25 & 0.75 & 0.75 & $6,041.11$ & $789,534.964$ & 12.15 & 17.756 & $6,053.25$ & $792,432,841$ \\
\hline $\mathrm{JB}$ & Owner & 96 & 0.25 & 0.75 & 0.75 & $6,032.43$ & $794,746.201$ & 11.42 & 5.977 & $6,043.85$ & $791,242.658$ \\
\hline$\amalg$ & Owner & 96 & 0.25 & 0.75 & 0.75 & 5,483.34: & $677,967.100$ & 562.66 & $11,586.572$ & $6,046.00$ & $793,060.761$ \\
\hline $\mathrm{HW}$ & Capped & 96 & 0.25 & 0.75 & 0.75 & $6,033.25$ & $753,724.194$ & 22.32 & 608.454 & $6,055.57$ & $795,241.423$ \\
\hline $\mathrm{JB}$ & Capped & 96 & 0.25 & 0.75 & 0.75 & $6,004.70$ & $749,392.313$ & 41.93 & 739.550 & $6,046.62$ & $794,344.662$ \\
\hline 凹 & Capped & 96 & 0.25 & 0.75 & 0.75 & 5,450.22 & $642,149.434$ & 597.04 & $18,789.005$ & 6,047.26! & $794,032.547$ \\
\hline $\mathrm{HW}$ & No-Omner & 50 & 0.25 & 0.75 & 0.75 & $5,107.52$ & $715,868.407$ & 941.02 & $240,180.042$ & $6,048.53$ & $793,104.846$ \\
\hline $\mathrm{JB}$ & No-Owner & 50 & 0.25 & 0.75 & 0.75 & $5,032.58$ & $630,063.907$ & $1,007.09$ & $175,581.309$ & $6,039.67$ & $790,911.941$ \\
\hline 凹 & No-Owner & 50 & 0.25 & 0.75 & 0.75 & 4,716.74: & $669,984.398$ & $1,331.97$ & $315,187.706$ & $6,048.71$ & $793,134.410$ \\
\hline $\mathrm{HW}$ & Owner & 50 & 0.25 & 0.75 & 0.75 & $5,113.48$ & $575,196.226$ & 934.19 & $23,567.028$ & $6,047.67 !$ & $792,071.334$ \\
\hline $\mathrm{JB}$ & Owner & 50 & 0.25 & 0.75 & 0.75 & $5,036.78$ & $566,687.139$ & $1,003.33$ & $37,034.984$ & $6,040.11$ & $790,685.490$ \\
\hline 凹 & Owner & 50 & 0.25 & 0.75 & 0.75 & $4,720.63$ & $492,870.503$ & $1,325.40$ & $63,310.456$ & $6,046.03$ & $793,033.792$ \\
\hline $\mathrm{HW}$ & Capped & 50 & 0.25 & 0.75 & 0.75 & $5,067.26$ & $473,242.605$ & 982.74 & $46,932.501$ & $6,050.00$ & $794,810.417$ \\
\hline $\mathrm{JB}$ & Capped & 50 & 0.25 & 0.75 & 0.75 & $4,929.54$ & $434,387.675$ & $1,113.07$ & $68,035.368$ & $6,042.61$ & $793,183.905$ \\
\hline 凹 & Capped & 50 & 0.25 & 0.75 & 0.75 & $4,463.42$ & $353,050.153$ & 1,583.91: & $103,698.557$ & $6,047.33$ & $793,878.721$ \\
\hline $\mathrm{HW}$ & No-Owner & 25 & 0.25 & 0.75 & 0.75 & $3,845.07$ & $429,928.862$ & $2,197.44$ & $289,246.966$ & $6,042.50$ & $791,623.650$ \\
\hline $\mathrm{JB}$ & No-Owner & 25 & 0.25 & 0.75 & 0.75 & $3,854.04$ & $403,860.300$ & 2,191.97! & $255,836.480$ & $6,046.02$ & $792,477.887$ \\
\hline щ & No-Owner & 25 & 0.25 & 0.75 & 0.75 & $3,625.61$ & $407,949.848$ & $2,420.86 !$ & $318,140.543$ & $6,046.48$ & $792,591.684$ \\
\hline $\mathrm{HW}$ & Owner & 25 & 0.25 & 0.75 & 0.75 & $3,846.96$ & $348,877.047$ & $2,194.48$ & $167,790.088$ & $6,041.45$ & $791,062.572$ \\
\hline $\mathrm{JB}$ & Owner & 25 & 0.25 & 0.75 & 0.75 & $3,848.28$ & $359,947.975$ & $2,190.45$ & $184,651.299$ & $6,038.73$ & $790,439.816$ \\
\hline 凹 & Owner & 25 & 0.25 & 0.75 & 0.75 & $3,631.10$ & $291,135.067$ & $2,415.66$ & $154,376.919$ & $6,046.76$ & $793,191.730$ \\
\hline $\mathrm{HW}$ & Capped & 25 & 0.25 & 0.75 & 0.75 & $3,651.27$ & $158,017.662$ & $2,392.65$ & $314,348.712$ & $6,043.92$ & $793,798.854$ \\
\hline $\mathrm{JB}$ & Capped & 25 & 0.25 & 0.75 & 0.75 & $3,664.39$ & $178,105.604$ & $2,376.77$ & $333,687.538$ & $6,041.17$ & $792,770.476$ \\
\hline แL & Capped & 25 & 0.25 & 0.75 & 0.75 & $3,301.60$ & $109,642.209$ & $2,746.06 !$ & $330,774.565$ & $6,047.66$ & $793,018.440$ \\
\hline
\end{tabular}

Table 4-41 - Drivers Required \#4

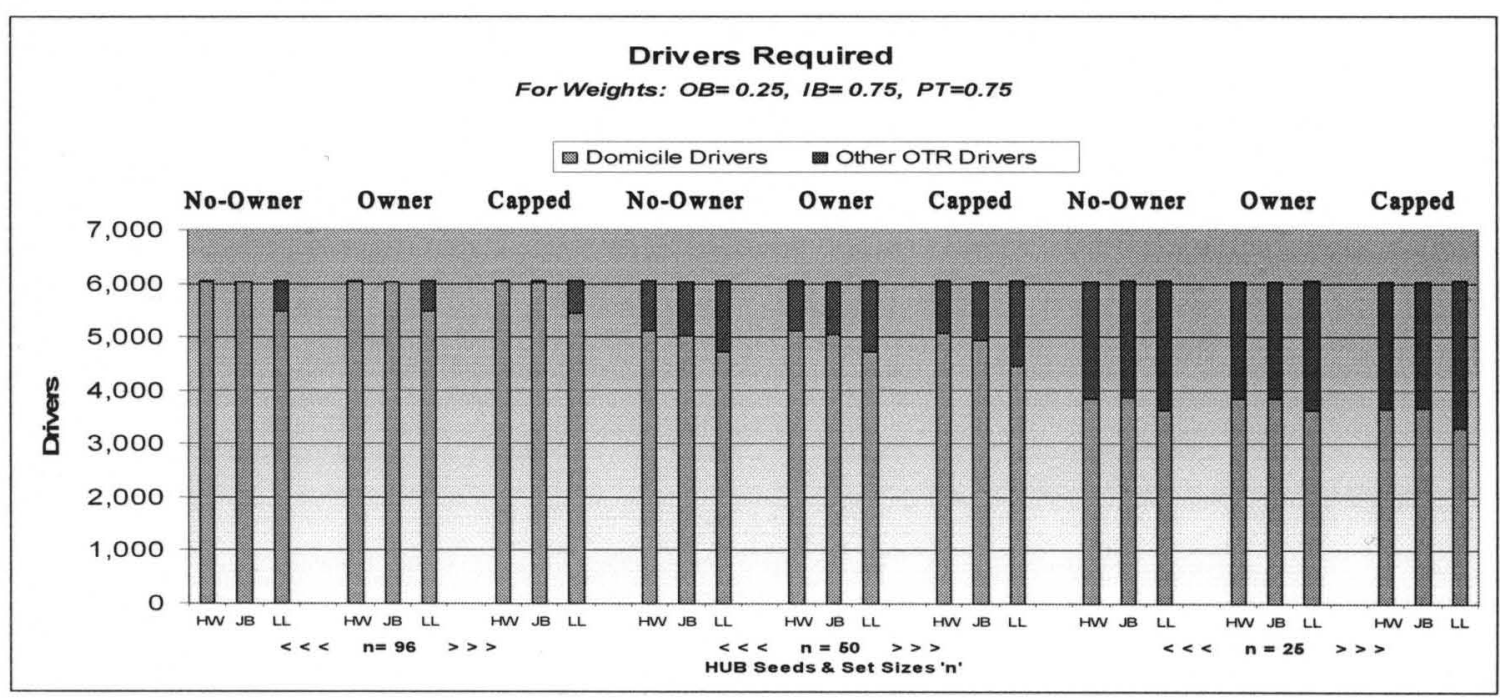




\begin{tabular}{|c|c|c|c|c|c|c|c|c|c|c|c|}
\hline \multirow{3}{*}{ Data } & \multirow[t]{2}{*}{ Type } & \multirow[t]{2}{*}{ Size } & \multirow[t]{2}{*}{ OB } & \multirow[t]{2}{*}{ IB } & \multirow[t]{2}{*}{ PT } & \multicolumn{2}{|c|}{ Drivers Domicile } & \multicolumn{2}{|c|}{ Drivers OTR } & \multicolumn{2}{|c|}{ Drivers Al } \\
\hline & & & & & & \multirow[t]{2}{*}{ Mean : } & \multirow[t]{2}{*}{$\underline{\text { Var }}$} & \multirow{2}{*}{ Mean } & \multirow[t]{2}{*}{$\underline{\text { Var }}$} & \multirow{2}{*}{ Mean } & \multirow[t]{2}{*}{$\underline{\text { Var }}$} \\
\hline & & & & & & & & & & & \\
\hline HW & No-Owner & 96 & 0.75 & 0.25 & 0.25 & $6,018.99$ & $956,809.613$ & 19.90 & $233,645.678$ & 6,038.89: & $790,688.165$ \\
\hline$J B$ & No-Owner & 96 & 0.75 & 0.25 & 0.25 & $6,026.47$ & $881,099.063$ & 17.30 & $143,662.439$ & $6,043.77$ & $791,916.615$ \\
\hline щ & & 96 & 0.75 & 0.25 & 0.25 & $5,473.92$ & $916,593.972$ & 572.01 & $381,547.129$ & 6,045.93: & $792,455.548$ \\
\hline $\mathrm{HW}$ & Owner & 96 & 0.75 & 0.25 & 0.25 & $6,027.15$ & $787,732.306$ & 11.48 & 16.064 & $6,038.63$ & $790,317.098$ \\
\hline $\mathrm{JB}$ & Ow & 96 & 0.75 & 0.25 & 0.25 & 6,03 & $794,746.201$ & 11.42 & 5.977 & 043.85 & $791,242.658$ \\
\hline ㄴ & Owner & 96 & 0.75 & 0.25 & 0.25 & $5,483.34$ & $677,967.100$ & 562.66 & $11,586.572$ & $6,046.00$ & $793,060.761$ \\
\hline $\mathrm{HW}$ & & 96 & 0.75 & 0.25 & 0.25 & & & 2107 & 477.465 & $6,040.53$ & $792,157.089$ \\
\hline$J B$ & & 96 & 0.75 & 0.25 & 0.25 & 6,00 & 2.313 & 41.93 & 739.550 & $6,046.62$ & $794,344.662$ \\
\hline ㄴ & Capped & 96 & 0.75 & 0.25 & 0.25 & $5,450.22$ & $642,149.434$ & 597.04 & $18,789.005$ & $6,047.26$ & $794,032.547$ \\
\hline $\mathrm{HW}$ & & 50 & & 0.25 & 0.25 & & & 948.30 & $239,902.622$ & $6,038.59$ & $790,637.100$ \\
\hline $\mathrm{JB}$ & & 50 & & 0.25 & 0.25 & & & $1,007.09$ & $175,581.309$ & $6,040.07$ & $791,009.200$ \\
\hline ㄴ & No-Owner & 50 & 0.75 & 0.25 & 0.25 & 4,713.98: & $669,200.662$ & $1,331.97$ & $315,187.706$ & $6,045.95$ & $792,458.738$ \\
\hline $\mathrm{HW}$ & Mnor & 50 & 0.75 & 0.25 & 0.25 & & & 941 & $22, \pi$ & 6,038 & 790, \\
\hline $\mathrm{JB}$ & & 50 & 0.75 & 0.25 & 0.25 & 5 , & & $1,003.33$ & $37,034.984$ & 6,040 . & $790,685.490$ \\
\hline$\amalg$ & Owner & 50 & 0.75 & 0.25 & 0.25 & 4,720.63: & $492,870.503$ & $1,325.40$ & $63,310.456$ & $6,046.03$ & $793,033.792$ \\
\hline $\mathrm{HW}$ & nned & 50 & 0.75 & 0.25 & 0.25 & & & 989.43 & $44,337.954$ & $6,04 \mathrm{C}$ & $792,593.984$ \\
\hline $\mathrm{JB}$ & & 50 & & 0.25 & 0.25 & & & $1,113.07$ & $68,035.368$ & 6,042 & $793,183.905$ \\
\hline ㄴ & Capped & 50 & 0.75 & 0.25 & 0.25 & $4,463.42$ & $353,050.153$ & $1,583.91$ & $103,698.557$ & $6,047.33 i$ & $793,878.721$ \\
\hline HW & & 25 & 0.75 & 0.25 & 0.25 & $3,844.04 !$ & $429,699.688$ & 2,193.11! & $289,165.681$ & 6,037.15! & $790,328.600$ \\
\hline $\mathrm{JB}$ & Mner & 25 & 0.75 & 0.25 & 25 & & & $2,191.97$ & $255,836.480$ & 6,038 & $790,692.128$ \\
\hline 凹 & No-Owner & 25 & 0.75 & 0.25 & 0.25 & $3,625.83$ & $408,001.001$ & $2,420.86$ & $318,140.543$ & $6,046.69$ & $792,640.804$ \\
\hline HW & & 25 & 0.75 & 0.25 & 0.25 & & $349,903.459$ & 210010 & $165,165.298$ & $6,037.31$ & $790,199.339$ \\
\hline $\mathrm{JB}$ & & 25 & 0.7 & 0.25 & 25 & & & $2,190.45$ & $184,651.299$ & $6,038.73$ & $790,439.816$ \\
\hline ㄴ & Owner & 25 & 0.75 & 0.25 & 0.25 & $3,631.10$ & $291,135.067$ & $2,415.66$ & $154,376.919$ & $6,046.76$ & $793,191.730$ \\
\hline HW & & 25 & 0.7 & 0.25 & 0.25 & & & & & & $792,391.478$ \\
\hline $\mathrm{JB}$ & & 25 & 0.7 & 0.25 & 0.25 & 3,664 . & & $2,376.77$ & $333,687.538$ & $6,041.17$ & $792,770.476$ \\
\hline$\amalg$ & Capped & 25 & 0.75 & 0.25 & 0.25 & $3,301,60$ & $109,642.209$ & $2,746.06$ & $330,774.565$ & $6,047.66$ & $793,018.440$ \\
\hline
\end{tabular}

Table 4-42 - Drivers Required \#5

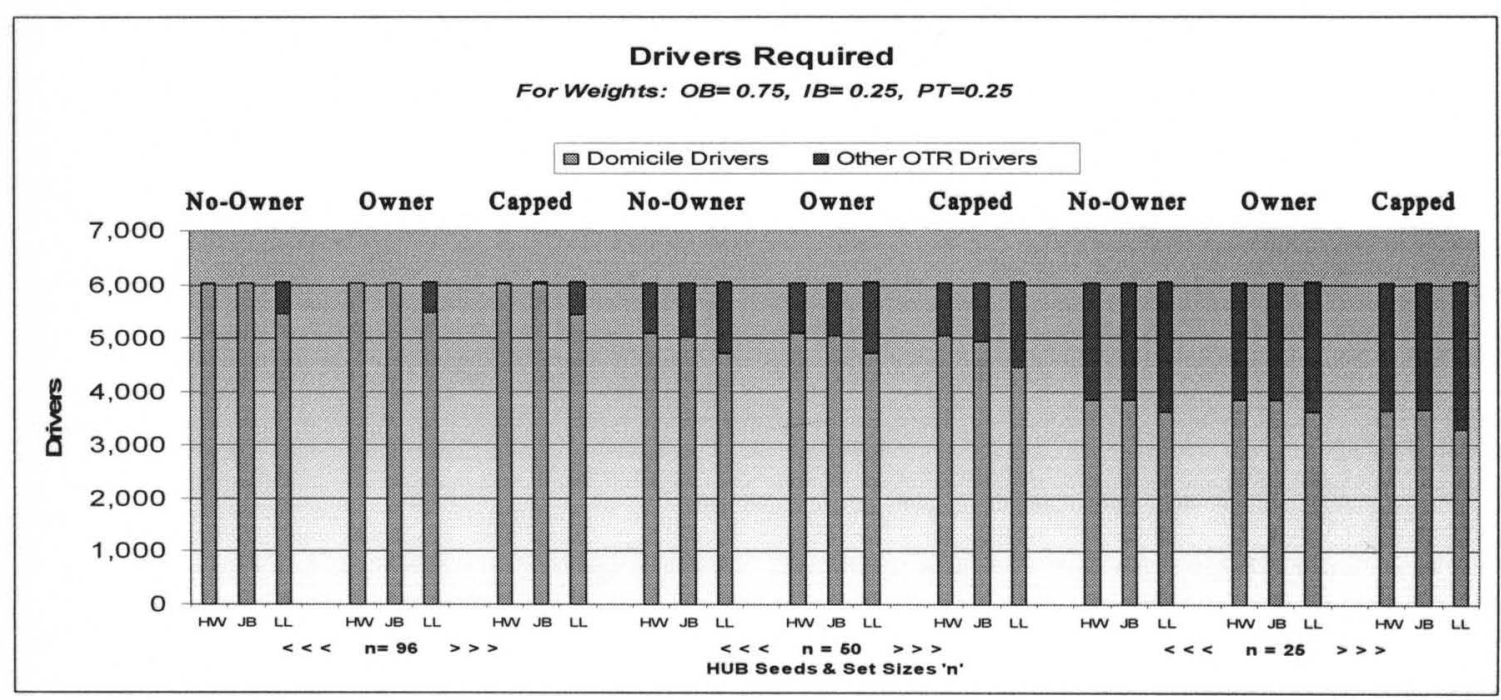




\begin{tabular}{|c|c|c|c|c|c|c|c|c|c|c|c|}
\hline \multirow{3}{*}{$\begin{array}{c}\text { Data } \\
\text { Weights: } \\
\text { OB: } 0.75\end{array}$} & \multirow[t]{2}{*}{ Type } & \multirow[t]{2}{*}{ Size } & \multirow[t]{2}{*}{ OB } & \multirow[t]{2}{*}{ IB } & \multirow[t]{2}{*}{ PT } & \multicolumn{2}{|c|}{ Drivers Domicile } & \multicolumn{2}{|c|}{ Drivers OTR } & \multicolumn{2}{|c|}{ Drivers All } \\
\hline & & & & & & \multirow[t]{2}{*}{ Mean : } & \multirow{2}{*}{$\underline{\text { Var }}$} & \multirow[t]{2}{*}{ Mean } & \multirow{2}{*}{$\underline{\text { Var }}$} & \multirow[t]{2}{*}{ Mean : } & \multirow{2}{*}{$\underline{\text { Var }}$} \\
\hline & 0.25 PT: & 0.75 & & & & & & & & & \\
\hline HW & No-Owner & 96 & 0.75 & 0.25 & 0.75 & $6,019.97$ & $957,267.337$ & 20.04 & $233,769.183$ & $6,040.01$ & $790,975.229$ \\
\hline$J B$ & No-Owner & 96 & 0.75 & 0.25 & 0.75 & $6,024.73$ & $880,588.205$ & 17.30 & $143,662.439$ & $6,042.03$ & $791,471.219$ \\
\hline แ & No-Owner & 96 & 0.75 & 0.25 & 0.75 & $5,475.76$ & $917,212.818$ & 572.01 & $381,547.129$ & $6,047.77$ & $792,903.000$ \\
\hline HW & Owner & 96 & 0.75 & 0.25 & 0.75 & $6,041.33$ & $789,289.832$ & 11.62 & 16.098 & $6,052.94$ & $791,890.868$ \\
\hline $\mathrm{JB}$ & Owner & 96 & 0.75 & 0.25 & 0.75 & $6,032.43$ & $794,746.201$ & 11.42 & 5.977 & $6,043.85$ & $791,242.658$ \\
\hline แ & Owner & 96 & 0.75 & 0.25 & 0.75 & $5,483.34$ & $677,967.100$ & 562.66 & $11,586.572$ & $6,046.00$ & $793,060.761$ \\
\hline $\mathrm{HW}$ & Capped & 96 & 0.75 & 0.25 & 0.75 & $6,033.59$ & $756,523.970$ & 21.57 & 504.643 & $6,055.16$ & $794,336.553$ \\
\hline $\mathrm{JB}$ & Capped & 96 & 0.75 & 0.25 & 0.75 & $6,004.70$ & $749,392.313$ & 41.93 & 739.550 & $6,046.62$ & $794,344.662$ \\
\hline แ & Capped & 96 & 0.75 & 0.25 & 0.75 & $5,450.22$ & $642,149.434$ & 597.04 & $18,789.005$ & $6,047.26$ & $794,032.547$ \\
\hline $\mathrm{HW}$ & No-Owner & 50 & 0.75 & 0.25 & 0.75 & $5,095.97$ & $712,716.967$ & 941.43 & $240,242.027$ & $6,037.40$ & $790,346.442$ \\
\hline $\mathrm{JB}$ & No-Owner & 50 & 0.75 & 0.25 & 0.75 & $5,032.58$ & $630,063.907$ & $1,007.09$ & $175,581.309$ & $6,039.67$ & $790,911.941$ \\
\hline uL & No-Owner & 50 & 0.75 & 0.25 & 0.75 & $4,716.74$ & $669,984.398$ & $1,331.97$ & $315,187.706$ & $6,048.71$ & $793,134.410$ \\
\hline $\mathrm{HW}$ & Owner & 50 & 0.75 & 0.25 & 0.75 & $5,112.29$ & $573,744.490$ & 934.59 & $23,771.118$ & $6,046.88$ & $791,753.834$ \\
\hline $\mathrm{JB}$ & Owner & 50 & 0.75 & 0.25 & 0.75 & $5,036.78$ & $566,687.139$ & $1,003.33$ & $37,034.984$ & $6,040.11$ & $790,685.490$ \\
\hline$\amalg$ & Owner & 50 & 0.75 & 0.25 & 0.75 & 4,720.63 & $492,870.503$ & $1,325.40$ & $63,310.456$ & $6,046.03$ & $793,033.792$ \\
\hline $\mathrm{HW}$ & Capped & 50 & 0.75 & 0.25 & 0.75 & $5,067.28$ & $476,650.915$ & 981.90 & $45,863.906$ & $6,049.18$ & $794,337.261$ \\
\hline $\mathrm{JB}$ & Capped & 50 & 0.75 & 0.25 & 0.75 & $4,929.54$ & $434,387.675$ & 1,113.07? & $68,035.368$ & $6,042.61$ & $793,183.905$ \\
\hline 凹 & Capped & 50 & 0.75 & 0.25 & 0.75 & $4,463.42$ & $353,050.153$ & 1,583.91: & $103,698.557$ & $6,047.33$ & $793,878.721$ \\
\hline $\mathrm{HW}$ & No-Owner & 25 & 0.75 & 0.25 & 0.75 & $3,856.01$ & $432,377.761$ & $2,195.68 !$ & $289,215.529$ & $6,051.69$ & $793,852.155$ \\
\hline $\mathrm{JB}$ & No-Owner & 25 & 0.75 & 0.25 & 0.75 & $3,854.04$ & $403,860.300$ & $2,191.97$ & $255,836.480$ & $6,046.02$ & $792,477.887$ \\
\hline แ & No-Owner & 25 & 0.75 & 0.25 & 0.75 & $3,625.61$ & $407,949.848$ & $2,420.86$ & $318,140.543$ & $6,046.48$ & $792,591.684$ \\
\hline $\mathrm{HW}$ & Owner & 25 & 0.75 & 0.25 & 0.75 & $3,849.06$ & $348,034.214$ & $2,192.71$ & $167,948.234$ & $6,041.77$ & $790,783.866$ \\
\hline $\mathrm{JB}$ & Owner & 25 & 0.75 & 0.25 & 0.75 & $3,848.28$ & $359,947.975$ & $2,190.45$ & $184,651.299$ & $6,038.73$ & $790,439.816$ \\
\hline $\mathrm{LL}$ & Owner & 25 & 0.75 & 0.25 & 0.75 & $3,631.10$ & $291,135.067$ & $2,415.66$ & $154,376.919$ & $6,046.76$ & $793,191.730$ \\
\hline $\mathrm{HW}$ & Capped & 25 & 0.75 & 0.25 & 0.75 & $3,653.44$ & $159,335.104$ & $2,390.75$ & $311,806.957$ & $6,044.19$ & $793,334.710$ \\
\hline $\mathrm{JB}$ & Capped & 25 & 0.75 & 0.25 & 0.75 & $3,664.39$ & $178,105.604$ & 2,376.77! & $333,687.538$ & $6,041.17 i$ & $792,770.476$ \\
\hline$\longleftrightarrow \mathrm{L}$ & Capped & 25 & 0.75 & 0.25 & 0.75 & $3,301.60$ & $109,642.209$ & $2,746.06 !$ & $330,774.565$ & $6,047.66$ & $793,018.440$ \\
\hline
\end{tabular}

Table 4-43 - Drivers Required \#6

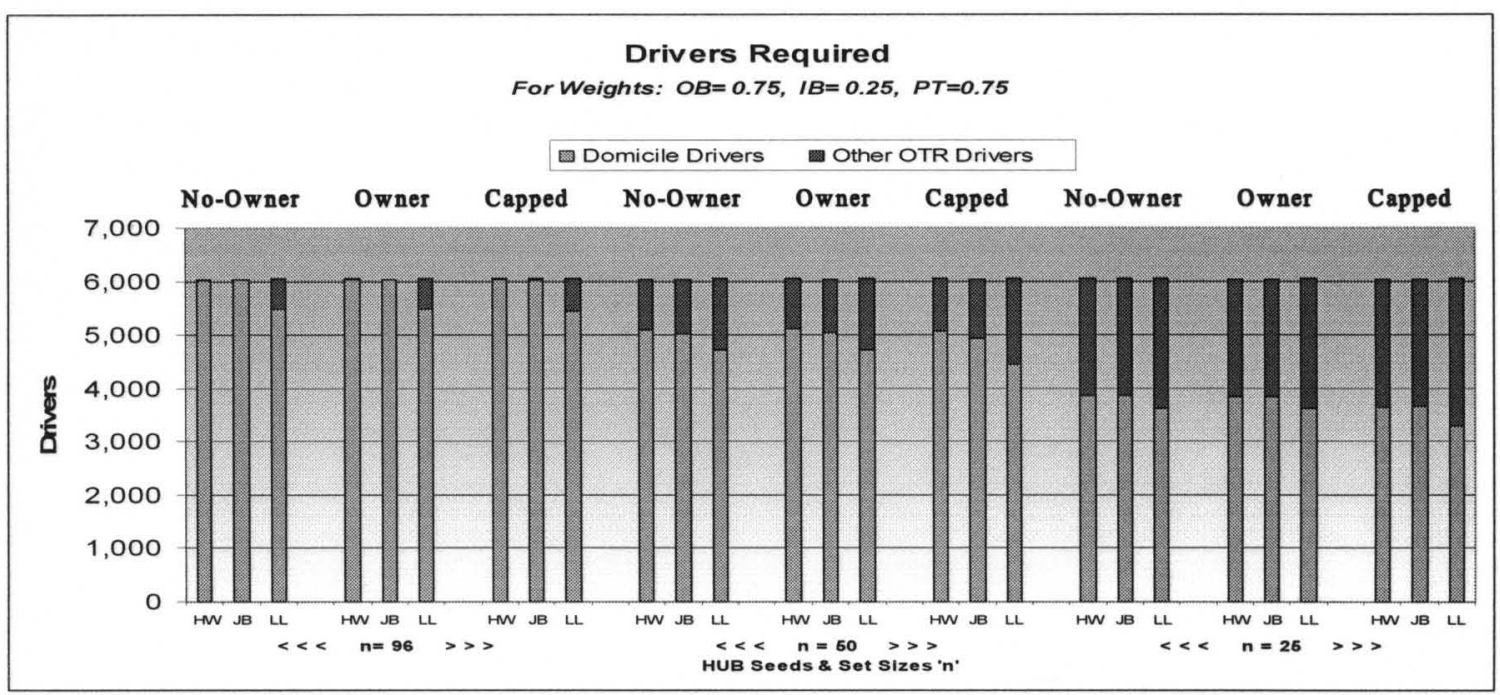




\begin{tabular}{|c|c|c|c|c|c|c|c|c|c|c|c|}
\hline \multirow{3}{*}{\begin{tabular}{|c} 
Data \\
Weights: \\
OB: 0.75
\end{tabular}} & \multirow[t]{2}{*}{ Type } & \multirow[t]{2}{*}{ Size } & \multirow[t]{3}{*}{ OB } & \multirow[t]{3}{*}{ IB } & \multirow[t]{3}{*}{ PT } & \multicolumn{2}{|c|}{ Drivers Domicile } & \multicolumn{2}{|c|}{ Drivers OTR } & \multicolumn{2}{|c|}{ Drivers Al } \\
\hline & & & & & & \multirow[t]{2}{*}{ Mean : } & \multirow[t]{2}{*}{$\underline{\text { Var }}$} & \multirow[t]{2}{*}{ Mean : } & \multirow[t]{2}{*}{$\underline{\text { Var }}$} & \multirow[t]{2}{*}{ Mean } & \multirow[t]{2}{*}{$\underline{\text { Var }}$} \\
\hline & 0.75 PT: & 0.25 & & & & & & & & & \\
\hline $\mathrm{HW}$ & No-Owner & 96 & 0.75 & 0.75 & 0.25 & $6,032.89$ & $961,418.165$ & 20.21 & $233,750.510$ & $6,053.10$ & $794,272.409$ \\
\hline JB & No-Owner & 96 & 0.75 & 0.75 & 0.25 & $6,026.47$ & $881,099.063$ & 17.30 & $143,662.439$ & $6,043.77$ & $791,916.615$ \\
\hline 凹 & No-Owner & 96 & 0.75 & 0.75 & 0.25 & $5,473.92$ & $916,593.972$ & 572.01 & $381,547.129$ & $6,045.93$ & $792,455.548$ \\
\hline $\mathrm{HW}$ & Owner & 96 & 0.75 & 0.75 & 0.25 & $6,024.27$ & $787,237.214$ & 11.79 & 15.953 & $6,036.06 !$ & $789,770.725$ \\
\hline $\mathrm{JB}$ & Owner & 96 & 0.75 & 0.75 & 0.25 & $6,032.43$ & $794,746.201$ & 11.42 & 5.977 & $6,043.85$ & $791,242.658$ \\
\hline 凹 & Owner & 96 & 0.75 & 0.75 & 0.25 & $5,483.34$ & $677,967.100$ & 562.66 & $11,586.572$ & $6,046.00$ & $793,060.761$ \\
\hline $\mathrm{HW}$ & Capped & 96 & 0.75 & 0.75 & 0.25 & $6,016.23$ & $753,821.513$ & 21.77 & 512785 & $6,038.00 !$ & $791,804.090$ \\
\hline $\mathrm{JB}$ & Capped & 96 & 0.75 & 0.75 & 0.25 & $6,004.70$ & $749,392.313$ & 41.93 & 739.550 & $6,046.62$ & $794,344.662$ \\
\hline 凹 & Capped & 96 & 0.75 & 0.75 & 0.25 & $5,450.22$ & $642,149.434$ & 597.04 & $18,789.005$ & $6,047.26$ & $794,032.547$ \\
\hline $\mathrm{HW}$ & No-Owner & 50 & 0.75 & 0.75 & 0.25 & $5,106.03$ & $715,531.586$ & 941.53 & $240,208.582$ & 6,047.56: & $792,864.419$ \\
\hline $\mathrm{JB}$ & No-Owner & 50 & 0.75 & 0.75 & 0.25 & $5,032.98$ & $630,158.432$ & $1,007.09$ & $175,581.309$ & $6,040.07$ & $791,009.200$ \\
\hline แ & No-Owner & 50 & 0.75 & 0.75 & 0.25 & 4,713.98: & $669,200.662$ & $1,331.97$ & $315,187.706$ & $6,045.95$ & $792,458.738$ \\
\hline $\mathrm{HW}$ & Owner & 50 & 0.75 & 0.75 & 0.25 & $5,101.73$ & $576,175.899$ & 934.67 & $22,763.609$ & $6,036.41$ & $790,112.221$ \\
\hline $\mathrm{JB}$ & Owner & 50 & 0.75 & 0.75 & 0.25 & $5,036.78$ & $566,687.139$ & $1,003.33$ & $37,034.984$ & $6,040.11$ & $790,685.490$ \\
\hline 凹 & Owner & 50 & 0.75 & 0.75 & 0.25 & 4,720.63 & $492,870.503$ & $1,325.40$ & $63,310.456$ & $6,046.03$ & $793,033.792$ \\
\hline $\mathrm{HW}$ & Capped & 50 & 0.75 & 0.75 & 0.25 & $5,054.14$ & $474,625.859$ & 984.29 & $45,636.490$ & $6,038.42$ & $792,352.847$ \\
\hline $\mathrm{JB}$ & Capped & 50 & 0.75 & 0.75 & 0.25 & $4,929.54$ & $434,387.675$ & $1,113.07$ & $68,035.368$ & $6,042.61$ & $793,183.905$ \\
\hline ㄴ & Capped & 50 & 0.75 & 0.75 & 0.25 & $4,463.42$ & $353,050.153$ & $1,583.91$ & $103,698.557$ & $6,047.33$ & $793,878.721$ \\
\hline $\mathrm{HW}$ & No-Owner & 25 & 0.75 & 0.75 & 0.25 & $3,849.82$ & $431,079.834$ & $2,191.58 !$ & $289,184.854$ & $6,041.39$ & $791,352.944$ \\
\hline $\mathrm{JB}$ & No-Owner & 25 & 0.75 & 0.75 & 0.25 & $3,846.73$ & $402,329.421$ & $2,191.97$ & $255,836.480$ & $6,038.70$ & $790,692.128$ \\
\hline 凹 & No-Owner & 25 & 0.75 & 0.75 & 0.25 & $3,625.83$ & $408,001.001$ & $2,420.86 !$ & $318,140.543$ & $6,046.69$ & $792,640.804$ \\
\hline $\mathrm{HW}$ & Owner & 25 & 0.75 & 0.75 & 0.25 & $3,847.47$ & $350,625.408$ & $2,188.50$ & $161,973.657$ & $6,035.97$ & $790,113.596$ \\
\hline $\mathrm{JB}$ & Owner & 25 & 0.75 & 0.75 & 0.25 & $3,848.28$ & $359,947.975$ & $2,190.45$ & $184,651.299$ & $6,038.73$ & $790,439.816$ \\
\hline 凹 & Owner & 25 & 0.75 & 0.75 & 0.25 & $3,631.10$ & $291,135.067$ & $2,415.66 !$ & $154,376.919$ & $6,046.76$ & $793,191.730$ \\
\hline $\mathrm{HW}$ & Capped & 25 & 0.75 & 0.75 & 0.25 & $3,646.22$ & $158,851.161$ & $2,391.97$ & $306,833.637$ & $6,038.19$ & $792,426.056$ \\
\hline $\mathrm{JB}$ & Capped & 25 & 0.75 & 0.75 & 0.25 & $3,664.39$ & $178,105.604$ & $2,376.77$ & $333,687.538$ & $6,041.17$ & $792,770.476$ \\
\hline 凹 & Capped & 25 & 0.75 & 0.75 & 0.25 & $3,301.60$ & $109,642.209$ & $2,746.06 !$ & $330,774.565$ & $6,047.66$ & $793,018.440$ \\
\hline
\end{tabular}

Table 4-44 - Drivers Required \#7

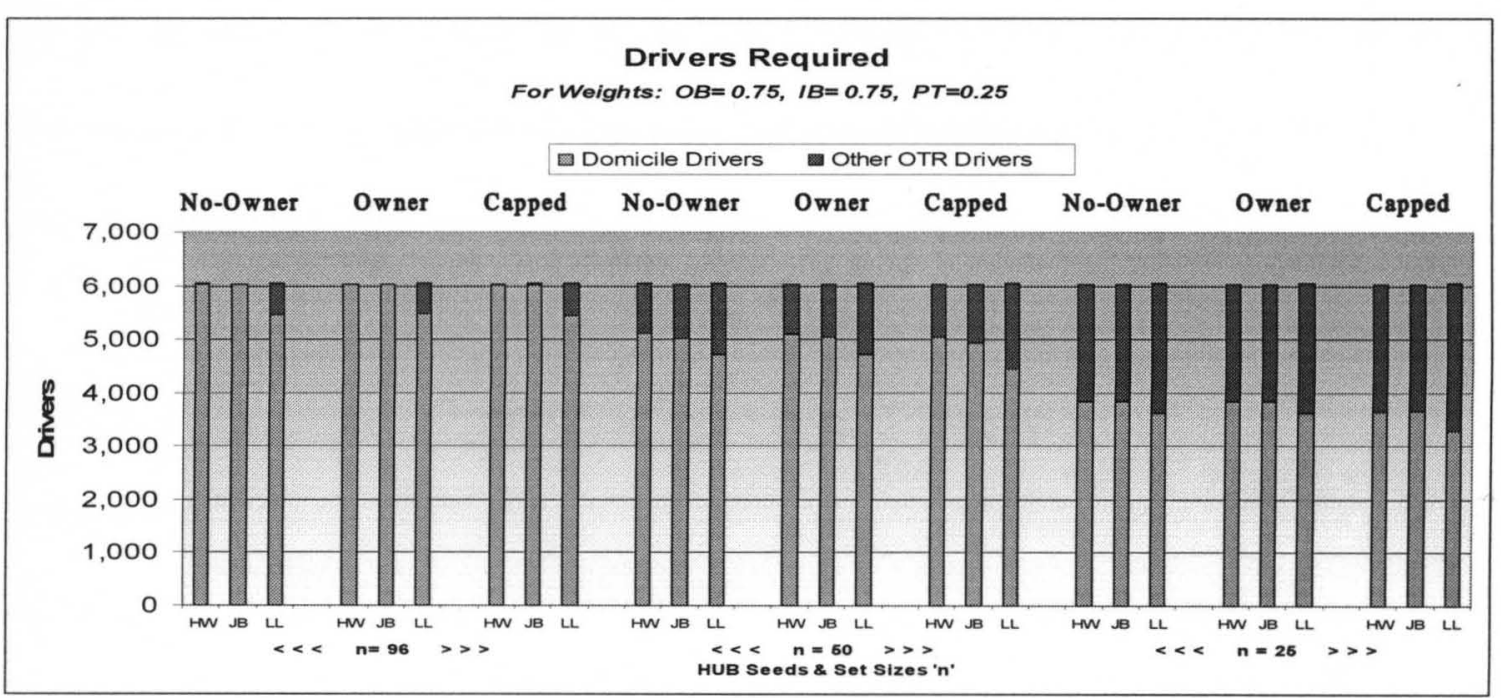




\begin{tabular}{|c|c|c|c|c|c|c|c|c|c|c|c|}
\hline \multirow{3}{*}{$\begin{array}{c}\text { Data } \\
\text { Weights: } \\
\text { OB: } 0.75\end{array}$} & \multirow[t]{2}{*}{ Type } & \multirow[t]{2}{*}{ Size } & \multirow[t]{3}{*}{ OB } & \multirow[t]{3}{*}{ IB } & \multirow[t]{3}{*}{ PT } & \multicolumn{2}{|c|}{ Drivers Domicile } & \multicolumn{2}{|c|}{ Drivers OTR } & \multicolumn{2}{|c|}{ Drivers All } \\
\hline & & & & & & \multirow{2}{*}{ Mean : } & \multirow{2}{*}{$\underline{\text { Var }}$} & \multirow{2}{*}{ Mean } & \multirow{2}{*}{ Var } & \multirow{2}{*}{ Mean : } & \multirow{2}{*}{$\underline{\text { Var }}$} \\
\hline & 0.75 PT: & 0.75 & & & & & & & & & \\
\hline $\mathrm{HW}$ & No-Owner & 96 & 0.75 & 0.75 & 0.75 & $6,030.93$ & $960,611.312$ & 19.90 & $233,645.678$ & $6,050.83$ & $793,699.868$ \\
\hline JB & No-Owner & 96 & 0.75 & 0.75 & 0.75 & $6,024.73$ & $880,588.205$ & 17.30 & $143,662.439$ & $6,042.03$ & $791,471.219$ \\
\hline 凹 & No-Owner & 96 & 0.75 & 0.75 & 0.75 & $5,475.76$ & $917,212.818$ & 572.01 & $381,547.129$ & $6,047.77$ & $792,903.000$ \\
\hline $\mathrm{HW}$ & Owner & 96 & 0.75 & 0.75 & 0.75 & $6,032.63$ & $788,254.081$ & 11.48 & 16.055 & $6,044.11$ & $790,842.763$ \\
\hline$J B$ & Owner & 96 & 0.75 & 0.75 & 0.75 & $6,032.43$ & $794,746.201$ & 11.42 & 5.977 & $6,043.85^{i}$ & $791,242.658$ \\
\hline 凹 & Owner & 96 & 0.75 & 0.75 & 0.75 & $5,483.34$ & $677,967.100$ & 562.66 & $11,586.572$ & $6,046.00$ & $793,060.761$ \\
\hline $\mathrm{HW}$ & Capped & 96 & 0.75 & 0.75 & 0.75 & $6,024.40$ & $752,894.011$ & 21.83 & 574.320 & $6,046.23$ & $793,161.757$ \\
\hline $\mathrm{JB}$ & Capped & 96 & 0.75 & 0.75 & 0.75 & $6,004.70$ & $749,392.313$ & 41.93 & 739.550 & $6,046.62$ & $794,344.662$ \\
\hline せ & Capped & 96 & 0.75 & 0.75 & 0.75 & $5,450.22$ & $642,149.434$ & 597.04 & $18,789.005$ & 6,047.26: & $794,032.547$ \\
\hline $\mathrm{HW}$ & No-Owner & 50 & 0.75 & 0.75 & 0.75 & $5,103.88$ & $714,796.626$ & (939.53 & $240,181.176$ & $6,043.40$ & $791,831.464$ \\
\hline $\mathrm{JB}$ & No-Owner & 50 & 0.75 & 0.75 & 0.75 & $5,032.58$ & $630,063.907$ & $1,007.09$ & $175,581.309$ & $6,039.67$ & $790,911.941$ \\
\hline せ & No-Owner & 50 & 0.75 & 0.75 & 0.75 & $4,716.74$ & $669,984.398$ & $1,331.97$ & $315,187.706$ & $6,048.71$ & $793,134.410$ \\
\hline $\mathrm{HW}$ & Owner & 50 & 0.75 & 0.75 & 0.75 & $5,109.59$ & $573,782.195$ & 932.70 & $23,765.974$ & $6,042.28$ & $790,856.892$ \\
\hline$J B$ & Owner & 50 & 0.75 & 0.75 & 0.75 & $5,036.78$ & $566,687.139$ & $1,003.33 !$ & $37,034.984$ & $6,040.11$ & $790,685.490$ \\
\hline แ & Owner & 50 & 0.75 & 0.75 & 0.75 & $4,720.63$ & $492,870.503$ & $1,325.40$ & $63,310.456$ & $6,046.03$ & $793,033.792$ \\
\hline$\overline{H W}$ & Capped & 50 & 0.75 & 0.75 & 0.75 & $5,063.25$ & $472,035.650$ & 981.21 & $47,129.008$ & $6,044.46$ & $793,295.666$ \\
\hline $\mathrm{JB}$ & Capped & 50 & 0.75 & 0.75 & 0.75 & $4,929.54$ & $434,387.675$ & $1,113.07$ & $68,035.368$ & $6,042.61$ & $793,183.905$ \\
\hline แL & Capped & 50 & 0.75 & 0.75 & 0.75 & $4,463.42$ & $353,050.153$ & $1,583.91$ & $103,698.557$ & $6,047.33$ & $793,878.721$ \\
\hline HW & No-Owner & 25 & 0.75 & 0.75 & 0.75 & $3,843.17$ & $429,505.442$ & $2,198.96 !$ & $289,275.618$ & $6,042.12$ & $791,531.234$ \\
\hline $\mathrm{JB}$ & No-Owner & 25 & 0.75 & 0.75 & 0.75 & $3,854.04$ & $403,860.300$ & $2,191.97$ & $255,836.480$ & $6,046.02$ & $792,477.887$ \\
\hline LL & No-Owner & 25 & 0.75 & 0.75 & 0.75 & $3,625.61$ & $407,949.848$ & $2,420.86$ & $318,140.543$ & $6,046.48$ & $792,591.684$ \\
\hline $\mathrm{HW}$ & Owner & 25 & 0.75 & 0.75 & 0.75 & $3,843.27$ & $348,112.404$ & $2,196.01 i$ & $168,336.661$ & $6,039.28$ & $790,360.675$ \\
\hline $\mathrm{JB}$ & Owner & 25 & 0.75 & 0.75 & 0.75 & $3,848.28$ & $359,947.975$ & $2,190.45$ & $184,651.299$ & $6,038.73$ & $790,439.816$ \\
\hline แ & Owner & 25 & 0.75 & 0.75 & 0.75 & $3,631.10$ & $291,135.067$ & $2,415.66$ & $154,376.919$ & $6,046.76$ & $793,191.730$ \\
\hline $\mathrm{HW}$ & Capped & 25 & 0.75 & 0.75 & 0.75 & $3,647.16$ & $159,002.425$ & $2,394.51$ & $312,859.640$ & $6,041.66$ & $792,874.497$ \\
\hline $\mathrm{JB}$ & ped & 25 & 0.75 & 0.75 & 0.75 & $3,664.39$ & $178,105.604$ & $2,376.77$ & $333,687.538$ & $6,041.17$ & $792,770.476$ \\
\hline แ & Capped & 25 & 0.75 & 0.75 & 0.75 & $3,301.60$ & $109,642.209$ & $2,746.06 !$ & $330,774.565$ & $6,047.66$ & $793,018.440$ \\
\hline
\end{tabular}

Table 4-45 - Drivers Required \#8

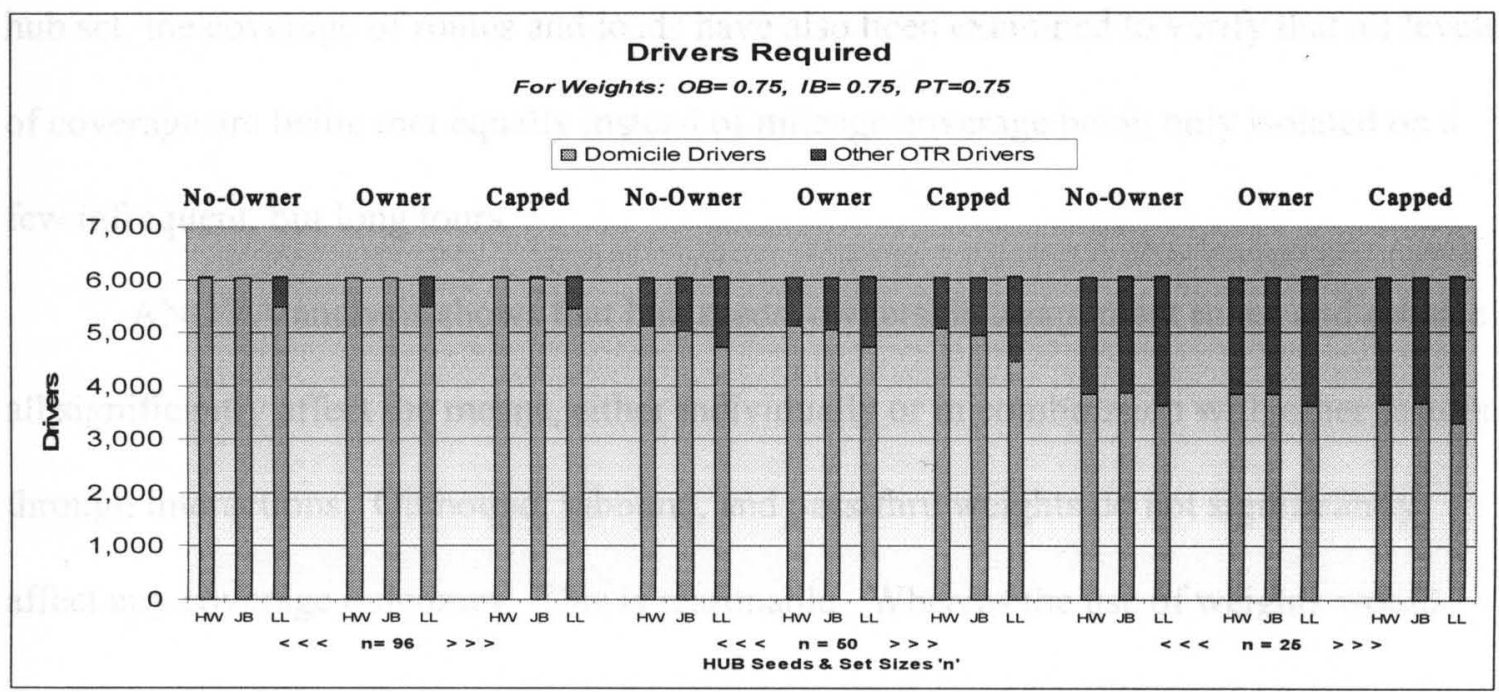




\subsection{Discussion and Analysis}

This section discusses and provides statistical analysis to the experimental results presented in Section 4.6. Also, the reader may refer to Section 4.5 which summarizes the experimental design and discusses the factors and responses that will be examined here.

The results for effective ownership coverage are found in Tables 4-5 through 4-13 with ANOVA' $s$ in Tables 4-46, 4-47, and 4-48. Since the goal of the computer model is to analyze freight data and make appropriate outbound, inbound, and pass-thru ownership assignments, effective ownership coverage is therefore an indicator of how good a fit each hub set is with the freight data. For instance, higher coverages indicate that the hubs would be able to domicile more drivers who could be dispatched on tours with a higher frequency of getting home regularly. Infrequency of return trips home has been cited as a common cause of driver turnover.

The analysis of ownership coverage looks at the coverage of routes (freight lanes), loads (a number of trips), and mileage (miles multiplied by loads). The results also show that, in general, the coverage of mileage is better than either the coverage of routes or loads. Whereas mileage coverage may be the best overall predictor of a good hub set, the coverage of routes and loads have also been examined to verify that all levels of coverage are being met equally instead of mileage coverage being only isolated on a few infrequent, but long tours.

ANOVA analysis shows that hub seeds, ownership assignment rules, and set size all significantly affect the means, either individually or in combination with other factors through interactions. Outbound, inbound, and pass-thru weights do not significantly affect any coverage outcomes. This is reasonable. Whereas the use of weights would 
ANOVA: Percentage of Routes Owned

(significant factors and interactions for $\alpha=0.05$ highlighted)

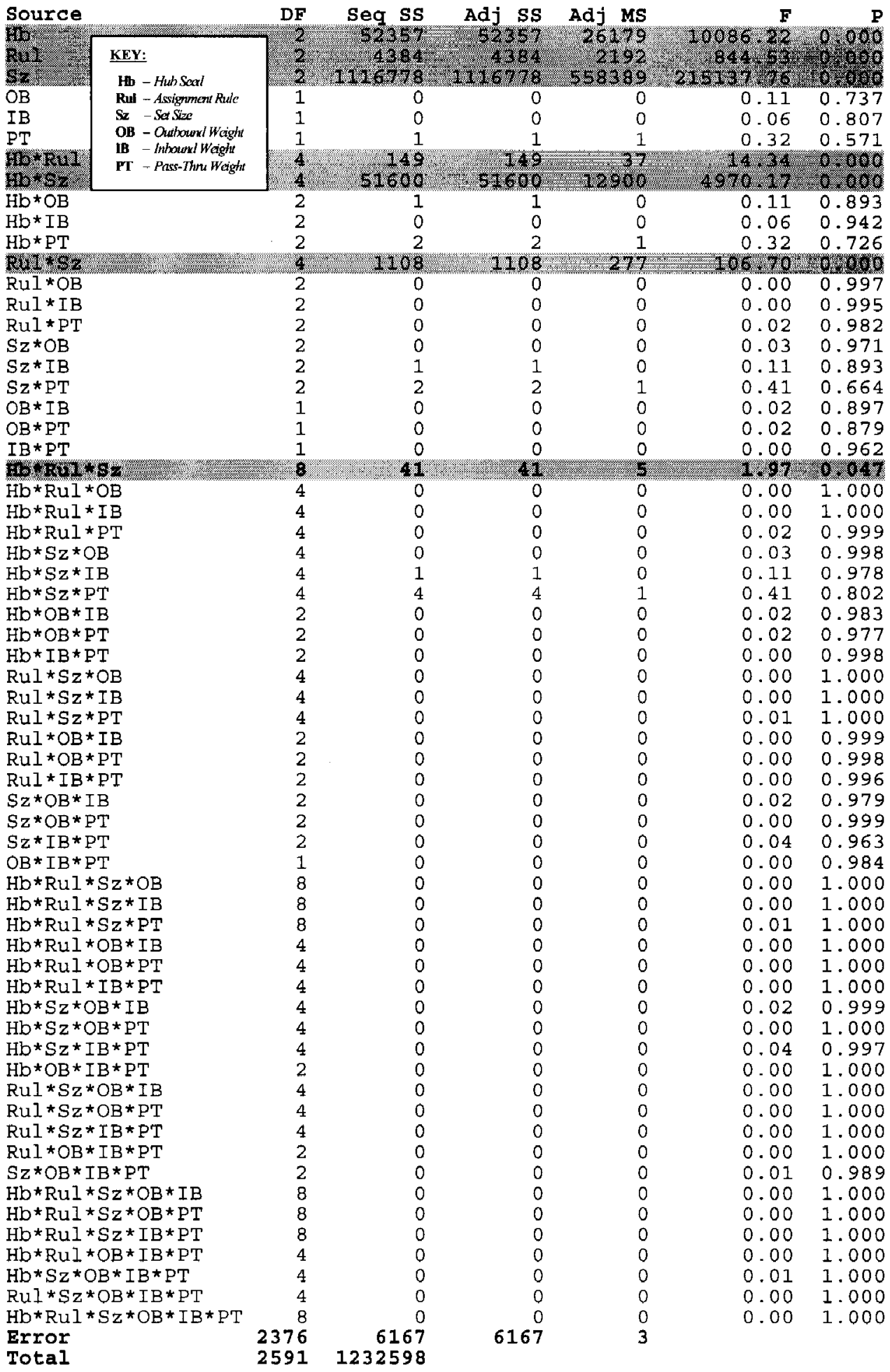

$S=1.61105 \quad R-S q=99.50 \% \quad R-S q(\operatorname{adj})=99.45 \%$

Table 4-46 - ANOVA: Percentage of Routes Owned 
ANOVA: Percentage of Loads Owned

(significant factors and interactions for $\alpha=0.05$ highlighted)

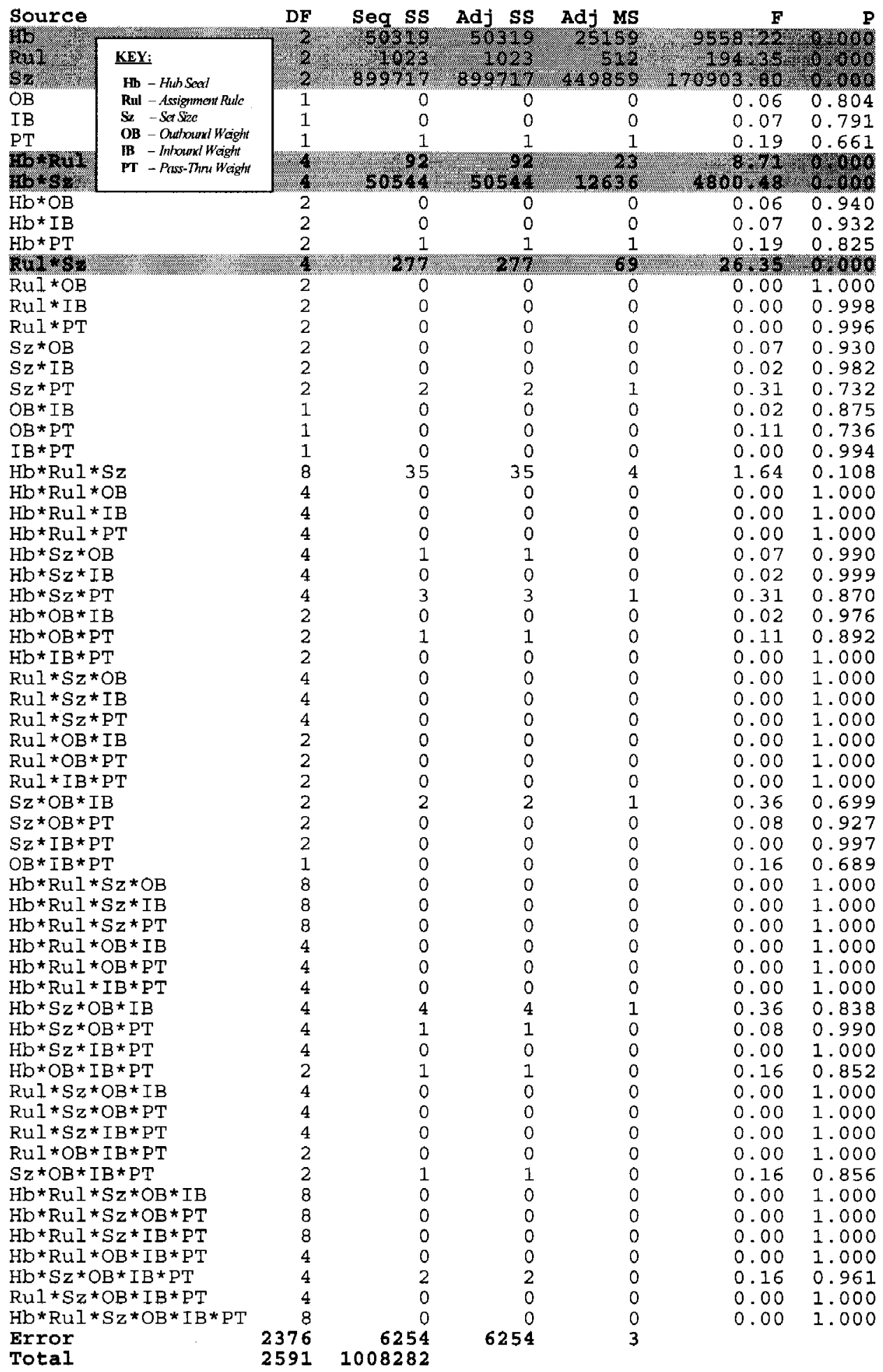

$S=1.62242 \quad R-S q=99.38 \% \quad R-S q(\operatorname{adj})=99.32 \%$

Table 4-47 - ANOVA: Percentage of Loads Owned 
ANOVA: Percentage of Miles Owned

(significant factors and interactions for $\alpha=0.05$ highlighted)

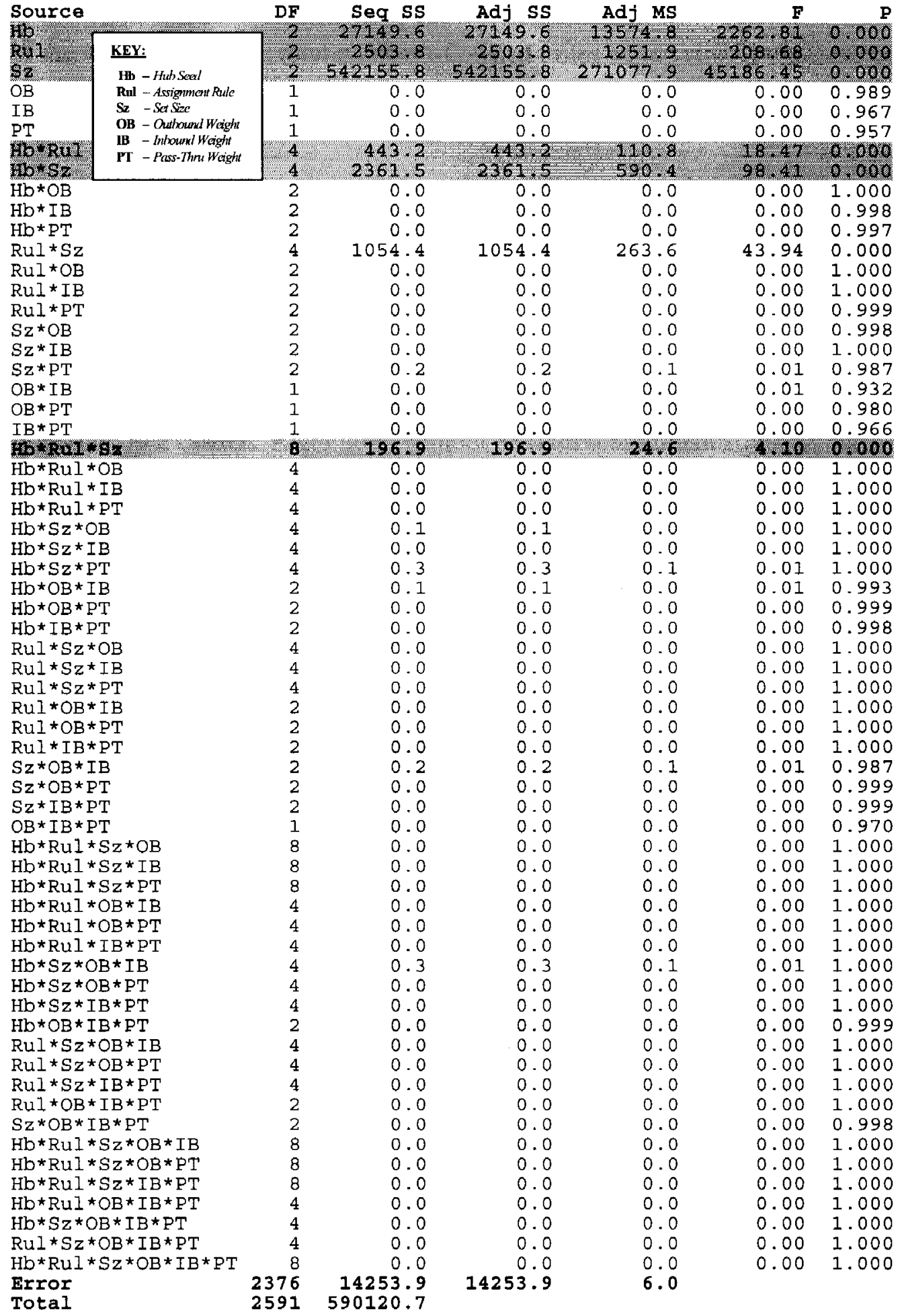

$S=2.44931 \quad R-S q=97.58 \% \quad R-S q(\operatorname{adj})=97.37 \%$

Table 4-48 - ANOVA: Percentage of Miles Owned 
have a bearing on the way ownership claims were distributed (outbound, inbound, or pass-thru), they would not have a bearing on the summation of ownerships. Regardless of the weight, the same total number of owned miles would still be claimed. However, because of the weights, the way the owned miles are distributed across the owned mile types changes.

The results in Tables 4-6-4-13 show that coverage will decrease as the number of hubs ( ' $\mathrm{n}$ ' ) under consideration decreases. However, even for $n=25$, approximately $60 \%$ of all mileage is owned for all data sets and ownership assignment rules. This is still important to a carrier. Right now, without a driver recruitment strategy, carriers are already experiencing huge turnover. But if even if as few as 25 locations could be targeted for future driver recruitment, the carrier would be encouraged to know that over $50 \%$ (and maybe $60 \%$ as these experiments show) of their driver base would be located in high volume areas with good opportunities to return home regularly.

The results show that the J.B. Hunt (JB) and highway (HW) hub sets have nearly the same ownership coverage. However, HW has slightly better coverage across all scenarios. On the other hand, the latitude and longitude (LL) hub set has significantly less ownership coverage than either HW or JB. The gap between LL and HW or JB is worst for the $n=96$ set size. However, as $n$ approaches 25, LL becomes more like both the JB and HW across all scenarios.

Another observation is that the HW hub set appears to be influenced more by the priority weights whereas the ownership coverage of both the JB and LL sets are not affected. However the ANOVA results indicate that the HW hub set is not significantly affected by the priority weights. 
Since the three way interaction of hub set, assignment rule, and data set are found to be significant, Figure 4-6 provides mileage interaction plots and helps make inferences about the best choice of these factors. From these plots we can discern that HW is the best hub set (though is almost as good), No-Owner and Owner are the best assignment types, and $n=96$ is the best set size. Interaction plots for both percentage loads and percentage routes are similar. These plots show significant drops in coverage for $L L, n=$ $25, \mathrm{n}=50$, or capped ownership assignment.

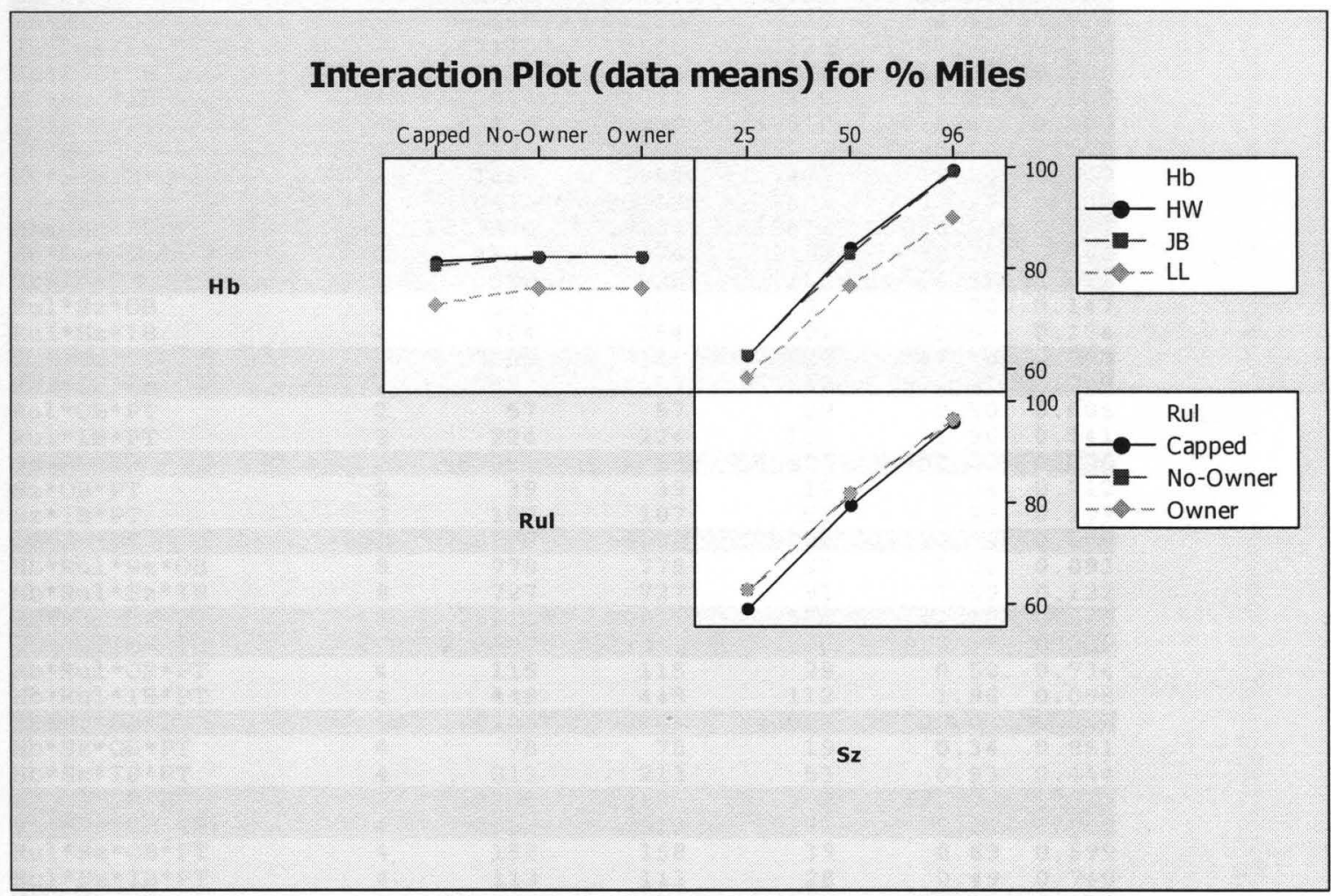

Figure 4-6 - Interaction Plot - 3-Way - \% Miles

The results for imbalance are found in Tables 4-13 through 4-20 with ANOVA's in Tables 4-49, 4-50, and 4-51. Regarding imbalance, the ANOVA results show that all 


\section{ANOVA: Route Imbalance}

(significant factors and interactions for $\alpha=0.05$ highlighted)

\begin{tabular}{|c|c|c|c|c|c|c|}
\hline Source & DF & Seq SS & Adj SS & Adj MS & $\mathbf{F}$ & $P$ \\
\hline $\mathrm{Hb}$ & 2 & 2197319 & 2197319 & 1098660 & 19214.66 & 0.000 \\
\hline KEY: & 2 & 618246 & 618246 & 309123 & 5406.31 & 0.000 \\
\hline Hb - Hub Seal & 2 & 818247 & 818247 & 409124 & 7155.24 & 0.000 \\
\hline Rul - Assignment Rule & 1 & 13170 & 13170 & 13170 & 230.34 & 0.000 \\
\hline $\mathrm{Sz}$ - Set Size & 1 & 18156 & 18156 & 18156 & 317.53 & 0.000 \\
\hline OB - Outbound Weight & 1 & 120965 & 120965 & 120965 & 2115.58 & 0.000 \\
\hline $\begin{array}{l}\text { IB - Inbound Weight } \\
\text { PT - Pass-Thru Weight }\end{array}$ & 4 & 163417 & 163417 & 40854 & 714.51 & 0.000 \\
\hline $\mathrm{Hb} * \mathrm{Sz}$ & 4 & 417243 & 417243 & 104311 & 1824.31 & 0.000 \\
\hline $\mathrm{Hb} * \mathrm{OB}$ & 2 & 26341 & 26341 & 13170 & 230.34 & 0.000 \\
\hline $\mathrm{Hb} * \mathrm{IB}$ & 2 & 36311 & 36311 & 18156 & 317.53 & 0.000 \\
\hline $\mathrm{Hb} * \mathrm{PT}$ & $\overline{2}$ & 241930 & 241930 & 120965 & 2115.58 & 0.000 \\
\hline $\mathrm{RuI}$ *Sz & 4 & 38641 & 38641 & 9660 & 168.95 & 0.000 \\
\hline $\mathrm{RuI} * \mathrm{OB}$ & 2 & 1267 & 1267 & 634 & 11.08 & 0.000 \\
\hline $\mathrm{RuI} * \mathrm{IB}$ & 2 & 1517 & 1517 & 759 & 13.27 & 0.000 \\
\hline $\mathrm{Rul}$ *PT & 2 & 93620 & 93620 & 46810 & 818.66 & 0.000 \\
\hline $\mathrm{Sz} * \mathrm{OB}$ & 2 & 5585 & 5585 & 2793 & 48.84 & 0.000 \\
\hline$S z * I B$ & 2 & 942 & 942 & 471 & 8.24 & 0.000 \\
\hline $\mathrm{Sz} * \mathrm{PT}$ & 2 & 15206 & 15206 & 7603 & 132.97 & 0.000 \\
\hline$O B * I B$ & 1 & 859612 & 859612 & 859612 & 15033.91 & 0.000 \\
\hline$O B * P T$ & 1 & 2187 & 2187 & 2187 & 38.25 & 0.000 \\
\hline $\mathrm{IB} * \mathrm{PT}$ & 1 & 260 & 260 & 260 & 4.55 & 0.033 \\
\hline $\mathrm{Hb} * \mathrm{Rul}$ *Sz & 8 & 17110 & 17110 & 2139 & 37.40 & 0.000 \\
\hline $\mathrm{Hb} * \mathrm{RuI} * \mathrm{OB}$ & 4 & 2534 & 2534 & 634 & 11.08 & 0.000 \\
\hline $\mathrm{Hb} * \mathrm{RuI} * \mathrm{IB}$ & 4 & 3034 & 3034 & 759 & 13.27 & 0.000 \\
\hline $\mathrm{Hb} * \mathrm{RuI} * \mathrm{PT}$ & 4 & 187239 & 187239 & 46810 & 818.66 & 0.000 \\
\hline $\mathrm{Hb} * \mathrm{Sz} * \mathrm{OB}$ & 4 & 11171 & 11171 & 2793 & 48.84 & 0.000 \\
\hline $\mathrm{Hb} * \mathrm{Sz} * \mathrm{IB}$ & 4 & 1884 & 1884 & 471 & 8.24 & 0.000 \\
\hline$H b * S z * P T$ & 4 & 30412 & 30412 & 7603 & 132.97 & 0.000 \\
\hline $\mathrm{Hb} * \mathrm{OB} * \mathrm{IB}$ & 2 & 1719224 & 1719224 & 859612 & 15033.91 & 0.000 \\
\hline $\mathrm{Hb} * \mathrm{OB} * \mathrm{PT}$ & 2 & 4374 & 4374 & 2187 & 38.25 & 0.000 \\
\hline $\mathrm{Hb} * \mathrm{IB} * \mathrm{PT}$ & 2 & 520 & 520 & 260 & 4.55 & 0.011 \\
\hline $\mathrm{Rul}$ *Sz*OB & 4 & 389 & 389 & 97 & 1.70 & 0.147 \\
\hline $\mathrm{Rul} * \mathrm{Sz}$ * IB & 4 & 364 & 364 & 91 & 1.59 & 0.174 \\
\hline Rul *Sz*PT & 4 & 10106 & 10106 & 2526 & 44.18 & 0.000 \\
\hline Rul $* O B * I B$ & 2 & 111693 & 111693 & 55847 & 976.71 & 0.000 \\
\hline $\mathrm{Rul}$ *OB * $\mathrm{PT}$ & 2 & 57 & 57 & 29 & 0.50 & 0.605 \\
\hline $\mathrm{Rul}$ *IB*PT & 2 & 224 & 224 & 112 & 1.96 & 0.141 \\
\hline $\mathrm{Sz} * \mathrm{OB} * \mathrm{IB}$ & 2 & 80053 & 80053 & 40026 & 700.03 & 0.000 \\
\hline $\mathrm{Sz}$ *OB*PT & 2 & 39 & 39 & 19 & 0.34 & 0.712 \\
\hline$S z * I B * P T$ & 2 & 107 & 107 & 53 & 0.93 & 0.393 \\
\hline$O B * I B * P T$ & 1 & 6902 & 6902 & 6902 & 120.72 & 0.000 \\
\hline $\mathrm{Hb} * \mathrm{Rul} * \mathrm{Sz} * \mathrm{OB}$ & 8 & 778 & 778 & 97 & 1.70 & 0.093 \\
\hline $\mathrm{Hb} * \mathrm{RuI} * \mathrm{Sz}^{*} \mathrm{IB}$ & 8 & 727 & 727 & 91 & 1.59 & 0.122 \\
\hline $\mathrm{Hb} * \mathrm{RuI} * \mathrm{Sz} * \mathrm{PT}$ & 8 & 20211 & 20211 & 2526 & 44.18 & 0.000 \\
\hline $\mathrm{Hb} * \mathrm{RuI} * \mathrm{OB} * \mathrm{IB}$ & 4 & 223387 & 223387 & 55847 & 976.71 & 0.000 \\
\hline $\mathrm{Hb} * \mathrm{Rul} * \mathrm{OB} * \mathrm{PT}$ & 4 & 115 & 115 & 29 & 0.50 & 0.734 \\
\hline $\mathrm{Hb} * \mathrm{RuI} * \mathrm{IB} * \mathrm{PT}$ & 4 & 448 & 448 & 112 & 1.96 & 0.098 \\
\hline $\mathrm{Hb} * \mathrm{SZ} * \mathrm{OB} * \mathrm{IB}$ & 4 & 160106 & 160106 & 40026 & 700.03 & 0.000 \\
\hline $\mathrm{Hb} * \mathrm{Sz} * \mathrm{OB} * \mathrm{PT}$ & 4 & 78 & 78 & 19 & 0.34 & 0.851 \\
\hline $\mathrm{Hb} * \mathrm{Sz} * \mathrm{IB} * \mathrm{PT}$ & 4 & 213 & 213 & 53 & 0.93 & 0.444 \\
\hline $\mathrm{Hb} * \mathrm{OB} * \mathrm{IB} * \mathrm{PT}$ & 2 & 13805 & 13805 & 6902 & 120.72 & 0.000 \\
\hline $\mathrm{RuI} * \mathrm{Sz} * \mathrm{OB} * \mathrm{IB}$ & 4 & 8923 & 8923 & 2231 & 39.01 & 0.000 \\
\hline $\mathrm{Rul} * \mathrm{Sz}$ *OB*PT & 4 & 158 & 158 & 39 & 0.69 & 0.599 \\
\hline $\mathrm{RuI} * \mathrm{Sz} * \mathrm{IB} * \mathrm{PT}$ & 4 & 113 & 113 & 28 & 0.49 & 0.740 \\
\hline $\mathrm{RuI} * O B * I B * \mathrm{PT}$ & 2 & 51567 & 51567 & 25783 & 450.93 & 0.000 \\
\hline $\mathrm{Sz} * \mathrm{OB} * \mathrm{IB} * \mathrm{PT}$ & 2 & 338 & 338 & 169 & 2.96 & 0.052 \\
\hline $\mathrm{Hb} * \mathrm{Ru}$ * $* \mathrm{Sz} * \mathrm{OB} * \mathrm{IB}$ & 8 & 17846 & 17846 & 2231 & 39.01 & 0.000 \\
\hline $\mathrm{Hb} * \mathrm{Rul} * \mathrm{Sz}$ *OB*PT & 8 & 315 & 315 & 39 & 0.69 & 0.701 \\
\hline $\mathrm{Hb} \star \mathrm{Rul} * \mathrm{Sz}$ *IB $* \mathrm{PT}$ & 8 & 226 & 226 & 28 & 0.49 & 0.861 \\
\hline $\mathrm{Hb} * \mathrm{RuI} * \mathrm{OB} * \mathrm{IB} * \mathrm{PT}$ & 4 & 103134 & 103134 & 25783 & 450.93 & 0.000 \\
\hline $\mathrm{Hb} * \mathrm{Sz} * \mathrm{OB} * \mathrm{IB} * \mathrm{PT}$ & 4 & 677 & 677 & 169 & 2.96 & 0.019 \\
\hline$R u 1 * S z * O B * I B * P T$ & 4 & 5210 & 5210 & 1302 & 22.78 & 0.000 \\
\hline $\mathrm{Hb}$ * RuI $* \mathrm{Sz} * \overline{O B} * \mathrm{IB} * \mathrm{PT}$ & 8 & 10420 & 10420 & 1302 & 22.78 & 0.000 \\
\hline $\begin{array}{l}\text { Error } \\
\text { Total }\end{array}$ & $\begin{array}{l}2376 \\
2591\end{array}$ & $\begin{array}{r}135855 \\
8632267\end{array}$ & 135855 & 57 & & \\
\hline
\end{tabular}

$S=7.56163 \quad R-S q=98.43 \% \quad R-S q(\operatorname{adj})=98.28 \%$

Table 4-49 - ANOVA: Route Imbalance 


\section{ANOVA: Load Imbalance}

(Significant factors and interactions for $\alpha=0.05$ highlighted)

\begin{tabular}{|c|c|c|c|c|c|c|}
\hline & DF & Seq SS & Adj SS & Adj MS & $F$ & P \\
\hline Source & 2 & 2938091580 & 2938091580 & 1469045790 & 2881.99 & 0.000 \\
\hline Rul & 2 & 1860922718 & 1860922718 & 930461359 & 1825.39 & 0.000 \\
\hline $\mathrm{Hb}-\mathrm{HubSeed}$ & 2 & 2087838813 & 2087838813 & 1043919406 & 2047.97 & 0.000 \\
\hline Rul - Assignment Rule & 1 & 43548141 & 43548141 & 43548141 & 85.43 & 0.000 \\
\hline Sz - Set Size & 1 & 60001509 & 60001509 & 60001509 & 117.71 & 0.000 \\
\hline $\begin{array}{l}\text { OB - Outbound Weight } \\
\text { IB - Inbound Wcight }\end{array}$ & 1 & 263415641 & 263415641 & 263415641 & 516.77 & 0.000 \\
\hline $\begin{array}{l}\text { IB - Inbound Waght } \\
\text { PT - Pass-Thru Weight }\end{array}$ & 4 & 317379238 & 317379238 & 79344809 & 155.66 & 0.000 \\
\hline $\mathrm{Hb}$ *Sz & 4 & 1197418100 & 1197418100 & 299354525 & 587.28 & 0.000 \\
\hline $\mathrm{Hb} * \mathrm{OB}$ & 2 & 87096282 & 87096282 & 43548141 & 85.43 & 0.000 \\
\hline $\mathrm{Hb} * \mathrm{IB}$ & 2 & 120003018 & 120003018 & 60001509 & 117.71 & 0.000 \\
\hline $\mathrm{Hb} * \mathrm{PT}$ & 2 & 526831283 & 526831283 & 263415641 & 516.77 & 0.000 \\
\hline $\mathrm{Rul}$ *Sz & 4 & 256428570 & 256428570 & 64107143 & 125.77 & 0.000 \\
\hline $\mathrm{Rul}$ *OB & 2 & 12283196 & 12283196 & 6141598 & 12.05 & 0.000 \\
\hline $\mathrm{Rul}$ *IB & 2 & 4742146 & 4742146 & 2371073 & 4.65 & 0.010 \\
\hline Rul *PT & 2 & 172208986 & 172208986 & 86104493 & 168.92 & 0.000 \\
\hline $\mathrm{Sz} * \mathrm{OB}$ & 2 & 13921135 & 13921135 & 6960568 & 13.66 & 0.000 \\
\hline$S z * I B$ & 2 & 7655427 & 7655427 & 3827713 & 7.51 & 0.001 \\
\hline$S z * P T$ & 2 & 36240838 & 36240838 & 18120419 & 35.55 & 0.000 \\
\hline$O B * I B$ & 1 & 1119616963 & 1119616963 & 1119616963 & 2196.48 & 0.000 \\
\hline$O B * P T$ & 1 & 4241862 & 4241862 & 4241862 & 8.32 & 0.004 \\
\hline $\mathrm{IB} * \mathrm{PT}$ & 1 & 5337842 & 5337842 & 5337842 & 10.47 & 0.001 \\
\hline $\mathrm{Hb} * \mathrm{Rul}$ *Sz & 8 & 72585463 & 72585463 & 9073183 & 17.80 & 0.000 \\
\hline $\mathrm{Hb} * \mathrm{Rul} * \mathrm{OB}$ & 4 & 24566392 & 24566392 & 6141598 & 12.05 & 0.000 \\
\hline $\mathrm{Hb} * \mathrm{RuI}$ *IB & 4 & 9484292 & 9484292 & 2371073 & 4.65 & 0.001 \\
\hline $\mathrm{Hb} * \mathrm{Rul}$ *PT & 4 & 344417972 & 344417972 & 86104493 & 168.92 & 0.000 \\
\hline $\mathrm{Hb} * \mathrm{Sz} * \mathrm{OB}$ & 4 & 27842270 & 27842270 & 6960568 & 13.66 & 0.000 \\
\hline $\mathrm{Hb} * \mathrm{Sz} * \mathrm{IB}$ & 4 & 15310854 & 15310854 & 3827713 & 7.51 & 0.000 \\
\hline $\mathrm{Hb} * \mathrm{Sz} * \mathrm{PT}$ & 4 & 72481677 & 72481677 & 18120419 & 35.55 & 0.000 \\
\hline $\mathrm{Hb} * \mathrm{OB} \star \mathrm{IB}$ & 2 & 2239233927 & 2239233927 & 1119616963 & 2196.48 & 0.000 \\
\hline $\mathrm{Hb} * \mathrm{OB} * \mathrm{PT}$ & 2 & 8483724 & 8483724 & 4241862 & 8.32 & 0.000 \\
\hline $\mathrm{Hb} * \mathrm{IB} * \mathrm{PT}$ & 2 & 10675685 & 10675685 & 5337842 & 10.47 & 0.000 \\
\hline $\mathrm{Rul} * \mathrm{Sz} * \mathrm{OB}$ & 4 & 2453916 & 2453916 & 613479 & 1.20 & 0.307 \\
\hline $\mathrm{Rul}$ *Sz*IB & 4 & 1183870 & 1183870 & 295967 & 0.58 & 0.677 \\
\hline $\mathrm{Ru} 1$ *Sz * PT & 4 & 22501842 & 22501842 & 5625460 & 11.04 & 0.000 \\
\hline $\mathrm{Ru} 1 * \mathrm{OB} * \mathrm{IB}$ & 2 & 177911592 & 177911592 & 88955796 & 174.51 & 0.000 \\
\hline $\mathrm{Rul}$ *OB*PT & 2 & 1193995 & 1193995 & 596997 & 1.17 & 0.310 \\
\hline $\mathrm{Rul}$ *IB*PT & 2 & 227551 & 227551 & 113776 & 0.22 & 0.800 \\
\hline$S z * O B * I B$ & 2 & 102901384 & 102901384 & 51450692 & 100.94 & 0.000 \\
\hline $\mathrm{Sz} * \mathrm{OB} * \mathrm{PT}$ & 2 & 419743 & 419743 & 209872 & 0.41 & 0.663 \\
\hline$S z * I B * P T$ & 2 & 349357 & 349357 & 174679 & 0.34 & 0.710 \\
\hline $\mathrm{OB} * \mathrm{IB} * \mathrm{PT}$ & 1 & 2062368 & 2062368 & 2062368 & 4.05 & 0.044 \\
\hline $\mathrm{Hb} * \mathrm{Rul} * \mathrm{Sz} * \mathrm{OB}$ & 8 & 4907833 & 4907833 & 613479 & 1.20 & 0.293 \\
\hline $\mathrm{Hb} * \mathrm{Rul} * \mathrm{Sz} * \mathrm{IB}$ & 8 & 2367739 & 2367739 & 295967 & 0.58 & 0.795 \\
\hline $\mathrm{Hb} * \mathrm{RuI} * \mathrm{Sz} * \mathrm{PT}$ & 8 & 45003683 & 45003683 & 5625460 & 11.04 & 0.000 \\
\hline $\mathrm{Hb} * \mathrm{RuI} * \mathrm{OB} * \mathrm{IB}$ & 4 & 355823184 & 355823184 & 88955796 & 174.51 & 0.000 \\
\hline $\mathrm{Hb} * \mathrm{Rul} * \mathrm{OB} * \mathrm{PT}$ & 4 & 2387990 & 2387990 & 596997 & 1.17 & 0.321 \\
\hline $\mathrm{Hb} * \mathrm{Rul}$ *IB*PT & 4 & 455103 & 455103 & 113776 & 0.22 & 0.926 \\
\hline $\mathrm{Hb} * \mathrm{Sz} * \mathrm{OB} * \mathrm{IB}$ & 4 & 205802768 & 205802768 & 51450692 & 100.94 & 0.000 \\
\hline $\mathrm{Hb} * \mathrm{Sz} * \mathrm{OB} * \mathrm{PT}$ & 4 & 839487 & 839487 & 209872 & 0.41 & 0.800 \\
\hline $\mathrm{Hb} * \mathrm{Sz}$ *IB*PT & 4 & 698715 & 698715 & 174679 & 0.34 & 0.849 \\
\hline $\mathrm{Hb} * \mathrm{OB} * \mathrm{IB} * \mathrm{PT}$ & 2 & 4124735 & 4124735 & 2062368 & 4.05 & 0.018 \\
\hline $\mathrm{RuI} I \mathrm{Sz} * \mathrm{OB} * \mathrm{IB}$ & 4 & 14130097 & 14130097 & 3532524 & 6.93 & 0.000 \\
\hline $\mathrm{Rul}$ *Sz *OB*PT & 4 & 21491 & 21491 & 5373 & 0.01 & 1.000 \\
\hline $\mathrm{Rul}$ *Sz*IB*PT & 4 & 144736 & 144736 & 36184 & 0.07 & 0.991 \\
\hline $\mathrm{Ru} 1$ *OB*IB*PT & 2 & 52792510 & 52792510 & 26396255 & 51.78 & 0.000 \\
\hline $\mathrm{Sz} * \mathrm{OB} * \mathrm{IB} * \mathrm{PT}$ & 2 & 415604 & 415604 & 207802 & 0.41 & 0.665 \\
\hline $\mathrm{Hb} * \mathrm{Rul} * \mathrm{Sz} * \mathrm{OB} * \mathrm{IB}$ & 8 & 28260195 & 28260195 & 3532524 & 6.93 & 0.000 \\
\hline $\mathrm{Hb} * \mathrm{Rul}$ *Sz*OB*PT & 8 & 42982 & 42982 & 5373 & 0.01 & 1.000 \\
\hline $\mathrm{Hb} * \mathrm{RuI} * \mathrm{Sz}$ *IB*PT & 8 & 289473 & 289473 & 36184 & 0.07 & 1.000 \\
\hline $\mathrm{Hb} * \mathrm{RuI}$ *OB*IB*PT & 4 & 105585021 & 105585021 & 26396255 & 51.78 & 0.000 \\
\hline $\mathrm{Hb} * \mathrm{Sz} * \mathrm{OB} * \mathrm{IB} * \mathrm{PT}$ & 4 & 831207 & 831207 & 207802 & 0.41 & 0.803 \\
\hline $\mathrm{Rul} * \mathrm{Sz} * \mathrm{OB} * \mathrm{IB} * \mathrm{PT}$ & 4 & 4432599 & 4432599 & 1108150 & 2.17 & 0.070 \\
\hline $\mathrm{Hb} * \mathrm{Rul}$ *Sz *OB*IB*PT & 8 & 8865198 & 8865198 & 1108150 & 2.17 & 0.027 \\
\hline $\begin{array}{l}\text { Error } \\
\text { Total }\end{array}$ & $\begin{array}{l}2376 \\
2591\end{array}$ & $\begin{array}{r}1211124452 \\
16320857966\end{array}$ & 1211124452 & 509733 & & \\
\hline
\end{tabular}

$S=713.956 \quad R-S q=92.58 \% \quad R-S q(\operatorname{adj})=91.91 \%$

Table 4-50 - ANOVA: Load Imbalance 


\section{ANOVA: Mile Imbalance}

(significant factors and interactions for $\alpha=0.05$ highlighted)

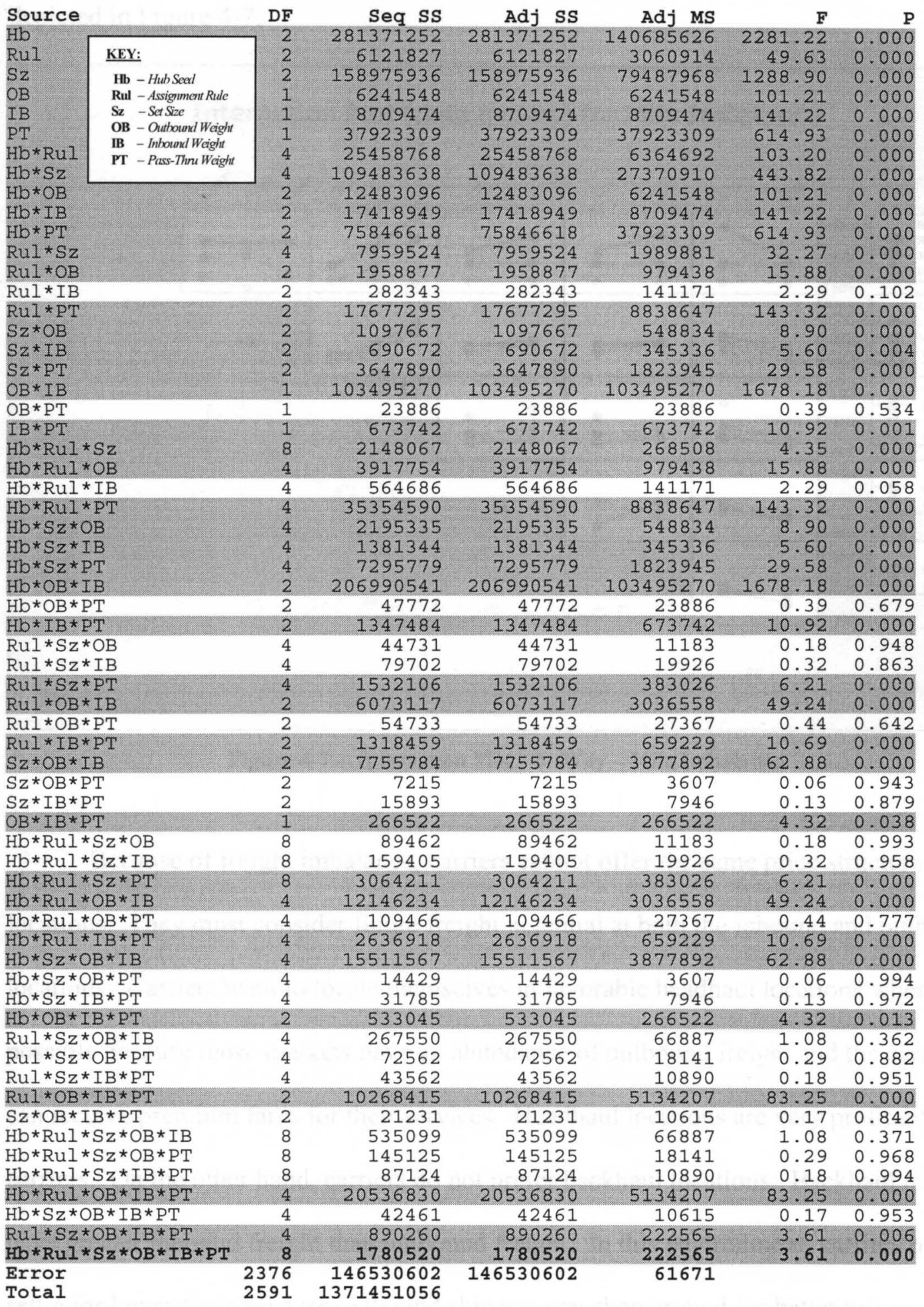

$S=248.337 \quad R-S q=89.32 \% \quad R-S q(\operatorname{adj})=88.35 \%$

Table 4-51 - ANOVA: Mile Imbalance 
six factors are significant in multiple ways, including a six-way interaction which is depicted in Figure 4-7.

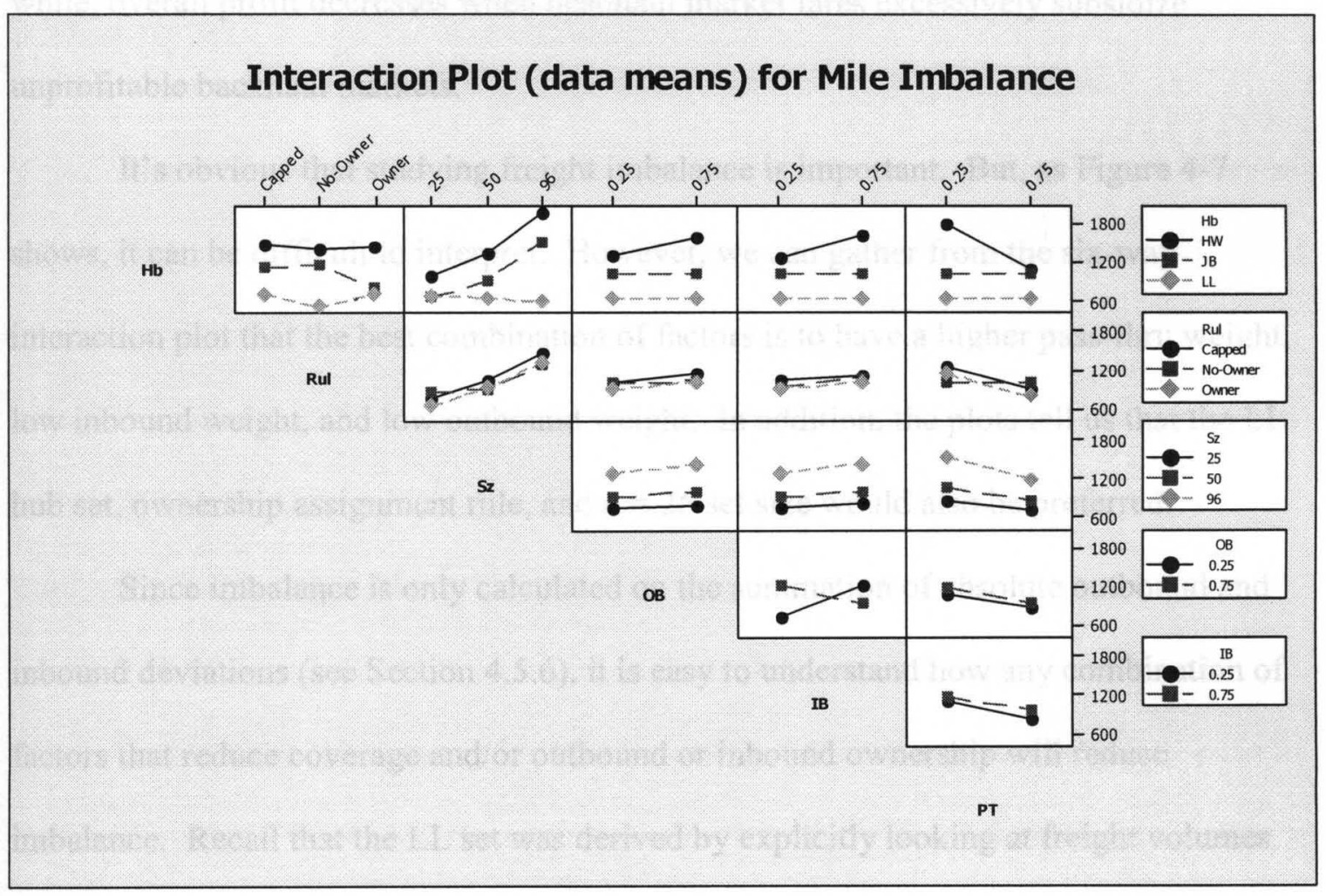

Figure 4-7 -- Interaction Plot - 6 -Way - Mile Imbalance

Because of freight imbalance, carriers cannot offer the same price structure for all locations. They must consider future freight potential at both the inbound and outbound locations. Carriers want to locate themselves in favorable headhaul locations when possible because those markets have an abundance of outbound freight and the carrier can receive premium fares for their services. Headhaul locations are very profitable for carriers. On the other hand, carriers do not prefer backhaul locations. Backhaul markets have greater inbound freight than outbound freight. In this environment, carriers must settle for lower fares because outbound shippers can shop around for better prices. In some instances, the carrier may be unable to obtain a backhaul load and must therefore 
drive empty (deadhead) to another location where freight is available. Revenues obtained from backhaul locations, if any, are not always high enough to cover expenses. After a while, overall profit decreases when headhaul market fares excessively subsidize unprofitable backhaul markets.

It's obvious that studying freight imbalance is important. But, as Figure 4-7 shows, it can be difficult to interpret. However, we can gather from the six-way interaction plot that the best combination of factors is to have a higher pass-thru weight, low inbound weight, and low outbound weight. In addition, the plots tell us that the LL hub set, ownership assignment rule, and $n=25$ set size would also be preferred.

Since imbalance is only calculated on the summation of absolute outbound and inbound deviations (see Section 4.5.6), it is easy to understand how any combination of factors that reduce coverage and/or outbound or inbound ownership will reduce imbalance. Recall that the LL set was derived by explicitly looking at freight volumes and locations were chosen based on their freight density. As a result, the LL set identified locations that may not have been cities. These isolated locations would therefore incur a greater amount of pass-thru volume instead of outbound or inbound.

Both the HW and JB sets have worse imbalance than the LL set. Whereas the LL set benefited by having isolated locations, the HW and JB sets had higher inbound and outbound volumes than the LL set because they were situated in cities. Of the two sets, HW performs worst. Its derivation, however, was based only on the premise that freight density may exist at or near the major interstate highway interchanges, although no prior knowledge about freight density nor business infrastructure was used. Imbalance results show that may be a poor assumption. The JB set, however, performs somewhere in 
between HW and LL. It was derived based on the existing J.B. Hunt business infrastructure, so it also makes sense it could have a low imbalance.

The results for miles owned are found in Tables 4-22 through 4-29 and their ANOVA' $s$ are in Tables 4-52, 4-53, and 4-54.

The results show that pass-thru freight receives the largest mile volume. The ratio of pass-thru volumes to either outbound or inbound volumes is usually between 20-1 and 50-1, regardless of the outbound or inbound priority weights. Although outbound and inbound weights significantly affect the owned mile volumes, pass-thru volumes remain both substantially larger. This would appeal to a carrier. Although carriers prefer headhaul areas (where outbound freight is an abundance and the carrier can receive a premium for their services), it may be more difficult to domicile a large number of drivers in that location because of freight imbalance. A similar relationship may exist in backhaul markets. However, since these results show that drivers should be domiciled at intermediate pass-thru locations, the drivers domiciled there may have more get home opportunities because freight will be crossing pass-thru locations in both directions.

All factors are significant either as a main effect or in an interaction. However, there is not a six-way interaction. The largest interaction is four-way.

The results for miles driven are found in Tables 4-30 through 4-37 and their ANOVA's are in Tables 4-55, 4-56, and 4-57. Whereas the 'owned mile' statistics describe the miles claimed by a set of hubs, the 'miles driven' statistics, which include added circuitous mileage, approximate the actual miles driven to support the domicile plan. These mileage statistics, calculated both in terms of domicile miles and other OTR miles, are subsequently used to calculate driver requirements. Also, these mileage 


\section{ANOVA: Outbound Miles Owned}

(significant factors and interactions for $\alpha=0.05$ highlighted)

\begin{tabular}{|c|c|c|c|c|c|c|}
\hline Source & DF & Seq SS & Adj SS & Adj MS & $\mathbf{F}$ & P \\
\hline $\mathrm{Hb}$ & 2 & 48215890 & 48215890 & 24107945 & 129.69 & 0.000 \\
\hline Rul & 2 & 71847392 & 71847392 & 35923696 & 193.26 & 0.000 \\
\hline $\mathbf{H b}-$ HubSead & 2 & 286753534 & 286753534 & 143376767 & 771.31 & 0.000 \\
\hline Rul - Assignment Rule & 1 & 202063931 & 202063931 & 202063931 & 1087.02 & 0.000 \\
\hline Sz - Set Size & 1 & 2723744 & 2723744 & 2723744 & 14.65 & 0.000 \\
\hline $\begin{array}{l}\text { OB - Outbound Weight } \\
\text { IB - Inbound Weight }\end{array}$ & 1 & 175165519 & 175165519 & 175165519 & 942.32 & 0.000 \\
\hline $\begin{array}{l}\text { IB - Inbound Weight } \\
\text { PT - Pass-Thru Weight }\end{array}$ & 4 & 293705617 & 293705617 & 73426404 & 395.00 & 0.000 \\
\hline $\mathrm{Hb} * \mathrm{Sz}$ & 4 & 240302213 & 240302213 & 60075553 & 323.18 & 0.000 \\
\hline $\mathrm{Hb} * \mathrm{OB}$ & 2 & 404127862 & 404127862 & 202063931 & 1087.02 & 0.000 \\
\hline $\mathrm{Hb}$ * IB & 2 & 5447489 & 5447489 & 2723744 & 14.65 & 0.000 \\
\hline $\mathrm{Hb} * \mathrm{PT}$ & 2 & 350331039 & 350331039 & 175165519 & 942.32 & 0.000 \\
\hline $\mathrm{Rul} * \mathrm{Sz}$ & 4 & 8715114 & 8715114 & 2178778 & 11.72 & 0.000 \\
\hline $\mathrm{Rul}$ *OB & 2 & 5301467 & 5301467 & 2650733 & 14.26 & 0.000 \\
\hline $\mathrm{RuI}$ * IB & 2 & 1361475 & 1361475 & 680737 & 3.66 & 0.026 \\
\hline $\mathrm{Ru} I$ *PT & 2 & 2307044 & 2307044 & 1153522 & 6.21 & 0.002 \\
\hline $\mathrm{Sz} \star \mathrm{OB}$ & 2 & 15656801 & 15656801 & 7828400 & 42.11 & 0.000 \\
\hline $\mathrm{Sz}$ * IB & 2 & 395212 & 395212 & 197606 & 1.06 & 0.346 \\
\hline $\mathrm{Sz} * \mathrm{PT}$ & 2 & 13753511 & 13753511 & 6876755 & 36.99 & 0.000 \\
\hline$O B * I B$ & 1 & 501052 & 501052 & 501052 & 2.70 & 0.101 \\
\hline $\mathrm{OB} * \mathrm{PT}$ & 1 & 787955 & 787955 & 787955 & 4.24 & 0.040 \\
\hline $\mathrm{IB} * \mathrm{PT}$ & 1 & 1679643 & 1679643 & 1679643 & 9.04 & 0.003 \\
\hline $\mathrm{Hb} * \mathrm{Ru} 1$ *Sz & 8 & 29502183 & 29502183 & 3687773 & 19.84 & 0.000 \\
\hline $\mathrm{Hb} * \mathrm{RuI} * \mathrm{OB}$ & 4 & 10602934 & 10602934 & 2650733 & 14.26 & 0.000 \\
\hline $\mathrm{Hb} * \mathrm{Ru} I * \mathrm{IB}$ & 4 & 2722949 & 2722949 & 680737 & 3.66 & 0.006 \\
\hline $\mathrm{Hb} * \mathrm{RuI} * \mathrm{PT}$ & 4 & 4614087 & 4614087 & 1153522 & 6.21 & 0.000 \\
\hline $\mathrm{Hb} * \mathrm{Sz} * \mathrm{OB}$ & 4 & 31313602 & 31313602 & 7828400 & 42.11 & 0.000 \\
\hline $\mathrm{Hb} * \mathrm{Sz}$ * IB & 4 & 790424 & 790424 & 197606 & 1.06 & 0.373 \\
\hline $\mathrm{Hb} * \mathrm{Sz}^{*} \mathrm{PT}$ & 4 & 27507021 & 27507021 & 6876755 & 36.99 & 0.000 \\
\hline $\mathrm{Hb} * \mathrm{OB} * \mathrm{IB}$ & 2 & 1002104 & 1002104 & 501052 & 2.70 & 0.068 \\
\hline $\mathrm{Hb} * \mathrm{OB} * \mathrm{PT}$ & 2 & 1575911 & 1575911 & 787955 & 4.24 & 0.015 \\
\hline $\mathrm{Hb} * \mathrm{IB} * \mathrm{PT}$ & 2 & 3359286 & 3359286 & 1679643 & 9.04 & 0.000 \\
\hline $\mathrm{Rul} * \mathrm{Sz}$ *OB & 4 & 320947 & 320947 & 80237 & 0.43 & 0.786 \\
\hline $\mathrm{Rul} * \mathrm{Sz}$ * IB & 4 & 196144 & 196144 & 49036 & 0.26 & 0.901 \\
\hline $\mathrm{Rul}$ *Sz *PT & 4 & 149120 & 149120 & 37280 & 0.20 & 0.938 \\
\hline Rul *OB* IB & 2 & 255458 & 255458 & 127729 & 0.69 & 0.503 \\
\hline $\mathrm{Ru} 1 * \mathrm{OB} * \mathrm{PT}$ & 2 & 16073745 & 16073745 & 8036873 & 43.24 & 0.000 \\
\hline Rul * IB*PT & 2 & 847581 & 847581 & 423791 & 2.28 & 0.103 \\
\hline $\mathrm{Sz} * \mathrm{OB}$ * IB & 2 & 83194 & 83194 & 41597 & 0.22 & 0.800 \\
\hline $\mathrm{Sz}$ *OB*PT & 2 & 120844 & 120844 & 60422 & 0.33 & 0.723 \\
\hline$S z$ * IB * PT & 2 & 256554 & 256554 & 128277 & 0.69 & 0.502 \\
\hline $\mathrm{OB} * \mathrm{IB} * \mathrm{PT}$ & 1 & 141747 & 141747 & 141747 & 0.76 & 0.383 \\
\hline $\mathrm{Hb} * \mathrm{Rul}$ *Sz*OB & 8 & 641894 & 641894 & 80237 & 0.43 & 0.903 \\
\hline $\mathrm{Hb} * \mathrm{Rul}$ *Sz * IB & 8 & 392288 & 392288 & 49036 & 0.26 & 0.977 \\
\hline $\mathrm{Hb} * \mathrm{Rul}$ *Sz * PT & 8 & 298241 & 298241 & 37280 & 0.20 & 0.991 \\
\hline $\mathrm{Hb} * \mathrm{Rul}$ *OB* IB & 4 & 510917 & 510917 & 127729 & 0.69 & 0.601 \\
\hline $\mathrm{Hb}$ * Ru1 * OB * PT & 4 & 32147490 & 32147490 & 8036873 & 43.24 & 0.000 \\
\hline $\mathrm{Hb}$ * Rul * IB * PT & 4 & 1695163 & 1695163 & 423791 & 2.28 & 0.059 \\
\hline $\mathrm{Hb} * \mathrm{Sz} * \mathrm{OB} * \mathrm{IB}$ & 4 & 166387 & 166387 & 41597 & 0.22 & 0.925 \\
\hline $\mathrm{Hb} * \mathrm{Sz} * \mathrm{OB} * \mathrm{PT}$ & 4 & 241687 & 241687 & 60422 & 0.33 & 0.861 \\
\hline $\mathrm{Hb} * \mathrm{Sz}$ * IB * PT & 4 & 513108 & 513108 & 128277 & 0.69 & 0.599 \\
\hline $\mathrm{Hb} * \mathrm{OB} * \mathrm{IB} * \mathrm{PT}$ & 2 & 283494 & 283494 & 141747 & 0.76 & 0.467 \\
\hline $\mathrm{Rul}$ *Sz*OB*IB & 4 & 41588 & 41588 & 10397 & 0.06 & 0.994 \\
\hline $\mathrm{Rul}$ *Sz*OB *PT & 4 & 1233851 & 1233851 & 308463 & 1.66 & 0.157 \\
\hline Rul *Sz*IB*PT & 4 & 127548 & 127548 & 31887 & 0.17 & 0.953 \\
\hline $\mathrm{Rul}$ *OB*IB*PT & 2 & 72138 & 72138 & 36069 & 0.19 & 0.824 \\
\hline $\mathrm{Sz} * \mathrm{OB} * \mathrm{IB} * \mathrm{PT}$ & 2 & 40277 & 40277 & 20139 & 0.11 & 0.897 \\
\hline $\mathrm{Hb} * \mathrm{Rul}$ *Sz*OB*IB & 8 & 83176 & 83176 & 10397 & 0.06 & 1.000 \\
\hline $\mathrm{Hb}$ * Rul *Sz *OB*PT & 8 & 2467701 & 2467701 & 308463 & 1.66 & 0.103 \\
\hline $\mathrm{Hb}$ * Rul *Sz*IB*PT & 8 & 255095 & 255095 & 31887 & 0.17 & 0.995 \\
\hline $\mathrm{Hb}$ * $\mathrm{Rul}$ *OB*IB*PT & 4 & 144275 & 144275 & 36069 & 0.19 & 0.942 \\
\hline $\mathrm{Hb} * \mathrm{Sz} * \mathrm{OB} * \mathrm{IB} * \mathrm{PT}$ & 4 & 80554 & 80554 & 20139 & 0.11 & 0.980 \\
\hline $\mathrm{Rul}$ *Sz*OB*IB*PT & 4 & 19257 & 19257 & 4814 & 0.03 & 0.999 \\
\hline $\mathrm{Hb}$ * Rul * Sz*OB* IB * PT & 8 & 38514 & 38514 & 4814 & 0.03 & 1.000 \\
\hline Error & 2376 & 441668230 & 441668230 & 185887 & & \\
\hline
\end{tabular}

$S=431.146 \quad R-S q=83.91 \% \quad R-S q(\operatorname{adj})=82.46 \%$

Table 4-52 - ANOVA: Outbound Miles Owned 


\section{ANOVA: Inbound Miles Owned}

(significant factors and interactions for $\alpha=0.05$ highlighted)

\begin{tabular}{|c|c|}
\hline $\begin{array}{l}\text { Source } \\
\mathrm{Hb}\end{array}$ & \\
\hline Rul & KEY: \\
\hline $\mathrm{Sz}$ & Hb - Hub Seed \\
\hline$O B$ & Rul - Assignment Rule \\
\hline IB & Sz - Set Size \\
\hline PT & OB - Outbound Weight \\
\hline $\mathrm{Hb} * \mathrm{Rul}$ & $\begin{array}{l}\text { IB - Inbound Weight } \\
\text { PT - Pass-Thru Weight }\end{array}$ \\
\hline $\mathrm{Hb} * \mathrm{Sz}$ & \\
\hline $\mathrm{Hb} * \mathrm{OB}$ & \\
\hline $\mathrm{Hb} * \mathrm{IB}$ & \\
\hline $\mathrm{Hb} * \mathrm{PT}$ & \\
\hline $\mathrm{Rul}$ *Sz & \\
\hline $\mathrm{Ru} 1$ *OB & \\
\hline Ru1 * IB & \\
\hline Rul *PT & \\
\hline
\end{tabular}

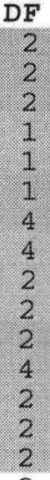

Seq SS

Adj ss Adj MS 7745210

278763801

218074725

2077852

195175528

175794688

442976606

236914604

4155704

390351057

351589376

15617404

1036978

4012712

$\mathrm{Sz} * \mathrm{OB}$

2016446 7745210
278763801

218074725

2077852

195175528

175794688

442976606

236914604

4155704

390351057

351589376

15617404

1036978

4012712 238307

2016446

$\mathrm{Sz} * \mathrm{IB}$

4602363 238307

$\mathrm{Sz} * \mathrm{PT}$

12314308

14602363

364554

$\begin{array}{lr}O B * I B & 1 \\ O B * P T & 1\end{array}$

1351899

364554

584855

$\mathrm{Hb} * \mathrm{Ru} 1 * \mathrm{Sz}$

$\mathrm{Hb} * \mathrm{Rul} * \mathrm{OB}$

$\mathrm{Hb} * \mathrm{Rul}$ * IB

$\mathrm{Hb} * \mathrm{Rul} * \mathrm{PT}$

$\mathrm{Hb} * \mathrm{Sz} * \mathrm{OB}$

$\begin{array}{rrrrr}32831868 & 32831868 & 4103984 & 23.99 & 0.000 \\ 2073955 & 2073955 & 518489 & 3.03 & 0.017\end{array}$

1351899

3872605
139381901

109037363

2077852

195175528

175794688

110744152

59228651

2077852

195175528

175794688

3904351

518489

2006356

1008223

119153

$\begin{array}{rr}\text { F } & \text { P } \\ 22.63 & 0.000\end{array}$

814.63

637.28

$1140.73 \quad 0.000$

1027.450 .000

$\begin{array}{ll}647.26 & 0.000\end{array}$

$\begin{array}{ll}346.17 & 0.000\end{array}$

12.140 .000

$\begin{array}{ll}1140.73 & 0.000\end{array}$

$\begin{array}{ll}1027.45 & 0.000\end{array}$

$\begin{array}{ll}22.82 & 0.000\end{array}$

$\begin{array}{ll}3.03 & 0.048\end{array}$

$11.73 \quad 0.000$

$\begin{array}{lll}1 & .89 & 0.003\end{array}$

$\begin{array}{lll}6157154 & 35.99 & 0.000\end{array}$

$\begin{array}{lll}364554 & 2.13 & 0.145\end{array}$

$\begin{array}{rrr}584855 & 3.42 & 0.065\end{array}$

$\begin{array}{lllll}8025423 & 8025423 & 2006356 & 11.73 & 0.000\end{array}$

$\begin{array}{rrrrr}4032893 & 4032893 & 1008223 & 5.89 & 0.000 \\ 476613 & 476613 & 119153 & 0.70 & 0.594\end{array}$

(1)

$\mathrm{Hb} * \mathrm{Sz} * \mathrm{PT}$

$\mathrm{Hb} * \mathrm{OB} * \mathrm{IB}$

476613

119153

29204726

29204726

7301181

$42.67 \quad 0.000$

24628615

24628615

6157154

$\begin{array}{ll}35.99 & 0.000\end{array}$

$\mathrm{Hb} * \mathrm{OB} * \mathrm{PT}$

729107

729107

364554

$\begin{array}{ll}2.13 & 0.119\end{array}$

270379

2703797

1351899

$7.90 \quad 0.000$

$\mathrm{Rul} * \mathrm{Sz} * \mathrm{OB}$

116665

116665

84855

$\begin{array}{lll}3.42 & 0.033\end{array}$

$\mathrm{Rul}$ *Sz * IB

$\mathrm{Rul} * \mathrm{Sz}$ *PT

468090

468090

29166
117022

$\begin{array}{lll}0.17 & 0.954\end{array}$

213085

213085

192318

Rul *OB*PT

686138

$\mathrm{RuI}$ *IB*PT

0445897

192318

28960

686138

$\mathrm{Sz} * \mathrm{OB}$ * IB

$\mathrm{Sz} * \mathrm{OB} * \mathrm{PT}$

$S z$ * IB*PT

$O B * I B * P T$

139971

119039

123557

233330

936180

426170

384637

$1 * S z * I B$

1372275

$\mathrm{Hb} * \mathrm{Rul}$ *OB * IB

20445897

53271

0.603

96159

$\begin{array}{lll}0.31 & 0.871\end{array}$

343069

$0.56 \quad 0.570$

$\begin{array}{lll}10222949 & 59.75 & 0.000\end{array}$

$\begin{array}{rrr}222949 & 59.75 & 0.000 \\ 14480 & 0.08 & 0.919\end{array}$

$\begin{array}{llll}139971 & 69985 & 0.41 & 0.664\end{array}$

$\begin{array}{llll}119039 & 59519 & 0.35 & 0.706\end{array}$

$\begin{array}{llll}123557 & 123557 & 0.72 & 0.396\end{array}$

$\begin{array}{lll}29166 & 0.17 & 0.995\end{array}$

$\begin{array}{lrll}233330 & 29166 & 0.17 & 0.995 \\ 936180 & 117022 & 0.68 & 0.706\end{array}$

$\begin{array}{llll}426170 & 53271 & 0.31 & 0.962\end{array}$

$\begin{array}{llll}384637 & 96159 & 0.56 & 0.690\end{array}$

\section{$\mathrm{Hb} * \mathrm{RuI}$ *IB*PT}

40891794

13722

343069

$\mathrm{B} * \mathrm{Sz} * \mathrm{OB} * \mathrm{IB}$

$\mathrm{Hb} * \mathrm{Sz} * \mathrm{OB} * \mathrm{PT}$

$\mathrm{Hb} * \mathrm{Sz} * \mathrm{IB} * \mathrm{PT}$

$\mathrm{Hb} * \mathrm{OB} * \mathrm{IB} * \mathrm{PT}$

$\mathrm{Rul} * \mathrm{Sz}$ *OB*IB

$\mathrm{Ru}$ * $* \mathrm{Sz} * \mathrm{OB} * \mathrm{PT}$

$\mathrm{Rul} * \mathrm{Sz}$ *IB*PT

$\mathrm{Rul}$ *OB*IB*PT

$S z * O B * I B * P T$

$\mathrm{Hb} * \mathrm{Rul} * \mathrm{Sz} * \mathrm{OB} * \mathrm{IB}$

$\mathrm{Hb} * \mathrm{Rul} * \mathrm{Sz} * \mathrm{OB} * \mathrm{PT}$

$\mathrm{Hb} * \mathrm{Rul} * \mathrm{Sz}$ * IB*PT

$\mathrm{Hb} * \mathrm{Rul}$ *OB*IB*PT

$\mathrm{Hb} * \mathrm{Sz} * \mathrm{OB} * \mathrm{IB} * \mathrm{PT}$

$\mathrm{RuI}$ * $\mathrm{Sz} * \mathrm{OB} * \mathrm{IB} * \mathrm{PT}$

$\mathrm{Hb} * \mathrm{Rul}$ * $\mathrm{Sz}$ *OB * IB * PT

Error

Total

279941

238077

40891794

10222949

$\begin{array}{ll}2.01 & 0.091\end{array}$

57921

14480

$59.75 \quad 0.000$

279941

238077

69985

0.410 .802

247113

247113

14233

69541

948896

62236

6232

28466

139083

1897791

124472

12463

2664

5327

406527835

14233

69541

948896

62236

6232

28466

139083

1897791

124472

12463

2664

59519

0.350 .846

$\begin{array}{lll}53557 & 0.72 & 0.486\end{array}$

$\begin{array}{lll}3558 & 0.02 & 0.999\end{array}$

$\begin{array}{lll}17385 & 0.10 & 0.982\end{array}$

$\begin{array}{lll}237224 & 1.39 & 0.236\end{array}$

$\begin{array}{lll}31118 & 0.18 & 0.834\end{array}$

$\begin{array}{lll}3116 & 0.02 & 0.982\end{array}$

$\begin{array}{lll}3558 & 0.02 & 1.000\end{array}$

$\begin{array}{lll}17385 & 0.10 & 0.999\end{array}$

$\begin{array}{lll}237224 & 1.39 & 0.197\end{array}$

$\begin{array}{lll}31118 & 0.18 & 0.948\end{array}$

$\begin{array}{lll}3116 & 0.02 & 0.999\end{array}$

$\begin{array}{lll}666 & 0.00 & 1.000\end{array}$

$\begin{array}{lll}666 & 0.00 \quad 1.000\end{array}$

171098

406527835

$2591 \quad 2939076082$

$\mathrm{S}=413.639 \quad \mathrm{R}-\mathrm{Sq}=86.17 \% \quad \mathrm{R}-\mathrm{Sq}(\operatorname{adj})=84.92 \%$

Table 4-53 - ANOVA: Inbound Miles Owned 
ANOVA: Pass-Thru Miles Owned

(significant factors and interactions for $\alpha=0.05$ highlighted)

\begin{tabular}{|c|c|c|c|c|c|c|}
\hline Source & DF & Seq SS & Adj ss & Adj MS & F & $\mathbf{P}$ \\
\hline $\mathrm{Hb}$ & 2 & 20249041923 & 20249041923 & 10124520961 & 73.04 & 0.000 \\
\hline KEY: & 2 & 2177785636 & 2177785636 & 1088892818 & 7.86 & 0.000 \\
\hline Hb - Hub Seal & 2 & $4.20055 \mathrm{E}+11$ & $4.20055 \mathrm{E}+11$ & $2.10028 \mathrm{E}+11$ & 1515.23 & 0.000 \\
\hline Rul - Assignment Rule & 1 & 163534617 & 163534617 & 163534617 & 1.18 & 0.278 \\
\hline Sz - Set Size & 1 & 154241193 & 154241193 & 154241193 & 1.11 & 0.292 \\
\hline $\begin{array}{l}\text { OB - Outbound Weight } \\
\text { IB - Inbound Weight }\end{array}$ & 1 & 707751335 & 707751335 & 707751335 & 5.11 & 0.024 \\
\hline $\begin{array}{l}\text { IB - Inbound Weight } \\
\text { PT - Pass-Thru Weight }\end{array}$ & 4 & 2315441887 & 2315441887 & 578860472 & 4.18 & 0.002 \\
\hline $\mathrm{Hb} * \mathrm{Sz}$ & 4 & 357224600 & 357224600 & 89306150 & 0.64 & 0.631 \\
\hline $\mathrm{Hb} * \mathrm{OB}$ & 2 & 327069234 & 327069234 & 163534617 & 1.18 & 0.308 \\
\hline $\mathrm{Hb} * \mathrm{IB}$ & 2 & 308482387 & 308482387 & 154241193 & 1.11 & 0.329 \\
\hline $\mathrm{Hb} * \mathrm{PT}$ & 2 & 1415502670 & 1415502670 & 707751335 & 5.11 & 0.006 \\
\hline $\mathrm{Rul}$ *Sz & 4 & 817792368 & 817792368 & 204448092 & 1.47 & 0.207 \\
\hline $\mathrm{Rul} * \mathrm{OB}$ & 2 & 1707054 & 1707054 & 853527 & 0.01 & 0.994 \\
\hline $\mathrm{Rul}$ *IB & 2 & 758547 & 758547 & 379274 & 0.00 & 0.997 \\
\hline $\mathrm{Rul}$ *PT & 2 & 8793699 & 8793699 & 4396849 & 0.03 & 0.969 \\
\hline $\mathrm{Sz} * \mathrm{OB}$ & 2 & 12362522 & 12362522 & 6181261 & 0.04 & 0.956 \\
\hline$S z * I B$ & 2 & 10112487 & 10112487 & 5056243 & 0.04 & 0.964 \\
\hline $\mathrm{Sz} * \mathrm{PT}$ & 2 & 53080689 & 53080689 & 26540345 & 0.19 & 0.826 \\
\hline$O B * I B$ & 1 & 2253211 & 2253211 & 2253211 & 0.02 & 0.899 \\
\hline$O B * P T$ & 1 & 121470 & 121470 & 121470 & 0.00 & 0.976 \\
\hline$I B * P T$ & 1 & 390090 & 390090 & 390090 & 0.00 & 0.958 \\
\hline $\mathrm{Hb} * \mathrm{Rul}$ *Sz & 8 & 214957259 & 214957259 & 26869657 & 0.19 & 0.992 \\
\hline $\mathrm{Hb} * \mathrm{Rul} * \mathrm{OB}$ & 4 & 3414107 & 3414107 & 853527 & 0.01 & 1.000 \\
\hline $\mathrm{Hb} * \mathrm{Rul}$ *IB & 4 & 1517094 & 1517094 & 379274 & 0.00 & 1.000 \\
\hline $\mathrm{Hb} * \mathrm{Rul} * \mathrm{PT}$ & 4 & 17587398 & 17587398 & 4396849 & 0.03 & 0.998 \\
\hline $\mathrm{Hb} * \mathrm{Sz} * \mathrm{OB}$ & 4 & 24725044 & 24725044 & 6181261 & 0.04 & 0.996 \\
\hline $\mathrm{Hb} * \mathrm{Sz} * \mathrm{IB}$ & 4 & 20224974 & 20224974 & 5056243 & 0.04 & 0.997 \\
\hline $\mathrm{Hb} * \mathrm{Sz} * \mathrm{PT}$ & 4 & 106161378 & 106161378 & 26540345 & 0.19 & 0.943 \\
\hline $\mathrm{Hb} * \mathrm{OB} * \mathrm{IB}$ & 2 & 4506421 & 4506421 & 2253211 & 0.02 & 0.984 \\
\hline $\mathrm{Hb} * \mathrm{OB} * \mathrm{PT}$ & 2 & 242939 & 242939 & 121470 & 0.00 & 0.999 \\
\hline $\mathrm{Hb} * \mathrm{IB} * \mathrm{PT}$ & 2 & 780180 & 780180 & 390090 & 0.00 & 0.997 \\
\hline $\mathrm{Rul}$ *Sz*OB & 4 & 130983 & 130983 & 32746 & 0.00 & 1.000 \\
\hline $\mathrm{Rul}$ *Sz*IB & 4 & 107877 & 107877 & 26969 & 0.00 & 1.000 \\
\hline $\mathrm{Rul}$ *Sz*PT & 4 & 623134 & 623134 & 155783 & 0.00 & 1.000 \\
\hline $\mathrm{Rul}$ *OB*IB & 2 & 883991 & 883991 & 441996 & 0.00 & 0.997 \\
\hline $\mathrm{Rul}$ *OB*PT & 2 & 10124673 & 10124673 & 5062337 & 0.04 & 0.964 \\
\hline $\mathrm{Rul}$ *IB*PT & 2 & 13088046 & 13088046 & 6544023 & 0.05 & 0.954 \\
\hline$S z * O B * I B$ & 2 & 243393 & 243393 & 121696 & 0.00 & 0.999 \\
\hline$S z * O B * P T$ & 2 & 54899 & 54899 & 27450 & 0.00 & 1.000 \\
\hline$S z * I B * P T$ & 2 & 295764 & 295764 & 147882 & 0.00 & 0.999 \\
\hline$O B * I B * P T$ & 1 & 653733 & 653733 & 653733 & 0.00 & 0.945 \\
\hline $\mathrm{Hb} * \mathrm{Rul} * \mathrm{Sz} * \mathrm{OB}$ & 8 & 261967 & 261967 & 32746 & 0.00 & 1.000 \\
\hline $\mathrm{Hb} * \mathrm{Rul} * \mathrm{Sz} * \mathrm{IB}$ & 8 & 215754 & 215754 & 26969 & 0.00 & 1.000 \\
\hline $\mathrm{Hb} * \mathrm{Rul} * \mathrm{Sz} * \mathrm{PT}$ & 8 & 1246267 & 1246267 & 155783 & 0.00 & 1.000 \\
\hline $\mathrm{Hb} * \mathrm{Rul} * \mathrm{OB} * \mathrm{IB}$ & 4 & 1767982 & 1767982 & 441996 & 0.00 & 1.000 \\
\hline $\mathrm{Hb} * \mathrm{Rul} * \mathrm{OB} * \mathrm{PT}$ & 4 & 20249347 & 20249347 & 5062337 & 0.04 & 0.997 \\
\hline $\mathrm{Hb} * \mathrm{Rul}$ * IB*PT & 4 & 26176092 & 26176092 & 6544023 & 0.05 & 0.996 \\
\hline $\mathrm{Hb} * \mathrm{Sz} * \mathrm{OB} * \mathrm{IB}$ & 4 & 486786 & 486786 & 121696 & 0.00 & 1.000 \\
\hline $\mathrm{Hb} * \mathrm{Sz} * \mathrm{OB} * \mathrm{PT}$ & 4 & 109798 & 109798 & 27450 & 0.00 & 1.000 \\
\hline $\mathrm{Hb} * \mathrm{Sz} * \mathrm{IB} * \mathrm{PT}$ & 4 & 591528 & 591528 & 147882 & 0.00 & 1.000 \\
\hline $\mathrm{Hb} * \mathrm{OB} * \mathrm{IB} * \mathrm{PT}$ & 2 & 1307465 & 1307465 & 653733 & 0.00 & 0.995 \\
\hline $\mathrm{Rul}$ *Sz*OB*IB & 4 & 103249 & 103249 & 25812 & 0.00 & 1.000 \\
\hline $\mathrm{Rul} * \mathrm{Sz}$ *OB*PT & 4 & 717730 & 717730 & 179433 & 0.00 & 1.000 \\
\hline$R u l$ * Sz*IB*PT & 4 & 372322 & 372322 & 93080 & 0.00 & 1.000 \\
\hline $\mathrm{Rul}$ *OB*IB*PT & 2 & 267728 & 267728 & 133864 & 0.00 & 0.999 \\
\hline$S z * O B \star I B * P T$ & 2 & 45517 & 45517 & 22758 & 0.00 & 1.000 \\
\hline $\mathrm{Hb}$ * Rul*Sz*OB*IB & 8 & 206499 & 206499 & 25812 & 0.00 & 1.000 \\
\hline $\mathrm{Hb} * \mathrm{Rul} * \mathrm{Sz} * \mathrm{OB} * \mathrm{PT}$ & 8 & 1435461 & 1435461 & 179433 & 0.00 & 1.000 \\
\hline $\mathrm{Hb}$ *Rul*Sz*IB*PT & 8 & 744643 & 744643 & 93080 & 0.00 & 1.000 \\
\hline $\mathrm{Hb}$ * Rul*OB*IB*PT & 4 & 535456 & 535456 & 133864 & 0.00 & 1.000 \\
\hline $\mathrm{Hb} * \mathrm{Sz}$ *OB*IB*PT & 4 & 91034 & 91034 & 22758 & 0.00 & 1.000 \\
\hline $\mathrm{Rul}$ *Sz*OB*IB*PT & 4 & 35150 & 35150 & 8787 & 0.00 & 1.000 \\
\hline $\mathrm{Hb} * \mathrm{Rul} * \mathrm{Sz} * \mathrm{OB}$ *IB*PT & 8 & 70299 & 70299 & 8787 & 0.00 & 1.000 \\
\hline Error & 2376 & $3.29340 \mathrm{E}+11$ & $3.29340 \mathrm{E}+11$ & 138610979 & & \\
\hline
\end{tabular}

$S=11773.3 \quad R-S q=57.72 \% \quad R-S q(\operatorname{adj})=53.89 \%$

Table 4-54 - ANOVA: Pass-Thru Miles Owned 
calculations do not include any distances from a hub to an outbound or inbound location. These miles exist regardless of the domicile scenario. However, these calculations depend on the distances from origin ' $\boldsymbol{i}$ ' to destination ' $\boldsymbol{j}$ ' as well as the scenario specific out of route miles incurred going from ' $\boldsymbol{i}$ ' to ' $\boldsymbol{j}$ ' via pass-thru domicile ' $\boldsymbol{k}$ '.

The number of miles driven by domiciled drivers and the number of miles driven by other OTR drivers are both significantly affected by hub set, assignment type, and set size. The outbound, inbound, and pass-thru weights do not make a significant difference. However, although those factors affect the individual mileage values, the values for total mileage (the sum of domicile miles and other OTR miles) are not significantly affected by any factor even though the total mile values include circuitous miles. The reason there is no significant difference is understandable. The total mileage stays relatively the same, except for minimal circuity. However, the proportionment of miles assigned to domiciled drivers versus miles assigned to other OTR drivers is influenced by hub sets, hub size, and ownership assignment rules.

Figures 4-8 and 4-9 show the interactions among hub sets, hub size, and ownership assignment rules for domicile and other OTR drivers, respectively. These two sets of plots are mirror images of one another because miles can fall into either one of the two categories. From these plots we see that domicile miles decrease and OTR miles increase as the set size decreases. The reason this happens is because, as was shown earlier, the effective ownership coverage area decreases as the set size decreases. 
ANOVA: Miles Driven - Domicile

(significant factors and interactions for $\alpha=0.05$ highlighted)

\begin{tabular}{|c|c|c|c|c|c|c|c|}
\hline Source & & DF & $\begin{array}{l}\text { Seg SS } \\
22569616\end{array}$ & ${ }_{2239}{ }^{\text {Adj }} \mathbf{s S}$ & $\begin{array}{r}\text { Adj MS } \\
17298 \text { 80 }\end{array}$ & $\mathbf{F}$ & $\mathbf{P}$ \\
\hline 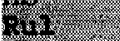 & KEY: & 2 & 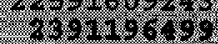 & 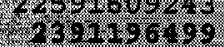 & 1.29350046 & 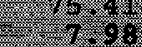 & 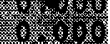 \\
\hline Suz & $\mathbf{H b}-H u b$ Scal & 12 & $4.62116 \mathrm{~d}+1$ & $4.6,1162.11$ & $2.30682+11$ & $3542=60$ & $6=-80$ \\
\hline $\mathrm{OB}$ & Rul - Assignment Rule & 1 & 409513 & 409513 & 409513 & 0.00 & 0.958 \\
\hline IB & $\mathbf{S} \mathbf{z}-\mathrm{Set}$ Size & 1 & 39997 & 39997 & 39997 & 0.00 & 0.987 \\
\hline $\mathrm{PT}$ & OB - Outbound Wright & 1 & 1197722 & 1197722 & 1197722 & 0.01 & 0.929 \\
\hline $\mathrm{Hb} * \mathrm{Rul}$ & $\begin{array}{l}\text { IB - Inhowak/ Waght } \\
\text { PT - Pass-Thru Waight }\end{array}$ & 4 & 376126512 & 376126512 & 94031628 & 0.63 & 0.643 \\
\hline & & & 2011954264 & $20111 \times 6264$ & s02920stor. & & \\
\hline $\mathrm{Hb} * \mathrm{OB}$ & & 2 & 819025 & 819025 & 409513 & 0.00 & 0.997 \\
\hline $\mathrm{Hb} \star \mathrm{IB}$ & & 2 & 79995 & 79995 & 39997 & 0.00 & 1.000 \\
\hline $\mathrm{Hb} * \mathrm{PT}$ & & 2 & 1577025 & 1577025 & 788513 & 0.01 & 0.995 \\
\hline $\mathrm{Rul} * \mathrm{Sz}$ & & 4 & 1044569446 & 1044569446 & 261142361 & 1.74 & 0.138 \\
\hline $\mathrm{Rul} * \mathrm{OB}$ & & 2 & 308 & 308 & 154 & 0.00 & 1.000 \\
\hline $\mathrm{Rul}$ * IB & & 2 & 519768 & 519768 & 259884 & 0.00 & 0.998 \\
\hline $\mathrm{Rul} * \mathrm{PT}$ & & 2 & 124113 & 124113 & 62057 & 0.00 & 1.000 \\
\hline $\mathrm{Sz} * \mathrm{OB}$ & & 2 & 108993 & 108993 & 54496 & 0.00 & 1.000 \\
\hline$S z * I B$ & & 2 & 36186 & 36186 & 18093 & 0.00 & 1.000 \\
\hline $\mathrm{Sz} * \mathrm{PT}$ & & 2 & 56421 & 56421 & 28211 & 0.00 & 1.000 \\
\hline$O B * I B$ & & 1 & 50385 & 50385 & 50385 & 0.00 & 0.985 \\
\hline $\mathrm{OB} * \mathrm{PT}$ & & 1 & 45602 & 45602 & 45602 & 0.00 & 0.986 \\
\hline $\mathrm{IB} * \mathrm{PT}$ & & 1 & 187646 & 187646 & 187646 & 0.00 & 0.972 \\
\hline $\mathrm{Hb} * \mathrm{Rul}$ & & 8 & 168317381 & 168317381 & 21039673 & 0.14 & 0.997 \\
\hline $\mathrm{Hb} * \mathrm{Rul}$ & & 4 & 616 & 616 & 154 & 0.00 & 1.000 \\
\hline $\mathrm{Hb} * \mathrm{Rul}$ & & 4 & 1039537 & 1039537 & 259884 & 0.00 & 1.000 \\
\hline $\mathrm{Hb} * \mathrm{Rul}$ & & 4 & 820125 & 820125 & 205031 & 0.00 & 1.000 \\
\hline $\mathrm{Hb} \star \mathrm{Sz} \star \mathrm{C}$ & & 4 & 217986 & 217986 & 54496 & 0.00 & 1.000 \\
\hline $\mathrm{Hb} \star S z \star$ & & 4 & 72372 & 72372 & 18093 & 0.00 & 1.000 \\
\hline $\mathrm{Hb} * \mathrm{Sz} * 1$ & & 4 & 398618 & 398618 & 99654 & 0.00 & 1.000 \\
\hline $\mathrm{Hb} * \mathrm{OB} *$ & & 2 & 100771 & 100771 & 50385 & 0.00 & 1.000 \\
\hline $\mathrm{Hb} * \mathrm{OB} * 1$ & & 2 & 91204 & 91204 & 45602 & 0.00 & 1.000 \\
\hline $\mathrm{Hb} * \mathrm{IB} * \mathrm{I}$ & & 2 & 375292 & 375292 & 187646 & 0.00 & 0.999 \\
\hline $\mathrm{Rul} \star \mathrm{Sz}$ & & 4 & 1051 & 1051 & 263 & 0.00 & 1.000 \\
\hline $\mathrm{Rul} * \mathrm{Sz}$ & & 4 & 328714 & 328714 & 82179 & 0.00 & 1.000 \\
\hline $\mathrm{Rul}$ * $\mathrm{Sz}$ & & 4 & 432385 & 432385 & 108096 & 0.00 & 1.000 \\
\hline$R u l * O B$ & & 2 & 10793 & 10793 & 5396 & 0.00 & 1.000 \\
\hline $\mathrm{RuI} * \mathrm{OB}$ & & 2 & 17395 & 17395 & 8698 & 0.00 & 1.000 \\
\hline $\mathrm{Rul} * \mathrm{IB}$ & & 2 & 30857 & 30857 & 15428 & 0.00 & 1.000 \\
\hline $\mathrm{Sz} * \mathrm{OB} *$ & & 2 & 116764 & 116764 & 58382 & 0.00 & 1.000 \\
\hline$S z * O B \star I$ & & 2 & 4764 & 4764 & 2382 & 0.00 & 1.000 \\
\hline$S z * I B * I$ & & 2 & 35625 & 35625 & 17813 & 0.00 & 1.000 \\
\hline $\mathrm{OB} * \mathrm{IB} * \mathrm{I}$ & & 1 & 905 & 905 & 905 & 0.00 & 0.998 \\
\hline $\mathrm{Hb} * \mathrm{Rul}$ & $5 z * O B$ & 8 & 2101 & 2101 & 263 & 0.00 & 1.000 \\
\hline $\mathrm{Hb} * \mathrm{Rul}$ & $3 z * I B$ & 8 & 657429 & 657429 & 82179 & 0.00 & 1.000 \\
\hline $\mathrm{Hb} * \mathrm{Rul}$ & $5 z * P T$ & 8 & 461539 & 461539 & 57692 & 0.00 & 1.000 \\
\hline $\mathrm{Hb} * \mathrm{Rul}$ & $\mathrm{B} * \mathrm{IB}$ & 4 & 21585 & 21585 & 5396 & 0.00 & 1.000 \\
\hline $\mathrm{Hb} * \mathrm{Rul}$ & $\mathrm{B} * \mathrm{PT}$ & 4 & 34790 & 34790 & 8698 & 0.00 & 1.000 \\
\hline $\mathrm{Hb} * \mathrm{Rul}$ & {$[\mathrm{B} * \mathrm{PT}$} & 4 & 61713 & 61713 & 15428 & 0.00 & 1.000 \\
\hline $\mathrm{Hb} * \mathrm{Sz} *$ & $3 * I B$ & 4 & 233529 & 233529 & 58382 & 0.00 & 1.000 \\
\hline $\mathrm{Hb} * \mathrm{Sz} * \mathrm{C}$ & $3 * \mathrm{PT}$ & 4 & 9527 & 9527 & 2382 & 0.00 & 1.000 \\
\hline $\mathrm{Hb} * \mathrm{Sz}$ * & $3 * \mathrm{PT}$ & 4 & 71250 & 71250 & 17813 & 0.00 & 1.000 \\
\hline $\mathrm{Hb} * \mathrm{OB} *$ & $8 * \mathrm{PT}$ & 2 & 1811 & 1811 & 905 & 0.00 & 1.000 \\
\hline $\mathrm{Rul} * \mathrm{Sz}$ & $D B * I B$ & 4 & 13597 & 13597 & 3399 & 0.00 & 1.000 \\
\hline $\mathrm{Rul} * \mathrm{Sz}$ & $\mathrm{DB} * \mathrm{PT}$ & 4 & 12462 & 12462 & 3116 & 0.00 & 1.000 \\
\hline $\mathrm{RuI} * \mathrm{Sz}$ & {$[\mathrm{B} * \mathrm{PT}$} & 4 & 76472 & 76472 & 19118 & 0.00 & 1.000 \\
\hline $\mathrm{Rul}$ * $\mathrm{OB}$ & {$[\mathrm{B} * \mathrm{PT}$} & 2 & 2729 & 2729 & 1364 & 0.00 & 1.000 \\
\hline$S z * O B *$ & $3 * \mathrm{PT}$ & 2 & 23839 & 23839 & 11919 & 0.00 & 1.000 \\
\hline $\mathrm{Hb} * \mathrm{Rul}$ & $z z * O B * I B$ & 8 & 27193 & 27193 & 3399 & 0.00 & 1.000 \\
\hline $\mathrm{Hb} * \mathrm{RuI}$ & $\mathrm{z} * \mathrm{OB} * \mathrm{PT}$ & 8 & 24924 & 24924 & 3116 & 0.00 & 1.000 \\
\hline $\mathrm{Hb} * \mathrm{RuI}$ & $3 z \star I B * P T$ & 8 & 152944 & 152944 & 19118 & 0.00 & 1.000 \\
\hline $\mathrm{Hb} * \mathrm{Rul}$ & $B * I B * P T$ & 4 & 5457 & 5457 & 1364 & 0.00 & 1.000 \\
\hline $\mathrm{Hb} * \mathrm{Sz} *$ & $3 \star I B * P T$ & 4 & 47677 & 47677 & 11919 & 0.00 & 1.000 \\
\hline $\mathrm{Rul} \star \mathrm{Sz}$ & $\mathrm{B} * \mathrm{IB} * \mathrm{PT}$ & 4 & 2771 & 2771 & 693 & 0.00 & 1.000 \\
\hline $\mathrm{Hb} * \mathrm{RuI}$ & $3 z \star O B \star I B \star P T$ & 8 & 5541 & 5541 & 693 & 0.00 & 1.000 \\
\hline Error & & $\begin{array}{l}2376 \\
2591\end{array}$ & $\begin{array}{l}3.55889 \mathrm{E}+11 \\
8.46601 \mathrm{E}+11\end{array}$ & $3.55889 E+11$ & 149785091 & & \\
\hline
\end{tabular}

$S=12238.7 \quad \mathrm{R}-\mathrm{Sq}=57.96 \% \quad \mathrm{R}-\mathrm{Sq}(\operatorname{adj})=54.16^{\circ}$

Table 4-55 - ANOVA: Miles Driven - Domicile 
ANOVA: Miles Driven - OTR

(significant factors and interactions for $\alpha=0.05$ highlighted)

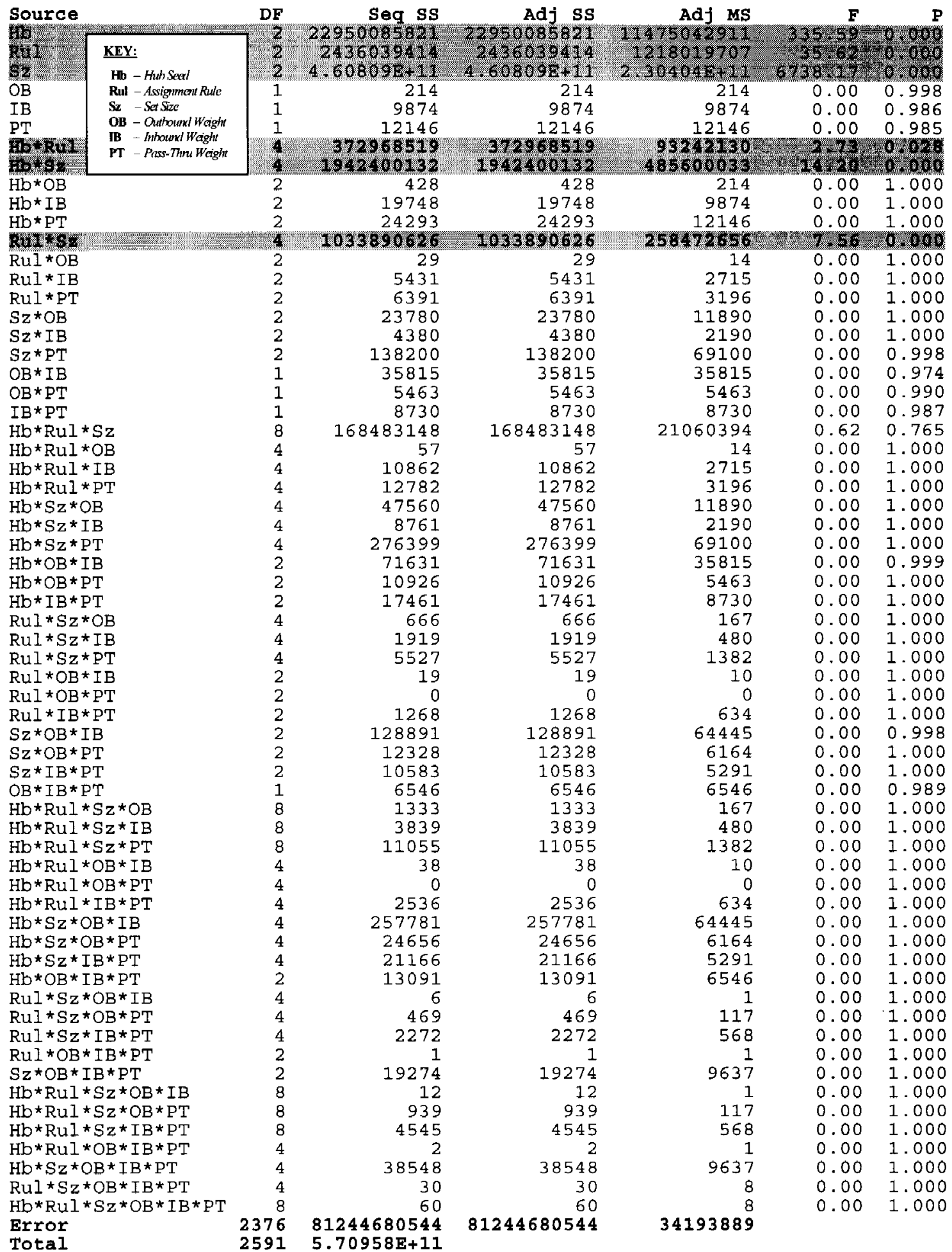

$S=5847.55 \quad R-S q=85.77 \% \quad R-S q(\operatorname{adj})=84.48 \%$

Table 4-56 - ANOVA: Miles Driven - OTR 


\section{ANOVA: Miles Driven - Total}

Significant factors and interactions for $\alpha=0.05$ highlighted)

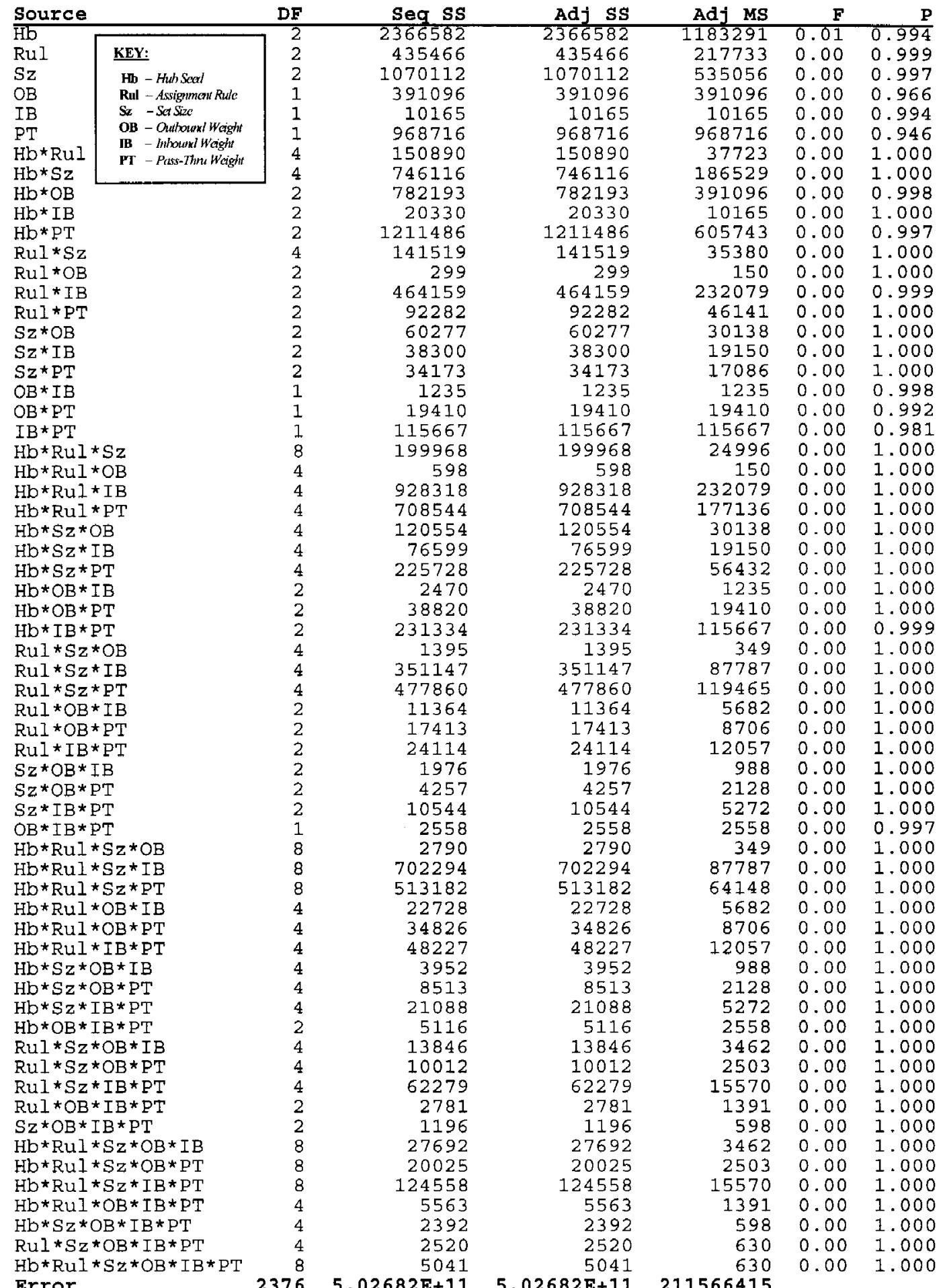

$5.02682 \mathrm{E}+11 \quad 211566415$

$S=14545.3 \quad R-S q=0.00 \% \quad R-S q(\operatorname{adj})=0.00 \%$

Table 4-57 - ANOVA: Miles Driven - Total 
Figure 4-8 shows that the ownership capped assignment rule decreases the number of miles that can be driven by domiciled drivers. Presumably, the reason that this would occur is that driver capacity limits from primary hubs may eliminate some freight lanes from being claimed by a neighboring, or secondary, hub. Although most freight is able to be claimed by a secondary hub after the primary hub had reached its capacity limit, some freight lanes may not have a nearby secondary hub close enough to the freight lane to be able to meet the qualifications from claiming ownership. Or, perhaps the secondary hub had also reached its driver capacity limits. Either way, if a second or subsequent hub can not claim ownership for either of these two reasons, the freight lanes' volume would default to OTR status, resulting in more OTR miles driven as depicted in Figure 4-9.

Finally, the plots of Figure 4-8 reveal that of the three hub sets, set LL could not claim as many domicile miles as either HW or JB. As a result, set LL had to take on a greater number of other OTR miles than either of the HW or JB sets as well.

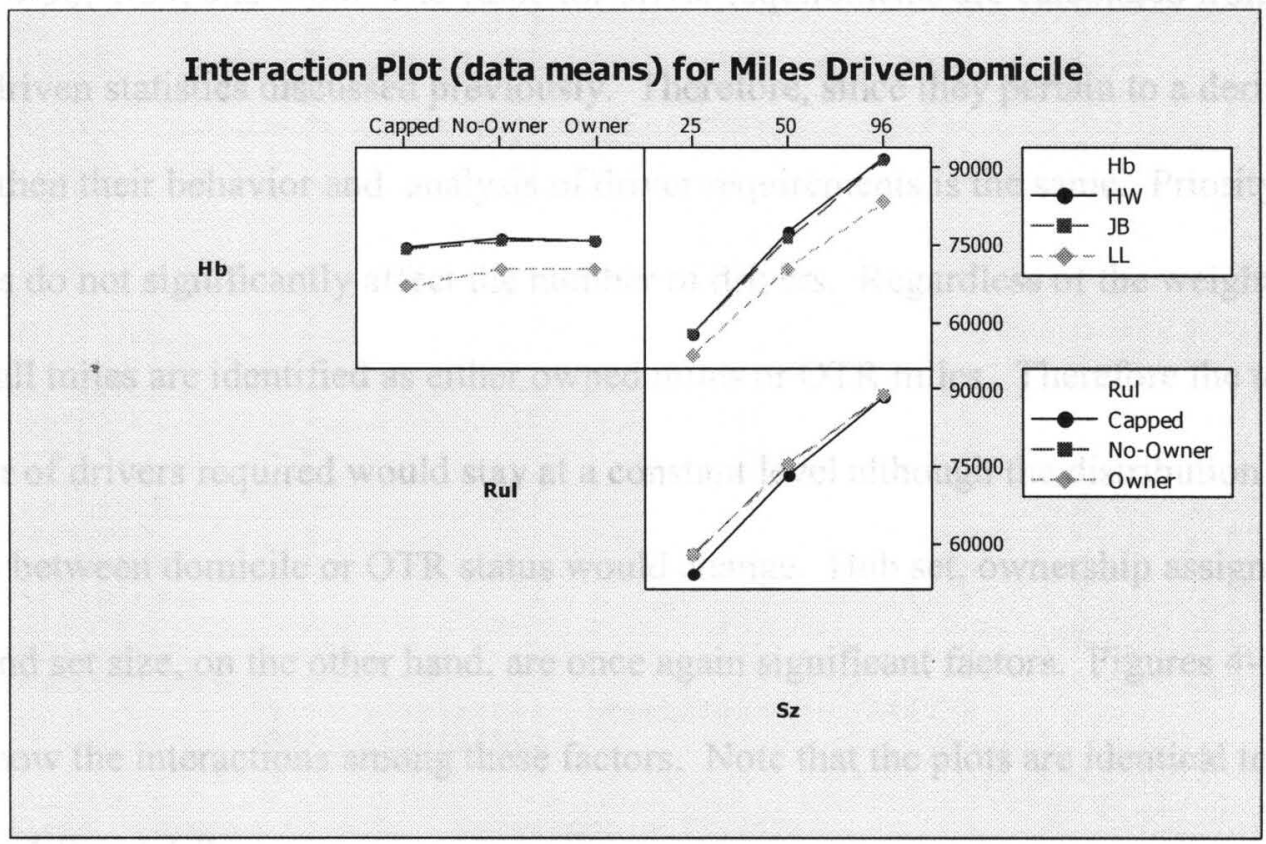

Figure 4-8 -- Interaction Plot - 3-Way - Miles Driven Domicile 


\section{Interaction Plot (data means) for Miles Driven OTR}

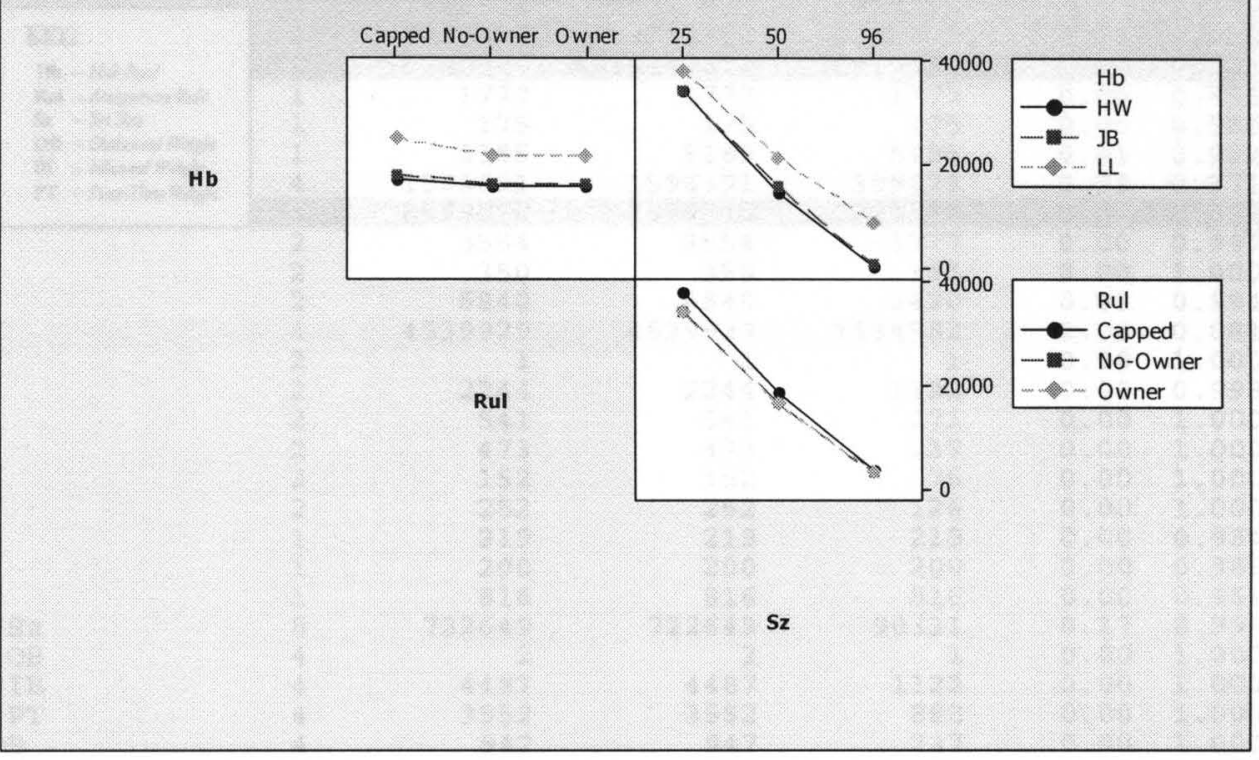

Figure 4-9 - Interaction Plot - 3-Way - Miles Driven OTR

Finally, the last measurements to be reviewed are the driver requirement values.

These results are found in Tables 4-38 through 4-45 and their ANOVA's are in

Tables 4-58, 4-59, and 4-60. The value for driver requirements are calculated from the miles driven statistics discussed previously. Therefore, since they pertain to a derived value, then their behavior and analysis of driver requirements is the same. Priority weights do not significantly affect the number of drivers. Regardless of the weights in place, all miles are identified as either owned miles or OTR miles. Therefore the total number of drivers required would stay at a constant level although the distribution of drivers between domicile or OTR status would change. Hub set, ownership assignment type, and set size, on the other hand, are once again significant factors. Figures 4-10 and 4-11 show the interactions among these factors. Note that the plots are identical to Figures 4-8 and 4-9. 
ANOVA: Driver Requirements - Domicile

(significant factors and interactions for $\alpha=0.05$ highlighted)

\begin{tabular}{|c|c|c|c|c|c|c|c|}
\hline Source & & DF & Seq SS & Adj $\mathrm{SS}$ & Adj MS & F & P \\
\hline $\mathrm{Hb}$ & & 2 & 97849514 & 97849514 & 48924757 & 89.48 & 0.000 \\
\hline Rul & KEY: & 2 & 9763350 & 9763350 & 4881675 & 8.93 & 0.000 \\
\hline $\mathrm{Sz}$ & Hb - Hub Seal & 2 & 1996740320 & 1996740320 & 998370160 & 1825.93 & 0.000 \\
\hline $\mathrm{OB}$ & Rul-Assignment Rule & 1 & 1777 & 1777 & 1777 & 0.00 & 0.955 \\
\hline IB & Sz - Set Size & 1 & 175 & 175 & 175 & 0.00 & 0.986 \\
\hline PT & OB - Outbound Weight & 1 & 5185 & 5185 & 5185 & 0.01 & 0.922 \\
\hline $\mathrm{Hb} * \mathrm{Rul}$ & $\begin{array}{l}\text { IB - Inboutud Waight } \\
\text { PT - Pass-Thru Waight }\end{array}$ & 4 & 1596691 & 1596691 & 399173 & 0.73 & 0.571 \\
\hline $\mathrm{Hb} * \mathrm{Sz}$ & P1 - Plass-thru waght & 4 & 8899570 & 8899570 & 2224893 & 4.07 & 0.003 \\
\hline $\mathrm{Hb} * \mathrm{OB}$ & & 2 & 3554 & 3554 & 1777 & 0.00 & 0.997 \\
\hline $\mathrm{Hb} * \mathrm{IB}$ & & 2 & 350 & 350 & 175 & 0.00 & 1.000 \\
\hline $\mathrm{Hb} * \mathrm{PT}$ & & 2 & 6840 & 6840 & 3420 & 0.01 & 0.994 \\
\hline $\mathrm{Rul} * \mathrm{Sz}$ & & 4 & 4539929 & 4539929 & 1134982 & 2.08 & 0.081 \\
\hline $\mathrm{Rul}$ *OB & & 2 & 1 & 1 & 1 & 0.00 & 1.000 \\
\hline Rul * IB & & 2 & 2244 & 2244 & 1122 & 0.00 & 0.998 \\
\hline $\mathrm{Rul}$ * $\mathrm{PT}$ & & 2 & 541 & 541 & 271 & 0.00 & 1.000 \\
\hline $\mathrm{Sz} * \mathrm{OB}$ & & 2 & 473 & 473 & 237 & 0.00 & 1.000 \\
\hline$S z * I B$ & & 2 & 152 & 152 & 76 & 0.00 & 1.000 \\
\hline $\mathrm{Sz} * \mathrm{PT}$ & & 2 & 252 & 252 & 126 & 0.00 & 1.000 \\
\hline$O B * I B$ & & 1 & 219 & 219 & 219 & 0.00 & 0.984 \\
\hline $\mathrm{OB} * \mathrm{PT}$ & & 1 & 200 & 200 & 200 & 0.00 & 0.985 \\
\hline $\mathrm{IB} * \mathrm{PT}$ & & 1 & 816 & 816 & 816 & 0.00 & 0.969 \\
\hline $\mathrm{Hb} * \mathrm{Rul}$ * & & 8 & 722649 & 722649 & 90331 & 0.17 & 0.995 \\
\hline $\mathrm{Hb} * \mathrm{Rul}$ * & & 4 & 2 & 2 & 1 & 0.00 & 1.000 \\
\hline $\mathrm{Hb} * \mathrm{Rul}$ * & & 4 & 4487 & 4487 & 1122 & 0.00 & 1.000 \\
\hline $\mathrm{Hb} * \mathrm{Rul}$ * & & 4 & 3552 & 3552 & 888 & 0.00 & 1.000 \\
\hline $\mathrm{Hb} * \mathrm{Sz} * \mathrm{C}$ & & 4 & 947 & 947 & 237 & 0.00 & 1.000 \\
\hline $\mathrm{Hb} * \mathrm{Sz} * \mathrm{I}$ & & 4 & 304 & 304 & 76 & 0.00 & 1.000 \\
\hline $\mathrm{Hb} \star \mathrm{Sz} * \mathrm{~F}$ & & 4 & 1750 & 1750 & 438 & 0.00 & 1.000 \\
\hline $\mathrm{Hb} * \mathrm{OB} * \mathrm{I}$ & & 2 & 437 & 437 & 219 & 0.00 & 1.000 \\
\hline $\mathrm{Hb} * \mathrm{OB} * \mathrm{~F}$ & & 2 & 400 & 400 & 200 & 0.00 & 1.000 \\
\hline $\mathrm{Hb} * \mathrm{IB} * \mathrm{I}$ & & 2 & 1632 & 1632 & 816 & 0.00 & 0.999 \\
\hline $\mathrm{Rul}$ *Sz* & & 4 & 5 & 5 & 1 & 0.00 & 1.000 \\
\hline $\mathrm{Rul} * \mathrm{Sz} *$ & & 4 & 1421 & 1421 & 355 & 0.00 & 1.000 \\
\hline $\mathrm{Rul} * \mathrm{Sz}$ * & & 4 & 1882 & 1882 & 471 & 0.00 & 1.000 \\
\hline $\mathrm{Rul}$ *OB* & & 2 & 47 & 47 & 24 & 0.00 & 1.000 \\
\hline $\mathrm{Rul} * \mathrm{OB}$ * & & 2 & 77 & 77 & 38 & 0.00 & 1.000 \\
\hline $\mathrm{Rul}$ * IB ${ }^{*}$ & & 2 & 130 & 130 & 65 & 0.00 & 1.000 \\
\hline$S z * O B \star I$ & & 2 & 506 & 506 & 253 & 0.00 & 1.000 \\
\hline $\mathrm{Sz} * \mathrm{OB} * \mathrm{E}$ & & 2 & 20 & 20 & 10 & 0.00 & 1.000 \\
\hline$S z * I B * E$ & & 2 & 156 & 156 & 78 & 0.00 & 1.000 \\
\hline$O B * I B * E$ & & 1 & 4 & 4 & 4 & 0.00 & 0.998 \\
\hline $\mathrm{Hb} * \mathrm{Rul}$ * & $S z * O B$ & 8 & 10 & 10 & 1 & 0.00 & 1.000 \\
\hline $\mathrm{Hb} * \mathrm{Rul}$ * & $S z$ *IB & 8 & 2843 & 2843 & 355 & 0.00 & 1.000 \\
\hline $\mathrm{Hb} * \mathrm{Rul}$ * & $\mathrm{Sz} * \mathrm{PT}$ & 8 & 2009 & 2009 & 251 & 0.00 & 1.000 \\
\hline $\mathrm{Hb} \star \mathrm{Rul}$ * & $D B * I B$ & 4 & 94 & 94 & 24 & 0.00 & 1.000 \\
\hline $\mathrm{Hb} * \mathrm{Rul}$ * & $\mathrm{DB} * \mathrm{PT}$ & 4 & 154 & 154 & 38 & 0.00 & 1.000 \\
\hline $\mathrm{Hb} * \mathrm{Rul}$ * & $I B * P T$ & 4 & 260 & 260 & 65 & 0.00 & 1.000 \\
\hline $\mathrm{Hb} * \mathrm{Sz} * \mathrm{C}$ & $B * I B$ & 4 & 1012 & 1012 & 253 & 0.00 & 1.000 \\
\hline $\mathrm{Hb} * \mathrm{Sz} * \mathrm{C}$ & $B * P T$ & 4 & 40 & 40 & 10 & 0.00 & 1.000 \\
\hline $\mathrm{Hb} * \mathrm{Sz} * \mathrm{I}$ & $B * P T$ & 4 & 312 & 312 & 78 & 0.00 & 1.000 \\
\hline $\mathrm{Hb} * \mathrm{OB} * \mathrm{I}$ & $\mathrm{B} * \mathrm{PT}$ & 2 & 7 & 7 & 4 & 0.00 & 1.000 \\
\hline $\mathrm{Rul} * \mathrm{Sz}$ * & $O B * I B$ & 4 & 59 & 59 & 15 & 0.00 & 1.000 \\
\hline $\mathrm{Rul}$ *Sz * & $\mathrm{OB}$ *PT & 4 & 54 & 54 & 13 & 0.00 & 1.000 \\
\hline $\mathrm{Rul} * \mathrm{Sz}$ * & $I B * P T$ & 4 & 326 & 326 & 82 & 0.00 & 1.000 \\
\hline $\mathrm{Rul}$ *OB* & $I B * P T$ & 2 & 12 & 12 & 6 & 0.00 & 1.000 \\
\hline$S z * O B * I$ & $\mathrm{~B} \star \mathrm{PT}$ & 2 & 104 & 104 & 52 & 0.00 & 1.000 \\
\hline $\mathrm{Hb} * \mathrm{Rul}$ * & $S z * O B * I B$ & 8 & 118 & 118 & 15 & 0.00 & 1.000 \\
\hline $\mathrm{Hb} * \mathrm{Rul}$ * & $S z * O B * P T$ & 8 & 107 & 107 & 13 & 0.00 & 1.000 \\
\hline $\mathrm{Hb} * \mathrm{Rul}$ * & $S z * I B * P T$ & 8 & 653 & 653 & 82 & 0.00 & 1.000 \\
\hline $\mathrm{Hb} * \mathrm{Rul}$ * & $\mathrm{DB}$ * IB*PT & 4 & 23 & 23 & 6 & 0.00 & 1.000 \\
\hline $\mathrm{Hb} * \mathrm{Sz} * \mathrm{C}$ & $B * I B * P T$ & 4 & 207 & 207 & 52 & 0.00 & 1.000 \\
\hline $\mathrm{Rul}$ *Sz* & $O B * I B * P T$ & 4 & 12 & 12 & 3 & 0.00 & 1.000 \\
\hline $\mathrm{Hb} * \mathrm{Rul}$ * & $S z * O B * I B * P T$ & 8 & 23 & 23 & 3 & 0.00 & 1.000 \\
\hline $\begin{array}{l}\text { Error } \\
\text { Total }\end{array}$ & & $\begin{array}{l}2376 \\
2591\end{array}$ & $\begin{array}{l}1299137028 \\
3419298028\end{array}$ & 1299137028 & 546775 & & \\
\hline
\end{tabular}

$S=739.442 \quad \mathrm{R}-\mathrm{Sq}=62.01 \% \quad \mathrm{R}-\mathrm{Sq}(\operatorname{adj})=58.57 \%$

Table 4-58 - ANOVA: Driver Requirements - Domicile 
ANOVA: Driver Requirements - OTR

(significant factors and interactions for $\alpha=0.05$ highlighted)

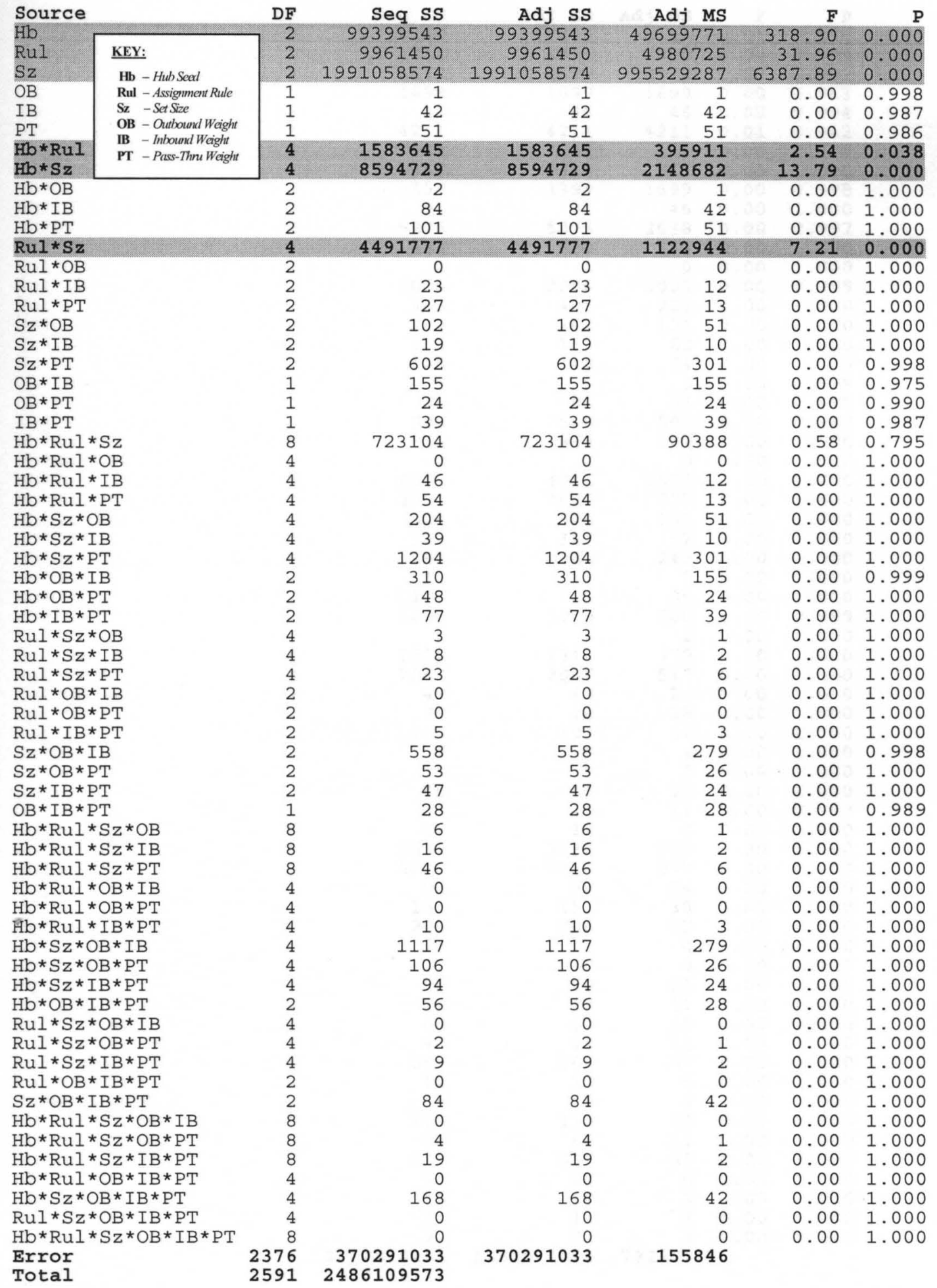

$\mathrm{S}=394.774 \quad \mathrm{R}-\mathrm{Sq}=85.11 \% \quad \mathrm{R}-\mathrm{Sq}(\operatorname{adj})=83.76 \%$

Table 4-59 - ANOVA: Driver Requirements - OTR 
ANOVA: Driver Requirements - Total

(Significant factors and interactions for $\alpha=0.05$ highlighted)

\begin{tabular}{|c|c|c|c|c|c|c|c|}
\hline Source & & DF & Seg SS & Adj SS & Adj MS & $\mathbf{F}$ & $\mathbf{P}$ \\
\hline $\mathrm{Hb}$ & & 2 & 10248 & 10248 & 5124 & 0.01 & $\overline{0.994}$ \\
\hline Rul & KEY: & 2 & 1815 & 1815 & 908 & 0.00 & 0.999 \\
\hline $\mathrm{Sz}$ & Hb $-H u$ S S $x a t$ & 2 & 4677 & 4677 & 2339 & 0.00 & 0.997 \\
\hline $\mathrm{OB}$ & Rul - Assigyman Rudc & 1 & 1699 & 1699 & 1699 & 0.00 & 0.963 \\
\hline IB & Sa - Set Size & 1 & 46 & 46 & 46 & 0.00 & 0.994 \\
\hline PT & OB - Outhound Wcight & 1 & 4211 & 4211 & 4211 & 0.01 & 0.942 \\
\hline $\mathrm{Hb} * \mathrm{Rul}$ & 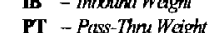 & 4 & 642 & 642 & 161 & 0.00 & 1.000 \\
\hline $\mathrm{Hb} * \mathrm{Sz}$ & & 4 & 3246 & 3246 & 812 & 0.00 & 1.000 \\
\hline $\mathrm{Hb} \star \mathrm{OB}$ & & 2 & 3399 & 3399 & 1699 & 0.00 & 0.998 \\
\hline $\mathrm{Hb} * \mathrm{IB}$ & & 2 & 91 & 91 & 46 & 0.00 & 1.000 \\
\hline $\mathrm{Hb} \star \mathrm{PT}$ & & 2 & 5275 & 5275 & 2638 & 0.00 & 0.997 \\
\hline $\mathrm{Rul}$ *Sz & & 4 & 623 & 623 & 156 & 0.00 & 1.000 \\
\hline $\mathrm{Rul} * \mathrm{OB}$ & & 2 & 1 & 1 & 0 & 0.00 & 1.000 \\
\hline Rul *IB & & 2 & 2006 & 2006 & 1003 & 0.00 & 0.999 \\
\hline $\mathrm{Rul} * \mathrm{PT}$ & & 2 & 405 & 405 & 203 & 0.00 & 1.000 \\
\hline $\mathrm{Sz} * \mathrm{OB}$ & & 2 & 262 & 262 & 131 & 0.00 & 1.000 \\
\hline$S z * I B$ & & 2 & 163 & 163 & 82 & 0.00 & 1.000 \\
\hline $\mathrm{Sz} * \mathrm{PT}$ & & 2 & 148 & 148 & 74 & 0.00 & 1.000 \\
\hline$O B * I B$ & & 1 & 5 & 5 & 5 & 0.00 & 0.998 \\
\hline $\mathrm{OB} * \mathrm{PT}$ & & 1 & 85 & 85 & 85 & 0.00 & 0.992 \\
\hline $\mathrm{IB} * \mathrm{PT}$ & & 1 & 500 & 500 & 500 & 0.00 & 0.980 \\
\hline $\mathrm{Hb} * \mathrm{Rul}$ * & & 8 & 868 & 868 & 109 & 0.00 & 1.000 \\
\hline $\mathrm{Hb} * \mathrm{Rul}$ * & & 4 & 2 & 2 & 0 & 0.00 & 1.000 \\
\hline $\mathrm{Hb} * \mathrm{Rul}$ * & & 4 & 4011 & 4011 & 1003 & 0.00 & 1.000 \\
\hline $\mathrm{Hb} \star \mathrm{RuI}$ * & $\mathrm{PT}$ & 4 & 3087 & 3087 & 772 & 0.00 & 1.000 \\
\hline $\mathrm{Hb} * \mathrm{Sz} * \mathrm{C}$ & & 4 & 524 & 524 & 131 & 0.00 & 1.000 \\
\hline $\mathrm{Hb} * \mathrm{Sz} * \mathrm{I}$ & & 4 & 327 & 327 & 82 & 0.00 & 1.000 \\
\hline $\mathrm{Hb} * \mathrm{Sz} * \mathrm{~F}$ & & 4 & 981 & 981 & 245 & 0.00 & 1.000 \\
\hline $\mathrm{Hb} * \mathrm{OB} * \mathrm{I}$ & & 2 & 11 & 11 & 5 & 0.00 & 1.000 \\
\hline $\mathrm{Hb} * \mathrm{OB} * \mathrm{~F}$ & & 2 & 171 & 171 & 85 & 0.00 & 1.000 \\
\hline$H b * I B * F$ & & 2 & 1000 & 1000 & 500 & 0.00 & 0.999 \\
\hline Rul * Sz* & & 4 & 6 & 6 & 2 & 0.00 & 1.000 \\
\hline $\mathrm{RuI} I$ * $\mathrm{zz}$ * & & 4 & 1516 & 1516 & 379 & 0.00 & 1.000 \\
\hline $\mathrm{Rul}$ * Sz* & & 4 & 2067 & 2067 & 517 & 0.00 & 1.000 \\
\hline $\mathrm{Rul} * \mathrm{OB}$ * & & 2 & 49 & 49 & 24 & 0.00 & 1.000 \\
\hline 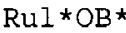 & & 2 & 76 & 76 & 38 & 0.00 & 1.000 \\
\hline Rul * IB* & $\mathrm{PT}$ & 2 & 103 & 103 & 52 & 0.00 & 1.000 \\
\hline$S z * O B * I$ & & 2 & 9 & 9 & 4 & 0.00 & 1.000 \\
\hline $\mathrm{Sz} * \mathrm{OB} * \mathrm{Z}$ & & 2 & 19 & 19 & 9 & 0.00 & 1.000 \\
\hline $\mathrm{Sz} * \mathrm{IB} * \mathrm{~F}$ & & 2 & 45 & 45 & 23 & 0.00 & 1.000 \\
\hline$O B * I B * F$ & & 1 & 11 & 11 & 11 & 0.00 & 0.997 \\
\hline $\mathrm{Hb} * \mathrm{Rul}$ * & $S z * O B$ & 8 & 12 & 12 & 2 & 0.00 & 1.000 \\
\hline $\mathrm{Hb} \star \mathrm{Rul}$ * & $\mathrm{Sz}$ *IB & 8 & 3032 & 3032 & 379 & 0.00 & 1.000 \\
\hline $\mathrm{Hb} \star \mathrm{Rul}$ * & $\mathrm{Sz} * \mathrm{PT}$ & 8 & 2216 & 2216 & 277 & 0.00 & 1.000 \\
\hline $\mathrm{Hb}^{\star} \mathrm{Rul}$ * & $\mathrm{OB}$ * IB & 4 & 98 & 98 & 24 & 0.00 & 1.000 \\
\hline $\mathrm{Hb} * \mathrm{Rul} *$ & $\mathrm{OB} * \mathrm{PT}$ & 4 & 151 & 151 & 38 & 0.00 & 1.000 \\
\hline $\mathrm{Hb} \mathrm{R}^{\mathrm{Rul}} \mathrm{l}^{\star}$ & $\mathrm{IB} * \mathrm{PT}$ & 4 & 206 & 206 & 52 & 0.00 & 1.000 \\
\hline $\mathrm{Hb}^{*} \mathrm{Sz} * \mathrm{C}$ & $B * I B$ & 4 & 17 & 17 & 4 & 0.00 & 1.000 \\
\hline $\mathrm{Hb} * \mathrm{Sz} * \mathrm{C}$ & $B * P T$ & 4 & 37 & 37 & 9 & 0.00 & 1.000 \\
\hline $\mathrm{Hb} * \mathrm{Sz} * \mathrm{I}$ & $B * P T$ & 4 & 90 & 90 & 23 & 0.00 & 1.000 \\
\hline $\mathrm{Hb} * \mathrm{OB} * \mathrm{I}$ & $\mathrm{B} * \mathrm{PT}$ & 2 & 22 & 22 & 11 & 0.00 & 1.000 \\
\hline $\mathrm{Rul}$ *Sz* & $O B * I B$ & 4 & 60 & 60 & 15 & 0.00 & 1.000 \\
\hline $\mathrm{Rul} * \mathrm{Sz}$ * & $O B \star P T$ & 4 & 43 & 43 & 11 & 0.00 & 1.000 \\
\hline Rul*Sz & $I B * P T$ & 4 & 269 & 269 & 67 & 0.00 & 1.000 \\
\hline $\mathrm{Rul}$ *OB* & $I \mathrm{I} * \mathrm{PT}$ & 2 & 12 & 12 & 6 & 0.00 & 1.000 \\
\hline$S z * O B * I$ & $\mathrm{~B} \star \mathrm{PT}$ & 2 & 5 & 5 & 3 & 0.00 & 1.000 \\
\hline $\mathrm{Hb} * \mathrm{Rul}$ * & $S z \star O B \star I B$ & 8 & 119 & 119 & 15 & 0.00 & 1.000 \\
\hline $\mathrm{Hb} * \mathrm{Rul} *$ & $\mathrm{Sz} * \mathrm{OB} * \mathrm{PT}$ & 8 & 86 & 86 & 11 & 0.00 & 1.000 \\
\hline $\mathrm{Hb} * \mathrm{Ru} \mathrm{I}^{*}$ & $S z * I B * P T$ & 8 & 537 & 537 & 67 & 0.00 & 1.000 \\
\hline $\mathrm{Hb} * \mathrm{RuI}$ * & $O B * I B * P T$ & 4 & 24 & 24 & 6 & 0.00 & 1.000 \\
\hline $\mathrm{Hb} * \mathrm{Sz} * \mathrm{C}$ & $B * I B * P T$ & 4 & 10 & 10 & 3 & 0.00 & 1.000 \\
\hline $\mathrm{Rul}$ *Sz* & $O B * I B * P T$ & 4 & 11 & 11 & 3 & 0.00 & 1.000 \\
\hline $\mathrm{Hb} * \mathrm{Rul}$ * & $S z \star O B \star I B * P T$ & 8 & 22 & 22 & 3 & 0.00 & 1.000 \\
\hline $\begin{array}{l}\text { Error } \\
\text { Total }\end{array}$ & & $\begin{array}{l}2376 \\
2591\end{array}$ & $\begin{array}{l}1882874205 \\
1882935718\end{array}$ & 1882874205 & 792455 & & \\
\hline
\end{tabular}

$S=890.200 \quad R-S q=0.00 \% \quad R-S q(\operatorname{adj})=0.00 \%$

Table 4-60 - ANOVA: Driver Requirements - Total 


\section{Interaction Plot (data means) for Drivers Domicile}

Hb

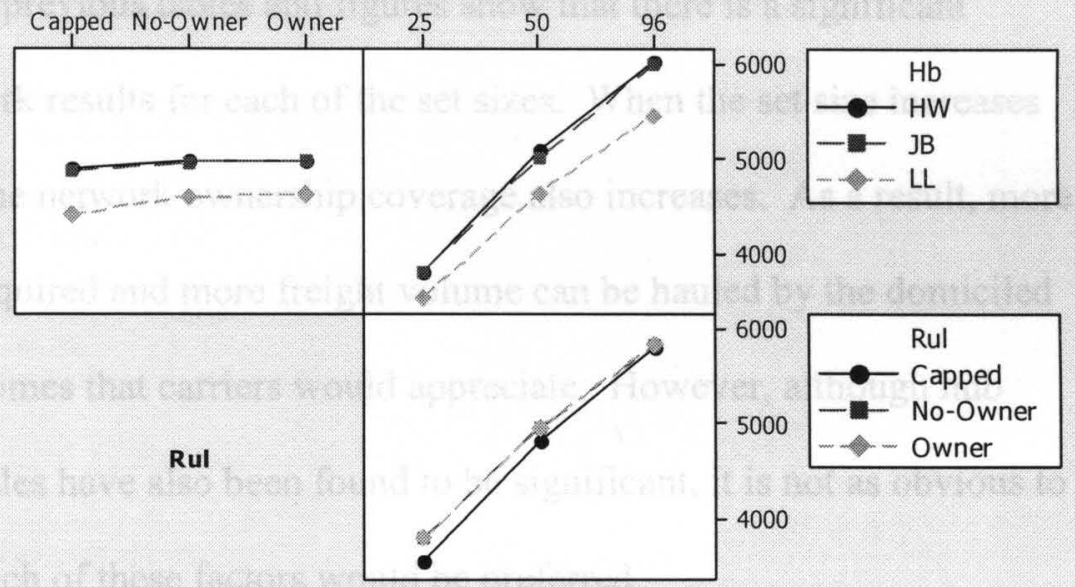

Sz

Figure 4-10 - Interaction Plot - 3-Way - Drivers Required Domicile

\section{Interaction Plot (data means) for Drivers OTR}

Hb

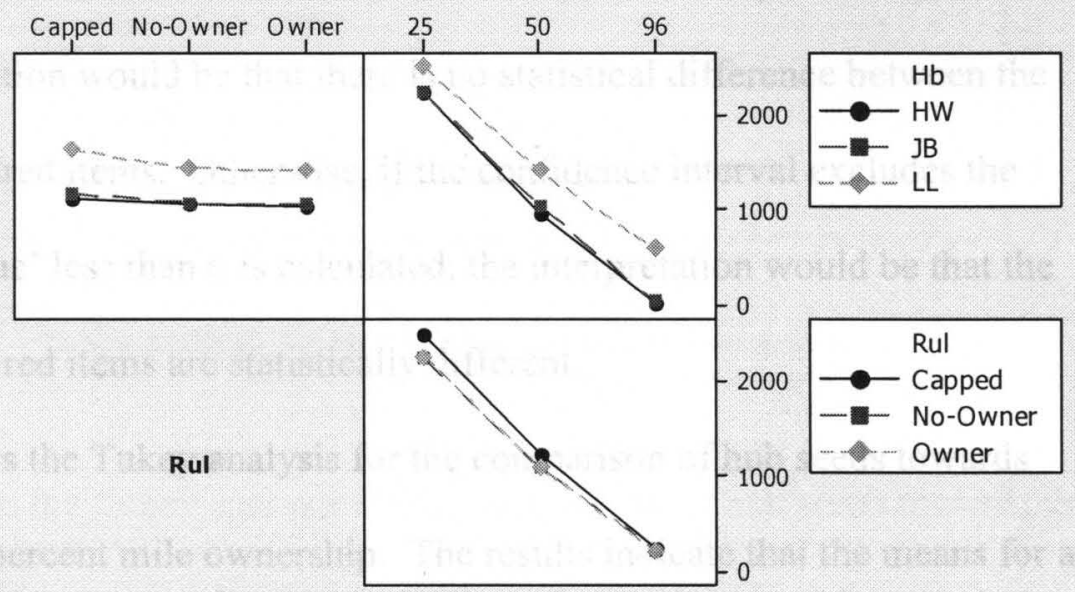

Sz

Figure 4-11 - Interaction Plot - 3-Way - Drivers Required OTR 
Results show that hub seeds, set size, and assignment rules are the most significant factors. The previous tables and figures show that there is a significant difference among network results for each of the set sizes. When the set size increases from $n=25$ to $n=96$, the network ownership coverage also increases. As a result, more domiciled drivers are required and more freight volume can be hauled by the domiciled drivers. These are outcomes that carriers would appreciate. However, although hub seeds and assignment rules have also been found to be significant, it is not as obvious to know which levels of each of these factors would be preferred.

The HW hub seeds and the JB hub seeds appear to both be very good. Previous results show that the LL hub seeds are significantly worse. But to understand whether or not HW should be preferred over JB would require additional analysis. The Tukey statistical test would be appropriate. The Tukey obtains confidence intervals for all pairwise differences between level means. If the confidence interval for any pairwise differences includes the value zero then the Tukey would calculate a ' $p$-value' greater than $\alpha$ and the interpretation would be that there is no statistical difference between the means of each of the paired items. Otherwise, if the confidence interval excludes the value zero, and a ' $p$-value' less than $\alpha$ is calculated, the interpretation would be that the means of each of the paired items are statistically different.

Table 4-61 shows the Tukey analysis for the comparison of hub seeds towards response measurement percent mile ownership. The results indicate that the means for all three hub seeds $(\alpha=0.05)$ are significantly different from one another (i.e. each pairwise comparison has a p-value of 0.000). Therefore, for mileage ownership, the Tukey concludes that the HW hub seeds would yield the greatest ownership coverage. Similar 
Tukey analysis for route and load ownership as well as all imbalance measurements show that the HW hub seeds also perform better than either the JB or LL hub seeds.

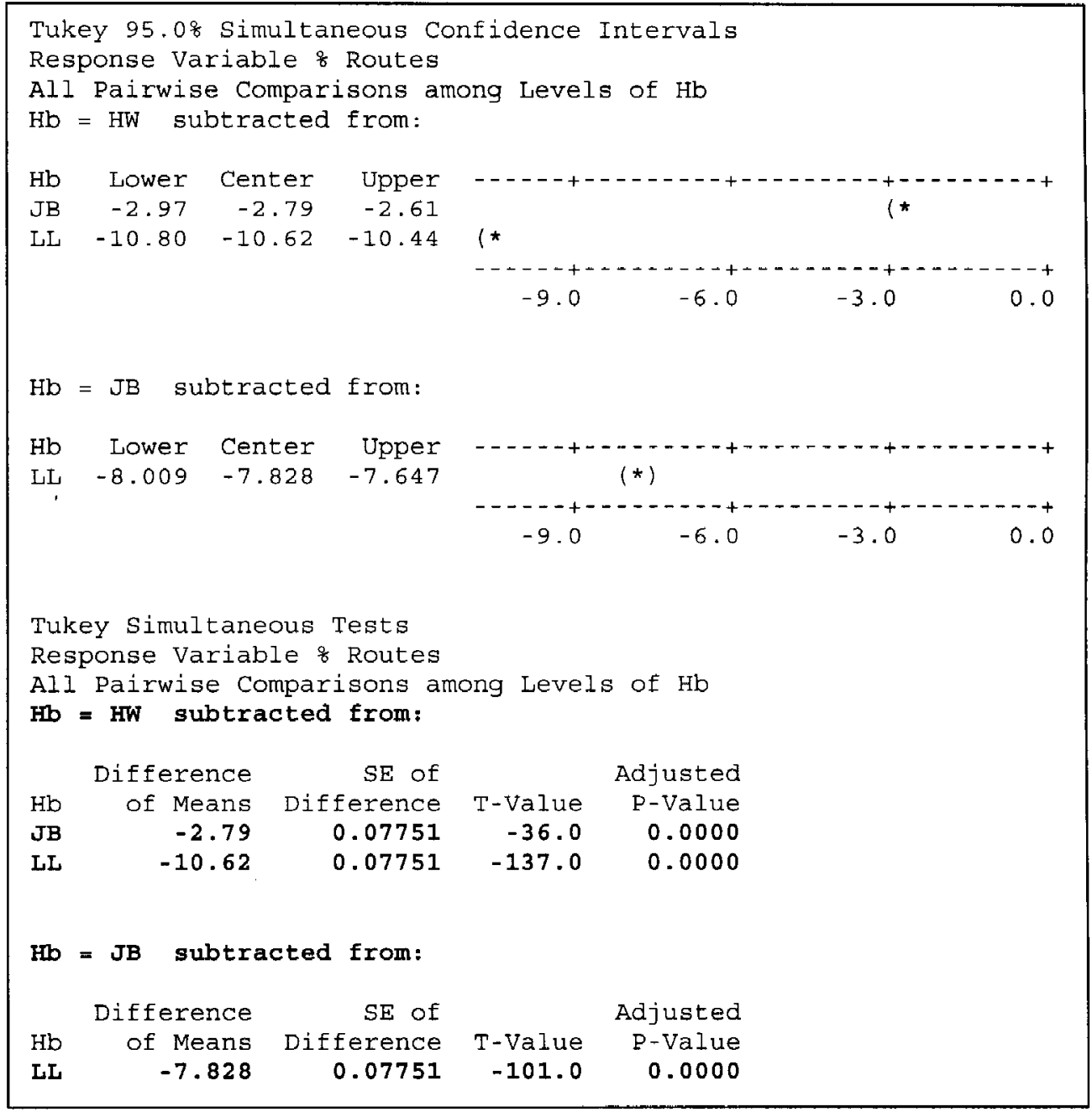

Table 4-61 - Tukey Analysis for Hub Seeds and Mileage Ownership

Table 4-62 shows the Tukey analysis for the comparison of hub seeds towards the response measurement for domicile drivers required. The results indicate that there is a significant difference between the means for HW and LL $(p=0.000)$ and JB and LL $(p=$ 0.000). However, the Tukey concludes that there is no significant difference between the means of HW and JB $(p=0.6462)$. Additional Tukey tests analyzing drivers required 
(OTR and Total) and miles driven (domicile drivers, OTR drivers, Total) reached similar conclusions. No significant difference was determined between HW and JB, yet both performed better than the LL hub seeds.

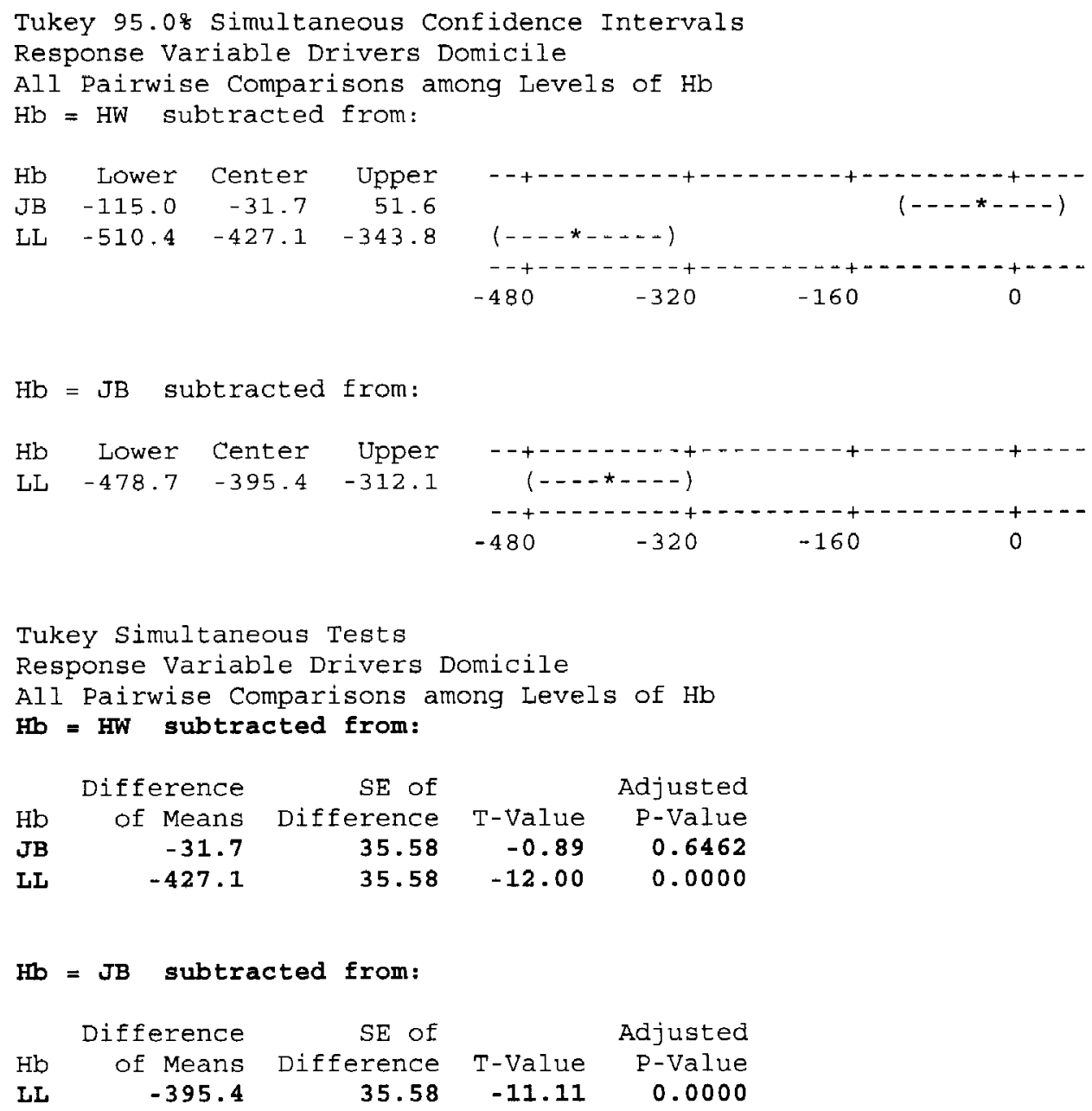

Table 4-62 - Tukey Analysis for Hub Seeds and Domiciled Drivers

Table 4-63 provides the Tukey analysis for the pairwise comparisons of the assignment rules towards response measurement percent mile ownership. These results indicate that there is a significant difference between the means for the assignment rules Capped and Ownership $(p=0.000)$ and Capped and No-Ownership $(p=0.000)$.

However, the Tukey concludes that there is no significant difference between the means 
of Ownership and No-Ownership $(p=1.000)$. Additional Tukey tests for all other response measurements determined that the Capped assignment rule was significantly different than both the Ownership and No-Ownership rules. However, no significant difference was found between the Ownership and No-Ownership rules for all responses except imbalance, inbound miles owned, and outbound miles owned.

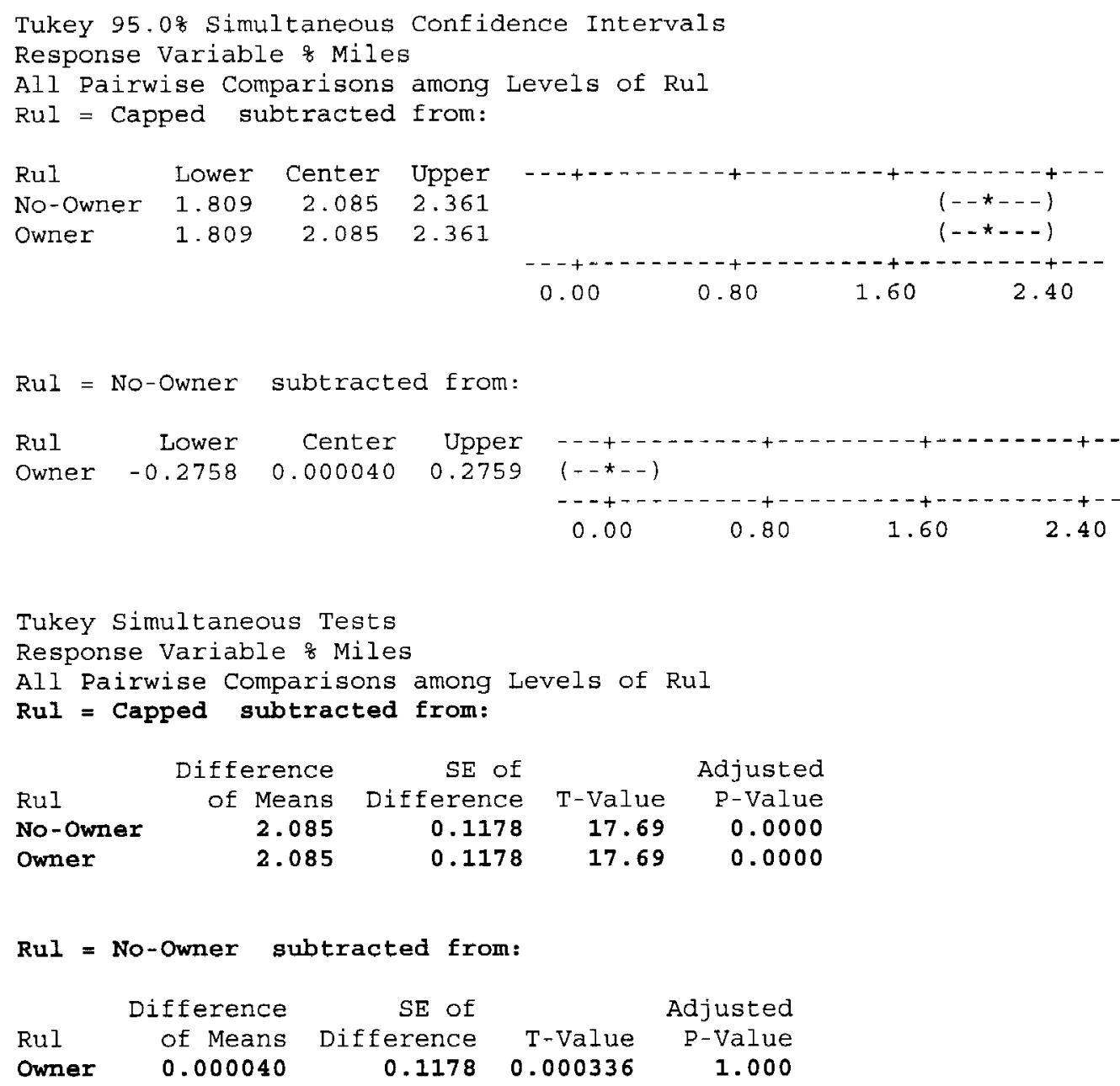

Table 4-63 - Tukey Analysis for Assignment Rule and Mileage Ownership 


\subsection{Conclusions}

The previous section completed a thorough analysis of the six factors and discussed how they contributed to the each of the fifteen response measurements. Although each of the factors significantly affected the response measurements in a variety of ways, the three most prevalent factors affecting domicile solutions were the set size, hub seeds, and assignment rules. Priority weights had negligible impact on network performance except for imbalance and for owned mileage breakdown statistics.

The most important factor is set size. Ideally, it should be allowed to assume the largest value possible ( $n=96$ for this research) to maximize the ownership of routes, loads, and miles. However, from a carrier perspective this number of hubs may be too large to adequately manage. Therefore, a smaller set size $(n=25)$ is still effective (with $60 \%+$ mileage ownership) and is likely to outperform current recruitment strategies. Furthermore, this research concludes that recruiting drivers with domiciles near large highway intersections (HW) outperforms both networks built along an existing infrastructure (JB) and a latitude-longitude grid (LL). Furthermore, by recruiting drivers based on the HW hub seed strategy, a better pool of potential drivers may be found because the highway intersections would already be situated along major metropolitan populations. By comparison, the potential to recruit drivers domiciled near the LL hubs would be limited because a sufficient population base may not exist. In addition, a carrier would benefit better if domicile hubs did not have capacity restrictions placed on the number of drivers that would be dispatched from the hub.

Since the HW hub seeds have been determined to be the best domicile locations, Figure 4-12 depicts the location of the 25 best locations within the HW hub set. Research 
has shown that most of the miles owned come by way of pass-thru ownership. This map verifies why this is true. Figure 4-12 shows that the ideal locations for domiciles are in the interior of the United States. From these locations, the hubs are in great position to claim a majority of pass-thru miles which would insure drivers could get home more frequently. From the original 96 hubs depicted in Table 4-3, these 25 hubs have been determined to be the best domicile locations. As additional domicile locations enter the recruitment network, outlying hubs located in states such as Florida, Texas, Washington, Minnesota, New York, and North Carolina eventually begin to enter the network.

However, because of their outlying positions, they do not claim as great an amount of pass-thru ownership miles as the hubs shown in Figure 4-12. The outlying positions, instead, rely more on inbound and outbound miles.

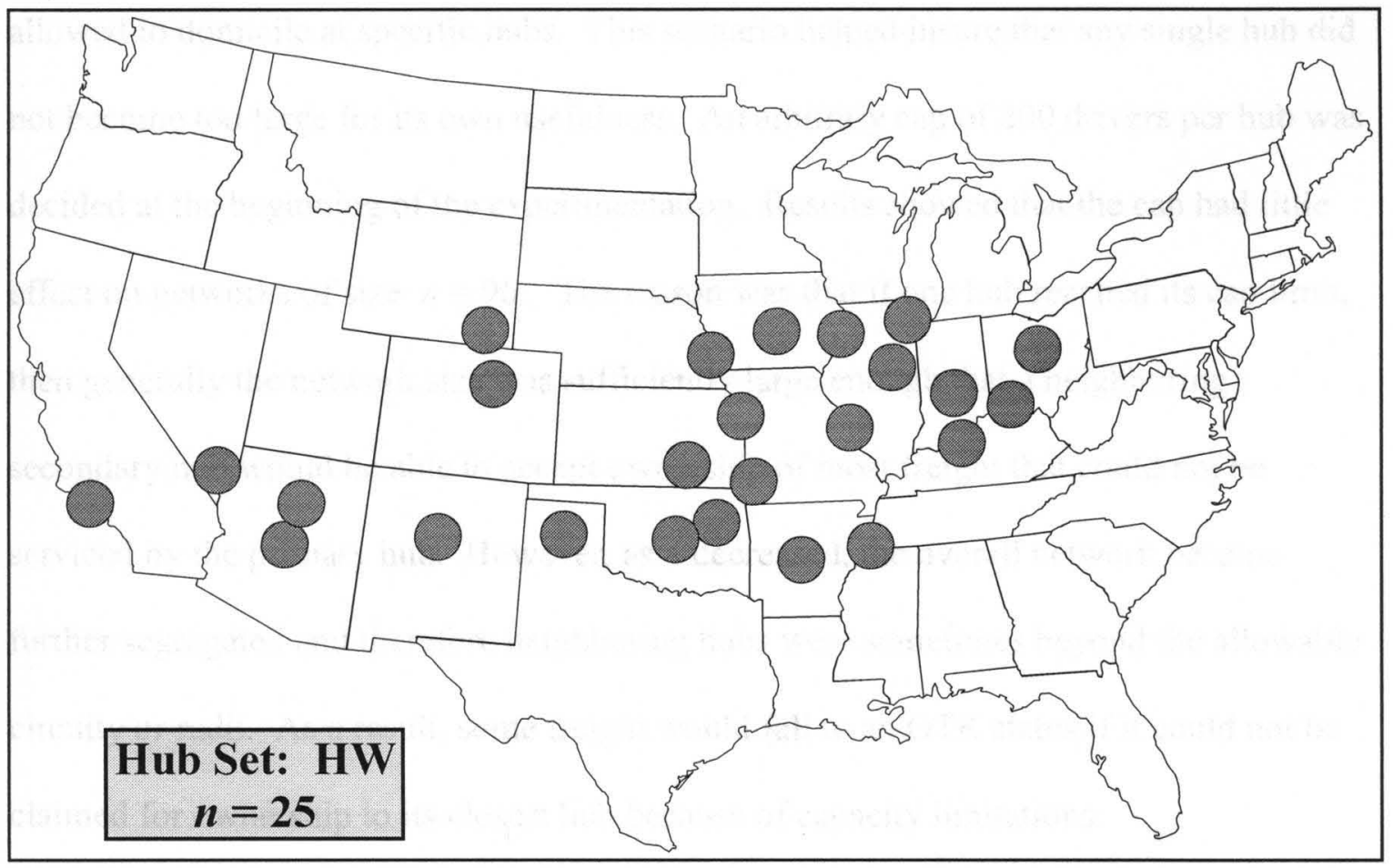

Figure 4-12 - Preferred Domicile Network 
From a carrier's standpoint, if they wanted to develop a driver recruitment plan based on exploiting domiciles in regions of high freight density, then this research has shown that they can do the following things.

First of all, a carrier would want to use hubs that were based on something other than an arbitrary latitude and longitude density map. In numerous examples the LL hub seeds did not perform as well as the HW and JB seeds. Although a carrier may be best served by examining their own business infrastructure and using existing hubs or other company specific locations (example: the JB seeds), this research has shown that other locations built solely around an interstate highway network actually are more effective.

The ownership assignment rules also significantly affected outcomes. The capacitated experimental scenarios placed restrictions on the number of drivers that were allowed to domicile at specific hubs. This scenario helped insure that any single hub did not become too large for its own usefulness. An arbitrary cap of 200 drivers per hub was decided at the beginning of the experimentation. Results showed that the cap had little effect on networks of size $n=96$. The reason was that if one hub reached its cap limit, then generally the network size was sufficiently large enough that a neighboring secondary hub would be able to accept ownership of most freight that could not be serviced by the primary hub. However, as $n$ decreased, the overall network became further segregated and therefore neighboring hubs were sometimes beyond the allowable circuity or radii. As a result, some freight would fall to an OTR status if it could not be claimed for ownership to its closest hub because of capacity limitations.

Finally, regardless of the hub seeds or ownership assignment method used, this research has shown that set size is one of the best predictors of response outcomes. In 
general, the larger set size that can be operated by a carrier will have the largest effective ownership coverage area. The ownership coverage area contributes to the outcome of all other response measurements. But, even though the research shows that a coverage area of $n=96$ would be ideal because of its nearly $100 \%$ coverage area, national carriers should be encouraged to know that the benefits of approximately $60 \%$ coverage of miles and $40 \%$ coverage of routes and loads can be obtained from operating a domicile network of size $n=25$ (Figure 4-12). Results have shown that as the set size increases beyond $n=25$, the effective coverage area undergoes a rate of diminishing returns. Therefore, a national carrier should understand that a smaller set of properly placed hubs (i.e. the HW and JB sets) will yield a better return than a larger set of poorly placed hubs (i.e. the LL set).

In summary, this research has shown that freight density and domicile placement decisions can be utilized together. The results of this research could be a means for defining a corporate recruitment strategy. If so, then both carriers and drivers may be able to satisfy their personal goals. A higher segment of drivers could be given more reasonable tours with regular trips home. If this outcome helps retain drivers, then a carrier would realize lower costs associated with driver turnover.

\subsection{Future Research}

Several options exist for future domicile research as an extension to what has been performed here.

This research found that a network built around latitude and longitude locations alone was only moderately effective. However, there were scenarios when the LL hub 
set performed better than the HW and JB sets. Perhaps future research could concentrate on building a hybrid set. For instance, if the "best set" could claim the bulk of the volume, then subsequent OTR analysis could be re-run using a lat-long analysis. From the lat-long analysis perhaps high areas of concentration could be identified that could either be potential new hub locations or areas of high recruitment. The current model does nothing with the remaining OTR freight and uses it primarily for tabulation and post model analysis.

Secondly, since so many of the loads were found to be owned as pass-thru freight, resulting imbalance calculations may not have been indicative of the overall network imbalance. For instance, future research could look at a methodology for scoring passthru freight for its inclusion in imbalance calculations. Could a threshold be defined for freight with pass-thru ownership such that pass-thru freight was marked as either outbound or inbound for calculation purposes? Should the distance from the hub to the freight origin or destination be considered on pass-thru freight when calculating hub imbalance?

Another aspect of research would be to examine the sensitivity of solutions if the outbound radius, inbound radius, and circuity factor were allowed to be varied from their default values. How would this affect coverage and miles driven? And, could it be determined to what extent these boundaries could be increased before network solutions began to deteriorate or before empty movement costs become excessive?

This research has focused on truckload trucking without intermodal implications. Future research could examine intermodal ramp lanes and could consider the domiciling of drivers near intermodal ramps. The current model issues weights on outbound, 
inbound, and pass-thru freight to prioritize assignments and make them more predictable. For intermodal, future research could also look at weighting domicile locations (locations that may be near intermodal ramp locations) to make them more attractive for set inclusion. The current model examines only freight density, but for an intermodal study, the criteria for selecting "the best" domicile locations may need to change.

Location of dense freight lanes enables the development of regularly scheduled driving tours. This, in turn, helps in finding backhaul freight and in returning drivers more regularly to their domiciles. The net effect of domicile planning is that carriers can use the information to assist in targeted marketing, to improve their planning ability, and to ultimately achieve greater operational profitability.

Another area to be addressed would be the seasonality issues of domicile planning. This research looked at one year of historical data. However, the freight volumes for each of the months appeared to vary significantly. If additional historical data could be obtained, then future research could consider what domicile planning issues would be appropriate for different months and seasons. Also, the problem of trying to formulate decisions that maintained a relatively even driver workforce could be addressed.

Finally, Figure 4-12 shows that interior U.S. hub locations make the best domicile candidates. However, as the hub set sizes increase, there becomes a rate of diminishing returns for ownership coverage. Future research could examine the network based on freight prices and costs. Network size could again be examined with regard to determining the break even point for extending the network size versus the costs that would be incurred to support a larger network. 


\section{CHAPTER V \\ STRATEGIC PLANNING The Distribution Center Location Problem}

\subsection{Introduction}

A distribution network is characterized by one or more geographically dispersed distribution centers serving as central sites for handling customer demands more efficiently. Distribution centers are typically consolidation points that accumulate aggregate inventory for future customer shipments. Inventory or products are shipped from plants via distribution centers to an overall customer base. Typical decisions involved in this type of problem are the determination of the number and location of distribution centers and the assignment of distribution centers to customers. Due to strong economies of scale exhibited by transportation consolidation, using distribution centers generally results in greater cost savings over the case of separate shipments from individual plants to each customer.

Locating a warehouse is a decision that takes considerable amount of time and planning (Logistics Management 2003). The task is not undertaken lightly. Rather, it is an example of a long-term strategic planning problem. A simple objective of many facility location problems is to minimize the average distance or time it would take to supply a given customer base from a single distribution facility or a network of distribution facilities. This strategy appeals to a company's customer service objectives. 
The goal is to provide a network with blanketed coverage so that potential customers can anticipate receiving replenishments within an expected average amount of time. Whereas customer consumption is rarely uniformly distributed throughout the entire customer base, the placement of distribution facilities should not be based on geography alone. Instead, the network should be weighted proportionately to the weight of the customer base.

Realistically, the delivery distance/time customer service approach represents only one variable in the overall consideration of facility location analysis. In addition, for a company to remain competitively viable, site selection analysis should also include other economic and geographic factors such as labor rates, land acquisition, housing and living costs, tax rates, construction versus lease analysis, regulatory burdens, utility costs, availability of trained personnel, transportation, etc (Foster 2005). However, the concurrent multi-variable consideration of each of these factors is difficult and perhaps time prohibitive. Therefore, although a delivery distance/time minimization approach may provide a good solution quickly, this approach is built upon the presumption that delivery costs are proportional to distance. A more practical solution may be found by factoring realistic freight rates in the analysis.

\subsection{Examination of Freight Rate Structures}

In the truckload freight industry, rate structures are designed to recognize the existence of network imbalance and the empty miles that can result from the imbalance. Because of imbalance, all freight rates among pairs of origin and destination locations vary substantially. Rates are not influenced by any specific origin or destination alone. 
Instead, rates are dependent upon the combination of origin and destination pairs, the markets in which each are located, and the direction that freight moves.

For example, Figure 5-1 shows two possible destinations $\left(\mathbf{D}_{1}\right.$ and $\left.\mathbf{D}_{2}\right)$ that could be reached from routes that originated at origin location $\mathbf{O}$. Each of these routes has individual rates of $\mathbf{R}_{\mathbf{D} 1}$ and $\mathbf{R}_{\mathbf{D} 2}$ respectively. Because of the nature of truckload rate structures, $\mathbf{R}_{\mathbf{D} 1}$ and $\mathbf{R}_{\mathbf{D 2}}$ probably are unequal.

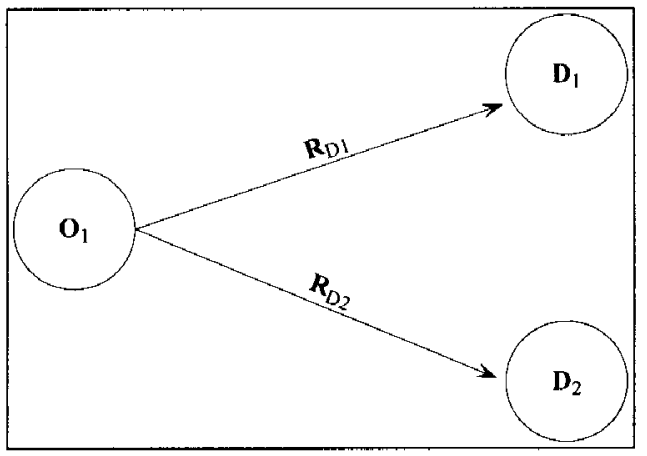

Figure 5-1 - Truckload Freight Structures

The reason that $\mathbf{R}_{\mathbf{D} 1}$ and $\mathbf{R}_{\mathbf{D} 2}$ would be unequal hinges on the fact that $\mathbf{D}_{1}$ and $\mathbf{D}_{2}$ are located in uniquely different freight markets. For example, the total outbound freight volume located at $\mathbf{D}_{\mathbf{1}}$ may be substantially less than the total outbound volume located at D. This could cause a freight carrier to have greater difficulty in dispatching a subsequent outbound haul at $\mathbf{D}_{1}$ than would occur at $\mathbf{D}_{2}$. In fact, a truck located at $\mathbf{D}_{1}$ may even face the possibility of being moved empty to another location to acquire outbound freight. As a result, the rate $\mathbf{R}_{\mathbf{D} 1}$ would have to be sufficiently higher than the rate $\mathbf{R}_{\mathbf{D} 2}$ to compensate for the higher probability of a difficult dispatch at $\mathbf{D}_{\mathbf{1}}$. In addition, 
the rates $\mathbf{R}_{\mathbf{D} 1}$ and $\mathbf{R}_{\mathbf{D} 2}$ are directionally dependent. In other words, those rates are only valid when going along the lane from $\mathbf{O}$ to $\mathbf{D}_{1}$ or $\mathbf{D}_{2}$ respectively. Other rates would be incurred (perhaps better, perhaps worse) in situations when freight was moved along lanes in the reverse direction from either $\mathbf{D}_{1}$ or $\mathbf{D}_{2}$ to $\mathbf{O}$.

Truckload rate structures recognize locations where backhaul or headhaul conditions exist. Explicit consideration of freight markets can lead to improved solutions from a total cost viewpoint by providing the opportunity to ship goods at reduced freight rates. For example, truckload trucking companies charge less for shipments from poor (backhaul) markets. In these markets, there is more inbound freight than outbound freight and consequently more competition and lower prices for outbound freight. In good (headhaul) markets, freight imbalance goes the other way. This results in low inbound rates and high outbound rates. As a result, backhaul markets present great value to shippers who are trying to purchase transportation. Often the rates offered by carriers in backhaul markets will be either at or below operating costs as a hedge to returning or repositioning empty (LMS Logistics Inc. 2002). As a result, to cover non-revenue empty miles and below-cost backhaul lanes, carriers will price their services in headhaul markets to levels that help subsidize the lower revenues generated by backhaul markets.

\subsection{Background Research}

As introduced in Chapter 2, Chicago Consulting (2005) creates an annual list of cities that it proclaims would be ideal locations to support the operation of warehouses for networks that seek to minimize the average delivery lead times to their customers. Chicago Consulting designed a general network considering the lowest possible time to 
market as the sole warehouse placement strategy. Their network is based on providing the lowest over-the-road transportation service time to the entire U.S. population. The location method used by Chicago Consulting (Foster 2005) was based on an assumption that delivery costs would be proportional to distance traveled, regardless of the origin or destination freight rate or location characteristics. Table 5-1 shows the recommendations made by Chicago Consulting. Practically, most companies today do not have the means to embark upon building a ten warehouse network from the ground up. Therefore Chicago Consulting's list can also help small or immediate companies understand where it may be beneficial to locate a first warehouse or successive warehouses. However, because this list of "hot spots" is widely disseminated, it is the research basis for 10 "traditional" distribution center location scenarios.

\begin{tabular}{|c|c|c|c|c|}
\hline \multirow{2}{*}{$\begin{array}{c}\begin{array}{c}\text { Number of } \\
\text { Warehouses in The } \\
\text { Network }\end{array} \\
\text { One }\end{array}$} & \multirow{2}{*}{$\begin{array}{c}\begin{array}{c}\text { Average Lead Time } \\
\text { To Customers } \\
\text { (Days) }\end{array} \\
2.28\end{array}$} & & \multicolumn{2}{|c|}{ "Best" Warehouse Locations } \\
\hline & & Bloomington, IN & & \\
\hline Two & 1.48 & Ashland, $\mathrm{KY}$ & Palmdale, CA & McKenzie, TN \\
\hline Three & 1.29 & Allentown, PA & Palmdale, CA & McKenzie, TN \\
\hline Four & 1.2 & $\begin{array}{l}\text { Edison, NJ } \\
\text { Meridian, MS }\end{array}$ & Palmdale, CA & Chicago, IL \\
\hline Five & 1.13 & $\begin{array}{l}\text { Madison, NJ } \\
\text { Dallas, TX }\end{array}$ & $\begin{array}{l}\text { Palmdale, CA } \\
\text { Macon, GA }\end{array}$ & Chicago, IL \\
\hline Six & 1.08 & $\begin{array}{l}\text { Madison, NJ } \\
\text { Dallas, TX } \\
\end{array}$ & $\begin{array}{l}\text { Pasadena, CA } \\
\text { Macon, GA }\end{array}$ & $\begin{array}{l}\text { Chicago, IL } \\
\text { Tacoma, WA }\end{array}$ \\
\hline Seven & 1.07 & $\begin{array}{l}\text { Madison, NJ } \\
\text { Dallas, TX } \\
\text { Lakeland, FL }\end{array}$ & $\begin{array}{l}\text { Pasadena, CA } \\
\text { Gainseville, GA }\end{array}$ & $\begin{array}{l}\text { Chicago, IL } \\
\text { Tacoma, WA }\end{array}$ \\
\hline Eight & 1.05 & $\begin{array}{l}\text { Madison, NJ } \\
\text { Dallas, TX } \\
\text { Lakeland, FL }\end{array}$ & $\begin{array}{l}\text { Pasadena, CA } \\
\text { Gainseville, GA } \\
\text { Denver, CO }\end{array}$ & $\begin{array}{l}\text { Chicago, IL } \\
\text { Tacoma, WA }\end{array}$ \\
\hline Nine & 1.04 & $\begin{array}{l}\text { Madison, NJ } \\
\text { Dallas, TX } \\
\text { Lakeland, FL }\end{array}$ & $\begin{array}{l}\text { Pasadena, CA } \\
\text { Gainseville, GA } \\
\text { Denver, CO }\end{array}$ & $\begin{array}{l}\text { Chicago, IL } \\
\text { Tacoma, WA } \\
\text { Oakland, CA }\end{array}$ \\
\hline Ten & 1.04 & $\begin{array}{l}\text { Newark, NJ } \\
\text { Palestine, TX } \\
\text { Lakeland, FL } \\
\text { Mansfield, } \mathrm{OH}\end{array}$ & $\begin{array}{l}\text { Alhambra, CA } \\
\text { Gainseville, GA } \\
\text { Denver, CO }\end{array}$ & $\begin{array}{l}\text { Rockford, IL } \\
\text { Tacoma, WA } \\
\text { Oakland, CA }\end{array}$ \\
\hline
\end{tabular}

Table 5-1 - Chicago Consulting's "10 Best Warehouse Network 2005" 
The work of Taylor et al. (2004) sought to establish alternative warehouse networks based on market rates resulting from inherent freight imbalance. Exploiting low rates that exist in backhaul markets was the goal of their research. For instance, if freight networks were not inherently imbalanced, then neither 'good' nor 'bad' freight markets would exist. Hypothetically, this would be a balanced network and all freight in and out of all origin and destination pairs would be priced the same, regardless of the direction it moved. This is the type of view presented by Chicago Consulting. But Taylor et al. challenged their approach by proposing a market-based total delivery cost minimization solution and deliberately placing warehouses in backhaul markets. They accomplished this by using Chicago Consulting's networks and identifying locations within a reasonable distance (most within 200 miles, one within 250 miles) that were known to have lower freight rates. Their model used population data and population centroids for each of the 48 contiguous states and Washington D.C. to calculate cost and distance metrics and establish delivery density in their network. They acknowledge that this assumption was a rough estimator of freight flow and that future research might replicate their study with increased population data resolution.

In addition, Taylor et al. (2004) noted that the U.S. spends approximately $\$ 450$ $\$ 500$ billion annually in trucking and that truckload trucking accounts for approximately half of those expenses. Their model assumed that each person in the general population would be responsible for the consumption of one truckload of goods per year. Based on this assumption they expected to validate their model by comparing their calculated annual delivery costs with the approximated U.S. annual truckload costs. 


\subsection{Population Density}

The 2000 U.S. Census records show that the population of the United States and Washington D.C. is $281,421,906$ (U.S. Department of Commerce 2006). The population for the 48 contiguous states and Washington D.C. is $279,583,437$. There are 3,109 contiguous counties in the United States where population is dispersed. However, the population is not evenly distributed across the country. Figure 5-2 is a three-dimensional density map illustrating where the U.S. population resides. Each block on the map illustrates one U.S. county. The height of each block is proportional to that county's population density found during the 2000 U.S. Census. With few exceptions, the map shows that most our country's general population is concentrated heavily along the coasts, the extreme west, major cities in the mideast and southeast, as well as in the east northeast states. Other locations have relatively lower populations.

\subsection{Problem Examination}

A difficult task associated with this research is the design of an appropriate experiment to determine potential benefits associated from evaluating a facility location problem with freight rate data. This section describes a case based approach to the problem. The case compares various distribution networks created via traditional means to an alternative distribution network design approach that explicitly considers truckload delivery costs to a U.S. customer base. For the case study, it is assumed that each person consumes one truckload of goods per year. 


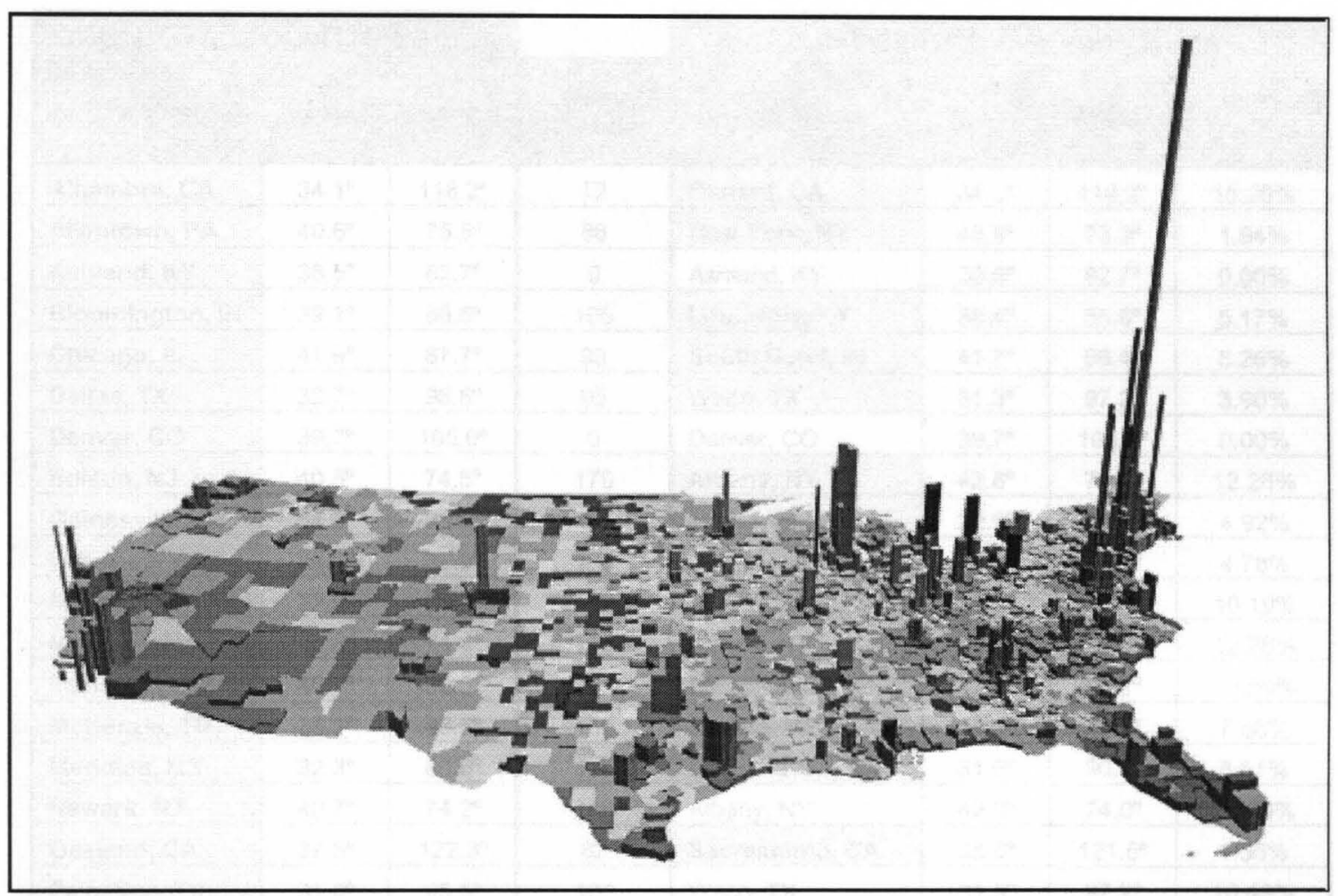

Figure 5-2 - U.S. Population Density Map (U.S. Department of Commerce 2006)

Whereas Chicago Consulting - CCON - (see Table 5-1) proposed a list of 10 network solutions ranging from a single-facility problem to a ten-facility problem designed to minimize travel time to the U.S. population, J.B. Hunt (JBHT) provided data for the development of an alternative network based on cost minimization (Table 5-2). The goal of this research is to determine what service and delivery compromises would be incurred, if any, by focusing on cost minimization as the primary network metric and distance minimization as a secondary metric.

In developing the ten $\mathrm{CCON}$ networks, twenty-two sites were identified as potential warehouse locations. Based on the JBHT freight data, thirteen alternative locations (within approximately a 200 mile radius) were identified that have better freight 


\begin{tabular}{|c|c|c|c|c|c|c|c|}
\hline \multicolumn{3}{|c|}{ CCON "Traditional" Hot Spots } & & \multicolumn{4}{|c|}{ JBHT "Alternative" Hot Spots } \\
\hline Location & Lat. & Long. & $\begin{array}{l}\text { Miles } \\
\text { Separated }\end{array}$ & Location & Lat: & Long. & $\begin{array}{l}\text { Rate } \\
\text { Savings }\end{array}$ \\
\hline Alhambra, CA & $34.1^{\circ}$ & $118.2^{\circ}$ & 72 & Oxnard, CA & $34.2^{\circ}$ & $119.2^{\circ}$ & $15.26 \%$ \\
\hline Allentown, PA & $40.6^{\circ}$ & $75.5^{\circ}$ & 88 & New York, NY & $40.9^{\circ}$ & $73.3^{\circ}$ & $1.94 \%$ \\
\hline Ashland, $\mathrm{KY}$ & $38.5^{\circ}$ & $82.7^{\circ}$ & 0 & Ashland, KY & $38.5^{\circ}$ & $82.7^{\circ}$ & $0.00 \%$ \\
\hline Bloomington, IN & $39.1^{\circ}$ & $86.5^{\circ}$ & 105 & Louisville, KY & $38.4^{\circ}$ & $85.6^{\circ}$ & $5.17 \%$ \\
\hline Chicago, IL & $41.9^{\circ}$ & $87.7^{\circ}$ & 93 & South Bend, IN & $41.7^{\circ}$ & $86.4^{\circ}$ & $8.26 \%$ \\
\hline Dallas, TX & $32.7^{\circ}$ & $96.8^{\circ}$ & 95 & Waco, TX & $31.3^{\circ}$ & $97.2^{\circ}$ & $3.90 \%$ \\
\hline Denver, CO & $39.7^{\circ}$ & $105.0^{\circ}$ & 0 & Denver, CO & $39.7^{\circ}$ & $105.0^{\circ}$ & $0.00 \%$ \\
\hline Edison, NJ & $40.5^{\circ}$ & $74.5^{\circ}$ & 179 & Albany, NY & $42.8^{\circ}$ & $74.0^{\circ}$ & $12.26 \%$ \\
\hline Gainesville, GA & $34.3^{\circ}$ & $83.8^{\circ}$ & 121 & LaGrange, GA & $32.9^{\circ}$ & $85.0^{\circ}$ & $4.92 \%$ \\
\hline Lakeland, FL & $28.1^{\circ}$ & $82.0^{\circ}$ & 195 & Jacksonville, FL & $29.8^{\circ}$ & $81.7^{\circ}$ & $4.78 \%$ \\
\hline Macon, GA & $32.8^{\circ}$ & $83.7^{\circ}$ & 103 & Tifton, GA & $31.5^{\circ}$ & $83.1^{\circ}$ & $10.19 \%$ \\
\hline Madison, NJ & $40.8^{\circ}$ & $74.4^{\circ}$ & 149 & Albany, NY & $42.8^{\circ}$ & $74.0^{\circ}$ & $12.26 \%$ \\
\hline Mansfield, $\mathrm{OH}$ & $40.7^{\circ}$ & $82.5^{\circ}$ & 221 & Lansing, MI & $42.9^{\circ}$ & $84.2^{\circ}$ & $13.50 \%$ \\
\hline McKenzie, TN & $36.1^{\circ}$ & $88.5^{\circ}$ & 150 & Tupelo, MS & $34.5^{\circ}$ & $88.9^{\circ}$ & $7.58 \%$ \\
\hline Meridian, MS & $32.3^{\circ}$ & $88.6^{\circ}$ & 145 & Brookhaven, MS & $31.6^{\circ}$ & $90.4^{\circ}$ & $8.51 \%$ \\
\hline Newark, NJ & $40.7^{\circ}$ & $74.2^{\circ}$ & 146 & Albany, NY & $42.8^{\circ}$ & $74.0^{\circ}$ & $12.26 \%$ \\
\hline Oakland, CA & $37.8^{\circ}$ & $122.3^{\circ}$ & 82 & Sacramento, CA & $38.6^{\circ}$ & $121.6^{\circ}$ & $1.56 \%$ \\
\hline Palestine, TX & $31.6^{\circ}$ & $95.5^{\circ}$ & 100 & Waco, TX & $31.3^{\circ}$ & $97.2^{\circ}$ & $10.49 \%$ \\
\hline Palmdale, CA & $34.4^{\circ}$ & $118.1^{\circ}$ & 94 & Oxnard, CA & $34.2^{\circ}$ & $119.2^{\circ}$ & $15.26 \%$ \\
\hline Pasadena, CA & $34.1^{\circ}$ & $118.1^{\circ}$ & 65 & Oxnard, CA & $34.2^{\circ}$ & $119.2^{\circ}$ & $15.26 \%$ \\
\hline Rockford, IL & $42.2^{\circ}$ & $89.1^{\circ}$ & 179 & South Bend, IN & $41.7^{\circ}$ & $86.4^{\circ}$ & $8.26 \%$ \\
\hline Tacoma, WA & $47.1^{\circ}$ & $122.5^{\circ}$ & 0 & Tacoma, WA & $47.1^{\circ}$ & $122.5^{\circ}$ & $0.00 \%$ \\
\hline
\end{tabular}

Table 5-2 - Chicago Consulting vs. J.B. Hunt Hot Spots

rates than the traditional CCON group. Each unique warehouse in Table 5-2 is

highlighted. It should be noted that Ashland, KY, Denver, CO, and Tacoma, WA have no locations within approximately 200 miles that offer significantly better freight rates.

Also, some of the JBHT alternative locations can actually serve as an improved distribution center location for more than one member of the CCON group. For example, Albany, NY is a better alternative for Edison, NJ; Madison, NJ; and Newark, NJ. In addition, Table 5-2 shows the number of miles that separate each CCON site to its corresponding JBHT site as well as the overall rate savings that each JBHT site provides. 
One of the assumptions made by Taylor et al. (2004) is that the U.S. population consumes goods more or less equally and that a general population density profile would be a good representative of overall U.S. freight demand. Furthermore, this assumption helps to ensure that proprietary freight data does not inadvertently influence research outcomes. However, although Taylor et al. used state population data, they expressed that future research could improve upon this assumption by using a customer base with greater resolution. Greater population resolution would enable a more equivalent comparison with the Chicago Consulting warehouses which were derived using a greater population density than state centroids.

\subsection{Solution Approach}

\subsubsection{Computer Model}

A computer model has been written to collect appropriate delivery costs and distances. The model was developed using the SIMNET II simulation software (see Appendix 5). The inputs to the computer model include:

- Chicago Consulting $(\mathrm{CCON})$ recommended warehouse locations,

- Specific latitude and longitude coordinates for each CCON location,

- J.B. Hunt Transport Inc. (JBHT) alternative warehouse locations,

- Note: JBHT proposed these alternative locations by identifying a city within a 200 mile radius of each CCON corresponding location that has the lowest outbound freight rate. If, however, no city within the prescribed radius had lower rates, then the CCON location was accepted into the JBHT warehouse set by default.

- Specific latitude and longitude coordinates for each JBHT location, 
- Specific latitude and longitude coordinates for 48 contiguous U.S. state population centroids plus Washington D.C. (49 centroids total),

- Specific latitude and longitude coordinates for 3,109 contiguous U.S. county population centroids (includes Washington D.C.),

- Population statistics for 3,109 county centroids,

- JBHT freight rates (actual per-mile market rates) between each CCON or JBHT facility location to each state population centroid (1,715 rates).

CCON examined ten different warehouse network sets. The simplest set consisted of only a single warehouse site $(i=1)$. Subsequent sets added warehouse sites one at a time until the final set consisted of ten warehouse sites $(i=10)$. For comparison purposes, ten JBHT network sets were assembled that also ranged in size from $i=1$ to 10. As mentioned previously, the JBHT networks were similar to the networks developed by CCON. However, the JBHT sets proposed alternative warehouse sites (within an approximate 200 mile radius) with better outbound freight rates than the CCON locations.

The model began by progressively looping through ten network sizes $(I=1$ to 10$)$ and two network types (CCON, JBHT) according to the CCON and JBHT scenarios outlined in Tables 5-1 and 5-2. For each network size/type combination, location and demand characteristics were read into the computer model. Next, the model iteratively assigned warehouses to specific demand points (the county population centroids) by searching for and identifying demand locations closest to each warehouse in the network set based on distance. After the warehouse and centroid assignments were made, 
delivery costs were calculated using the proprietary (and unpublishable) JBHT market rates. Travel distances, costs, and city specific statistics were accumulated and tabulated. This process is repeated for each of the 3,109 demand locations. Finally, after accumulating the results for two pure CCON and JBHT network types, a hybrid $\mathrm{CCON} / \mathrm{JBHT}$ was assembled incorporating the "best" locations of each pure network type. The hybrid analysis examines the cost differences between two pairs of pure CCON and JBHT networks to make a city-by-city recommendation based on the lower cost location. Figure 5-3 is a flowchart showing a visual description of the model's flow.

\subsubsection{Mathematical Problem Description}

A mathematical description of the problem is described below. First of all, the variables and model inputs are provided and the mathematical relationships are shown.

$\begin{array}{lll}\mathbf{I} & =\text { Index of warehouse network scenarios } & (i=1,2,3, \ldots 10) \\ \mathbf{J} & =\text { Index of county demand centroids } & (j=1,2,3, \ldots 3109) \\ \mathbf{K} & =\text { Index of warehouse sites for each scenario ' } i \text { ' } & (k=1,2,3, \ldots i) \\ \mathbf{L} & =\text { Index of state demand centroids } & (l=1,2,3, \ldots 49) \\ \mathbf{D L A T}_{j} & =\text { Latitude of demand centroid ' } j & \\ \mathbf{D L N G}_{j} & =\text { Longitude of demand centroid ' } j & \\ \mathbf{D M D}_{j} & =\text { Total demand for associated with demand centroid ' } j \text { ' } \\ \mathbf{W L A T}_{\boldsymbol{L}}=\text { Latitude of warehouse site ' } k & \\ \mathbf{W}_{\mathbf{L N G}} \text { ' } & =\text { Longitude of warehouse site ' } k\end{array}$




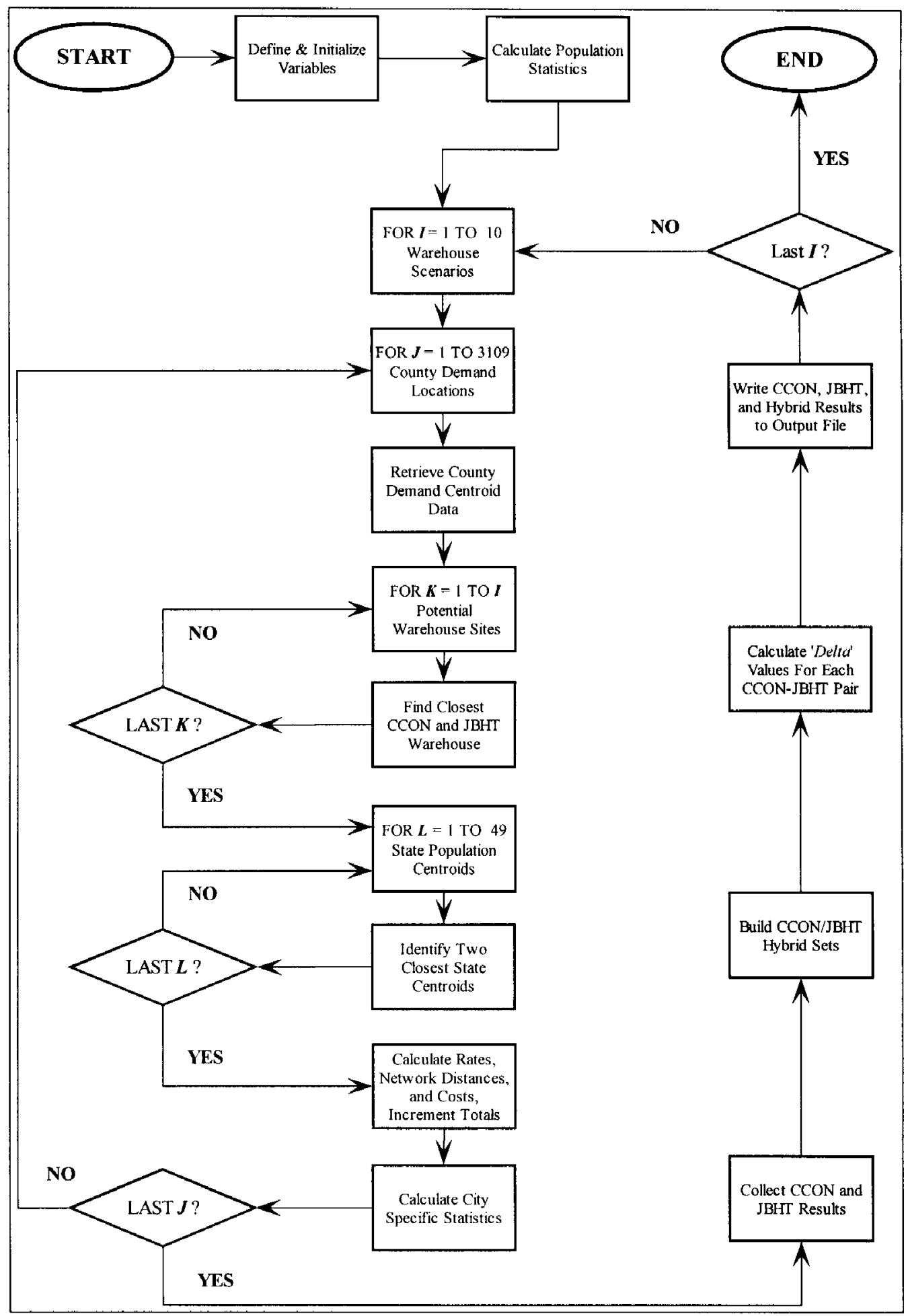

Figure 5-3 - Computer Model Flow Chart 
$d \quad=\quad$ Physical distance between lines of latitude $\left(1^{\circ}=66.67\right.$ miles $)$

$\boldsymbol{k}=$ Roadway circuity factor (1.17 for Continental U.S.)

POP $=$ Total population demand

DIST $_{j k}=$ Distance from warehouse site ' $k$ ' to demand centroid ' $j$ '

RATES $_{l k}=$ Freight rate (from table) for warehouse ' $k$ ' and state demand centroid ' $l$ '

$\operatorname{RATEC}_{j k}=$ Freight rate (calculated) for warehouse ' $k$ ' and county demand centroid ' $j$ ',

SHIP $_{j k}= \begin{cases}1 & \text { if warehouse ' } \mathrm{k} \text { ' has the shortest distance to countydemand centroid ' } \mathrm{j} \text { ' } \\ 0 & \text { else }\end{cases}$

$\mathbf{T}_{-\mathbf{C O S T}_{i}}=$ The total transportation cost for network scenario ' $i$ '

AvGDist $_{i}=$ The average distance for all warehouses to their respective customers in scenario ' $i$ '

The mathematical model can be described as follows. For examination of each network warehouse scenario ' $i$ ' do the following:

\section{Objective,}

\section{Minimize}

$$
\mathrm{T}-\mathrm{COST}_{i}=\sum_{j} \sum_{k}\left(\mathrm{DIST}_{j k}\right) *\left(\operatorname{RATEC}_{j k}\right) *\left(\operatorname{SHIP}_{j k}\right) \quad \forall i
$$

Subject to,

$$
\operatorname{DIST}_{j \boldsymbol{k}}=\boldsymbol{k} * \sqrt{\left(\left(\mathrm{D}_{\mathrm{LAT} j}-\mathrm{W}_{\mathrm{LAT}}\right) * d\right)^{2}+\left(\left(\left(\mathrm{D}_{\mathrm{LNG}}-\mathrm{W}_{\mathrm{LNG}}\right) * d\right) * \cos \left(\frac{\mathrm{D}_{\mathrm{LAT} j}+\mathrm{W}_{\mathrm{LAT}}}{2}\right)\right)^{2}}
$$

Equation (5-2) calculates distances or proximities. All warehouse and population data records include descriptive latitude and longitude identifiers. Distances between 
locations are calculated using the previous formulation for $\operatorname{DIST}_{j k}$ which determines an approximate Euclidean distance between locations. The values ' $\boldsymbol{d}$ ' and ' $\boldsymbol{k}$ ' used in Equation (5-2) are roadway surface adjustments for latitude and average roadway circuity respectively.

Equation (5-3) determines which warehouse location will be assigned the responsibility for supplying each demand centroid.

$$
\mathbf{S H I P}_{j k}=\left\{\begin{array}{ll}
1 & \text { if } D I S T_{j k}<D I S T_{l k} \\
0 & \text { else }
\end{array} \quad \forall j, l \neq k,\right.
$$

Equation (5-4) sums the total demand over all demand centroids.

$$
\mathbf{P O P}=\sum_{j} \mathbf{D M D}_{j}
$$

Equation (5-5) calculates the average distance from each warehouse to its assigned customer based in scenario ' $i$ '.

$$
\mathbf{A v G D i s T}_{i}=\sum_{j} \sum_{k} \frac{(\mathrm{DISTjk}) *(\mathrm{SHIPjk})^{*}(\mathrm{DMDjk})}{\operatorname{POP}} \quad \forall i(\mathbf{5 - 5})
$$

Equation (5-6) assures that each demand centroid will be supplied by one and only one warehouse.

$$
\sum_{k} \operatorname{SHIP}_{j k}=1 \quad \forall j
$$

An important calculation for this problem is the determination of the outbound truckload rates RATEC $_{j k}$ and how they relate to RATES $_{l k}$. For this research, J.B. Hunt provided truckload freight rates (derived from actual per-mile market rates) between each warehouse location (both CCON or JBHT sites) to each state's population centroid. This 
resulted in 1,715 rate values ( $\{35$ unique CCON and JBHT sites $\} *\{49$ centroids $\})$ stored in table form by the variable RATES $l k$. Each of these rates provided by J.B. Hunt represented weighted averages of the summation of all individual rates to all serviceable locations within each state. Whereas cost-data could not be obtained specifically at the county level of detail, a method had to be used to estimate rates from each warehouse location to each of the county centroids. The derivation of $\mathrm{RATEC}_{j k}$ is based on the premise that if the true rate for a county centroid is unknown, then it is probably influenced by the rates of the closest known neighbors of the given county centroid.

Consider Figure 5-4 with warehouse ' $k$ ' and county centroid ' $j$ '. The computer model examined the location of ' $j$ ' and iteratively used Equation (5-2), the distance equation, to identify two state centroids, ' $l_{l}$ ' and ' $l_{2}$ ', located in closest proximity to location ' $j$ '. The state centroid closest to ' $j$ ' would be ' $l$ '. The distances from ' $j$ ' to each of the two locations are $D_{l}$ and $D_{2}$ respectively.

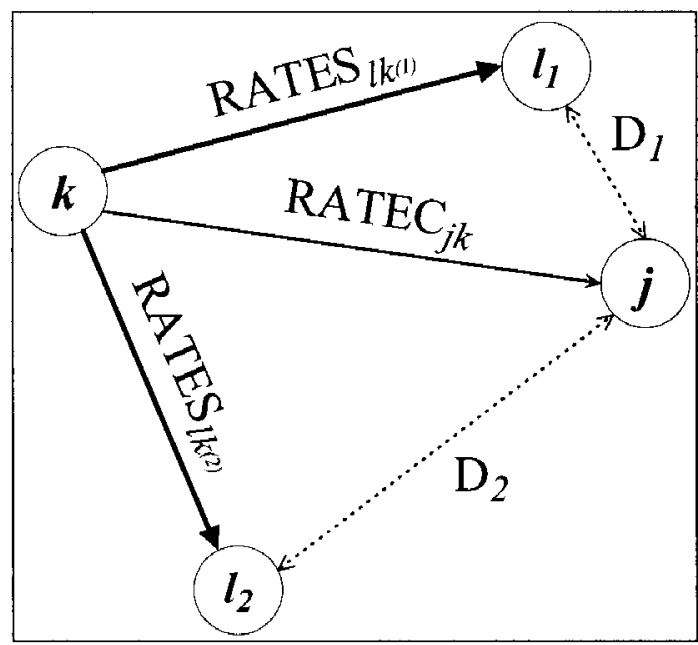

Figure 5-4 - Rate Calculation for County Centroids

For most counties, either ' $l_{1}$ ' or ' $l$ ' was actually determined to be the state in which county ' $j$ ' resided. However, due to geographical and population anomalies, this was not always the case. Sometimes the search returned two state centroids where each 
was different from the home state of ' $j$ '. For example, searches among the northernmost counties of California found that some border counties were actually closer in proximity to the population centroids of Oregon and Washington rather than to the population centroid of California. Other counties in other states were also found to have similar proximity characteristics.

As mentioned previously, J.B. Hunt provided outbound freight rates $\left(R A T E S_{l k(t)}\right.$ and $R A T E S_{l k \Omega)}$ ) from ' $k$ ' to both ' $l$ ' and ' $l_{2}$ ' respectively. Therefore, using the values for $D_{l}$ and $D_{2}$ obtained earlier, the rate RATEC $_{j k}$ could be calculated by Equation (5-8). This equation considers the county's distances, $D_{I}$ and $D_{2}$, to each of the closest state centroids. RATEC ${ }_{j k}$ is calculated by a weighted average formulation involving $\operatorname{RATES}_{l k(l)}$ and RATES $S_{l k(2)}$. Since $D_{l} \leq D_{2}$, Equation (5-7) forces RATEC ${ }_{j k}$ to receive a proportionately greater percentage from the value of RATES $\left.\right|_{l(k)}$ than it received from $\operatorname{RATES}_{l k(2)}$

$$
\operatorname{RATE}_{j k}=\left(\frac{D_{1}}{D_{1}+D_{1}}\right) \operatorname{RATES}_{l k(2)}+\left(\frac{D_{2}}{D_{1}+D_{2}}\right) \operatorname{RATES}_{l k(1)}
$$

After individual scenarios have been examined and individual values of T-COST $i$ and AvGDist $i$ have been determined for all scenarios $(i=1,2,3, \ldots 10)$ of both CCON and JBHT warehouse sets, post analysis comparisons can be made. The primary comparisons are between CCON and JBHT sets of the same size ' $i$ '. For instance, post simulation analysis could compare the total costs of each $i$-sized Chicago Consulting warehouse network versus each corresponding $i$-sized J.B. Hunt warehouse network. Other comparisons may be within CCON sets of various sizes and within JBHT sets of various sizes. For instance, one could examine how a JBHT warehouse network of size $i=7$ compares to all other JBHT warehouse networks. Regardless of the comparison, the 
primary metric for determining the better/best warehouse network is the network with the lowest value for $\mathrm{T}_{-} \mathrm{COST}_{i}$. A secondary metric would be the network with the lowest value of AvGDist . $_{\text {. }}$

\subsection{Results}

The results of testing the CCON traditional network using county demand centroids are presented in Table 5-3. Annual delivery costs and average distance to the U.S. population are identified. Note that for comparison purposes, the results obtained here are shown next to the results obtained by Taylor et al. (2004) using their state demand centroids. Table 5-3 shows that the solutions range in annual cost from $\$ 369.2$ billion for the 1-city network to $\$ 123.0$ billion for the 10 -city network. Given the annual trucking expenses presented earlier, the cost figures shown in Table 5-3 seem to justify that the previous one truckload per person assumption is a reasonable approximation of the total U.S. truckload demand.

\begin{tabular}{|c|c|c|c|c|}
\hline \multirow[b]{2}{*}{$\begin{array}{l}\text { Network } \\
\text { Type / Size }\end{array}$} & \multicolumn{2}{|c|}{$\begin{array}{l}\text { Annual Delivery Cost } \\
\text { (Millions of } \$ \text { ) }\end{array}$} & \multicolumn{2}{|c|}{$\begin{array}{c}\text { Average Distance to } \\
\text { Population (Miles) }\end{array}$} \\
\hline & $\begin{array}{l}\text { County } \\
\text { Centroids }\end{array}$ & $\begin{array}{c}\text { State } \\
\text { Centroids } \\
\text { (Taylor et al. 2004) }\end{array}$ & $\begin{array}{l}\text { County } \\
\text { Centroids }\end{array}$ & $\begin{array}{l}\text { State } \\
\text { Centroids } \\
\text { (Taylor et al. 2004) }\end{array}$ \\
\hline $\mathrm{CCON} / 1$ & $\$ 369,184.90$ & $\$ 362,519.40$ & 878.23 & 872.03 \\
\hline $\mathrm{CCON} / 2$ & $\$ 285,232.20$ & $\$ 273,871.20$ & 535.55 & 525.91 \\
\hline $\operatorname{CCON} / 3$ & $\$ 236,545.20$ & $\$ 227,960.90$ & 409.82 & 397.80 \\
\hline $\operatorname{CCON} / 4$ & $\$ 196,803.90$ & $\$ 185,966.40$ & 339.61 & 324.03 \\
\hline CCON / 5 & $\$ 168,514.20$ & $\$ 153,604.00$ & 281.34 & 260.14 \\
\hline $\mathrm{CCON} / 6$ & $\$ 152,034.30$ & $\$ 138,288.00$ & 250.11 & 230.90 \\
\hline $\operatorname{CCON} / 7$ & $\$ 141,352.00$ & $\$ 129,224.10$ & 228.67 & 206.04 \\
\hline $\mathrm{CCON} / 8$ & $\$ 132,378.30$ & $\$ 118,562.50$ & 211.75 & 189.16 \\
\hline CCON / 9 & $\$ 119,542.90$ & $\$ 118,277.60$ & 197.41 & 188.84 \\
\hline CCON / 10 & $\$ 123,021.50$ & $\$ 123,378.90$ & 180.66 & 174.01 \\
\hline
\end{tabular}

Table 5-3 - Cost and Distance Results for CCON Networks 
From Table 5-3 it can be seen that transportation costs will decrease as the number of distribution centers increases. This cost decrease is the result of a growing network of strategically placed distribution centers being responsible for customer bases with subsequently smaller radii. However, from a total logistics standpoint, the decrease in total transportation costs would be offset by a corresponding increase in total inventory carrying costs. An investment in aggregate inventories would increase as distribution centers carried an overlap of duplicate items as well as maintaining minimal safety stocks. However, since the inventory increases would be a function of network size rather than distribution center location (either CCON or JBHT), it is not specifically considered in this study.

When comparing the CCON results based on demand type, Table 5-3 shows that the increase in demand resolution going from state demand centroids to county demand centroids generally produce results that are both higher in annual delivery cost and average distance to population. Although the work of Taylor et al. and this research both used identical total demand, their work restricted that demand to only 49 unique points. By establishing demand points based on county centroids, this research exhibited greater demand breadth and was able to explicitly look at extreme locations of demand (even unto the outlying regions of each state) that Taylor et al. could not. As a result, the values for delivery costs and average distance both increased versus that of Taylor et al. and may be assumed to be more reflective of the true cost and distance values, given that the rate approximation to the various counties is valid. Recall from Section 5.6.2 that specific rates to individual counties could not be obtained. Therefore, using the available state rates, calculations estimated county rates based on the proximity of the county to its 
neighboring states. The estimates are believed to be strong predictors of the freight flow patterns that governed actual freight rates within the area.

Table 5-4, showing results for the JBHT alternative networks, presents the same type of information shown before with the traditional CCON networks. Direct comparisons to Table 5-3 show which network scenarios exhibit better total cost performances. Although some JBHT networks show improvements versus their corresponding CCON network, this is not the case in all direct comparisons. For instance, in the single city network, the $\mathrm{CCON}$ solution (Bloomington, $\mathbb{N}$ ) would be preferred over the JBHT solution (Louisville, KY) by a $\$ 27$ billion advantage. Even though Louisville has lower outbound rates on a "per mile" basis, the savings is overcome by the added miles that would be incurred for operating the Louisville distribution center. However, for a two city network, the JBHT solution (Ashland, KY and Oxnard, CA) would be preferred over the CCON solution (Ashland, KY and Palmdale, CA) by about $\$ 6.9$ billion. The JBHT network continues to outperform its corresponding CCON network for each of the four city ( $\$ 7.9$ billion) and five city ( $\$ 4.2$ billion) scenarios as well. All other CCON networks were found to be cost advantageous. Whereas using demand based upon counties was hopeful to expose more instances where a JBHT alternative network might be better, this research found fewer JBHT improvements (3) than did the previous research using less demand resolution (5). On another note, although the JBHT networks have shown to have a few cost improvements versus the CCON networks, the CCON networks continually outperform their comparable JBHT networks in regard to the metric for annual distance. Taylor et al. (2004) also found similar results. This is an intuitive result given that the CCON 


\begin{tabular}{|c|c|c|c|c|}
\hline \multirow[b]{2}{*}{$\begin{array}{l}\text { Network } \\
\text { Type / Size }\end{array}$} & \multicolumn{2}{|c|}{$\begin{array}{l}\text { Annual Delivery Cost } \\
\text { (Millions of } \$ \text { ) }\end{array}$} & \multicolumn{2}{|c|}{$\begin{array}{c}\text { Average Distance to } \\
\text { Population (Miles) }\end{array}$} \\
\hline & $\begin{array}{l}\text { County } \\
\text { Centroids }\end{array}$ & $\begin{array}{l}\text { State } \\
\text { Centroids } \\
\text { (Taylor et al. 2004) }\end{array}$ & $\begin{array}{l}\text { County } \\
\text { Centroids }\end{array}$ & $\begin{array}{l}\text { State } \\
\text { Centroids } \\
\text { (Taylor et al. 2004) }\end{array}$ \\
\hline JBHT / 1 & $\$ 396,147.80$ & $\$ 394,488.10$ & 882.09 & 876.10 \\
\hline JBHT / 2 & $\$ 278,288.20$ & $\$ 265,038.70$ & 541.49 & 527.88 \\
\hline JBHT / 3 & $\$ 242,213.80$ & $\$ 233,222.00$ & 432.55 & 421.29 \\
\hline JBHT / 4 & $\$ 188,936.70$ & $\$ 177,060.70$ & 368.05 & 349.57 \\
\hline JBHT / 5 & $\$ 164,384.60$ & $\$ 148,106.80$ & 308.28 & 276.83 \\
\hline JBHT / 6 & $\$ 152,792.00$ & $\$ 136,107.20$ & 276.63 & 244.74 \\
\hline JBHT / 7 & $\$ 147,772.90$ & $\$ 131,890.20$ & 260.68 & 228.47 \\
\hline JBHT / 8 & $\$ 137,934.80$ & $\$ 120,826.70$ & 241.28 & 208.93 \\
\hline JBHT / 9 & $\$ 128,158.50$ & $\$ 120,826.70$ & 229.39 & 208.93 \\
\hline JBHT / 10 & $\$ 125,274.40$ & $\$ 114,763.00$ & 223.29 & 201.94 \\
\hline
\end{tabular}

Table 5-4 - Cost and Distance Results for JBHT Networks

networks seek to minimize travel time to the U.S. population. As delivery distance increases, delivery time would be anticipated to increase. Though the distance differences between each of the JBHT and CCON scenarios increases as the network size increases, most differences between the JBHT scenarios and the CCON scenarios are under 30 miles. This would constitute less than a half an hour in travel time and should not significantly impact customer service requirements.

Tables 5-3 and 5-4 presented results for both a 'pure' CCON network and a 'pure' JBHT network, respectively. In other words, each specific network scenario used either the entire traditional locations recommended by CCON, or they used the entire JBHT alternative locations. The results of Table 5-4 show that under some scenarios the JBHT networks yielded lower annual costs. However, recall that the JBHT locations were identified based because of their low rates. Therefore, though collective groups of JBHT locations may not yield networks with lower costs, perhaps individually analyzing and 
selecting specific cities and forming hybrid networks with both CCON and JBHT cities would be a useful research extension.

Because some of the JBHT alternative cities are as much as 221 miles from the original CCON cities, this may result in some demand being assigned to JBHT alternative hubs that do not directly correspond with the associated CCON hub. By building a hybrid CCON/JBHT network, the best performing warehouse cities from each network, regardless if they began exclusively as a CCON or JBHT hub, can be identified and incorporated into the hybrid network. To support this analysis, however, it is desirable to use identical service areas to ensure that all demand locations are serviced. Appropriate CCON or JBHT cities can be included in the hybrid network based on what is learned from the city to city comparisons (assuming equivalent service areas) summarized by Table 5-5.

To read Table 5-5, one should locate the positive values for 'Cost Delta' that have been highlighted. Each of these values indicates that for the given network scenario, inclusion of a specific JBHT location into the hybrid network rather than settling for the traditional CCON location would produce a cost savings of the positive magnitude shown in the table. Negative table values indicate that the CCON location would be preferred. For example, in a six city network, if Tifton, GA (the JBHT location) were chosen over Macon, GA (the CCON location), the resulting hybrid network would realize a savings of approximately $\$ 3.5$ billion if no other swaps were made. However, considering the same six city network, if South Bend, IN (a JBHT location) were chosen over Chicago, IL (a CCON location) and no other swaps were made, then $\$ 2.9$ billion in increased network 


\begin{tabular}{|c|c|c|c|c|}
\hline Network & $\begin{array}{l}\text { CCON } \\
\text { Location }\end{array}$ & Lacation & $\begin{array}{l}\text { County } \\
\text { Centroids }\end{array}$ & 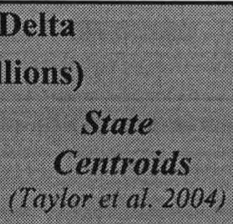 \\
\hline $1 \mathrm{CITY}$ & BLOOMINGTON, IN & LOUISVILLE, KY & $-26,962.81$ & $-31,968.69$ \\
\hline \multirow{2}{*}{$2 \mathrm{CITY}$} & ASHLAND, KY & ASHLAND, KY & - & - \\
\hline & PALMDALE, CA & OXNARD, CA & $6,975.97$ & $8,832.54$ \\
\hline \multirow{3}{*}{3 CITY } & ALLENTOWN, PA & NEW YORK, NY & $-3,263.41$ & $-9,476.70$ \\
\hline & MCKENZIE, TN & TUPELO, MS & $-7,881.54$ & $-4,616.92$ \\
\hline & PALMDALE, CA & OXNARD, CA & $6,439.05$ & 8.832 .54 \\
\hline \multirow{4}{*}{4 CITY } & CHICAGO, IL & SOUTH BEND, IN & $-2,326.75$ & $-2,604.81$ \\
\hline & EDISON, NJ & ALBANY, NY & $-2,437.32$ & $-3,216.76$ \\
\hline & MERIDIAN, MS & BROOKHAVEN, MS & $5,996.44$ & $4,811.37$ \\
\hline & PALMDALE, CA & OXNARD, CA & $6,329.11$ & $8,832.54$ \\
\hline \multirow{5}{*}{5 CITY } & CHICAGO, IL & SOUTH BEND, IN & $-2,794.33$ & -2887.77 \\
\hline & DALLAS, TX & WACO, TX & $1,604.89$ & 5.139 .51 \\
\hline & MACON, GA & TIFTON, GA & $3,459.21$ & -861.45 \\
\hline & MADISON, NJ & ALBANY, NY & $-1,550.37$ & $-2,718.22$ \\
\hline & PALMDALE, CA & OXNARD, CA & $4,303.44$ & $0,654.82$ \\
\hline \multirow{6}{*}{$6 \mathrm{CITY}$} & CHICAGO, IL & SOUTH BEND, IN & $-2,946.32$ & -2887.77 \\
\hline & DALLAS, TX & WACO, TX & $1,591.20$ & $5,139.57$ \\
\hline & MACON, GA & TIFTON, GA & $3,459.21$ & -861.45 \\
\hline & MADISON, NJ & ALBANY, NY & $-1,550.37$ & -2718.22 \\
\hline & PASADENA, CA & OXNARD, CA & -487.71 & $3,338.28$ \\
\hline & TACOMA, WA & TACOMA, WA & - & - \\
\hline \multirow{7}{*}{$7 \mathrm{CITY}$} & CHICAGO, IL & SOUTH BEND, IN & $-3,093,77$ & -3407.17 \\
\hline & DALLAS, TX & WACO, TX & $1,510.68$ & $5,139.51$ \\
\hline & GAINESVILLE, GA & LAGRANGE, GA & 746.95 & $1,215,18$ \\
\hline & LAKELAND, FL & JACKSONVILLE, FL & $-3,919.09$ & -6646.97 \\
\hline & MADISON, NJ & ALBANY, NY & $-1,383.06$ & -2375.39 \\
\hline & PASADENA, CA & OXNARD, CA & -487.71 & $3,338.28$ \\
\hline & TACOMA, WA & TACOMA, WA & - & - \\
\hline \multirow{8}{*}{$8 \mathrm{CITY}$} & CHICAGO, IL & SOUTH BEND, IN & $-3,700.23$ & $-4,314.56$ \\
\hline & DALLAS, TX & WACO, TX & $2,146.25$ & $5,961.87$ \\
\hline & DENVER, CO & DENVER, CO & - & - \\
\hline & GAINESVILLE, GA & LAGRANGE, GA & 746.95 & $1,215,18$ \\
\hline & LAKELAND, FL & JACKSONVILLE, FL & $-3,919.09$ & $-6,646.97$ \\
\hline & MADISON, NJ & ALBANY, NY & $-1,383.06$ & $-2,375.39$ \\
\hline & PASADENA, CA & OXNARD, CA & -595.92 & 3.457 .07 \\
\hline & TACOMA, WA & TACOMA, WA & - & - \\
\hline \multirow{9}{*}{9 CITY } & ALAHAMBRA, CA & OXNARD, CA & $-3,219.29$ & 3.172 .15 \\
\hline & CHICAGO, IL & SOUTH BEND, IN & $-3,700.23$ & $-4,314.56$ \\
\hline & DALLAS, TX & WACO, TX & $2,146.25$ & $5,961,87$ \\
\hline & DENVER, CO & DENVER, CO & - & - \\
\hline & GAINESVILLE, GA & LAGRANGE, GA & 746.95 & 1.215 .18 \\
\hline & LAKELAND, FL & JACKSONVILLE, FL & $-3,919.09$ & $-6,646.97$ \\
\hline & MADISON, NJ & ALBANY, NY & $-1,383.06$ & $-2,375.39$ \\
\hline & OAKLAND, CA & SACRAMENTO, CA & -412.20 & 0 \\
\hline & TACOMA, WA & TACOMA, WA & - & - \\
\hline \multirow{10}{*}{$10 \mathrm{CITY}$} & ALAHAMBRA, CA & OXNARD, CA & $-3,219.29$ & $3,172,15$ \\
\hline & DENVER, CO & DENVER, CO & - & - \\
\hline & GAINESVILLE, GA & LAGRANGE, GA & $1,058.26$ & $1,561.00$ \\
\hline & LAKELAND, FL & JACKSONVILLE, FL & $-3,919,09$ & $-6,646.97$ \\
\hline & MANSFIELD, $\mathrm{OH}$ & LANSING, MI & $-1,090.65$ & $1,694.01$ \\
\hline & NEWARK, NJ & ALBANY, NY & $-2,433.21$ & -553.43 \\
\hline & OAKLAND, CA & SACRAMENTO, CA & -412.20 & 0 \\
\hline & PALESTINE, TX & WACO, TX & $9,164,75$ & $12,373.34$ \\
\hline & ROCKFORD, IL & SOUTH BEND, IN & $-3,526.61$ & $-4,635.08$ \\
\hline & TACOMA, WA & TACOMA, WA & - & - \\
\hline
\end{tabular}

Table 5-5 - City-by-City Cost Comparisons for CCON vs JBHT Alternatives 
costs would be incurred. Therefore the best JBHT locations to include within the hybrid network would be those locations with positive Cost Delta's. The greatest savings between any city-city pair is associated with moving the warehouse 'hot spot' in a ten city network from Palestine, TX to Waco, TX. More than $\$ 9.0$ billion in annual savings in the nation's freight bill can be achieved by making this change alone.

Based on city-to-city comparisons and the individual selections of the 'better' CCON/JBHT alternatives, hybrid networks are formed from the 'best' CCON and JBHT cities identified in Table 5-5. The annual delivery costs and the average distance to the population for the networks are shown in Table 5-6. Since this heuristic seeks to only select cost beneficial alternatives, each of the hybrid networks are therefore shown to be equal to or better than their CCON or JBHT alternatives in all 10 scenarios. The one city network is the same in performance to the original CCON (Bloomington, IN) network. However, each of the nine remaining scenarios offer significant delivery cost improvements over both the CCON and JBHT network solutions.

\begin{tabular}{|c|c|c|c|c|}
\hline \multirow[b]{2}{*}{$\begin{array}{l}\text { Network } \\
\text { Type / Size }\end{array}$} & \multicolumn{2}{|c|}{$\begin{array}{c}\text { Annual Delivery Cost } \\
\text { (Millions of } \$ \text { ) }\end{array}$} & \multicolumn{2}{|c|}{$\begin{array}{c}\text { Average Distance to } \\
\text { Population (Miles) }\end{array}$} \\
\hline & $\begin{array}{l}\text { County } \\
\text { Centroids }\end{array}$ & $\begin{array}{l}\text { State } \\
\text { Centroids } \\
\text { (Taylor et al. 2004) }\end{array}$ & $\begin{array}{l}\text { County } \\
\text { Centroids }\end{array}$ & $\begin{array}{l}\text { State } \\
\text { Centroids } \\
\text { (Taylor et al. 2004) }\end{array}$ \\
\hline HYBRID / 1 & $\$ 369,184.90$ & $\$ 362,519.40$ & 878.23 & 872.03 \\
\hline HYBRID / 2 & $\$ 278,256.30$ & $\$ 265,038.70$ & 541.54 & 527.88 \\
\hline HYBRID / 3 & $\$ 230,106.20$ & $\$ 219,128.30$ & 415.26 & 399.77 \\
\hline HYBRID / 4 & $\$ 184,478.20$ & $\$ 172,322.50$ & 348.42 & 328.15 \\
\hline HYBRID / 5 & $\$ 159,146.70$ & $\$ 141,809.80$ & 290.71 & 256.64 \\
\hline HYBRID / 6 & $\$ 146,984.30$ & $\$ 129,810.20$ & 255.60 & 224.55 \\
\hline HYBRID / 7 & $\$ 139,094.20$ & $\$ 119,531.10$ & 237.44 & 205.29 \\
\hline HYBRID / 8 & $\$ 129,485.00$ & $\$ 107,928.40$ & 219.18 & 186.96 \\
\hline HYBRID / 9 & $\$ 116,649.70$ & $\$ 107,928.40$ & 204.84 & 186.96 \\
\hline HYBRID / 10 & $\$ 112,798.60$ & $\$ 104,578.40$ & 187.44 & 175.73 \\
\hline
\end{tabular}

Table 5-6 - Cost and Distance Results for Hybrid CCON/JBHT Networks 
The greatest hybrid network savings is achieved with a ten city network comprised of two JBHT locations (Lagrange, GA in place of Gainesville, GA and Waco, TX in place of Palestine, TX) and the remaining eight CCON locations. This ten city network results in a savings of over $\$ 10.2$ billion annually.

This analysis has shown that as the network size increases, both annual delivery costs and average distance to the population decrease too. However, in each of the three network types - CCON, JBHT, Hybrid - Figures 5-5, 5-6, and 5-7 show that as the network size increases, the value for the average distance to the population drops more quickly and more substantially than does the value for the annual delivery cost. This finding shows that distance is more sensitive to network size than is cost. With a one city network receiving a baseline score of 1.0, Figures 5-5, and 5-6, and 5-7 plot the relative baseline reduction of costs and distance for each of the network types.

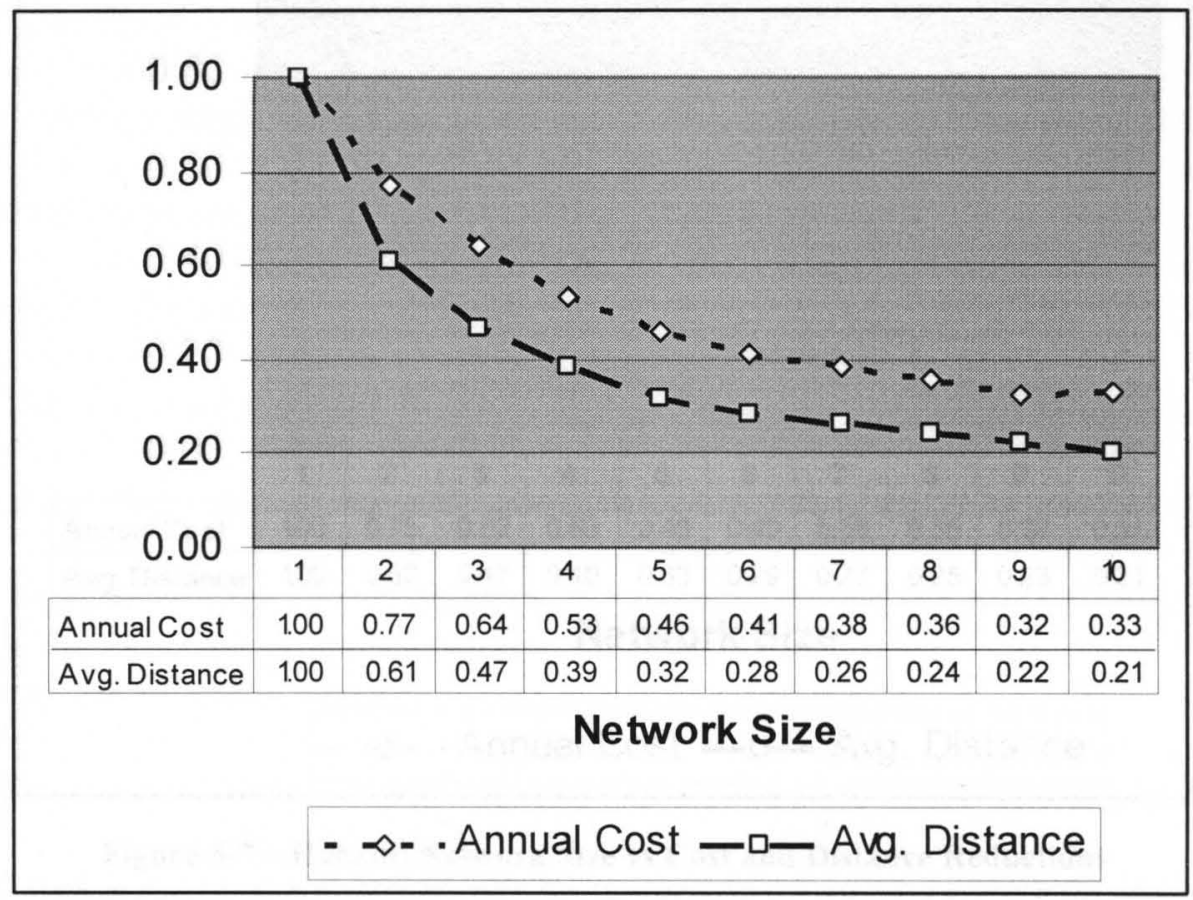

Figure 5-5-CCON: Network Size vs Cost and Distance Reductions 


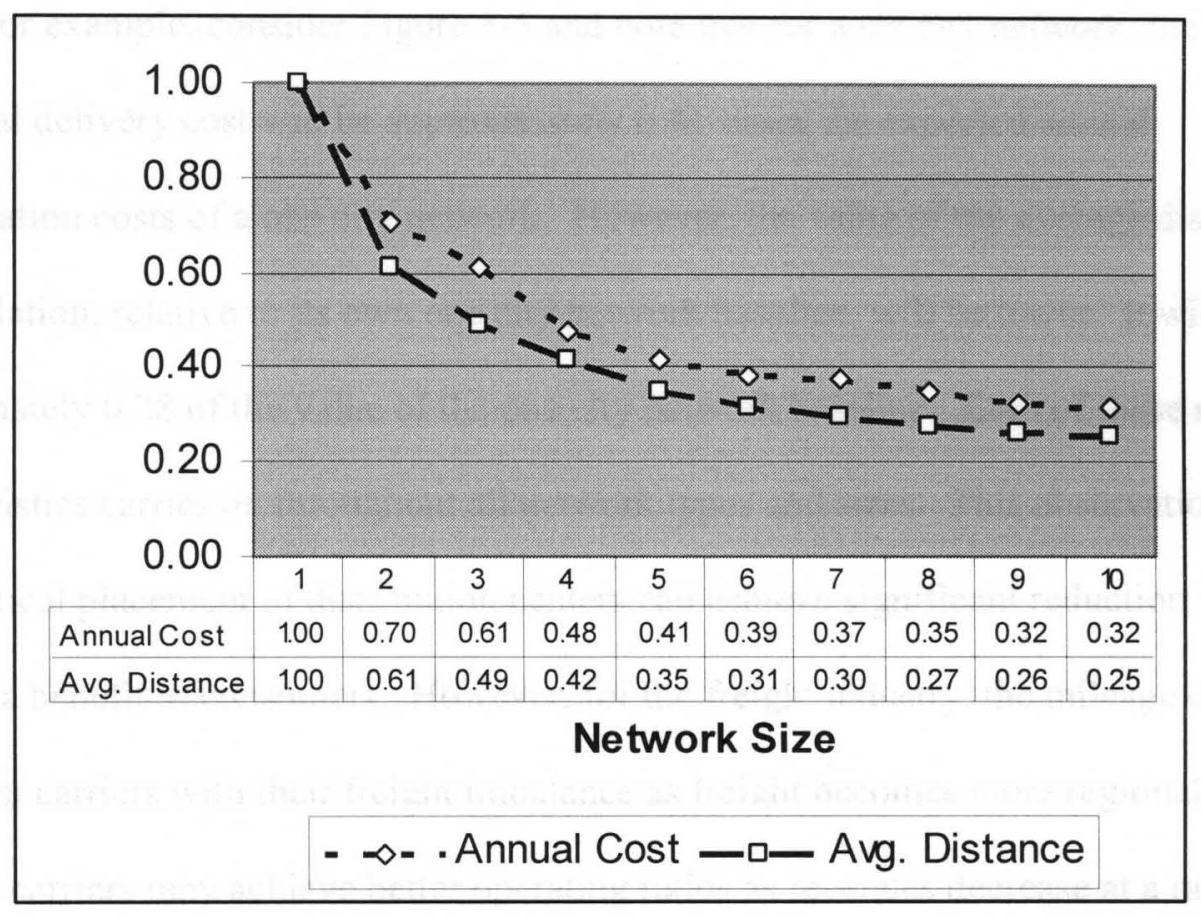

Figure 5-6 - JBHT: Network Size vs Cost and Distance Reductions

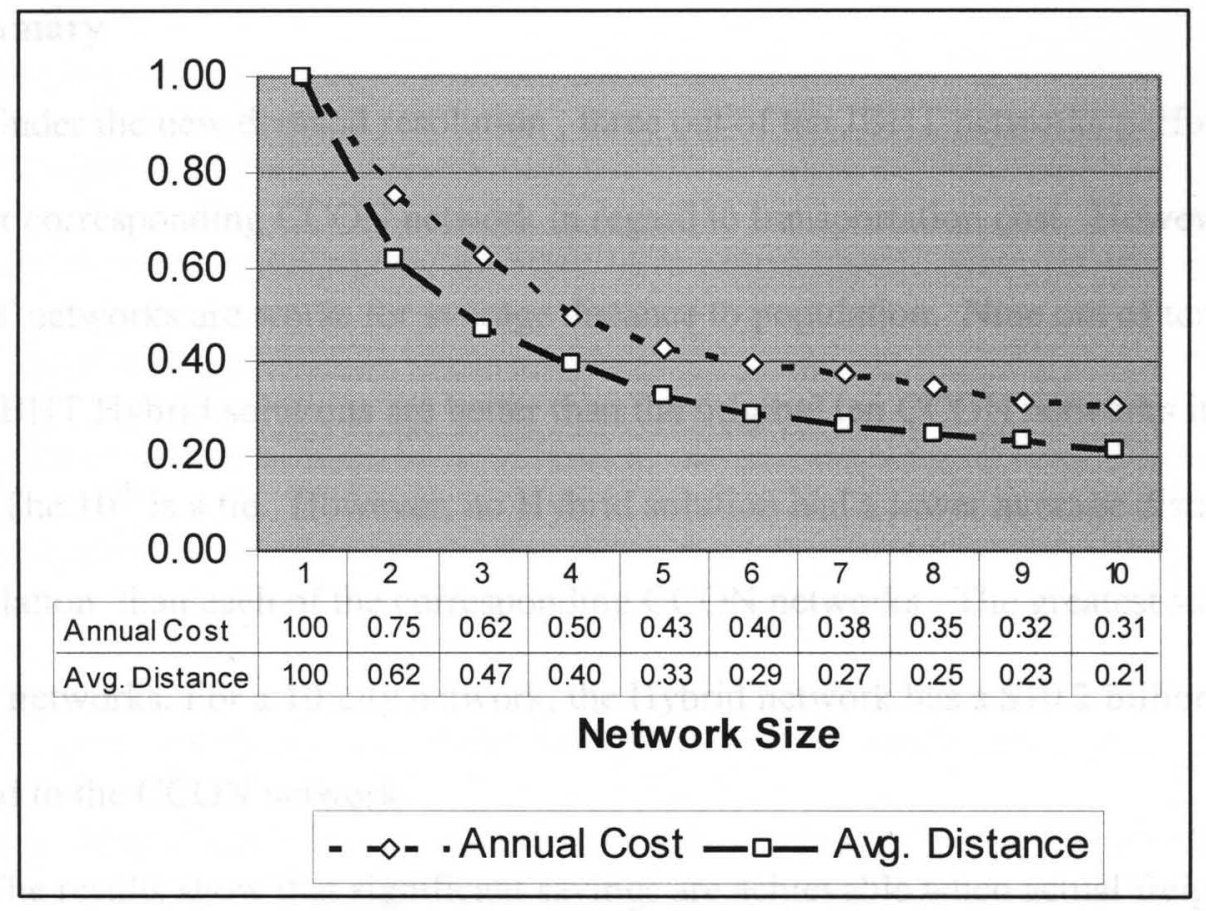

Figure 5-7 - Hybrid: Network Size vs Cost and Distance Reductions 
For example, consider Figure 5-5 and note that for a six city network, the value of the annual delivery cost will be approximately 0.41 times the expected annual transportation costs of a one city network. However, the value of the average distance to the population, relative to its own one city network baseline, will be lower. It will be approximately 0.28 of the value of the one city network baseline. Each of these relational characteristics carries on throughout all network types and sizes. This observation shows that practical placement of distribution centers can achieve significant reduction in terms of costs, a benefit to consumers. However, for the freight industry, the mileage decline may assist carriers with their freight imbalance as freight becomes more regionalized. In addition, carriers may achieve better operating ratios as revenues decrease at a rate slower than the rate that miles required to support the level of revenue decrease.

\subsection{Summary}

Under the new demand resolution, three out of ten JBHT networks perform better than their corresponding CCON network in regard to transportation cost. However, all of the JBHT networks are worse for average distance to population. Nine out of ten CCON/JBHT Hybrid solutions are better than the original ten CCON networks in terms of cost. The $10^{\text {th }}$ is a tie. However, no Hybrid solution had a lower average distance to the population than each of the corresponding CCON networks. The greatest savings are for large networks. For a 10 -city network, the Hybrid network has a $\$ 10.2$ billion savings compared to the CCON network.

The results show that significant savings are achievable when actual freight costs and imbalance-based market considerations are considered in the development of distribution networks. Through strategic planning and selection of outbound locations 
where freight rates are cheaper, analysis of the JBHT and Hybrid networks show that it is possible to reduce total annual transportation costs with little change in customer service.

The results of this strategy could be three-fold as surmised in the comments of a 2002 report prepared by the Federal Highway Administration (ICF and HLB 2002). First, for shippers, transportation savings to and from markets could result in reduced delivery costs for goods and services that could be passed on to consumers. These savings could stimulate economic growth. Second of all, by increasing freight volume in poor backhaul markets, carriers could improve their freight efficiency by increasing their loaded trip miles. And finally, over time, perhaps a strategic plan for the placement of future warehouses could move the freight network towards a balanced state.

One long term implication of the adoption of this type of network strategy would likely be that over time the migration of warehouses to new locations would redistribute the freight base resulting in new headhaul and backhaul markets. However, from an imbalance standpoint, the redistribution of warehousing and distribution centers to backhaul markets could greatly reduce the effects of imbalance. This outcome would be a goal of the strategic plan. Carriers would be enabled to competitively price freight with fewer backhaul concerns. Carriers could better plan and dispatch drivers. The results of which could see better engineered driving jobs - a key to solving the driver retention issue.

A significant observation of this research has been a validation of the CCON networks in terms of both distance and cost metrics. Although the CCON networks were built on customer service and time to customer statistics, an original argument of this research questioned how the CCON networks would perform in terms of total 
transportation costs. However, this challenge failed many times as the CCON networks were found to be very cost effective and often better than the JBHT networks. But, when hybrid networks were developed, this research showed that even the CCON networks could be improved by analyzing transportation costs on a city-to-city basis.

The outcomes of this analysis show that it would be valuable to re-think the way we select distribution center locations. The distribution center migration to the recommended locations of the Hybrid network would likely change the cost structures and possible negate some savings. However, the migration of freight leads to better freight balance overall and consequently better efficiency and total cost for everyone. In addition, better dispatching functions, better driver retention, and better freight planning could result.

\subsection{Future Research}

The approach taken in this research leads to other research potential. For instance, warehouse locations do not necessarily represent manufacturing centers. Both Taylor et al. (2004) and Chicago Consulting (2005) proclaim the benefits of their location strategies for potential warehouse sites. However, they do not consider our nation's existing manufacturing infrastructure nor do they examine the costs related to transporting goods from suppliers to warehouses. For instance, what will be the costs in moving manufactured goods from a factory to either of the warehouse sites proposed by Taylor et al. (2004) and Chicago Consulting (2005). Research in this realm would be motivated at looking at the inbound side of the transportation cost problem. Larger network in particular increase inbound significance due to modal choices. 
The first assumption made by Taylor et al. (2004) (with the help of J.B. Hunt Inc.) was to identify potential warehouse sites located arbitrarily within approximately a 200 mile radius to the sites proposed by Chicago Consulting. New research could be conducted on the sensitivity of the solution to different sized radii. Furthermore, a baseline scenario could be established that disregarded radii altogether and only considered the location of potential warehouses that had the lowest outbound freight costs in the United States.

This research examined a U.S. population distribution, but it did not consider how populations may change in the future. Populations are dynamic and change over time. In fact, today's methods of controlling imbalance could actually spur changes in future network imbalance. New research could examine the effects of population shifts by obtaining historical census data and making projections for future years. Furthermore, the DOT also publishes projections for future interstate freight volumes and freight flows. This examination would show the sensitivity of the network to dynamic changes that redistribute freight and subsequently create new headhaul and backhaul markets.

In addition, another area that could be examined would be to change the emphasis from attempting to locate manufacturing-positioned warehouses in a network. An alternative approach would be to examine and compare a network built upon the location of market positioned-warehouses. Whereas manufacturing-positioned warehouses could be located in backhaul markets where low outbound exist, market positioned warehouses could be located in headhaul markets where low inbound freight rates exist. Headhaul market based networks were not examined by Taylor et al. (2004) but were proposed as a reasonable extension. An examination could look at transportation costs related to 
moving goods from where they are built to the nearest distribution center. Distribution centers are collection points for a variety of products, but they are not necessarily the manufacturing sites. Instead, it would be interesting to establish a broader representation of the total costs of the freight network by identifying large manufacturing centers and calculating the costs to distribute goods from the manufacturing centers to the strategically planned distribution centers. These costs could be added to the previously obtained transportation costs from distribution centers to the general population.

Other areas showing research promise include the examination of related LTL problems, developing a mathematical programming based solution, and determining which regions or shippers could benefit the most from this distribution center planning approach. 


\section{CHAPTER VI}

\section{SUMMARY}

\subsection{Imbalance}

Freight imbalance has shown to be an inherent characteristic of the truckload freight industry. However, as trucking companies continually seek to balance their loads in and out of all markets, imbalance remains a problematic issue for all carriers. Some of the effects of imbalance include elevated transportation costs, reduced driver morale, and inefficient resource utilization. High annual driver turnover may be considered the most significant effect of imbalance. The turnover results from driver dissatisfaction in response to carriers unable to provide regular driving tours. But, it has been shown that imbalance is not easily corrected.

\subsection{Hierarchical Summary}

This dissertation has focused on three problems that address freight imbalance. The uniqueness of this dissertation is that each problem has potential benefits over different hierarchical planning horizons. This dissertation shows how a carrier can address the problems associated with freight imbalance by applying the concepts of one, two, or three of the solution strategies either individually or simultaneously.

'The Weekend Problem, presented in Chapter 3, looked at a short term (operational planning) problem called. That chapter presented and tested a methodology 
for helping a carrier acquire more weekend freight while increasing the utilization of the resources they currently have. Since there is no significant capital investment, and because the infrastructure that could serve as yard stacking locations is likely to already exist, the weekend dispatching strategy could be implemented quickly. Through creative dispatching, the results of this research show that a carrier could exceed the amount of freight that they currently pick-up on Fridays without significantly incurring any additional driver miles. This increase can occur without compromising customer requested delivery dates. When one considers the cost savings that the carrier would experience for not having to reposition the driver empty or return him/her to their domicile early versus the added revenue gained from accepting instead of refusing Friday freight, this dispatching strategy has a large carrier benefit. Furthermore, based on driver turnover research, drivers who receive regular weekend tours (whereas now they do not) would be less likely to quit.

Chapter 4 examined a medium-term (tactical planning) problem called 'The Driver Domicile Problem'. This level of planning requires more detail than did the previous operational plan. An analysis of a carrier's freight base would present areas that the carrier would be interested in recruiting drivers from. Successful recruitment of drivers from the beginning, before they were hired, with their get home potential in mind from the onset, could benefit a carrier by having a more satisfied driver fleet. Research showed that as few as 25 hub locations could be identified where more than $60 \%$ of the existing freight could be the freight comes within 50 miles of perspective domicile locations. With freight lanes passing, almost literally, "in a driver's back yard", drivers would have an abundance of "get home" opportunities that currently do not exist. 
Expanding recruitment beyond these 25 locations would further increase the mileage coverage. Although the carrier would likely have some or all of the infrastructure in place, broad personnel and recruitment issues as presented here could not be implemented as quickly as the dispatching decisions of the Weekend Problem. Nevertheless, domicile planning, by turning the problems associated with freight imbalance into a tactical plan for future driver recruitment has far reaching implications for improving driver and carrier relations

A long-term (strategic planning) problem called 'The Distribution Center Location Problem' was examined in Chapter 5. This problem primarily examined where distribution center should be located to take advantage of better freight rates without compromising customer service delivery goals. The results found that a network built solely on proximity characteristics to a customer base could be unnecessarily expensive. By moving distribution centers to locations with favorable outbound market rates, significant savings could be obtained that could more than offset the cost of the additional mileage that would be incurred.

\subsection{Hierarchical Interactions}

The hierarchical planning levels would mean that each outcome of planning would be implemented in different phases. Therefore effects stemming from the implementation of a lower level could affect higher levels. And, eventually, as a strategic plan becomes reality, it would then have an impact on things that were set in place prior. For example, understanding discovered during freight density analysis for domicile recruitment could identify new locations where weekend yard stacking would be 
effective. Whereas even under the new weekend dispatching strategy there would be a limit to the number of drivers who could benefit from the increased number of weekend loads, the driver domicile analysis could help the remaining divers get home for the weekend. This combination effect is productive to both drivers and carriers in two ways. First of all, some drivers would get an extra weekend load that they currently aren't receiving, and the remaining drivers could get a quicker trip home that they many not be currently experiencing.

When looking at the distribution center location problem, it was mentioned that the migration of freight to new locations may change cost structures. However, it could also lead to better freight balance and therefore a more efficient system. The new efficiencies would likely change where drivers should be domiciled and where weekend yard stacking should take place. So, with the eventual change in distribution center planning, each of the two lower levels of planning will need to be re-examined to determine if they are still effective at their current state or of thy must be altered to function better under the new conditions.

\subsection{Closing Remarks}

The objective of this dissertation has been addressing freight imbalance. Through addressing freight imbalance a carrier can achieve reduction in driver turnover and subsequently increased profitability. The three problems presented in this dissertation each addressed freight imbalance from a truckload carrier's perspective in unique ways along different time horizons. Together they have shown different approaches in working with freight imbalance and carriers could find any of these procedures to be 
useful. Collectively these approaches present one comprehensive scheme that could help carriers combat freight imbalance and improve their profitability through potential turnover reduction. Today's truckload freight industry needs relief from the turnover levels that they have been experiencing. Turnover is highly unproductive and inefficient. Addressing freight imbalance could help offer the solution to turnover that existing researchers have failed to uncover.

This dissertation has shown that although freight imbalance research exists, a comprehensive hierarchical planning approach as described herein had not previously been attempted. In addition, this research has shown to be industrially relevant to the truckload freight industry through the participation of J.B. Hunt Inc. and through the findings uncovered during the search of existing literature. The collective scenarios have shown how a proactive truckload freight carrier could combat freight imbalance throughout short-term to long-range planning horizons. In closing, the research presented herein has provided a strong contribution to the current breadth of existing research. 


\section{REFERENCES}

American Trucking Association (ATA) (2005), "Driver Turnover Drops from Record Levels but Remains High", Retrieved from http://www.truckline.com/NR/ exeres/894352FC-3153-41AE-BDAA-B6E956E050DE.htm.

Arcelus, F. J., Eiselt, H. A., and Lin, E. Y. H. (1998), "Minimizing Empty Hauls in Multi-day, Multi-depot Trucking", International Transactions in Operational Research, vol. 5 no. 3, pp. 201-210.

Arunapuram, S., Mathur, K., and Solow, D. (2003), "Vehicle Routing and Scheduling with Full Truckloads", Transportation Science, vol. 37 no. 2, pp. 170-182.

Banks, J., Carson II, J. S., Nelson, B. L., and Nicol, D. M. (2005), Discrete-Event System Simulation, $4^{\text {th }}$ Edition, Prentice Hall, Upper Saddle River, NJ.

Barnhart, C., Cohn, A. M., Johnson, E. J., Klabjan, D., Nemhauser, G. L., and Vance, P. H. (2003), "Airline Crew Scheduling", Handbook of Transportation Science, R.W. Hall (Ed.), $2^{\text {nd }}$ edition, Kluwer Academic Publishers, Norwell, MA, pp. 517-560.

Berman, O., and Simchi-Levi, D. (1986), "Minisum Location of a Traveling Salesman", Networks, vol. 16, pp. 239-254.

Berman, O., and Simchi-Levi, D. (1988a), "Minisum Location of a Traveling Salesman on Simple Networks", European Journal of Operations Research, vol. 36, pp. 241-250.

Berman, O. and Simchi-Levi, D. (1988b), "A Heuristic Algorithm for the Traveling Salesman Location Problem on Networks", Operations Research, vol. 36 no. 3, pp. $478-484$.

Berman, O., and Simchi-Levi, D. (1988c), "Finding the Optimal a Priori Tour and Location of a Traveling Salesman with Nonhomogeneous Customers", Transportation Science, vol. 22, pp. 148-154.

Berman, O., and Simchi-Levi, D. (2001), "The Traveling Salesman Location Problem on Stochastic Networks", Transportation Science, vol. 23, pp. 54-57. 
Bodin, L., Maniezzo, V., and Mingozzi, A. (2003), "Street Routing and Scheduling Problems", Handbook of Transportation Science, R.W. Hall (Ed.), $2^{\text {nd }}$ edition, Kluwer Academic Publishers, Norwell, MA, pp. 413-450.

Bohman, R. (2004), "Challenges Abound For Truckload Shippers", Logistics Management, June 1, 2004, Retrieved from http://www.manufacturing.net/lm/ index.asp?layout=articlePrind\&articleID $=\mathrm{CA} 425642$.

Bowers, S., Gelfand, J., Marar, A., and Powell, W. B. (2002), "Implementing Operational Planning Models: A Case Application from the Motor Carrier Industry", Operations Research, vol. 50 no. 4, pp. 571-581.

Braver, E. R., Preusser, C. W., and Ulmer, R. G. (1999), "How Long-Haul Motor Carriers Determine Truck Driver Work Schedules: The Role of Shipper Demands", Journal of Safety Research, vol. 30 no. 3, pp. 193-204.

Burness, R. C., and White, J. A. (1976), "The Traveling Salesman Location Problem", Transportation Science, vol. 10 no. 4, pp. 348-360.

Calişkan, C., and Hall, R. W. (2003), "A Dynamic Empty Equipment and Crew Allocation Model for Long-Haul Networks", Transportation Research Part A, vol. 37 no. 5 , pp. $405-418$.

Campbell, J. F. (1990), "Locating Transportation Terminals to Serve an Expanding Demand", Transportation Research B, vol. 24 no. 3, pp. 173-192.

Campbell, J. F. (1993), "Continuous and Discrete Demand Hub Location Problems", Transportation Research B, vol. 27 no. , pp. 473-482.

Carson, J. S., Manivannan, M. S., Brazier, M., Miller, E., and Ratliff, H. D. (1997), "Panel on Transportation and Logistics Modeling", Proceedings of the 1997 Winter Simulation Conference, Atlanta, GA, December 7-10, 1997, pp. 1244-1250.

Cheung, R. K. and Chen, C. Y. (1998), "Two-stage Stochastic Network Model and Solution Methods for the Dynamic Empty Container Allocation Problem", Transportation Science, vol. 32 no. 2, pp. 132-162.

Chicago Consulting (2005), "The 10 Best Warehouse Networks 2005", On-line article, Retrieved from http://www.chicago-consulting.com/10best.shtml.

Christenson, D., Aames, R., Hughes, J., and, Kinney, M., (1997). "Empty Seats and Musical Chairs: Critical Success Factors in Truck Driver Retention", The Gallup Organization, Prepared for the American Trucking Association Foundation, Arlington, VA., October 1997, 39 pp. 
Cordeau, J. F., Toth, P., and Vigo, D. (1998), "A Survey of Optimization Models for Train Routing and Scheduling", Transportation Science, vol. 32 no. 4, pp. 380-404.

Corsi, T. M., and Fanara Jr., P. (1988), "Driver Management Policies and Motor Carrier Safety", Logistics and Transportation Review, vol. 24 no. 2, pp. 153-164.

Coslovich, L., Pesenti, R., and Ukovich, W. ( 2003), "Minimizing Operations Costs for a Container Road Carrier", Proceedings of the Odysseus - Second International Workshop on Freight Transportation and Logistics, Mondello (PA), Italy, May 26-30, 2003.

Cox, K., (2004), "Truckload Driver Turnover Rate Reaches New Record High", Transport Topics, January 5, 2004, p. 5.

Crainic, T. G. (2003), "Long-Haul Freight Transportation", Handbook of Transportation Science, R.W. Hall (Ed.), $2^{\text {nd }}$ edition, Kluwer Academic Publishers, Norwell, MA, pp. 451-516.

Crainic, T. G., Gendreau, M., and Dejax, P. (1993), "Dynamic and Stochastic Models for the Allocation of Empty Containers", Operations Research, vol. 41 no. 1, pp. 102-126.

Crainic, T. G., and Laporte, G. (1997), "Planning Models For Freight Transportation", European Journal of Operational Research, vol. 97 no. 3, pp. 409-438.

Cullen, D. (2003), "The Driver Shortage: It Never Goes Away", Fleet Owner, May 2003.

Current, J., Min, H., and Schilling, D. (1990), "Multiobjective Analysis of Facility Location Decisions", European Journal of Operational Research, vol. 49 no. 3, pp. 295-307.

Daskin, M. S., and Owen, S. H. (2003), "Location Models in Transportation", Handbook of Transportation Science, R.W. Hall (Ed.), $2^{\text {nd }}$ edition, Kluwer Academic Publishers, Norwell, MA, pp. 321-372.

Daskin, M. S. (1995), Network and Discrete Location: Models, Algorithms, and Applications, Wiley Publishers, New York.

Deloitte (2003), "Mastering Complexity in Global Manufacturing: Powering Profits and Growth Through Value Chain Synchronization," Deloitte Global Manufacturing Study, October 2003.

Engel, C. (1998), "Competition Drives the Trucking Industry", Monthly Labor Review, pp. 34-41, April 1998. 
Fekpe, E., Alam, M., Foody, T., and Gopalakrishna, D. (2002), "Freight Analysis

Framework Highway Capacity Analysis: Methodology Report", U.S. Department of Transportation, Office of Freight Management and Operations, Washington, D.C., April 18, 2002, $51 \mathrm{pp}$.

Fernández L., J. E., Cea Ch, J. de, and Soto O, A. (2003), "A Multi-Model SupplyDemand Equilibrium Model For Predicting Intercity Freight Flows", Transportation Research Part B, vol. 37 no 7, pp. 615-640.

FleetOwner (2004), “TL Driver Turnover Hits Record High”, PRIMEDIA Business Magazines \& Media Inc., January 7, 2004, Retrieved from http://www. fleetowner.com/news/fleet_tl_driver_turnover/.

Foster, T. A. (2005), "The Best Locations for Supply Chain Management Facilities: The Best DC Locations in the U.S.”, Global Logistics \& Supply Chain Strategies, Online article, March, 2005, Retrieved from http://www.glscs.com/archives 103.05.flp dc.htm? adcode $=75$.

Francis, R. L., McGinnis, L. F., and White, J. A. (1992), Facility Layout and Location: An Analytical approach, $2^{\text {nd }}$ Edition, Prentice Hall, Englewood Cliffs, New Jersey.

Friesz, T. L., Tobin, R. L., and Harker, P. T. (1983), "Predictive Intercity Freight Network Models", Transportation Research A: Policy and Practice, vol. 17, pp. 409-417.

Friesz, T. L., Suo, Z.G., and Bernstein, D. H. (1998), “A Dynamic Disequilibrium Interregional Commodity Flow Model", Transportation Research Part B, vol. 32 no. 7 , pp. $467-483$.

Global Insights, Inc. (2005), "The U.S. Truck Driver Shortage: Analysis and Forecasts", prepared for the American Trucking Association, Arlington, VA, May, 2005, $39 \mathrm{pp}$.

Godfrey, G. A. and Powell, W. B. (2000), "Adaptive Estimation of Daily Demands with Complex Calendar Effects for Freight Transportation", Transportation Science, vol. 34 no. 6, pp. 451-469.

Goodson, D. (1999), "Old Habits are Hard to Break", The National Survey of Driver Wages, vol. 4 no. 1, May 1999.

Goodson, D. (2000), "How Friendly is Your Freight?", The National Survey of Driver Wages, vol. 5 no. 1, May 2000. 
Goodson, D. (2003), “Expensive Insurance You Don't Need", Commercial Carrier University Online, August 2003, Retrieved from www.etrucker.com /apps/ news/article.asp?id=41007.

Griffin, G., Kalnbach, L., Lantz, B., and Rodriguez, J. (2000), "Driver Retention Strategy: The Role of a Career Path", Upper Great Plains Transportation Institute Final Report \# DP-135, March 2000, 120 pp.

Gupta, N., Jenkins Jr., G. D., and Delery, J. E. (1996), "Motor Carrier Effectiveness", Feedback Report, Mack-Blackwell Rural Transportation Study Center, July 1996.

Gutin, G., and Punnen, A.P., eds. (2002), The Traveling Salesman Problem and its Variations, Kluwer Academic Publishers, Boston.

Hakimi, S. L. (1964), "Optimum Locations of Switching Centers and the Absolute Centers and Medians of a Graph", Operations Research, vol. 12, pp. 450-459.

Hall, R. W. (1999), "Stochastic Freight Flow Patterns: Implications for Fleet Optimization", Transportation Research, Part A: Policy and Practice, vol. 33 no. 6 , pp 449-465.

Hall, R. W. (2003), "Transportation Science", Handbook of Transportation Science, R.W. Hall (Ed.), $2^{\text {nd }}$ edition, Kluwer Academic Publishers, Norwell, MA, pp. 1-6.

Hall, R. W. (2004), “Domicile Selection and Risk Pooling For Trucking Networks", IIE Transactions, vol. 36 no. 4, pp. 209-305.

Handler, G. Y., and Mirchandani, P.B. (1979), "Location on Network: Theory and Algorithims", The M.I.T. Press, Cambridge, MA.

Harker, P. T. (1987), Predicting Intercity Freight Flows, VNU Science Press, Utrech, The Netherlands.

Harker, P. T., and Friesz, T. L. (1986a), "Prediction of Intercity Freight Flows I: Theory", Transportation Research B: Methodological, vol. 20, no. 2, pp. 139-153.

Harker, P. T., and Friesz, T. L. (1986b), "Prediction of Intercity Freight Flows II: Mathematical Formulations, Transportation Research B: Methodological, vol. 20 no. 2, pp. 155-174.

Harris, T. (2005a), "The Network Is Not Enough", On-line article, Retrieved from http://www.chicago-consulting.com/articles/networkIsNotEnough.shtml.

Harris, T. (2005b), "Why Warehouse Networks Don't Work", On-line article, Retrieved from http://www.chicago-consulting.com/articles/whyWarehouseNetworks Won'tWork.shtml. 
Harris, T. (2005c), "How To Design a Warehouse Network: Six Steps to a Low Cost, High Service Warehouse Network That Beats Competitors", On-line article, Retrieved from http://www.chicago-consulting.com/articles/design WarehouseNetwork.shtml.

Harris, T. (2005d), "Order Sourcing - The Hidden Gold Mine", On-line article, Retrieved from http://www.chicago-consulting.com/articles/orderSourcing.shtml.

Huang, F. Y., and Walter, C. K. (2000), "Hours of Service Preferences: A Case Study of a Midwest Carrier's Drivers", Proceedings of the Mid-Continent Transportation Symposium 2000, Center for Transportation Research and Education, Iowa State University, Ames, Iowa, May 15-16, 2000.

ICF Consulting and HLB Decision-Economics (2002), "Economic Effects of Transportation: The Freight Story", Final-Report, Prepared for the Federal Highway Administration, January 2002, 24 pp.

J.B. Hunt (2005), "Investor Relations", J.B. Hunt Transport Services Inc., Retrieved from http://ww2.jbhunt.com/appl/newsroomredesign.nsf/financials?openpage.

Johnston, W. B., and Packer, A. E. (1987), Workforce 2000: Work and Workers for the Twenty-first Century, Hudson Institute, Indianapolis, IN.

Jordan, W. C. (1987), "Truck Backhauling on Networks With Many Terminals", Transportation Research Part B, vol. 21 no. 3, pp. 183-193.

Jordan, W. C., and Burns, L. D. (1984), "Truck Backhauling on Two Terminal Networks", Transportation Research Part B, vol. 18 no.6, pp. 487-503.

Kalnbach, L., and Griffen, G. (2002), "Predicting and Classifying Voluntary Turnover Decisions for Truckload Drivers", Upper Great Plains Transportation Institute Final Report \# MPC02-135, December 2002, 40 pp.

Keaton, M.H. (1993), "Are There economies of Traffic Density in the Less-ThanTruckload Motor Carrier Industry? An Operations Planning Analysis", Transportation Research B, vol. 27 no. 5, pp. 343-358.

Keller, S. B. and Ozment, J. (1999), "Managing Driver Retention: Effects of The Dispatcher, Journal of Business Logistics, vol. 20 no. 2, pp. 97-119.

Kilcarr, S. (2001), "Paradigm Shift for Drivers", Drivers Magazine, July 2, 2001, Retrieved from http://driversmag.com.

Klincewicz, J. G., and Rosenwein, M. B. (1995), "The Airline Exception Scheduling Problem", Transportation Science, vol. 29 no. 1, pp. 4-16. 
Kontogiorgis, S., and Acharya, S. (1999), "US Airways Automates Its Weekend Fleet Assignment", Interfaces, vol. 29 no. 3, pp. 52-62.

Kutanoglu, E., Taylor, G. D., and Tjokroamidjojo, D. (2001), "MBTC 2004 Final Report: Efficient Dispatching in a Terminal City Network", Mack-Blackwell Transportation Center Final Report.

Lafontaine, F., and Masten, S. E. (2002), "Contracting in the Absence of Specific Investments and Moral Hazard: Understanding Carrier-Driver Relations in US Trucking", NBER Working Papers 8859, National Bureau of Economic Research, Inc., January 14, 2002.

Lambert, D. M., Stock, J. R., and Ellram, L. M. (1998), Fundamentals of Logistics Management, McGraw Hill Book Company, Boston, MA.

Ledyard, J. O., Olson, M., Porter, D., Swanson, J. A., and Torma, D. P. (2002), "The First Use of a Combined-Value Auction for Transportation Services", Interfaces, vol. 32 no. 5, September-October 2002, pp. 4-12.

Lindo Systems Inc. (2006), Chicago, IL, Retrieved from http://www.lindo.com/.

Logistics Management (2003), "Blooming, Ind., Selected As Best Warehouse Location", On-line article, March 1, 2003, Retrieved from http://www.logisticsmgmt .com/article/CA282465.html.

LMS Logistics Inc. (2002), "Best Practices for Motor Freight Management", LMS White Papers, On-line article, Retrieved from http://www.lmslogistics.com.

Meinert, T. S., and Taylor, G. D. (1999), "Summary of Route Regularization Alternatives: A Historical Perspective," Proceedings of the 1999 Industrial Engineering Research Conference, Phoenix, AZ, May 23-24, 1999, 5 pp.

Mele, J. (1989a), "Carriers Cope With Driver Shortage", FleetOwner, vol. 84 no. 1, pp. 104-111.

Mele, J. (1989b), "Solving Driver Turnover", FleetOwner, vol. 84 no. 9, pp. 45-52.

Merriam-Webster (2005), Webster's Third New International Dictionary, Unabridged, Retrieved from http://www.webster.com.

Migliore, M., and Catalano, M. (2003), "A Demand-Oriented Approach to Design a Logistics Network for Optimizing Freight Transport", Proceedings of the Odysseus - Second International Workshop on Freight Transportation and Logistics, Mondello (PA), Italy, May 26-30, 2003. 
Min, H., and Lambert, T. (2000), "Truck Driver Shortage Revisited", Transportation Journal, vol. 42 no. 2, pp. 5-16.

Min, H. (2002), "Examining Sources of Driver Turnover from a Managerial Perspective", International Journal of Transportation Management, vol. 13 no. 2, pp. 59-68.

Min, H. and Emam, A. (2003), "Developing the Profiles of Truck Drivers For Their Successful Recruitment and Retention: A Data Mining Approach", International Journal of Physical Distribution and Logistics Management, vol. 33 no. 2, pp. 149-162.

Min, H., and Zhou, G. (2002), "Supply Chain Modeling: Past, Present, and Future", Computers and Industrial Engineering, vol. 43, pp. 231-249.

Mirchandani, P. and Odoni, A. (1979), "Location of Medians on Stochastic Networks", Transportation Science, vol. 13 no. 2, pp. 85-97.

Muto, S. (1996), "A Special Period Peak Load Forecasting Method Based On Order Relations", Proceedings of the International Conference for Intelligent Systems Applications to Power Systems, January 28-February 2, 1996, pp. 120-125.

Nagurney, A. (2005) "Spatial Equilibrium in Transport Networks", Handbook on Transport Geography and Spatial Systems, Stopher, P., Hensher, D., Haynes, K., and Button, K.F. editors, pp. 583-608.

Nguyen, T. (2005), "Truckload Turnover Still Rising”, Drivers Magazine, June 23, 2005, Retrieved from http://driversmag.com.

Nguyen, T. (2006), “Turnover Going from Bad to Worse", FleetOwner, April 4, 2006, Retrieved from http://fleetowner.com/news/topstory/driver turnover truckload lt1 truck_ata_040406/.

Powell, W. B. (1991), "Optimization Models and Algorithms: An Emerging Technology for the Motor Carrier Industry", IEEE Transactions on Vehicular Technology, vol. 40 no. 1 , pp. 68-80.

Powell, W. B. (1996), "A Stochastic Formulation of the Dynamic Assignment Problem, with an Application to Truckload Motor Carriers", Transportation Science, vol. 30 no. 3 , pp. $195-219$.

Powell, W. B., Carvalho, T. A., Godfrey, G. A., and Simao, H. P. (1995), "Dynamic Fleet Management as a Logistics Queueing Network", Statistics and Operations Research Technical Report SOR-94-18, June 20, 1995. 
Powell, W. B., Shapiro, J. A., and Simao, H. P. (2003), "A Representational Paradigm for Dynamic Resource Transformation Problems", Technical Report \#CL-01-05, Castle Laboratory Department of Operations Research and Financial Engineering, January 2003, $63 \mathrm{pp}$.

Powell, W. B., Towns, M. T, and Marar, A. (2000), "On the Value of Optimal Myopic Solutions for Dynamic Routing and Scheduling Problems in the Presence of User Noncompliance", Transportation Science, vol. 34 no. 1, pp. 67-85.

Raychaudhuri, S., and Veeramani, R. (2005), "Bidding Strategies in Multi-round Auctions for Transportation Services", Proceedings of the 2005 Industrial Engineering Research Conference, Atlanta, GA, May 14-18, 2005.

Richardson, H. L. (1994), "Can We Afford the Driver Shortage?”, Transportation \& Distribution, August 1994, pp. 30-34.

Rodríguez, D. A., Rocha, M., Khattak, A. J., and Belzer, M. H. (2003), "The Effects of Truck Driver Wages and Working Conditions on Highway Safety: A Case Study", Transportation Research Record: Journal of the Transportation Research Board, no. 1833, pp. 95-102.

Rodriquez, J., Kosir, M., Lantz, B., Griffin, G., and Glatt, J. (2000), “The Costs of Truckload Driver Turnover", Upper Great Plains Transportation Institute Final Report, SP-146, April 2000, 18 pp.

Ronen, D., (1997), "Alternate Mode Dispatching: The Impact of Cost Minimization", Journal of the Operational Research Society, vol. 48 no. 10, pp. 973-977.

Roy, J., and Delorme, L. (1989), "Netplan: A Network Optimization Model for Tactical Planning in the Less-Than-Truckload Motor-Carrier Industry", INFOR, vol. 27 no. 1, pp. 22-35.

Rushmeier, R. A., and Kontogiorgis, S. A. (1997), "Advances in the Fleet Optimization of Airline Fleet Assignment", Transportation Science, vol. 31. no. 2, pp. 159-169.

Schmidt, G. and Wilhelm, W. E. (2000), "Strategic, Tactical, and Operational Decisions in Multinational Logistics Networks: A Review and Discussion of Modeling Issues", International Journal of Production Research, vol. 38 no. 7, pp. 1501-1523.

Schwartz, M. (1992), J.B. Hunt: The Long Haul to Success, University of Arkansas Press, Fayetteville, AR, 1992.

Shapiro, J. F. (2001), Modeling the Supply Chain, Duxbury Printing, $1^{\text {st }}$ Edition, Thomson Learning Academic Resource Center. 
Sherali, H. D., and Suharko, A. B. (1998), "Tactical Decision Support System for Empty Railcar Management", Transportation Science, vol. 32, pp. 306-329.

Simchi-Levi, D., and Simchi-Levi, E., (2003). "Finding The Right Balance", Logistics Today, December 2003, pp. 16-19.

Srinivasan, D., Chang, C. S., and Liew, A. C. (1995), "Demand Forecasting Using Fuzzy Neural Computation, With Special Emphasis On Weekend and Public Holiday Forecasting", IEEE Transactions on Power Systems, vol. 10 no. 4, pp. 1897-1903.

Staplin, L., Gish, K. W., Decina, L. E., and Brewster, R. M. (2003), "Commercial Motor Vehicle Driver Retention and Safety", Federal Motor Carrier Safety Administration Technical Report \# FMCSA-RT-03-004, March 2003, 48 pp.

Suzuki, Y. (2005), “Truck Driver Turnover Rate: What Rate is Good Enough?”, Transportation Journal, in review October 2005, retrieved from http://www.bus.iastate.edu/ysuzuki/TrLog462/Articles/desirable\%20turn.pdf.

Taha, H. A. (1991), Simulation with SIMNET II, SimTec, Inc., Fayetteville, AR.

Taniguchi, E., Noritake, M., Yamada, T., and Izumitani, T. (1997), "Optimal Size and Location Planning of Public Logistics Terminals", Transportation Research Part E, vol. 35, pp 207-222.

Taylor, G. D. (2003), "Managing Freight Imbalance in Truckload Trucking", Proceedings of the $5^{\text {th }}$ International Industrial Engineering Conference, Quebec City, Canada, October 26-29, 2003.

Taylor, G. D., Meinert, T.S., Killian, R.C., and Whicker, G.L. (1999a), "Development and Analysis of Alternative Dispatching Methods in Truckload Trucking", Transportation Research - Part E, vol. 35, pp. 191-205.

Taylor, G. D. (2002), "Improved Trucking Operations Through Creative Exploitation of Freight Information", The 7 International Logistics Conference, Prague, Czech Republic, April 2002.

Taylor, G. D., and McDowell, C. A. (2002), "Efficient Timing of Freight Pickup Assignments Through Simulation", Mack Blackwell Final Research Report \#MBTC-FR-2013, March 2002, 34 pp.

Taylor, G. D., and Meinert, T. S. (2000), "Improving the Quality of Operations in Truckload Trucking", IIE Transactions, vol. 32 no. 1, pp. 551-562.

Taylor, G. D., Broadstreet, F., Meinert, T. S., and Usher, J. S. (2002), "An Analysis of Intermodal Ramp Selection Methods", Transportation Research Part E, vol. 38, pp. 117-134. 
Taylor, G. D., Onggowijaya, S. N., DuCote, W. G., Broadstreet, F., and Whicker, G L. (2004), "Consideration of Freight Market Considerations in Distribution Network Design", $8^{\text {th }}$ International Material Handling Research Colloquium (IMHRC), Graz, Austria, June 2004.

Taylor, G. D., Whicker, G. L., and Usher, J. S. (2001), "Multi-Zone Dispatching in Truckload Trucking", Transportation Letters E, vol. 37, pp. 375-390.

Taylor, G. D., Zakaria, F., and Petre, M. K. (1999b), "New Marketing Paradigms for Truckload Trucking: Using Agile Dedicated Fleets to Regularize Distribution," Final Research Report \#MBTC-FR-1080, Mack-Blackwell National rural Transportation Study Center, $47 \mathrm{pp}$.

Taylor, G. D., and Whicker, G. L. (2002), "Optimization and Heuristic Methods Supporting Distributed Manufacturing," International Journal of Production Planning and Control, vol. 13 no. 6, pp. 517-528.

Tompkins, J. A., and Harmelink, D. A. (1992), "Strategic Master Planning: A Distribution Imperative", Industrial Development, vol. 161 no. 6, pp. 12-14.

Toth, P. and Vigo, D. editors (2001), The Vehicle Routing Problem, SIAM Monographs on Discrete Mathematics and Applications, SIAM.

Transport Topics (2005), "Driver Turnover Reached Record in 4Q, ATA says", March 28, 2005, Retrieved from http://www.ttnews.com/members/topnews/ 0012732.html.

United States Department of Commerce, Bureau of the Census (2006), Retrieved from http://www.census.gov/geo/www/cenpop/county/ctyctrpg.html.

United States Department of Transportation, Bureau of Transportation Statistics (2005), Retrieved from http://products.bts.gov/publications/national transportation statistics 12004/html/table 01 02.html

Vise, A. (2004), "Show Them the Money", Commercial Carrier Journal Magazine, November 2004, Retrieved from http://www.etrucker.com/apps/news/ article.asp?id=45365

Whicker, G. L. (1998), "Industrial Engineering in Truckload Transportation and Logistics", Presentation at the $10^{\text {th }}$ Annual Productivity and Quality Conference, Institute of Industrial Engineers - Chapter 200, Ft. Smith, AR.

Yang, J., Jaillet, P., and Mahmassani, H. (2002), "Real-Time Multi-Vehicle Truckload Pick-Up and Delivery Problems", Transportation Science, vol. 28 no. 2, pp. 135-148. 
Zhou, G., Min, H., and Gen, M. (2002), "The Balanced Allocation of Customers to Distribution Centers in the Supply Chain Network: A Genetic Algorithm Approach", Computers and Industrial Engineering, vol. 43 no. 2, pp. 251-261. 


\section{APPENDIX 1}

\section{SIMNET Code: The Weekend Problem}

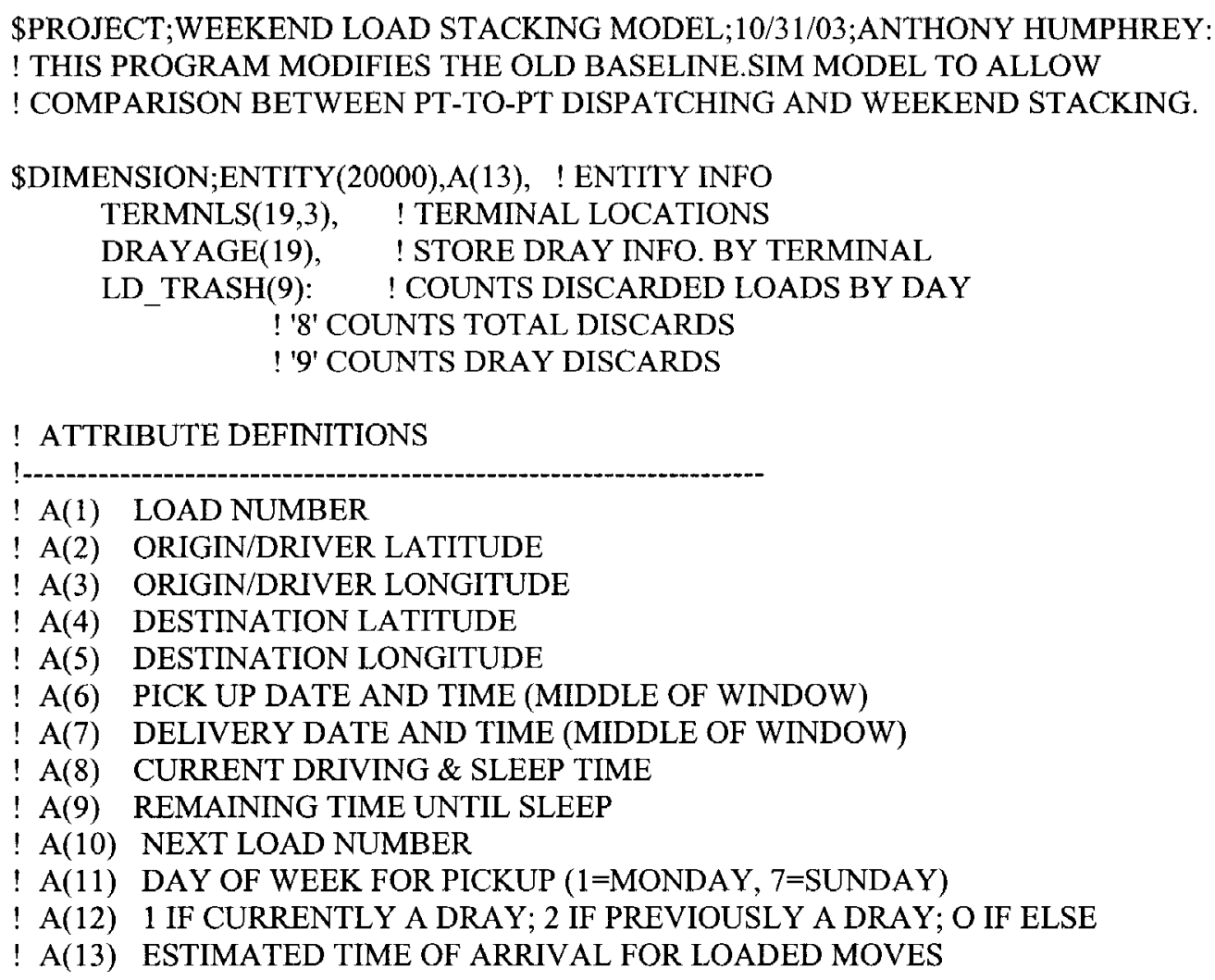

\$VARIABLES;

VarWEEKEND;RUN.END;WEEKEND:

VarDATA;RUN.END;DATA:

VarHUBS;RUN.END;HUBS:

MAX_DRVR;RUN.END;ACTIVE:

AVG_DRVR;TIME.BASED;ACTIVE:

NUM DRAY(1-19);;DRAYAGE(K):

DISCARD;RUN.END;(LD_TRASH(8)/MAX(1,TOT_LDS-1))*100:!\% OF LDS DISCARDED

LATE_HRS;;LATE:

LDS_LATE_PCT;:LT_PCT:

MI_CIRCUITY;;CIRC/AVG_DR/7: MI_MTY_REG;;MTY/AVG_DR/7:
! LATENESS STATISTICS

!OUT OF ROUTE MILEAGE STATISTICS

!EMPTY (Deadhead) MILEAGE STATISTICS 
MI MTY2DRAY;MTY2DRAY/AVG DR/7:

MI DRAY;DRAY/AVG DR/7: !DRAY MILEAGE STATISTICS

MI_MTY2HAUL;;MTY2HAUL/AVG_DR/7:

MI_HAUL;;HAUL/AVG_DR/7: !DELIVERY MILEAGE STATISTICS

MI TOTAL;;(MTY+MTY2DRAY+DRAY+MTY2HAUL+HAUL)/AVG_DR/7:

XLD_TRASH8;RUN.END;LD_TRASH(8):

XTOT_LDS;RUN.END;TOT_LDS:

XLATĒERUN.END;LATE:

XLT_PCT;RUN.END;LT_PCT:

XAVG_DR;RUN.END;AVG DR:

XTR PRD;RUN.END;TR.PRD:

XCIRC;RUN.END;CIRC:

XMTY;RUN.END;MTY:

XMTY2DRAY;RUN.END;MTY2DRAY:

XDRAY;RUN.END;DRAY:

XMTY2HAUL;RUN.END;MTY2HAUL:

XHAUL;RUN.END;HAUL:

DAY_DISC(1-7);;LD_TRASH(K): ITRASHED LOADS BY DAY

DRAY DISCARD;RUN.END;LD TRASH(9):

DRAY_RECYCLE;RUN.END;RECYCLE:

DRAY_TOTAL;RUN.END;TOT_NUM_DRY:

\$BEGIN:

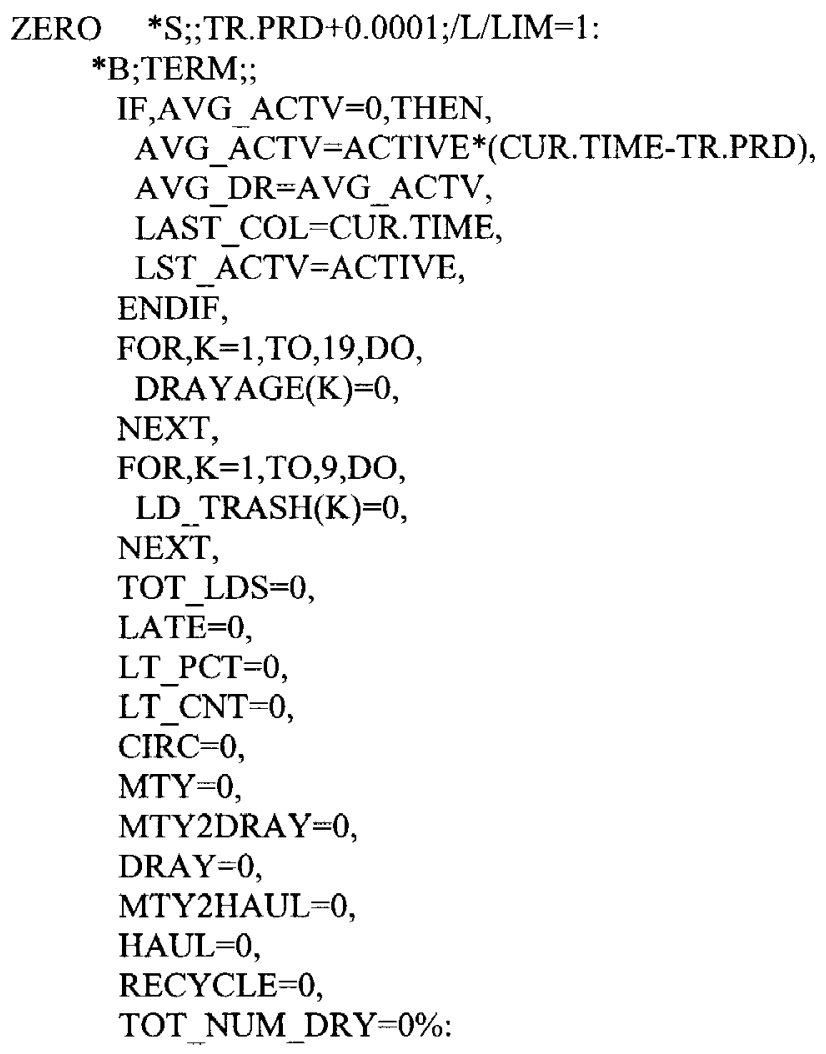




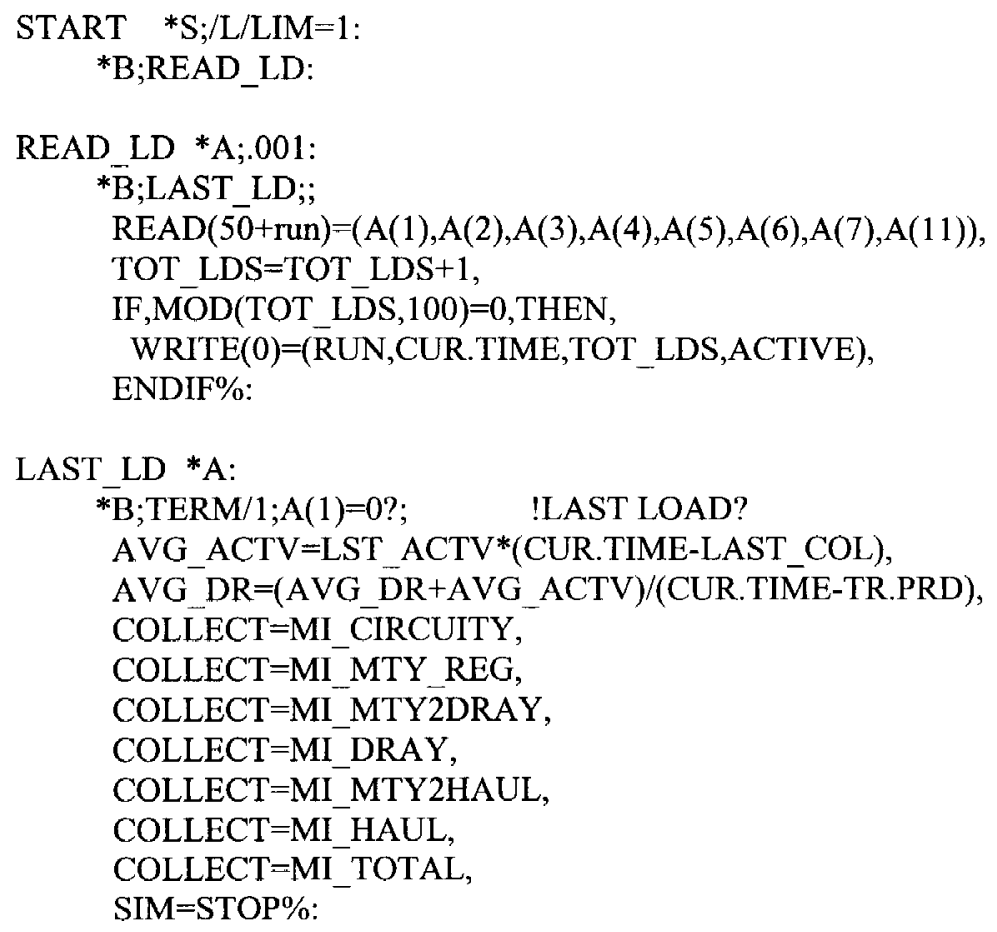

*B;ROUTER $/ 1 ; \mathrm{A}(6)<=$ CUR.TIME +8 ?: !IS LOAD P/U WITHIN 8 HOURS?

*B;DLAY/L;;A(8)=A(6)-(CUR.TIME+8)\%:

\section{DLAY $\quad * A ; A(8): \quad$ !DELAY MAKING LOAD ASSIGNMENT UNTIL 8 HRS BEFORE P/U}

\section{ROUTER *A:}

*B;READ_LD/2;A(1)>0?: !Get a NEW LOAD to be read from data file

*B;LD_ORIG/2;A(1)>0?: !Send CURRENT LOAD for Driver Assignment

QLD_ORIG *Q:

LD_ORIG *A:

*B;TERM;

LOAD_NUM $=A(1)$,

ORIG_LAT $=A(2)$,

ORIG_LON $=A(3)$,

DEST_LAT $=A(4)$,

DEST_LON $=A(5)$,

$\mathrm{PICK} \mathrm{UP}=\mathrm{A}(6)$,

DRV CAND $=-1$,

DRY $\mathrm{CAND}=1$,

DRY $\mathrm{CIRC}^{\wedge}=999999$,

DRAY $\_$STATUS $=A(12)$,

DISPATCH=MAX(MAX_DISP,A(12)*MAX_DISP), !This allows for the !possibility of drayed loads to have a larger !maximum dispatch distance to guarantee that !they are picked up.

IF,WEEKEND=2,AND,A(11)=5,THEN, !IF WEEKEND 'ON' AND 'FRIDAY' IF,NO DRAY $<$ DRAY TGT,THEN, !IF DRAY TARGET NOT REACHED DR_LAT $=(\mathrm{A}(2)+\mathrm{A}(4) \overline{)}) /(2 * 57.3), \quad$ ! CALC. DRIVE DIST

DRV_DIST $=\left(\left(((67 *(\mathrm{~A}(2)-\mathrm{A}(4))))^{* *} 2\right)+\&\right.$ 
$\left.\left.\left(\left(67^{*} \mathrm{COS}\left(\mathrm{DR} \_\mathrm{LAT}\right) *(\mathrm{~A}(3)-\mathrm{A}(5))\right)\right)^{* *} 2\right)\right) \&$

$* *(1 / 2))^{*} 1.17$

DR TIME $=$ DRV DIST/NO(SPEED, $0.03 *$ SPEED $)$,

IF,DR TIME $>10$, THEN,

DR_TIME=DR_TIME+(INT(DR_TIME $\left./ 10)^{*} 8\right)$,

ENDIF,

SLACK $=\mathrm{A}(7)$-CUR.TIME-DR_TIME,

IF,SLACK $>$ REQ_SLAK,AND, IIF ENOUGH SLACK TO COMPLETE DRAY

DRV_DIST>REQ_MI,THEN， !AND ENOUGH HAUL MILES AFTER DRAY

FOR, $\bar{I}=1, T O, N O=\bar{T}$ TERMS,DO, !FIND BEST TERMINAL FOR DRAY

T_LAT $=$ TERMNLS $(I, 2)$,

T_LONG $=$ TERMNLS(I,3),

AV_T_LAT $=\left(T \_L A T+O R I G \_L A T\right) /(2 * 57.3)$,

DRA $\bar{Y}$ DIS $=\left(\left(\left((67 *(\text { ORIG_LAT-T_LAT }))^{* * 2}\right)+\&\right.\right.$

$\left.\left(\left(67 * \overline{\mathrm{COS}}\left(\mathrm{AV} \_\mathrm{T} \_\mathrm{LAT}\right)^{*}\left(\overline{\mathrm{O}} \mathrm{RIG} \_\mathrm{LON}-\mathrm{T} \_L O N G\right)\right)^{* *} 2\right)\right) \&$

$* *(1 / 2))^{*} 1.17$,

IF,DRAY_DIS $<$ MAX_DRAY,THEN,

DEL_LAT $=\left(T \_L A T+D E S T \_L A T\right) /(2 * 57.3)$,

DEL_DIS $=\left(\left(\left(67^{*}(\text { DEST_LAT-T_LAT })\right)^{* * 2}\right)+\&\right.$

$\left.\left(\left(67^{*} \mathrm{COS}(\mathrm{DEL} L \mathrm{LAT}) *(\mathrm{DEST} \text { LON-T_LONG })\right)^{* * 2}\right)\right) \&$

$* *(1 / 2))^{*} 1.17$,

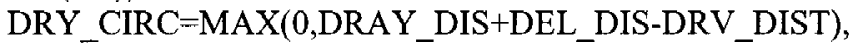

IF,DRY_CIRC $<$ DRY_CIRC ${ }^{\wedge}$, THEN,

DRY $\bar{C} A N D=I, \quad$ IIDENTIFY A BEST DRAY TERMINAL

DRY_CIRC $^{\wedge}=$ DRY_CIRC, !UPDATE BEST DRAY STATISTICS

ENDIF,

ENDIF,

NEXT,

IF,DRY_CAND $>0$,THEN, ! IF LOAD IS TO BE DRAYED

A(2)=TERMNLS(DRY_CAND,2), ! ADJUST 'ORIGin' TO TERMINAL

$A(3)=$ TERMNLS(DRY_CAND,3),

$\mathrm{A}(12)=1, \quad$ ! MARK CURRENT LOAD AS A DRAY LOAD

DRAY_STATUS $=1, \quad$ ! MARK DRAY_STATUS AS A DRAY LOAD

TOT_NUM_DRY $=$ TOT_NUM_DRY $+1, \overline{!}$ COUNT TOTAL NUMBER OF DRAYS

INS $(\bar{Q} D R A \bar{Y})=$ TRANS, ${ }^{-}$! REMAINING DRIVE IN QUE

DEST_LAT $=$ TERMNLS(DRY_CAND,2), !UPDATE NEW 'DESTination'

DEST_LON=TERMNLS(DRY_CAND,3),

CIRC $=$ CIRC + DRY CIRC ${ }^{\wedge}, \quad$ ! UPDATE DRAY STATS

NO_DRAY $=$ NO_DRAY +1 ,

DRAYYAGE(DRY_CAND)=DRAYAGE(DRY_CAND)+1,

ENDIF,

ENDIF,

ENDIF,

ENDIF,

IF,LEN(QAVAIL)>0,THEN, $\quad$ !LOOK FOR AVAIL DRVR...

COPY $=$ MAX (1,INT(LEN(QAVAIL)/2))(QAVAIL),

MID_PT $=A(4)$,

TRAN̄S=OLD,

IF,A(4)<=MID_PT,THEN, !Scan QAVAIL forwards

LIM1 $=1$,

LIM2=LEN(QAVAIL),

$\mathrm{INCR}=1$,

ELSE, !Scan QAVAIL backwards

LIM1 $=$ LEN(QAVAIL $)$,

LIM2 $=1$, 


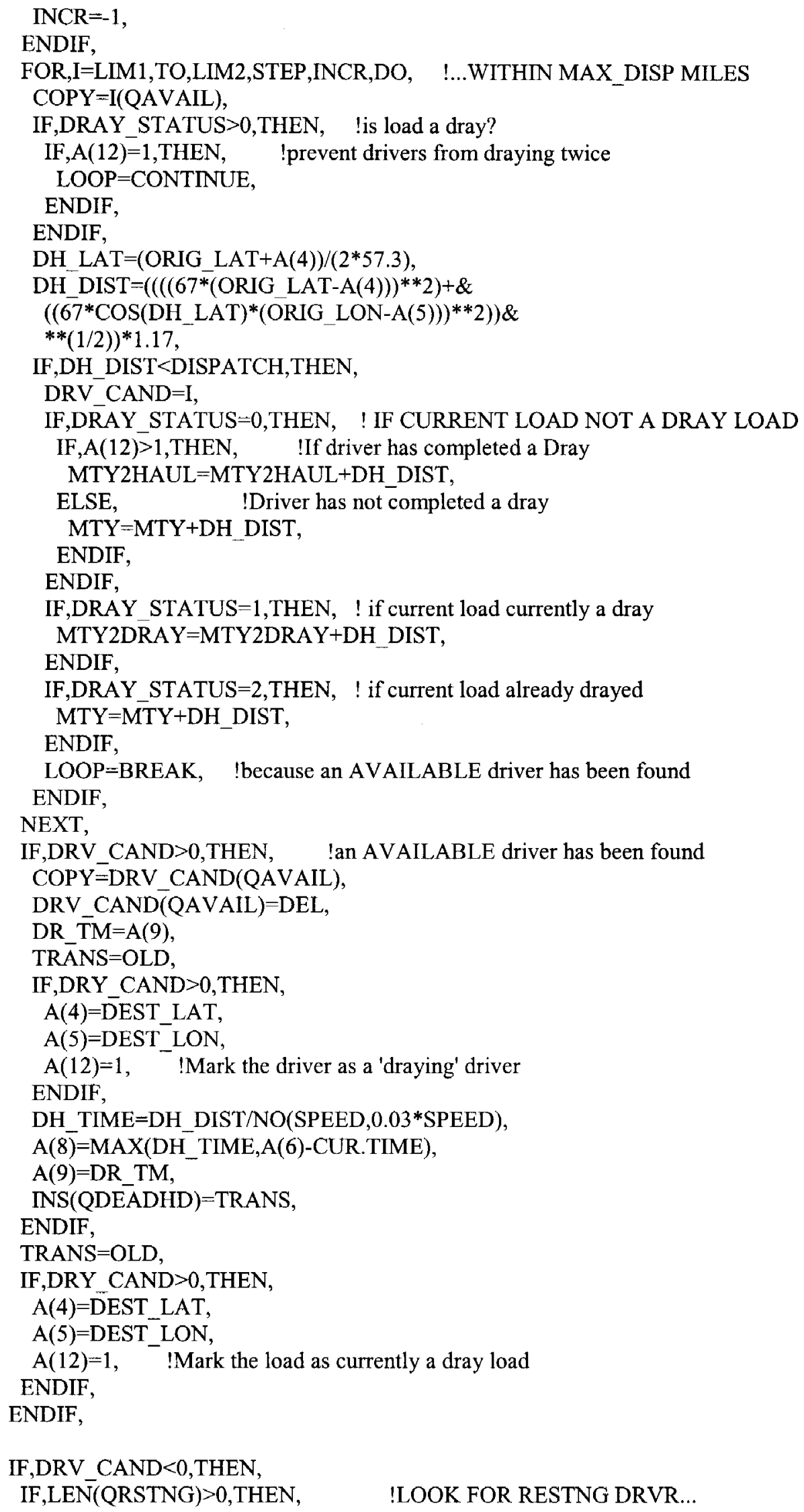




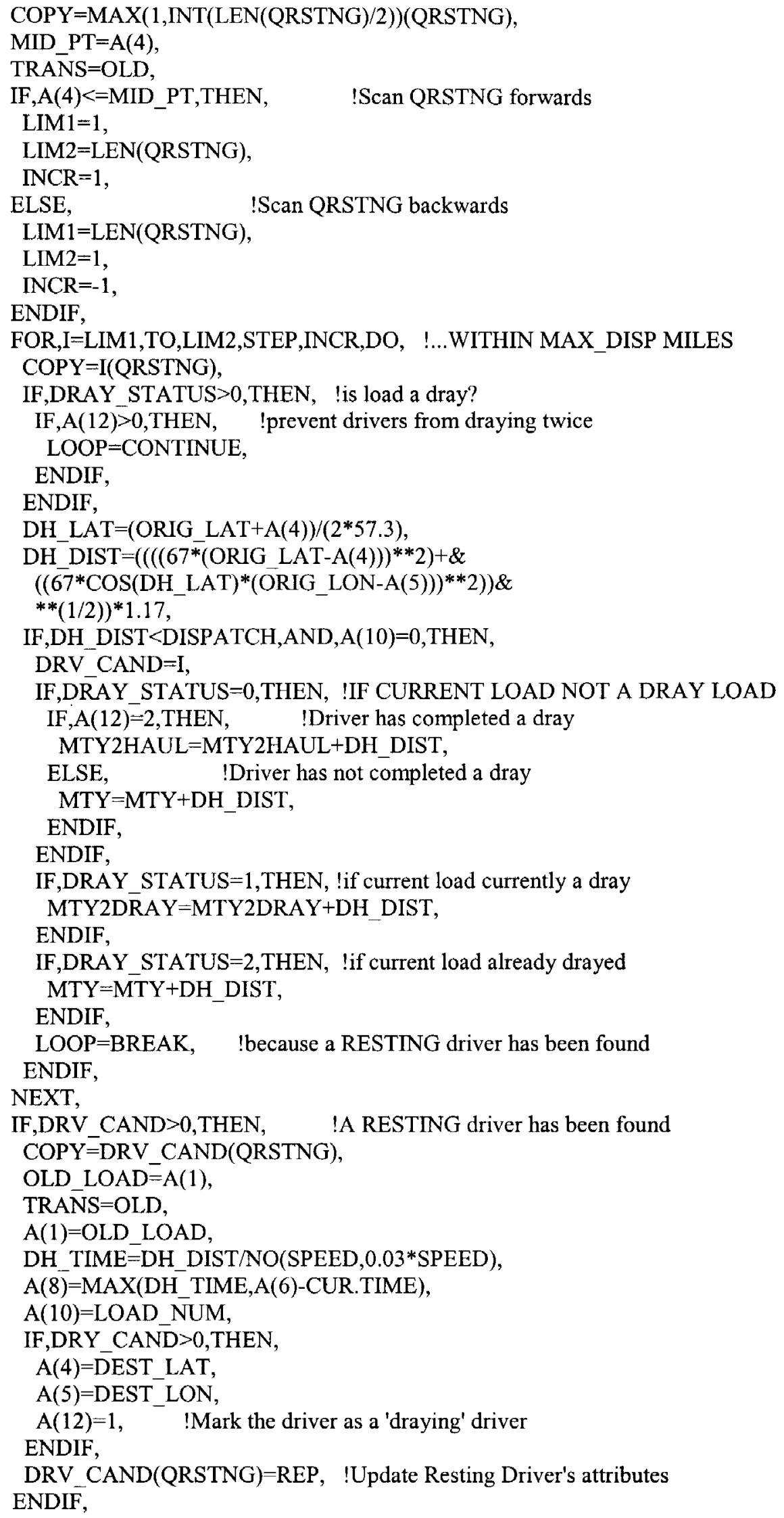


TRANS $=$ OLD,

IF,DRY_CAND $>0, T H E N$,

$A(4)=\overline{D E S T}$ LAT,

$\mathrm{A}(5)=\mathrm{DEST}$ LON,

$\mathrm{A}(12)=1, \quad$ !Mark the load as currently a dray load

ENDIF,

ENDIF,

ENDIF,

IF,DRV_CAND $<0$,THEN !LOOK FOR DRVNG DRVR...

IF,LEN(QDRVNG) $>0$, THEN, !...WITHIN MAX_DISP MILES

FOR,I=1,TO,LEN(QDRVNG),DO, COPY=I(QDRVNG),

IF,DRAY_STATUS $>0$,THEN, !is load a dray?

IF, A $(12)>0$, THEN, !prevent drivers from draying twice

LOOP $=$ CONTINUE,

ENDIF,

ENDIF,

IF,A(13)-(CUR.TIME +8$)<=$ MAX_DWEL,THEN,

DH_LAT $=($ ORIG_LAT + A $(4)) /(2 * 57.3)$,

DH_DIST $=\left(\left(\left(\left(67^{-}(\text {ORIG_LAT-A }(4))\right)\right)^{* *} 2\right)+\&\right.$

$\left(\left(67^{*} \mathrm{COS}\left(\mathrm{DH} \_\right.\right.\right.$LAT $) *\left(\mathrm{ORIG} \_\right.$LON-A $\left.\left.\left.\left.(5)\right)\right) * * 2\right)\right) \&$

$* *(1 / 2))^{*} 1.17$,

IF,DH_DIST $<$ DISPATCH,AND,A(10)=0,THEN,

DH_TIME=DH_DIST/NO(SPEED,0.03*SPEED),

IF, $\bar{A}(9)>$ DH TIME,THEN,

DRV CAND $=$ I,

IF,DRAY STATUS $=0$, THEN, ! if current load not a dray load

IF, $\mathrm{A}(12)=1, \mathrm{THEN}, \quad$ !if driver has completed a dray

MTY2HAUL $=$ MTY2HAUL + DH DIST,

ELSE, !driver has not completed a dray

MTY $=$ MTY+DH_DIST,

ENDIF,

ENDIF,

IF,DRAY_STATUS $=1$,THEN, ! if current load current a dray MTY2DRAY=MTY2DRAY+DH DIST,

ENDIF,

IF,DRAY_STATUS=2,THEN, !if current load already drayed MTY $=$ MTY + DH DIST,

ENDIF,

LOOP=BREAK, !because a DRIVING driver has been found

ENDIF,

ENDIF,

ELSE,

LOOP=BREAK,$\quad$ !BECAUSE QDRVNG DISCIPLINE IS LO(13)

ENDIF,

NEXT,

IF,DRV_CAND>0,THEN, !if a driver candidate has been found COPY $=$ DRV_CAND(QDRVNG),

$\mathrm{A}(10)=\mathrm{LOAD}-\mathrm{NUM}$,

DRV_CAND(Q $\bar{Q} D R V N G)=R E P, \quad$ !Update Driving Driver's attributes

TRAN $\bar{S}=\mathrm{OLD}$,

IF,DRY CAND $>0$, THEN,! if current load has been marked for dray $\mathrm{A}(4)=\overline{\mathrm{DEST}}$ LAT,

$\mathrm{A}(5)=$ DEST_LON,

$\mathrm{A}(12)=1, \quad$ !Mark the load as currently a dray load 


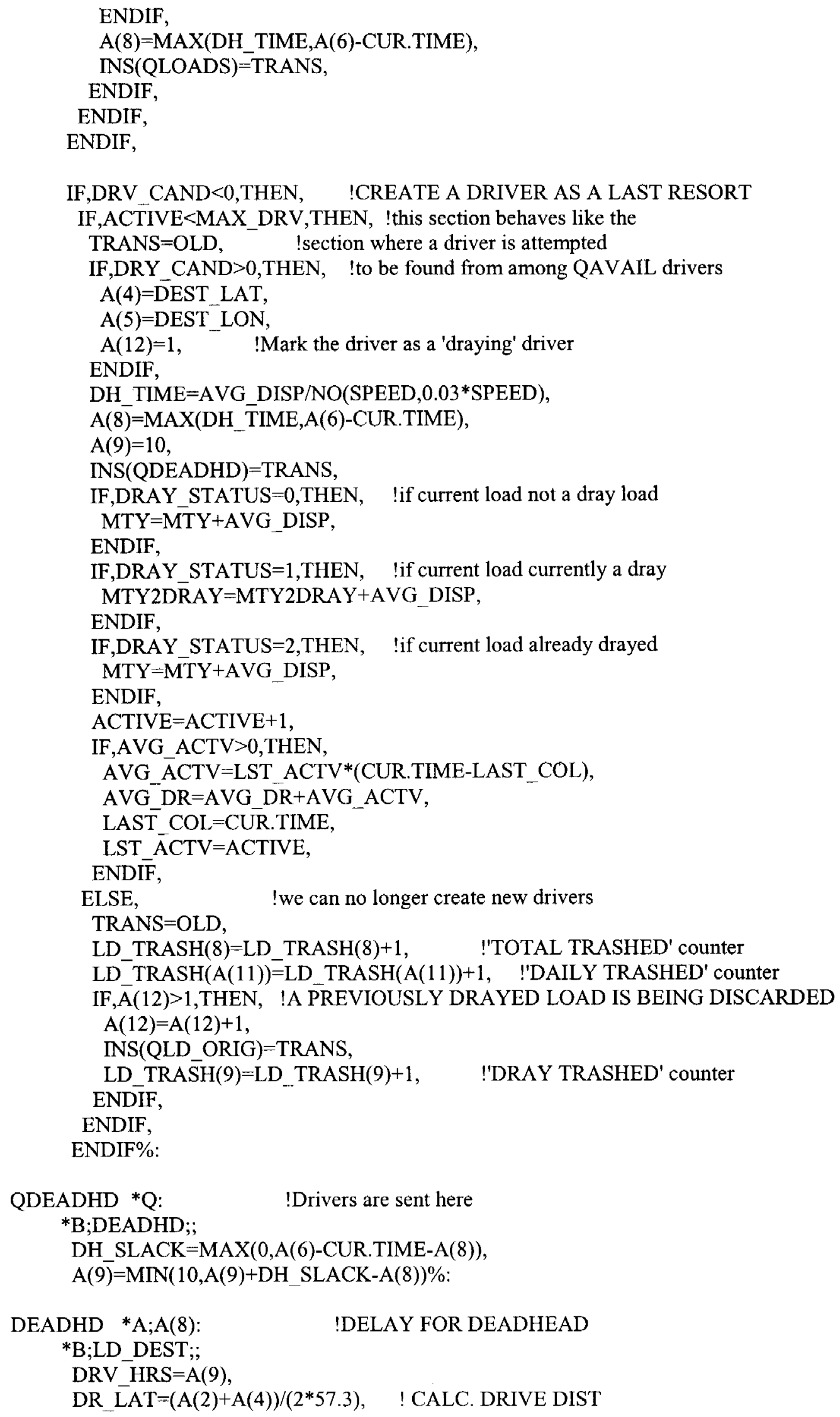




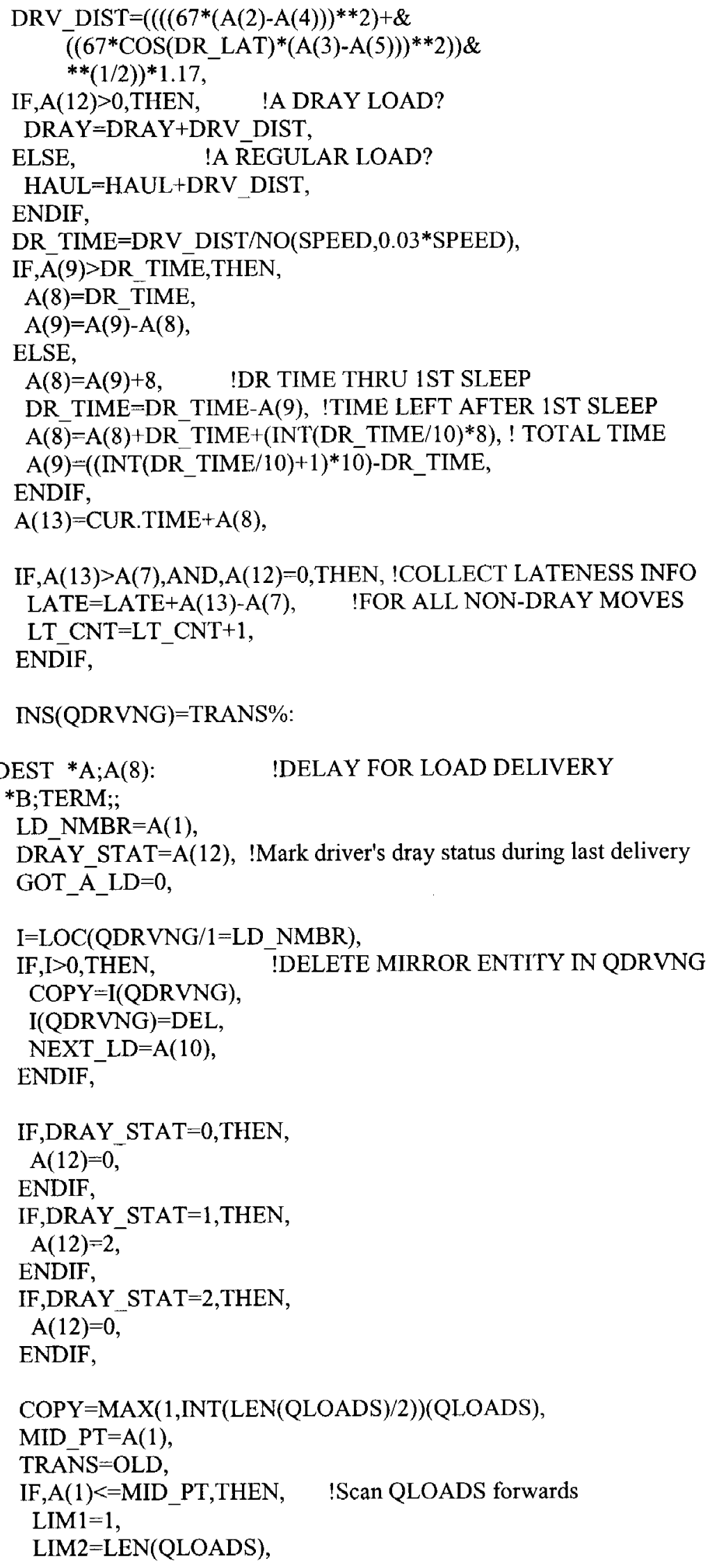




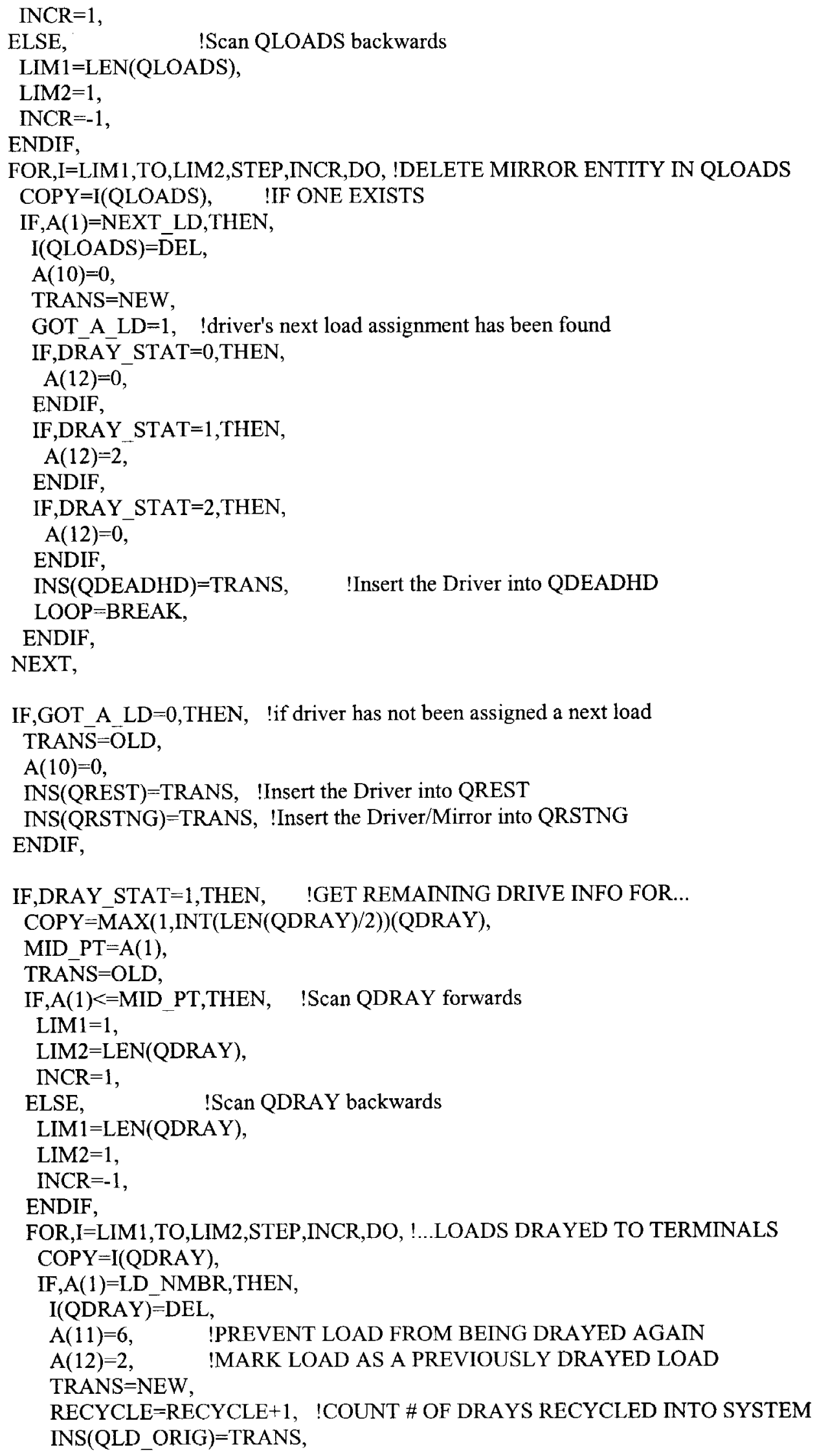


LOOP $=$ BREAK,

ENDIF,

NEXT,

ENDIF\%:

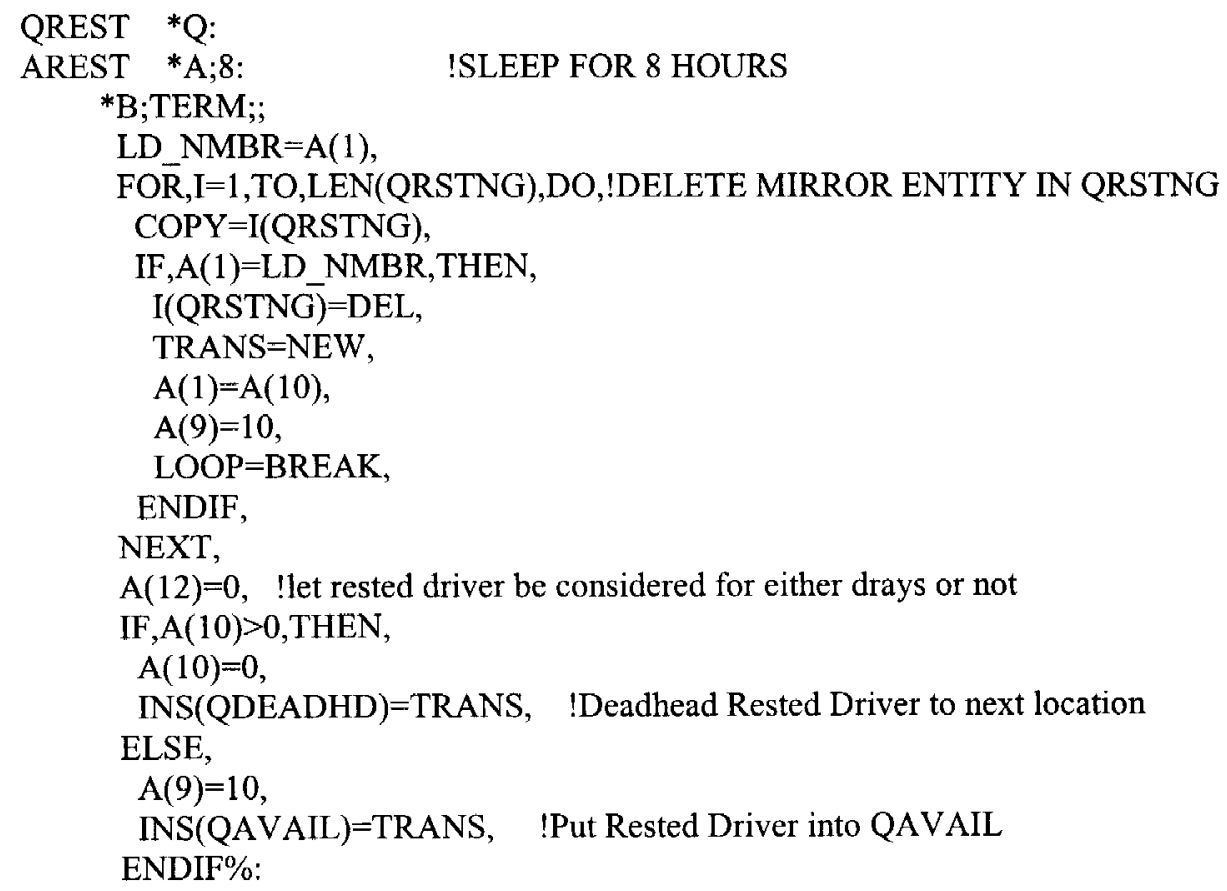




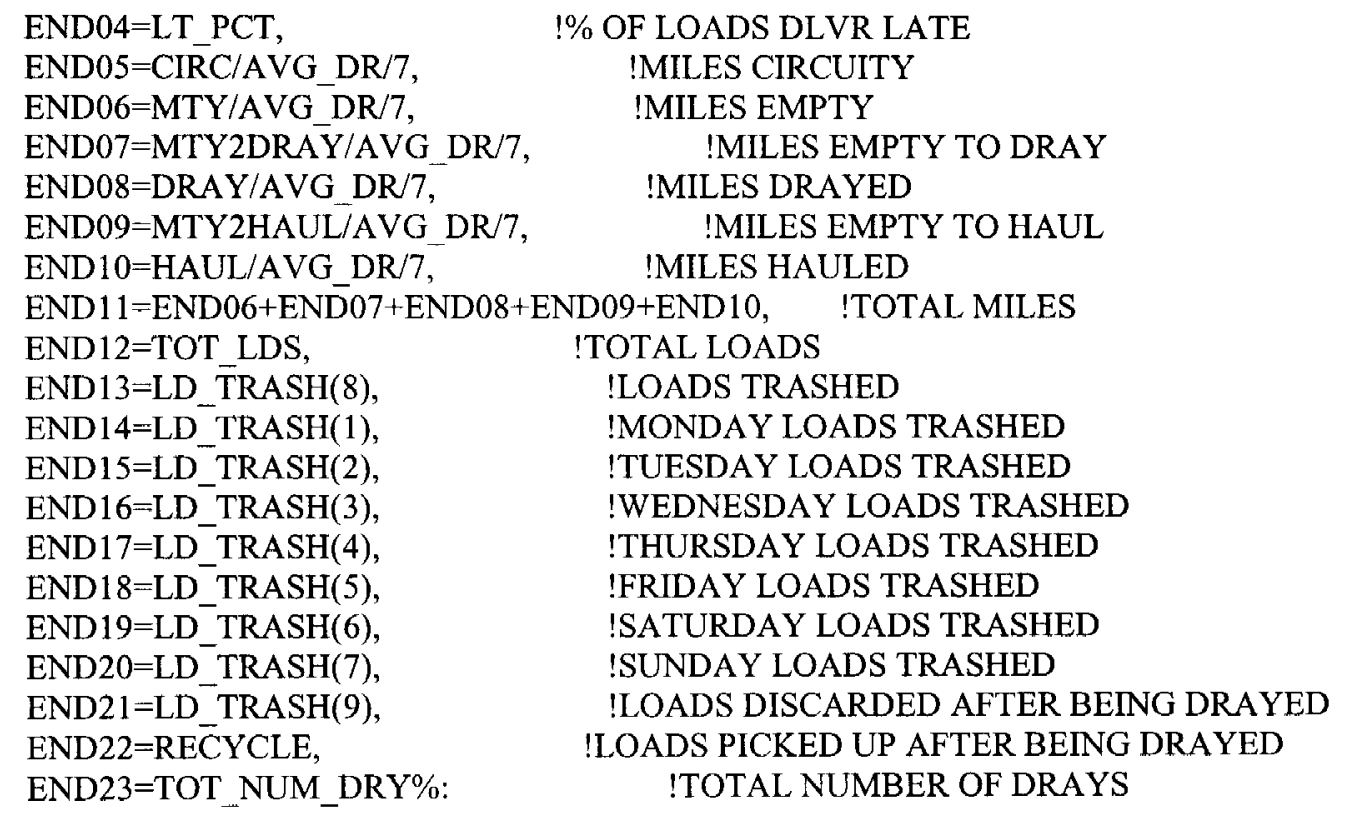

QAVAIL *Q;;;LO(4): !HOLDS AVAILABLE DRIVERS

\$SEGMENT:

QDRVNG *Q;;;LO(13): !HOLDS MIRROR ENTITIES REPRESENTING DRIVING DRIVERS \$SEGMENT:

QRSTNG ${ }^{*}$ Q;;;LO(4): !HOLDS MIRROR ENTITIES REPRESENTING SLEEPING DRIVERS \$SEGMENT:

QLOADS *Q; ;'LO(1): !HOLDS LOADS UNTIL DRIVING DRIVERS CAN PICK THEM UP \$SEGMENT:

QDRAY *Q;;:LO(1): :HOLDS INFO FOR LOADS BEING DRAYED TO TERMINAL \$SEGMENT:

\$END:

\$CONSTANTS:1-25/MAX_DRV=1550, ! MAX NUMBER OF DRIVERS ALLOWED SPEED $=50, \quad$ ! AVERAGE SPEED IN MILES PER HOUR

MAX_DISP $=75, \quad$ ! MAX ALLOWED DISPATCHING DISTANCE AVG_DISP $=50, \quad$ ! AVG DISPATCH DIST FOR NEW DRVRS MAX_DWEL $=16, \quad$ ! MAX ALLOWED DWELL TIME FOR DISP

NO TERMS $=19, \quad$ ! NUMBER OF TERMINALS FOR STACKING DRAY TGT $=10000, \quad$ ! TARGET FOR FRIDAY YARD STACKING MAX_DRAY $=200, \quad$ ! MAX ALLOWED FRIDAY DRAY DISTANCE REQ SLAK=8, ! NMBR OF HOURS OF SLACK FOR DRAY REQ MI $=500, \quad$ ! NMBR OF HAUL MILES REQUIRED FOR DRAY

WEEKEND $=1, \quad ! 1=$ WEEKEND OFF, $2=$ WEEKEND ON DATA $=1, \quad ! 1=$ BASELINE, $2=20+\%, 3=$ WARREN POWELL HUBS $=1: \quad ! 1=$ ORIGINAL, $2=$ HUB FINDER, $3=$ DOM FINDER 
!\$ARRAYS:TERMNLS;1-25/NS/1,39.1297, -85.0712, !Hubfinder Hubs $2,40.3257,-75.4948$, $3,34.1061,-118.0228$ $4,42.1499,-87.9694$, $5,33.6466,-84.0598$, $6,32.7893,-96.7511$, $7,35.0925,-92.0886$ $8,42.0997,-82.9497$ $9,39.1596,-94.8781$, $10,38.1198,-121.4829$, $11,38.6314,-90.4631$, $12,37.1532,-78.6813$ $13,29.7538,-95.3564$, $14,42.5586,-71.6581$, $15,43.6630,-92.4108$, $16,31.0244,-90.5641$, $17,46.3456,-122.5180$, $18,35.5103,-87.6825$, $19,43.2134,-76.6574$ :

!\$ARRAYS:TERMNLS; $1-25 / \mathrm{NS} / 1,40.0000,-83.0000, \quad$ !Domicile Hubs 2,38.0000, -86.0000 , $3,40.0000,-80.0000$, 4,40.0000, -86.0000 , 5,36.0000, -90.0000 , $6,38.0000,-82.0000$, $7,42.0000,-88.0000$, $8,42.0000,-81.0000$, $9,38.0000,-77.0000$, $10,39.0000,-86.0000$, $11,35.0000,-81.0000$, $12,40.0000,-88.0000$, $13,41.0000,-84.0000$, $14,37.0000,-91.0000$, $15,41.0000,-76.0000$, $16,39.0000,-84.0000$, $17,37.0000,-80.0000$, $18,36.0000,-88.0000$, 19,41.0000, -82.0000:

SARRAYS:TERMNLS; 1 -25/NS/1,33.8,-84.2, ! ATLANTA, GA

$2,35.1,-80.9$, ! CHARLOTTE, NC

$3,41.8,-87.6$, ! CHICAGO, IL 4,32.6,-96.6, ! DALLAS, TX $5,42.3,-83.1$, ! DETROIT, MI $6,40.5,-74.4$, ! EAST BRUNSWICK, NJ $7,36.4,-77.5$, ! EMPORIA, VA $8,29.8,-95.1$, ! HOUSTON, TX $9,39.1,-94.7$, ! KANSAS CITY, MO 10,34.6,-92.3, ! LITTLE ROCK, AR $11,38.3,-85.7$, ! LOUISVILLE, KY $12,36.2,-94.1$, ! LOWELL, AR $13,35.1,-90.0$, ! MEMPHIS, TN 14,37.5,-121.0, ! MODESTO, CA $15,35.5,-97.5$, ! OKLAHOMA CITY, OK $16,33.5,-112.0$, ! PHOENIX, AZ 
$17,33.7,-118.3$, ! SOUTH GATE, CA

$18,43.0,-76.1$, ! SYRACUSE, NY

19,31.3,-83.5: ! TIFTON, GA

\$RUN-LENGTH=504: $\quad$ !504 would be 3 weeks

!NOTE: Data needs to have P/U times from 0 to RUN-LENGTH $+8 \mathrm{hrs}$

\$TRANSIENT-PERIOD $=336: \quad$ !336 would be 2 weeks

I\$TRACE $=0-504$ :

$\$ R U N S=18$ :

! Use these references for the WRITE(91) POST-RUN's

!

! WEEKEND: $\mathrm{OFF}=\mathrm{OF}=1, \quad \mathrm{ON}=\mathrm{ON}=2$

! DATA: BASELINE $=\mathrm{BS}=1,+20=\mathbf{2 0}=2, \quad$ POWELL $=\mathrm{WP}=3$

! HUBS: ORIGINAL $=\mathrm{OR}=1$, HUBFINDER $=\mathrm{HF}=2$, DOMFINDER $-\mathrm{DF}=3$

\$POST-RUN:1-18/ WRITE(91)=(WEEKEND,DATA,HUBS),
WRITE(92) $=($ END01,END02,END03,ENDO4)
WRITE(93) $=($ END05,END06,END07,END08),
WRITE $(94)=($ END09,END10,END11,END12),
WRITE $(95)=($ END13,END14,END15,END16),
WRITE $(96)=($ END17,END18,END19,END20),
WRITE(97)=(END21,END22,END23),

WRITE(99)=(WEEKEND,END03,END04,END11)\%: \$STOP: 


\title{
APPENDIX 2
}

\section{SIMNET Code: In Support of The Domicile Problem}

\author{
\$PROJECT;DOMICILE FINDER;3/1/06;ANTHONY HUMPHREY: \\ ! THIS PROGRAM FINDS ORIGINATING, DESTINATING, AND PASS-THRU \\ ! FREIGHT VOLUMES FOR ALL (1 DEGREE LAT.) BY (1 DEGREE LONG.) \\ ! GRID LOCATIONS. AN EXCEL BACK-END CAN EASILY BE USED TO SORT AND \\ ! WEIGHT DATA. \\ ! THIS PROGRAM WAS USED TO DETERMINE THE "BEST" 96 LAT-LONG SEED \\ ! CANDIDATES (BASED ON THE OUTBOUND, INBOUND, AND PASS-THRU SUMMATIONS \\ ! FOR EACH LAT-LONG HUB CANDIDATE). THE FINAL SORT AND SEED \\ ! DETERMINATIONS WERE CONDUCTED IN EXCEL.
}

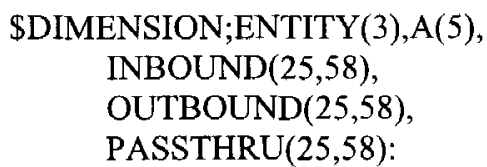

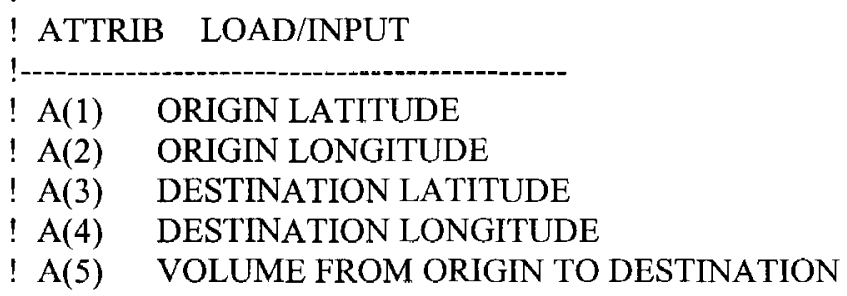

\$BEGIN:

INIT *S;1;1: ! DELAY ADDED TO SUPPORT DEBUGGING IN TRACE REPORT *B;TERM;; ! READ LANE INFORMATION

$\operatorname{READ}(60+\mathrm{RUN})=(\mathrm{A}(1), \mathrm{A}(2), \mathrm{A}(3), \mathrm{A}(4), \mathrm{A}(5))$,

CNTR $=$ CNTR $+1, \quad$ ! PROGRESS OUTPUT TO SCREEN

IF,MOD $($ CNTR, 100) $=0$, THEN, WRITE $(0)=(\mathrm{CNTR}), \mathrm{ENDIF}$,

IF, A(1)>0,THEN, ! IF MORE DATA IN FILE

AV_LAT $=(\mathrm{A}(1)+\mathrm{A}(3)) /(2 * 57.3)$,

$\mathrm{DIST}=((((67 *(\mathrm{~A}(1)-\mathrm{A}(3))) * * 2)+\&$

$\left.\left.\left(\left(67^{*} \operatorname{COS}\left(\mathrm{AV} \_L A T\right) *(\mathrm{~A}(2)-\mathrm{A}(4))\right)^{* *} 2\right)\right)^{* *}(1 / 2)\right)^{*} 1.17$,

IF,DIST $>$ PROX,THEN, ! FIND OUTBOUND GRID

LAT_OUT $=\mathrm{INT}(\mathrm{A}(1)+.5)-24$,

LONG_OUT=ABS(INT(A(2)-.5))-66, 


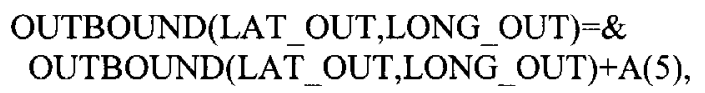

LAT_IN $=\mathrm{INT}(\mathrm{A}(3)+.5)-24, \quad$ ! FIND INBOUND GRID

LONG_IN=ABS(INT(A(4)-.5))-66,

INBOUND(LAT_IN,LONG_IN) $=\&$

INBOUND(LAT_IN,LONG_IN)+A(5),

IF,LAT_IN $>$ LAT_OUT,THEN, ! FIND PASSTHRU GRIDS

LAT_STR=LAT_OUT,

LAT_END $=\mathrm{LAT}_{-}^{-} \mathrm{N}$,

ELSE,

LAT STR=LAT IN,

LAT_END $=$ LAT_OUT,

ENDIF,

IF,LONG_IN $>$ LONG_OUT,THEN,

LONG_STR $=$ LONG_OUT,

LONG_END=LONG_IN,

ELSE,

LONG_STR=LONG_IN,

LONG_END=LONG_OUT,

ENDIF,

FOR,I=LAT STR,TO,LAT_END,DO,

FOR,J $=$ LONG_STR,TO,LONG_END,DO,

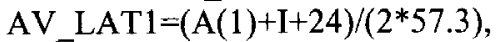

$\mathrm{AV}^{-} \mathrm{LAT} 2=(\mathrm{A}(3)+\mathrm{I}+24) /(2 * 57.3)$,

DIST $1=\left(\left(\left(\left(67^{*}(\mathrm{~A}(1)-\mathrm{I}-24)\right) * * 2\right)+\&\right.\right.$ ! DIST FROM ORIGIN

$\left.\left.\left(\left(67 * \operatorname{COS}(\text { AV L LAT1 })^{*}(\mathrm{~A}(2)+\mathrm{J}+66)\right)^{* *} 2\right)\right)^{* *}(1 / 2)\right)^{*} 1.17$,

DIST2 $=((((67 *(\mathrm{~A}(3)-\mathrm{I}-24)) * * 2)+\&$ ! DIST FROM DEST

$\left.\left.\left(\left(67^{*} \operatorname{COS}(\text { AV_LAT2 }) *(A(4)+\mathrm{J}+66)\right)^{* *} 2\right)\right)^{* *}(1 / 2)\right)^{*} 1.17$,

DIST $3=($ DIST $1+$ DIST 2$)-$ DIST,$\quad$ ! PASSTHRU DIST

IF,DIST $3<=$ CIRC,AND,DIST1 $>$ PROX,AND,DIST2 $>$ PROX,THEN,

$\operatorname{PASSTHRU}(\mathrm{I}, \mathrm{J})=\operatorname{PASSTHRU}(\mathrm{I}, \mathrm{J})+\mathrm{A}(5)$,

ENDIF,

NEXT,

NEXT,

ENDIF,

ELSE,

FOR,I $=1, T O, 25, \mathrm{DO}, \quad$ ! IF NO MORE DATA

FOR, J $=1, \mathrm{TO}, 58, \mathrm{DO}$,

WRITE $(80)=\left("(\mathrm{~F} 4.0, \mathrm{~F} 4.0, \mathrm{~F} 6.0, \mathrm{~F} 12.0, \mathrm{~F} 12.0, \mathrm{~F} 12.0)^{\prime \prime}, \&\right.$

RUN,I,J,INBOUND(I,J),PASSTHRU(I,J),OUTBOUND(I,J)),

NEXT,

NEXT,

SIM=STOP,

ENDIF\%:

\$END:

\$CONSTANTS: $1-10 / \mathrm{CIRC}=50, \quad$ ! MAX ALLOWABLE CIRCUITY

PROX $=50: \quad !$ MAX ALLOW DIST FROM HUB

!\$RUN-LENGTH=100:

\$RUNS $=1$ :

\$STOP: 
APPENDIX 3

LINGo Code: The Domicile Problem

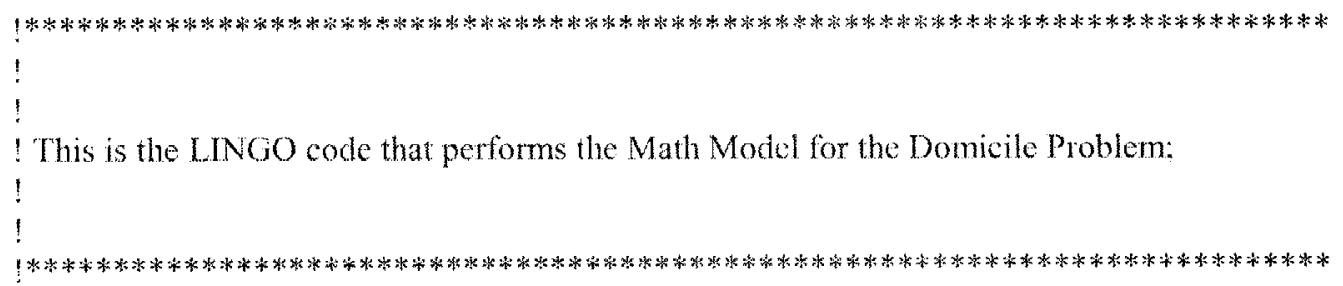

MODEL:

SETS:

LOAD:LatO,LonO, Latl,Lonl, Vol;

DOMICILE:LatD,LonD;

ClaimOB(LOAD,DOMICILE):OB;

ClaimIB(LOAD,DOMICILE):IB;

ClaimPT(LOAD,DOMICILE):PT;

DistIJ(LOAD):Dij;

DistIK(LOAD,DOMICILE):Dik;

DistJK(LOAD,DOMICILE):Djk;

\section{ENDSETS}

DATA:

Mileage Parameters -... in 1000 's of miles;

$\mathrm{RO}=0.05 ; \quad$ !50 Miles: Maximum allowable radius within which a Domicile may elaim freight as $\mathrm{OB}$ :

$\mathrm{RI}=0.05 ; \quad 150$ Miles: Maxinum allowable radius within which a Domicite may claim freight as IB:

$\mathrm{C}=0.05 ; \quad$ !50 Miles: Maximum allowable radius within which a Domicile may claim freight as PT;

MILES $=0.5 ; \quad 1500$ Miles: Miles that can be driven per driver per day;

ALPHA $=1 ; \quad$ !OUTBOUND WEIGHT:

BETA $=1 ; \quad$ !INBOUND WEIOHT;

GAMMA $=1 ; \quad$ IPASS THRU WEIGHT;

IVARIABLE NAMES;

LOAD $=\mathrm{IJ} 1 . . \mathrm{IJ} 500$;

DOMICILE $=\mathrm{K} 1 . . \mathrm{K} 96$; 
Import LOAD CHARACTERISTICS;

Import from External Text File;

! LatO $=$ Latitude of Load's Origin;

LonO $=$ Longitude of Load's Origin:

Latl - ..- Latitude of Load's Destination;

! Lonl - Longitude of Load's Destination;

! Vol - Volume for cach load (the number of loaded trips):

LatO, LonO, LatI, LonI, Vol=@FILE ('LOAD_DATA.txt');

IImport DOMICILE CHARACTERISTICS;

!mport from External Text File;

! LatD =- Latitude of Domicile Candidate;

! LonD $=$ Longitude of Domicile Candidate:

LatD, LonD = @FILE ('DOMICILE_DATA.txt');

\section{ENDDATA}

Maximize ;

MAX = @SUM(LOAD(ij): @SUM(DOMICILE(k): Dij(ij) *Vol(ij) * (ALPHA * OB(ij,k) + BETA * $\mathrm{IB}(\mathrm{ij}, \mathrm{k})+\mathrm{GAMMA} * \mathrm{PT}(\mathrm{ij}, \mathrm{k}))))$;

!f For each Load Origin ' $\mathrm{i}$ ' and for each Domicile ' $\mathrm{k}$ '.

!let $O B(i, k)$ be equal to 1 if $D i k(i, k)<=$ the allowable outbound radius $\mathrm{RO}$,

for force $O B(i, k)$ equal to 0 if $D i k(i, k)>$ the allowable outbound radius $R O$;

(a)FOR(LOAD(i):

(a)FOR(DOMICILE(k): Dik(i,k) * OB(i,k) <=RO));

IFor each Load Destination ' $\mathrm{j}$ ' and for each Domicile ' $k$ !,

let IB $(j, k)$ be equal to 1 if Dik $(j, k)<$ the allowable inbound radius RI,

tor force $I B(j, k)$ equal to 0 if $D j k(j, k)>$ the allowable inbound radius $R I$;

(a) $\mathrm{FOR}(\operatorname{LOAD}(\mathrm{j})$ :

(a)FOR(DOMICILE(k): Djk(j,k) * IB(j,k) <= RI));

IFor each Load Origin-Destination Pair 'ij' and for each Domicile ' $k$ '.

!let PT $(i j, k)$ be equal to 1 if the mileage from $i-k-j<$ the allowable circuity $c$,

lor force PT(ij,k) equal to 0 if the mileage from $i \cdot k . . . j>$ the allowable circuity $C$ :

@FOR(LOAD(ij):

(a)FOR(DOMICILE(k): 


$$
(\operatorname{Dik}(\mathrm{ij}, \mathrm{k})+\operatorname{Djk}(\mathrm{ij}, \mathrm{k})-\operatorname{Dij}(\mathrm{ij})) * \mathrm{PT}(\mathrm{ij}, \mathrm{k})<=\mathrm{C})) \text {; }
$$

tFor Each Domicile ' $k$ ', and for cach load 'ij',

the mileage can only be claimed, at most. one way (cither IB. OB, or PT);

@FOR(DOMICILE(k):

(a)FOR(LOAD(ij): OB(ij,k) + IB(ij,k) + PT(ij,k)<=1));

tFor Each Load 'ij,

the mileage can only be claimed by, at most. only one domicile;

$@$ FOR(LOAD(ij):

@SUM(DOMICILE(k): OB(ij,k) + IB(ij,k)+PT(ij,k))<=1);

tThis segment helps make the ownership assigmment and gives priority

!to those weights that are largest

!

!:

(a) FOR(LOAD(ij):

(a)FOR(DOMICILE(k):

IB(ij,k) <=@IF(Dik(ij,k) / ALPHA \#LT\# Djk(ij,k) / BETA, 0, 1)));

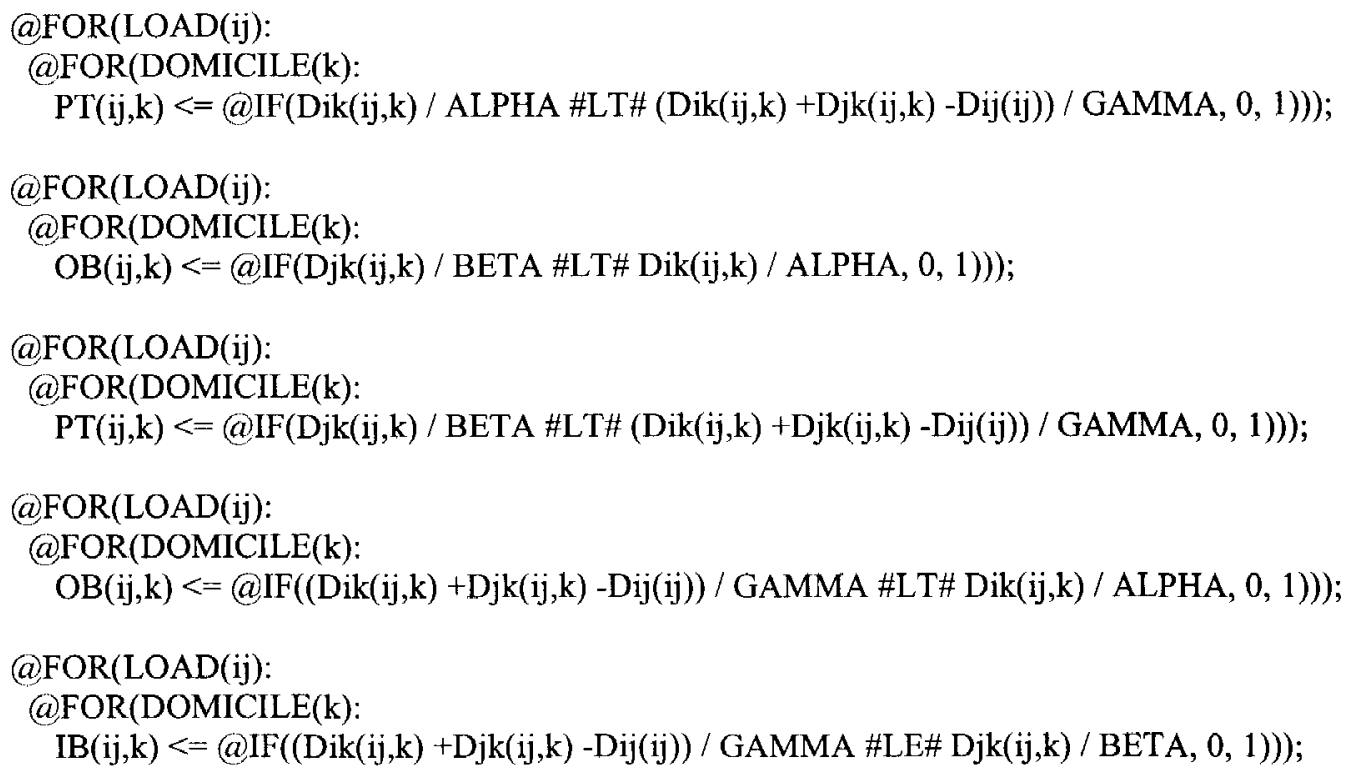


'Calculate the distances between Load Origin ' $i$ ' and Load Destination ' $\mathrm{j}$ '

Note: where ' $i$ ' equals 'i';

Divide by 1000 to scale down to 1000 's of miles;

@FOR(LOAD(i): Dij =(@)SQRT

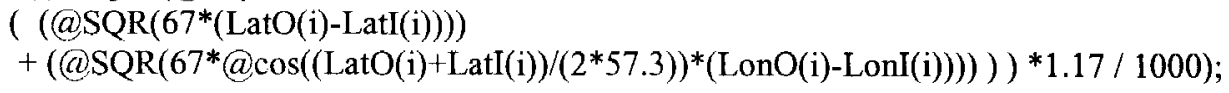

Calculate the distances between Load Origin ' $i$ ' and Domicile ' $k$ ';

Divide by 1000 to scale down to 1000 's of miles;

(a)FOR(LOAD(i):

@ $)$ FOR(DOMICILE $(\mathrm{k}):$ Dik $=((@) \mathrm{SQRT}$

( (@SQR(67*(LatO(i)-LatD(k))))

$+((a) \operatorname{SQR}(67 * @ \cos ((\operatorname{LatO}(\mathrm{i})+\operatorname{LatD}(\mathrm{k})) /(2 * 57.3)) *(\operatorname{LonO}(\mathrm{i})-\operatorname{LonD}(\mathrm{k})))))) * 1.17 /$

1000));

Calculate the distances between Load Destination ' $\mathrm{j}$ ' and Domicile ' $\mathrm{k}$ ':

!Divide by 1000 to scale down to 1000 's of miles;

@ $\mathrm{FOR}(\operatorname{LOAD}(\mathrm{j})$ :

(a)FOR(DOMICILE(k): Djk $=(@ S$ SQRT

( (@SQRR $\left.\left(67^{*}(\operatorname{LatI}(\mathrm{j})-\operatorname{LatD}(\mathrm{k}))\right)\right)$

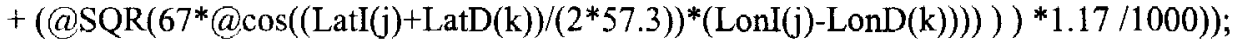

ISUMMARY STATISTICS:

TOTAL_MILES = $@ \operatorname{SUM}(\operatorname{LOAD}(\mathrm{ij}): \operatorname{Dij}(\mathrm{ij}) * \operatorname{Vol}(\mathrm{ij}))$;

OB_ML CLAIMED $=(@ \operatorname{SUM}(\operatorname{LOAD}(\mathrm{ij}): @ \operatorname{SUM}(\operatorname{DOMICILE}(\mathrm{k}): \operatorname{Dij}(\mathrm{ij}) * \mathrm{Vol}(\mathrm{ij}) * \mathrm{OB}(\mathrm{ij}, \mathrm{k})))$;

IB_ML_CLAIMED = @SUM(LOAD(ij): @SUM(DOMICILE(k): Dij(ij)*Vol(ij)*IB(ij,k)));

PT_ML_CLAIMED $=(\operatorname{SUM}(\operatorname{LOAD}(\mathrm{ij}):(\mathrm{SUM}(\mathrm{DOMICILE}(\mathrm{k}): \operatorname{Dij}(\mathrm{ij}) * \operatorname{Vol}(\mathrm{ij}) * \mathrm{PT}(\mathrm{ij}, \mathrm{k})))$;

MILES_CLAIMED $=$ OB_ML_CLAIMED + IB_ML_CLAIMED + PT_ML_CLAIMED;

MILES_DRIVEN $=@ \operatorname{SUM}\left(\operatorname{LOAD}(\mathrm{ij}): @ \operatorname{SUM}\left(\operatorname{DOMICILE}(\mathrm{k}): \operatorname{Vol}(\mathrm{ij}) *\left((\mathrm{PT}(\mathrm{ij}, \mathrm{k}))^{*}(\operatorname{Dik}(\mathrm{ij}, \mathrm{k})+\right.\right.\right.$ $\left.\left.\left.\mathrm{Djk}(\mathrm{ij}, \mathrm{k}))+(\mathrm{OB}(\mathrm{ij}, \mathrm{k})+(\mathrm{IB}(\mathrm{ij}, \mathrm{k})))^{*}(\mathrm{Dij}(\mathrm{ij}))\right)\right)\right)$;

END 


\section{APPENDIX 4}

\section{SIMNET Code: The Domicile Problem}

\section{\$PROJECT;DOMICILE;March 2006;ANTHONY HUMPHREY:}

$\begin{array}{cc}\text { \$DIMENSION;ENTITY }(5000), & \text { ! ENTITY INFO } \\ \text { A }(6), & \text { ! LOAD CHARACTERISTICS } \\ \text { HUB }(96,3), & \text { ! HUB CHARACTERISTICS } \\ \text { DAYS }(12), & \text { ! Number Days Per Month }\end{array}$

!SUMMARY ARRAYS...

!NOTE: There are only 96 HUBS, but, in the following arrays, !row '97' sums each column of statistics (across all HUBs), and 'column '4' sums each row of statistics (across each individual HUB).
ALL_RTD(97,5),!Holds ROUTES (Contains DUPLICATE HUB Claims) ALL_LDD(97,5),!Holds LOADS (Contains DUPLICATE HUB Claims) ALL_MID(97,5),!Holds MILES (Contains DUPLICATE HUB Claims)
ALL_RT $(97,6)$, !Holds ROUTES (Contains NO Duplicates) ALL_LD $(97,6)$, !Holds LOADS (Contains NO Duplicates) ALL_MI $(97,6)$, !Holds MILES (Contains NO Duplicates) ALL_DR(97),

!The arrays above are similar... However the 'ALL_xxD' arrays contains !all possible claims by all possible HUBS... therefore the totals !containted therein are inflated because multiple HUBs may actually !claim the same loads.

!(Remember... these are the "NO OWNERSHIP" models.

!However, the 'ALL $\mathrm{xx}^{\prime}$ arrays contain the same type of information, !but their are no duplicates. It just shows the specific miles that !could be claimed. These arrays should have similar or identical !values to the 'OWN_xx' arrays.

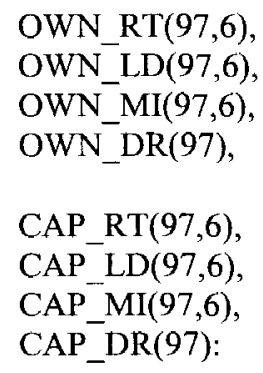


!\$ATTRIBUTES;

\$VARIABLES;

TOT_ROUT;;TOT_RT:

TOT_LOAD;;TOT_LDS:

TOT_MILE;;TOT_MI;

! TOTAL NON-LOCAL ROUTES

! TOTAL NON_LOCAL LOADS

! TOTAL NON-LOCAL MILES

OWN_PCT_RT;;OWN_RT $(97,4) / T O T \_R T * 100:$ ! \% ROUTES USED BY HUBS OWN PCT_LD; OWN_LD(97,4)/TOT_LDS* $100: ! \%$ LOADS USED BY HUBS OWN_PCT_MI;;OWN_MI $(97,4) / T O T \_M I * 100: ! \%$ MILES USED BY HUBS

ALL_RTD; ALL RTD $(97,4)$ :

$\mathrm{ALL}$ LDD; $; \mathrm{ALL} \operatorname{LDD}(97,4)$ :

ALL MID;;ALL MID $(97,4)$ :

ALL_MID_DV; $;$ ALL_MID $(97,5)$ :

ALL_RT;;ALL_RT(97,4):

ALL_LD;;ALL_LD $(97,4)$ :

ALL_MI;ALL_MI $(97,4)$ :

OWN_RT;;OWN_RT $(97,4): \quad$ ! \# ROUTES 'USED' BY HUBS

OWN_LD; OWN_LD $(97,4)$ : ! \# LOADS 'USED' BY HUBS

OWN_MI;;OWN_MI $(97,4)$ : ! \# MILES 'USED' BY HUBS

OWN_M_IMB;;OWN_MI(97,5): ! ABSOLUTE DEVIATION (IMBALANCE)

O_M_DRIVEN;;OWN_MI $(97,6):$ ! \# MILES 'DRIVEN'

CAP_RT;;CAP_RT $(97,4): \quad$ ! \# ROUTES 'USED' BY HUBS

CAP_LD; CAP_LD $(97,4): \quad$ ! \# LOADS 'USED' BY HUBS

CAP_MI;

CAP_M_IMB;;CAP_MI $(97,5): !$ ABSOLUTE DEVIATION (IMBALANCE)

C_M_DRIVEN;;CAP_MI $(97,6)$ : ! \# MILES 'DRIVEN'

ROUT_OTR;;RT_OTR: ! \# UN-USED ROUTES (i.e. "OTR")

LOAD_OTR;;LDS_OTR: ! \# UN-USED LOADS (i.e. "OTR")

MILE_OTR;;MI_OTR: ! \# UN-USED MILES (i.e. "OTR")

ALL_OB_MI;;ALL_MID(97,1): ! 'OB' NON-OWNERSHIP MILES

ALL_IB_MI;;ALL_MID(97,2): ! 'IB' NON-OWNERSHIP MILES

ALL_PT_MI; $;$ ALL_MID $(97,3):$ ! 'PT' NON-OWNERSHIP MILES

OWN_OB_MI; OWN_MI $(97,1)$ ! ! 'OB' OWNERSHIP MILES

OWN_IB_MI; OWN_MT $(97,2): \quad$ ! 'IB' OWNERSHIP MILES

OWN_PT_MI; OWN_MI $_{-}(97,3): \quad$ ! 'PT' OWNERSHIP MILES

CAP_OB_MI;;CAP_MI $(97,1): \quad$ ! 'OB' OWNERSHIP MILES

CAP_IB_MI; CAP_MI $(97,2): \quad$ ! 'IB' OWNERSHIP MILES

CAP_PT_MI;;CAP_MI $(97,3): \quad$ ! 'PT' OWNERSHIP MILES

HB_MI_OWN(1-97);;OWN_MI(I,4):

HB_MI_CAP(1-97); CAP_M $\mathrm{M}(\mathrm{I}, 4)$ :

HB_DR_OWN(1-97); OWN_DR(I):

HB_DR_CAP(1-97);;CAP_DR(I):

OTR_DR;;OTR_MI/DAYS(RUN)/MI_DR_DY: ! \# OF OTR DRIVERS 


\begin{tabular}{|c|c|}
\hline ! LOAD CF & HARACTERISTICS \\
\hline ! NUMBER & CONTENTS \\
\hline ! $A(1)$ & LOAD ORIGIN LATITUDE \\
\hline ! $A(2)$ & LOAD ORIGIN LONGITUDE \\
\hline ! $A(3)$ & LOAD DESTINATION LATITUDE \\
\hline ! A(4) & LOAD DESTINATION LONGITUDE \\
\hline ! $A(5)$ & LOAD VOLUME (i.e. \# Trips OR Loads \\
\hline ! A(6) & LOAD NUMBER \\
\hline
\end{tabular}

!

! ARRAY for 'HUB' CHARACTERISTICS

! NUMBER CONTENTS

! HUB(i,1) DOMICILE NUMBER

! HUB(i,2) DOMICILE LATITUDE

! HUB(i,3) DOMICILE LONGITUDE

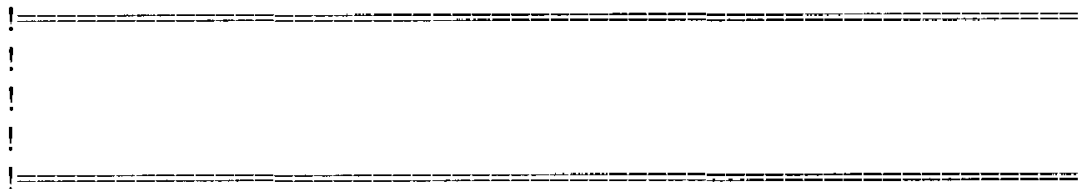

! $\sim$ SUMMARY ARRAY CHARACTERISTICS: For $\mathrm{i}=1-97$

\section{! NUMBER CONTENTS}

$! \operatorname{xxxx(i,1)}$ OutBound (OB) Values for HUB ' $i$ '

$! \operatorname{xxxx}(i, 2) \quad$ InBound (IB) Values for HUB ' $i$ '

$! \operatorname{xxxx}(i, 3) \quad$ PassThru (PT) Values for HUB ' $i$ '

$! \operatorname{xxxx}(i, 4) \quad$ Summary $(O B+I B+P T)$ Values for HUB ' $i$ '

$! \operatorname{xxxx}(i, 5) \quad$ Imbalance: Absolute Devation for HUB ' $i$ '

! Imbalance $=(\mathrm{ABS}(\mathrm{OB}-\mathrm{IB}))$

$! \operatorname{xxxx}(i, 6) \quad$ Miles Driven To Support OB,IB,PT Claims

!

$!=$

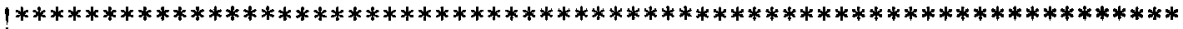

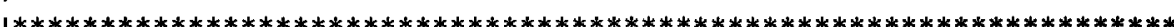

\$BEGIN:

INIT *S;1;1: ! DELAY ADDED TO SUPPORT DEBUGGING IN TRACE REPORT *B;STATCALC/1;QUIT=YES?: !SIM FINISHED... QUIT AND CALCULATE *B;TERM $/ 1 ; \mathrm{QUIT}=$ NO?; $\quad$ !SIM CONTINUES...

!"\%\%\%\%\%\%\%\%\%\%\%\%\%\%\%\%\%\%\%\%\%\%\%\%\%\%\%\%\%\%\%\%\%\%\%\%\%\%\%\%\%\%\%\%\%\%\%\%\%\% $\% \% \% \% \% \% \% \% \% \% \% \% "$

!"\%\%\%\%\%" GENERAL CALCULATIONS "\%\%\%\%\%" 
!"\%\%\%\%\%\%\%\%\%\%\%\%\%\%\%\%\%\%\%\%\%\%\%\%\%\%\%\%\%\%\%\%\%\%\%\%\%\%\%\%\%\%\%\%\%\%\%\%\%\% $\% \% \% \% \% \% \% \% \% \% \% "$

!READ LOAD AND DETERMINE LOAD OWNERSHIP NUM_LDS $=$ NUM_LDS +1 ,

!KEEP TRACK OF SIMULATION PROGRESS AND WRITE TO SCREEN

MONTH=MOD(RUN, 12),

IF,MONTH=0,THEN,MONTH=12,ENDIF,

DATA $=\mathbf{I N T}(\mathrm{RUN} / 12)$

IF,MOD(RUN, 12) $>0$, THEN,DATA=DATA+1,ENDIF,

IF,MOD(NUM LDS, 100) $=0$, THEN,

WRITE $(0)=("(/ / 5 x$, DATA \# ',f5.0,', LOAD \# ',f5.0)",DATA,NUM_LDS),

WRITE $(0)=("(/ / 10 \mathrm{x}$, MONTH \# ',f5.0)",MONTH),

ENDIF,

$\operatorname{READ}(20+\mathrm{RUN})=(\mathrm{A}(1), \mathrm{A}(2), \mathrm{A}(3), \mathrm{A}(4), \mathrm{A}(5))$,

$\mathrm{A}(1)=\mathrm{A}(1)$,

$A(2)=A(2)$,

$\mathrm{A}(3)=\mathrm{A}(3)$,

$\mathrm{A}(4)=\mathrm{A}(4)$,

$A(5)=A(5)$,

$A(6)=$ NUM_LDS,

IF,A(1)>0,THEN, $\quad$ ! IF MORE DATA IN FILE,

USED $=$ NO, $\quad$ ! RESET

!CALCULATE DISTANCE FROM OUTBOUND to INBOUND

$\mathrm{AV}$ LAT $=(\mathrm{A}(1)+\mathrm{A}(3)) /(2 * 57.3)$,

$\mathrm{dOI}=\left(\left(((67 *(\mathrm{~A}(1)-\mathrm{A}(3))))^{* * 2}\right)+\&\right.$

$((67 * \operatorname{COS}(\mathrm{AV} \mathrm{LAT}) *(\mathrm{~A}(2)-\mathrm{A}(4))) \&$

$\left.* * 2))^{* *}(1 / 2)\right)^{*} 1.17 / 1000$, !Divide by 1000 to convert

!Miles to Thousands of Miles

IF, dOI $>$ PROX,THEN,

TOT_RT $=$ TOT_RT +1 ,

TOT LDS $=$ TOT_LDS + A $(5)$,

TOT_MI $=$ TOT_MI $+\left(\mathrm{dOI}^{*} \mathrm{~A}(5)\right)$,

!RESET "OWNERSHIP" VARIABLES (BEFORE LOOPING THROUGH HUBS)

OB OWNER $=0, \quad$ ! POTENTIAL HUB OWNING OUTBOUND FREIGHT

IB OWNER $=0, \quad$ ! POTENTIAL HUB OWNING INBOUND FREIGHT

PT_OWNER=0, ! POTENTIAL HUB OWNING PASSTHRU FREIGHT

BST_dOH $=77777$, ! "BEST" DISTANCE from OB to HUB

BST_dIH=88888, ! "BEST" DISTANCE from IB to HUB

BST_dC $=99999$, ! "BEST" CIRCUITY from IB to OB via HUB

BST_dPT $=0$,

!RESET "CAPACITATED" VARIABLES (BEFORE LOOPING THROUGH HUBS) 
OB_OWNER_C $=0, \quad$ ! POTENTIAL HUB OWNING OUTBOUND FREIGHT

IB OWNER $\overline{\mathrm{C}}=0, \quad$ ! POTENTIAL HUB OWNING INBOUND FREIGHT

PT OWNER $\mathrm{C}=0, \quad$ ! POTENTIAL HUB OWNING PASSTHRU FREIGHT

BST_dOH_C $=77777$, ! "BEST" DISTANCE from OB to HUB

BST_dIH_C $=88888$, ! "BEST" DISTANCE from IB to HUB

BST_dC_C $=99999$, ! "BEST" CIRCUITY from IB to OB via HUB

BST_dPT_C $=0$,

!Each of the three 'BST' values should be set arbitrarily high, but

!they are not equal so they do not conflict with 'SCORE' calculations.

FOR,I=1,TO,NUM_HUBS,DO,

!CALCULATE OUTBOUND DISTANCE (from OUTBOUND to HUB)

AV_LAT $=(\mathrm{A}(1)+\mathrm{HUB}(\mathrm{I}, 2)) /(2 * 57.3)$,

$\mathrm{dO} \overline{\mathrm{H}}=\left(\left(\left(\left(67^{*}(\mathrm{~A}(1)-\mathrm{HUB}(\mathrm{I}, 2))\right)\right)^{* *} 2\right)+\&\right.$

$\left(\left(67^{*} \mathrm{COS}\left(\mathrm{AV} \_\mathrm{LAT}\right)^{*}(\mathrm{~A}(2)-\mathrm{HUB}(\mathrm{I}, 3))\right) \&\right.$

$\left.* * 2))^{* *}(1 / 2)\right)^{*} 1.17 / 1000$,!Divide by 1000 to convert

!Miles to Thousands of Miles

!CALCULATE INBOUND DISTANCE (from INBOUND to HUB)

$\mathrm{AV}$ LAT $=(\mathrm{A}(3)+\mathrm{HUB}(\mathrm{I}, 2)) /(2 * 57.3)$,

$\mathrm{dIH}=((((67 *(\mathrm{~A}(3)-\mathrm{HUB}(\mathrm{I}, 2))) * * 2)+\&$

$\left(\left(67^{*} \mathrm{COS}(\mathrm{AV} \mathrm{LAT}) *(\mathrm{~A}(4)-\mathrm{HUB}(\mathrm{I}, 3))\right) \&\right.$

$\left.* * 2))^{* *}(1 / 2)\right)^{*} 1.17 / 1000$,!Divide by 1000 to convert

!Miles to Thousands of Miles

!CALCULATE PASSTHRU DISTANCE (from OUTBOUND to INBOUND via HUB) $\mathrm{dPT}=\mathrm{dOH}+\mathrm{dIH}$,

!CALCULATE PASSTHRU CIRCUITY (the out of route miles)

$\mathrm{dC}=\mathrm{dPT}-\mathrm{dOI}$,

!IF A SINGLE HUB HAS MULTIPLE OB, IB, AND PT CLAIMS ON THE SAME LOAD, !DETERMINE WHICH ONE ('BEST FIT') SHOULD ACTUALLY CLAIM THE MILES !OB, IB, AND PT WEIGHTS ALSO COME TO PLAY IN THE DETERMINATION.

IF, W tOB $>0$, THEN,

OB_SCORE $=(1-\mathrm{WtOB}) * \mathrm{dOH}$,

ELSE,,$\quad$ !ELIMINATE CONSIDERATION FOR WEIGHTS OF "0"

OB SCORE $=999999$,

ENDIF,

IF, WtIB $>0$, THEN,

IB SCORE $=(1+$ WtIB $) *$ dIH,

ELSE, !ELIMINATE CONSIDERATION FOR WEIGHTS OF " 0 "

IB SCORE $=999999$,

ENDIF,

IF, WtPT $>0$, THEN, PT_SCORE $=(1-\mathrm{WtPT}) * \mathrm{dC}$,

ELSE, !ELIMINATE CONSIDERATION FOR WEIGHTS OF " 0 "

PT SCORE $=999999$,

ENDIF,

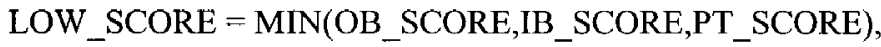




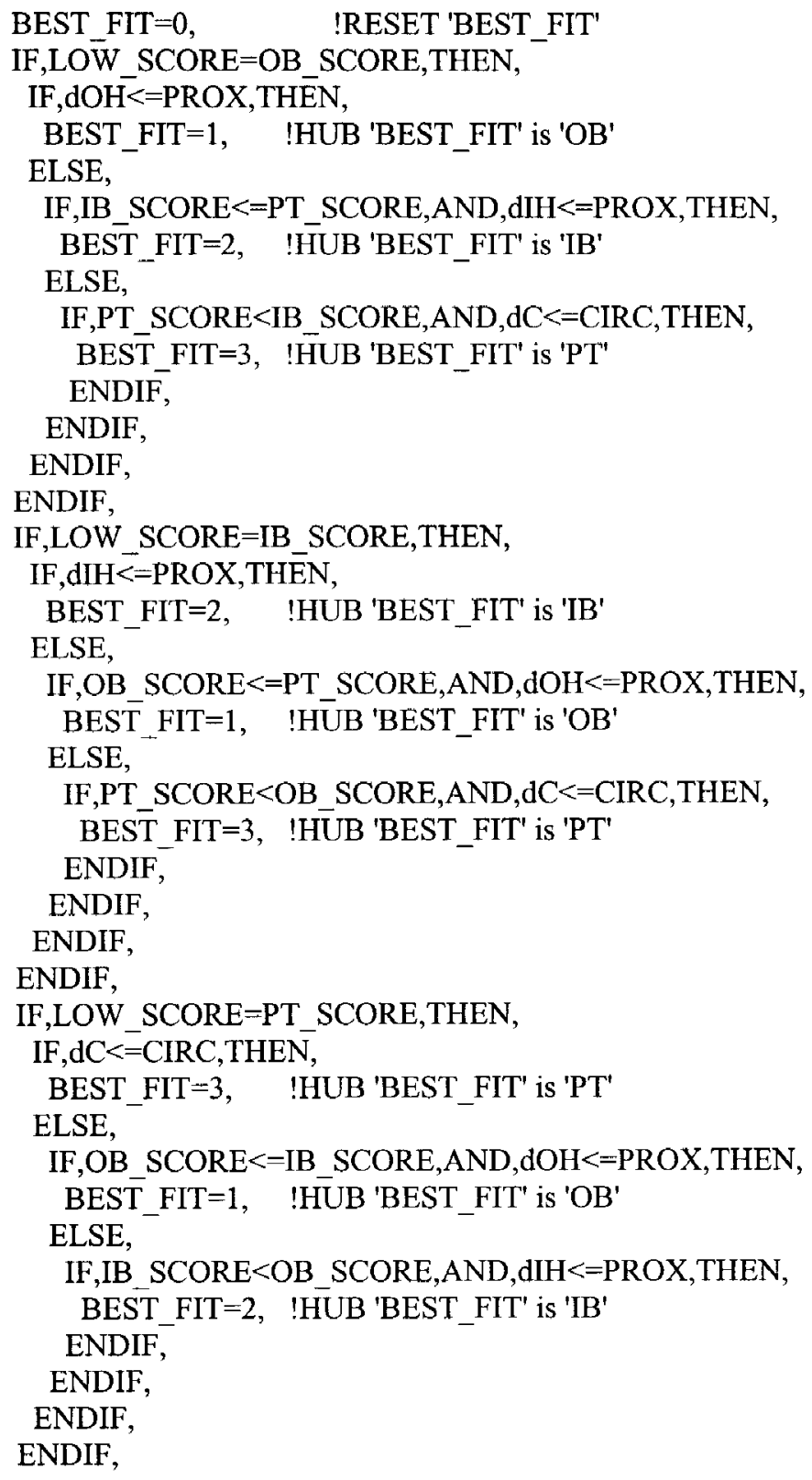

!"\%\%\%\%\%\%\%\%\%\%\%\%\%\%\%\%\%\%\%\%\%\%\%\%\%\%\%\%\%\%\%\%\%\%\%\%\%\%\%\%\%\%\%\%\%\%\%\%\%\%\%\%\%\%\%\% $\% \% \% \% \% \% \% \% \% \% \% \%$

!" $\% \% \% \% \% \% "$ N O OW NERSHIP S E G M N T " $\% \% \% \% \% \% "$

!" $\% \% \% \% \% \% \% \% \% \% \% \% \% \% \% \% \% \% \% \% \% \% \% \% \% \% \% \% \% \% \% \% \% \% \% \% \% \% \% \% \% \% \% \% \% \% \% \% \% \% \% \%$ $\% \% \% \% \% \% \% \% \% \% \% "$

!MAKE "NO OWNERSHIP" DETERMINATIONS AND ASSIGNMENTS

!MAKE SURE EACH HUB IS ASSIGNED, AT MOST, ONLY ONE OB, IB, or PT

!RELATIONSHIP PER LOAD.

!HOWEVER...

$! \quad$...MULTIPLE HUBS MAY ACTUALLY CLAIM THE SAME LOAD.

IF,BEST_FIT >0,THEN, 


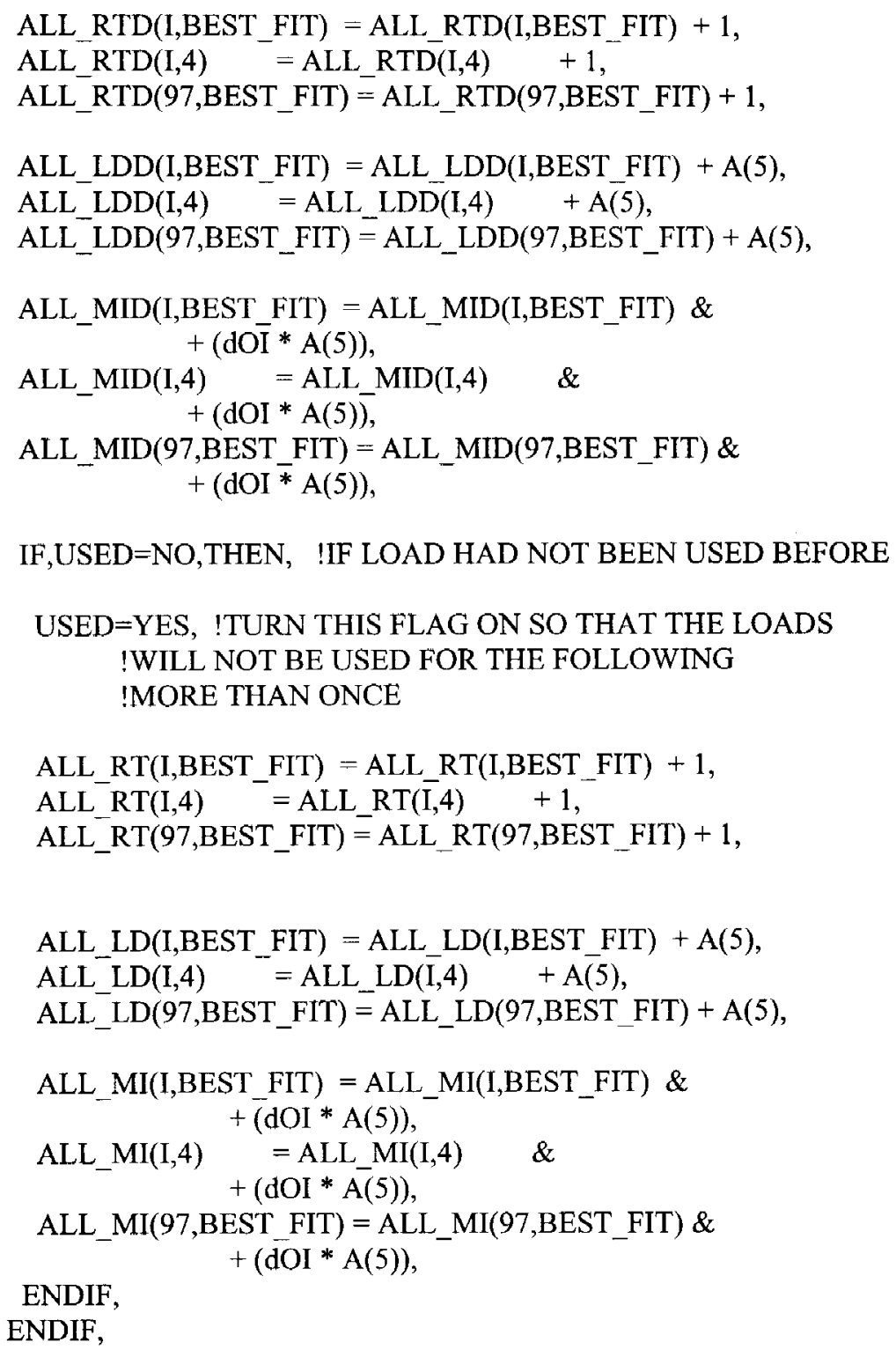

!MAKE PRELIMINARY "OWNERSHIP" DETERMINATIONS

!DETERMINE IF CURRENT HUB IS THE "BEST OUTBOUND-HUB" CANDIDATE IF,BEST FIT $=1$, THEN, IF,dOH<BST_dOH,THEN, OB_OWNER $=\mathrm{I}$, BST $\mathrm{dOH}=\mathrm{dOH}$, ENDIF, ENDIF,

!DETERMINE IF CURRENT HUB IS THE "BEST INBOUND-HUB" CANDIDATE IF,BEST_FIT $=2$, THEN, IF,dIH<BST_dIH,THEN, IB_OWNER $=$ I, BST_dIH=dIH, ENDIF, 
ENDIF,

!DETERMINE IF CURRENT HUB IS THE "BEST PASS THRU-HUB" CANDIDATE IF,BEST_FIT $=3$, THEN,

IF, dC $<$ BST dC,THEN,

PT OWNER=I,

BST $\mathrm{dC}=\mathrm{dC}$,

BST $d P T=d P T$,

ENDIF,

ENDIF,

!MAKE PRELIMINARY "CAPACITATED" DETERMINATIONS

!DETERMINE IF CURRENT HUB IS THE "BEST OUTBOUND-HUB" CANDIDATE !ALSO MAKE SURE NOT TO VIOLATE THE MAXIMUM DRIVER CONSTRAINT

!Calculate number of DRIVERS at HUB if HUB would end up claiming load.

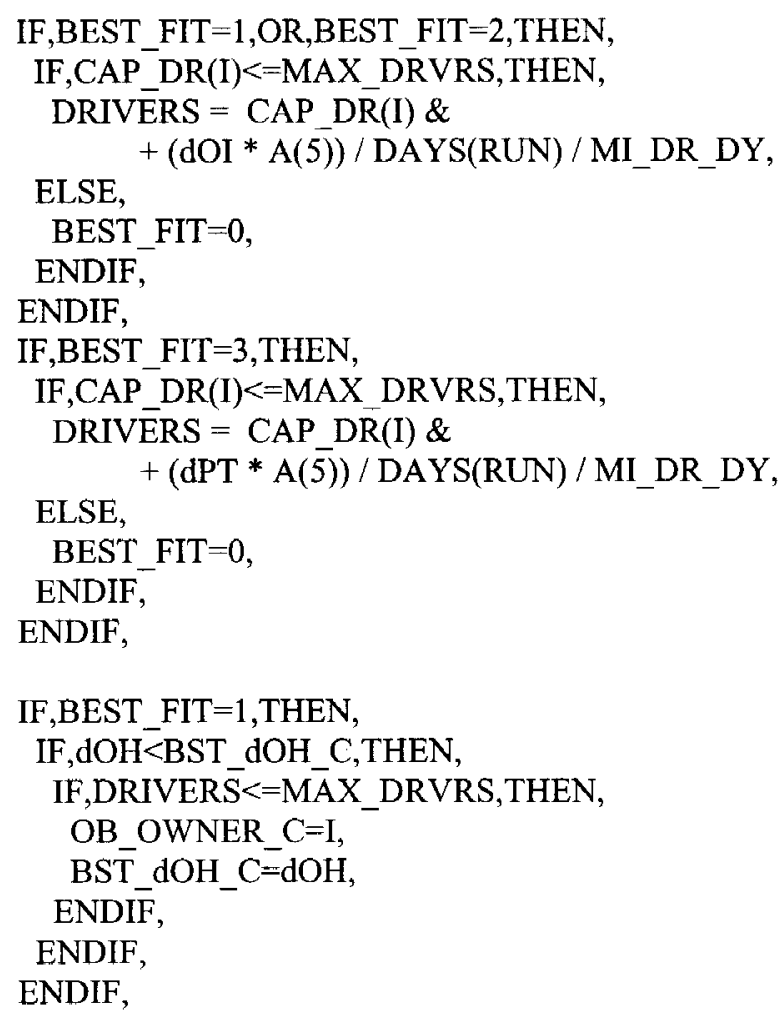

!DETERMINE IF CURRENT HUB IS THE "BEST INBOUND-HUB" CANDIDATE

!ALSO MAKE SURE NOT TO VIOLATE THE MAXIMUM DRIVER CONSTRAINT IF,BEST_FIT $=2$, THEN,

IF,dIH<BST_dIH_C,THEN,

IF,DRIVERS $<=\bar{M} A X \_D R V R S, T H E N$,

IB_OWNER_C $=$ I,

BST_dIH_C $=$ dIH,

ENDIF,

ENDIF,

ENDIF,

!DETERMINE IF CURRENT HUB IS THE "BEST PASS THRU-HUB" CANDIDATE 


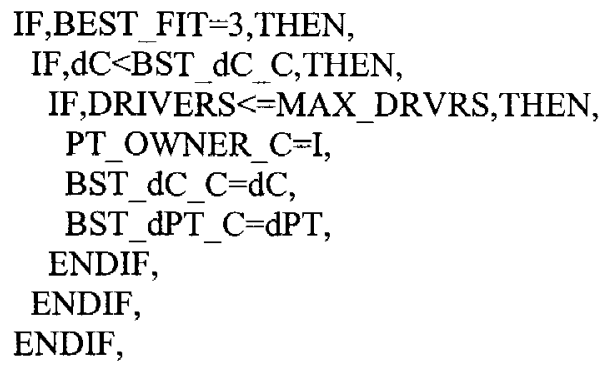

NEXT, INEXT "I" -- The Hub Loop

\begin{abstract}
!"\%\%\%\%\%\%\%\%\%\%\%\%\%\%\%\%\%\%\%\%\%\%\%\%\%\%\%\%\%\%\%\%\%\%\%\%\%\%\%\%\%\%\%\%\%\%\%\%\%\% $\% \% \% \% \% \% \% \% \% \% \% \% "$

!" $\% \% \% \% \% \% " \quad$ O W NERSHIP $\quad$ S E GMEN T $\quad " \% \% \% \% \% \% "$

!"\%\%\%\%\%\%\%\%\%\%\%\%\%\%\%\%\%\%\%\%\%\%\%\%\%\%\%\%\%\%\%\%\%\%\%\%\%\%\%\%\%\%\%\%\%\%\%\%\%\%\% $\% \% \% \% \% \% \% \% \% \% \% \% "$
\end{abstract}

!MAKE "OWNERSHIP" ASSIGNMENTS (CONSIDERING "BEST" of the "BESTS")

!FIRST OF ALL... SEE IF ANY "BESTS" EXIST,

!THEN DETERMINE WHICH OF "THE BEST" WILL GET TO OWN THE FREIGHT.

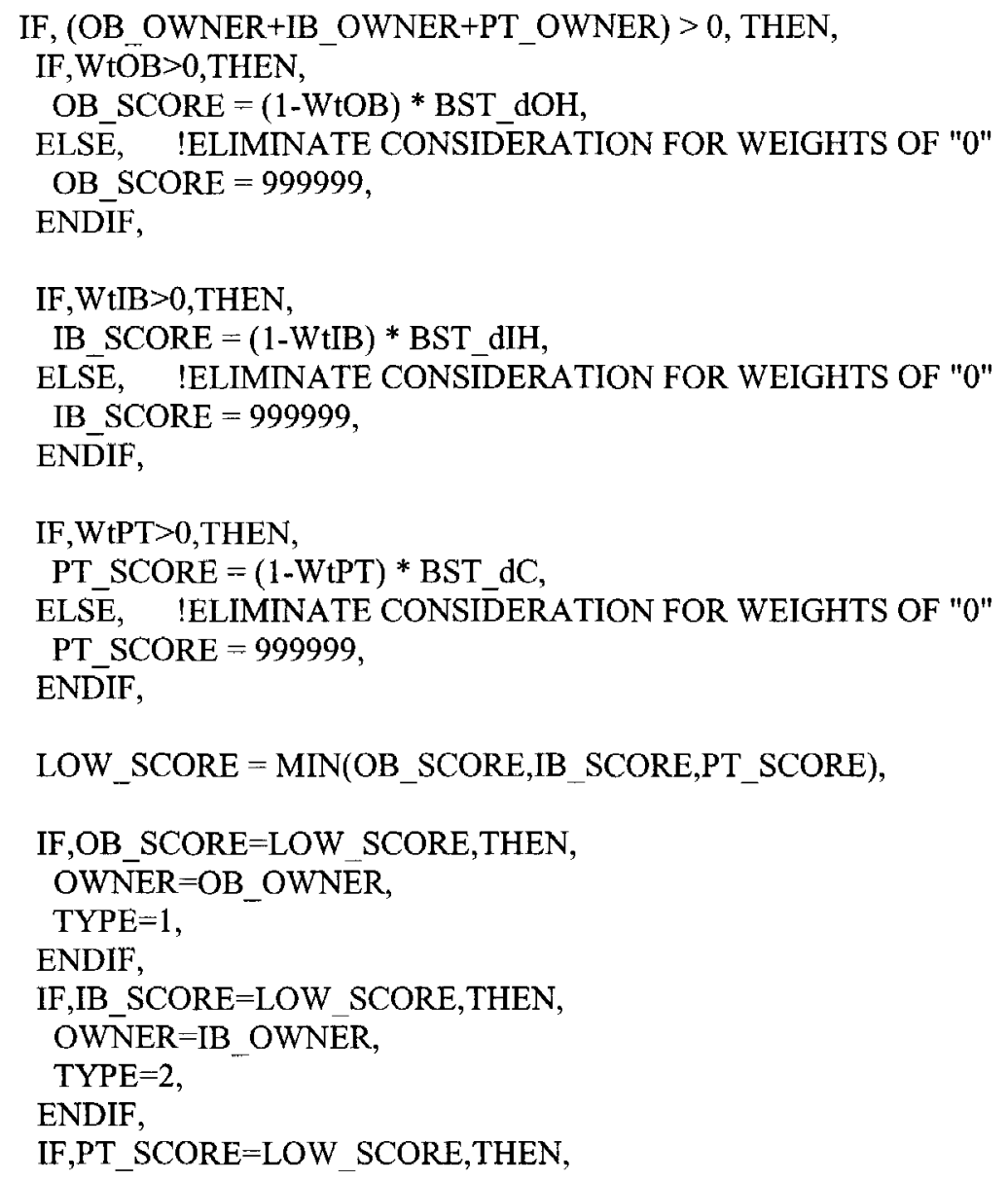




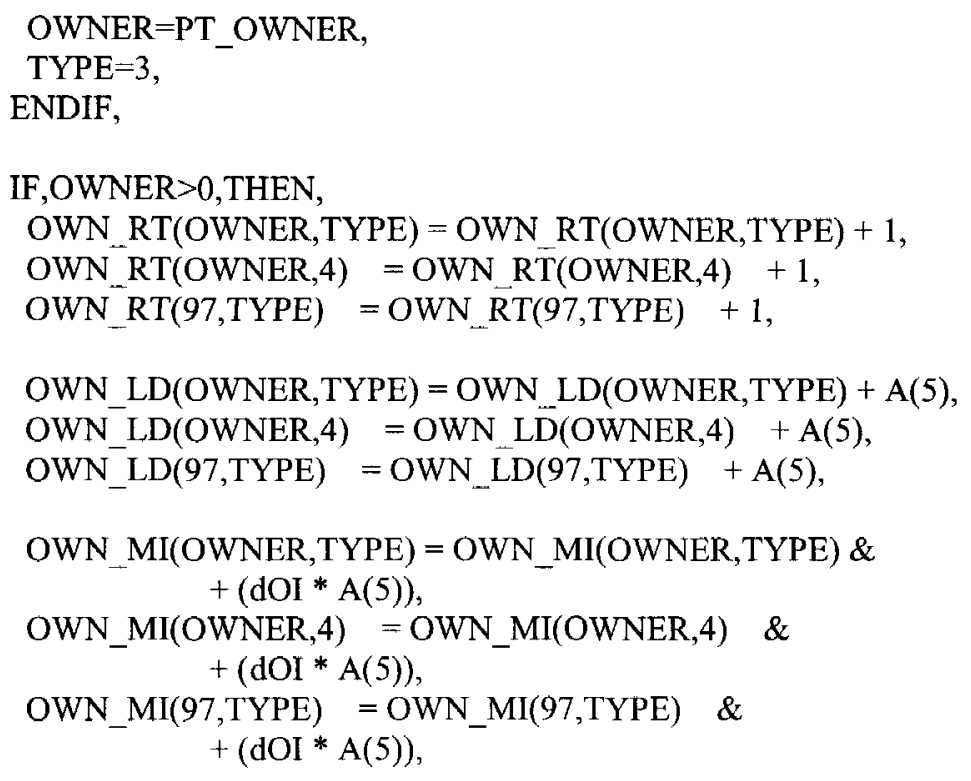

!UPDATE ACTUAL MILES DRIVEN

IF,TYPE=1,OR,TYPE=2,THEN, !MILES USED 'OB' OR 'IB'? OWN_MI $($ OWNER,6) $=$ OWN_MI $($ OWNER,6) $+($ dOI * A (5)), OWN_MI $(97,6)=$ OWN_MI $(97,6)+(\mathrm{dOI} * \mathrm{~A}(5))$, DRIVERS $=(\mathrm{dOI} * \mathrm{~A}(5)) / \mathrm{DAYS}(\mathrm{RUN}) / \mathrm{MI} D \mathrm{DR}$ DY , ENDIF,

IF,TYPE=3,THEN, !MILES USED 'PT'? $\mathrm{dPT}=\mathrm{BST}$ dPT, OWN_MI $(\bar{O} W N E R, 6)=$ OWN_MI $($ OWNER,6) $+(\mathrm{dPT} * \mathrm{~A}(5))$, OWN_MI $(97,6)=$ OWN_MI $(97,6)+(\mathrm{dPT} * \mathrm{~A}(5))$, DRIVERS $=(\mathrm{dPT} * \mathrm{~A}(5)) / \mathrm{DAYS}(\mathrm{RUN}) / \mathrm{MI}$ DR_DY, ENDIF,

!UPDATE NUMBER OF DRIVERS NEEDED OWN_DR(OWNER) $=$ OWN_DR(OWNER $)+$ DRIVERS, OWN_DR(97) $=$ OWN_DR(97) + DRIVERS,

ENDIF,

ELSE, RT_OTR $=$ RT_OTR +1 , LDS OTR $=$ LDS_OTR $+A(5)$, MI OTR $=$ MI_OTR $+\left(\mathrm{dOI}^{*} \mathrm{~A}(5)\right)$,

ENDIF,

!" $\% \% \% \% \% \% \% \% \% \% \% \% \% \% \% \% \% \% \% \% \% \% \% \% \% \% \% \% \% \% \% \% \% \% \% \% \% \% \% \% \% \% \% \% \% \% \% \% \% \% \%$ $\% \% \% \% \% \% \% \% \% \% \% \% "$

!"\%\%\%\%\%\%" CAPACITA T E D S E G M E T T $\quad$ "\%\%\%\%\%\%"

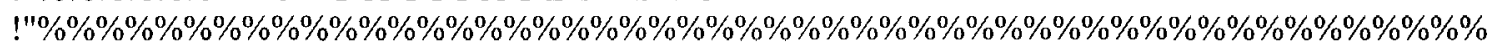
$\% \% \% \% \% \% \% \% \% \% \% \%$

!MAKE "CAPACITATED OWNERSHIP" ASSIGNMENTS

!CONSIDERING "BEST" of the "BESTS", BUT DO NOT VIOLATE MAX_DR LIMITS.

!FIRST OF ALL... SEE IF ANY "BESTS" EXIST, 
!THEN DETERMINE WHICH OF "THE BEST" WILL GET TO OWN THE FREIGHT.

!MAKE SURE THAT THE 'MAX_DRVRS' CONSTRAINT HAS NOT BEEN OR WILL !NOT BE EXCEEDED

IF, (OB_OWNER_C+IB_OWNER_C+PT_OWNER_C $)>0$, THEN,

IF, WtOBB $>0$, THEN,

OB_SCORE $=(1-\mathrm{WtOB}) *$ BST_dOH_C,

ELSE, !ELIMINATE CONSIDERATION FOR WEIGHTS OF "0"

OB SCORE $=999999$,

ENDIF,

IF, WtIB $>0$, THEN,

IB_SCORE $=(1-\mathrm{WtIB}) *$ BST dIH C,

ELSE, !ELIMINATE CONSIDERATION FOR WEIGHTS OF "0" IB_SCORE $=999999$,

ENDIF,

IF, WtPT $>0$, THEN,

PT_SCORE $=(1-\mathrm{WtPT}) *$ BST_dC_C,

ELSE, !ELIMINATE CONSIDERATION FOR WEIGHTS OF " 0 "

PT SCORE $=999999$,

ENDIF,

LOW_SCORE $=$ MIN(OB_SCORE,IB_SCORE,PT_SCORE),

IF,OB_SCORE=LOW_SCORE,THEN,

OWNER=OB_OWNER_C,

TYPE $=1$,

ENDIF,

IF,IB SCORE=LOW SCORE,THEN,

OWNER=IB_OWNER_C,

TYPE $=2$,

ENDIF,

IF,PT_SCORE=LOW_SCORE,THEN, OWNER=PT_OWNER_C,

TYPE $=3$,

ENDIF,

IF, OWNER $>0$, THEN,

CAP_RT $($ OWNER,TYPE $)=$ CAP_RT $($ OWNER,TYPE $)+1$,

CAP RT(OWNER,4) = CAP RT $($ OWNER,4) +1 ,

CAP_RT $(97, T Y P E)=$ CAP_RT $(97$, TYPE $)+1$,

CAP LD $($ OWNER, TYPE $)=$ CAP _LD $($ OWNER,TYPE $)+A(5)$,

CAP_LD(OWNER,4) = CAP_LD $($ OWNER,4) + A(5),

CAP_LD $(97$, TYPE $)=$ CAP_LD $(97$, TYPE $)+A(5)$,

CAP_MI $($ OWNER,TYPE $)=$ CAP_MI $($ OWNER,TYPE $) \&$ $+(\mathrm{dOI} * \mathrm{~A}(5))$,

CAP_MI $($ OWNER,4) = CAP_MI $(O W N E R, 4) \quad \&$ $+(\mathrm{dOI} * \mathrm{~A}(5))$,

CAP_MI $(97$, TYPE $) \quad=$ CAP_MI $(97$, TYPE $) \quad \&$ $+(\mathrm{dOI} * \mathrm{~A}(5))$, 
!UPDATE ACTUAL MILES DRIVEN

IF,TYPE=1,OR,TYPE=2,THEN, !MILES USED 'OB' OR 'IB'? CAP_MI(OWNER, 6) $=$ CAP_MT $($ OWNER, 6) $+($ dOI * A(5)), CAP MI $(97,6)=$ CAP MI $(97,6)+\left(\mathrm{dOI}^{*} \mathrm{~A}(5)\right)$, DRIVERS $=($ dOI * A(5) $) /$ DAYS $($ RUN $) /$ MI_DR_DY,

ENDIF,

IF, TYPE $=3$,THEN, IMILES USED 'PT'? dPT $=$ BST_dPT_C, CAP_MI $(\overline{O W N E R}, 6)=$ CAP_MI $($ OWNER,6) $+(\mathrm{dPT}$ * A(5)), CAP_MI $(97,6)=$ CAP MI $(\overline{97}, 6)+(\mathrm{dPT} * \mathrm{~A}(5))$, DRIV̄ERS $=\left(\mathrm{dPT}^{*} \mathrm{~A}(5)\right) / \mathrm{DAYS}(\mathrm{RUN}) /$ MI_DR_DY, ENDIF,

!UPDATE NUMBER OF DRIVERS NEEDED

CAP DR(OWNER $)=$ CAP DR(OWNER $)+$ DRIVERS,

CAP_DR $(97)=$ CAP_DR(97) + DRIVERS,

ENDIF,

ELSE,

RT_OTR $=$ RT OTR +1 ,

$\mathrm{LDS}$ OTR $=$ LDS OTR $+\mathrm{A}(5)$,

MI_OTR $=$ MI_OTR $+\left(\mathrm{dOI}^{*} \mathrm{~A}(5)\right)$,

ENDIF,

ENDIF,

ELSE,

QUIT $=$ YES,

ENDIF\%:

STATCALC *A:

*B;TERM;;

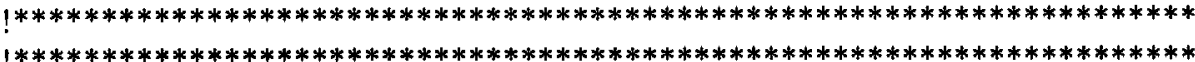

!NO MORE DATA... FINAL STATISTIC CALCULATIONS

\section{ICALCULATE SUMMARY STATISTICS}

ALL RTD $(97,4)=$ ALL_RTD $(97,1)+$ ALL_RTD $(97,2)+$ ALL_RTD $(97,3)$,

$\operatorname{ALL} \operatorname{LDD}(97,4)=\mathrm{ALL}_{-} \mathrm{LDD}(97,1)+\mathrm{ALL}_{-} \mathrm{LDD}(97,2)+\mathrm{ALL}_{-} \mathrm{LDD}(97,3)$,

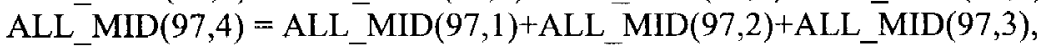

ALL_RT $(97,4)=A L L \_R T(97,1)+A L L \_R T(97,2) \&$ + ALL_RT $(\overline{9} 7,3)$,

$A L L \_L D(97,4)=A L L \_L D(97,1)+A L L \_L D(97,2) \&$ + ALL_LD $(97,3)$,

ALL_MI $(97,4)=A L L \_M I(97,1)+A L L \_M I(97,2) \&$ + ALL MI $(\overline{9} 7,3)$,

OWN RT $(97,4)=$ OWN RT $(97,1)+$ OWN RT $(97,2)+$ OWN RT $(97,3)$, OWN_LD $(97,4)=$ OWN_LD $(97,1)+O W N_{-} L D(97,2)+O W N \_L D(97,3)$, OWN_MI $(97,4)=$ OWN_MI $(97,1)+O W$ OW_MI $_{-}(97,2)+O W N_{-}$MI $(97,3)$, 
OTR_MI = TOT_MI - OWN_MI $(97,4)$,

CAP_RT $(97,4)=$ CAP_RT $(97,1)+C A P \_R T(97,2)+C A P \_R T(97,3)$,

CAP LD $(97,4)=\mathrm{CAP}^{-} \mathrm{LD}(97,1)+\mathrm{CAP}^{-} \mathrm{LD}(97,2)+\mathrm{CAP}^{-} \mathrm{LD}(97,3)$,

CAP_MI $(97,4)=$ CAP_MI $(97,1)+C A P \_M I(97,2)+C A P \_M I(97,3)$,

!CALCULATE IMBALANCES

FOR,I=1,TO,NUM_HUBS,DO, !CALCULATE IMBALANCES

!ROUTE IMBALANCES

IMBALANCE $=$ ABS(ALL_RTD(I,1) - ALL_RTD(I,2)),

ALL_RTD $(I, 5)=$ ALL_RTD $(I, 5)+$ IMBALANCE,

ALL_RTD $(97,5)=$ ALL_RTD $(97,5)+$ IMBALANCE,

IMBALANCE $=$ ABS(ALL_RT(I,1) - ALL_RT(I,2)),

ALL_RT $(\mathrm{I}, 5)=$ ALL RT $(1,5)+$ IMBALANCE,

ALL_RT $(97,5)=$ ALL_RT $(97,5)+$ IMBALANCE,

IMBALANCE $=$ ABS(OWN_RT(I,1) - OWN_RT(I,2)),

OWN RT(I,5) = OWN RT( $\overline{1}, 5)+$ IMBALANCE,

OWN_RT $(97,5)=$ OWN_RT $(97,5)+$ IMBALANCE,

IMBALANCE $=$ ABS(CAP_RT(I,1) - CAP_RT(I,2)),

CAP_RT $(I, 5)=$ CAP_RT(I,5) + IMBALAÑE,

CAP_RT $(97,5)=$ CAP_RT $(97,5)+$ IMBALANCE,

!LOAD IMBALANCES

IMBALANCE $=$ ABS(ALL_LDD(I,1) - ALL_LDD(I,2)),

$\operatorname{ALL} \operatorname{LDD}(\mathrm{I}, 5)=$ ALL_LDD $(\mathrm{I}, 5)+$ IMBALANCE,

$A L L \_L D D(97,5)=A L L_{-} L D D(97,5)+$ IMBALANCE,

IMBALANCE $=$ ABS(ALL_LD(I,1) - ALL LD(I,2)),

ALL_LD $(1,5)=$ ALL_LD(I,5) + IMBALANCE,

$A L L_{-} L D(97,5)=A L L_{-} L D(97,5)+$ IMBALANCE,

IMBALANCE $=$ ABS $\left(O W N \_L D(I, 1)-O W N \_L D(I, 2)\right)$,

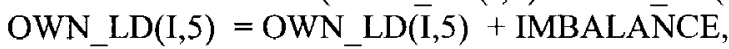

OWN_LD $(97,5)=$ OWN_LD $(97,5)+$ IMBALANCE,

IMBALANCE $=$ ABS $\left(C A P \_L D(I, 1)-\right.$ CAP_LD(I,2)),

CAP LD $(\mathrm{I}, 5)=$ CAP LD(I,5) + IMBALANCE,

CAP_LD $(97,5)=$ CAP_LD $\left._{-} \operatorname{L7}, 5\right)+$ IMBALANCE,

!MILE IMBALANCES

IMBALANCE $=$ ABS(ALL_MID(I,1) - ALL_MID(I,2)),

ALL_MID(I,5) = ALL_MID $(\mathrm{I}, 5)+$ IMBALA $\bar{A} N C E$,

$A L L \_M I D(97,5)=A L \bar{L} \_M I D(97,5)+$ IMBALANCE,

IMBALANCE $=$ ABS(ALL_MI(I,1) - ALL_MI(I,2)),

ALL_MI $(\mathrm{I}, 5)=$ ALL_MI $(\bar{I}, \overline{5})+$ IMBALAN $\bar{N} C E$,

ALL_MI $(97,5)=$ ALL__MI $(97,5)+$ IMBALANCE,

IMBALANCE $=$ ABS(OWN_MI $(I, 1)-$ OWN_MI $(\mathrm{I}, 2))$,

OWN_MI $(\mathrm{I}, 5)=$ OWN_MI $(\overline{\mathrm{I}}, 5)+$ IMBALAN̄CE, 


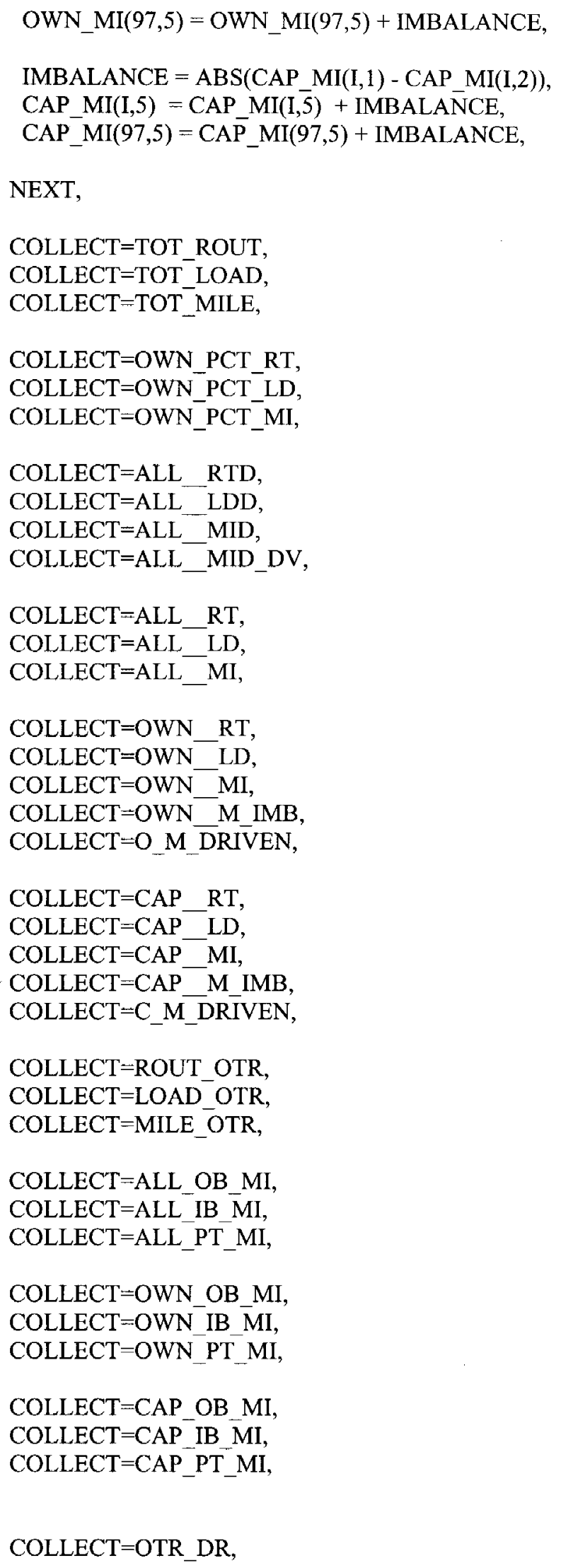


FOR,I $=1, T O, 97, \mathrm{DO}$,

COLLECT $=$ HB_MI_OWN(I),

COLLECT $=$ HB_MI_CAP(I),

COLLECT $=$ HB_DR_OWN(I),

COLLECT $=$ HB_DR_CAP(I),

NEXT,

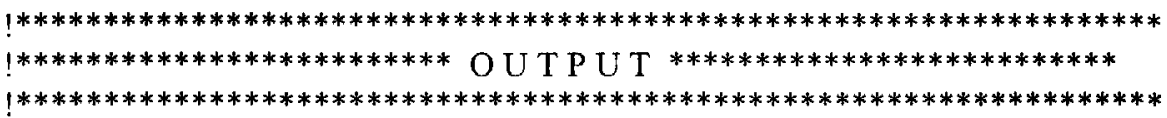

FOR,I=1,TO,NUM_HUBS,DO,

WRITE(51) $=$ \&

("(F15.2,F15.2,F15.2,F15.2,F15.2,F15.2,F15.2,F15.2)", \&

DATA, MONTH, TOT_RT, TOT_LDS, TOT_MI, WtOB, WtIB, WtPT),

WRITE $(52)=\&$

("(F15.2,F15.2,F15.2,F15.2,F15.2,F15.2,F15.2,F15.2,F15.2,F15.2)", \&

ALL RTD(I,1),ALL RTD(I,2),ALL_RTD(I,3),ALL RTD(I,4),ALL_RTD(I,5), \& ALL_RT (I,1),ALL_RT $\left.(1,2), A L L \_R T(I, 3), A L L+R T(I, 4), A L L \_R T(I, 5)\right)$,

WRITE $(53)=\&$

("(F15.2,F15.2,F15.2,F15.2,F15.2,F15.2,F15.2,F15.2,F15.2,F15.2)", \& OWN RT(I,1), OWN RT(I,2), OWN RT(I,3), OWN RT(I,4), OWN RT(I,5), \& CAP_RT(I,1), CAP_RT(I,2), CAP_RT(I,3), CAP_RT(I,4), CAP_RT(I,5)),

WRITE $(54)=\&$

("(F15.2,F15.2,F15.2,F15.2,F15.2,F15.2,F15.2,F15.2,F15.2,F15.2)", \&

ALL_LDD(I,1),ALL_LDD(I,2),ALL_LDD(I,3),ALL_LDD(I,4),ALL_LDD(I,5), \& ALL_LD (I,1),ALL_LD (I,2),ALL_LD $(\mathrm{I}, 3), \hat{\mathrm{ALL}} \mathrm{LD}(\mathrm{I}, 4), \mathrm{ALL}_{-} \mathrm{LD} \overline{(\mathrm{I}, 5))}$,

WRITE $(55)=\&$

("(F15.2,F15.2,F15.2,F15.2,F15.2,F15.2,F15.2,F15.2,F15.2,F15.2)", \& OWN LD(I,1), OWN LD(I,2), OWN LD(I,3), OWN LD(I,4), OWN LD(I,5), \& CAP_LD(I,1), CAP_LD(I,2), CAP_LD $\left.(\mathrm{I}, 3), \mathrm{CAP}_{-} \mathrm{LD}(\overline{\mathrm{I}}, 4), \mathrm{CAP} \_\mathrm{LD}(\overline{\mathrm{I}}, 5)\right)$,

WRITE $(56)=\&$

("(F15.2,F15.2,F15.2,F15.2,F15.2,F15.2,F15.2,F15.2,F15.2,F15.2)", \&

ALL_MID(I,1),ALL MID(I,2),ALL_MID(I,3),ALL MID(I,4),ALL_MID(I,5), \&

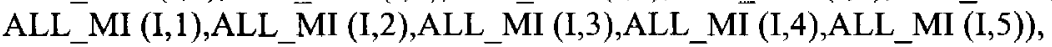

WRITE $(57)=\&$

("(F15.2,F15.2,F15.2,F15.2,F15.2,F15.2,F15.2,F15.2,F15.2,F15.2)", \& OWN MI(I,1), OWN MI(I,2), OWN MI(I,3), OWN MI(I,4), OWN MI(I,5), \& CAP_MI $\left.(I, 1), C A P \_M I(I, 2), C A P \_M I(I, 3), C A P \_M I(I, 4), C A P \_M I(\bar{I}, 5)\right)$,

WRITE $(58)=\&$

("(F15.2,F15.2,F15.2,F15.2)", \&

OWN_MI $(\mathrm{I}, 6), \mathrm{CAP} M \mathrm{MI}(\mathrm{I}, 6), \mathrm{OWN}$ DR(I), CAP_DR(I)),

NEXT,

! $* * * * * * * * * * * * * * * * * * * * * * * * * * * * * * * * * * * * * * * * * * * * * * * * * * * * * * * * * * * * * * * * * * *$

$\mid * * * * * * * * * * * * * * * * * * * * * * * * * * * * * * * * * * * * * * * * * * * * * * * * * * * * * * * * * * * * * * * * * * * * * * * * * * *$ 
$\mathrm{SIM}=\mathrm{STOP} \%$ :

\$END:

!\$TRACE $=0-3860$ :

! $* * * * * * * * * * * * * * * * * * * * * * * * * * * * * * * * * * * * * * * * * * * * * * * * * * * * * * * * * * * * * * * * * * *$

! $* * * * * * * * * * * * * * * * * * * * * * * * * * * * * * * * * * * * * * * * * * * * * * * * * * * * * * * * * * * * * * * * * * *$

\$CONSTANTS: $1-36 / \&$

\begin{tabular}{|c|c|}
\hline $\mathrm{YES}=1$ & ! "ON" SWITCH \\
\hline $\mathrm{NO}=0$ & ! "OFF" SWITCH \\
\hline QUIT $=0$, & ! "1" IF ON, "0" IF OFF \\
\hline $\mathrm{CIRC}=0.050$ & ! MAX ALLOWABLE CIRCUITY \\
\hline $\mathrm{PROX}=0.050$ & $\begin{array}{l}\text { ! MAX ALLOW DIST FROM HUB } \\
\text { MILES ARE IN THOUSANDS } \\
50 " \text { equals } 50 \text { MILES }\end{array}$ \\
\hline
\end{tabular}

NUM_HUBS $=96, \quad$ ! NO OF HUBS

WtOB $=0.2500, \quad !$ OUTBOUND WEIGHT

WtIB $=0.2500, \quad !$ INBOUND WEIGHT

WtPT $=0.2500, \quad$ ! PASS THRU WEIGHT

!Weights Are Relative

They do not have to sum to 1.000 .

!However for each weight: $0<=\mathrm{WtXX}<=1.0$

!If ANY ONE or TWO weights have values of

!0.000, then their parameter (OB,IB,or PT)

!will not be assigned any ownership miles.

!However, if ALL THREE weights are 0.000, !then the model will default by assigning !PT ownership only.

MAX_DRVRS $=200, \quad$ ! Maximum drivers per HUB in ! "Capacitated" Scenarios

MI_DR_DY $=0.500: \quad$ ! MILES PER DRIVER PER DAY ! NOTE: MILES ARE IN THOUSANDS

! SO "0.500" equals 500 MILES

! $* * * * * * * * * * * * * * * * * * * * * * * * * * * * * * * * * * * * * * * * * * * * * * * * * * * * * * * * *$

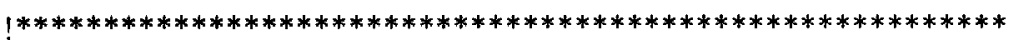

\$ARRAYS: DAYS;1-36/NS/\&

$31, \quad$ !January

28, !February

31, !March

30, !April

31, !May

30, !June 


$$
\begin{array}{ll}
\text { 31, } & \text { !July } \\
\text { 31, } & \text { !August } \\
\text { 30, } & \text { !Septembe } \\
\text { 31, } & \text { !October } \\
\text { 30, } & \text { !November } \\
\text { 31: } & \text { !December }
\end{array}
$$

!These 96 HUBS are prominent US highway intersections HUB; $1-12 / \mathrm{NS} / \&$

$1,44.3,-69.9$, !AUGUSTA, ME

2, 41.6, -71.2, !PROVIDENCE

$3,42.4,-71.2$, !BOSTON

$4,43.6,-72.4$, !WHITE RIVER JUNCTION

$5,42.1,-72.6$, !SPRINGFIELD, MA

$6,41.7,-72.7$, !HARTFORD

$7,41.2,-72.9$, !NEW HAVEN

$8,40.7,-73.9$, !NEW YORK CITY

$9,42.7,-74.0$, !ALBANY

$10,39.9,-75.1$, !PHILADELPHIA

$11,41.4,-75.5$, !SCRANTON

$12,36.8,-76.2$, !NORFOLK

$13,43.1,-76.2$, !SYRACUSE

$14,40.2,-76.9$, !HARRISBURG

$15,38.9,-77.0$, !WASHINGTON, DC

$16,37.4,-77.6$, !RICHMOND

$17,43.1,-77.7$, !ROCHESTER

$18,35.7,-78.8$, !RALEIGH

$19,42.9,-78.9$, !BUFFALO, NY

$20,40.3,-80.1$, !PITTSBURG

$21,26.1,-80.2$, !FORT LAUDERDALE

$22,35.2,-80.9$, !CHARLOTTE

$23,34.0,-81.0$, !COLUMBIA, SC

$24,36.9,-81.0$, !WYTHEVILLE, VA

$25,32.0,-81.2$, !SAVANNAH

$26,30.3,-81.6$, !JACKSONVILLE

$27,38.3,-81.6$, !CHARLESTON, WV

$28,41.5,-81.6$, !CLEVELAND

$29,35.0,-82.0, \quad$ !SPARTANBURG, SC

$30,28.0,-82.5$, !TAMPA

$31,35.6,-82.6$, !ASHVILLE, NC

$32,40.0,-83.0$, !COLUMBUS

$33,41.6,-83.1$, !TOLEDO

$34,42.3,-83.1$, !DETROIT

$35,35.9,-84.0$, !KNOXVILLE

$36,33.9,-84.5$, !ATLANTA

$37,38.0,-84.5$, !LEXINGTON

$38,39.1,-84.5$, !CINCINNATI

$39,42.7,-84.7$, !LANSING

$40,35.0,-85.3$, !CHATTANOOGA

$41,38.4,-85.8$, !LOUISVILLE

$42,32.3,-86.1$, !MONTGOMERY

$43,39.8,-86.2$, !INDIANAPOLIS

$44,36.1,-86.8$, !NASHVILLE

$45,33.5,-86.9$, !BIRMINGHAM

$46,41.9,-87.6$, !CHICAGO

$47,43.0,-88.0$, !MILWAUKEE 
$48,30.7,-88.1$, !MOBILE

$49,37.0,-88.3$, !LAKE CITY, KY

$50,40.5,-89.0$, !BLOOMINGTON, IL

$51,43.0,-89.4$, !MADISON

$52,35.1,-90.0$, !MEMPHIS

$53,32.3,-90.2$, !JACKSON

$54,30.0,-90.3$, !NEW ORLEANS

$55,38.6,-90.4$, !ST LOUIS

$56,41.5,-90.5$, !QUAD CITIES

$57,30.3,-91.1$, !BATON ROUGE

$58,34.9,-92.3$, !LITTLE ROCK

$59,44.9,-93.1$, !ST. PAUL

60, 43.6, -93.4, !ALBERT LEA, MN

$61,41.5,-93.6$, !DES MOINES

$62,32.5,-93.9$, !SHREVEPORT

$63,37.1,-94.5$, !JOPLIN

$64,39.0,-94.6$, !KANSAS CITY

65, 29.6, -95.4, !HOUSTON

$66,36.1,-96.0$, !TULSA

$67,41.2,-96.0$, !OMAHA

$68,43.5,-96.5$, !SOUIX FALLS

$69,32.5,-96.8$, !DALLAS

$70,46.9,-96.9$, !FARGO

$71,37.7,-97.2$, !WICHITA

$72,35.5,-97.5$, !OKLAHOMA CITY

73, 29.4, -98.6, !SAN ANTONIO

$74,35.1,-101.9$, !AMARILLO

75, 31.0, -104.0, !KENT, TX

76, 41.1, -104.9, !CHEYENNE

77, 39.8, -105.0, !DENVER

78, 35.1, -106.7, !ALBUQUERQUE

$79,44.4,-106.7$, !BUFFALO, WY

$80,32.3,-106.8$, !LAS CRUCES

$81,45.9,-108.4$, !BILLINGS

$82,32.1,-111.0$, !TUCSON

83, 35.2, -111.6, !FLAGSTAFF

$84,40.7,-111.9$, !SALT LAKE CITY

$85,33.3,-112.1$, !PHOENIX

$86,42.8,-112.5$, !POCATELLO

$87,46.0,-112.6$, !BUTTE

$88,38.6,-112.7$, !COVE FORT, UT

$89,36.1,-115.1$, !LAS VEGAS

$90,32.7,-117.0$, !SAN DIEGO

$91,34.0,-118.3$, !LOS ANGELES

$92,45.7,-119.4$, !HERMISTON, OR

$93,38.4,-121.3$, !SACRAMENTO

$94,37.5,-122.4$, !SAN FRANCISCO

$95,47.4,-122.4$, !SEATTLE

96, 45.5, -122.6: !PORTLAND, OR

!These 96 HUBS are prominent JBHT infrastructure locations

$13-24 / \mathrm{NS} / \&$

$1,33.5,-86.9$, !BIRMINGHAM, AL 
$2,32.3,-86.1$, !MONTGOMERY AL

$3,35.3,-94.4$, !FORT SMITH AR

$4,34.9,-92.3$, !LITTLE ROCK AR

5, 36.3, -94.1, !LOWELL AR

6, 33.3, -112.1, !PHOENIX AZ

$7,36.8,-119.7$, !FRESNO CA

8, 34.0,-118.3, !LOS ANGELES CA

$9,37.9,-122.4$, !RICHMOND CA

$10,34.1,-117.3$, !SAN BERNADINO CA

$11,37.9,-121.3$, !STOCKTON CA

$12,39.8,-105.0$, !DENVER CO

$13,30.3,-81.6$, !JACKSONVILLE FL

$14,29.2,-82.0$, !OCALA FL

$15,33.9,-84.5$, !ATLANTA GA

$16,32.7,-83.7, \quad$ !MACON GA

$17,32.0,-81.2$, !SAVANNAH GA

$18,31.4,-83.5$, !TIFTON GA

$19,42.0,-91.7$, !CEDAR RAPIDS IA

20, 41.5, -93.6, !DES MOINES IA

$21,40.1,-88.2$, !CHAMPAIGN IL

$22,41.9,-87.6$, !CHICAGO IL

$23,39.1,-88.6, \quad$ !EFFINGHAM IL

$24,42.3,-89.1$, !ROCKFORD IL

$25,38.0,-87.6$, !EVANSVILLE IN

$26,40.8,-85.5$, !HUNTINGTON IN

$27,39.8,-86.2$, !INDIANAPOLIS IN

$28,37.7,-97.2$, !WICHITA KS

$29,37.0,-86.5, \quad$ !BOWLING GREEN KY

30, 38.0, -84.5, !LEXINGTON KY

$31,38.4,-85.8$, !LOUISVILLE KY/IN

$32,30.3,-91.1$, !BATON ROUGE LA

$33,32.5,-93.9$, !SHREVEPORT LA

$34,42.3,-71.8$, !WORCESTER MA

$35,39.3,-76.6$, !BALTIMORE MD

$36,39.6,-77.8$, !HAGERSTOWN MD

$37,43.7,-70.3$, !PORTLAND ME

$38,42.3,-83.1$, !DETROIT MI

$39,42.9,-85.7$, !GRAND RAPIDS MI

40, 42.2, -85.6, !KALAMAZOO MI

$41,43.4,-83.9$, !SAGINAW MI

$42,45.0,-93.3$, !MINNEAPOLIS MN

$43,39.0,-94.6$, !KANSAS CITY MO

$44,37.2,-93.3$, !SPRINGFIELD MO

$45,38.6,-90.4$, !ST. LOUIS MO

$46,32.4,-88.6$, !MERIDIAN MS

$47,32.3,-90.1$, !RICHLAND MS

48, 35.6, -82.6, !ASHEVILLE NC

$49,35.2,-80.9$, !CHARLOTTE NC

$50,35.9,-77.8$, !ROCKY MOUNT NC

$51,41.2,-96.0$, !OMAHA NE

$52,42.9,-70.9$, !SEABROOK NH

$53,40.4,-74.4$, !EAST BRUNSWICK NJ

$54,42.7,-74.0$, !ALBANY NY

$55,42.9,-78.9$, !BUFFALO NY

$56,43.1,-76.2$, !SYRACUSE NY

$57,41.1,-82.9$, !ATTICA OH 
$58,39.1,-84.5$, !CINCINNATI OH

$59,40.0,-83.0$, !COLUMBUS OH

$60,40.7,-84.1$, !LIMA OH

$61,41.2,-80.7$, !NILES OH

$62,41.2,-81.5$, !PENINSULA OH

$63,41.6,-83.1$, !TOLEDO OH

$64,35.5,-97.5$, !OKLAHOMA CITY OK

$65,36.1,-96.0$, !TULSA OK

$66,45.5,-122.7$, !PORTLAND OR

$67,40.6,-75.4$, !ALLENTOWN PA

$68,40.2,-76.9$, !HARRISBURG PA

$69,39.9,-75.1$, !PHILADELPHIA PA

$70,40.3,-80.1, \quad$ !PITTSBURG PA

$71,41.4,-75.5$, !SCRANTON PA

$72,34.0,-81.0$, !COLUMBIA SC

$73,34.8,-82.4$, !GREENVILLE SC

$74,36.6,-82.2$, !BRISTOL TN

$75,35.0,-85.3$, !CHATTANOOGA TN

$76,35.9,-84.0$, !KNOXVILLE TN

$77,35.1,-90.0, \quad$ !MEMPHIS TN

$78,36.1,-86.8$, !NASHVILLE TN

$79,32.5,-96.8$, !DALLAS TX

$80,31.8,-106.4$, !EL PASO TX

$81,29.6,-95.4$, !HOUSTON TX

$82,31.9,-102.3$, !ODESSA TX

$83,29.4,-98.6$, !SAN ANTONIO TX

$84,32.3,-95.5$, !TYLER TX

$85,36.7,-79.9$, !MARTINSVILLE VA

$86,37.4,-77.6$, !RICHMOND VA

$87,37.3,-80.0$, !ROANOKE VA

$88,36.8,-76.1$, !VIRGINIA BEACH VA

$89,39.1,-78.2$, !WINCHESTER VA

$90,47.1,-122.3$, !SUMNER WA

91, 45.7, -122.7, !VANCOUVER WA

$92,44.8,-91.5$, !EAU CLAIRE WI

93, 43.0, -89.4, !MADISON WI

94, 43.0, -88.0 , !MILWAUKEE WI

$95,44.9,-89.6$, !WAUSAU WI

96, 38.4, -81.8: !NITRO WV

!'These 96 HUBS are the best LAT-LONG locations

$25-36 / \mathrm{NS} / \&$

$1,34,-118$,

$2,42,-88$,

$3,40,-83$,

$4, \quad 39,-90$,

$5,40,-86$,

$6,40,-88$,

$7, \quad 39,-85$,

$8,34,-116$,

$9, \quad 39,-88$,

$10,34,-115$,

$11,34,-114$, 
$12,34,-117$,

$13,34,-113$,

$14,38,-86$,

$15,34,-111$,

$16,40,-84$,

$17,40,-85$,

$18,39,-87$,

$19,34,-112$,

$20,38,-90$,

$21,41,-88$,

$22,40,-90$,

$23,39,-89$,

$24,40,-87$,

$25,33,-97$,

$26,41,-86$,

$27, \quad 38,-92$,

$28,34,-110$,

$29, \quad 35,-92$,

$30,34,-109$,

$31,40,-89$,

$32,38,-87$,

$33,39,-95$,

$34,41,-87$,

$35,35,-111$,

$36,38,-85$,

$37,41,-82$,

$38,38,-105$,

$39,36,-110$,

$40,38,-104$,

$41,39,-86$,

$42,38,-106$,

$43,35,-110$,

$44,35,-113$,

$45,35,-108$,

$46,40,-82$,

$47,35,-109$,

$48,38,-88$,

$49,35,-112$,

$50,36,-109$,

$51,38,-107$,

$52,39,-91$,

$53,41,-84$,

$54,35,-114$,

$55,34,-84$,

$56,38,-108$,

$57,39,-102$,

$58,35,-107$,

$59,36,-111$,

$60,39,-101$,

$61,39,-103$,

$62,38,-103$,

$63,35,-115$,

$64,40,-92$,

$65,41,-90$,

$66,34,-108$,

$67,39,-104$, 
$68,41,-89$,

$69,36,-108$

$70,36,-112$,

$71, \quad 38,-89$,

$72,36,-106$,

$73,38,-109$,

$74,40,-93$,

$75,39,-93$,

$76,36,-107$,

$77,38,-102$,

$78,38,-101$,

$79,35,-90$,

$80,39,-100$,

$81,38,-91$,

$82,36,-113$,

$83,39,-105$,

$84,38,-100$,

$85,36,-114$,

$86,36,-105$,

$87,39,-96$,

$88,37,-90$,

$89,41,-83$,

$90,38,-93$,

$91,41,-85$,

$92,39,-92$,

$93,38,-99$,

$94,39,-99$,

$95,38,-110$,

$96,40,-94$ :

!\$RUN-LENGTH=100:

$\$ R U N S=12$ :

\$STOP: 


\title{
APPENDIX 5
}

\author{
SIMNET Code: The D.C. Location Problem
}

\$PROJECT;DCPROB;JAN 2006;ANTHONY HUMPHREY:

!THIS PROGRAM USES US GEODETIC SURVEY DATA AS A SURROGATE FOR FREIGHT !DEMAND AND COMPARES CHICAGO CONSULTING HOT SPOTS TO ALTERNATE SPOTS !SELECTED BY JBHT FOR LOW TL FREIGHT RATES USING COST AND DISTANCE !

!THE DEMAND IS OBTAINED FROM COUNTY POPULATION CENTROIDS

! (http://www.census.gov/geo/www/cenpop/county/ctyctrpg.html)

\$DIMENSION;ENTITY(10),A(1), ! ENTITY INFORMATION

COUNTY $(3109,4)$, ! COUNTY POPS \& CENTROIDS

STATE $(49,3), \quad$ ! STATE CENTROIDS

CITIES $(35,3), \quad$ ! WHSE CITIES \& CENTROIDS

HUBS $(20,10), \quad$ ! CITY SCENARIOS FOR CHI CON \& JBHT

RATES(35,49), ! TL RATE PER MILE FROM CITY TO STATE

ALTS(35), ! JBHT ALTERNATE LOW COST CITIES

CAND_CC $(10,35)$, ! COLLECT COST DATA FOR EACH CHI CON CITY

CAND_AC $(10,35)$, ! COLLECT COST DATA FOR EACH ALT CITY

CAND_CD(10,35), ! COLLECT DIST DATA FOR EACH CHI CON CITY

CAND AD $(10,35), !$ COLLECT DIST DATA FOR EACH ALT CITY

DELTA $(10,35), \quad$ ! COLLECT \& WRITE IND CITY DELTA COST

TOT_CCST $(10), \quad$ ! TOTAL COST FOR CHICAGO CONSULTING LOCS

TOT_CDIS(10), ! TOTAL DIST FOR CHICAGO CONSULTING LOCS

TOT JCST(10), ! TOTAL COST FOR JBHT LOCS

TOT_JDIS(10), ! TOTAL DIST FOR JBHT LOCS

TOT_ACST(10), ! TOTAL COST FOR BEST CHI CON \& JBHT HUBS

TOT_ADIS(10): !'TOTAL DIST FOR BEST CHI CON \& JBHT HUBS

\$VARIABLES:CC_COST(1-10);;TOT_CCST(I)/1000000:! TOTAL CC DELIVER COST

CC_DIST(1-10); ;OT_CDIS(I)/TOT_POP: ! AVG DIST CC TO US POP

JB COST (1-10);;TOT_JCST(I)/1000000: ! TOTAL JB DELIVER COST

JB_DIST(1-10);;TOT_JDIS(I)/TOT_POP: ! AVG DIST JB TO US POP

ALT_COST(1-10);;TOT_ACST(I)/1000000:! TOTAL EITHER/OR COST

ALT_DIST(1-10);;TOT_ADIS(I)/TOT_POP:! AVG DIST E/O TO POP

! (BEST OF CC OR JB)

\$BEGIN:

S_INIT ${ }^{*}$ S; $/ \mathrm{L} / \mathrm{LIM}=1$ :

*B;TERM;

FOR,I=1,TO,3109,DO, ! CALC TOTAL POPULATION BY COUNTY

TOT_POP=TOT_POP+COUNTY $(I, 2)$,

NEXT, !I -- County Loop 


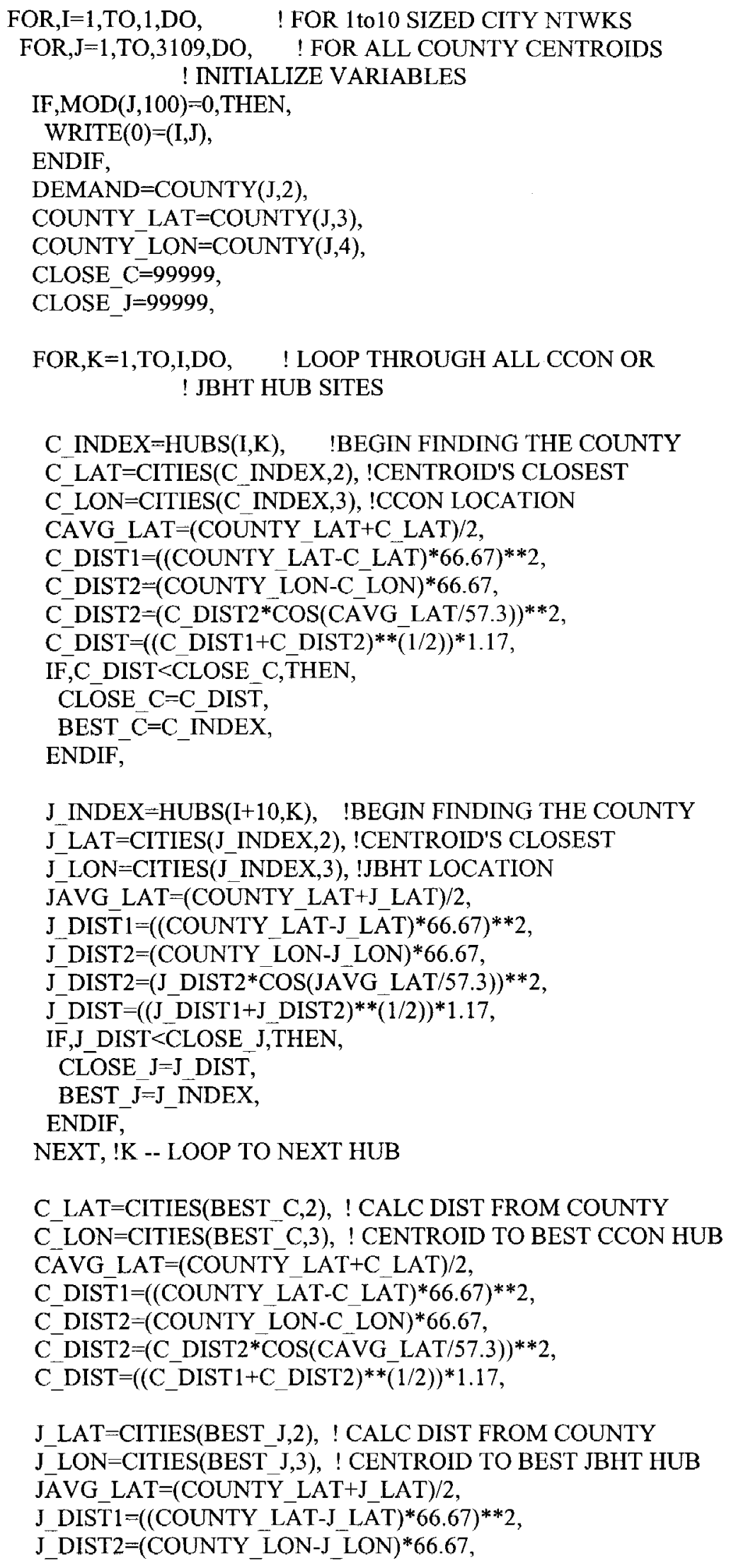


J_DIST2 $=\left(\mathrm{J} \_D I S T 2 * \operatorname{COS}(\mathrm{JAVG} L \mathrm{LAT} / 57.3)\right) * * 2$,

J_DIST $=\left(\left(\mathrm{J} \_D I S T 1+\mathrm{J} \_D I S T 2\right)^{* *}(1 / 2)\right)^{*} 1.17$,

BEST_A=ALTS(BEST_C), ! FOR CCON HUBS... CALC DIST

A_LAT $=$ CITIES(BEST A,2), ! FROM COUNTY CENTROID

A_LON=CITIES(BEST A,3), ! TO ALTERNATE JBHT HUB

AAVG_LAT $=($ COUNTY_LAT $+A$ LAT $) / 2$,

A_DIST $1=\left((\text { COUNTY_LAT-A_LAT })^{*} 66.67\right)^{* * 2}$,

A_DIST2 $=($ COUNTY_LON-A_LON $) * 66.67$,

A_DIST2 $=\left(\text { A_DIST } 2{ }^{*} \text { COS }(A A-\bar{A} \text { __LAT } / 57.3)\right)^{* * 2}$,

A_DIST $=\left(\left(\right.\right.$ A_DIST $\left.\left.1+A \_D I S T 2\right) * *(1 / 2)\right) * 1.17$,

!CALCULATE THE RATE FROM A COUNTY CENTROID TO IT'S CLOSEST !CCON OR JBHT HUB BASED ON THE RATES FROM THE HUBS TO EACH !OF THE STATE CENTROIDS.

!

!TO DO THIS, FOR EACH COUNTY CENTROID, THE 2 CLOSEST STATE CENTROIDS

!ARE FOUND AND A COUNTY RATE IS CALCULATED BASED ON THE PROPORTIONAL

!PROXIMITIES OF THE COUNTY CENTROID TO EACH OF THE STATE CENTROIDS.

CLOSE $1=9999$,

CLOSE2 $=9999$,

CLOSE1_ID $=0$,

CLOSE2 - ID $=0$,

FOR,L $=1$, TO,49,DO,$\quad$ ! LOOP THROUGH STATE CENTROIDS

LAT $=$ STATE $(\mathrm{L}, 2), \quad$ !CALCULATE DIST FROM COUNTY

LON $=$ STATE $(\mathrm{L}, 3), \quad$ !TO STATE CENTROID

AVG_LAT $=($ COUNTY_LAT+LAT $) / 2$,

DIST $\overline{1}=\left((\text { COUNTY_LAT-LAT })^{*} 66.67\right)^{* * 2}$,

DIST2 $=(\text { COUNTY_LON-LON })^{*} 66.67$,

DIST2 $=($ DIST2 $*$ COS(AVG_LAT/57.3) $) * 2$,

DIST $=\left((\text { DIST } 1+D I S T 2)^{* *}(\overline{1} / 2)\right)^{*} 1.17$,

IF,DIST $<=$ CLOSE 1 ,THEN, !DETERMINE IF STATE CENTROID

!IS 1 st CLOSEST CENTROID TO COUNTY

CLOSE2 $=$ CLOSE1,

CLOSE2_ID $=$ CLOSE1_ID,

CLOSE1 $=$ DIST,

CLOSE1_ID $=\mathrm{L}$,

ELSE,

IF,DIST $<=$ CLOSE2,THEN,!DETERMINE IF STATE CENTROID

!IS 2nd CLOSEST CENTROID TO COUNTY

CLOSE2 =DIST,

CLOSE2_ID $=$ L,

ENDIF,

ENDIF,

NEXT, $\quad$ !L -- LOOP TO NEXT STATE

!FOR CCON NETWORKS: CALCULATE TOTAL DISTANCES AND COSTS

TOT_CDIS $(\mathrm{I})=$ TOT_CDIS $(\mathrm{I})+\left(\mathrm{C} \_D I S T * D E M A N D\right)$,

RATE1=RATES(BEST_C,CLOSE 1 IID),

RATE2=RATES(BEST_C,CLOSE2_ID),

RATE $=($ CLOSE $1 /($ CLOSE $1+$ CLOSE 2$)) *$ RATE2,

RATE $=$ RATE $+($ CLOSE2 $/($ CLOSE $1+$ CLOSE2 $)) *$ RATE 1 , 
$T$ CCST $=$ RATE ${ }^{*}$ C_DIST ${ }^{*}$ DEMAND,

TOT_CCST $(\mathrm{I})=$ TOT_CCST $(\mathrm{I})+\mathrm{T}$ _CCST, WRITE $(51)=($ BEST_C,RATE1, CLOSE1,CLOSE1_ID), WRITE(51) $=($ BEST_C,RATE2,CLOSE2,CLOSE2 ID), WRITE $(51)=\left(B E S T-C, R A T E, T \_C C S T, T O T \_C C S T(I)\right)$, WRITE $(51)=(0$, RATE,C_DIST, $\bar{D} E M A N D)$,

$\operatorname{WRITE}(51)=(0,0,0,0)$,

!FOR JBHT NETWORKS: CALCULATE TOTAL DISTANCES AND COSTS TOT_JDIS(I)=TOT_JDIS (I)+(J_DIST*DEMAND),

RATE1=RATES(BEST_J,CLOSE1_ID), RATE2 $=$ RATES(BEST ${ }^{-}$,CLOSE2 ${ }^{-}$ID), RATE $=(\text { CLOSE } 1 /(\text { CLOSE } 1+\text { CLOSE } 2))^{*}$ RATE2, RATE $=$ RATE $+($ CLOSE2 $/($ CLOSE $1+$ CLOSE2 $)) *$ RATE1, T JCST $=$ RATE*J_DIST*DEMAND, TOT_JCST $(\mathrm{I})={ }^{\mathrm{T}} \overline{\mathrm{TO}}+\mathrm{JCST}(\mathrm{I})+\mathrm{T} \_\mathrm{JCST}$,

!FOR HYBRID NETWORKS: CALCULATE TOTAL DISTANCES AND COSTS

$!$ TEMPORARILY HOLD THE DISTANCE AND COST VALUES FOR EACH CCON AND ITS POTENTIAL ALTERNATE JBHT HUB.

! THESE VALUES WILL BE USED LATER FOR COMPARISONS AND

! FINAL HYBRID NETWORK DISTANCE AND COST EVALUATIONS

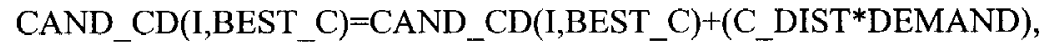
CAND_AD $(\mathrm{I}, \mathrm{BEST} C \mathrm{C})=\mathrm{CAND} \mathrm{AD}\left(\mathrm{I}, \mathrm{BEST}_{-} \mathrm{C}\right)+\left(\mathrm{A}_{-} \mathrm{DIST}{ }^{*} \mathrm{DEMAND}\right)$, RATE $1=$ RATES(BEST_A,CLOSE1_ID), RATE2=RATES(BEST_A,CLOSE2 ID), RATE $=(\text { CLOSE } 1 /(\text { CLOSE } 1+\text { CLOSE } 2))^{*}$ RATE2, RATE $=$ RATE $+($ CLOSE2/(CLOSE1+CLOSE2) $) *$ RATE1, T_ACST $=$ RATE*A_DIST*DEMAND, CAND_CC (I,BEST_C $)=$ CAND_CC $($ I,BEST_C $)+T$ CCST, CAND_AC $\left(I, B E S T \_C\right)=C A N D \_A C\left(I, B E S T \_C\right)+T_{-}^{-} A C S T$, NEXT, !J -- County Loop

!--- COLLECT AND DETERMINE FINAL STATISTICS

!COLLECT CCON HUB NETWORK STATISTICS COLLECT $=$ CC_COST $(\mathrm{I})$, COLLECT $=$ CC_DIST $(\mathrm{I})$,

!COLLECT JBHT HUB NETWORK STATISTICS COLLECT $=J B \quad \operatorname{COST}(\mathrm{I})$, COLLECT $=$ JB_DIST $(\mathrm{I})$,

!COMPARE CCON/JBHT ALTERNATIVE STATISTICS

! DETERMINE A HYBRID NETWORK BASED ON LOWEST CCON or JBHT COSTS FOR,J $=1, \mathrm{TO}, 35, \mathrm{DO}$, IF,CAND_AC(I,J)<CAND_CC(I,J),THEN, TOT_ADIS(I)=TOT_ADIS(I)+CAND_AD(I,J), TOT_ACST $(\mathrm{I})=$ TOT_ACST $(\mathrm{I})+\mathrm{CAND}{ }_{-}$AC $(\mathrm{I}, \mathrm{J})$, ELSE, TOT_ADIS(I)=TOT_ADIS(I)+CAND_CD(I,J), TOT_ACST $(\mathrm{I})=$ TOT_ACST $(\mathrm{I})+\mathrm{CAND} \_\mathrm{CC}(\mathrm{I}, \mathrm{J})$, 
ENDIF,

DELTA $(I, J)=$ CAND_CC(I,J)-CAND_AC $(I, J)$, !HYBRID SAVINGS

$\operatorname{WRITE}(60)=(\mathrm{I}, \mathrm{J}, \mathrm{DELTA}(\mathrm{I}, \mathrm{J}))$,

NEXT, !J -- Alternative Site Loop

!COLLECT HYBRID CCON/JBHT NETWORK STATISTICS

COLLECT=ALT_COST(I),

COLLECT=ALT_DIST(I),

NEXT, !I -- Network Size Loop $($ Size $=1$ - 10)

$\mathrm{SIM}=\mathrm{STOP} \%$ :

\$END:

! THIS ARRAY HOLDS COUNTY POPULATION \& CENTROID DATA: \#,POP,LAT,LON \$ARRAYS:COUNTY;1-25/NS/\&

$1,43671,32.50,86.50, ! \mathrm{AL}$,

$2,140415,30.57,87.76, \quad \mathrm{AL}$,

$3,29038,31.85,85.31, ! \mathrm{AL}$,

$4,20826,33.03,87.13, ! \mathrm{AL}$,

$5,51024,33.96,86.58, ! \mathrm{AL}$,

$6,11714,32.11,85.70, ! \mathrm{AL}$,

$7,21399,31.77,86.66, ! \mathrm{AL}$,

$8,112249,33.72,85.82, ! \mathrm{AL}$,

$9,36583,32.86,85.27, ! \mathrm{AL}$,

$10,23988,34.18,85.63, ! \mathrm{AL}$,

!3130, 3436, 58.42, 135.33, ! AK,

$! 3131,6174,63.81,144.47$, ! AK,

!3132, 10195, 61.26, 145.86, ! AK,

!3133, 7028, 62.11, 164.29, ! AK,

!3134, 6684, 56.68, 132.86, ! AK,

$13135,808,59.62,140.01, ! \mathrm{AK}$,

!3136, 6551, 64.97, 152.77, ! AK,

!3137, 148677, 19.69, 155.42, ! HI,

!3138, 876156, 21.38, 157.91, ! HI,

!3139, 147, 21.19, 156.98, ! HI,

!3140, 58463, 22.02, 159.45, ! HI,

!3141, 128094, 20.87, 156.50, ! HI, .

! THIS ARRAY HOLDS STATE CENTROID DATA: \#,LAT,LON

STATE; $1-25 / \mathrm{NS} / 1,33.0,86.8, ! \mathrm{AL}$
$2,35.1,92.6, ! \mathrm{AR}$
$3,33.4,111.8$, ! AZ
$4,35.5,119.4$, ! CA
$5,39.5,105.2, ! \mathrm{CO}$
$6,41.5,72.9$, ! CT
$7,38.9,77.0, ! \mathrm{DC}$
$8,39.4,75.6, ! \mathrm{DE}$
$9,27.8,81.6, ! \mathrm{FL}$
$10,33.3,83.7, ! \mathrm{GA}$ 
$11,42.0,93.0$, ! IA

$12,44.2,115.1$, ! ID

$13,41.3,88.4$, ! IL

$14,40.2,86.3$, ! IN

$15,38.5,96.5, ! \mathrm{KS}$

$16,37.8,85.2$, ! KY

$17,30.7,91.5$, ! LA

$18,42.3,71.4$, ! MA

$19,39.1,76.8$, ! MD

$20,44.3,69.7$, ! ME

$21,42.9,84.2$, ! MI

$22,45.2,93.6, ! \mathrm{MN}$

$23,38.4,92.2$, ! MO

$24,32.6,89.6$, ! MS

$25,46.8,111.2$, ! MT

$26,35.6,79.7$, ! NC

$27,47.4,99.3$, ! ND

$28,41.2,97.4, ! \mathrm{NE}$

$29,43.2,71.5, ! \mathrm{NH}$

$30,40.4,74.4$, ! NJ

$31,34.6,106.3$, ! NM

$32,37.2,116.3$, ! NV

$33,41.5,74.6$, ! NY

$34,40.5,82.7, ! \mathrm{OH}$

$35,35.6,96.8$, ! OK

$36,44.7,122.6$, ! OR

$37,40.5,77.1$, ! PA

$38,41.8,71.4$, ! RI

$39,34.0,81.0$, ! SC

$40,44.0,99.0$, ! SD

$41,35.8,86.4, ! \mathrm{TN}$

$42,30.9,97.4$, ! TX

$43,40.4,111.9$, ! UT

$44,37.8,77.8$, ! VA

$45,44.1,72.8$ ! ! VT

$46,47.3,121.6$, ! WA

$47,43.7,89.0$, ! WI

$48,38.8,80.8$, ! WV

$49,42.7,107.0:$ ! WY

$! 50,61.3,148.7, !$ AK

!51, 21.1, 157.5, ! HI

! THIS ARRAY HOLDS CITY/HUB LOCATATION DATA: \#,LAT,LON

CITIES;1-25/NS/1, 42.8, 74.0, ! ALBANY, NY

$2,34.1,118.2$, ! ALHAMBRA, CA CC

$3,40.6,75.5$, ! ALLENTOWN, PA CC

$4,38.5,82.7$, ! ASHLAND, KY CC JB

$5,39.1,86.5$, ! BLOOMINGTON, IN CC

6, 31.6, 90.4, ! BROOKHAVEN, MS JB

$7,41.9,87.7$, ! CHICAGO, IL CC

$8,32.7,96.8$, ! DALLAS, TX CC

9, 39.7, 105.0, ! DENVER, CO CC JB

$10,40.5,74.5$, ! EDISON, NJ CC

$11,34.3,83.8$, ! GAINESVILLE, GA CC

$12,29.8,81.7$, ! JACKSONVILLE, FL JB 


\begin{tabular}{|c|c|}
\hline $13,32.9,85.0, !$ LAGRANGE, GA & JB \\
\hline 14, 28.1, 82.0,! LAKELAND, FL & $\mathrm{CC}$ \\
\hline $15,42.9,84.2, !$ LANSING, MI & JB \\
\hline $16,38.4,85.6, !$ LOUISVILLE,KY & JB \\
\hline $17,32.8,83.7, !$ MACON, GA & $\mathrm{CC}$ \\
\hline $18,40.8,74.4, !$ MADISON, NJ & $\mathrm{CC}$ \\
\hline $19,40.7,82.5, !$ MANSFIELD, OH & $\mathrm{CC}$ \\
\hline $20,36.1,88.5, !$ MCKENZIE, TN & $\mathrm{CC}$ \\
\hline $21,32.3,88.6, !$ MERIDIAN, MS & $\mathrm{CC}$ \\
\hline $22,40.7,74.2, !$ NEWARK, NJ & $\mathrm{CC}$ \\
\hline $23,40.9,73.3$, ! NEW YORK, NY & JB \\
\hline $24,37.8,122.3$, ! OAKLAND, CA & $\mathrm{CC}$ \\
\hline $25,34.2,119.2$, ! OXNARD, CA & JB \\
\hline $26,31.6,95.5$, ! PALESTINE, TX & $\mathrm{CC}$ \\
\hline $27,34.4,118.1$, ! PALMDALE, CA & $\mathrm{CC}$ \\
\hline $28,34.1,118.1$, ! PASADENA, CA & $\mathrm{CC}$ \\
\hline $29,42.2,89.1, !$ ROCKFORD, IL & $\mathrm{CC}$ \\
\hline $30,38.6,121.6$, ! SACRAMENTO, C & $\mathrm{CA}$ \\
\hline $31,41.7,86.4, !$ SOUTH BEND, IN & $\sqrt{B}$ \\
\hline $32,47.1,122.5, !$ TACOMA, WA & CC JB \\
\hline $33,31.5,83.1, !$ TIFTON, GA & JB \\
\hline $34,34.5,88.9, !$ TUPELO, MS & JB \\
\hline $35,31.3,97.2:$ ! WACO, TX & JB \\
\hline
\end{tabular}

HUBS;1-25/NS/ $\quad 5,0,0,0,0,0,0,0,0,0, ! \mathrm{CHI}$ CON 1 $4,27,0,0,0,0,0,0,0,0$, ! CHI CON 2 $3,27,20,0,0,0,0,0,0,0, !$ CHI CON 3 $10,27,7,21,0,0,0,0,0,0$, ! CHI CON 4 $18,27,7,8,17,0,0,0,0,0, !$ CHI CON 5 $18,28,7,8,17,32,0,0,0,0, !$ CHI CON 6 $18,28,7,8,11,32,14,0,0,0$, ! CHI CON 7 $18,28,7,8,11,32,14,9,0,0$, ! CHI CON 8 $18,2,7,8,11,32,14,9,24,0, !$ CHI CON 9 $22,2,29,26,11,32,14,9,24,19$, ! CHI CON 10 $16,0,0,0,0,0,0,0,0,0, !$ JBHT 1 $4,25,0,0,0,0,0,0,0,0, !$ JBHT 2 $23,25,34,0,0,0,0,0,0,0$, ! JBHT 3 $1,25,31,6,0,0,0,0,0,0$, ! JBHT 4 $1,25,31,35,33,0,0,0,0,0, !$ JBHT 5 $1,25,31,35,33,32,0,0,0,0$, ! JBHT 6 $1,25,31,35,13,32,12,0,0,0$, ! JBHT 7 $1,25,31,35,13,32,12,9,0,0$, ! JBHT 8 $1,25,31,35,13,32,12,9,30,0$, ! JBHT 9 $1,25,31,35,13,32,12,9,30,15:$ ! JBHT 10

ALTS;1-25/NS/ 0,25,23, 4,16, 0,31,35, 9, 1, ! HUB 1-10 ALTERNATES

$13,0,0,12,0,0,33,1,15,34$, ! HUB 11-20 ALTERNATES

$6,1,0,30,0,35,25,25,31,0$, ! HUB 21-30 ALTERNATES $0,32,0,0,0: \quad$ ! HUB 31-35 ALTERNATES

! "0" values denote a JBHT hub (and therefore no alternate).

! Other values denote JBHT alternates for orginal CCON hubs.

! The 4,9 , and 32 CCON hubs DO NOT have alternative JBHT hubs.

RATES;1-25/NS/\&

$1.10,1.20,1.09,1.07,1.14,3.91,1.67,1.83,1.73,0.85$, $1.02,1.09,0.85,1.05,1.08,0.89,0.86,3.08,1.67,1.81$, 
$1.08,0.88,1.57,1.21,1.12,1.39,1.19,1.22,3.08,2.08$, $1.12,1.07,4.99,1.00,1.17,1.07,1.68,1.79,1.25,1.20$, $1.25,1.33,1.11,1.34,2.22,1.07,1.30,1.35,1.12$, ! ALBANY

$1.09,1.06,2.19,2.91,2.02,1.17,1.21,1.08,1.32,1.39$, $1.46,2.36,1.12,1.34,1.12,1.30,1.16,1.49,1.21,1.50$, $1.40,1.11,1.27,1.13,2.44,1.51,1.14,1.33,1.49,1.25$, $1.96,2.91,1.34,1.10,1.30,1.59,1.37,1.39,1.25,1.95$, $1.27,1.69,2.25,1.23,1.48,1.95,1.39,1.09,2.13$, ! ALHAMBRA

$1.31,1.24,1.28,1.21,1.15,4.09,2.73,2.33,1.28,1.12$, $1.04,1.09,1.42,0.99,1.38,0.96,1.22,2.70,2.73,1.72$, $0.99,1.08,1.27,1.25,1.12,1.30,1.20,1.37,2.70,4.98$, $1.13,1.21,3.90,0.94,1.20,1.07,4.23,3.16,1.45,1.21$, $1.16,1.55,1.90,1.56,2.83,1.07,0.91,1.63,1.13$, ! ALLENTOWN

$1.57,1.42,1.12,1.09,1.20,2.14,3.50,1.71,2.83,1.52$ $1.28,1.11,1.74,1.46,1.37,1.88,1.33,2.06,3.50,1.34$, $1.43,1.24,1.44,1.42,1.15,2.22,1.41,1.33,2.06,2.77$, $1.17,1.09,1.94,1.81,1.31,1.08,1.76,1.65,1.56,1.28$, $1.97,1.25,1.13,1.97,2.75,1.09,2.21,4.08,1.15$, ! ASHLAND

$1.39,1.64,1.85,1.23,1.75,2.00,1.80,1.80,1.60,1.47$, $1.35,1.13,2.62,6.25,1.30,4.06,1.40,1.80,1.80,1.73$, $1.98,1.42,1.59,1.56,1.19,1.55,2.17,2.24,1.80,1.69$, $1.21,1.23,1.77,2.14,1.37,1.10,1.60,1.70,1.13,1.55$, $1.35,1.40,1.17,1.46,2.31,1.33,1.61,1.79,1.84$, ! BLOOMINGTON

$1.43,1.65,1.40,1.43,1.48,1.49,1.81,1.25,1.72,1.30$, $1.36,1.12,1.24,1.10,1.29,1.19,2.00,1.33,1.81,1.56$, $1.05,1.27,1.48,2.44,1.15,1.27,1.34,1.13,1.33,1.57$, $1.26,1.43,1.21,1.10,1.65,1.09,1.46,1.42,1.77,1.60$, $1.25,1.63,1.15,1.34,1.44,1.29,1.47,1.32,1.17$, ! BROOKHAVEN

$1.54,1.39,1.78,1.43,1.95,1.83,1.88,1.74,1.71,1.52$, $2.07,1.98,2.36,2.18,1.80,1.86,1.47,1.71,1.88,1.70$, $2.13,1.73,1.58,1.62,2.44,1.55,2.61,1.59,1.71,1.74$, $2.02,1.43,2.52,1.54,1.63,1.69,1.90,1.83,1.48,2.18$, $1.72,1.46,1.83,1.54,1.89,1.51,3.30,1.84,2.38$, ! CHICAGO

$1.01,1.02,1.85,1.53,1.71,1.19,1.37,1.40,1.67,1.22$, $0.99,1.16,0.94,0.99,0.97,0.99,1.17,1.46,1.37,1.13$, $1.36,1.08,1.01,1.15,1.20,1.18,1.15,1.15,1.46,1.25$, $2.35,1.53,1.88,0.95,1.69,1.60,1.32,1.40,1.01,0.80$, $1.13,2.68,1.74,1.14,1.29,1.74,1.37,1.26,1.26$, ! DALLAS

$1.22,0.68,1.25,1.12,5.20,1.39,1.30,1.06,1.29,1.07$, $0.75,2.27,0.90,0.69,0.74,0.89,1.26,1.37,1.30,1.12$, $1.26,0.82,0.79,1.25,1.42,1.19,1.35,0.70,1.37,1.11$, $2.18,1.12,1.14,0.83,0.93,1.25,1.16,1.12,1.16,0.81$, $0.85,1.05,1.46,1.34,1.14,1.20,0.88,1.19,2.98$, ! DENVER

$1.04,1.01,1.69,0.73,1.36,3.48,2.48,2.20,1.55,1.10$ $0.89,1.09,0.90,0.96,1.10,1.05,1.09,2.88,2.48,2.39$ $0.91,1.04,0.87,1.08,1.12,1.05,1.19,1.53,2.88,5.38$, $1.12,0.73,8.63,0.83,0.95,1.30,2.68,2.79,1.07,0.90$, 
$1.00,1.18,1.68,1.56,2.66,1.43,0.99,1.20,1.12, !$ EDISON

$2.03,1.22,1.85,1.10,1.59,1.72,1.59,1.69,1.62,6.12$, $1.33,1.10,1.54,1.18,1.64,1.41,1.44,1.59,1.59,1.59$, $1.38,1.20,1.47,1.66,1.63,2.04,1.20,1.44,1.59,1.66$, $1.42,1.10,1.70,1.16,1.45,1.08,1.59,1.55,1.79,1.23$, $1.56,1.32,1.63,1.57,1.53,1.26,1.09,1.34,1.14$ ! GAINESVILLE

$0.79,1.14,1.22,1.09,1.19,1.12,1.12,1.19,3.27,0.79$, $0.92,1.08,1.05,0.91,0.95,0.88,0.91,1.18,1.12,1.19$, $0.95,1.28,1.26,0.90,1.11,0.96,1.15,1.20,1.18,1.16$, $1.15,1.09,1.50,0.92,0.93,1.07,1.11,1.15,1.00,1.17$, $0.91,1.27,1.23,1.20,1.15,1.06,1.30,1.41,2.74$, ! JACKSONVILLE

$1.40,1.41,1.44,1.61,1.55,1.75,1.44,1.79,1.78,3.57$, $1.34,1.10,1.50,1.25,1.24,1.20,1.27,1.52,1.44,1.54$ $1.24,1.18,1.64,1.81,1.13,1.49,1.20,1.28,1.52,1.55$, $1.19,1.61,2.99,1.14,1.19,1.08,1.45,1.61,1.71,1.23$, $1.44,1.38,1.13,1.44,1.50,1.70,1.39,1.48,1.14$, ! LAGRANGE

$0.70,0.88,1.56,1.60,1.40,1.93,1.27,1.30,2.62,0.64$ $1.22,1.08,0.86,0.85,1.16,1.01,1.05,1.29,1.27,1.90$, $1.24,1.17,1.25,1.04,1.10,1.04,1.14,1.19,1.29,1.18$, $1.15,1.60,2.17,0.86,1.36,1.06,1.25,1.30,0.65,1.17$, $0.69,1.16,1.10,1.73,1.22,1.06,1.33,1.33,1.11$, ! LAKELAND

$1.54,1.35,1.12,1.10,1.54,1.85,1.56,1.69,1.69,1.25$, $1.76,1.13,2.03,1.68,1.38,1.77,1.54,1.82,1.56,1.34$, $4.44,1.55,1.46,1.33,1.18,1.82,1.34,1.47,1.82,1.72$, $1.17,1.10,1.60,1.75,1.33,1.10,3.00,1.85,1.24,1.36$, $1.25,1.23,1.49,1.55,2.46,1.10,2.58,1.93,1.19$, ! LANSING

$1.37,1.29,1.70,1.52,1.54,1.81,1.86,1.95,1.89,1.49$, $1.18,1.13,2.20,2.38,1.28,5.74,1.25,1.66,1.86,1.63$, $1.74,1.33,1.10,1.35,1.19,1.40,2.24,1.61,1.66,1.87$, $1.77,1.52,2.47,1.46,1.58,1.61,1.20,1.72,1.16,1.35$, $1.78,1.59,1.69,1.46,1.83,1.40,1.14,1.49,1.36$, ! LOUISVILLE

$1.38,1.15,1.36,1.10,1.52,1.56,2.14,1.40,1.87,3.57$, $1.28,1.10,1.47,1.55,1.03,1.24,1.56,1.57,2.14,1.54$, $1.35,1.28,1.36,1.66,1.13,1.69,1.19,1.21,1.57,1.58$, $1.52,1.10,1.32,1.54,1.55,1.08,1.81,1.73,2.07,1.25$, $1.37,1.81,1.52,2.29,1.49,1.07,1.45,1.49,1.52, ! \mathrm{MACON}$

$1.04,1.01,1.69,0.73,1.36,3.48,2.48,2.20,1.55,1.10$, $0.89,1.09,0.90,0.96,1.10,1.05,1.09,2.88,2.48,2.39$, $0.91,1.04,0.87,1.08,1.12,1.05,1.19,1.53,2.88,5.38$, $1.12,0.73,8.63,0.83,0.95,1.30,2.68,2.79,1.07,0.90$, $1.00,1.18,1.68,1.56,2.66,1.43,0.99,1.20,1.11$, ! MADISON

$1.28,1.44,1.73,1.09,1.32,1.93,2.65,2.76,1.50,1.40$, $1.32,1.12,1.41,1.66,1.35,2.24,1.37,2.29,2.65,2.18$, $2.74,1.40,1.45,1.37,1.17,1.69,1.31,1.49,2.29,2.30$, $1.17,1.09,4.36,3.06,1.48,1.70,2.43,2.52,1.37,1.35$, $1.46,1.82,1.89,1.42,2.40,1.80,2.73,4.29,1.18$, ! MANSFIELD 
$2.18,2.47,4.02,1.63,1.59,1.74,1.71,1.41,2.02,1.78$, $1.57,1.13,1.32,1.53,2.08,2.60,1.92,1.79,1.71,2.00$, $1.46,1.55,1.74,2.38,1.17,1.54,1.50,1.44,1.79,1.62$, $1.26,1.63,1.54,1.45,2.27,3.01,1.72,1.86,1.68,1.34$, $3.18,2.87,1.29,1.77,2.13,1.09,1.53,3.26,1.19$, ! MCKENZIE

$3.42,1.40,1.45,1.12,1.96,1.52,1.78,1.29,1.45,1.37$, $1.37,1.12,1.30,1.29,1.50,1.27,2.53,1.57,1.78,1.40$, $1.42,1.55,1.50,2.99,1.15,1.50,1.39,1.42,1.57,1.66$, $1.24,1.12,1.40,1.54,1.96,1.09,1.73,1.51,1.61,1.27$, $1.46,2.05,1.14,1.82,1.50,1.08,1.38,1.38,1.16$, ! MERIDIAN

$1.04,1.01,1.69,0.73,1.36,3.48,2.48,2.20,1.55,1.10$ $0.89,1.09,0.90,0.96,1.10,1.05,1.09,2.88,2.48,2.39$, $0.91,1.04,0.87,1.08,1.12,1.05,1.19,1.53,2.88,5.38$, $1.12,0.73,8.63,0.83,0.95,1.30,2.68,2.78,1.07,0.90$, $1.00,1.18,1.68,1.56,2.66,1.43,0.99,1.20,1.12$, ! NEWARK

$1.27,1.11,1.09,1.09,1.14,5.56,2.41,1.70,1.52,1.33$, $1.27,1.09,1.35,1.40,1.35,1.37,1.19,2.16,2.41,1.94$, $1.43,1.22,1.24,1.22,1.11,1.35,1.18,1.21,2.16,5.48$, $1.12,1.09,3.67,1.56,1.18,1.07,2.05,3.27,1.33,1.19$, $1.31,1.15,1.10,1.51,2.87,1.07,1.29,1.58,1.12$, NEW YORK

$1.10,1.05,1.42,1.70,1.72,1.20,1.14,1.32,1.25,1.30$, $1.13,2.10,1.11,1.15,1.39,1.03,1.11,1.06,1.14,1.06$, $1.10,1.10,1.13,1.34,1.36,1.22,1.14,1.05,1.06,1.20$, $1.75,1.70,1.00,1.02,1.16,1.87,1.18,1.20,1.08,1.52$, $1.10,1.32,1.52,1.07,1.07,1.55,1.11,1.08,2.35$, ! OAKLAND

$1.11,1.15,2.19,2.67,1.26,1.07,1.08,1.07,1.15,1.24$, $1.25,1.34,1.11,1.11,1.17,1.11,1.13,1.06,1.08,1.06$, $1.10,1.54,1.15,1.13,1.22,1.08,1.13,1.16,1.06,1.18$, $2.04,2.67,1.07,1.10,1.28,1.48,1.08,1.06,1.09,1.15$, $1.11,1.17,2.20,1.08,1.07,1.53,1.12,1.09,1.33$, ! OXNARD

$1.48,1.67,1.25,1.39,1.49,1.36,1.36,1.19,1.87,1.41$, $1.69,1.15,1.08,1.40,1.13,1.24,1.61,1.21,1.36,1.13$, $1.24,1.08,1.50,1.80,1.18,1.36,1.24,1.35,1.21,1.32$, $1.39,1.39,2.00,1.10,1.88,1.27,1.19,1.14,1.30,1.32$, $1.07,4.67,1.20,1.23,2.03,1.11,1.27,1.52,1.22$, ! PALESTINE

$1.09,1.06,2.19,2.91,2.02,1.17,1.21,1.08,1.32,1.39$, $1.46,2.36,1.12,1.34,1.12,1.30,1.16,1.49,1.21,1.50$, $1.40,1.11,1.27,1.13,2.44,1.51,1.14,1.33,1.49,1.25$, $1.96,2.91,1.34,1.10,1.30,1.59,1.37,1.39,1.25,1.95$, $1.27,1.69,2.25,1.23,1.48,1.95,1.39,1.09,2.13$, ? PALMDALE

$1.09,1.06,2.19,2.91,2.02,1.17,1.21,1.08,1.32,1.39$ $1.46,2.36,1.12,1.34,1.12,1.30,1.16,1.49,1.21,1.50$, $1.40,1.11,1.27,1.13,2.44,1.51,1.14,1.33,1.49,1.25$, $1.96,2.91,1.34,1.10,1.30,1.59,1.37,1.39,1.25,1.95$, $1.27,1.69,2.25,1.23,1.48,1.95,1.39,1.09,2.13$, ! PASADENA 
$2.13,1.73,1.58,1.62,2.44,1.55,2.61,1.59,1.71,1.74$, $2.02,1.43,2.52,1.54,1.63,1.69,1.90,1.83,1.48,2.18$,

$1.72,1.46,1.83,1.54,1.89,1.51,3.30,1.84,2.38$, ! ROCKFORD

$1.12,1.24,1.35,1.91,1.60,1.20,1.14,1.07,1.07,1.68$, $1.06,2.59,1.31,1.10,1.15,1.10,1.11,1.06,1.14,1.06$, $1.28,1.34,1.14,1.11,1.26,1.08,1.15,1.16,1.06,1.07$, $1.79,1.91,1.07,1.02,1.16,1.30,1.08,1.06,1.08,1.16$, $1.26,1.38,1.62,1.07,1.07,1.55,1.12,1.09,1.35$, ! SACRAMENTO

$1.84,1.39,1.33,1.30,2.00,2.11,1.87,1.46,1.81,1.65$, $1.97,1.14,3.10,4.05,1.46,1.69,1.30,1.41,1.87,1.80$, $2.82,1.41,1.58,1.40,1.20,1.28,1.40,1.32,1.41,2.11$, $1.19,1.30,1.72,2.23,1.48,1.74,1.79,2.21,1.46,1.46$, $1.81,1.45,1.18,1.46,1.80,1.11,2.17,1.47,1.20$, ! SOUTH BEND

$1.08,1.40,1.26,1.28,1.75,1.06,1.29,1.25,1.09,1.08$, $1.13,1.64,1.11,1.01,1.11,1.06,1.09,1.07,1.29,1.07$, $1.10,1.24,1.29,1.09,1.09,1.10,1.19,1.15,1.07,1.34$, $1.19,1.28,1.07,1.09,0.81,2.83,1.11,1.18,1.18,1.17$, $1.09,1.11,1.53,1.22,1.17,2.94,1.03,1.09,1.31$, ! TACOMA

$1.40,1.15,1.28,1.10,1.37,1.49,1.71,1.79,2.71,1.66$, $1.18,1.10,1.42,1.29,1.16,1.09,1.34,1.44,1.71,1.21$, $1.31,1.32,1.46,1.00,1.12,1.15,1.17,1.34,1.44,1.79$, $1.18,1.10,1.50,1.48,1.29,1.07,1.35,1.57,1.59,1.20$, $1.20,1.33,1.12,1.59,1.37,1.07,1.67,1.43,1.13$, ! TIFTON

$2.79,1.79,2.08,1.13,1.97,1.79,1.53,1.63,2.61,1.91$, $1.50,1.13,1.69,2.09,1.78,1.85,2.19,1.43,1.53,1.19$, $1.38,1.83,1.69,2.60,1.17,2.90,1.26,1.74,1.43,1.53$, $1.26,1.13,2.54,1.78,1.66,1.10,1.32,1.21,1.77,1.33$, $3.38,2.57,1.16,1.56,1.46,1.09,1.47,1.47,1.18$, ! TUPELO

$1.43,0.98,1.27,1.39,2.08,1.27,1.30,1.18,1.26,1.27$ $1.32,1.16,0.88,0.88,0.93,0.92,1.20,1.40,1.30,1.12$, $1.23,1.39,2.06,1.69,1.26,1.29,1.20,1.25,1.40,1.13$, $1.47,1.39,1.15,0.88,1.85,1.22,1.32,1.23,1.02,1.56$, $1.40,1.25,1.21,1.09,1.15,1.18,1.45,1.23,1.23:$ ! WACO

\$TRACE $=0-1$ :

\$STOP: 


\section{CURRICULUM VITAE}

for

\section{ANTHONY SCOTT HUMPHREY}

\section{EDUCATION \& TRAINING}

\section{Doctor of Philosophy (Ph.D.), Industrial Engineering, UNIVERSITY OF LOUISVILLE,} Louisville, KY, May, 2006

Doctoral Candidacy Status - Fall 2005: 39 of 30 hours completed towards degree; G.P.A. of 3.769

Dissertation: "Addressing Freight Imbalance in the Truckload Trucking Industry through Hierarchical Planning"

Research: Logistics Simulation - Truckload Trucking Issues - Hierarchical Planning Graduate Committee:

- Dr. G. Don Taylor - Chairman, Charles O. Gordon Professor and Head, Grado Dept. of Industrial and Systems Engineering, Virginia Polytechnic Institute \& State University

- Dr. Suraj M. Alexander, Professor, Department of Industrial Engineering, J.B. Speed School of Engineering, University of Louisville

- Dr. Gail W. DePuy, Associate Professor, Department of Industrial Engineering, J.B. Speed School of Engineering, University of Louisville

- Dr. Richard Germain, Challenge for Excellence Chair in Supply Chain Management, College of Business \& Public Administration, University of Louisville

- Dr. John S. Usher, Professor and Chairman, Department of Industrial Engineering, J.B. Speed School of Engineering, University of Louisville

Master of Science (MS), Industrial Engineering, UNIVERSITY OF ARKANSAS, Fayetteville, AR, $1993 \quad$ G.P.A. of 3.50

Thesis: "Stock Level Determination in Repair/Rework Operations:"

Optimization Methods and Sensitivity Analysis"

Graduate Committee: Dr. G. Don Taylor - Chairman, Dr. John R. English, Dr. Thomas L. Landers

Bachelor of Science (BS), Industrial Engineering, LOUISIANA TECH UNIVERSITY, Ruston, LA, 1991 Magna Cum Laude; G.P.A. of 3.71

Engineer-In-Training Certification October 1991

Alpha Pi Mu Honor Society (Industrial Engineering), 1990-1991. President 1990-1991.

Institute of Industrial Engineers; Louisiana Tech University, 1987-1991. Vice-President 1990-1991.

Executive Series, Leadership in Supply Chain Management, Louisville, KY, May 252005.

2005 Simulation Solutions Conference, Institute of Industrial Engineers, Atlanta, GA, May 18-19, 2005. 
Annual Conference \& Exposition, Institute of Industrial Engineers (IIE), Atlanta, GA, May 14-18, 2005.

Clean Show 2001, World Educational Congress for Laundering \& Drycleaning, New Orleans, LA, July 19-21, 2001.

Am-Soft Conference, Logistics Planning Workstation (LPW), American Software, Inc., Atlanta, GA, April 1-3, 1996.

Strategic Forecasting \& Planning Training, Logistics Planning Workstation (LPW), American Software, Inc., Atlanta, GA, August 9-12, 1993.

\section{PROFESSIONAL EXPERIENCE}

UNIVERSITY OF LOUISVILLE, Louisville, KY. August 2002 - Present

Graduate Research Assistant - Logistics and Distribution Institute (LoDI)

\section{Fall 2004 - Present}

- Plan and conduct both guided and independent industrial engineering operations research related to truckload freight imbalance, a recurring and persistent problem through the industry.

- Propose yearly research objectives and play active role in supporting funding development activities.

- Develop and present research results and status reports.

- Carry out experimental design and simulation research in analysis of three hierarchical planning horizons - short term (operational planning), medium-term (tactical planning), and long-term (strategic planning) time horizons.

- In previous research, examined weekly cyclical imbalance and proposed a weekend dispatching strategy that addressed imbalance through operational planning.

- Currently expanding research to include a driver domicile problem (addressing imbalance at the tactical level) and a distribution center location problem (addressing imbalance at the strategic level), and developing discrete event simulations to examine the problems, provide analysis, and recommend solution strategies.

\section{Fall 2002 - Fall 2004}

- Conducted research examining freight leveling and daily freight imbalance issues in the truckload trucking industry, motivated by J.B. Hunt Transport (JBHT), the largest publicly held truckload trucking company in the United States.

- Via discrete event simulation (using SimNet II), examined ways to exploit freight hubbing to achieve a greater degree of freight leveling in the presence of varying weekly demand patterns.

- Used yard stacking alternatives to enable truckload carriers to operate more efficiently on weekends.

- Examined the effects of redistributing excess freight capacity from Fridays into weekends where capacity (drivers and equipment) was not fully being utilized.

- Defined the problem, proposed alternative strategies, developed and conducted discrete event simulation under both existing conditions and proposed alternatives and validated data; implemented comparative analysis and interpretation of independent simulation results.

- Research culminated in a journal submission to the International Journal of Physical Distribution and Logistics Management in October 2004. 


\section{PREMIER CLEANERS, Baton Rouge, LA. February 1999 - August 2002}

\section{General Manager}

- Developed overall strategy and managed all day-to-day tactical operations including purchasing / procurement, inventory management, logistics, staffing, accounting \& payroll, cash management, and plant production.

- Played major role in driving company growth from two processing plants and one customer site to eight processing plants and sites after two years in position.

- Assisted in the hiring, training, and managing of 45 cross-functional employees.

- Monitored cash position, oversaw accounting, coordinated bank relations, and analyzed costs and pricing for efficient resource utilization.

- Managed customer relations, claims and business correspondence.

RHEEM UNIVERSAL PARTS, Fort Smith, AR. June 1993 - January 1999 A Division of Rheem Manufacturing Company

\section{Manager of Forecasting \& Planning}

- Hired to manage and turn around a poorly performing purchasing department of a major heating and air conditioning replacement parts company operating with antiquated procedures.

- Improved critical benchmarks to enable company's aftermarket expansion objectives in the midst of complex, seasonal demand patterns.

- Used industrial engineering theories and best practices to analyze logistics, purchasing, production, and overall operations to streamline processes, increase productivity, and reduce on-hand inventory.

- Hired, trained, and managed a staff of purchasing agents at national warehouse.

- Forecasted and controlled a $\$ 5.0-6.0$ million inventory consisting of 5,000+ items.

- Directed the installation of modern forecasting software and oversaw system maintenance.

- Developed educational materials, exercises, and visual displays for staff training.

- Established staff goals, monitored progress, and administered evaluations.

- Solved complex demand situations with simplified strategies and procedures.

- Supported $48 \%$ company growth (886,000 units to $1,315,000$ units) while simultaneously producing outstanding inventory results:

- Out of stock situations decreased from $33.8 \%$ (1993) to $14.0 \%$ (1997).

- Inventory turns increased from 4.40 (1994) to 5.15 (1997).

- Inventory investment stabilized and remained near constant.

- Profit increased $42.1 \%$ and non-warranty sales increased $29.5 \%$.

UNIVERSITY OF ARKANSAS, Fayetteville, AR. January 1991 - May 1993 Graduate Research Assistant

- Worked on research consultation at Red River Army Depot (RRAD).

- Programmed a computer simulation using SIMNET to analyze inventory policies; proposed alternative methods and developed user-friendly software to assist in realtime stock determinations. 
RAFAEL F. OTERO, Ph.D., Texarkana, AR. September - December 1991

\section{Computer Programmer/ Consultant}

- Using $\mathrm{C}+$, developed innovative diagnostic software to test reading skills, identify problem areas, and strengthen vocabulary of clinical patients.

PREVIOUS EXPERIENCE INCLUDES:

ALUMAX MILL PRODUCTS, Hot Mill Assistant

WADLEY REGIONAL MEDICAL CENTER, Technician

McDONALD'S, Cook

\section{Publications \& Presentations}

Humphrey, A.S., "Addressing Freight Imbalance of Truckload Trucking Networks Through Driver Domicile Planning", Logistics and Distribution Institute (LoDI) Spring Seminar Series, University of Louisville, Louisville, KY, April 28, 2006.

Humphrey, A.S., "Alternative Approaches to Addressing Freight Imbalance in the Design of Truckload Trucking", $4^{\text {th }}$ Annual IIE Doctoral Colloquium Poster Session, Atlanta, GA, May 15, 2005.

Humphrey, A.S., "Alternative Approaches to Addressing Freight Imbalance in the Design of Truckload Trucking Networks", Logistics and Distribution Institute (LoDI) Spring Seminar Series, University of Louisville, Louisville, KY, April 1, 2005.

Humphrey, A.S., Taylor, G.D., Usher, J.S., and Whicker, G.L., "Evaluating the Efficiency of Trucking Operations with Weekend Freight Leveling", in review, International Journal of Physical Distribution and Logistics Management, October 2004.

Humphrey, A.S., "Anthony Humphrey - Professional Portfolio Presentation", Future Professors Program Seminar, University of Louisville, Louisville, KY, February 27, 2004.

Humphrey, A.S., "Logistics Research at U of L: The Weekend Draying Problem", Guest Lecturer for course IE 550: Fundamentals of Logistics Systems, University of Louisville, Louisville, KY, September 15, 2003.

Humphrey, A.S., "Increasing the Efficiency of Trucking Operations Via Freight Leveling", Logistics and Distribution Institute (LoDI) Spring Seminar Series, University of Louisville, Louisville, KY, April 18, 2003. 
Taylor, G.D., and Humphrey, A.S., Participant with Dr. G. Don Taylor in Poster Presentations of On-Going and Completed University of Louisville Research Projects, CELDi Annual Research Conference, Tulsa, OK, October 3, 2002.

Humphrey, A.S., Taylor, G.D., and Landers, T.L., "Stock Level Determination and Sensitivity Analysis in Repair/Rework Operations", International Journal of Operations and Production Management, 1997, Vol. 18, No. 6, pp 612-630.

Humphrey, A.S., "Stock Level Determination in Repair/Rework Operations: Optimization Methods and Sensitivity Analysis", Masters Thesis, University of Arkansas, Fayetteville, AR, May 1993.

Humphrey, A.S., Taylor, G.D., and Faddoul, N., "Stock Level Determination in Repair/Rework Operations: Optimization Methods and Sensitivity Analysis", Final Project Briefing, Red River Army Depot, New Boston, TX, March 11, 1993.

Humphrey, A.S., "Inventory Stock Level Determination in a Repair/Rework Environment", Graduate Student Seminar, University of Arkansas, Fayetteville, AR, March 10, 1993

Humphrey, A.S. and Taylor, G.D., "Stock Level Determination in Repair/Rework Operations: Optimization Methods and Sensitivity Analysis", Fall 1992 Material Handling Research Center Monitors Meeting, Georgia Tech University, Atlanta, GA, November 16-18, 1992.

\section{AWARDS \& HONORS}

Doctoral Candidacy, Industrial Engineering, University of Louisville Graduate School, Louisville, KY, October 2005.

Attendee (by nomination), $4^{\text {th }}$ Annual Institute of Industrial Engineers (IIE) Doctoral Colloquium, Atlanta, GA, May 14, 2005.

Recognition, "Champion for Children", Presented for outstanding commitment, time, and service to the students of the Jefferson County Public School District, Louisville, KY, May, 2005.

Future Professors Program, Appointed by mentors to participate in a one year, interdisciplinary program whose mission was to prepare future doctoral graduates with skills needed specifically for careers in academia. Both academic and practical / hands-on training at the graduate level were coordinated and monitored by faculty of the College of Education \& Human Development, University of Louisville, 2003-2004. 
Recipient, Graduate Research Assistantship, Logistics \& Distribution Institute (LoDI), University of Louisville, 2002-2003. Renewed 2003-2004, 2004-2005, 2005-2006.

Recipient - Graduate Research Assistantship, Department of Industrial Engineering, University of Arkansas, 1992-1993.

Certification, Fundamentals of Engineering Examination; Engineer-In-Training \#14428, January 7, 1992, (Tested in Ruston, Louisiana, October 1991).

Scholarship Recipient, Department of Mechanical and Industrial Engineering Scholarship, Louisiana Tech University, 1990-91.

Scholarship Recipient, Harry Talbot Scholarship, College of Engineering Awards and Scholarship Committee, Louisiana Tech University, 1990-1991.

Inducted, Tau Beta Pi, National Engineering Honor Society, Louisiana Tech University; October 1989.

Inducted, Gamma Beta Phi, National Scholastic Honor Society, Louisiana Tech University; May 5, 1988.

Finalist, Distinguished Freshman Engineering Student, Louisiana Tech University, April 1988.

Scholarship Recipient, Basic and Career Studies Scholarship, Louisiana Tech University, 1987-91. Renewed 1987-1988, 1988-1989, 1989-1990, and 1990-91.

National Delegate - Arkansas Representative, Department of Energy (DOE) High School Science Supercomputing Honors Program, sponsored by the U.S. Department of Energy at the Lawrence Livermore National Laboratory, Livermore, California, June 14-27, 1987.

Valedictorian, High School Class of 1987, Texarkana (Arkansas) High School, 1987.

Commendation, Department of Justice Young American Medal for Service, (for original design of computer hardware and software for the physically challenged), March 1987.

Commendation, Certificate of Excellence, 1987 American High School Mathematics Examination, University of Southern Arkansas, Magnolia Arkansas, January 1987. 
National Award Winner $-3^{\text {rd }}$ Place, Apple Computer Creative Computing Contest; Campus Life Magazine (I developed software and hardware to assist a non-speaking cerebral palsy individual communicate basic ideas and needs), December 1986.

Scholarship Recipient - Math, 1986 Arkansas Governor's School for the Arts and Sciences, Hendrix College, Conway Arkansas, June 15 - July 23, 1986.

Delegate, Arkansas American Legion Boys State, University of Central Arkansas, Conway Arkansas, June 8 - June 14, 1986.

\section{PUBLiC SeRVICE}

Chairman, Middletown Elementary Math \& Science Fair, Louisville, KY, 2004-present.

Member, Institute of Industrial Engineers, University of Louisville, Louisville, KY, 2002-present.

Member, National Parent Teacher Association, Middletown Elementary, Louisville, KY, 2002-present.

Teacher/Director, AWANA Clubs International, Highview Baptist, Louisville, KY, 2005-present.

Teaching Assistant Volunteer, Middletown Elementary Computer Technology Class, Louisville, KY, 2002-present.

Volunteer Group Leader, $32^{\text {nd }}$ Annual Girl Scouts "Festival of the Arts", Kentuckiana Troop \#1517, Louisville, KY, November 13, 2004.

Volunteer Technology Leader, 2004 Louisville Showcase of Schools, representative for Middletown Elementary Computer Technology Class, Louisville, KY, October 23, 2004.

Coach, Youth Baseball, Highview Baptist Church, Louisville, KY, Summer 2004.

Mission Volunteer, Food Service \& Distribution, Wayside Christian Mission, Louisville, KY, May 22, 2004.

Judge, Middletown Elementary Math \& Science Fair $\left(4^{\text {th }} \& 5^{\text {th }}\right.$ Grade), Louisville, KY, March 23-24, 2004.

Mission Volunteer, Food Service \& Distribution, Wayside Christian Mission, Louisville, KY, November 1, 2003. 
Coach, Children's YMCA Baseball, Louisville YMCA (Berrytown Branch), Summer 2003.

Member, Institute of Industrial Engineers; University of Arkansas, Fayetteville, AR, 1992-93. 